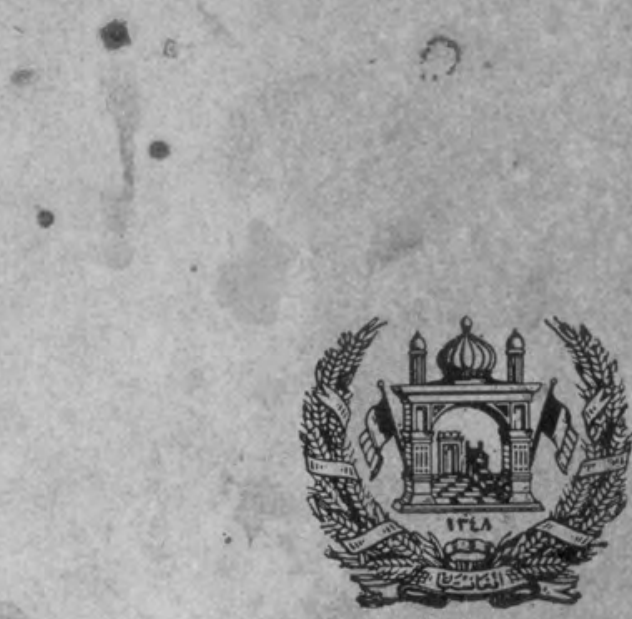

$$
\begin{aligned}
& \int_{0} \\
& \text {, } \\
& \text { كلم اوضاع اقصطا بك } \\
& \text { ira.j }
\end{aligned}
$$

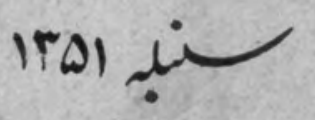

4.6

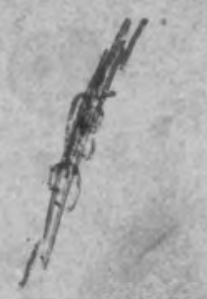

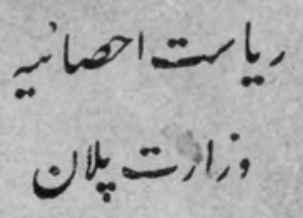



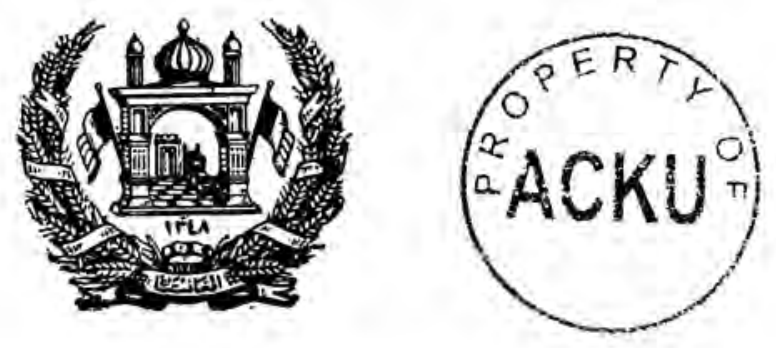

$$
\text { (1) }
$$

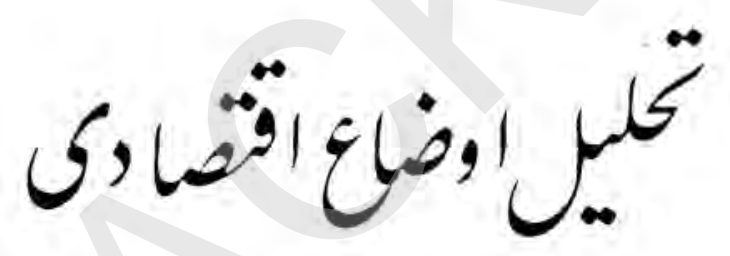

ira.j

|rat

$$
\begin{aligned}
& \text { رايحتانح } \\
& \text { 院=1; }
\end{aligned}
$$$$
\text { a.2. }
$$ 


$$
\text { قسمت اول - تحليلهاى عمو مى مطالب }
$$

صלקם

1

18

rr

ห^

YE

ra

\&7

IV

vy

97
- 1 ماليه عامه

r- بلانس تادياتوتجارت خارجى

r- بول و بانكدارى

ع- قيمتهـيا

م - قواى بشرى

ר- سرو يبهاى نمونوى

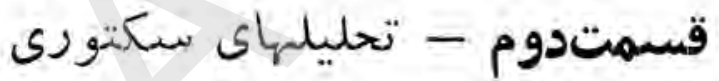

ا- زراعت و آبيارى

r

ب- خدمات اجتماعى

ع-ح>دل ونقل و Aواصلات

قسمت سوم-ضمايم احصائيوى 


$$
\text { تحليل قهمتاى عمونى }
$$




\section{dote who}

درشوايط كنونى تنظيـم فعاليـت ها ىانكشافى ودرنتيجه بلند بودن سطبح حيات

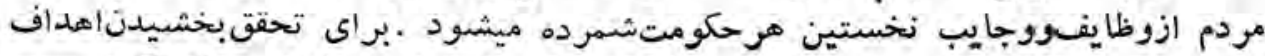

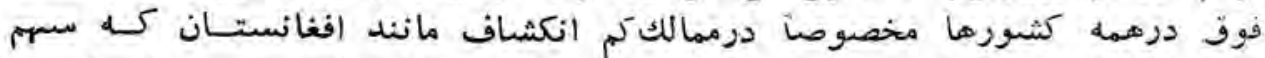

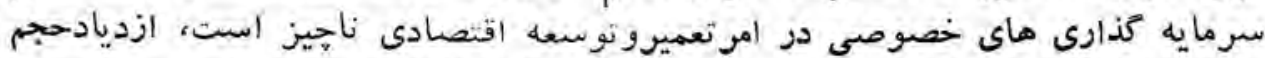

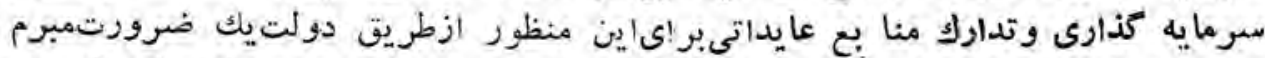

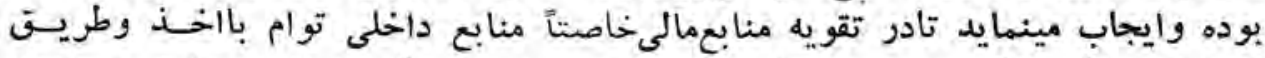

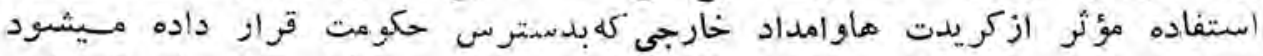

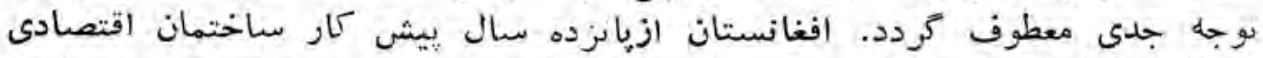

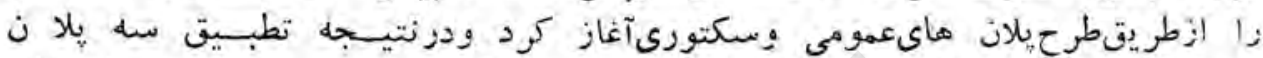

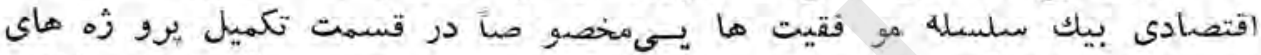

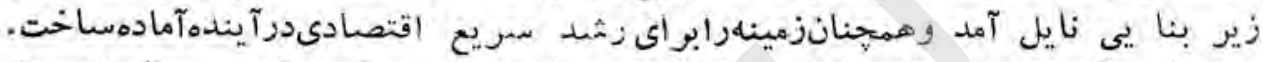

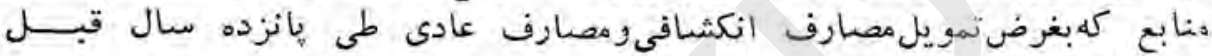

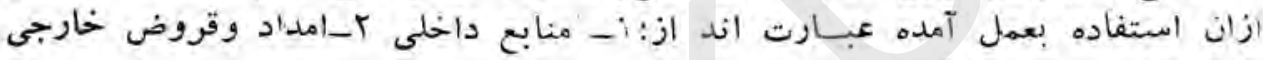
r

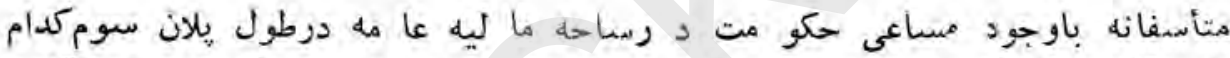

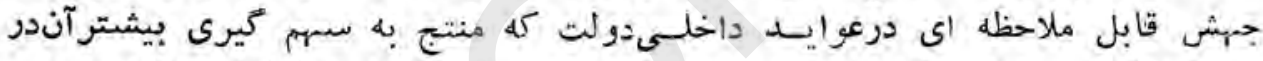

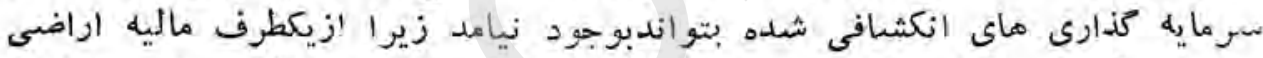

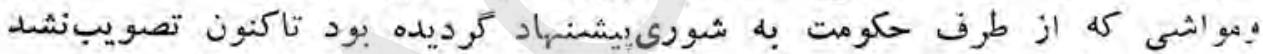

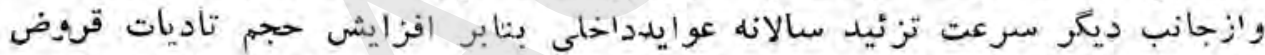

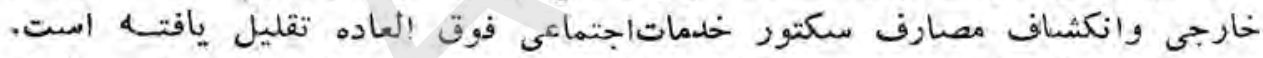

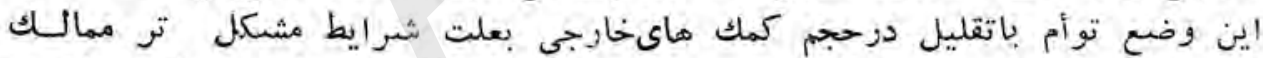

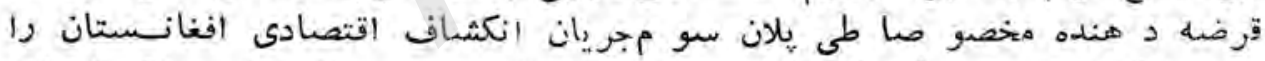

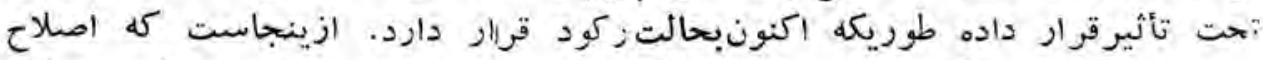

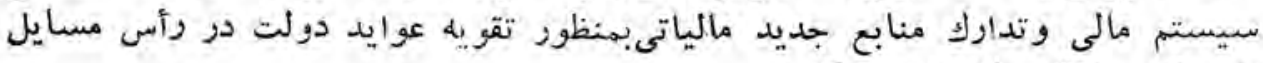

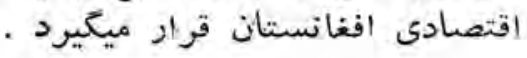

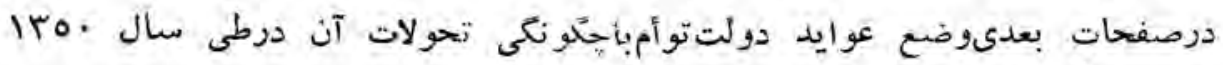

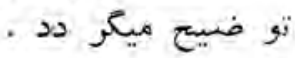

\section{الف) عوايد داخلى}

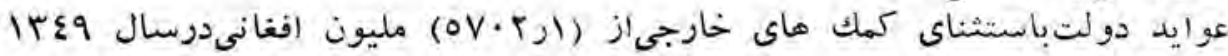

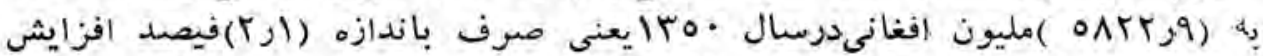

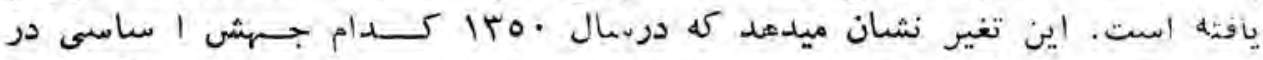

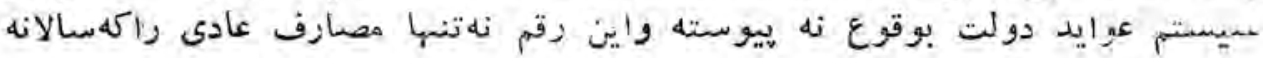




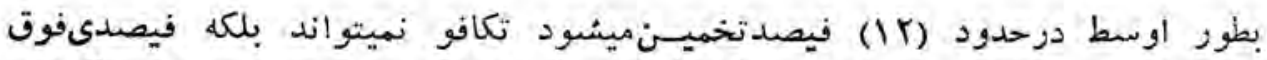

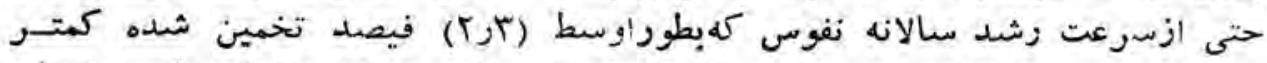

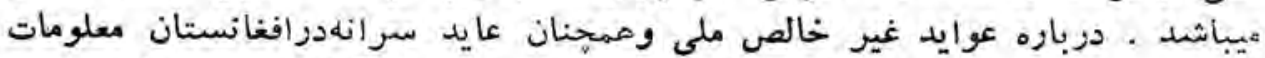

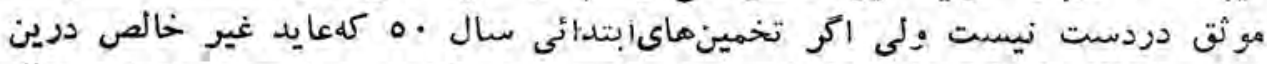

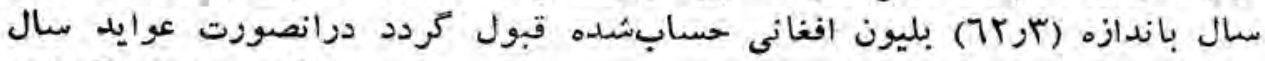

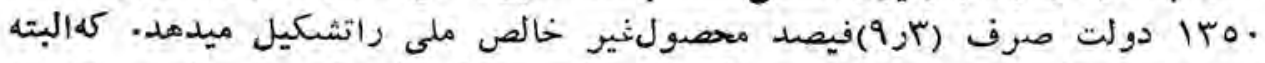

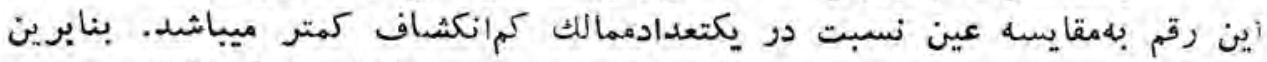

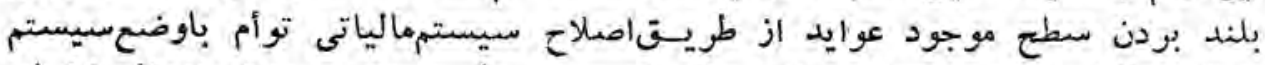

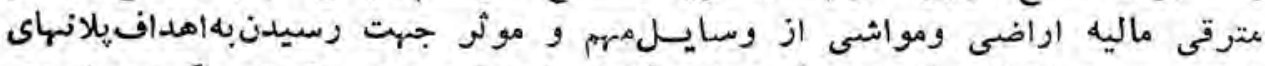

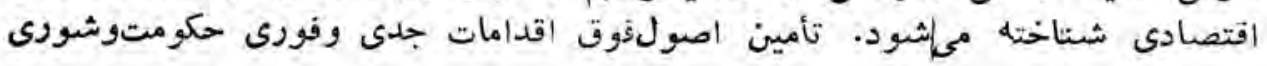

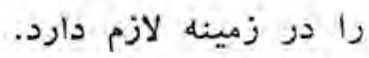

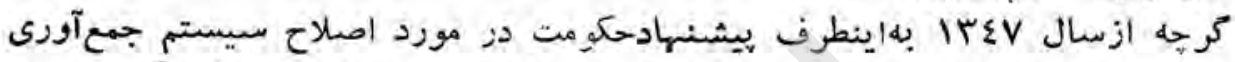

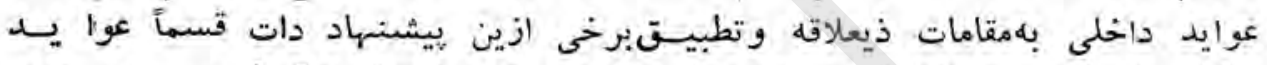

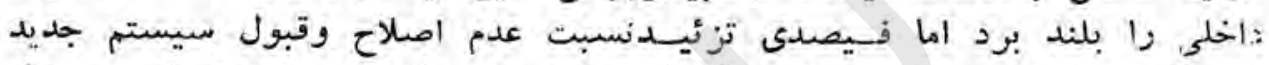

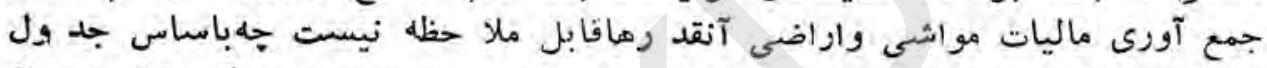

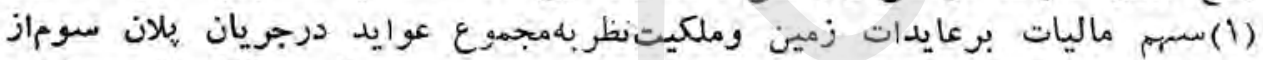
(1,0)

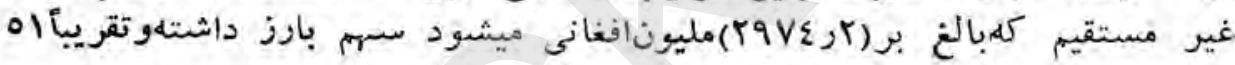

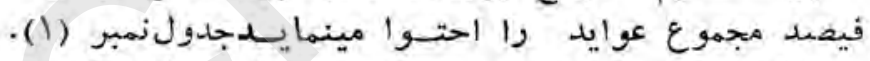

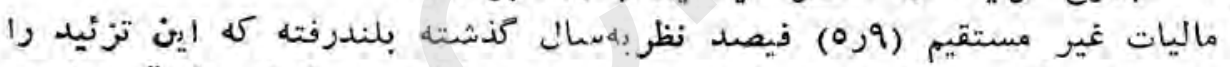

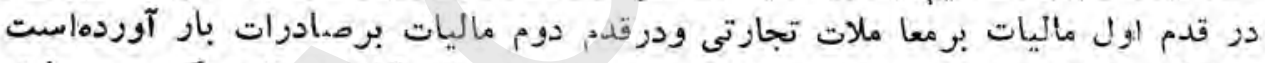

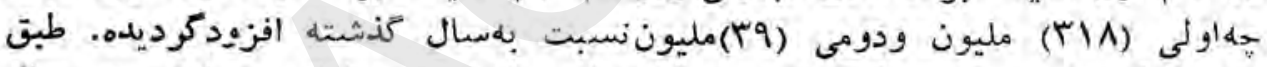

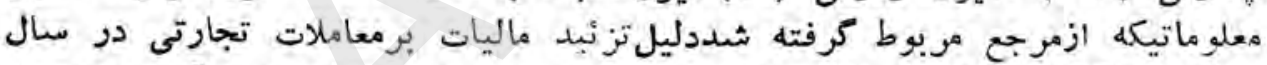

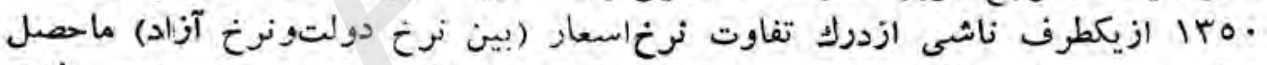

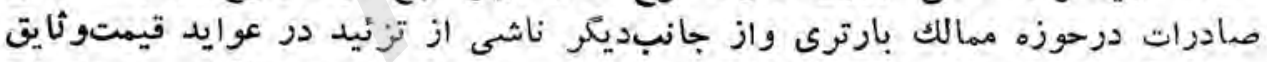

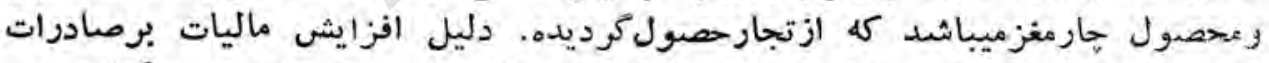

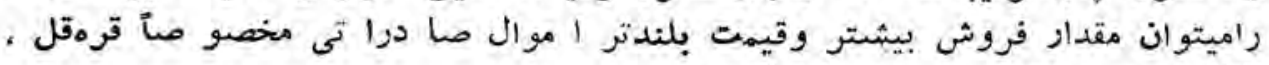

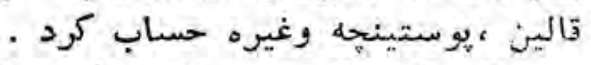

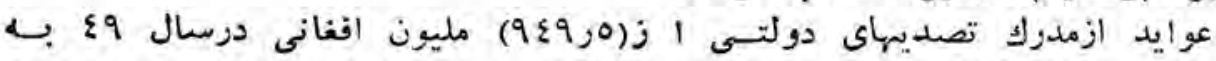

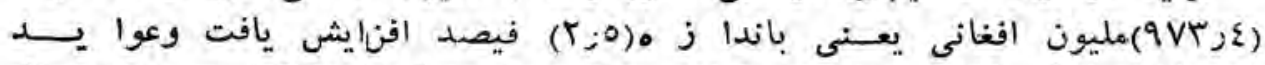

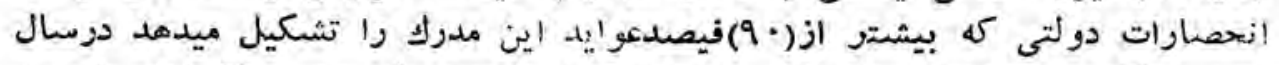

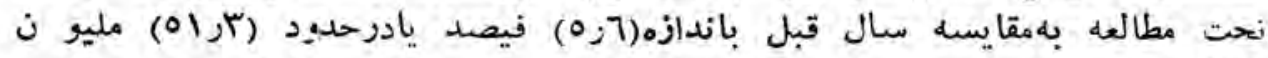
r.,.

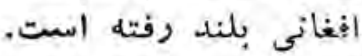

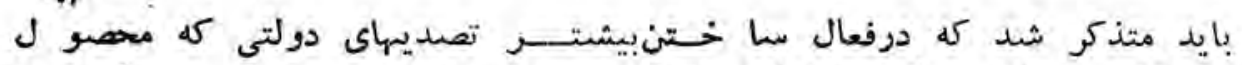

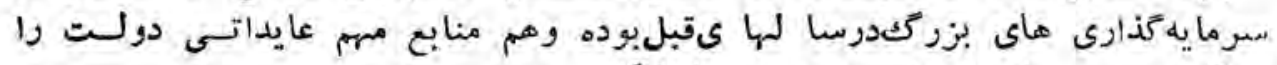

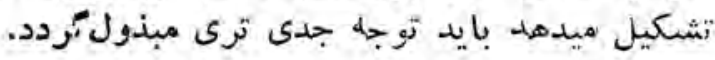




\section{(1) جدول}

عوايد داخلى به تفريق منابـع لآع

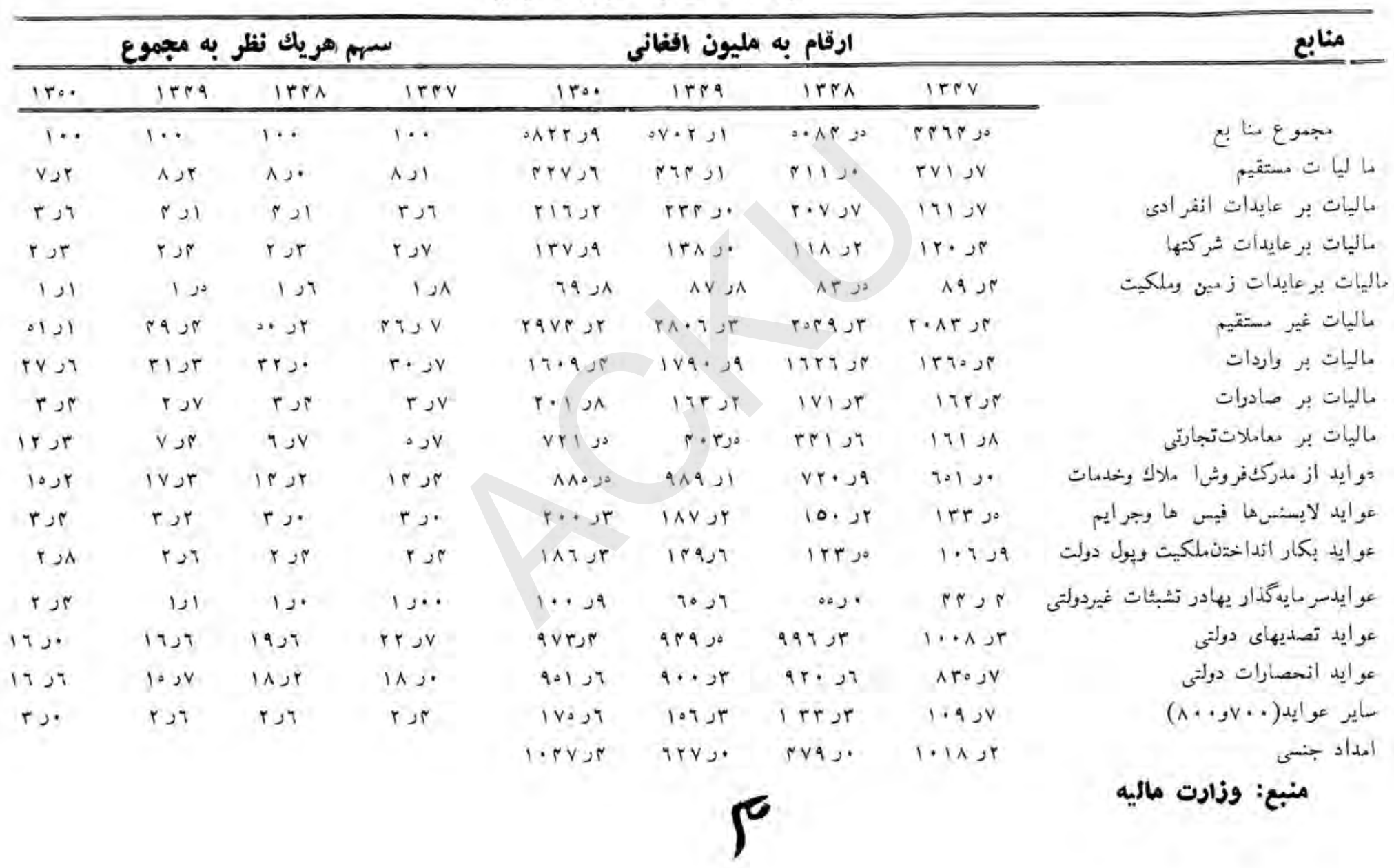




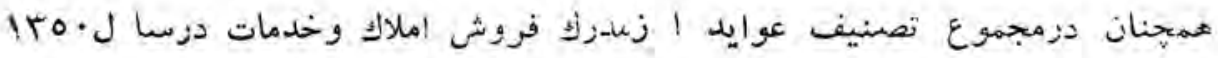

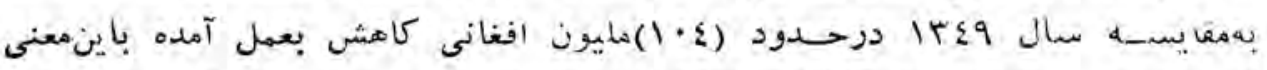

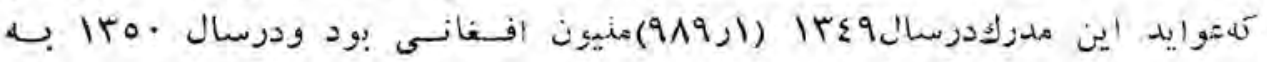

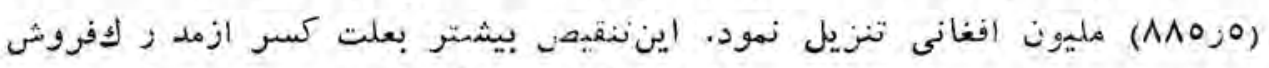

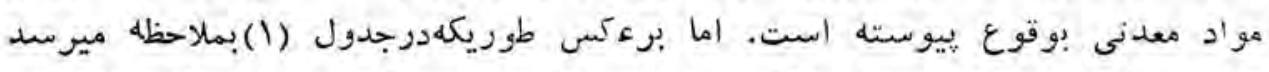

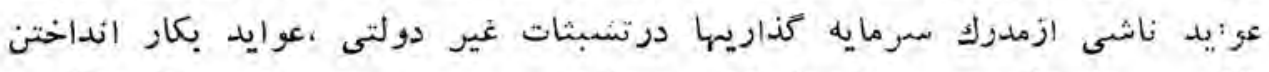

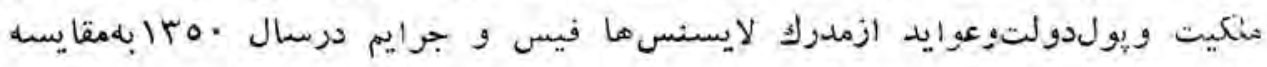

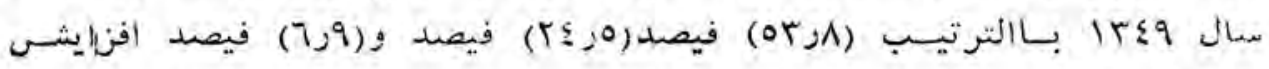

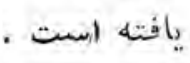

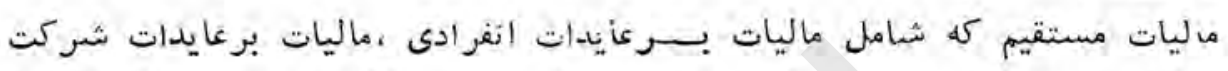

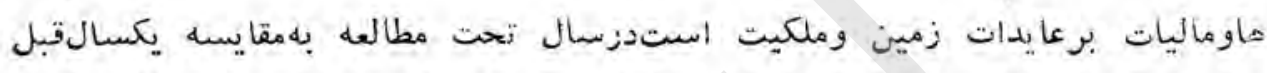

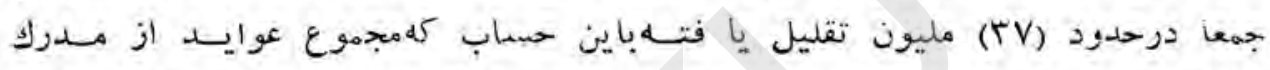

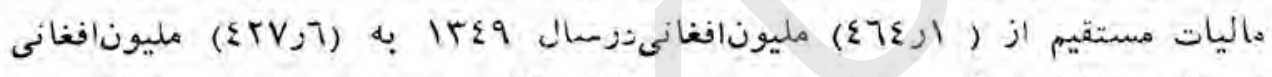

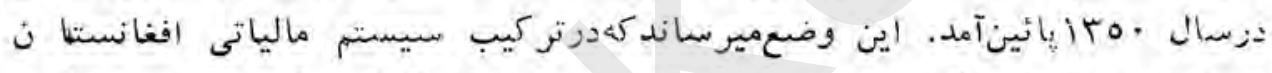

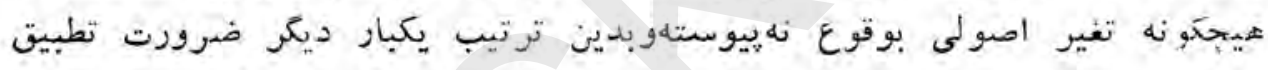

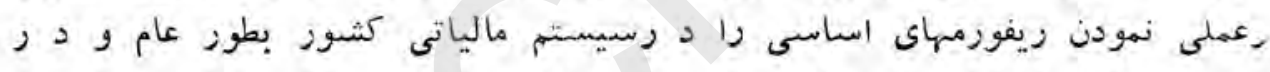

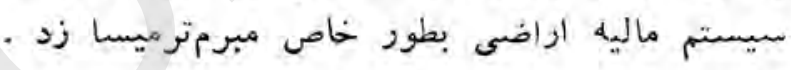

\section{(r) جدول}

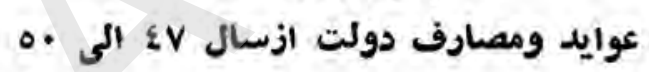

ارقامبهمليون افغاني

\begin{tabular}{|c|c|c|c|c|}
\hline Iro. & $15 \leqslant 9$ & $1 T \varepsilon \wedge$ & IrEV & اقـلام \\
\hline & & & & الف ه عوايد : \\
\hline$\varepsilon r V, \tau$ & $\sum 7 \varepsilon, 1$ & $\varepsilon 11$, & $r V I, v$ & ماليات مستقيم \\
\hline TaVE, r & $r \Lambda \cdot 7, r$ & $r 0 \leqslant 9, r$ & $r \cdot \Lambda r, \varepsilon$ & ماليات غيرمستقيم \\
\hline$\langle|\varepsilon r|\rangle$, & $r \leqslant r \mid, V$ & rire,r & $r \cdots q, \varepsilon$ & ساير عوايد \\
\hline ONrT, & ov.rol & $0 . \wedge \varepsilon, 0$ & $\varepsilon \varepsilon 7 \varepsilon, 0$ & مجموع ع \\
\hline $0 \leqslant \Lambda, 0$ & $009,$. & $1 \cdot \wedge \wedge ; 7$ & 091,7 & قروض بانكمر كزى \\
\hline $1 \cdot \varepsilon v, \varepsilon$ & $T r v_{0}$. & $v \varepsilon q,$. & $1 \cdot 1 \wedge, r$ & امداد جنسى \\
\hline$\vee \varepsilon \backslash \wedge, \Lambda$ & $7 \wedge \wedge \wedge, 1$ & 7704,1 & $7 \cdot v \varepsilon, r$ & مجموع عمومىعوايد \\
\hline
\end{tabular}


|

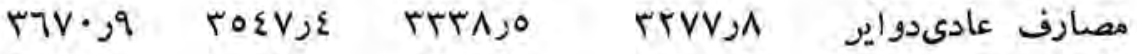

تادئئقوض

سبسائيديدولت

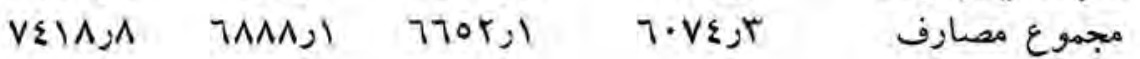

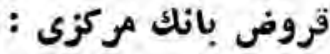

طوريكه از جدول نمبر (r) بملا حسظهيرسد هجموع عوايد دولت بشمبول امداد

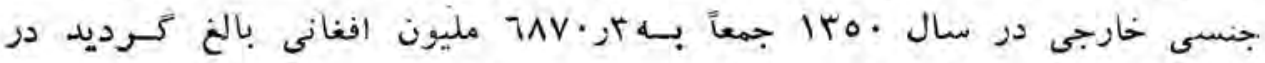

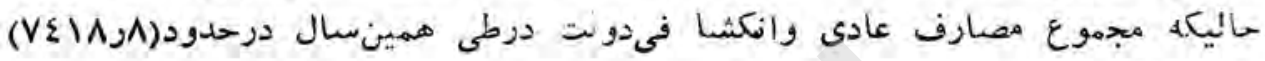

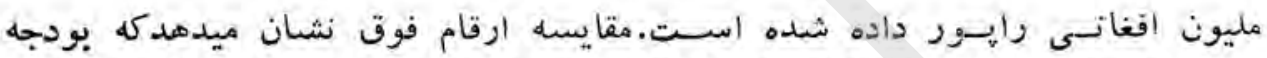

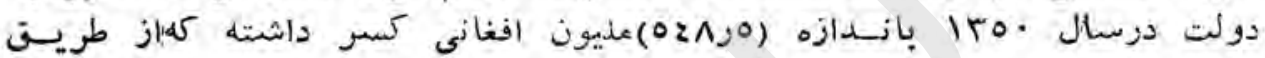

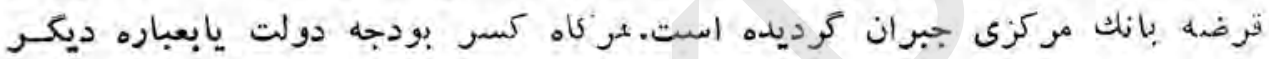

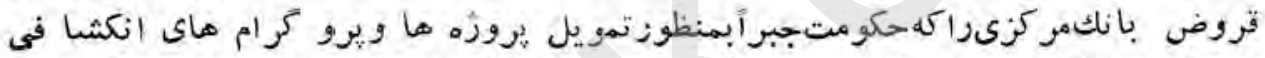

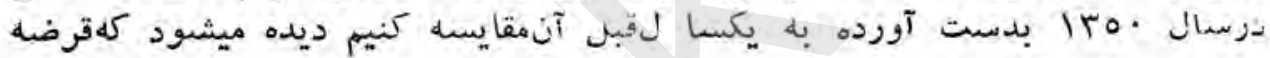

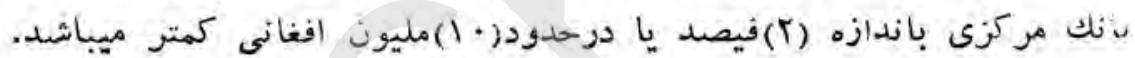

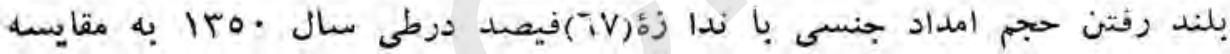

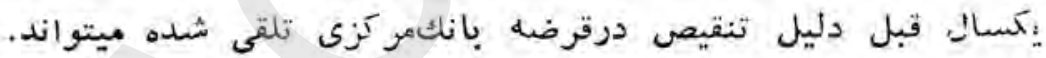

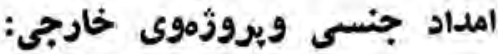

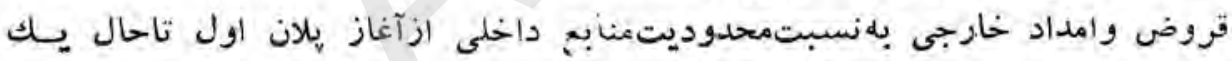

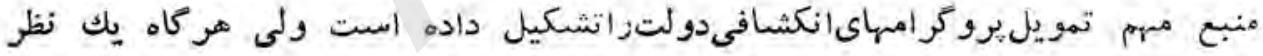

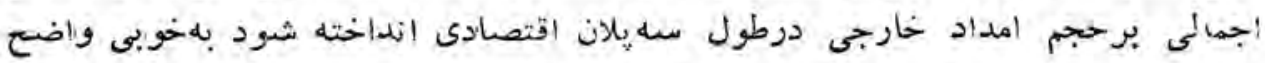

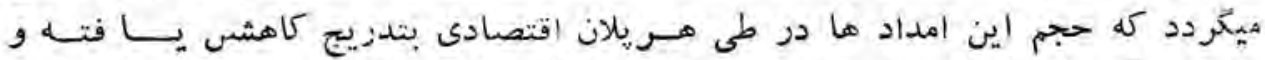

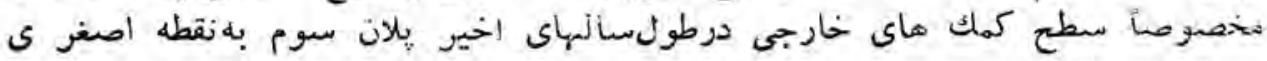

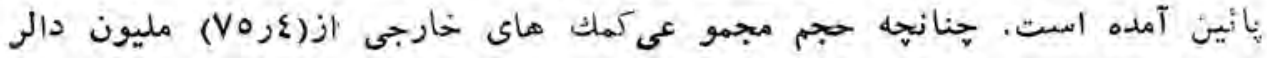

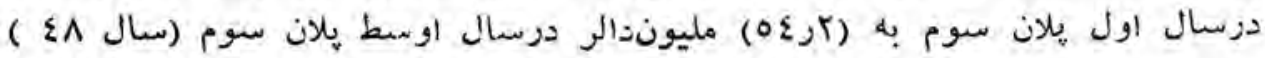

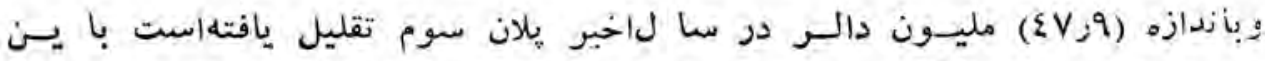

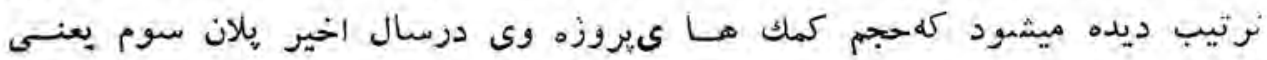




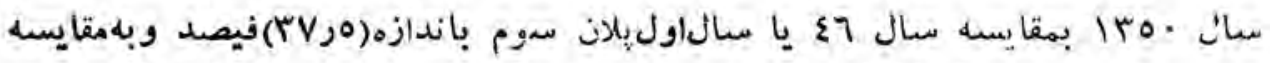

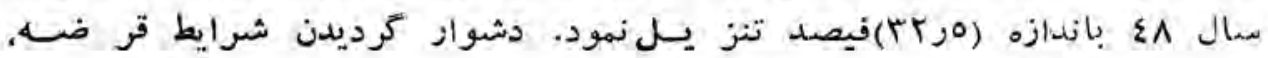

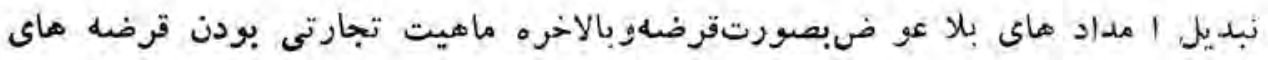

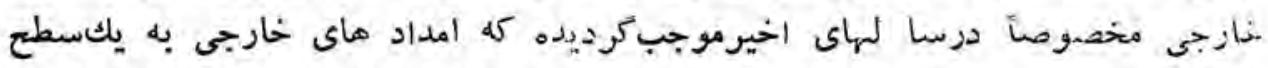

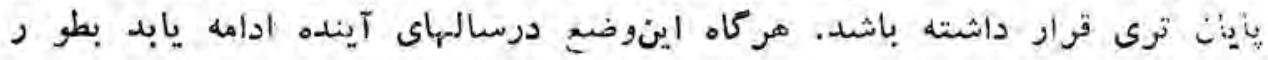

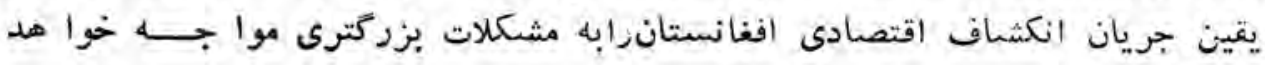
ساخت.

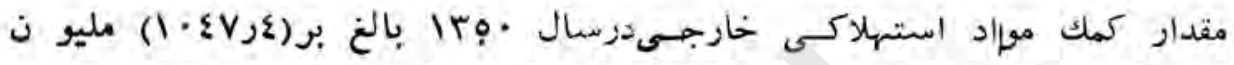

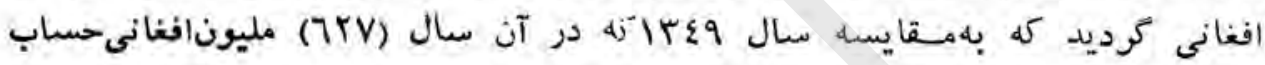

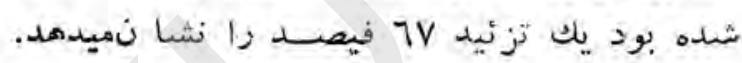
بليد متذكر شهد كلاين رقم بلند تويسنرقمى امداد مواد استهلاكى را در طولبنج

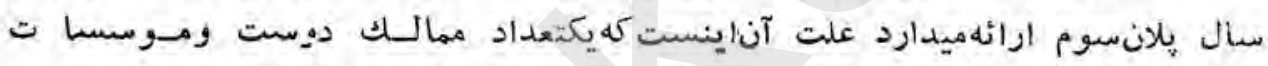

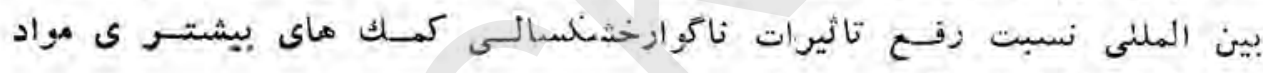

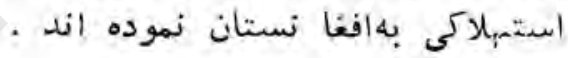

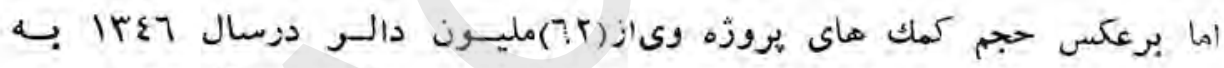

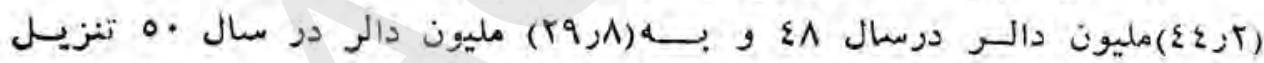

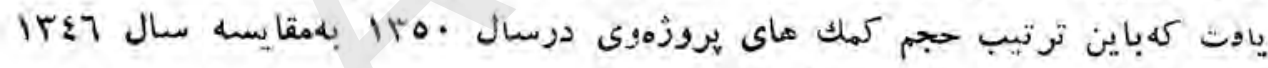

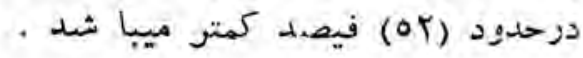

\section{ب)معبارف:}

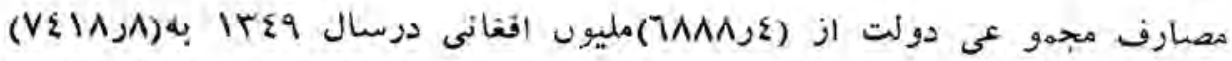

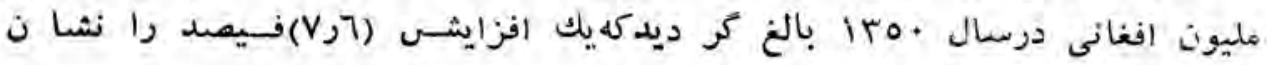

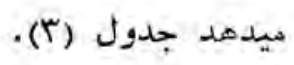




$$
\text { جدول (r) }
$$

مصارف مجموعى دولت بصورت فيصدى

$$
\text { ارقام به مليون افغانى دوري }
$$

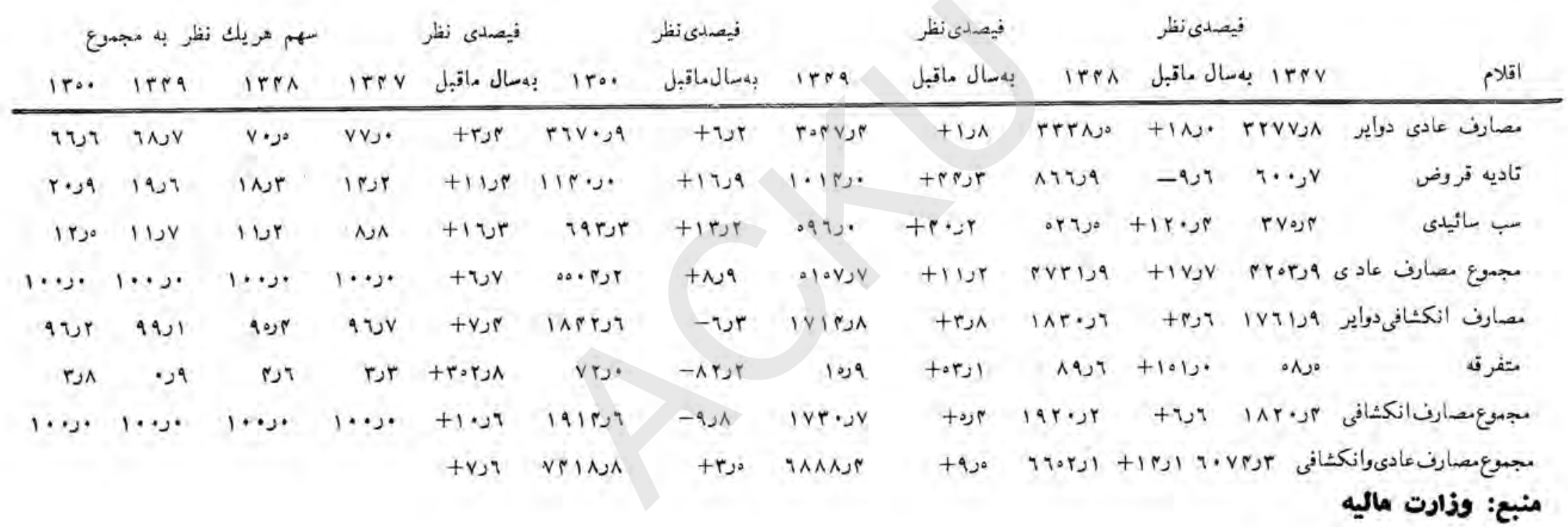




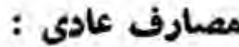

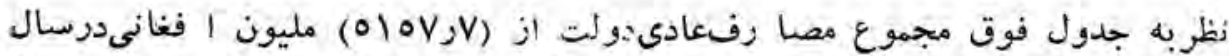
92

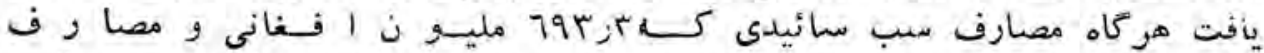

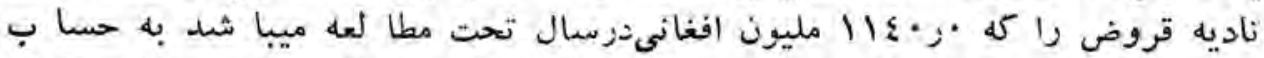

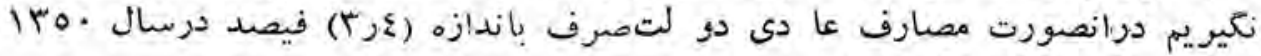

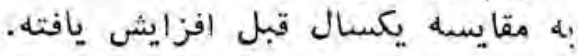

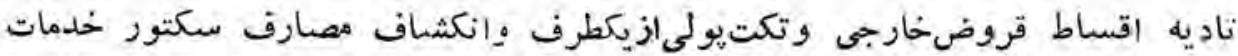

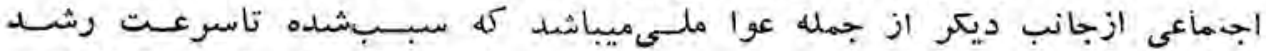

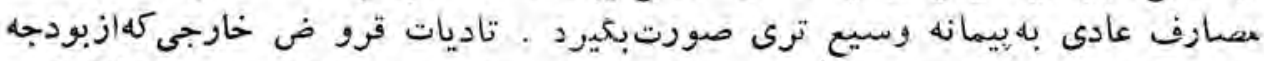

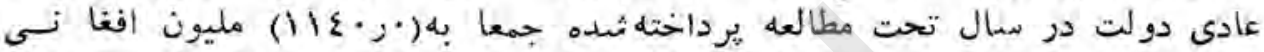

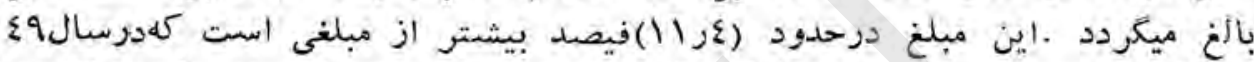

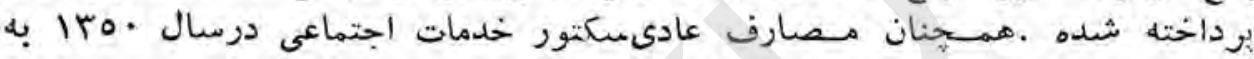

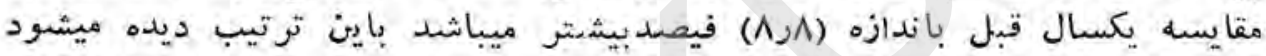

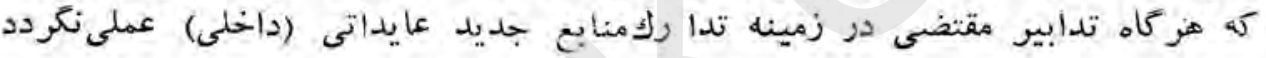

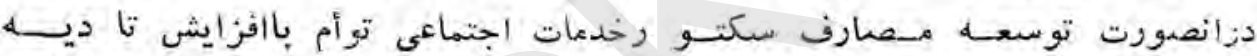

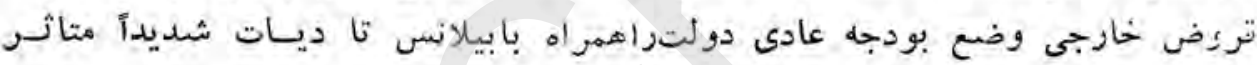
خو اهد ساخت.

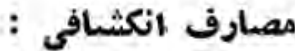

هصارف انكشافى دو لت درسال.

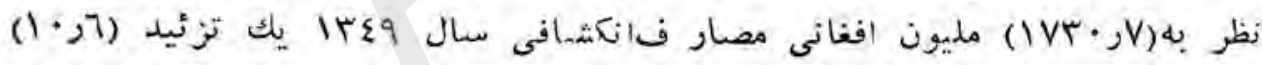

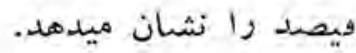

طو ريكهدر جدول (r) بملا حظه ميرسدفيصدى رشد هصارف انكشافى ازبودجه

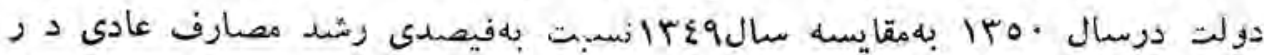

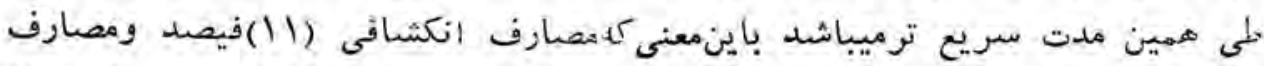

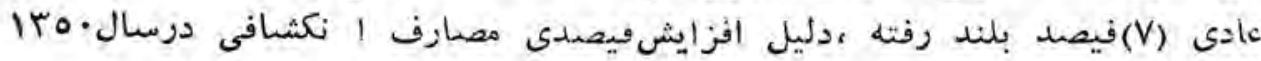

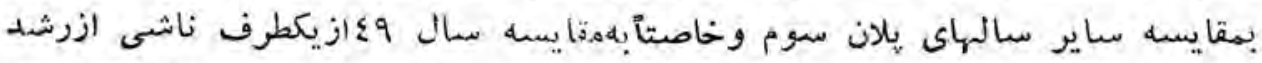

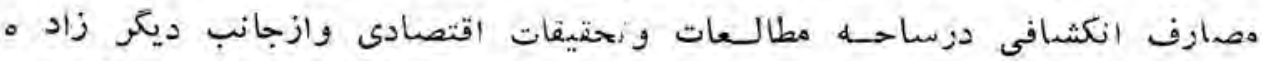

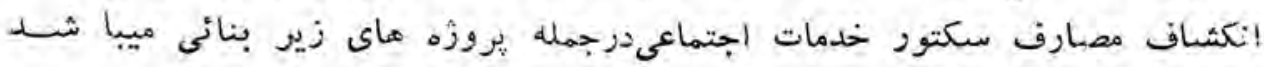
(مر اجعه به جدول ع) ). 


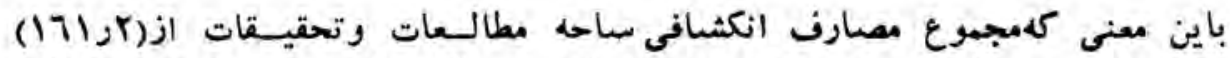

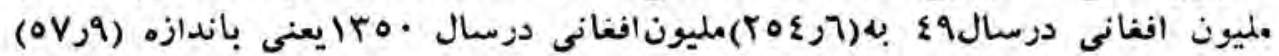

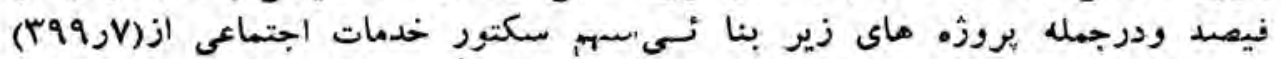

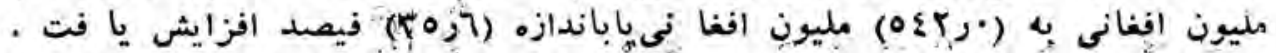

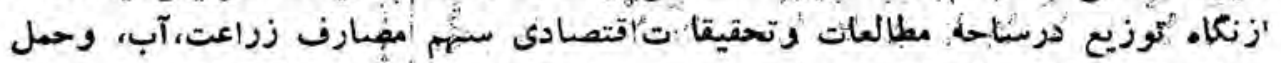

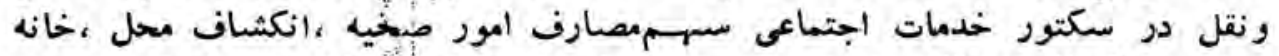

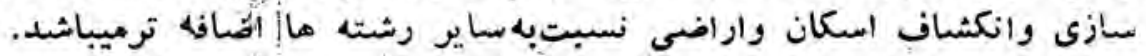

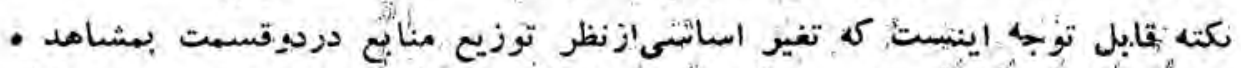

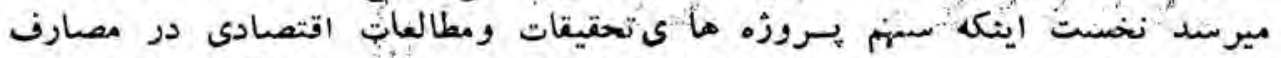

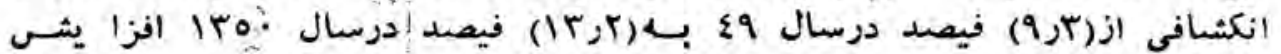

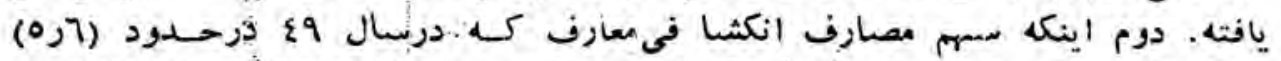

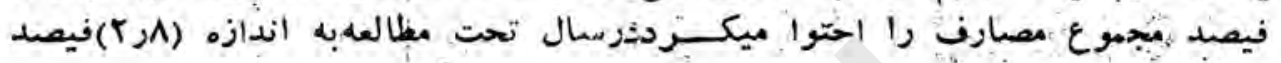
تنزيل نهوده امست.

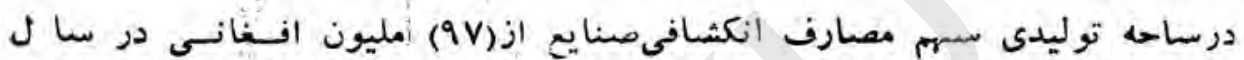
9

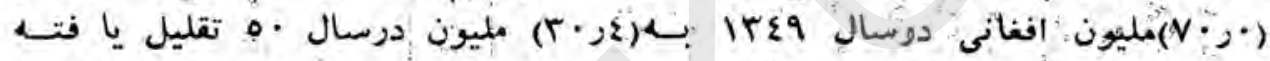

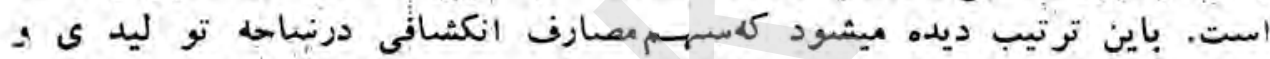

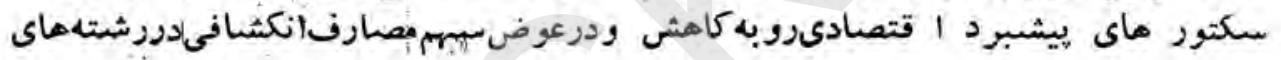

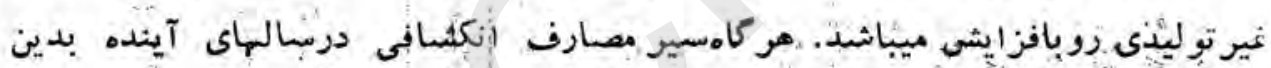

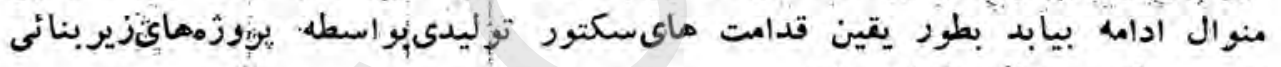

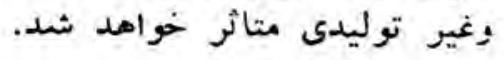

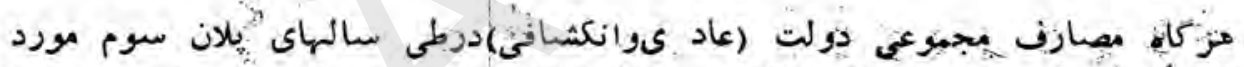

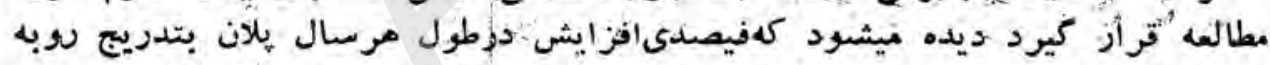

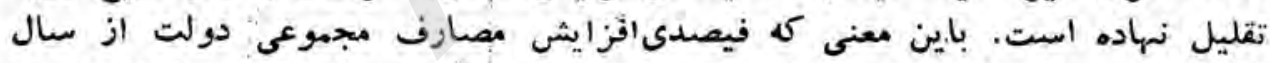

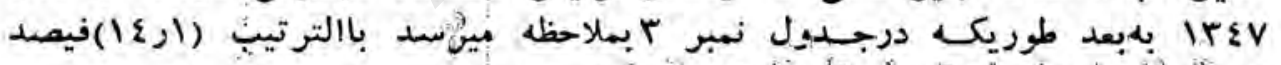
. فيطند (Y,0)

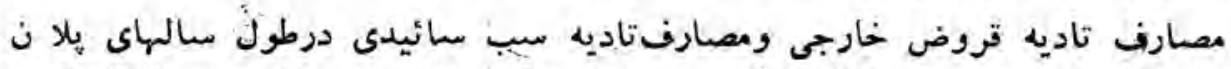

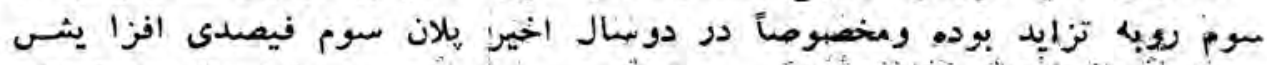

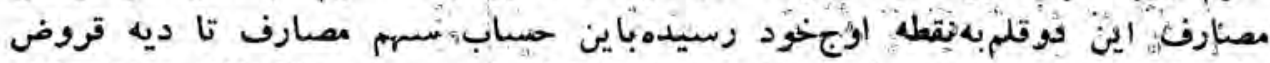

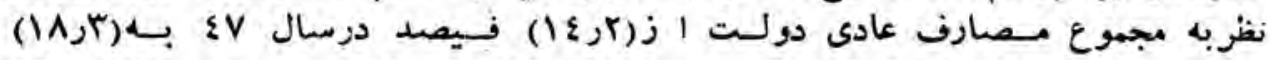

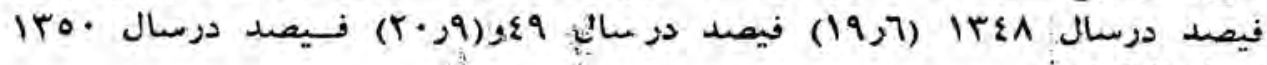

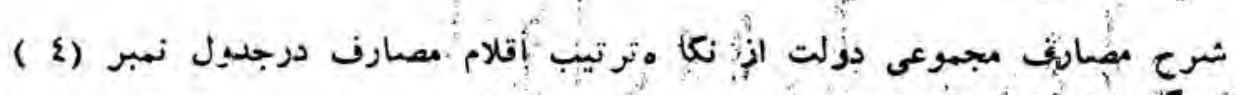

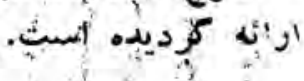




\section{جلول (2)}

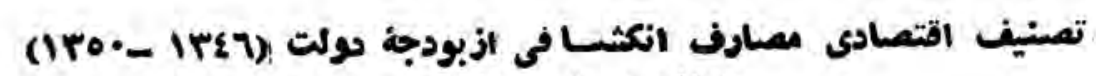

ارقام به مليون الغفانى أودج

\begin{tabular}{|c|c|c|c|c|c|c|c|c|}
\hline فيصدى & iro. & فيصدى & $1 T \varepsilon 9$ & فيصدى & $\mid r \varepsilon \wedge$ & فيصلى & IreV & سكتور اقتصادى \\
\hline $1 \cdots$ & $191 \varepsilon, 7$ & $1 \cdots$, & $I V K \cdot J V$ & $1 \cdots$ & $19 r \cdot j$ & $1 \cdots$, & IAT.رE & ا 1جموعمومى سمتمانهاى \\
\hline 70,1 & IrEv & 77,7 & $110 r, 9$ & $7 v, r$ & $18 \wedge 9,9$ & $7 v, 9$ & Iross & ذير \\
\hline vir & 1E.jr & $\cdot 2 v$ & 18,7 & ع & $A, r$ & 9, & $v \cdot s$ & انرزى برق ونقل و \\
\hline IrjE & $r V V, \Lambda$ & $r$ & ror,t & 17,8 & rIEj & $|\varepsilon j|$ & rovsr & مواصلات \\
\hline ratr & $0 \leqslant r$, & $r r_{2}$ & พ१९รV & $r \varepsilon, \Lambda$ & $\varepsilon V 7, r$ & raرغ & or $\varepsilon, 7$ & خدماتاجتماعى \\
\hline ris & or,g & 0,7 & $9 A$, & $\varepsilon ر$. & $v า, \varepsilon$ & 0,7 & $1 \cdot r, 2$ & معارف \\
\hline$\varepsilon, 0$ & $\Lambda V, \varepsilon$ & re & ०१,. & $1, n$ & rron & $I, \lambda$ & $r r, r$ & صحيـ \\
\hline لم. & $v_{j}$. & 9 & 10,9 & 1 & rr & ג & $10,$. & بنساروالى \\
\hline$v, 0$ & $1 \varepsilon \varepsilon, 0$ & & $r \varepsilon, q$ & $r, \varepsilon$ & $\varepsilon 0, v$ & $r, V$ & $\{9,7$ & انكشافحماتومحلات \\
\hline - & 1,9 & - 1 & r. & عرب & $v, 1$ & ו & $r_{2}$ & اطلاعاتو كلتور \\
\hline$r, \varepsilon$ & 70,0 & ror & ov, & ER & Al. & $\varepsilon, 7$ & $A T, 0$ & خانهبازى \\
\hline 9,0 & $|A|, \Lambda$ & $A, r$ & $|\varepsilon|, q$ & $1 \cdot, 9$ & $r v \cdot r$ & גנזיו & $r 0 ., 8$ & غيسر. \\
\hline
\end{tabular}




\begin{tabular}{|c|c|c|c|c|c|c|c|c|}
\hline A & $100, \pi$ & $\mid \varepsilon ر \varepsilon$ & ro.,. & $\mid \varepsilon ر$ & rAY,E & $\mid r, \Lambda$ & Arrikr & آبيارىوكنترولسيلاب \\
\hline 7,1 & iri,g & $v, q$ & IrAj. & $1 \cdot 9$ & $r \cdot N, A$ & $\Lambda, \Lambda$ & $109, \varepsilon$ & نزاضهى \\
\hline rilo & $\varepsilon I r, V$ & $r \varepsilon s^{*}$ & $\varepsilon \| V_{\mu}$. & $r 7, r$ & $\{\wedge 0\}$, & ros: & $\varepsilon 0 \wedge, 0$ & r- ساحةتوليدى \\
\hline$r, q$ & $00, \Lambda$ & 10,7 & $9 v_{2}$. & 1,7 & $17 \varepsilon, r$ & $v, 0$ & פנד & صنايع \\
\hline iv,. & (rדo & $1 \varepsilon, \varepsilon$ & ro.,. & $\mid r, \lambda$ & rnos. & Ir, & rra, & زراعت \\
\hline 1,7 & $r \cdot, \varepsilon$ & $\varepsilon$ ر & $v \cdot, \cdot$ & r, & 07, & $0,$. & ars & مaادن \\
\hline & & & & & & & & rـ ساحن مطالعات \\
\hline rrtr & $r 0 \varepsilon, T$ & T. & $171, \pi$ & $v, 0$ & $\mid \varepsilon \varepsilon, A$ & 9 & $1 \cdot v_{j} \Lambda$ & تعقيقات \\
\hline$r, \varepsilon$ & $\varepsilon 7,7$ & 1,7 & rAs. & 1) & rig. & 1 & $r \cdot g \cdot$ & زراعت \\
\hline$v, q$ & 101,0 & $v, r$ & irose. & דرם & $1 \cdot \Lambda_{j} \cdot$ & أر & $V \varepsilon, q$ & مادن \\
\hline ارץ & $\varepsilon \cdot\rangle$, & r & 0, . & عر. & $\Lambda, 0$ & . & 9,1 & آب \\
\hline$\cdot 2 \Lambda$ & $10, V$ & ار• & $r_{2}$. & عر. & vir & זر. & וر & حملونقل \\
\hline - & - & - & r & - & - & - & - & صناي \\
\hline
\end{tabular}




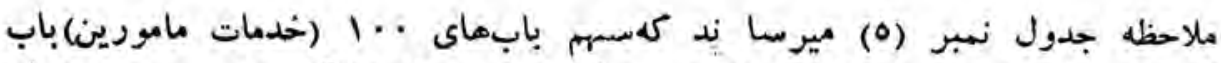

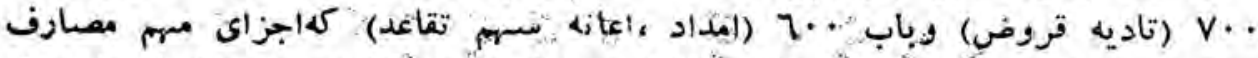

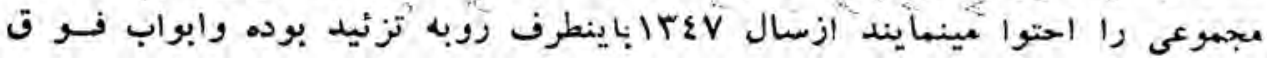

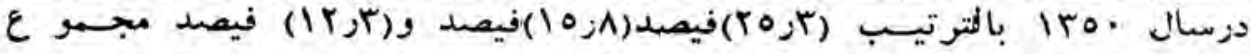

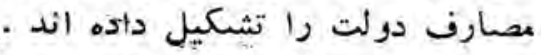

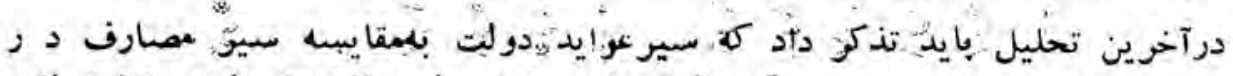

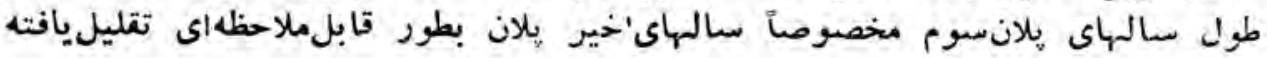

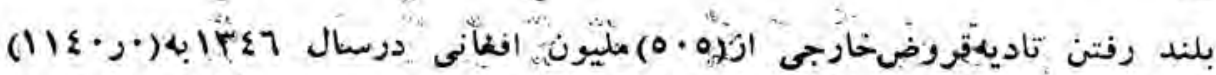

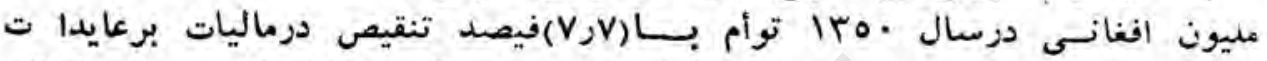

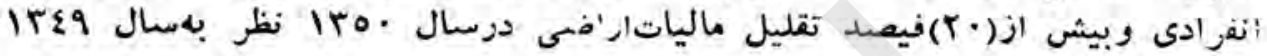

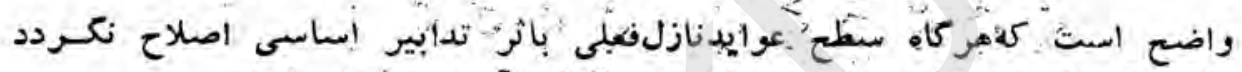

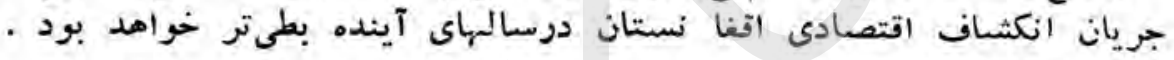

بrol بردجه سال

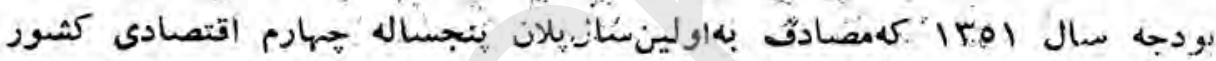

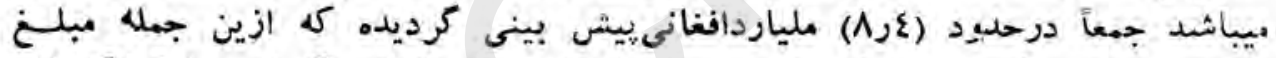

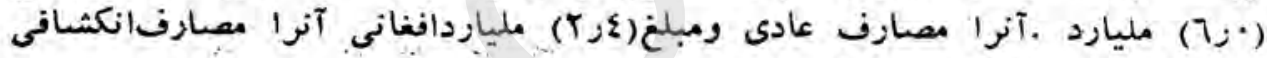

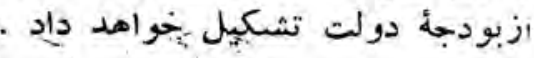

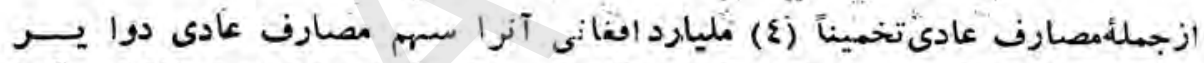

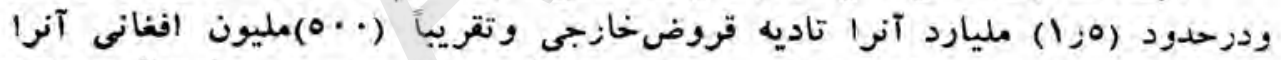

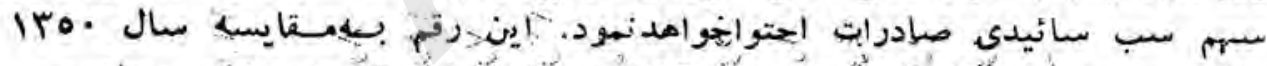

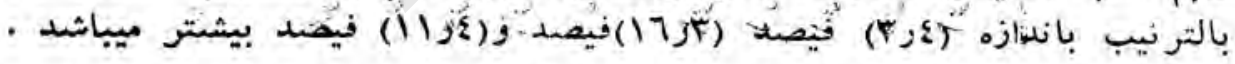

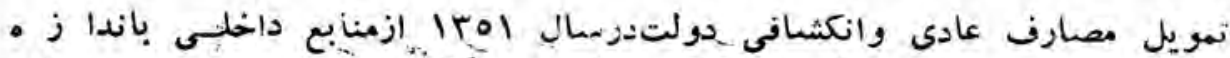

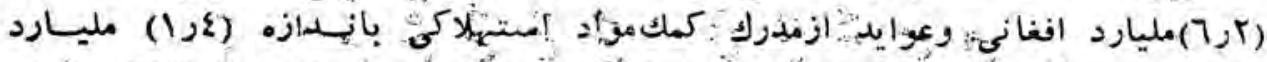

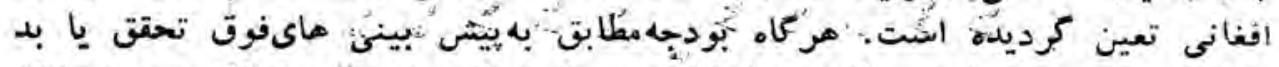

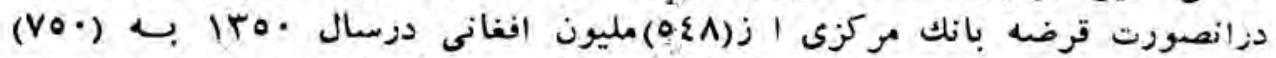

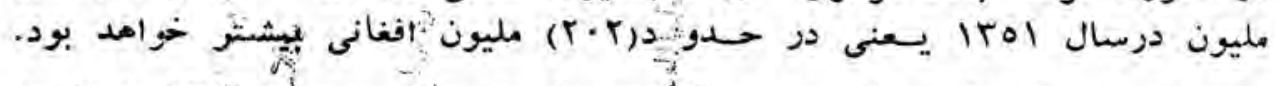

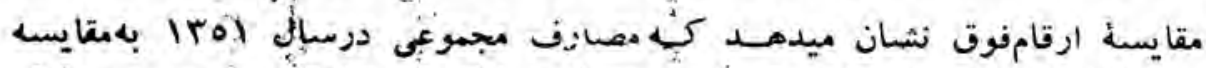

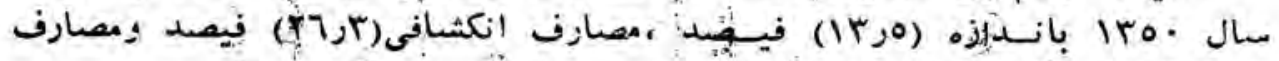

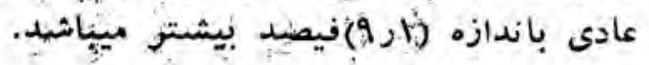




\section{جلول (0)}

مصارف عادى وانكثافى احولت بتفريسقابواب

\begin{tabular}{|c|c|c|c|c|c|c|c|c|}
\hline iro. & 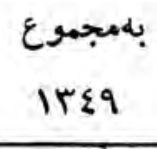 & هريكنظر & سrev & iro. & مليون افغانى & 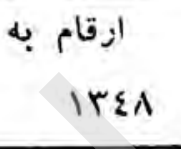 & $1 T \varepsilon V$ & كود نمبر و اقــلام \\
\hline rojr & 17,9 & $r 0, r$ & ros & $\mid \Lambda \Lambda \varepsilon, T$ & $1107, \varepsilon$ & ITAYj7 & $10 r \wedge, 7$ & . ا خدمات مامورين \\
\hline$\varepsilon, \Lambda$ & $\varepsilon, 7$ & $\varepsilon, 0$ & $0,$. & roy,A & rtr,o & $r T \leqslant, q$ & $r \cdot r, q$ & · r ديكرخدمات \\
\hline ir, & 10,1 & 171 & $10,$. & $1 . r 49$ & $1.91,9$ & $1 \cdot v 1,1$ & $914 \pi$ & • • اجناس إمان ولوازم \\
\hline $1, V$ & 1,9 & $r, 0$ & $r, 7$ & Itrov & $|r r|$ & Ivroo & $17 r, 9$ & •. . . تجهيزات ولوازم \\
\hline r. & $\varepsilon, 9$ & וקד & $\wedge, \varepsilon$ & $\langle\varepsilon||$, & $r \varepsilon r,$. & $\varepsilon \cdot V_{0}, \varepsilon$ & 0171 & •. \\
\hline$i r$ & $9>9$ & $1 \cdot s v$ & 11, & 917,9 & $\backslash \Lambda \varepsilon, \varepsilon$ & $V \backslash \varepsilon, \leq$ & 779,9 & · 7 حقوت تقاعدى كمكى \\
\hline 10,1 & $\mid \varepsilon, n$ & Irja & 1.j 1 1 & $11 v 5,9$ & $1 \cdot r \varepsilon, r$ & 919,9 & $719, \varepsilon$ & v. خدمات قرضس v \\
\hline r & - & r & $\cdot .29$ & 17,5 & $1 \varepsilon, 0$ & $1 v, 9$ & 00,9 & 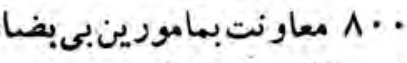 \\
\hline rrr & ri, & $r \cdot j \Lambda$ & risv & I $7 \vee \varepsilon,$. & $|\varepsilon| q, V$ & Irrajv & $1 r 90, r$ & خارج تصنيف \\
\hline $1 \cdots$, & $1 \cdots$, & $1 \cdots$, & $1 \cdots$, & 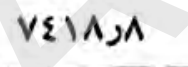 & \urcorner$\wedge \wedge \wedge, \varepsilon$ & 770521 & $7 \cdot v \varepsilon, r$ & مجموع : \\
\hline
\end{tabular}




\section{تاديات وتجاوت خارجى}

\section{وضع اسعار خارجى:}

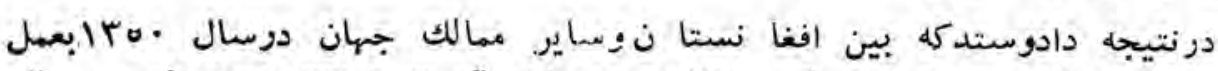

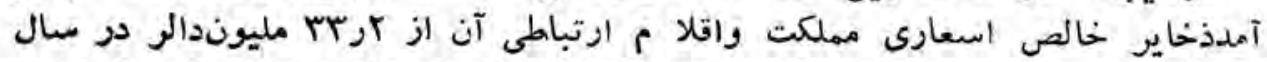

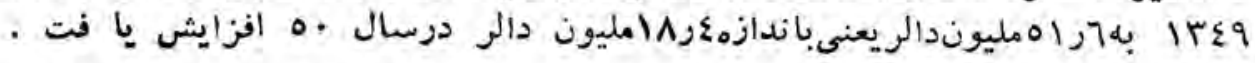

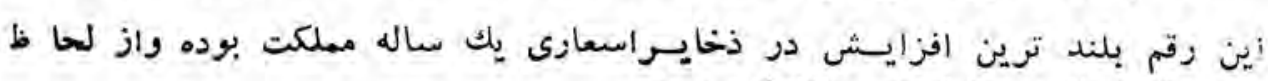

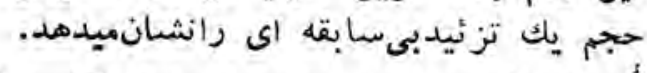

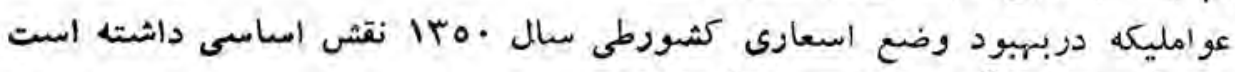

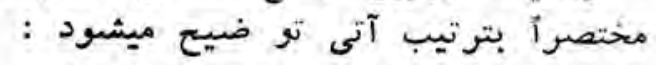

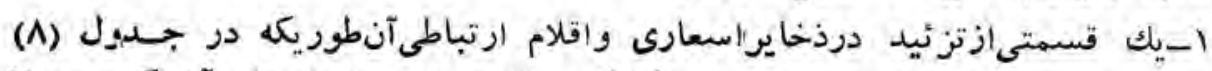

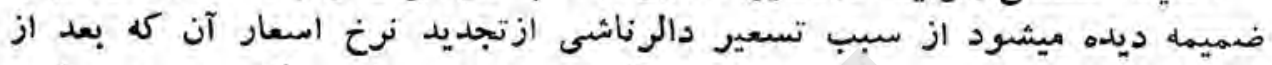
تنزيل نرخ دالر در ماه قوس • .

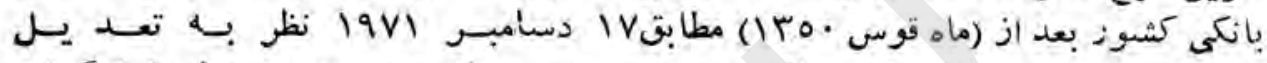

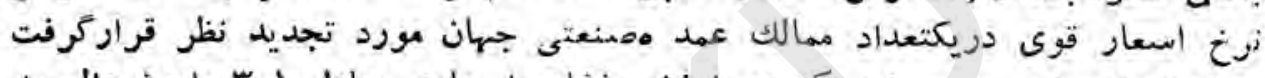

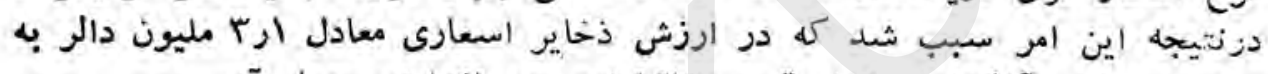

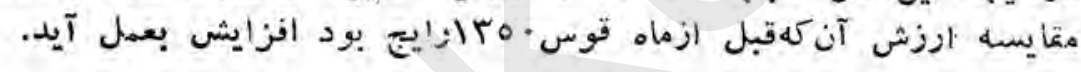

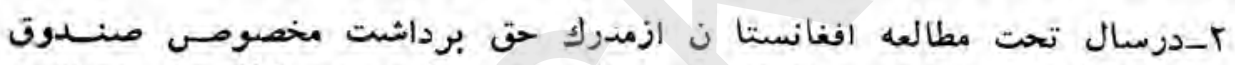

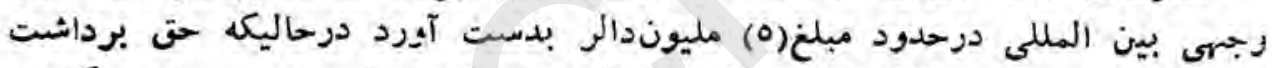

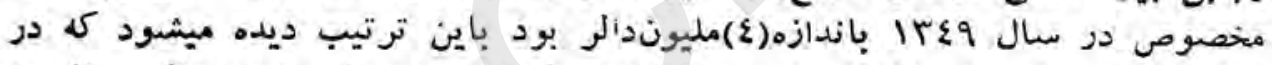

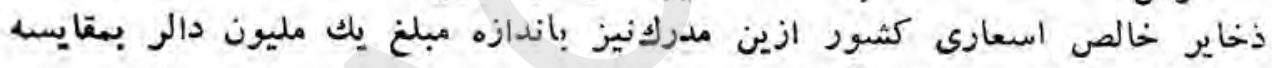

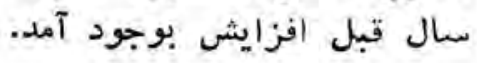

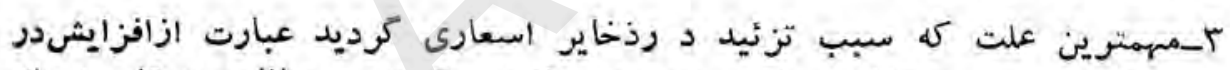

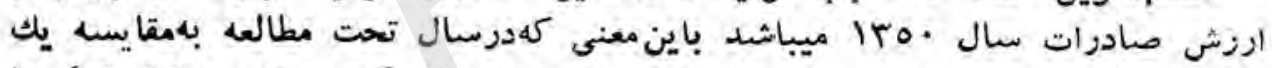

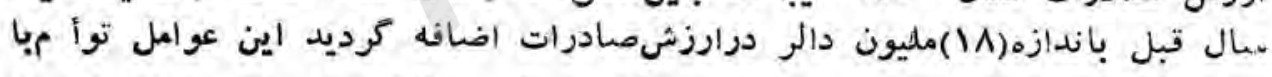

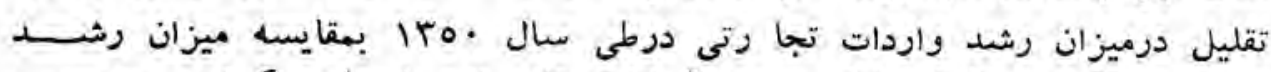

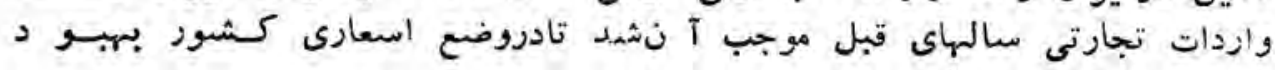

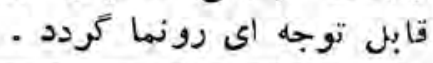

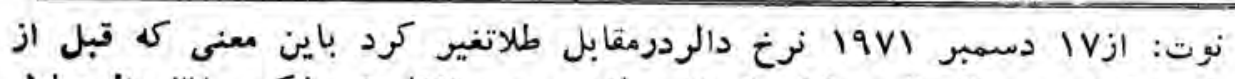

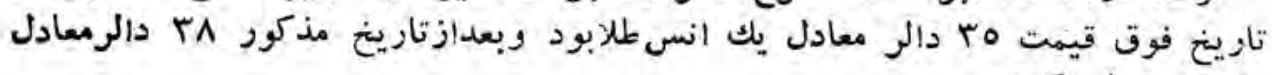

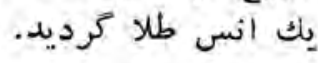

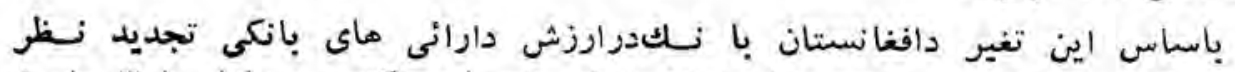

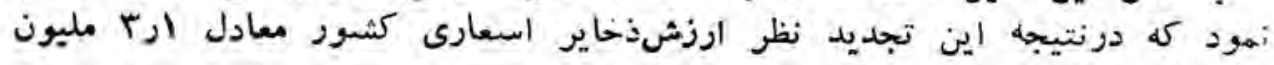
2יالر بلند رفت. 


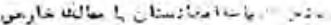

ارئام به لطبون دالم

\begin{tabular}{|c|c|c|c|c|c|c|c|c|c|c|c|c|c|c|c|c|c|c|c|}
\hline & & & 1769 & L & $=$ & & & & & & & $1 T(A)$ & JL & -- & & & & & \\
\hline بوب & - & -1 & ت. & اد , صند, & jo 10 & $\Rightarrow$ & مزنه بــا: & $=1$ & 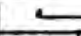 & $\rightarrow$ & $\longrightarrow$ & , & الم وصند & 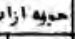 & ر & $\longrightarrow$ - & $\Rightarrow$ & 1. & \\
\hline w & $\Rightarrow 0$ & $=4 x^{2}$ & r & $\Rightarrow d$ & 5 & r & $\Rightarrow$ & $-x^{5}$ & wit & $\therefore x^{2}$ & $\mid-+x^{5}$ & | & ED & $=+y^{5}$ & N & $\because-\therefore$ & $\therefore+5$ & & \\
\hline-46, & irto & 1A, & $-19,5$ & A., T & 71,0 & $-16 \lambda$ & - & |مرYr| & 54 & $18 \times, 0$ & $10, x$ & $-|\lambda|$, & YA,T & | ז, & -rast & 36 & $-70,0$ & إد & , t? \\
\hline$r, t$ & ris. & $\alpha r, \pi$ & $-1, \pi$ & $0.7,0$ & $C A, T$ & 11,4 & $1 x, 0$ & $T \cdot x$ & $x$ & Yro & 11,1 & $-r_{2 \lambda}$ & 0 & $(4,0$ & $14, \pi$ & $\log x$ & $\therefore 24$ & (1) & \\
\hline tינד & . & - & is & ? & - & - & - & - & • & ro & - & -rja & $T 0^{\circ}$ & - & $-\overline{1}$ & - & - & (i) 5,4 & \\
\hline (s) & 12. & $2, y$ & हภ & is. & זנ4 & - & - & ות & קז' & $1, \mu$ & $\mathrm{en}$ & 1,4 & I & 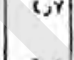 & -21 & - & 21 & is & \\
\hline in & 1,8 & $A r$ & " t & 1,1 & $x$ & $1, \pi$ & - $x$ & Iנ. & مرY & 1,0 & 3 & 0 & 1,0 & 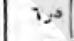 & : & $\because 0$ & 100 & 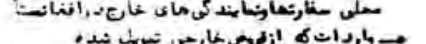 & \\
\hline$-1 v, 1$ & $r y, r$ & -1 & $-\lambda \boldsymbol{t}$ & 1,4 & - & $-1 \lambda, y$ & IA,Y & - & $-1, \pi$ & (ז) & - & ז & $1 \cdot \pi$ & - & - & ז & - & 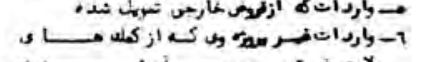 & \\
\hline$-16, y$ & 16,7 & - & $-0,1$ & 0,4 & - & $-\lambda ; \lambda$ & Ash & - & $\rightarrow \cdot \cdot$ & 1.0 & - & 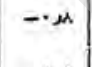 & $\cdot \mu$ & - & - : : & UT & -1 & 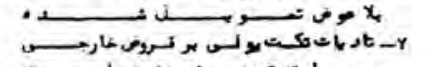 & \\
\hline$-1,9$ & 12 & - & $-i j$. & w. & - & $-\infty, 1$ & • & - & $-1,0$ & 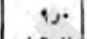 & - & $-1,1$ & (2) & - & $-5,1$ & 1,9 & - & 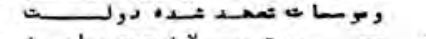 & \\
\hline TAJT & $1 \lambda, r$ & $(r, r)$ & 1, & Ast & $i r, \lambda$ & $11, \pi$ & $1 \cdot 1$ & rat & $(1, y$ & $17, y$ & ent & $0, y$ & $y, \gamma$ & $1 \pi, 6$ & 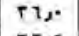 & 12. & 10,4 & 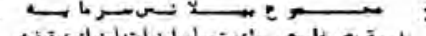 & 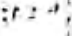 \\
\hline 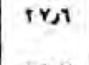 & - & $i r, 1$ & A, & - & 1,9 & $\mid \alpha, y$ & - & $\mid \lambda, \gamma$ & (1) & - & हE, & $1 \cdot \pi$ & - & $1+\pi$ & Tr/ & - & $r \Gamma, 9$ & 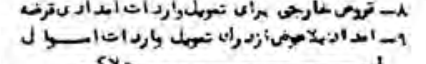 & \\
\hline 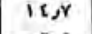 & - & 1,8 & •rt & - & ๑4 & A $2 \mathrm{~s}$ & $\rightarrow$ & $A+1$ & 1.,. & - & $1 \cdot$, & $\cdot 2 \mathrm{~A}$ & - & $\therefore \lambda$ & er & - & 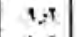 & ustan & \\
\hline T, & ז. & 2.1 & 1,2 & תנז & ז. & 1,4 & - & 1,1 & זرע & יטי & $t, \pi$ & זיני & $r$ & , & $12:$ & -1 & 129 & v $\quad \overrightarrow{\text { v }}$ & \\
\hline rut & 17,5 & $\cdots$ & זוד & is & - & $-1 \cdot, 1$ & $1 \cdot 1$ & - & -i $\varepsilon, y$ & $\mid c, y$ & -1 & $\rightarrow, r$ & 4 r & - & $-\because$, & 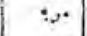 & - & 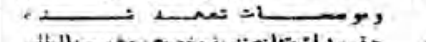 & \\
\hline t). & -1 & $\therefore$ & is. & - & $\because \cdot$ & - & - & - & se & -1 & 8,1 & 6,1 & - & (4) & $=1$ & - & - & 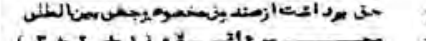 & $\left\{\operatorname{lot}_{0}\right.$ \\
\hline -11 & $10 \cdot 0.4$ & 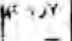 & ה & ANe & $\operatorname{crsi}^{-1}$ & $\left|\begin{array}{rl}8,8 \\
-1, y,\end{array}\right|$ & $r^{2}$, & 11,9 & 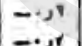 & $\mid x-1,4$ & 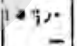 & $-y, 0$ & ᄉi, & $r \wedge, 0$ & $\begin{array}{l}4, \pi \\
-1,1\end{array}$ & $\begin{aligned} 2,1 \\
-1\end{aligned}$ & 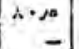 & 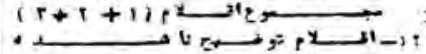 & \#n+ \\
\hline th & - & $\overline{-}$ & (נת & - & - & $-\infty, 1$ & - & - & 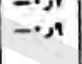 & $\overline{-}$ & $\overline{-1}$ & $\rightarrow \mu$ & - & -1 & 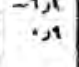 & - & - & 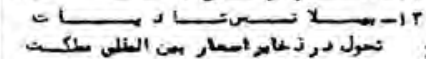 & \\
\hline זיגי & A, & $r, \lambda$ & - נו- & A. & ת. & ojh & -1 & - & $\cdot$, & . & $\mathrm{sen}$ & iر & $\bullet$ & $T \mu$ & -21 & 9 & - & وائلاءp' & \\
\hline ינז & & T. & $r_{j}$. & -1 & קנו & - & - & 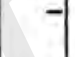 & - & - & - & - & - & - & - & - & -1 & 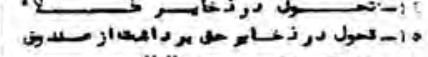 & \\
\hline-1, & $1,$. & - & -1, & 1,0 & - & - & - & - & $-1,4$ & \&, & - & $-1,1$ & $x, 9$ & -1 & - & -1 & - & 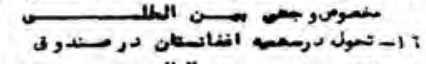 & \\
\hline - & - & - & - & - & - & - & - & - & - & - & -1 & - & - & - & -1 & - & - & 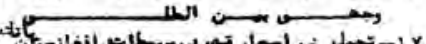 & \\
\hline 11 & 11 & - & -11 & 1ر & - & - & - & - & 1) & - & 121 & "1 & - & w & - & - & - & مرل & \\
\hline - & • & - & - & ק, & - & - & - & - & $-\pi$ & - & . & $\pi$ & - & • & 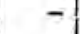 & - & - & 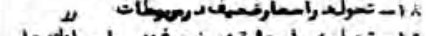 & \\
\hline ו-3י- & $\because$ & - & ו & זر• & - & - & - & - & וرים & ا & - & ונ.-- & ות. & - & 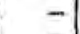 & 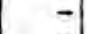 & 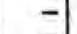 & 11 & \\
\hline$-1, x$ & is & - & $-1,1$ & is & - & - & - & -1 & -x & - & C & $\cdot x$ & - & $\cdot x$ & - & - & - & 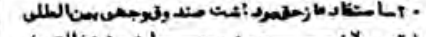 & \\
\hline - & - & $\because$ & - & $=$ & - & - & $=$ & - $\leadsto$ & 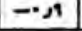 & *0 & -1 & = & $=$ & -1 &,- 1 & $\cdot \pi$ & -1 & ( & \\
\hline
\end{tabular}




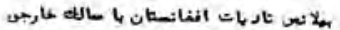

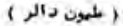

\begin{tabular}{|c|c|c|c|c|c|c|c|c|c|}
\hline \multicolumn{3}{|c|}{$\longrightarrow$} & \multicolumn{3}{|c|}{ 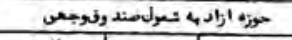 } & \multicolumn{3}{|c|}{ - } & \multirow{2}{*}{ 出1 } \\
\hline ren & נח & كريدث & r & J & 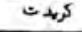 & (1) & دلهة & $=5$ & \\
\hline$-11 \mu$ & $100, y$ & 11rs & $-|V|$ & AAJT & Yit & $-1, y$ & $i v, t$ & $\because \mu$ & ارل : ال' \\
\hline 1., & 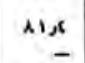 & is: & $\begin{aligned}-1,00 \\
1, r\end{aligned}$ & or & $\begin{array}{ll}-1 \mu \\
1, r\end{array}$ & Ir, & [A, & $8 \pi$ & 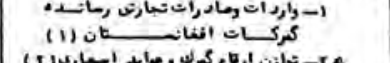 \\
\hline$\sqrt{11}$ & $r$. & $a x$ & or & קי. & $\begin{array}{l}1, r \\
y, y\end{array}$ & $\bar{y}$ & $\overline{-}$ & $-\bar{y}$ & 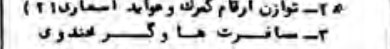 \\
\hline & & & i,r & |ر1 & Ix & & & & 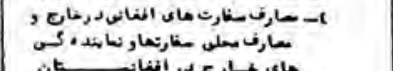 \\
\hline - & $i r, r$ & - & $-1+4$ & irgis & - & $\begin{aligned}-12 x \\
3 x\end{aligned}$ & ive & 1, & 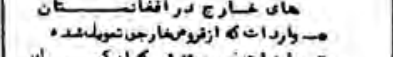 \\
\hline$-10,0$ & 10, & - & $-11,0$ & 110 & - & $-r$ & مرr & - & 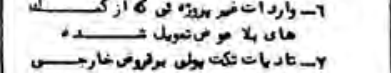 \\
\hline$-1, x$ & $a \lambda$ & - & זות & $r, r$ & - & -1, & tr. & - & 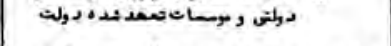 \\
\hline •rs & inst & ris. & ros & 1ر & $(1, \pi$ & ry. & $i \mu$ & Tis & 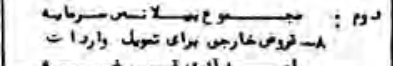 \\
\hline iytr & - & 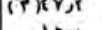 & $i v \mu$ & - & $i v \mu$ & $w x$ & - & $r a, x$ & 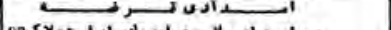 \\
\hline 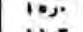 & - & 10. & 11,0 & - & 11, & Tر & - & 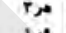 & 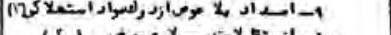 \\
\hline $11, \pi$ & Tر & iTh & 1,8 & 10 & 11,4 & 1,1 & - & 1,4 & 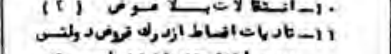 \\
\hline$-13 x$ & $13 x$ & - & - ת & וגז & - & $-1+\mu$ & $11, \mu$ & - & 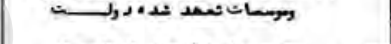 \\
\hline •• & - & 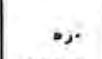 & ני. & - & •. & - & - & - & 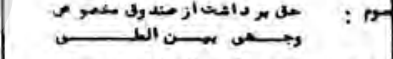 \\
\hline$r \cdot r$ & irest & in, & irs. & 11, & 118,8 & $-r, y$ & A.j. & rrot & $(r+r+1) r^{2}{ }^{\prime \prime}(x): 0$ rer \\
\hline$-1 \mu$ & - & - & $-i \pi$ & - & - & $r$ & - & - & 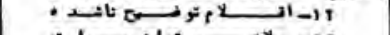 \\
\hline IAse & - & - & iagh & - & - & 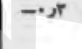 & - & - & 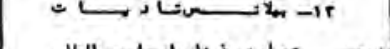 \\
\hline$-1 A, 0$ & 19 & $1, \mathrm{c}$ & $\rightarrow A \mu$ & 19,9 & וرי & •r & - & tr & 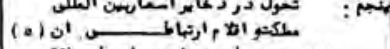 \\
\hline$-1, y$ & T,k & - & $-1, y$ & $1, y$ & - & - & - & - & "11 \\
\hline$x$ & $\cdots$ & 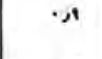 & יני & - & $\cdot x$ & - & - & - & 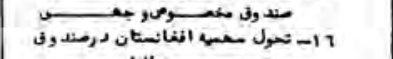 \\
\hline - & - & - & .. & - & - & - & + & $\rightarrow$ & 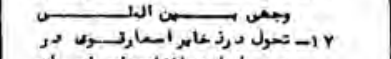 \\
\hline | & ir. & - & -15 & 15 & - & - & - & - & 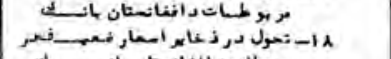 \\
\hline$\overline{-}$ & - & $\overline{-}$ & $\overline{-}$ & - & $\overline{-}$ & - & - & - & ت \\
\hline זני & - & זرث & 1 & - & זر: & - & - & - & 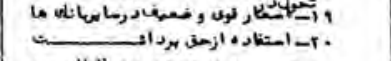 \\
\hline 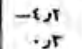 & ז & $\ddot{z}$ & $-8, r$ & ist & - & $\overline{-}$ & - & $\overline{-}$ & 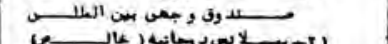 \\
\hline ot & - & ता & - & - & - & זער & - & $\mathrm{s}^{\mathrm{r}}$ & 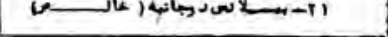 \\
\hline
\end{tabular}

(1)

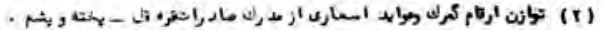

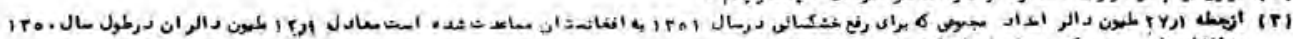

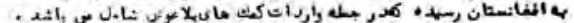

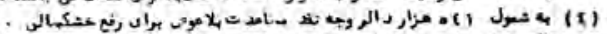

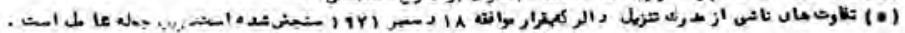

\section{$14 a 09$}




\section{بيلانس تجارت خارجى:}

الف :مادرات

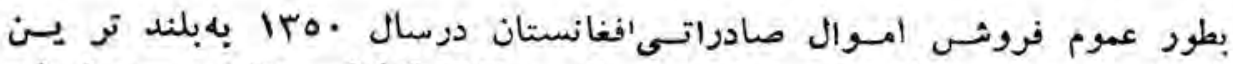

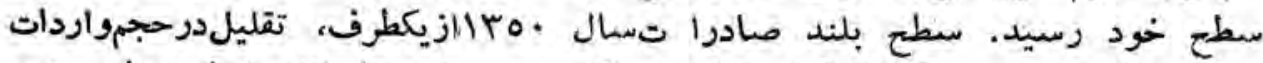

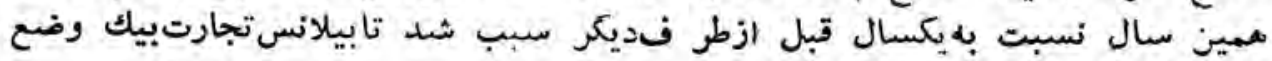

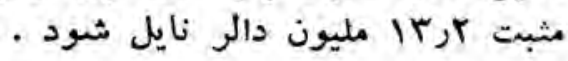

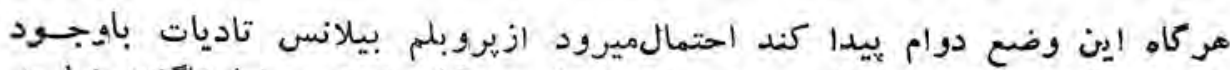

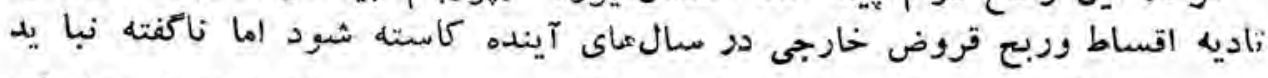

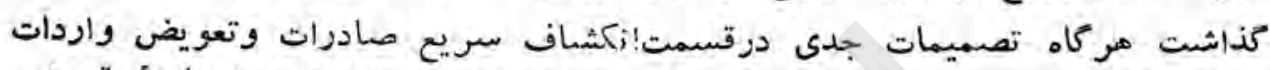

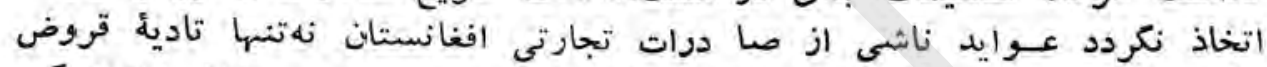

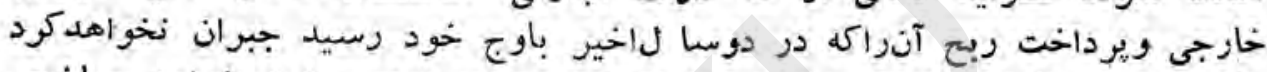

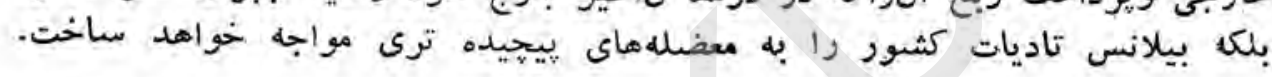

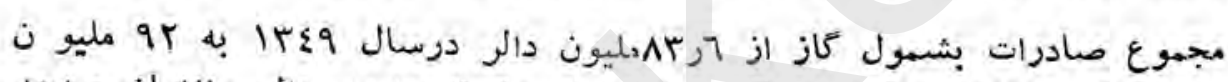

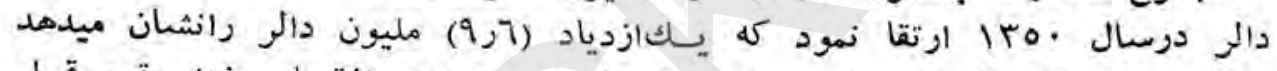

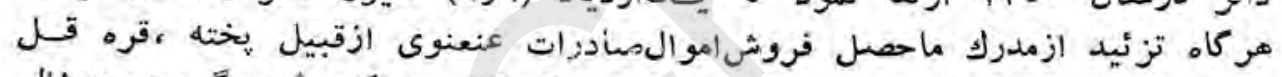

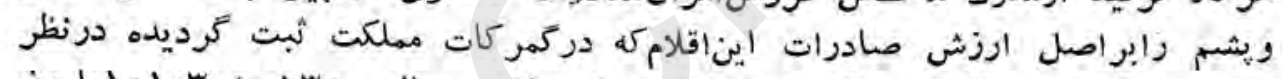

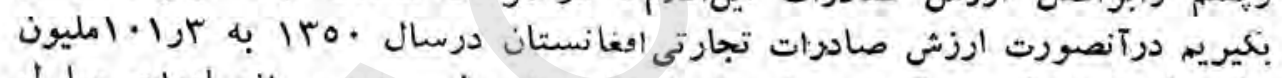

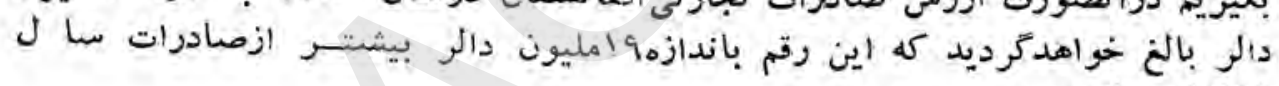

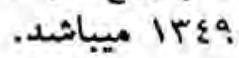

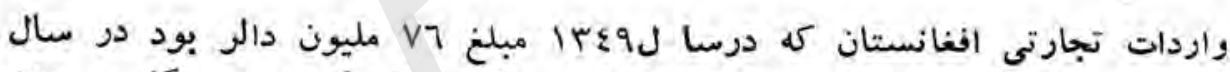
.

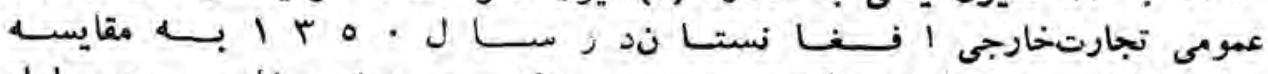

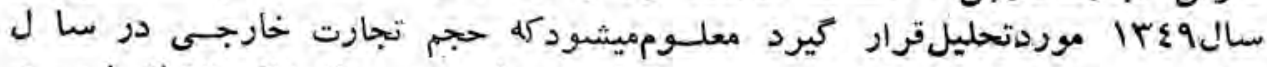

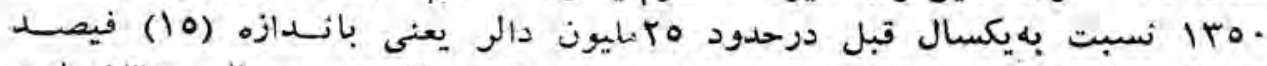

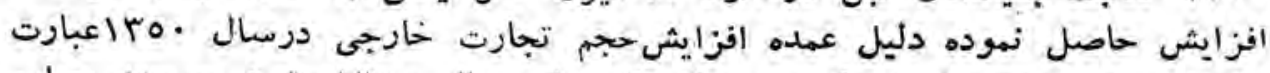

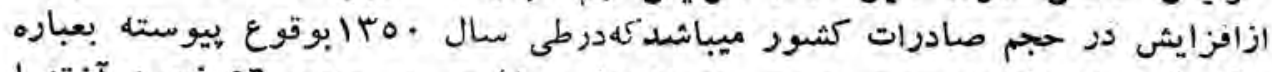

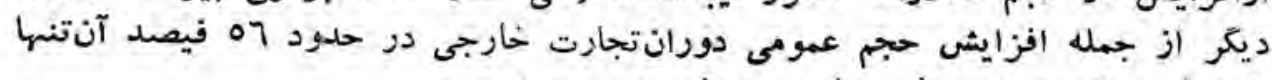

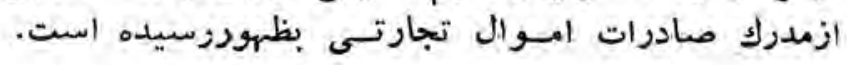

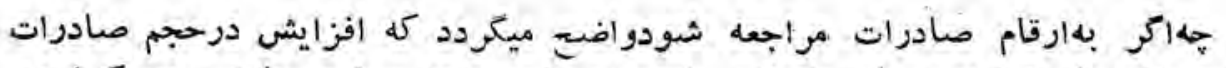

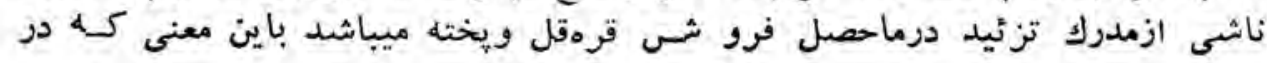

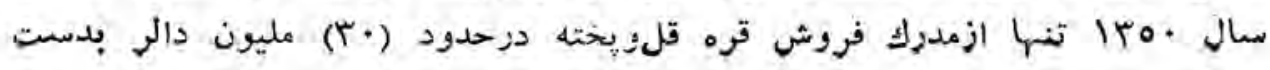




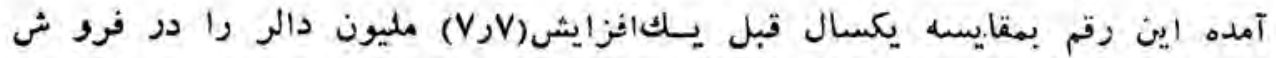

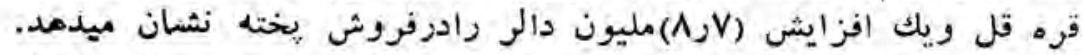

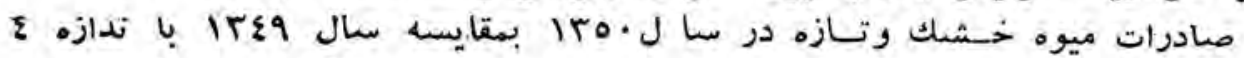

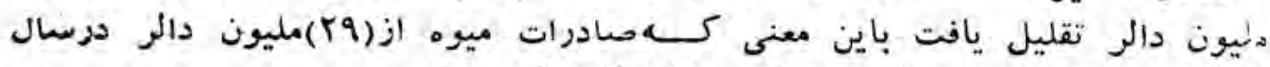

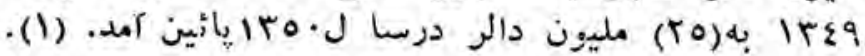

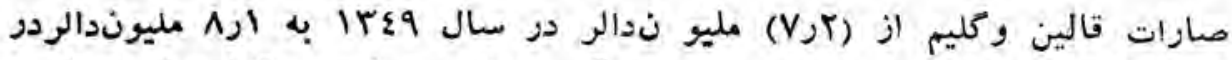

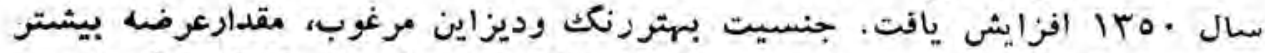

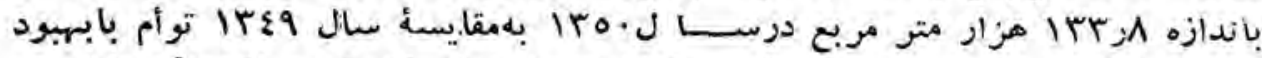

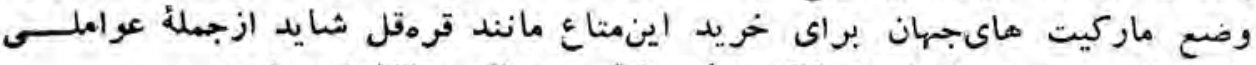

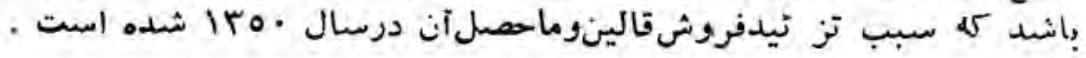

\section{صادرات قره قل:}

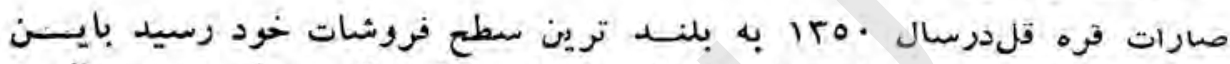

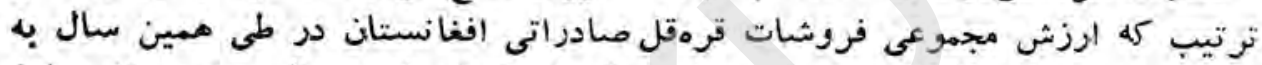

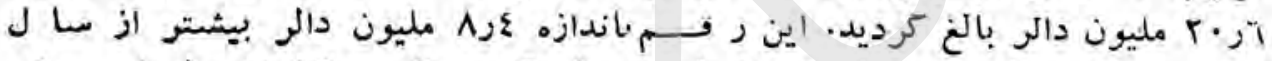

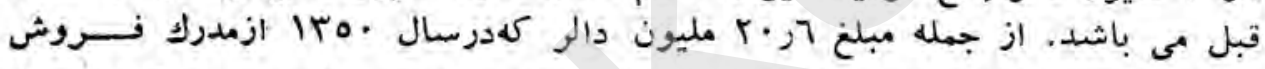

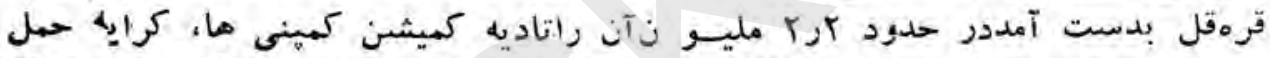

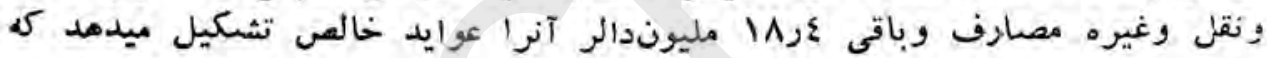

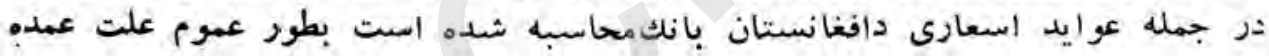

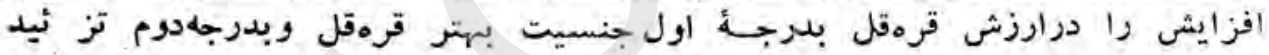

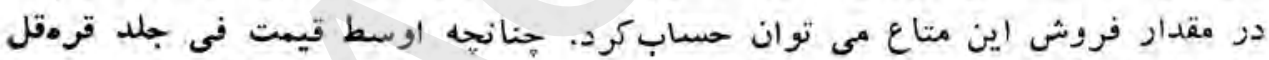

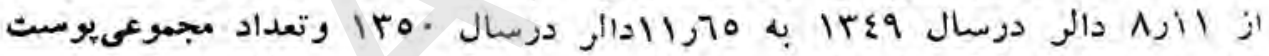

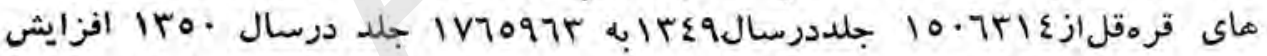

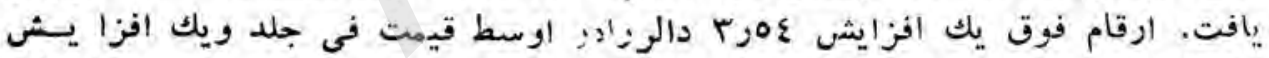
ro97za

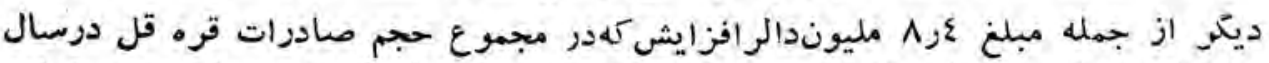
1Fo.

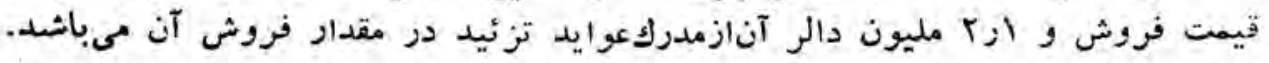

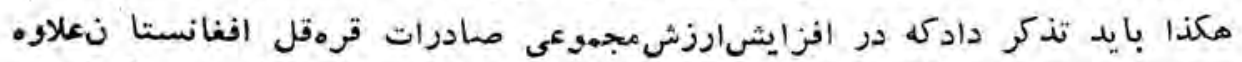

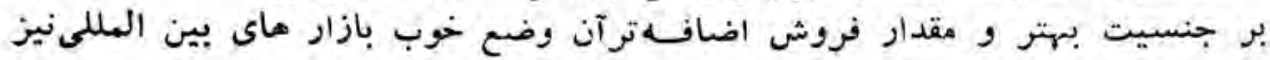
تائير داشنه است

ا- ارقام مربوط به صادرات ميوهخشكوتازه درسال

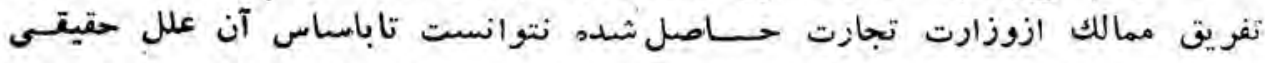

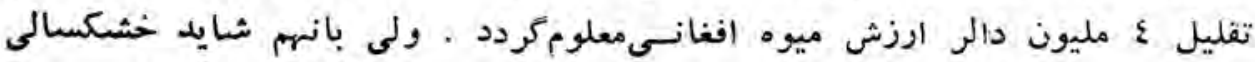

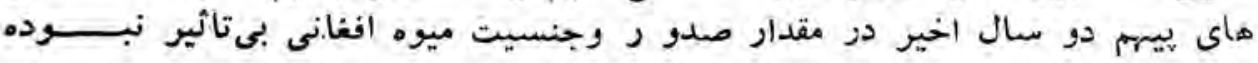




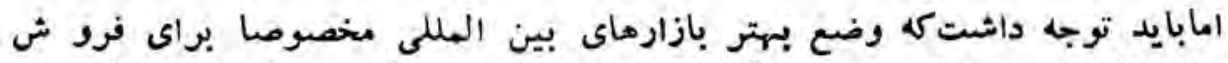

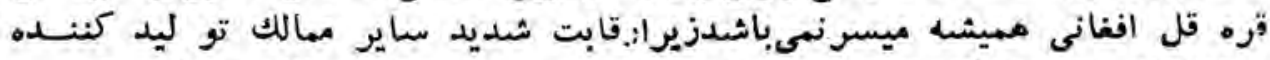

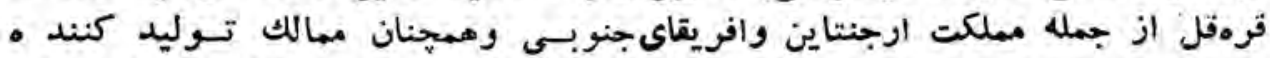

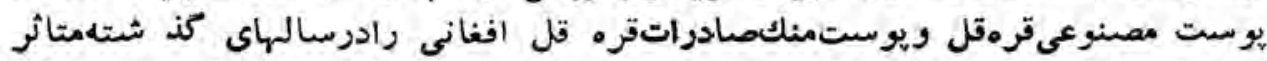

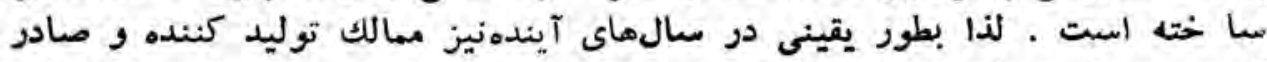

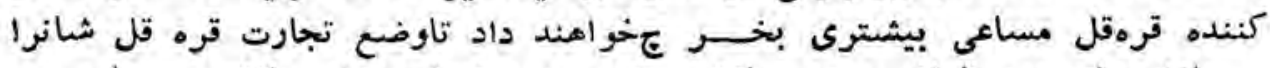

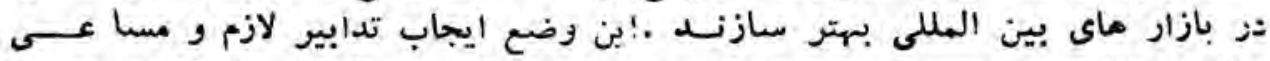

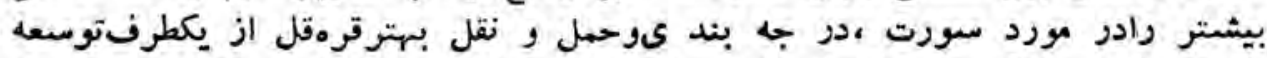

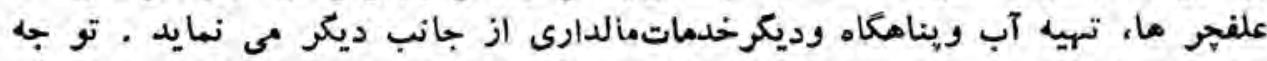

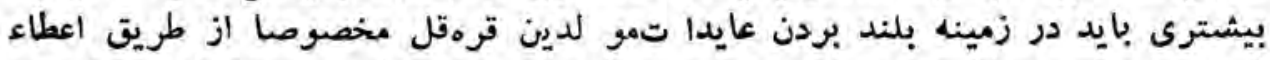

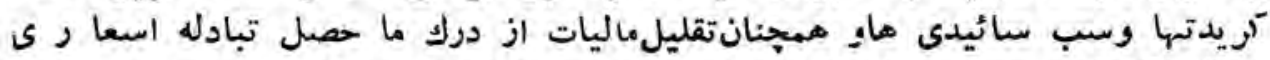

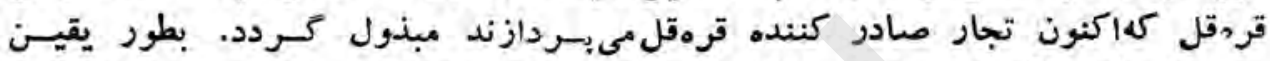

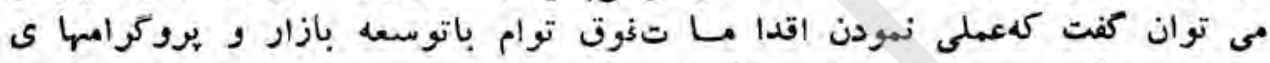

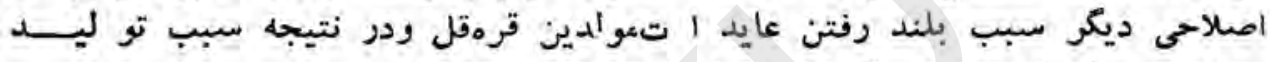

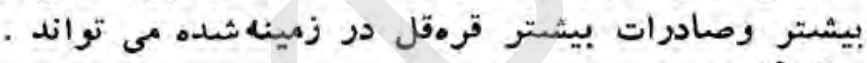

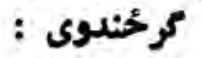

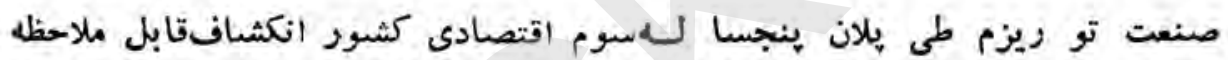

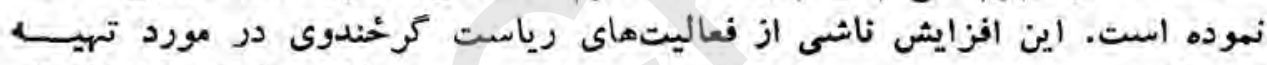

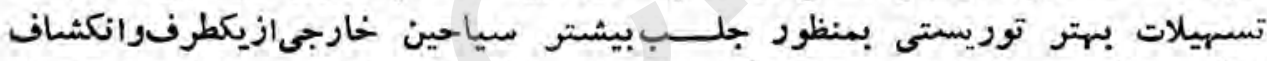

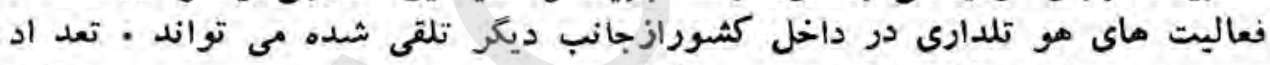

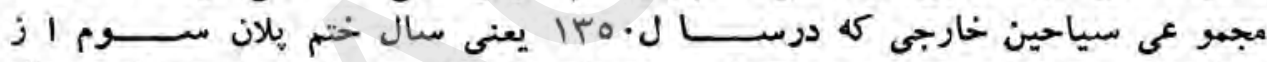

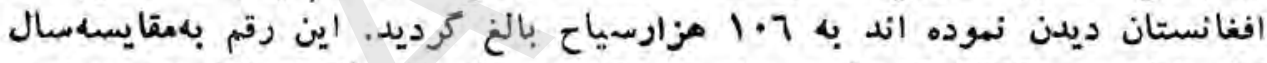

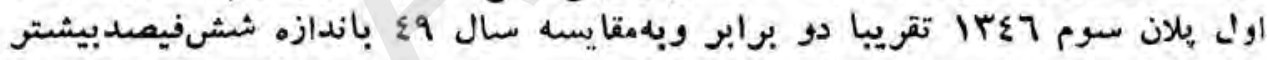

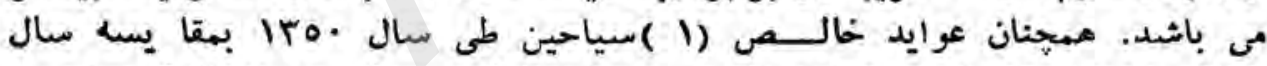

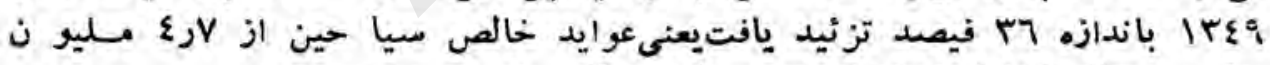

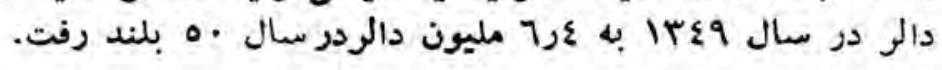

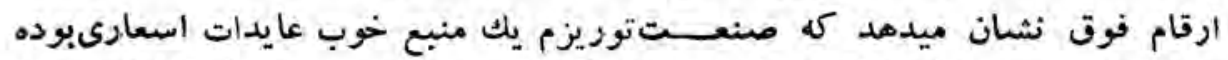

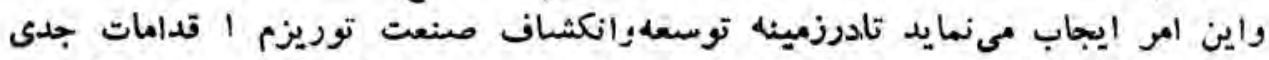

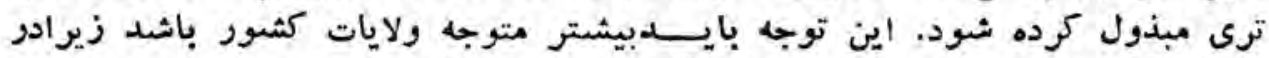

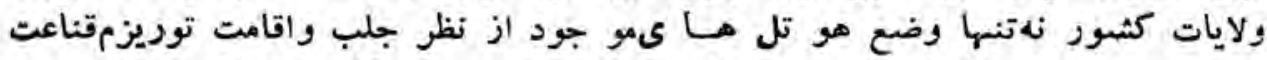

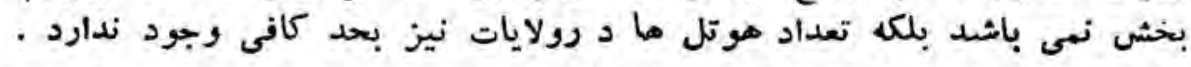

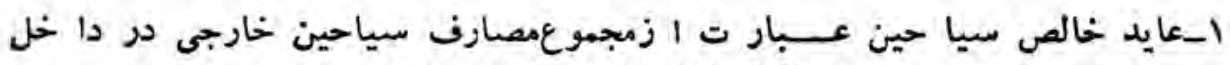
كثور منفى مصارف مسافرت افغانها د رخارج مى بـ باشدي. 
بى مورد نخواهل بوداكر كفته شـو دكلهرايور هاى واصله فيصدى هاى بيشتر

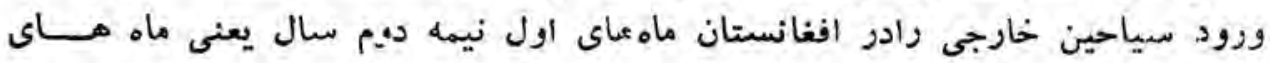

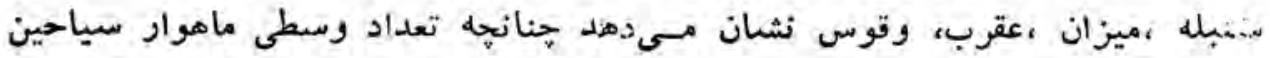

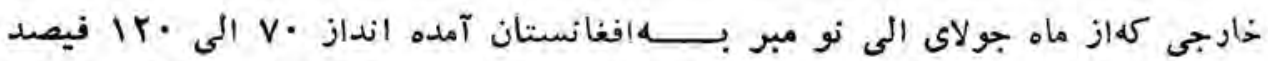

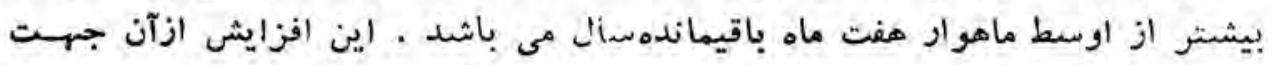

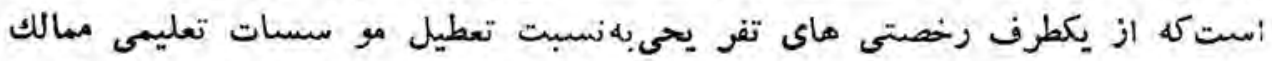

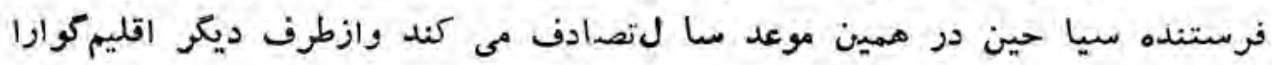

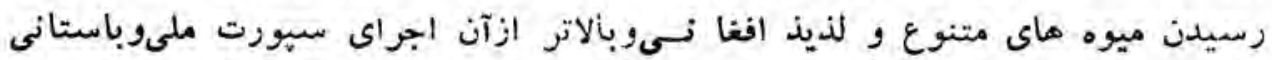

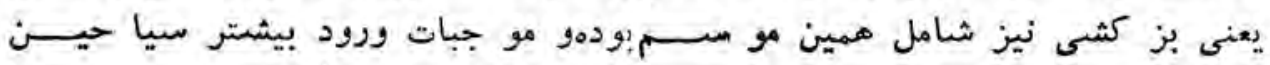

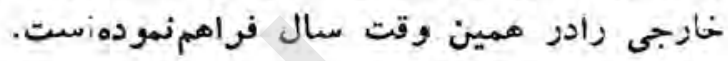

\section{بـ واردات :}

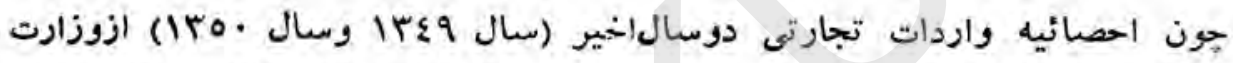

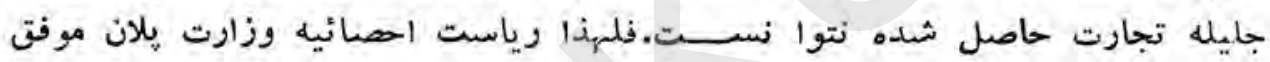

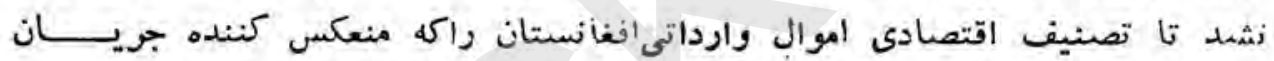

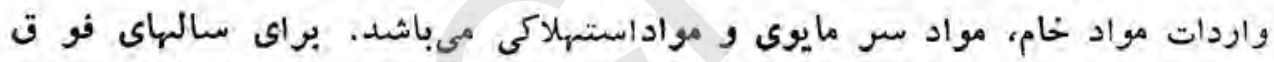

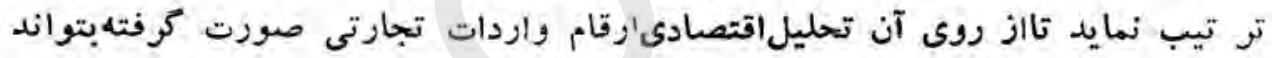

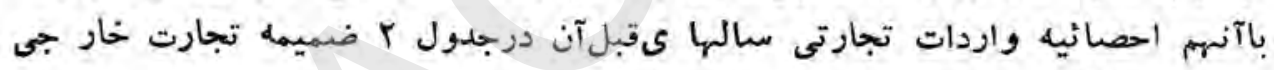
درج كرديد.

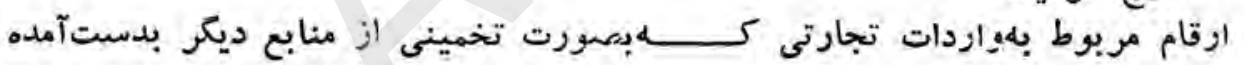

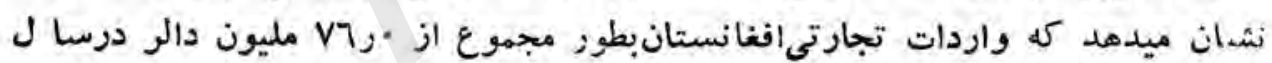

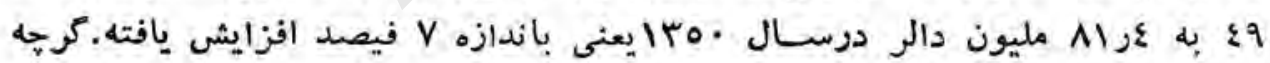

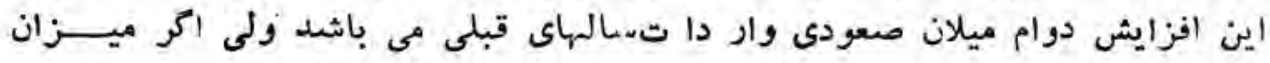

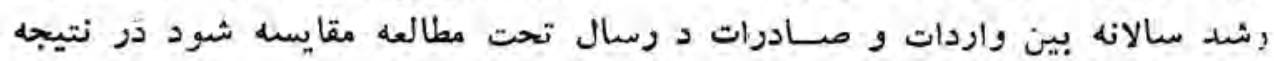

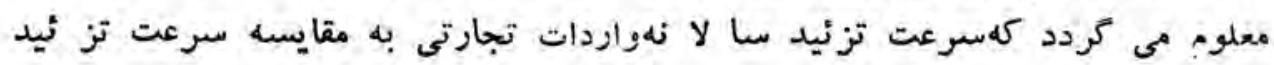

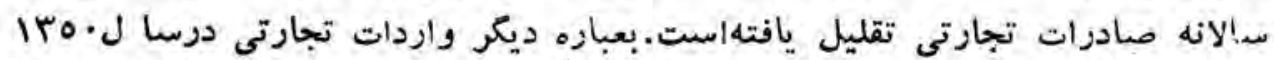

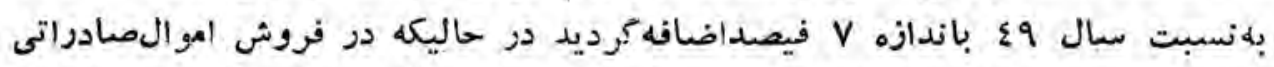

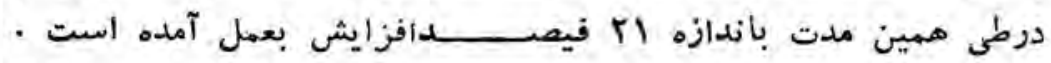

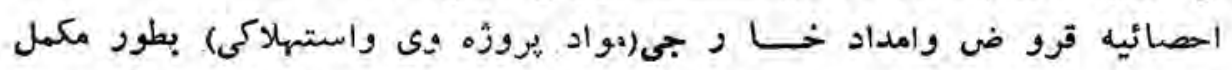

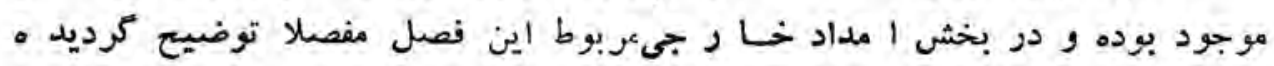




\section{ساير اقلام بيلا نس تاديات :}

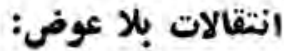

در تصنيف اقتصادى بيلانس تا ديا تالهسال تجديدنظرصورث كرفتواصلاحاتى

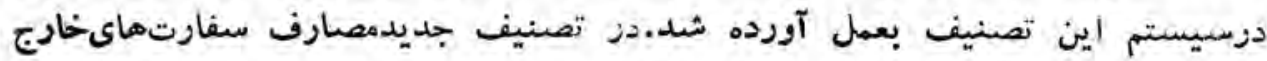

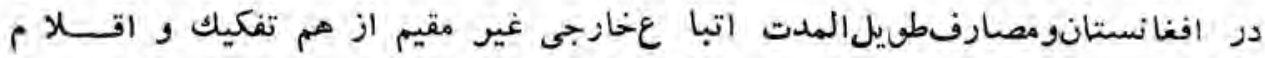

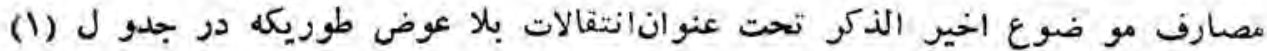

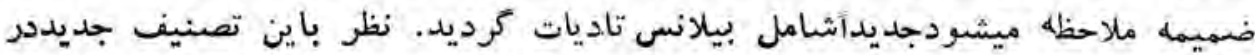

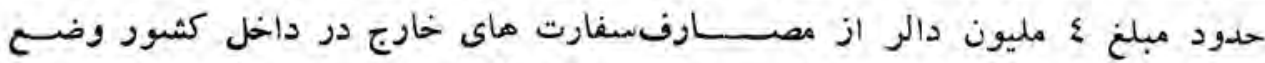

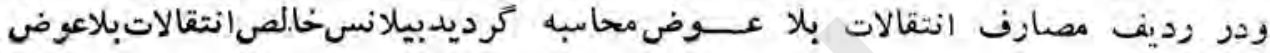

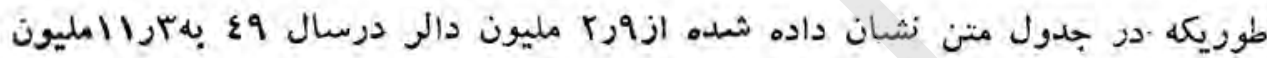

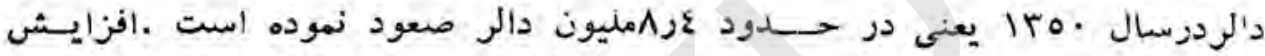

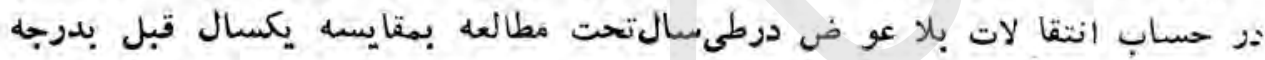

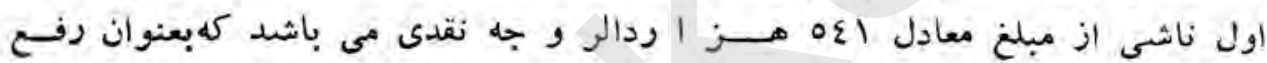

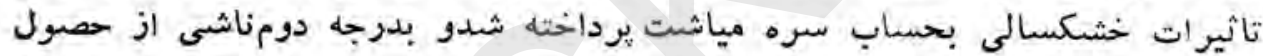

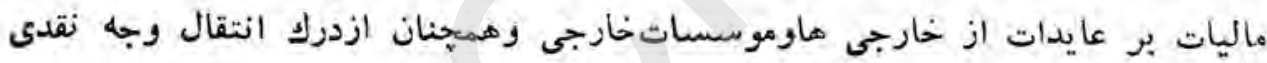

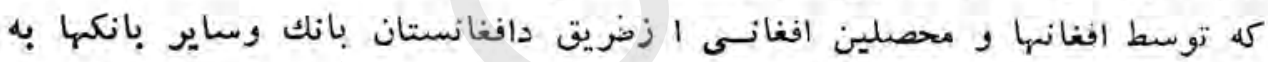

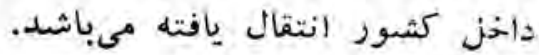

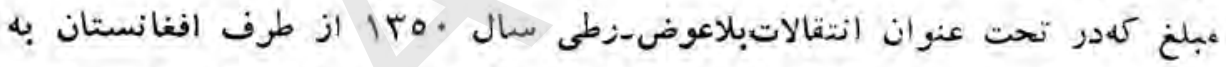

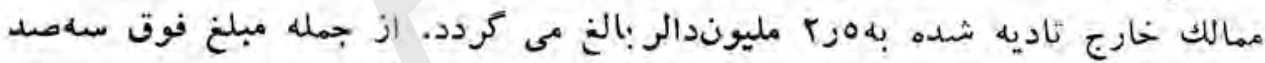

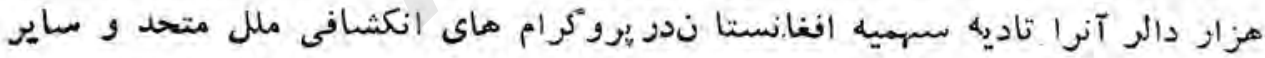

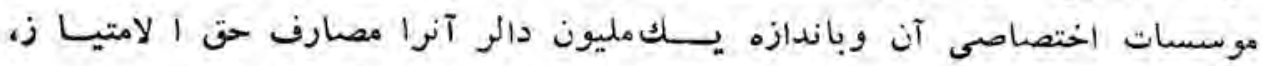

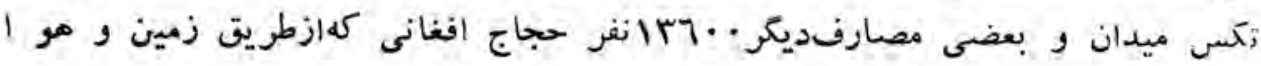

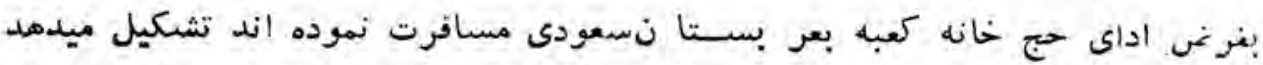

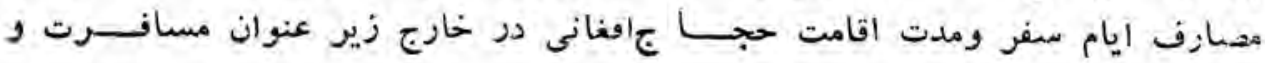

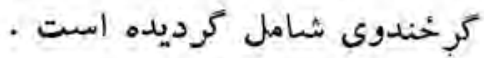

\section{فروض وامداد انخارجى :}

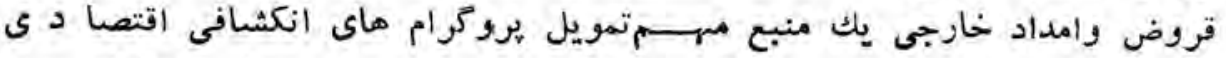

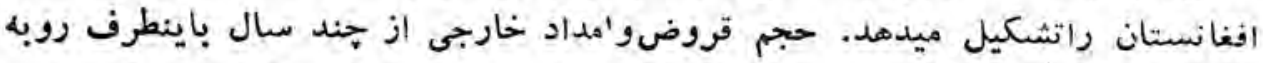

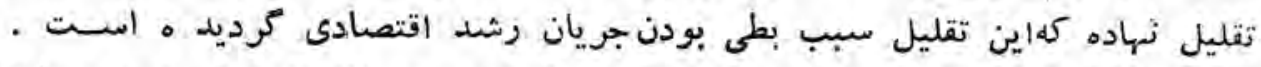

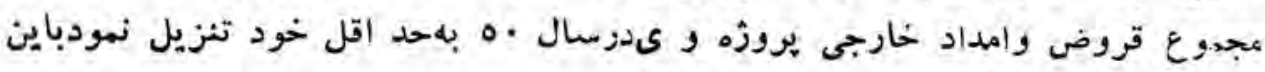




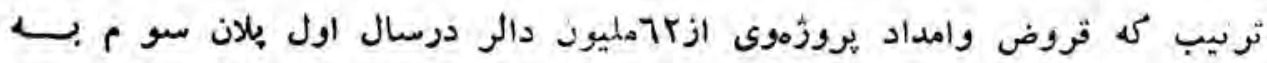

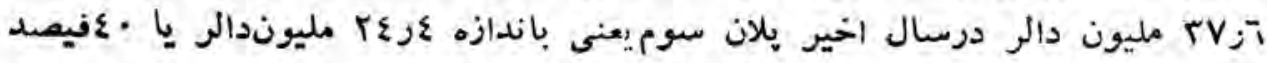

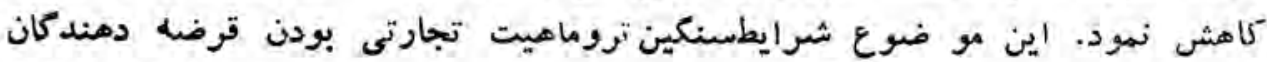

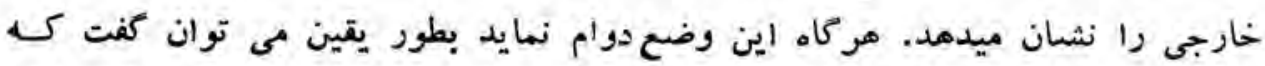

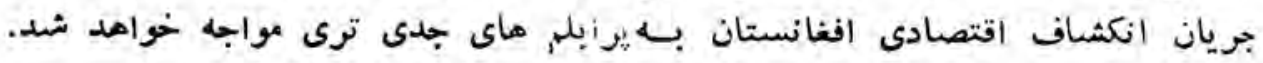

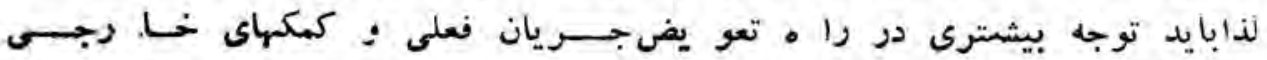

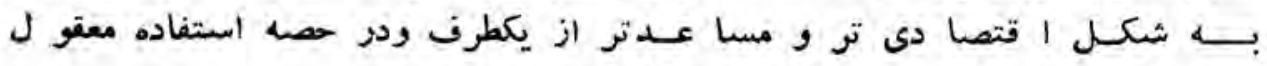

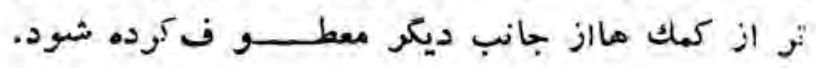

قروض و امداد خـــارجـى

\section{(بهمليوندالى)}

Iro. IrE9 IrEA IrEV IrE7

\begin{tabular}{|c|c|c|c|c|c|}
\hline$r v, t$ & $r v, r$ & $\varepsilon \varepsilon, r$ & 0.5 & (r. & قرضسوكرانت يروزوى \\
\hline$r q, \varepsilon$ & $1 \varepsilon, V$ & $1 \cdot 2$ & 15,9 & $1 r, \varepsilon$ & قرضهو كر انتمو اداستهلاكى \\
\hline $7 v_{2}$. & $\varepsilon r, r$ & $0 \varepsilon, r$ & ارץד & $v_{0, \varepsilon}$ & مجموع كمكهاىخارجى \\
\hline ro,. & $r 7, r$ & $r r s$ & 17. & 15,5 & رضهبشمولتكتيولى \\
\hline Er. & 17 & $r \cdot, 0$ & $\sum V, 1$ & ( & كمكهاى خالص خارجى \\
\hline
\end{tabular}

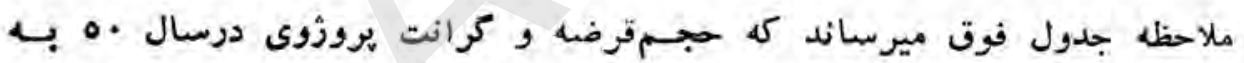

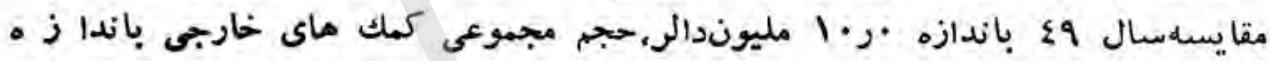

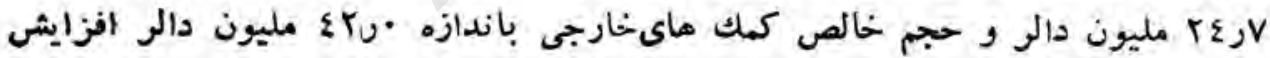

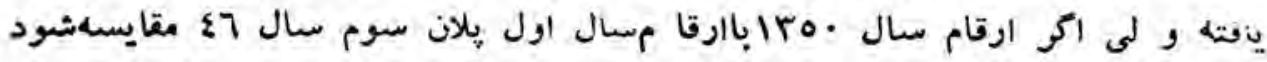

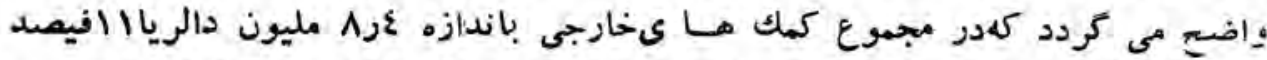

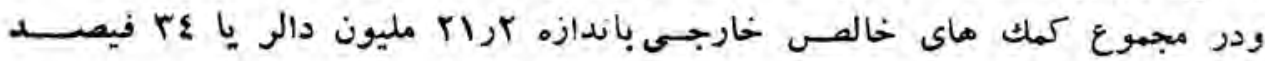

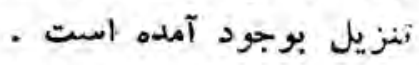

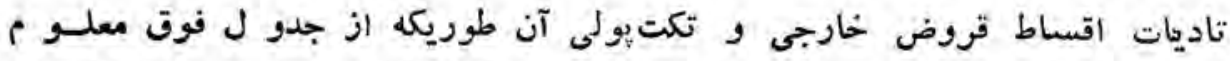

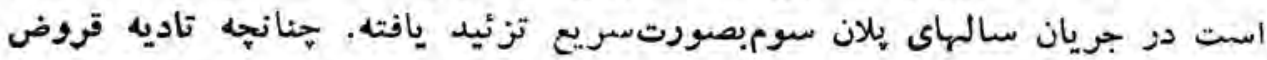

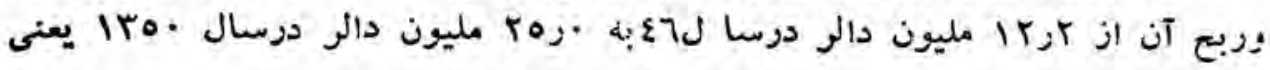

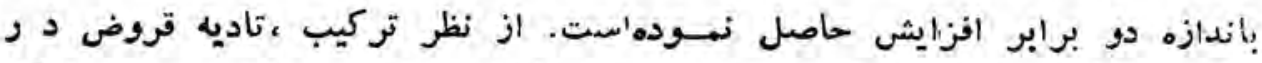

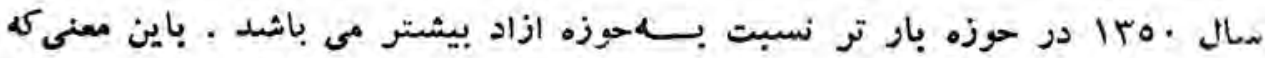




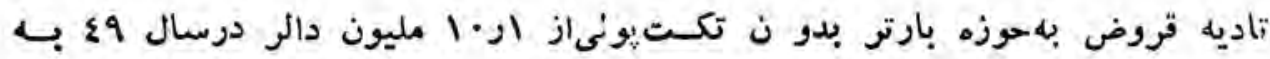

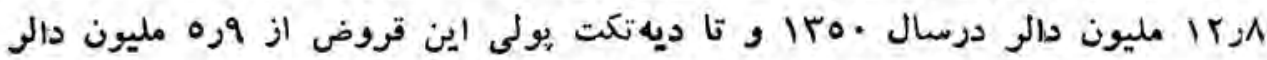

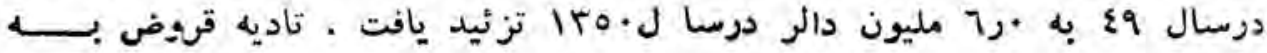

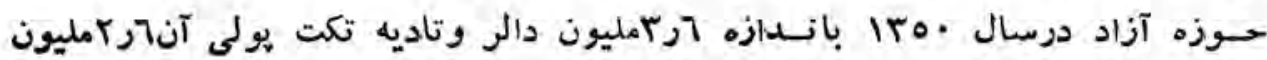

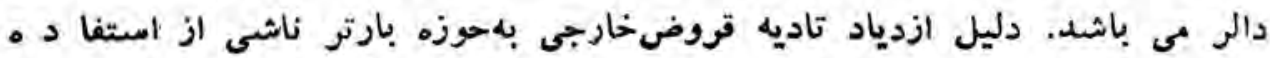

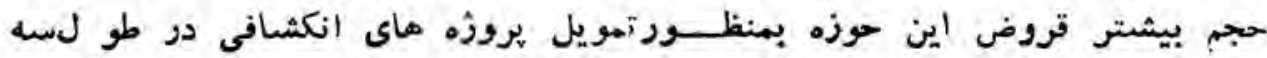

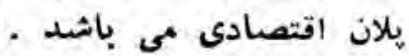

هر كاه قرضه وكرانت يووزوى و كمكموند استهلاكى خارجى باهم يكجا وتاديات

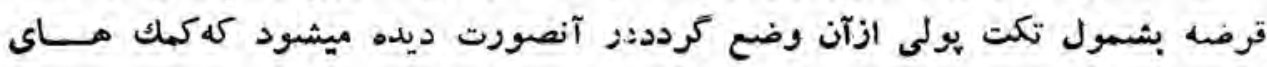

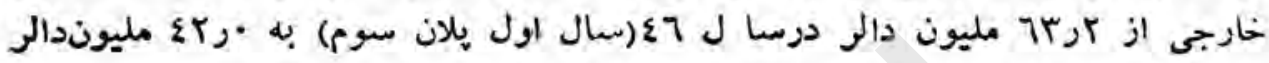

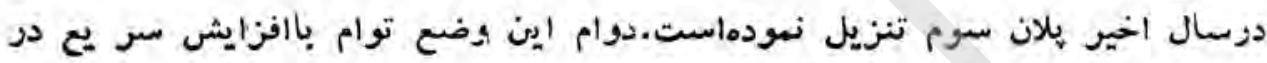

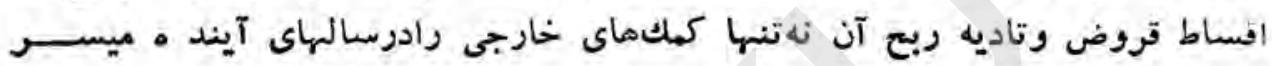

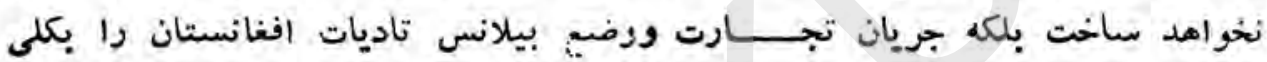

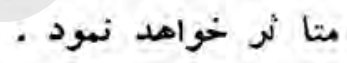

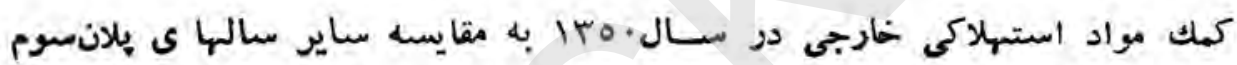

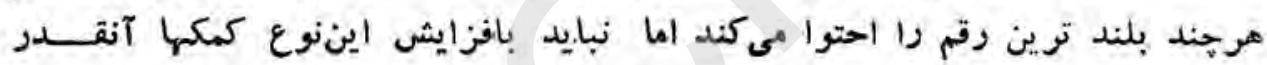

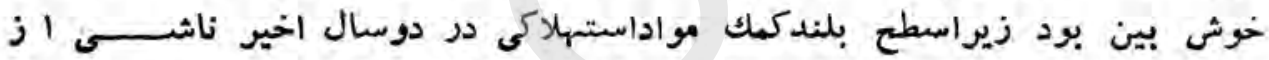

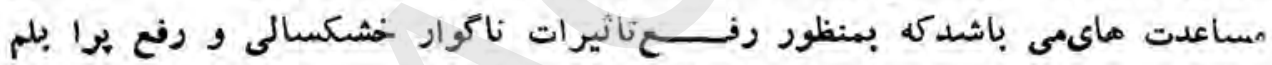

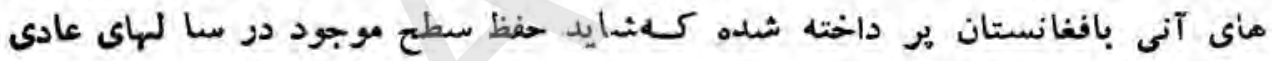
مهكن و ميسر شيد نتوانئ

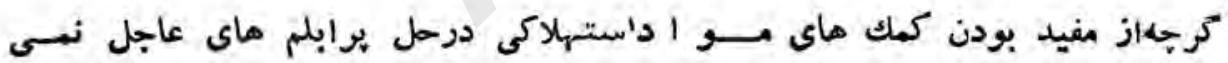

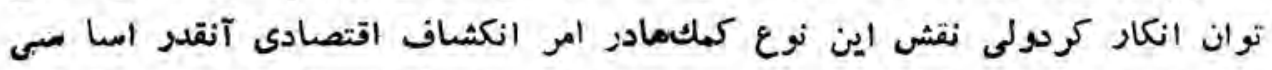

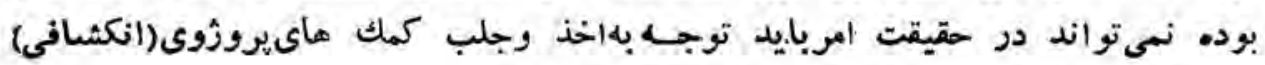

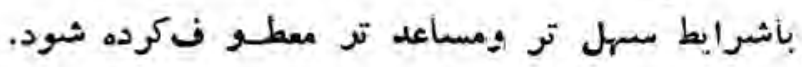




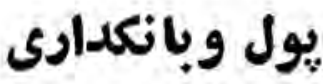

ا- مو بسمات بانكى :

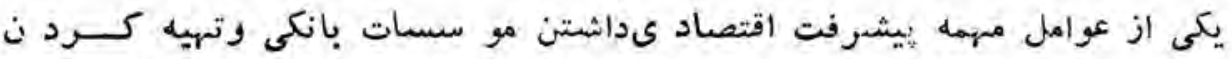

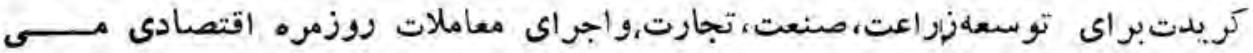

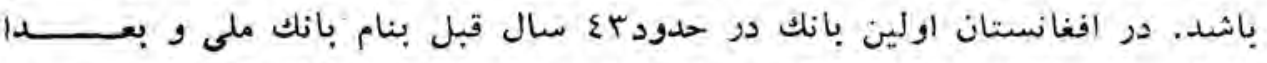

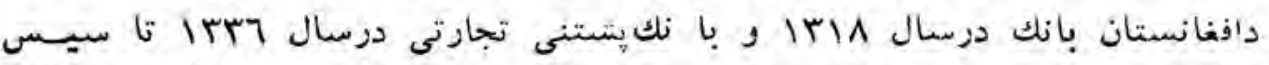

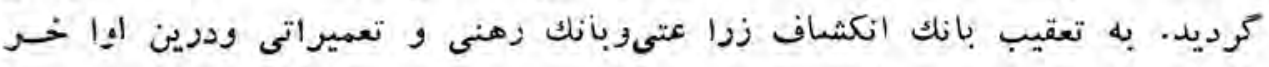

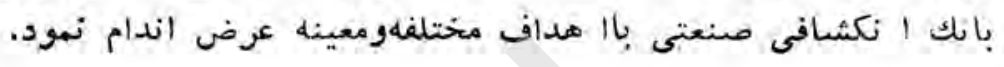

درافغانستان باو جود افزايش درتعدادمو سسات بانكى نسبت بهسالها ى قبل

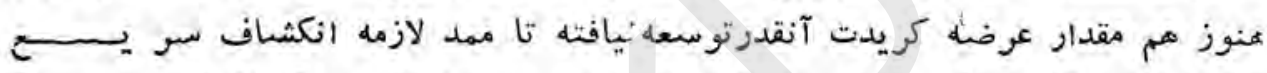

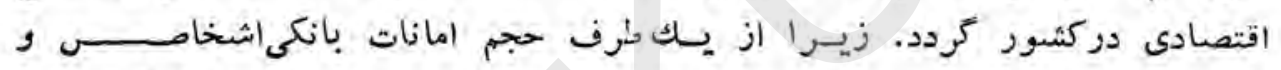

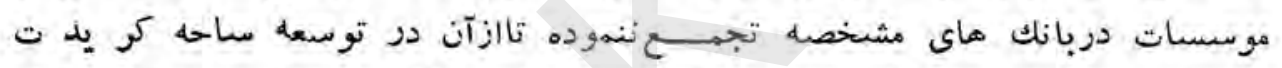

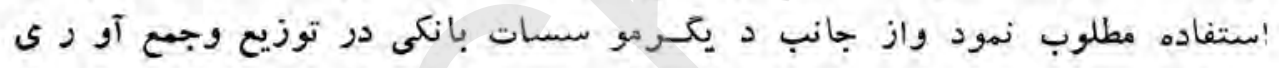

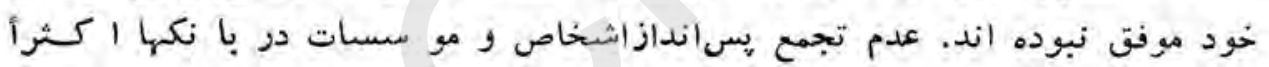

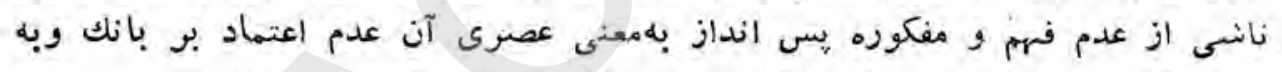

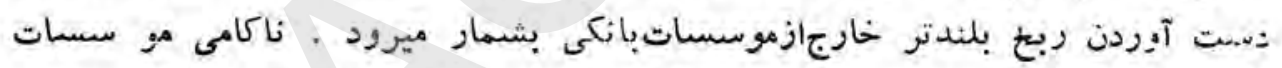

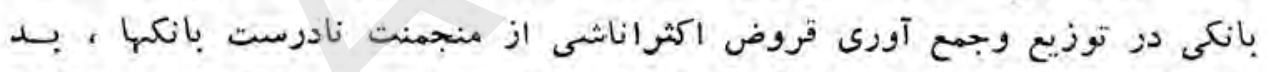

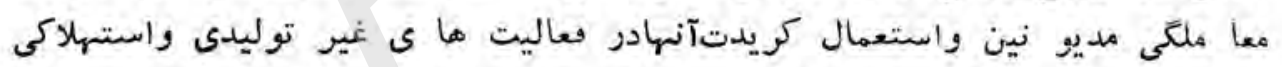

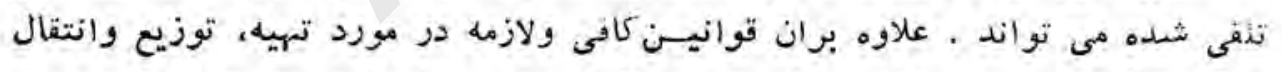

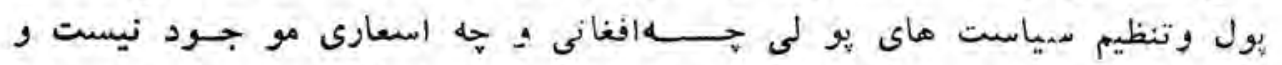

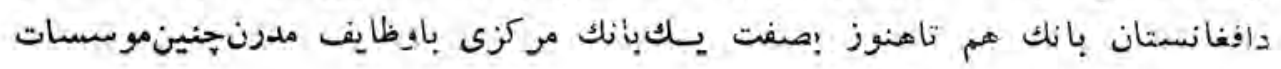
اجراى وظيفه كرده نمى تواند .

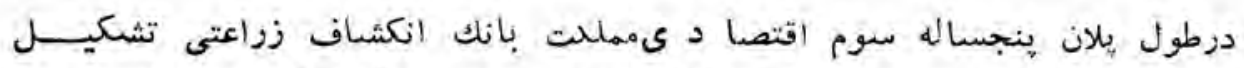

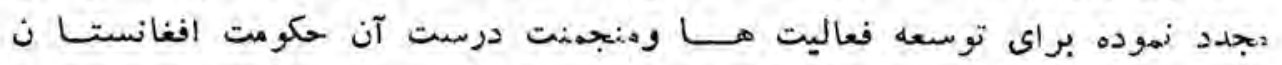

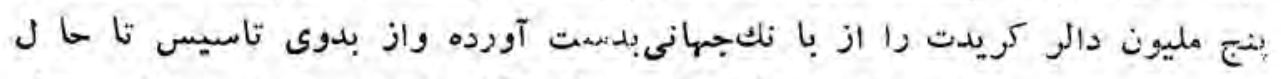

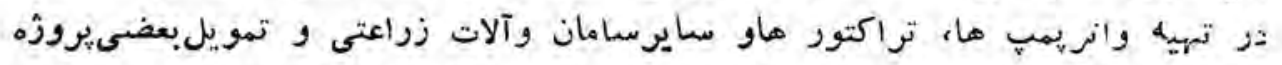

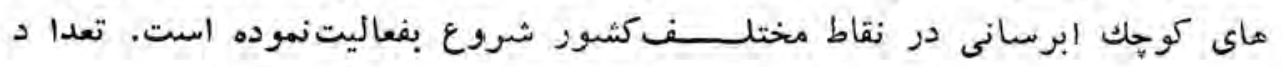

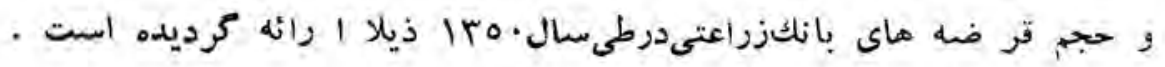




\section{جلول (1)}

\section{Iro. تعدادوحجمقروض بانكانكشافزراعتىدرسال}

\begin{tabular}{|c|c|c|c|}
\hline فيصدىنسبتبه & بهالغ قرضه & تعدادقروض & ولايـات \\
\hline$\wedge, v$ & גנוררז & in & قندز \\
\hline T, & \^৭ะ,. & ro & فراه \\
\hline$r q, \Lambda$ & AVArjo & $w$ & كابل \\
\hline$r \wedge ر$ & $119 v 0, r$ & K19 & قندهار \\
\hline $1, \pi$ & ryl, & $\varepsilon$ & ننكر مار \\
\hline r. & $91 \varepsilon, t$ & ir & غزنى \\
\hline$\Lambda, \varepsilon$ & r. r rool & 11 & بلغ \\
\hline . & Irv,E & $r$ & يكتيا \\
\hline$\varepsilon$ ر & Iroov & $1 \wedge$ & هرات \\
\hline $1 \cdots$, & r.orA,q & $\varepsilon \cdots$ & مجموع \\
\hline
\end{tabular}

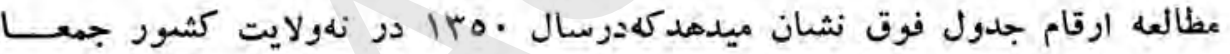

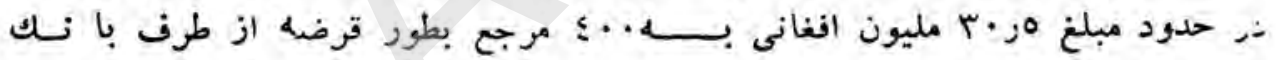

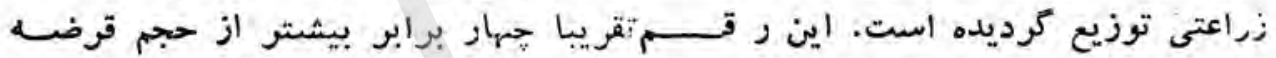

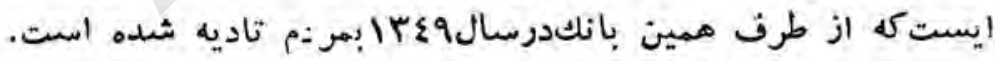

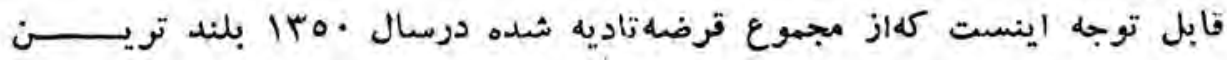

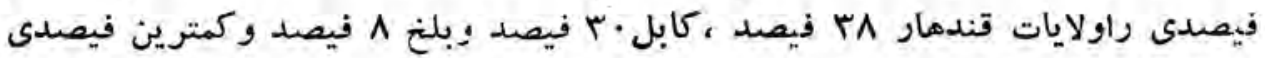

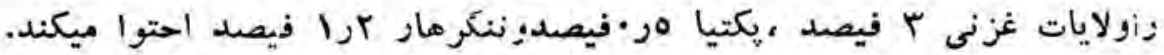

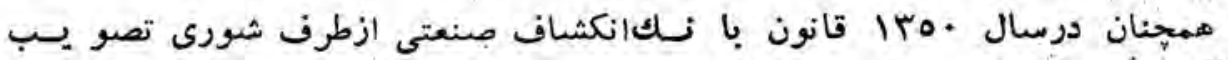

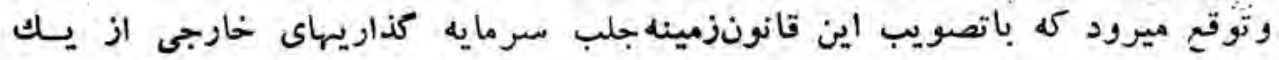

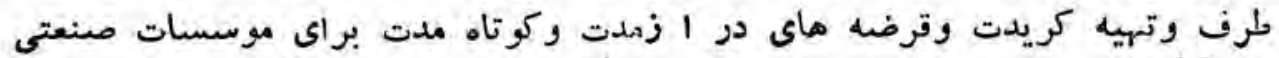

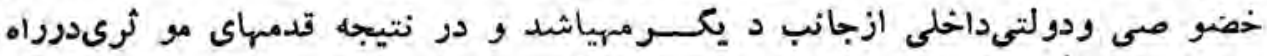

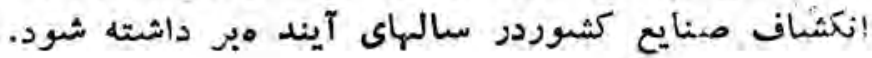




\section{(r) جلول}

كويدتهاى سميستم بانكىددطول يـلان بنجسالـهة سوم

(بكمليارد افغانسى)

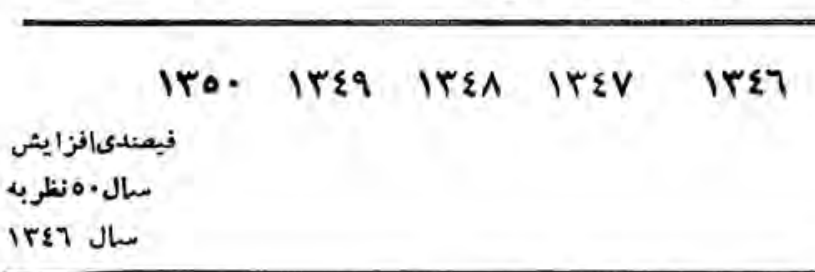

\begin{tabular}{|c|c|c|c|c|c|c|}
\hline 01,9 & $1 \cdot, \varepsilon \varepsilon$ & $1 ., .9$ & $q, r$. & $V, \leqslant \geq 7$ & $7, \wedge \Lambda$ & بانكى : \\
\hline $7 \cdot, \cdot$ & $v>\varepsilon$ & 7,71 & $7, r$ & $\varepsilon, V r$ & $\varepsilon, \varepsilon 0$ & ا- بهسكتوردولتى \\
\hline rוקרץ & r. & r & riv & rovr & ror & عسى \\
\hline$r \varepsilon, \varepsilon$ & • & • & $1, r$ & • & $.27 v$ & ـ ازدافغانستانبانك \\
\hline$\varepsilon j$. & $r, \leqslant \Lambda$ & $r, 0$. & rot & 1,9r & 1,vר & ايربانكهاى \\
\hline
\end{tabular}

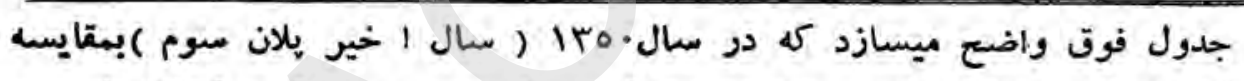

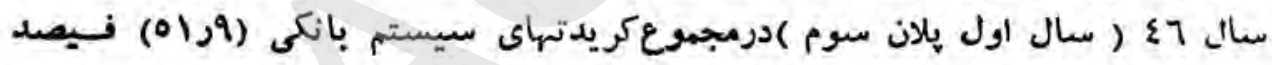

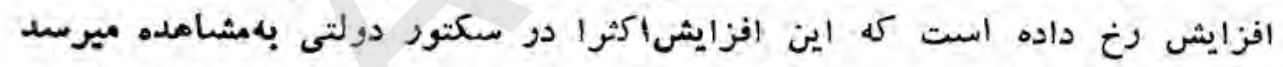

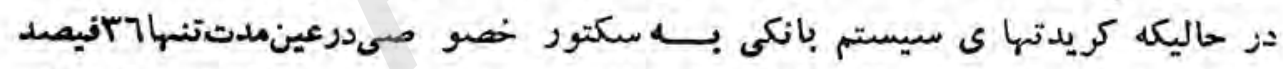

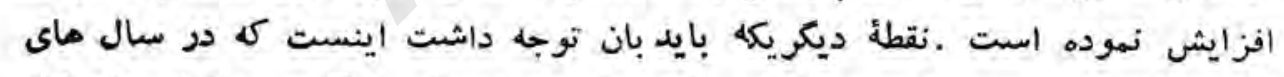

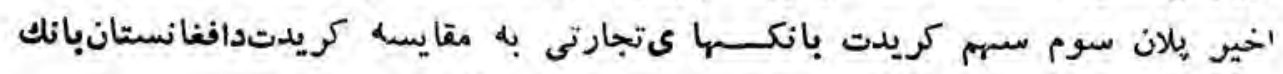

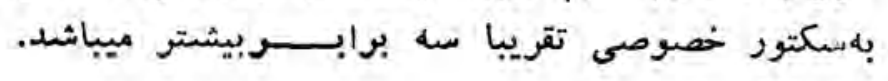

\section{جريان يول:}

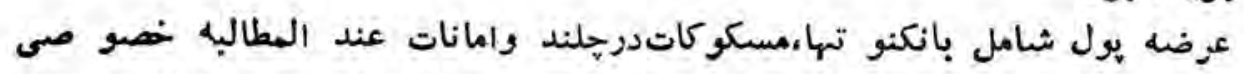

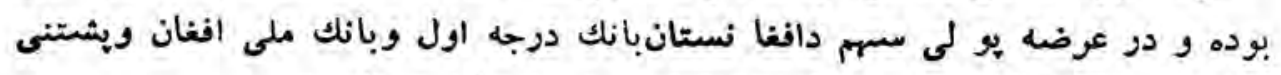

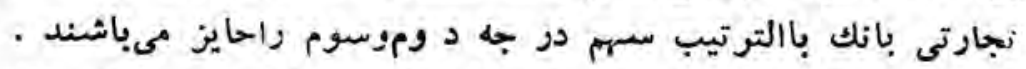

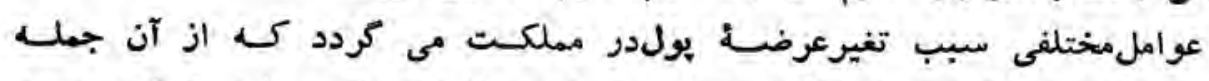

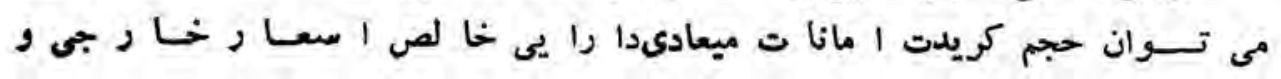
بعضى عوامل ديكر وان حساب كردو. 


\section{(V) جدول

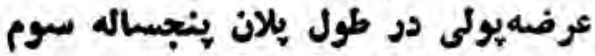

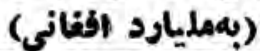

\begin{tabular}{|c|c|c|c|c|c|}
\hline 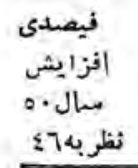 & Iro. & Irะq & $\mid r E \Lambda$ & ITEV & IYET \\
\hline El, & $V, \Lambda \varepsilon$ & vgor & $v_{j} \cdot 7$ & 0,91 & مجهوع عرضسأيولى : \\
\hline ( & אור & ( & $7, \ldots$ & 0,1 . & 1- بانكنوتومسكو كات ·درع \\
\hline$r \Lambda, 0$ & 7,01 & ר & $0, \wedge 9$ & $0, .$. & r- بانكنو تها \\
\hline$r \cdot j \cdot$ & r & . & $\cdot 31$ & • & r- مسكو كات $\quad$. \\
\hline ar & IJr & 11 & 1,7 & 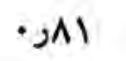 & خصوصى \\
\hline
\end{tabular}

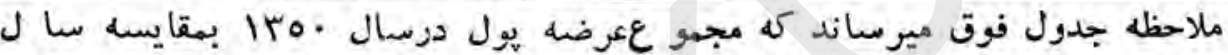

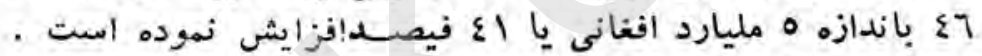

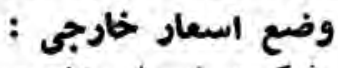

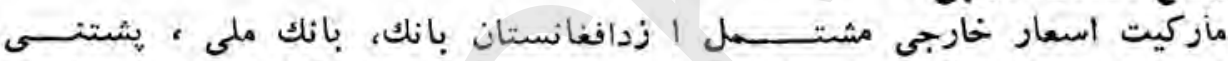

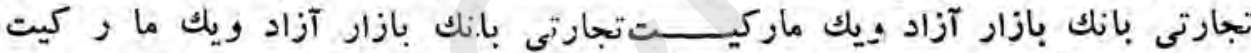

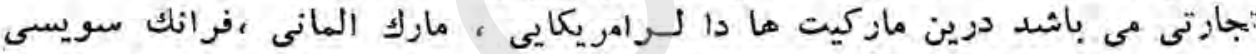

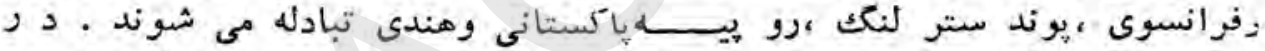

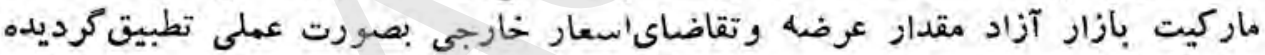

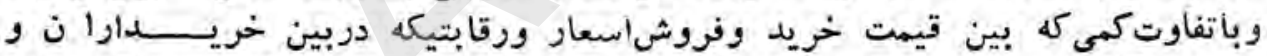

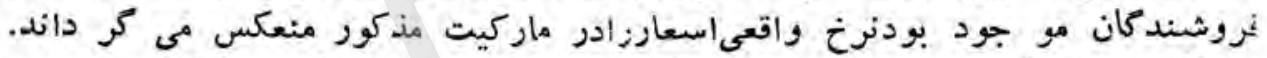

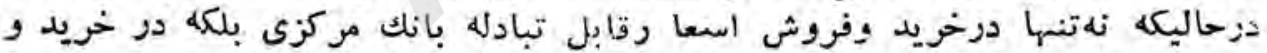

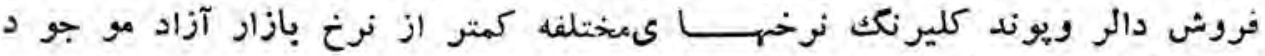

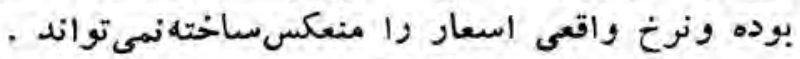

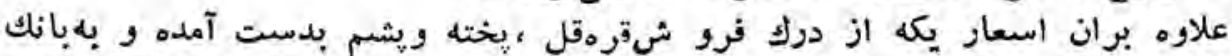

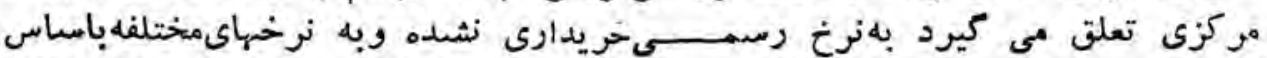

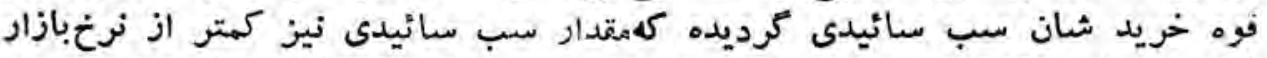

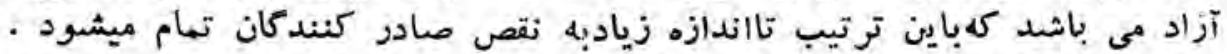

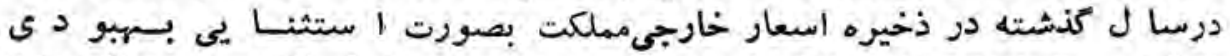

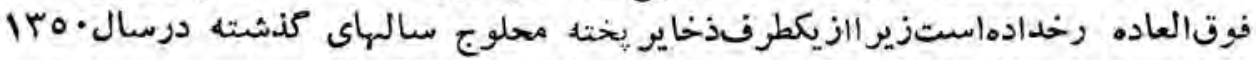

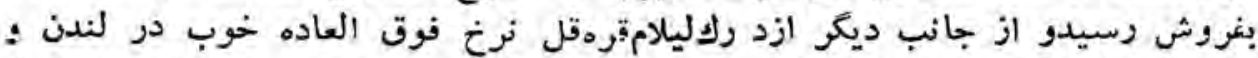

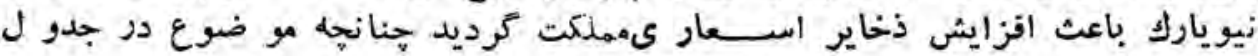

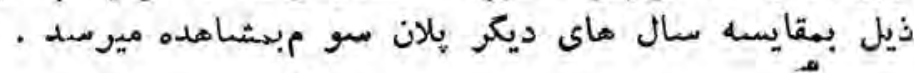




\section{(ع) جلغول)}

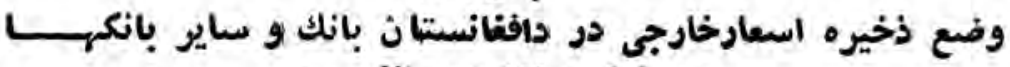

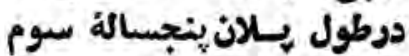

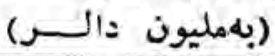

فيصدى تزئيد

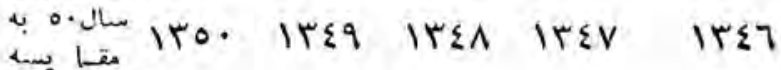

מ- مقال

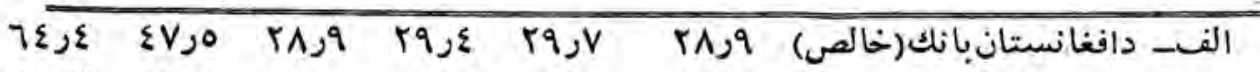

ب -

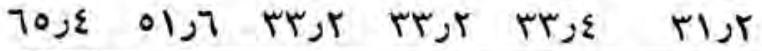

مجموع

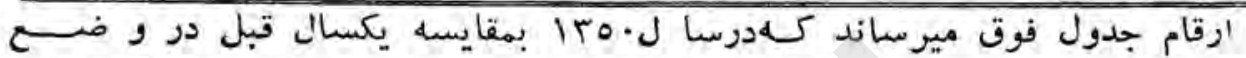

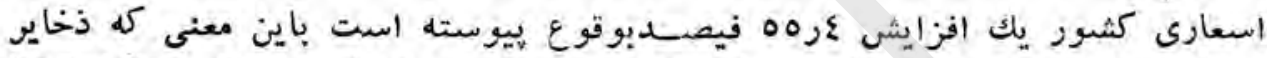

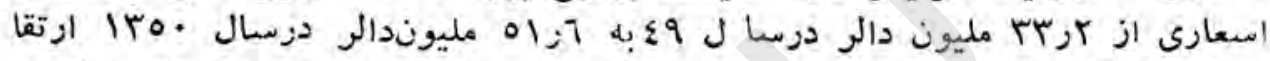

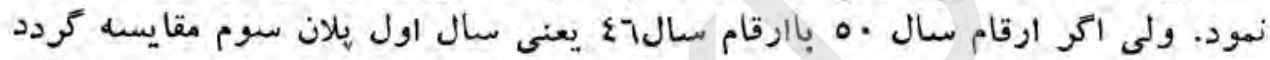

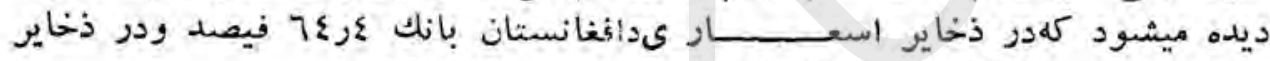

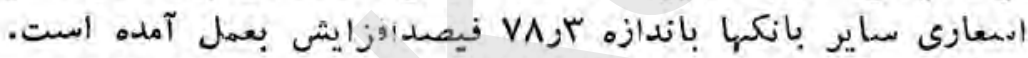

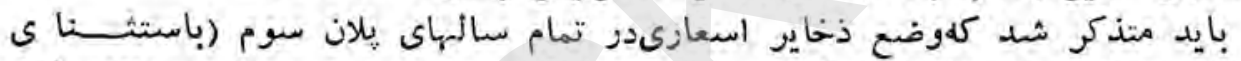

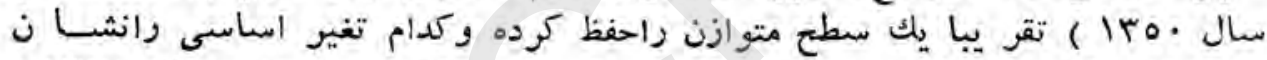

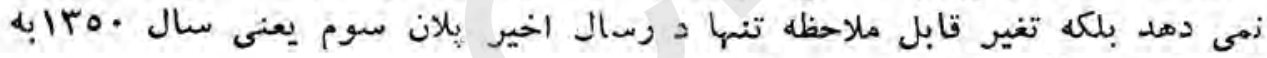

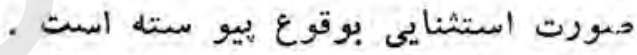

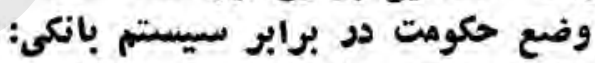

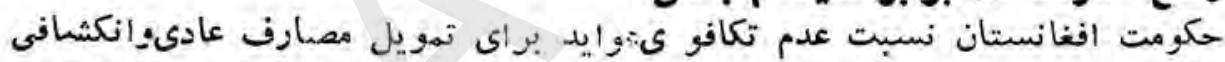

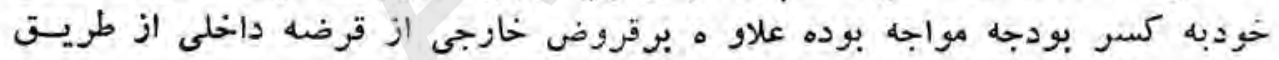

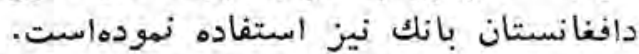

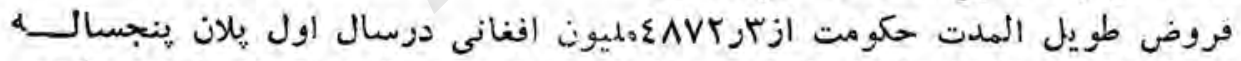

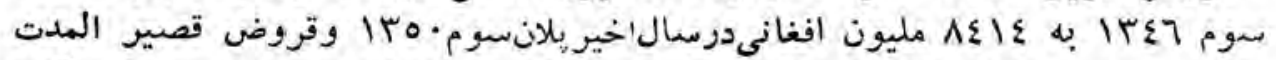

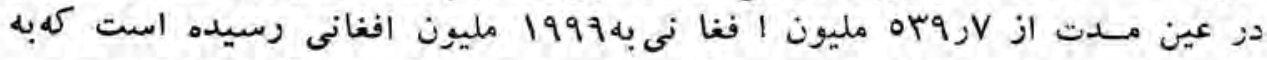

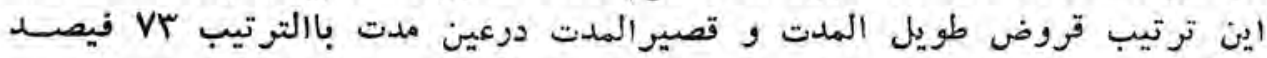

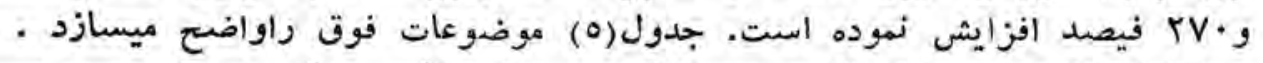

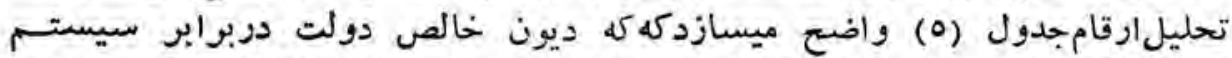

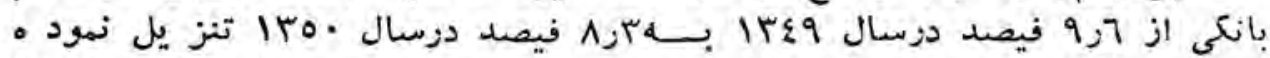

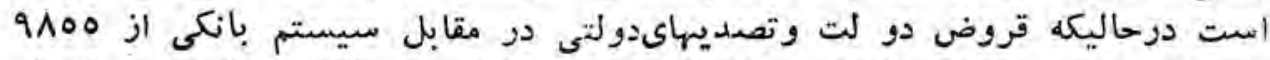

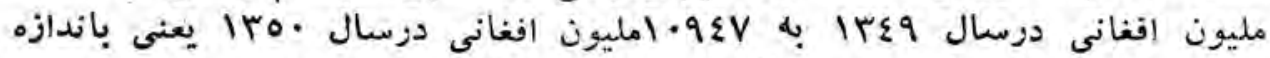

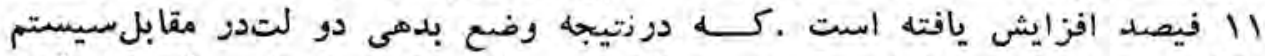

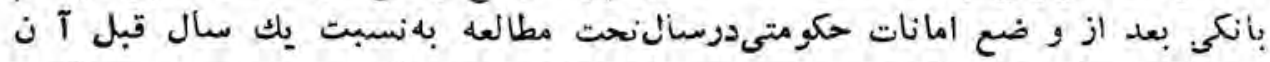

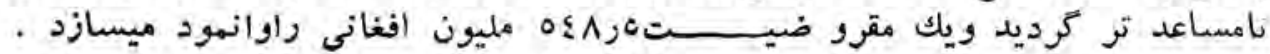


جدول (0)

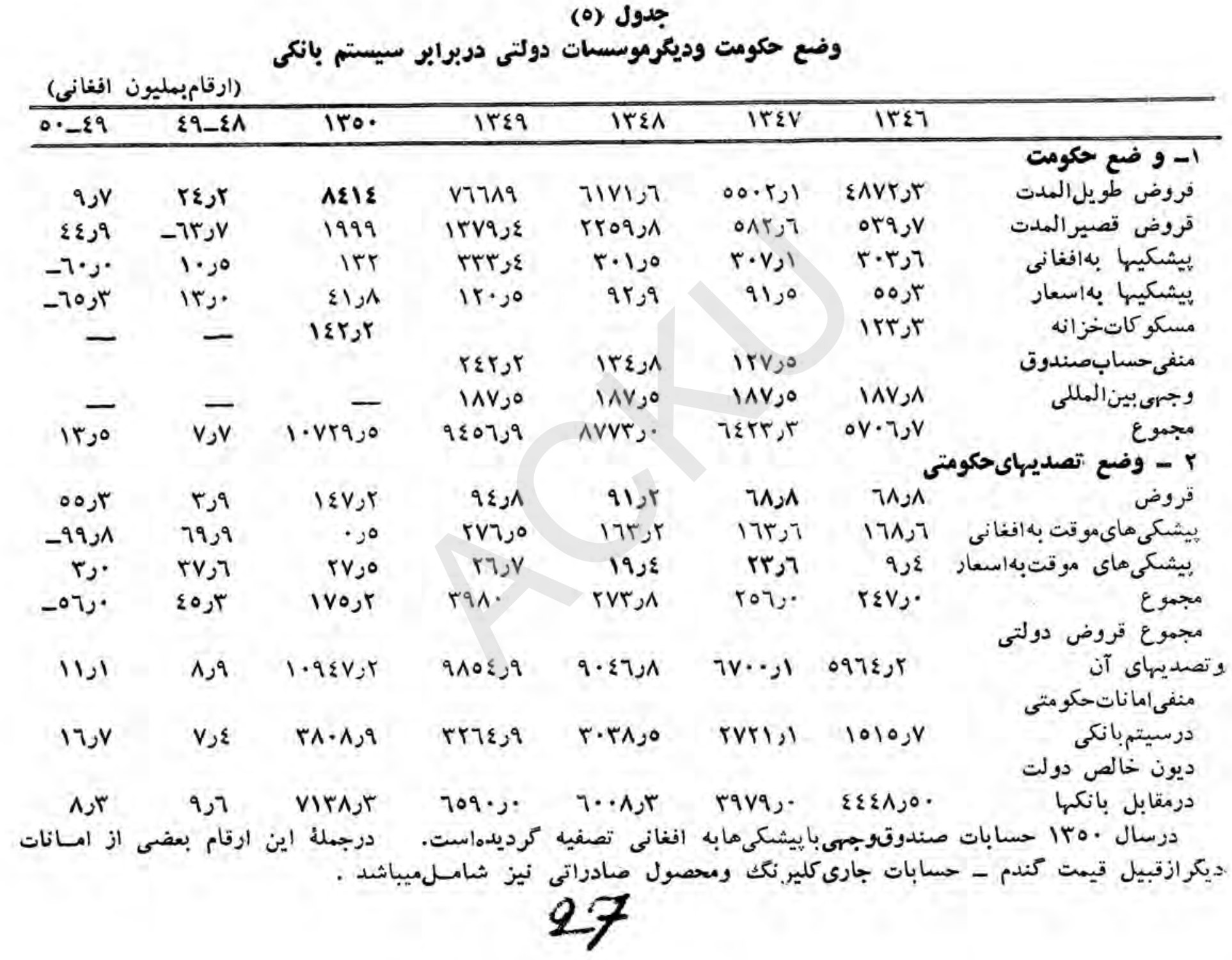




\section{قيمتها}

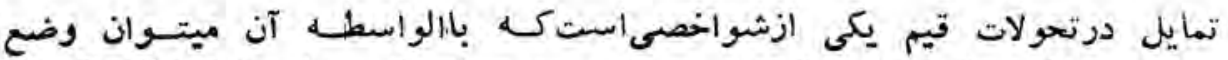

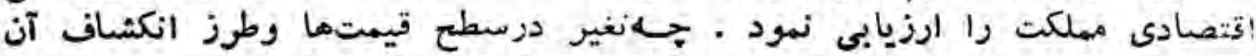

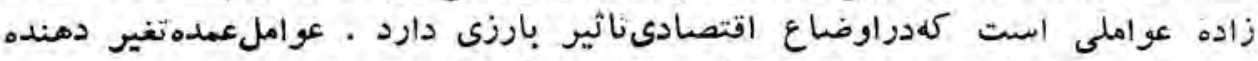

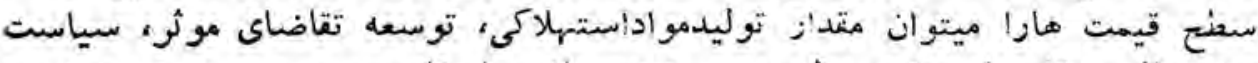

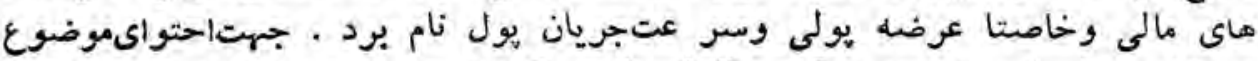

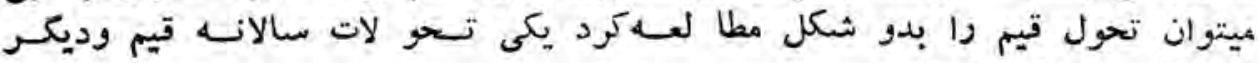

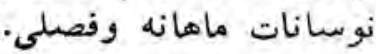

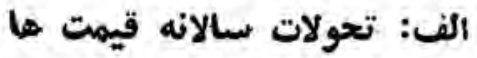

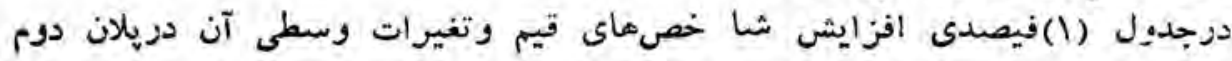

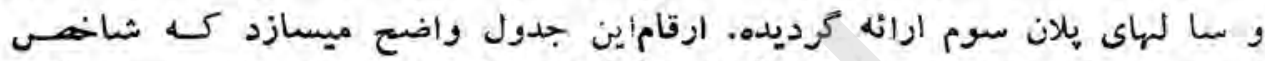

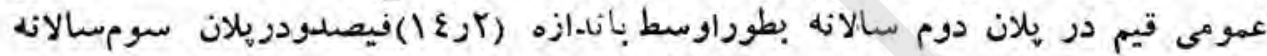

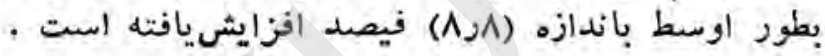

\section{(1) جدول}

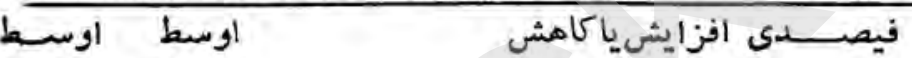

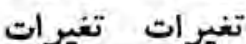

\begin{tabular}{|c|c|c|c|c|c|}
\hline $0 \cdot-\{7$ & $\varepsilon 0 \_\varepsilon r$ & 1ro. & $1 r \varepsilon 9$ & ITEAITEV & IrE7 1 TES \\
\hline$\overline{\Lambda, \Lambda}$ & $\overline{1 \varepsilon, T}$ & IE & Tr & $-r-r o$ & $r 7$ \\
\hline
\end{tabular}

1.,. $10, .0$ r 10 \&

$\begin{array}{llllllll}-1 & 11, r & A & \varepsilon & \text { Ir } & -11 & -r & r \varepsilon\end{array}$

عيوهجات

سيزيجات

سايرموادغذائى

وأدغيرغذأئى

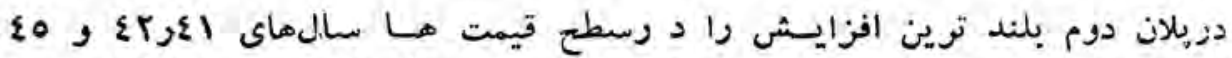

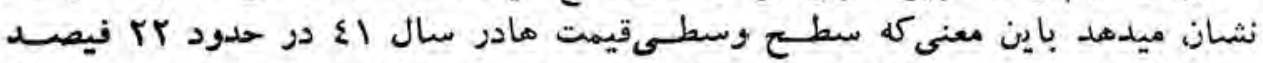

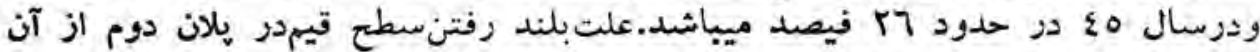

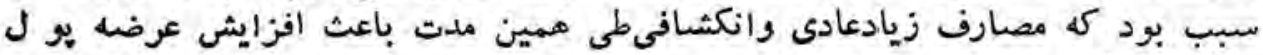

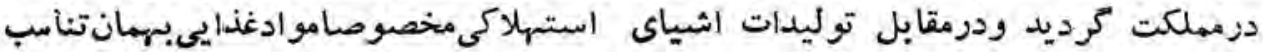

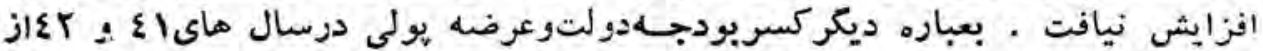

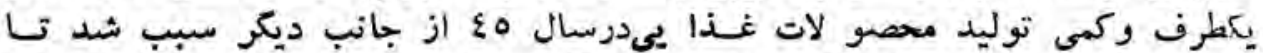

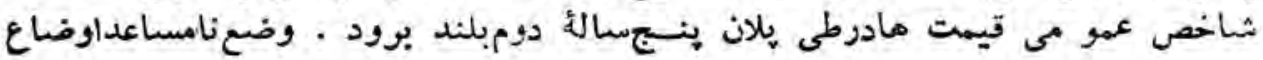




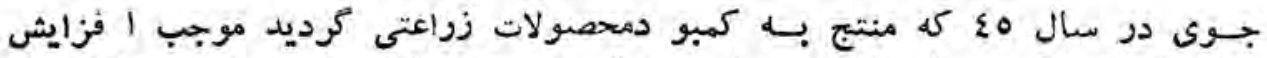

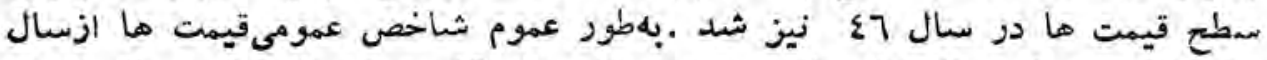

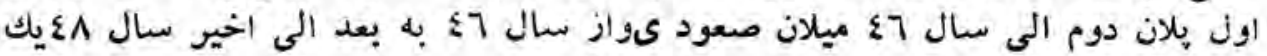

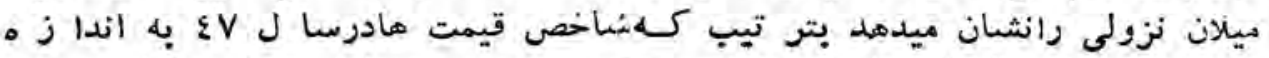

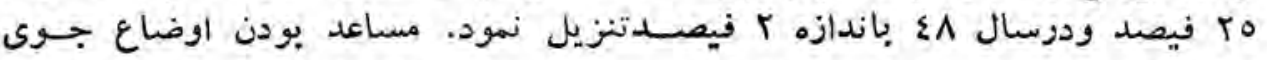

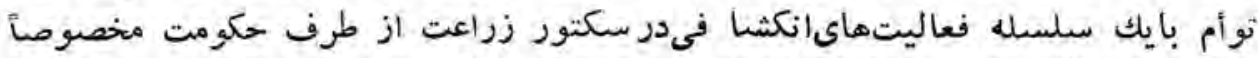

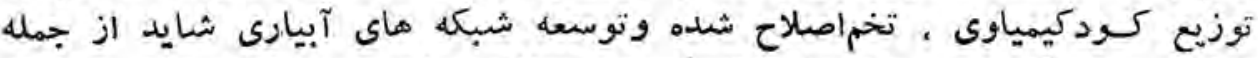

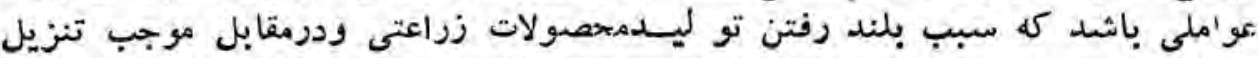

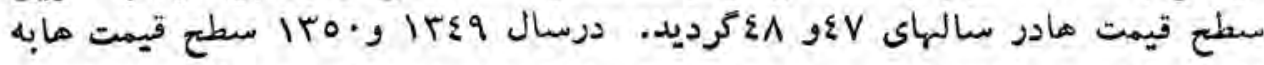

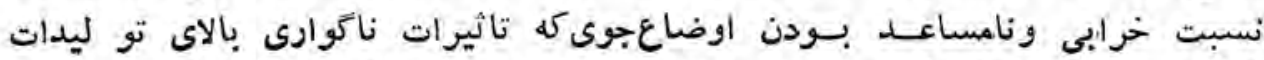

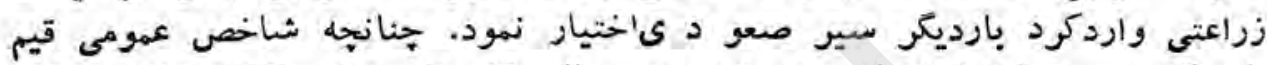

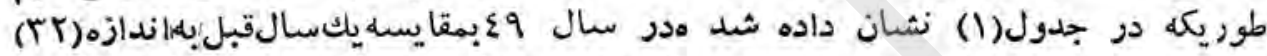

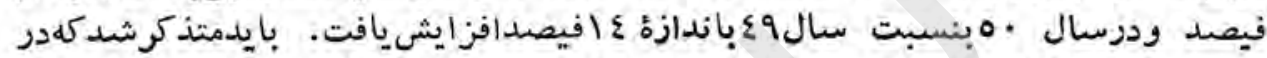

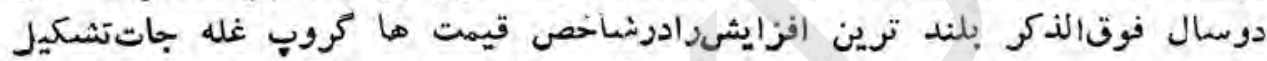

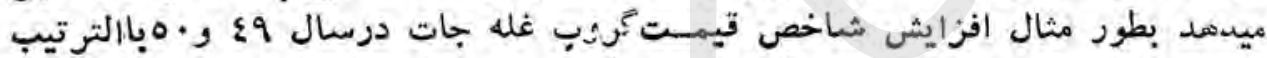

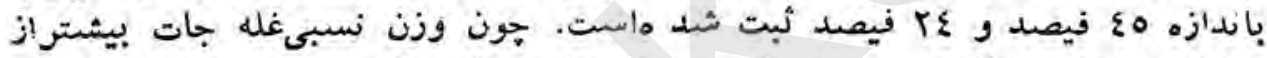

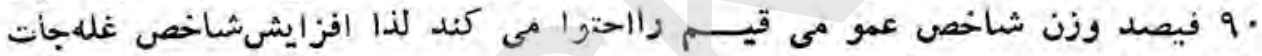

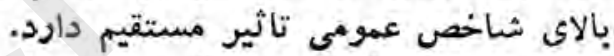

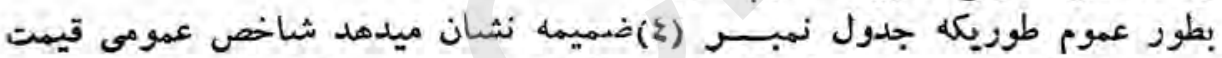

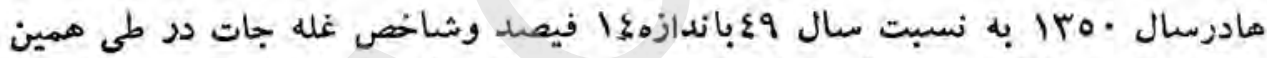

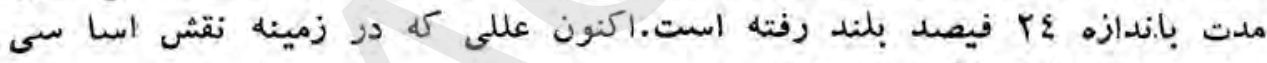

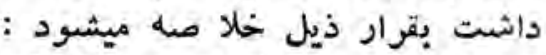

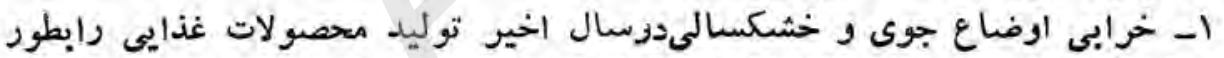

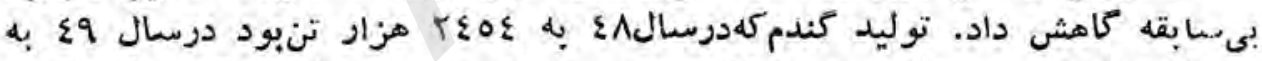

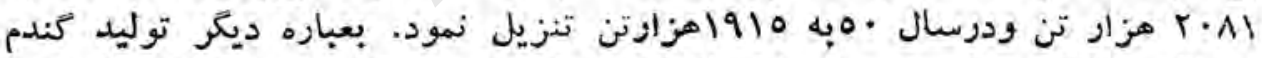

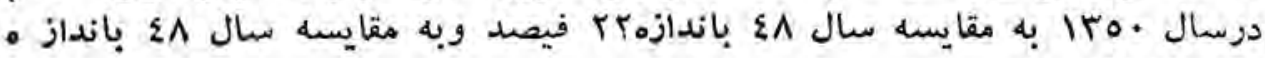

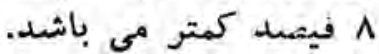

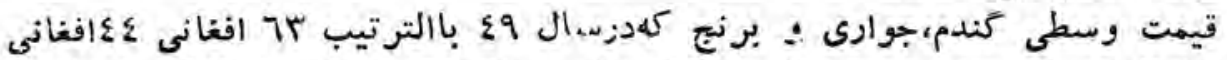

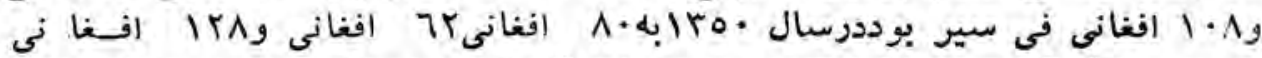

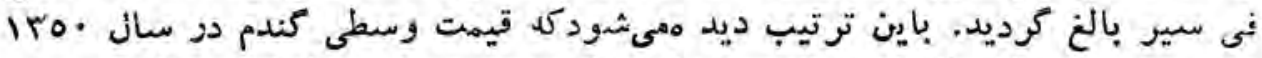

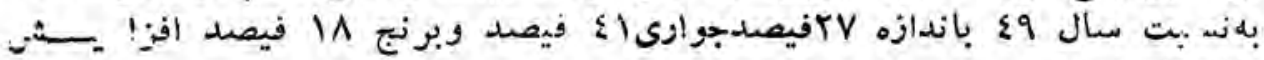
يافته است .

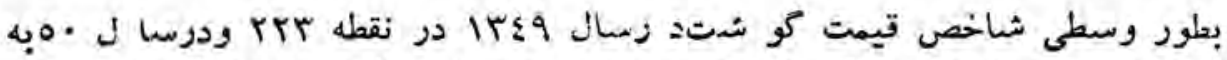

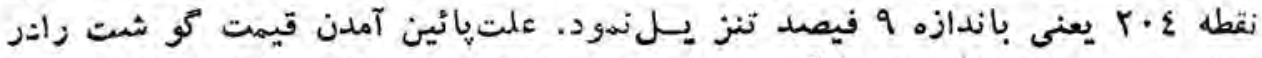

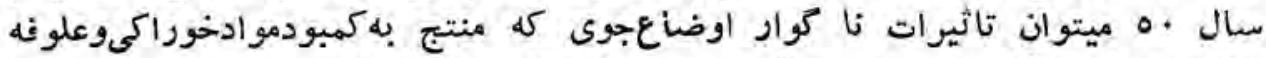

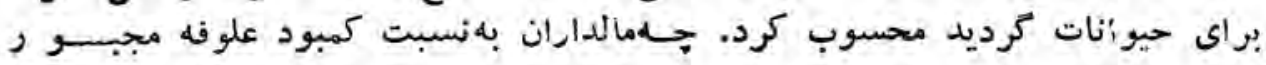




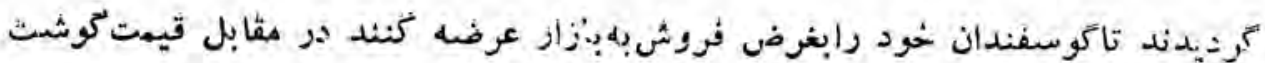

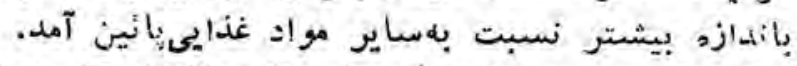

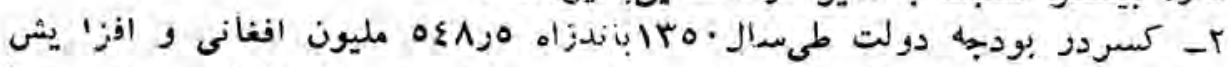

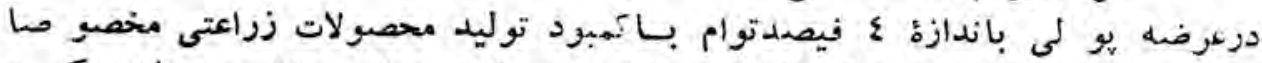

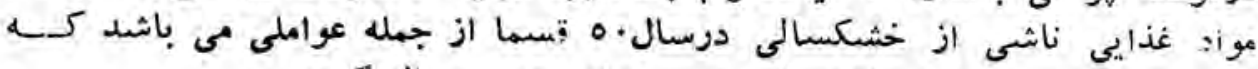

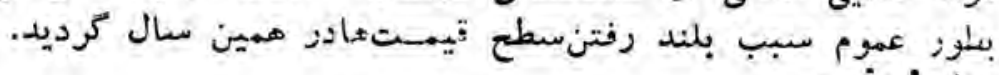
Nypictoli

\section{بـ نوسانات فصلى و ماهوار قيهتها:}

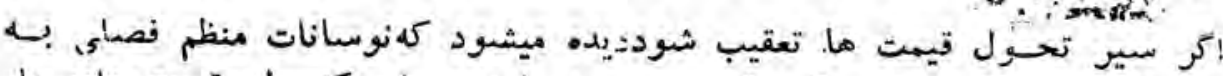

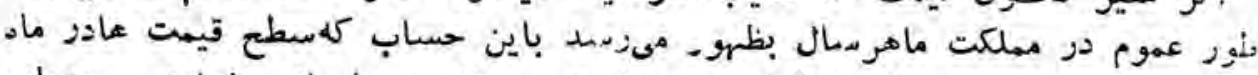

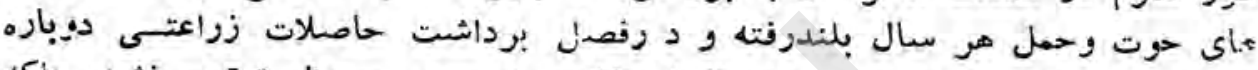

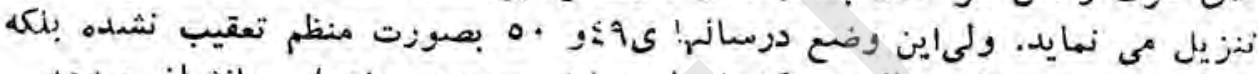

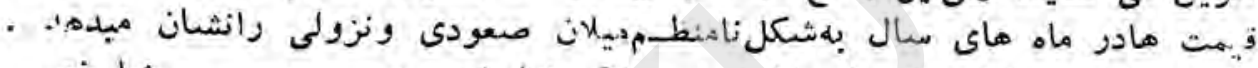

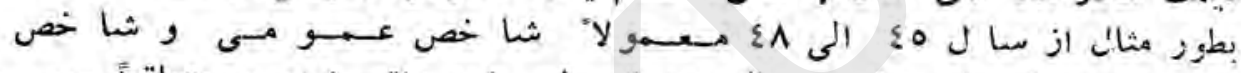

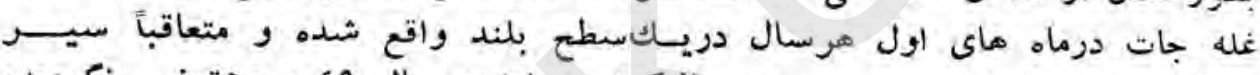

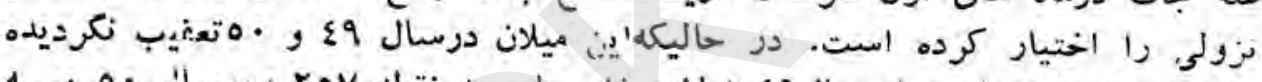

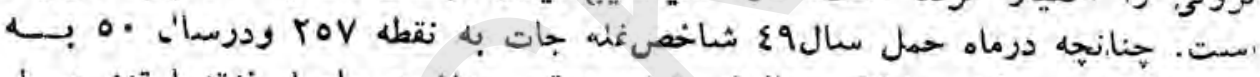

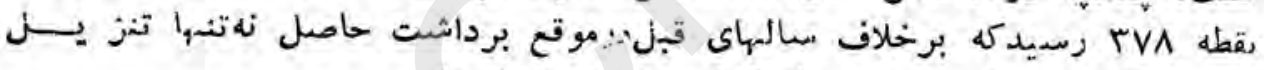

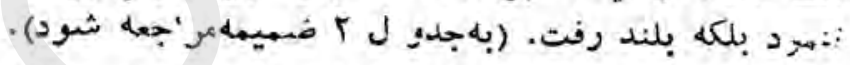

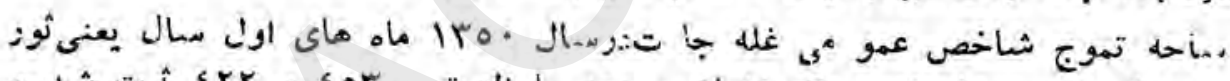

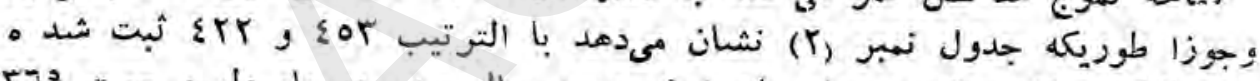

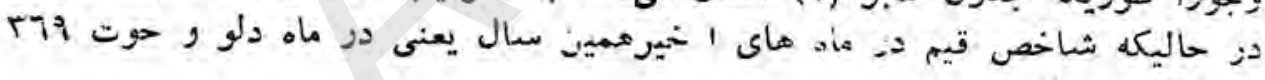

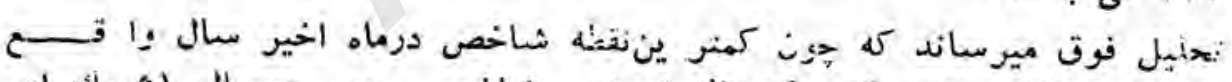

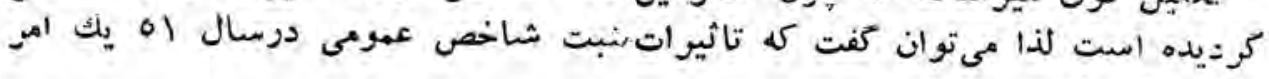

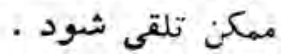


شاخصقيم ملى ماهانه

it 0 .

\begin{tabular}{|c|c|c|c|c|c|c|c|}
\hline شاخص مجموعى & هو اد غيرغذائى & موادغذائى & سبزيجات & ميوهجات & كوشت & حبوبات & سال. ماهol \\
\hline ו & & $|\varepsilon \wedge|$, & rrt,g & $r r o, v$ & rorjt & rVA,r & حهل \\
\hline roljr & 117,5 & $|\varepsilon \varepsilon ر|$ & พาq,q & $r r v$ & r19, & \{०r, & ثور \\
\hline riqur & 119. & $10.2 \mathrm{~V}$ & rII, & $r \cdot \varepsilon, V$ & |9vر| & हrा, q & جوزا \\
\hline$r 99,1$ & $\| v, \varepsilon$ & $10 \cdot 5$ & $|\wedge T|$, & $I A \cdot, V$ & $\backslash \wedge \varepsilon,$. & $r 9 \Lambda, r$ & سرطان \\
\hline rqV,q & 117,5 & lor & $10 \wedge ر$. & $\mid r V, \varepsilon$ & $|v v j|$ & $\varepsilon \cdot \wedge, r$ & اسد \\
\hline$r \wedge 0,0$ & $\| \wedge$, & $10 r, 7$ & $17 V_{j}$ & $r \varepsilon \varepsilon, q$ & IAT,E & $r \wedge, j$ & سنبله \\
\hline rIEjo & 119,0 & 100,1 & $\mid \wedge \wedge, 7$ & $r \cdot 7, r$ & IAr,o & घ1^j, & ميزان \\
\hline$r \cdot r,$. & $I r \cdot s V$ & $1 \Sigma \wedge, 0$ & $19 \varepsilon, \varepsilon$ & roq,r & & rars & عقرب \\
\hline$r \cdot q, r$ & $r r \cdot s$ & $1 \wedge \varepsilon, r$ & 570,7 & $r v r s$ & 197,8 & rareo & قوس \\
\hline rrr.r & Irit, & $1 v \cdot, 9$ & $r \circ \Lambda, \Lambda$ & rVA,r & $r \mid 0,1$ & rvi,. & جدى \\
\hline r.r & Irron & IVT, T & ارغ & rVrot & rro,o & $r 79, v$ & دلو \\
\hline 511,7 & Irror & IVT, & $r \Delta \cdot r$ & rATr & r & rvve. & حوت \\
\hline
\end{tabular}




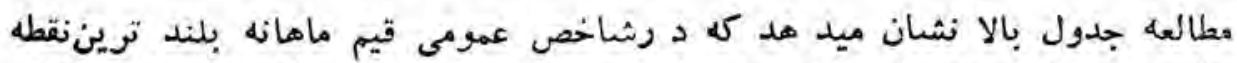

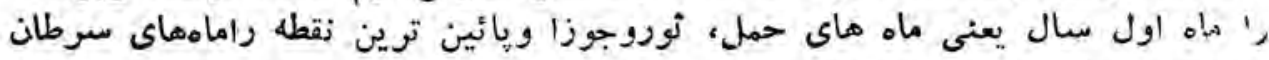

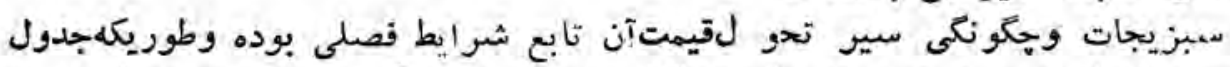

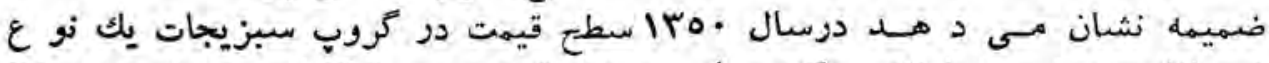

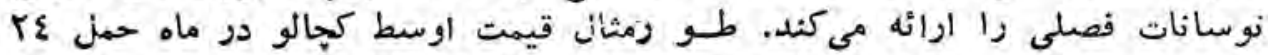

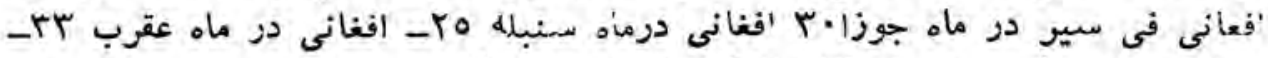

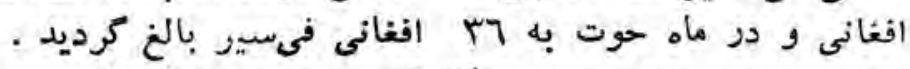

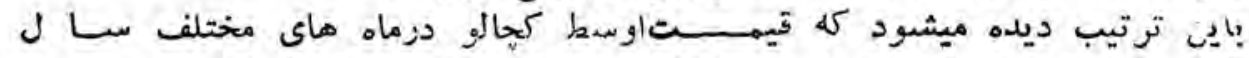

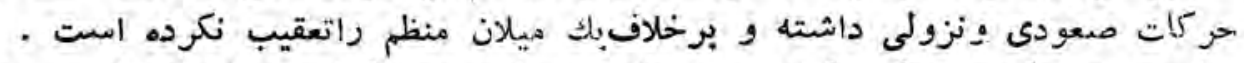

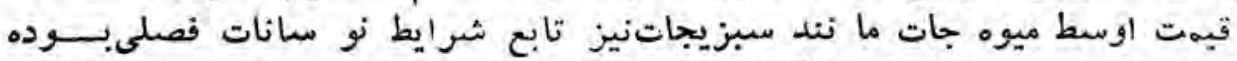

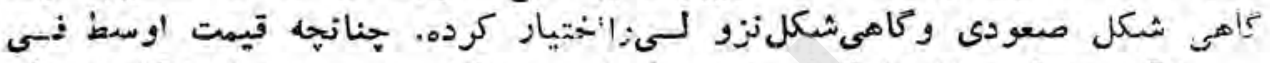

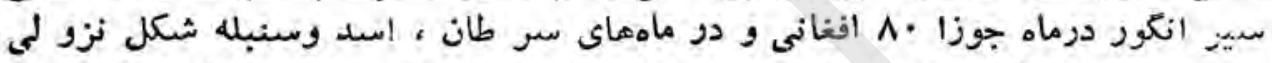

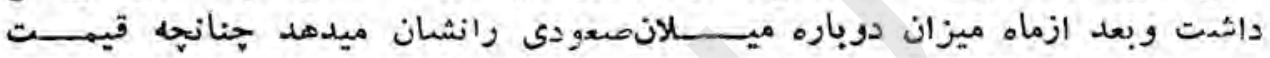

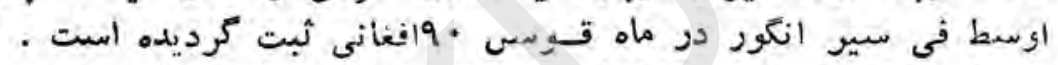

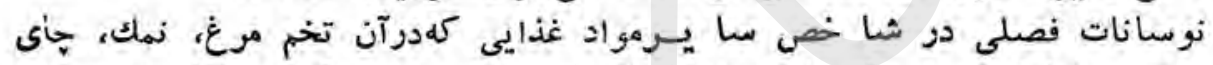

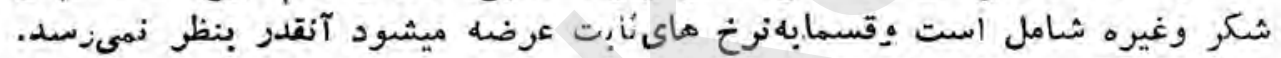

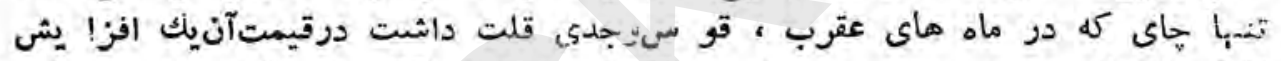

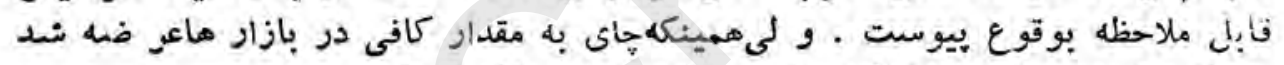

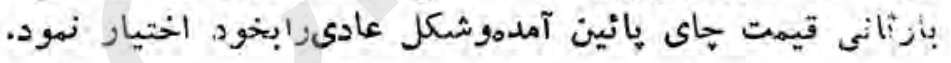

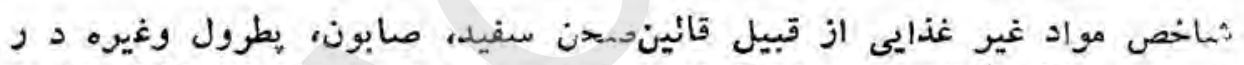

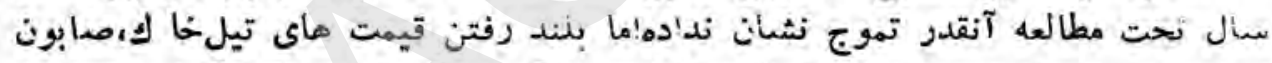

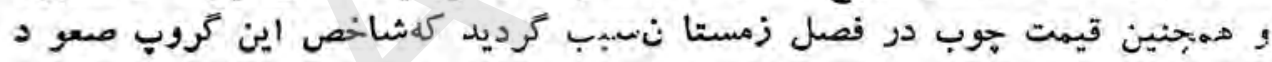

\section{ج- ميتود ولوثى شاخص قيمت ها :}

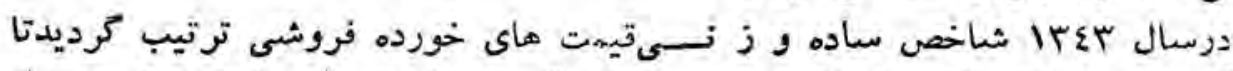

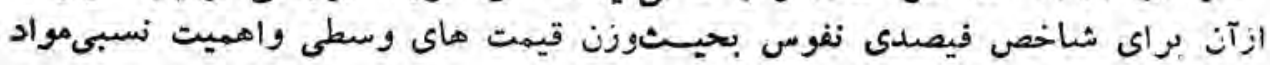

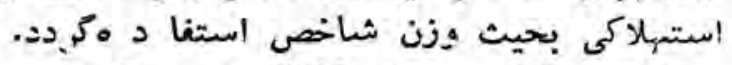

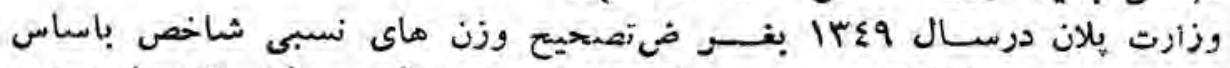

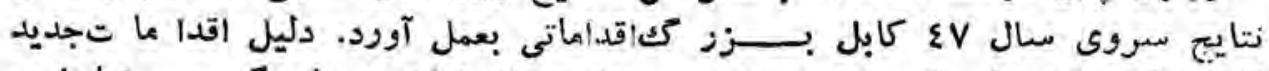

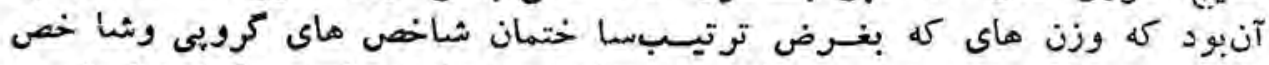

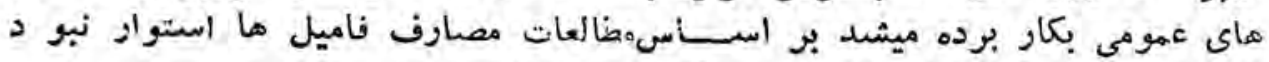

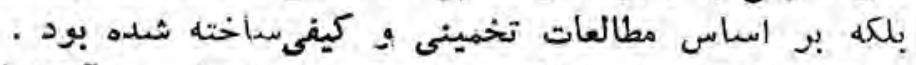

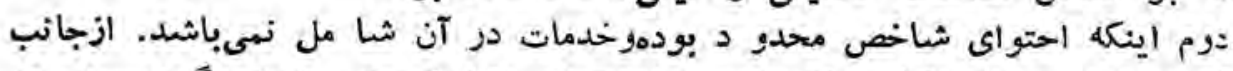

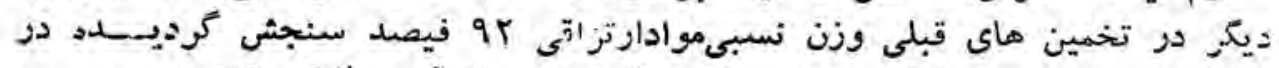

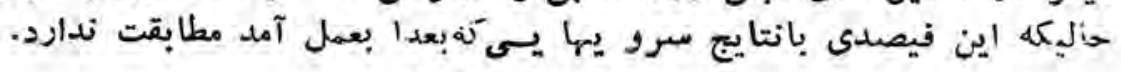


درسال •مبال وزارت يلان بار ديكر درتوتيب شا خص قيمت ها نجديد نظر كرد و

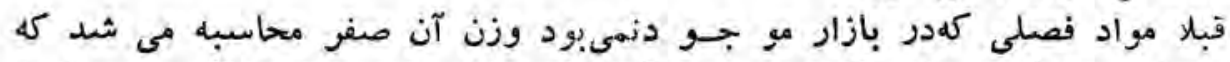

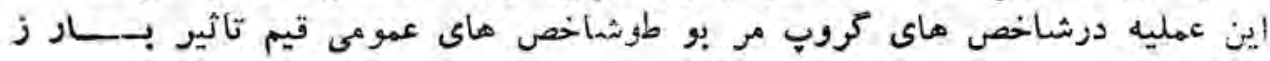
إثنت

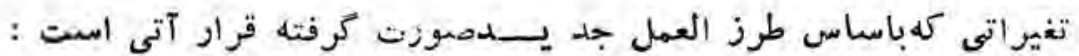

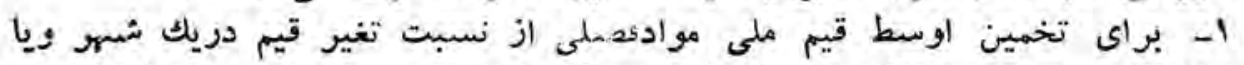

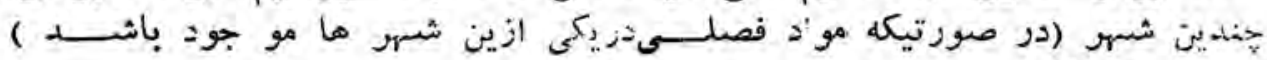

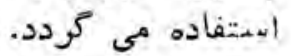

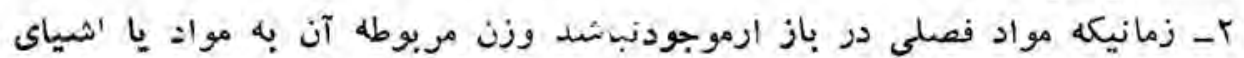

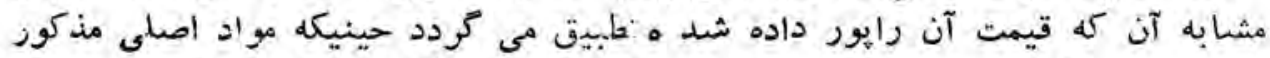

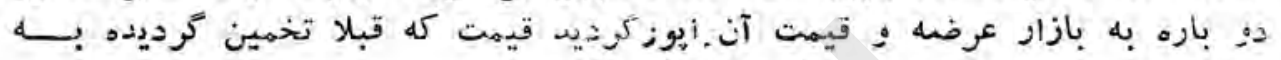

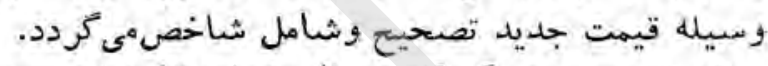

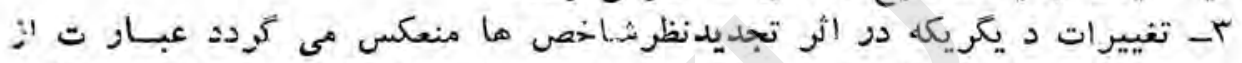

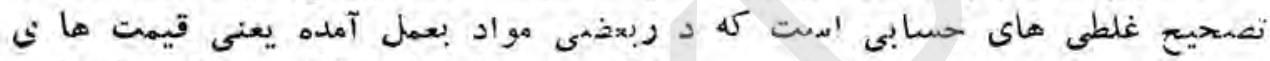

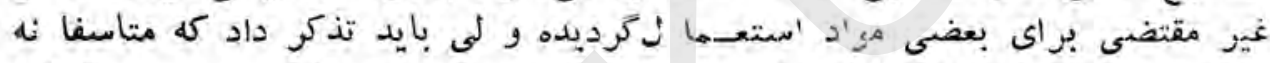

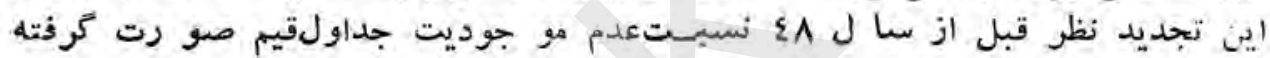

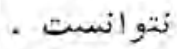

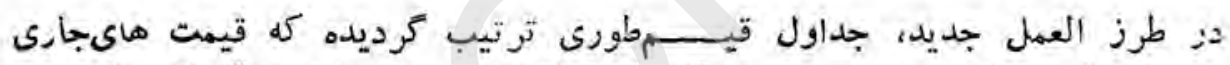

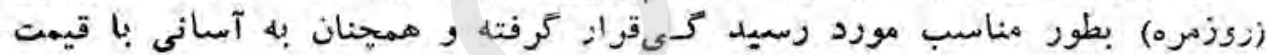

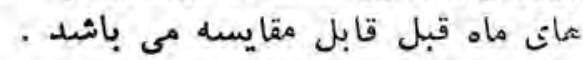

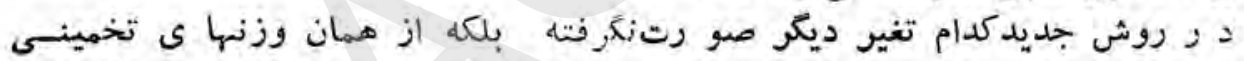

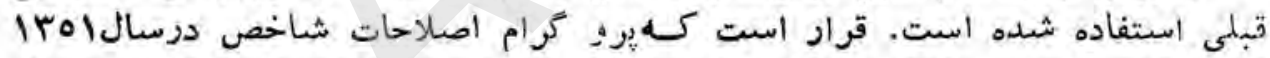

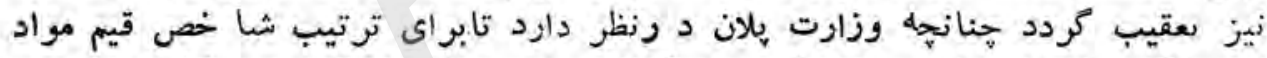

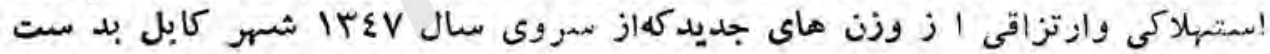

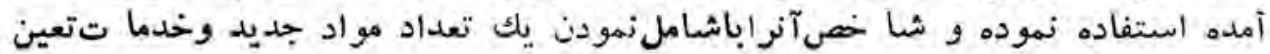
وترتيب زمايد. 


\section{قواى بشرى}

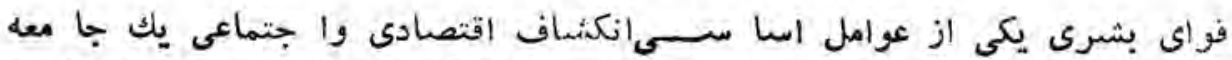

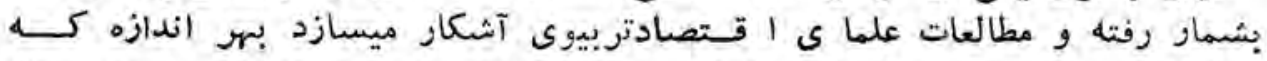

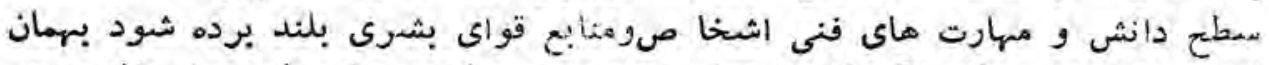

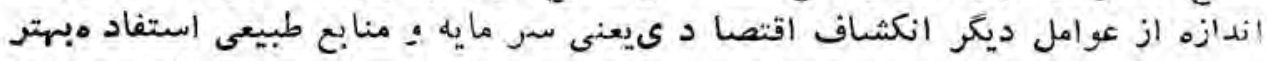

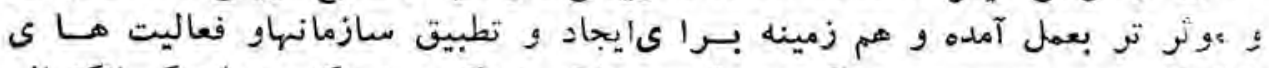

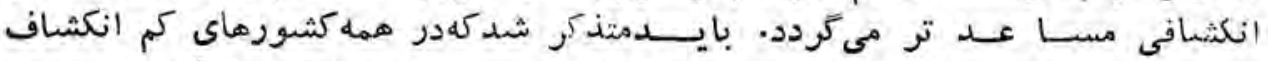

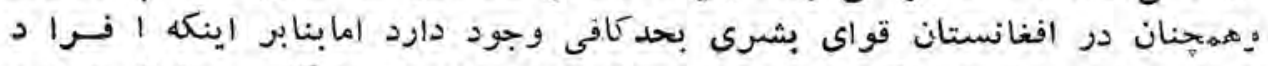

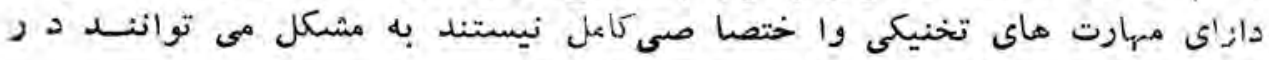

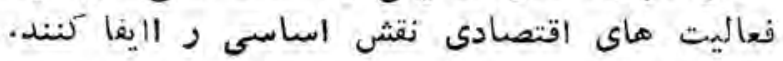

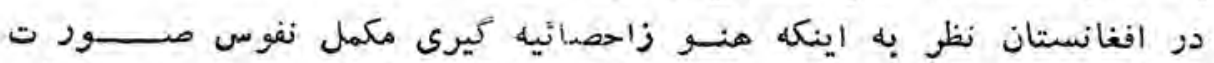

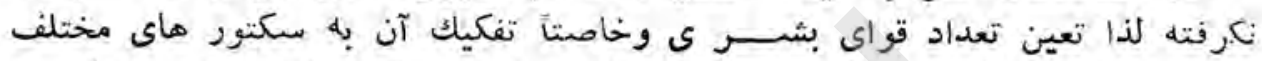

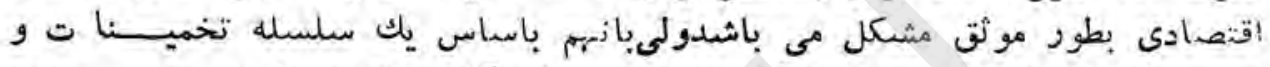

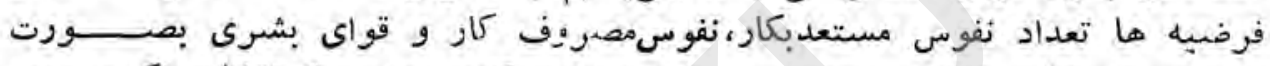

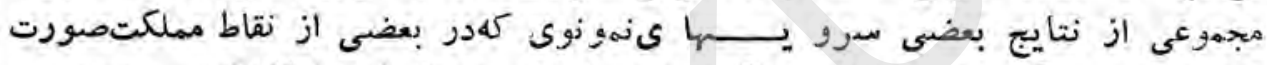

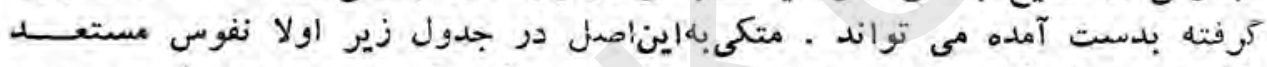

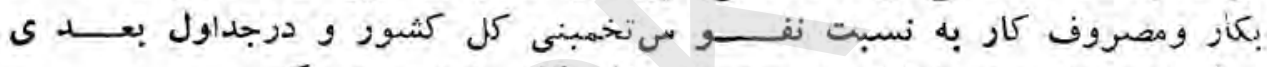

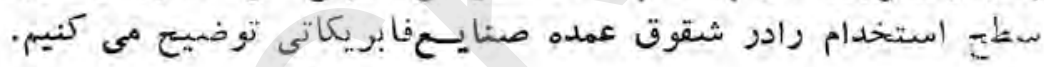

جدول

تعداد نفوس- نفوس شهوىو دهاتسى نفوس مستعد بكار و نفوس مصروف كار

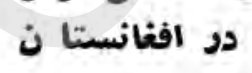

ارقام به هزاد نغ

\begin{tabular}{|c|c|c|}
\hline Iro. & IrEO & \\
\hline $1 \leqslant 7 \cdot 1$ & $\mid K \cdot \varepsilon \varepsilon$ & 1- نفوس كشود به استثناىكوحى ها \\
\hline 519. & $19 \cdots$ & الف: نفو س شهرى \\
\hline \multirow[t]{2}{*}{ ITEIA } & $11 \varepsilon \varepsilon$ & بـ نفوبى دهاتى \\
\hline & & r- نفوس عستعدبه كار (10-7" (1ال) \\
\hline rvo. & rra. & الف:مرد \\
\hline$r \varepsilon V$. & $r \cdot r \cdot$ & 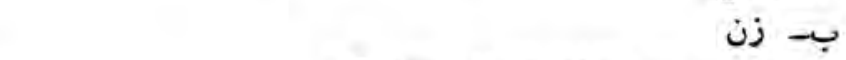 \\
\hline 7 . & 0 . & متعلمان : محصلان داراى سن كار \\
\hline v. & 7 . & معيو بين دازاى سن كار \\
\hline$\{0\}$. & ५97. & r- نفوس مصروف كار \\
\hline rar. & rive. & ألفـ-مردداراى سن كار (10-7سال) \\
\hline$\Sigma V \cdot$ & \&1. & 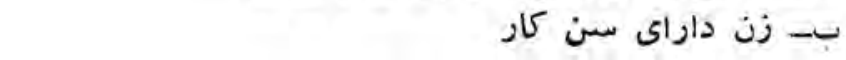 \\
\hline re. & $r \wedge$. & ج- مصروفين دازاى سن يائين از هاوبالاتراز •جسال \\
\hline
\end{tabular}




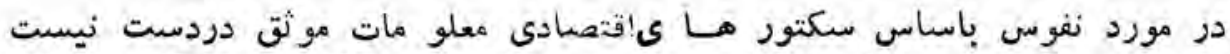

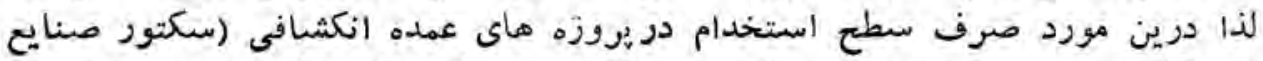

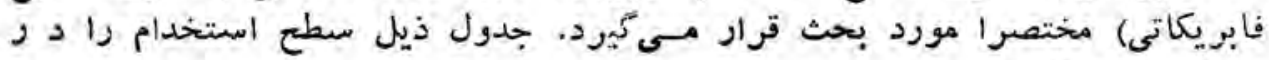

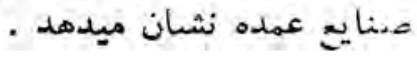

\section{(r) جدول \\ استخدام در شقوق عمله صنايع}

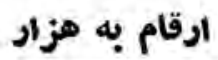

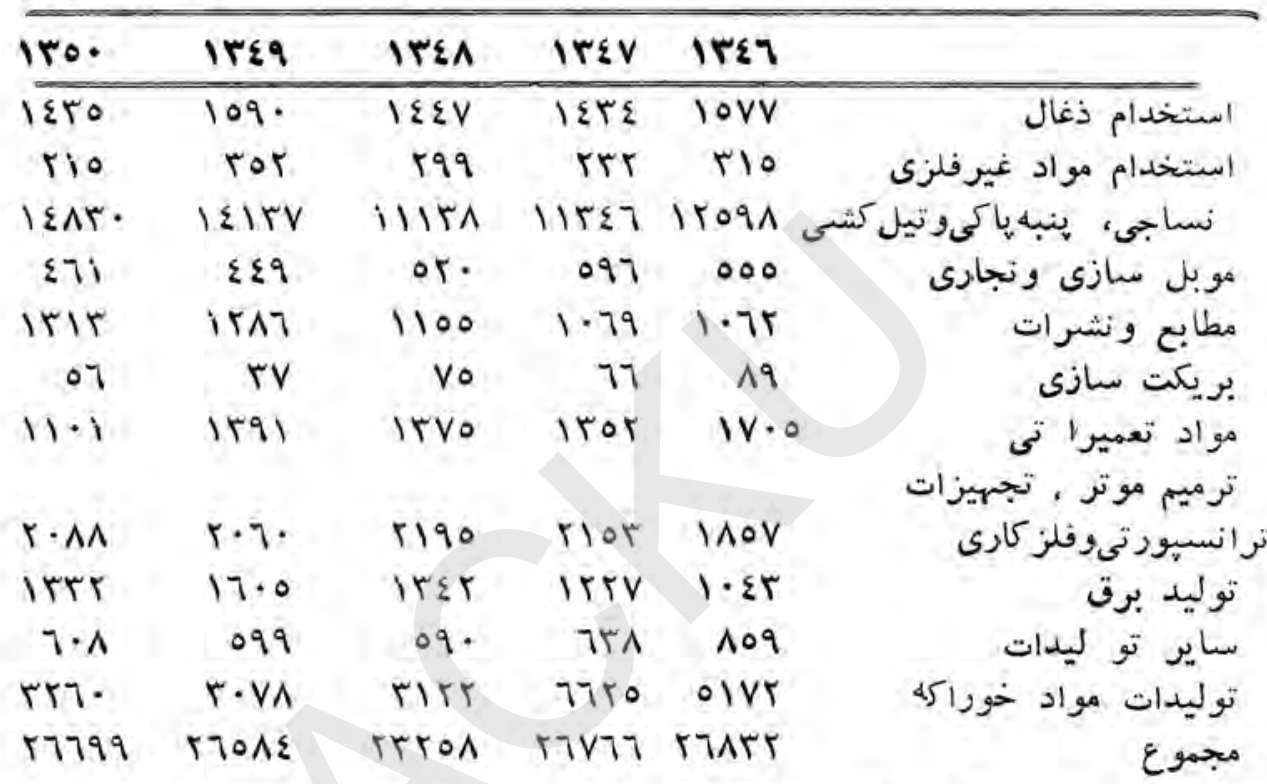

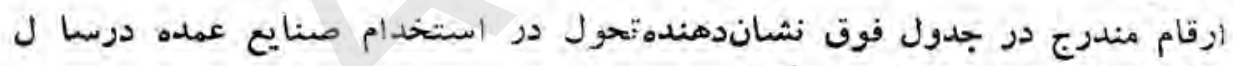

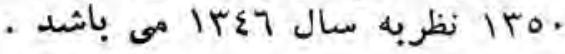

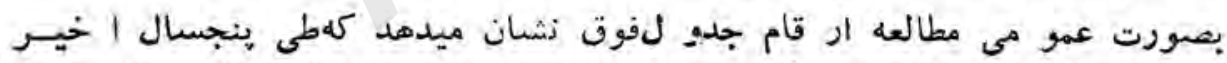

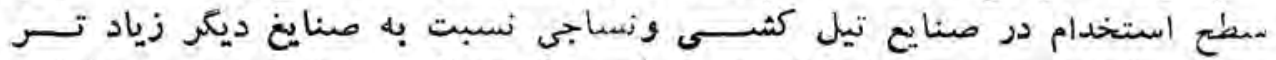

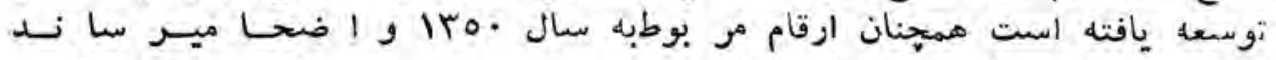

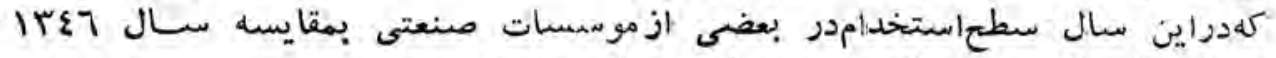

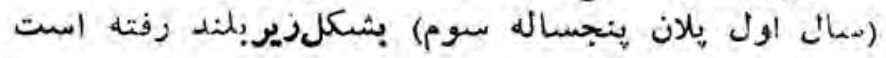

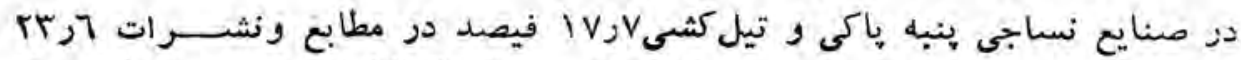

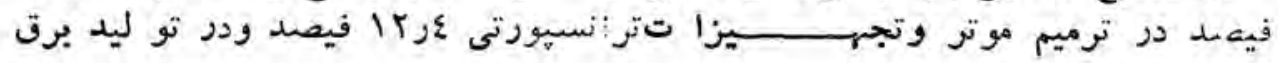
V TV V TV

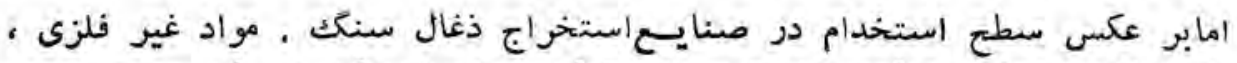

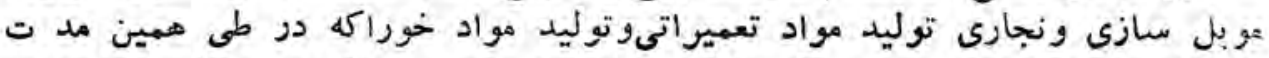

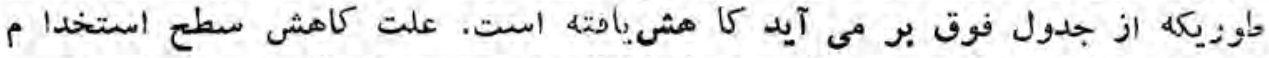

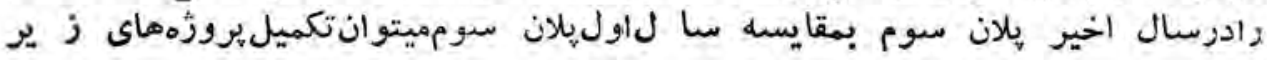




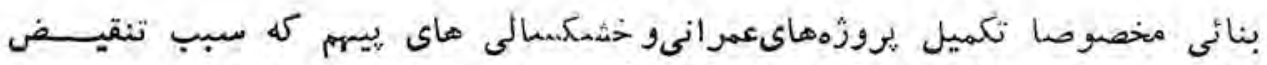

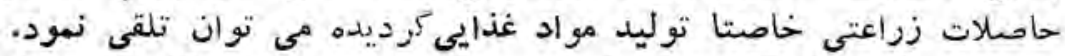

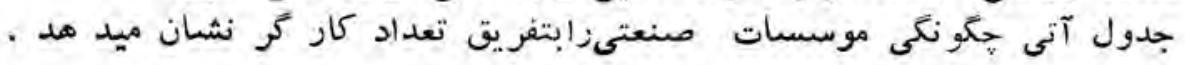

\section{(i) جدول}

\section{تصنيف مو سسات صنعتى با سا سئعداد كار تر}

\begin{tabular}{|c|c|c|c|c|c|}
\hline 150. & $1 r \varepsilon q$ & $\mid r E \Lambda$ & $\mid r \varepsilon V$ & $1 r \leqslant 7$ & \\
\hline ro & rV & ro & 57 & ra & 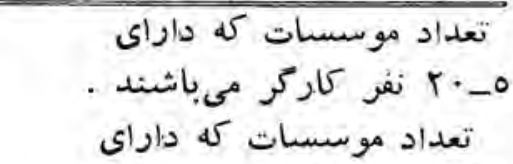 \\
\hline$\varepsilon \wedge$ & $\varepsilon r$ & $\varepsilon r$ & r7 & rV & 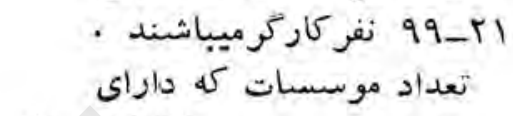 \\
\hline$\varepsilon T$ & rA & ri & rt & $r$. & 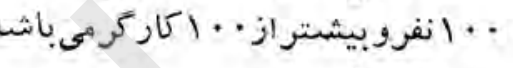 \\
\hline 110 & $1 \cdot v$ & 99 & 90 & 90 & مجموع \\
\hline
\end{tabular}

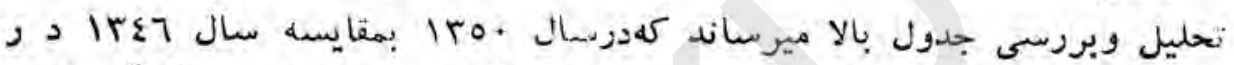

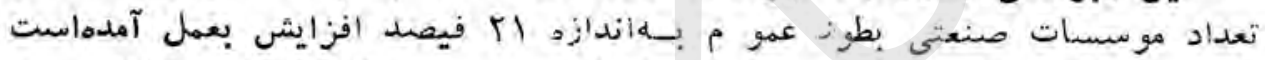

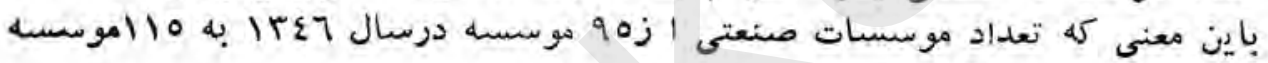

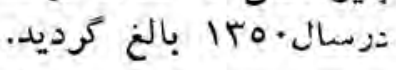

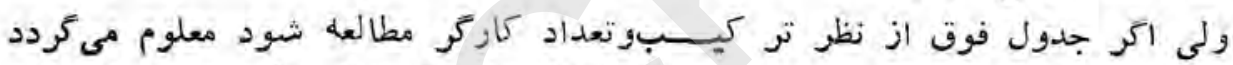

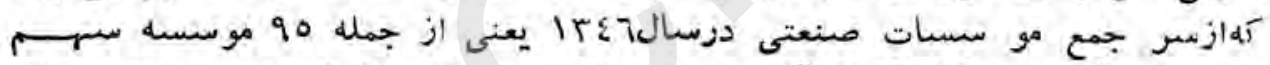

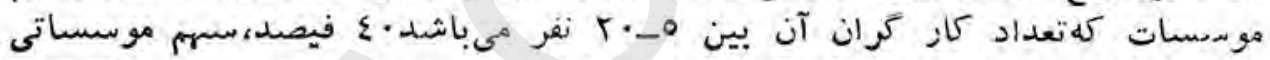

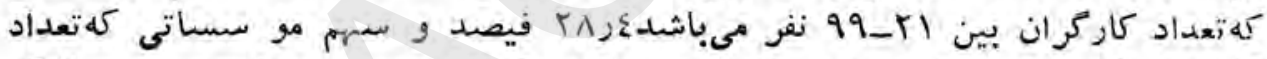

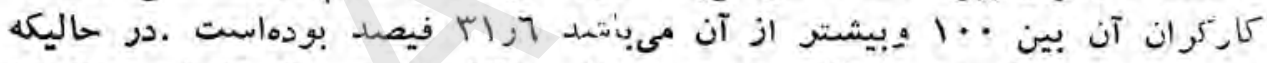

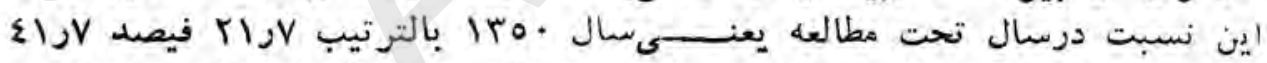

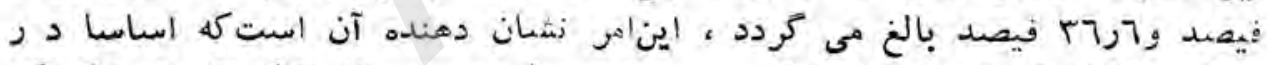

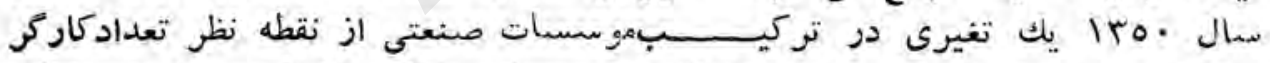

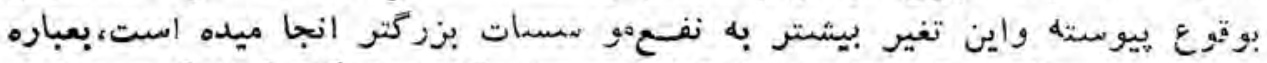

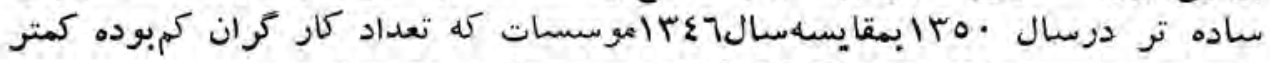

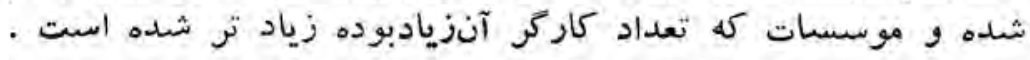

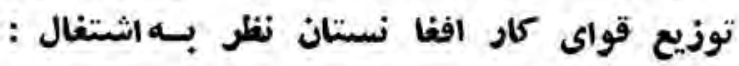

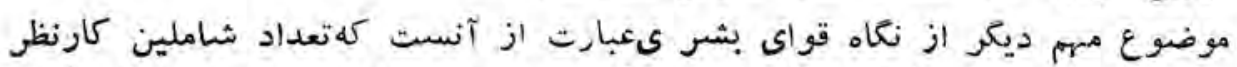

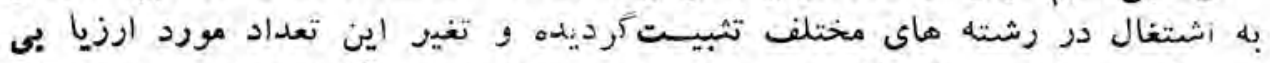

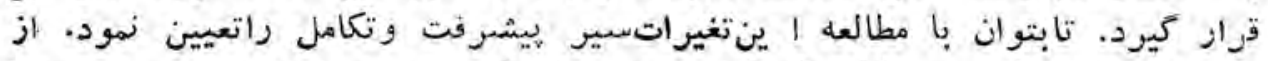

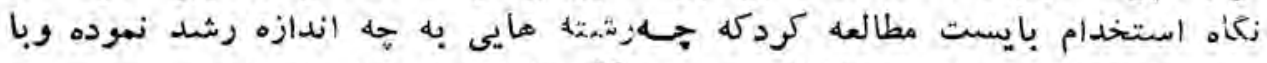

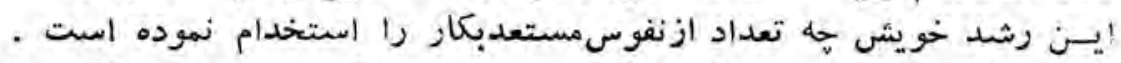

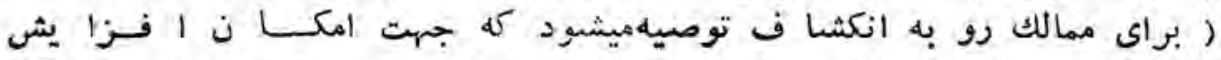

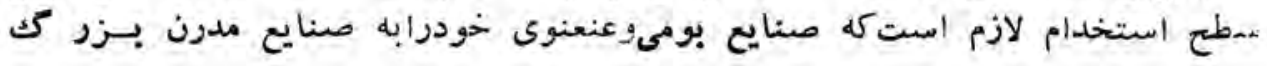




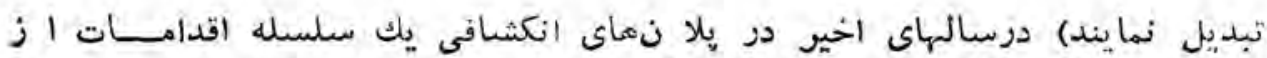

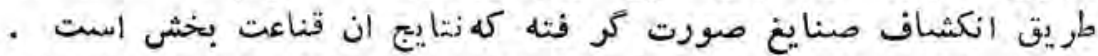

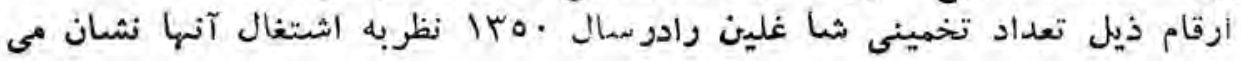

.003

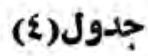

\section{توزيع قواى بشرى نظربه اشتغال}

\section{ارقامبهزارنفر}

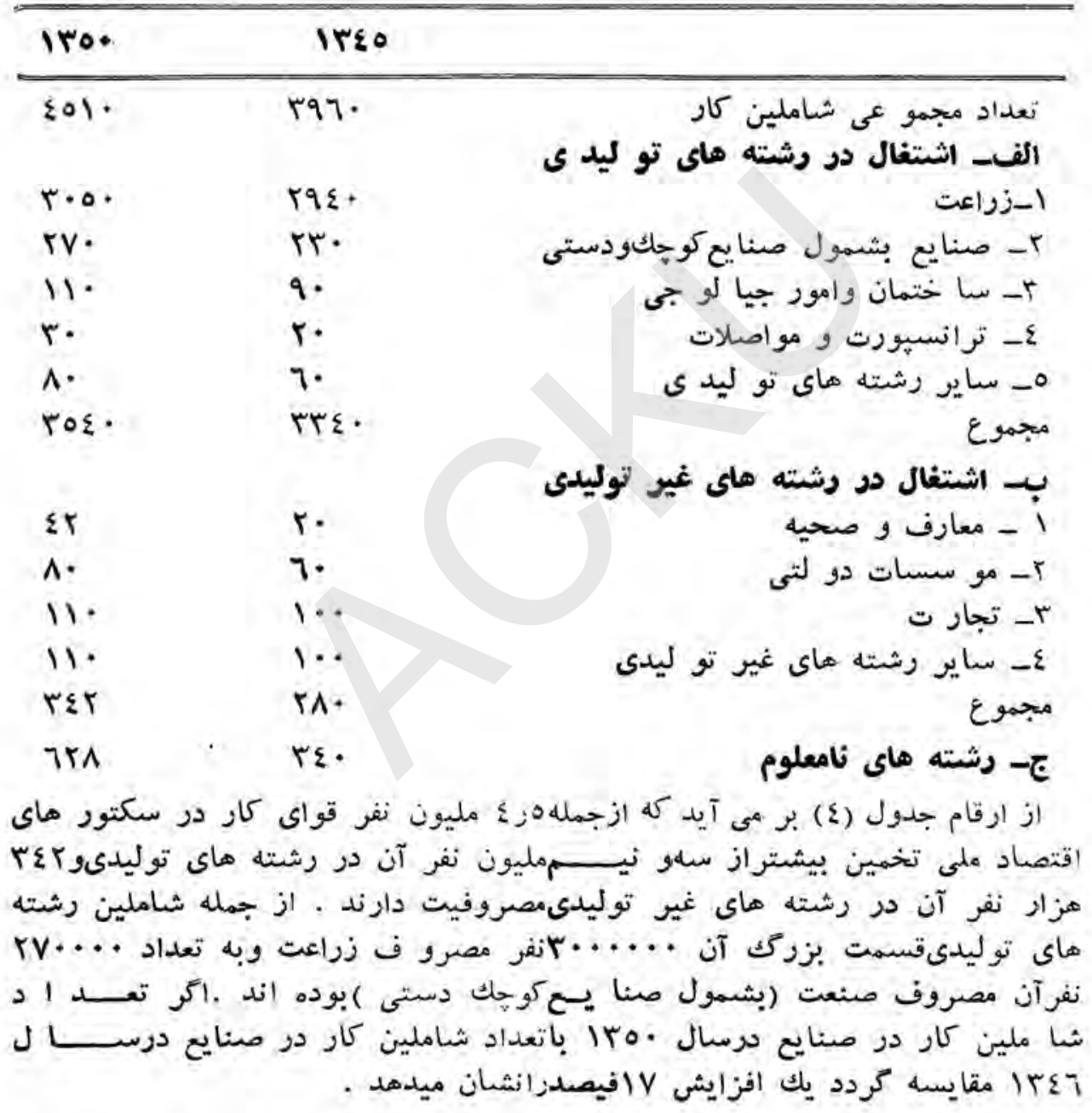




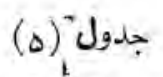

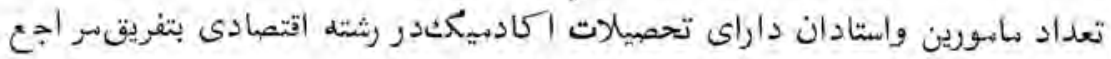

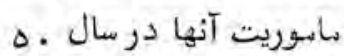

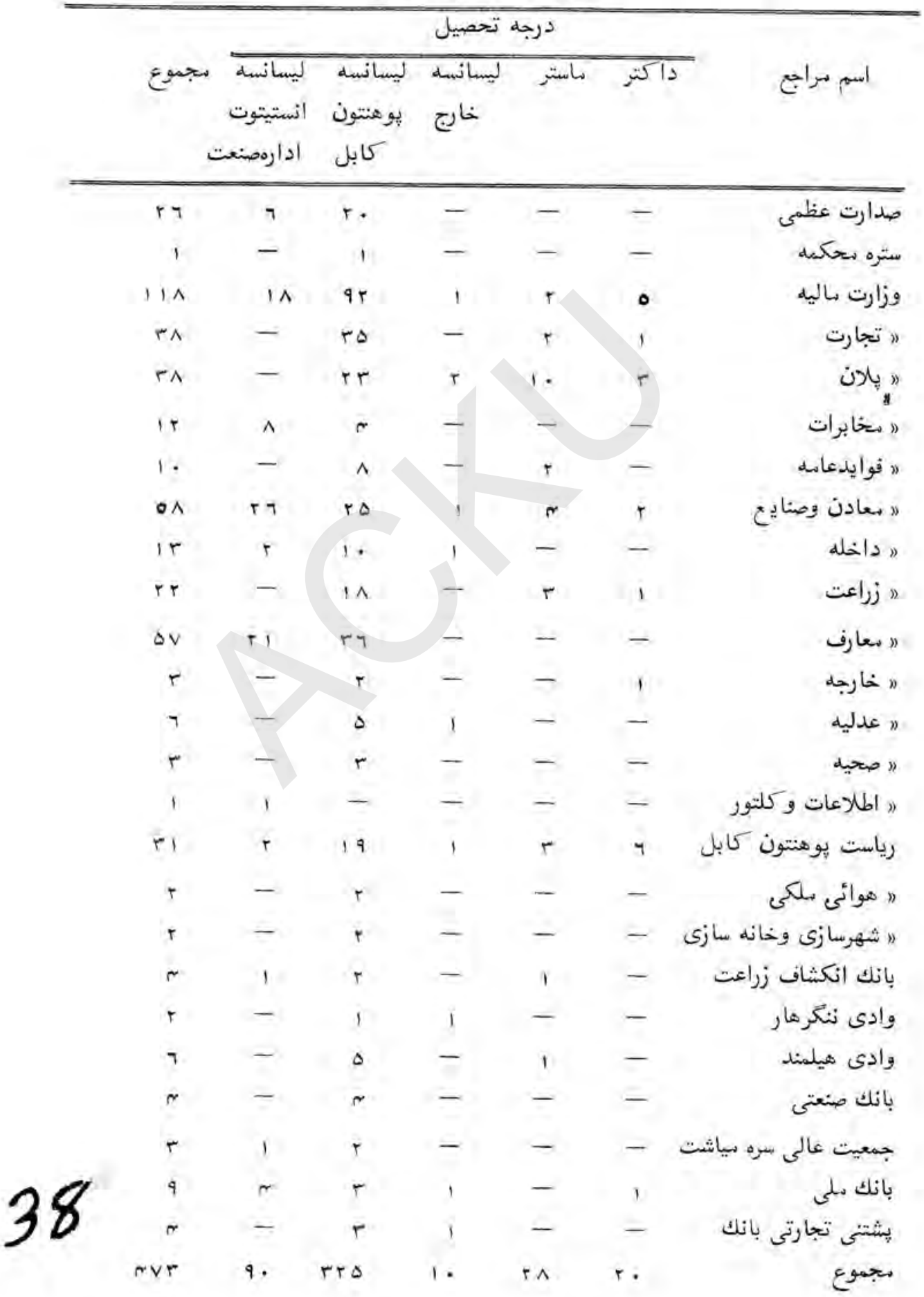




\section{سروى هاىنمونوى}

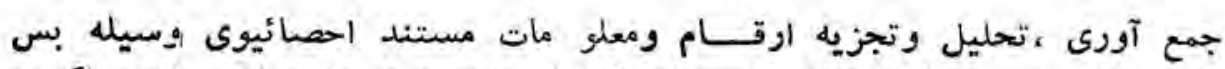

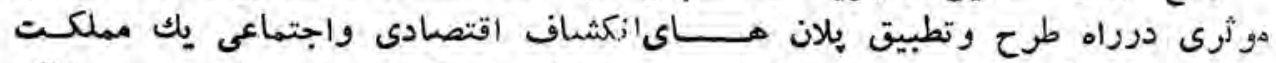

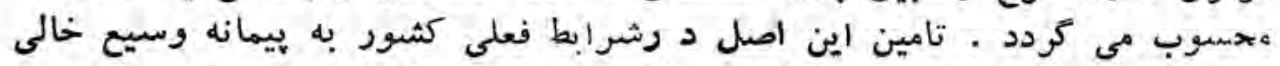

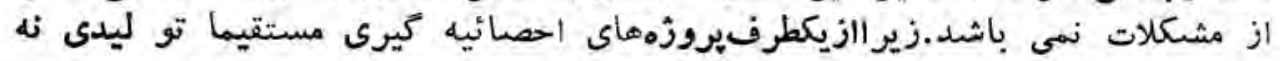

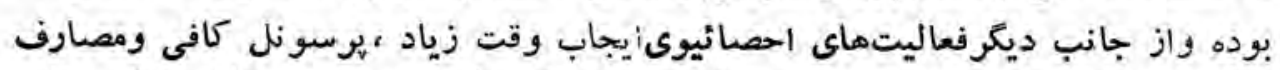

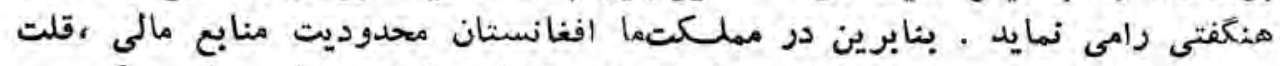

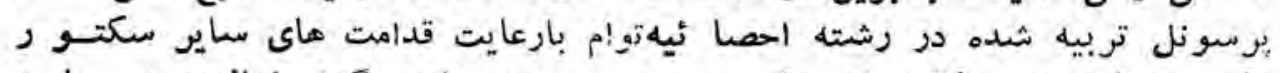

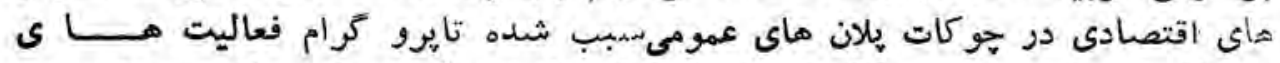

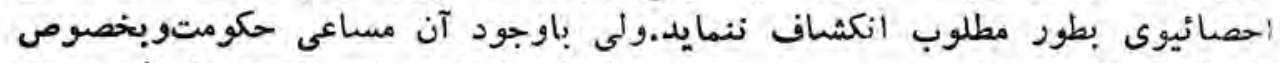

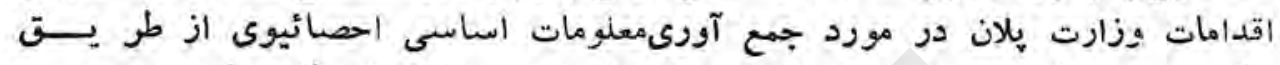

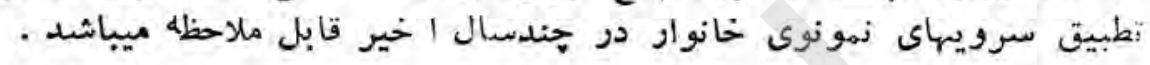

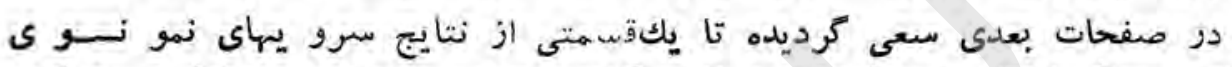

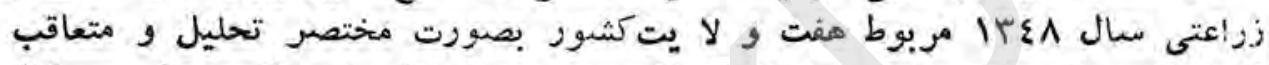

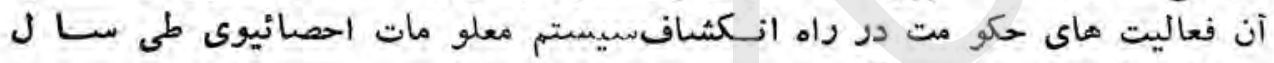
أ.

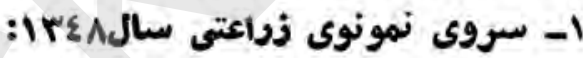

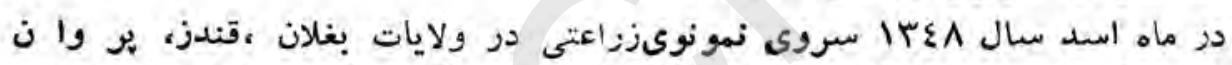

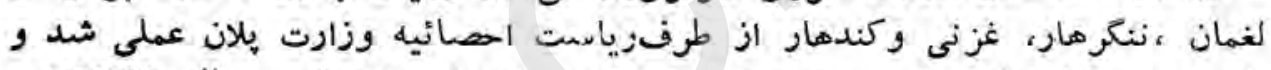

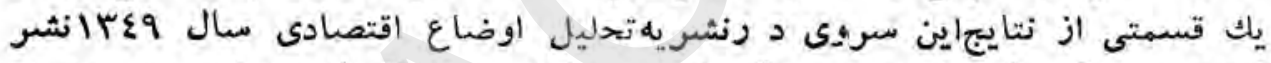

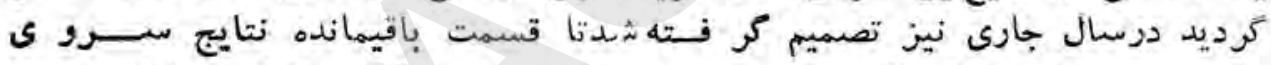

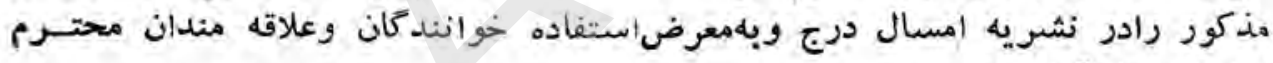
إين نشريه قرار دهيم نشريه

تعدادنفوس و مجموع خا نوار شا مل سروى برادر هفت ولايت ارائه ميـدا ر د

\begin{tabular}{|c|c|c|}
\hline تعدادنفوسدرساحه شاهل & تعداد خا نو 1 د & ولايات \\
\hline 1.10 & 1.0 & بغلان \\
\hline 1150 & 1.0 & قـند ز \\
\hline $7 \wedge \varepsilon$ & Al & هـر وان \\
\hline rAo & \&1 & لـغمان \\
\hline $1.9 \varepsilon$ & 111 & ننكر هار \\
\hline אשדו & IVr & غز نى \\
\hline 99. & $|r|$ & كند هلار \\
\hline 79ז7 & Vrv & مجموع \\
\hline
\end{tabular}




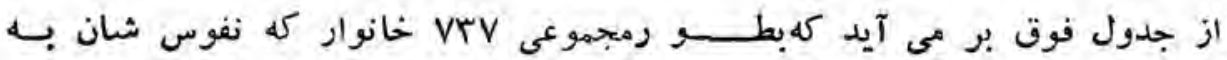

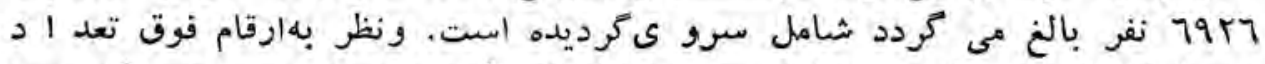

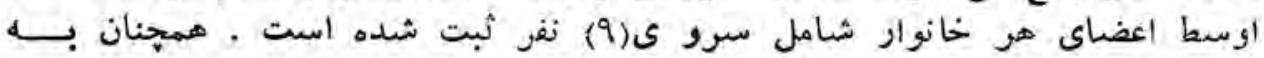

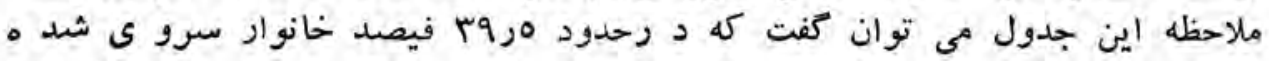

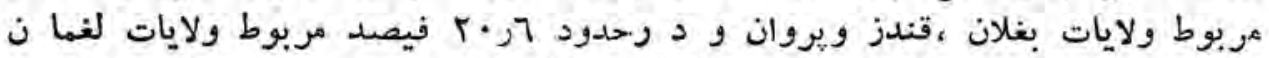

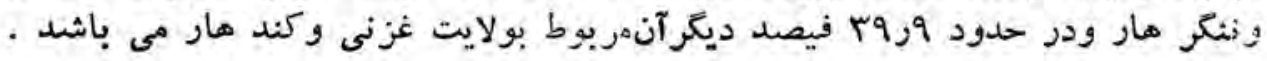

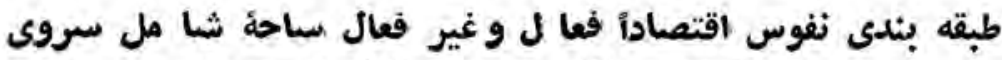

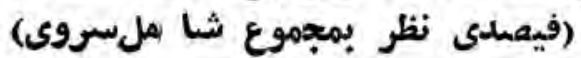

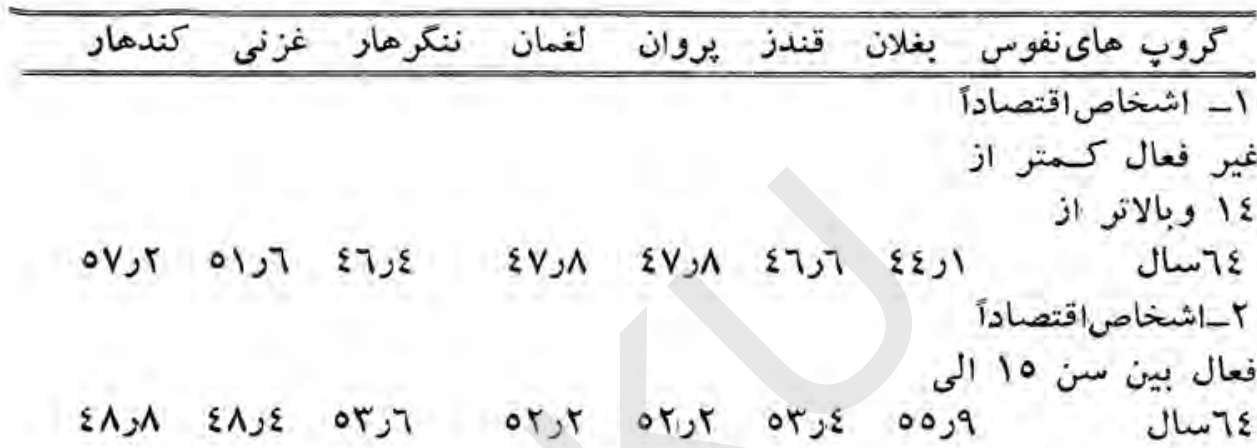

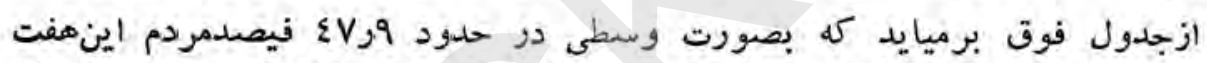

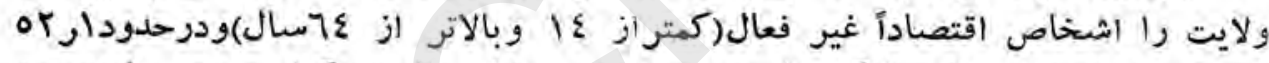

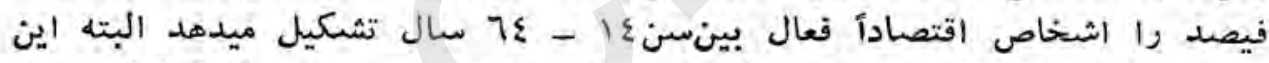

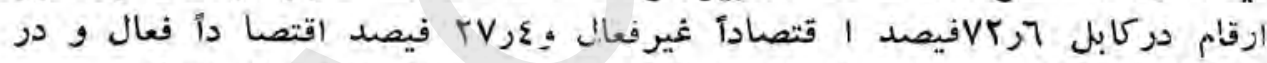

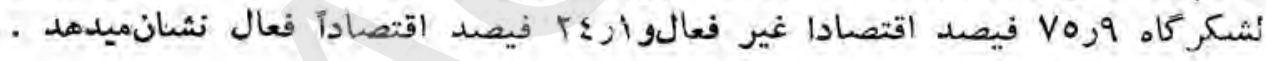

\section{طبقهبندى نفوس هفت ولايت بهتفكيك جنس}

فيصدى نظو بهمجمو عنفوس

\begin{tabular}{|c|c|c|c|c|c|c|c|}
\hline كندهار & غزنى & ننكر هاز & لغمان & بروان & قندز & بغلان & جنس \\
\hline $0 . j r$ & $\sum \wedge, 0$ & $01,$. & $0 \varepsilon, V$ & 01,4 & or & $\varepsilon V, q$ & ذكـور \\
\hline
\end{tabular}

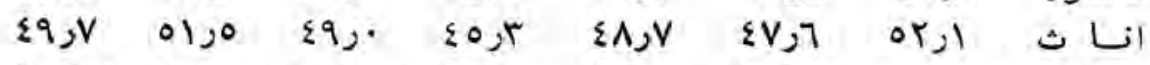

مجموع

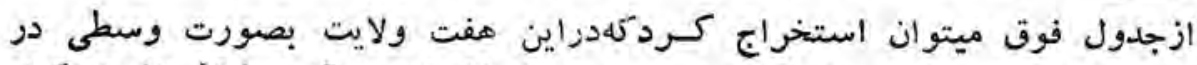

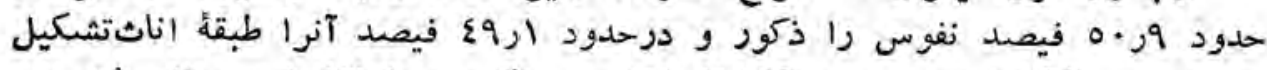

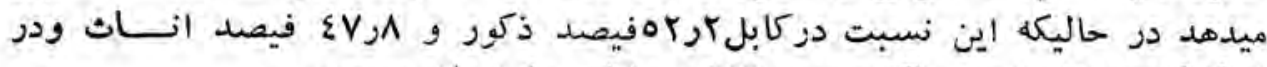

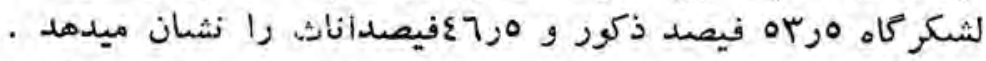

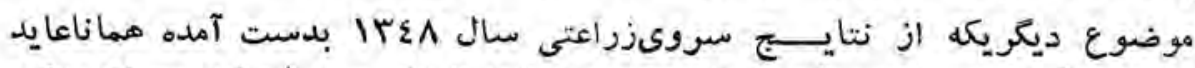

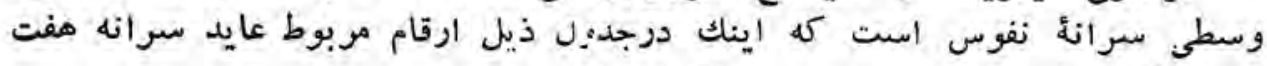

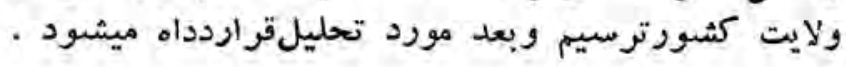


(ई) جدول

عايد ومثطى غير خالص سمالا زه في نسفر

\begin{tabular}{|c|c|c|c|}
\hline سالانهاتفىنفي & نفوسوسوعايداتشالانه & تعداد نفوس شده & \\
\hline 778. & $T V V \cdot 0 \cdot V$ & 1.10 & بغلان \\
\hline$\varepsilon 0 \cdot \wedge$ & OOVIVEE & IIro & قندز \\
\hline rior & $|\wedge| \varepsilon \varepsilon r q$ & $7 \Lambda \varepsilon$ & يروان \\
\hline rTVV & $1 \cdot r \cdot \varepsilon 00$ & rAo & لغهان \\
\hline$r \cdot \varepsilon 1$ & rrTrogr & $1.9 \varepsilon$ & ننكر هار \\
\hline rols & $\{1 \cdot \varepsilon 791$ & אוr & غزنى \\
\hline OTrI & ०OVEרT० & 99. & كندهار \\
\hline$r \wedge \varepsilon$. & $r 7099 \cdot \varepsilon r$ & 7957 & مجموع \\
\hline
\end{tabular}

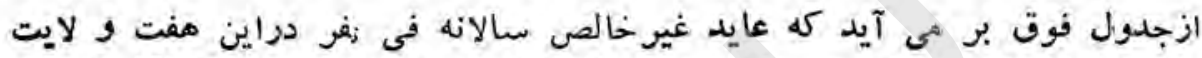

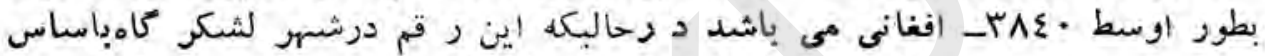

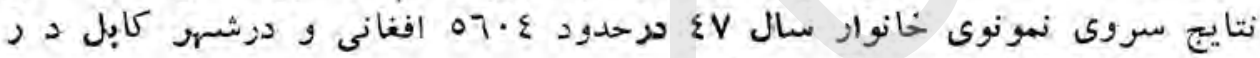

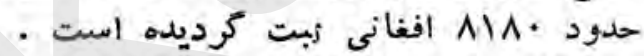

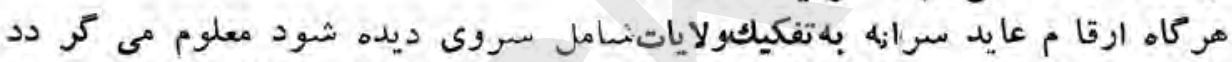

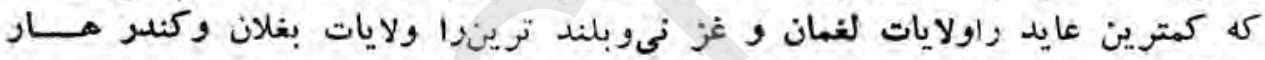

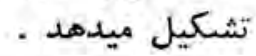

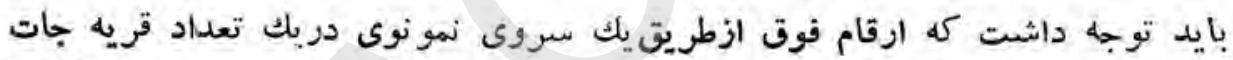

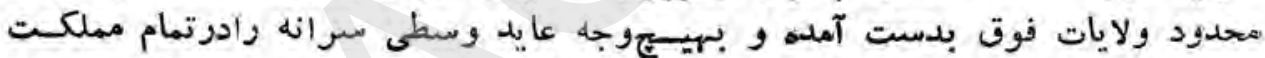

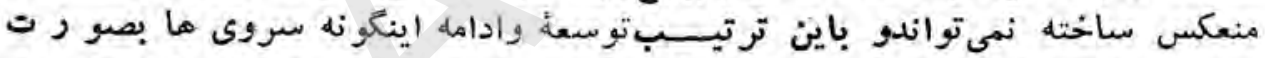

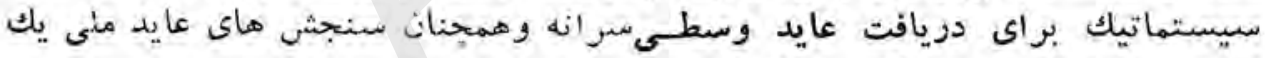

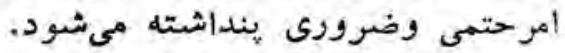

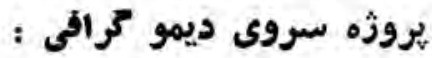

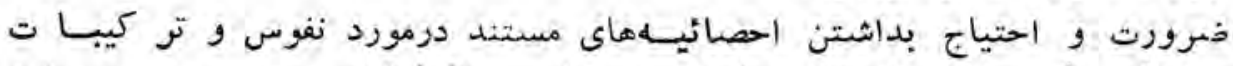

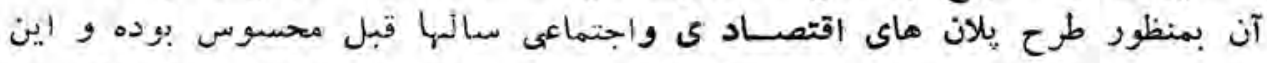

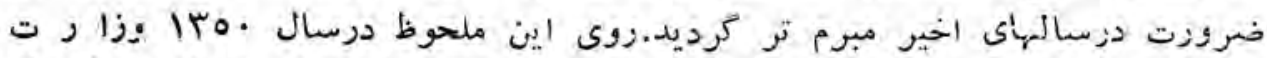

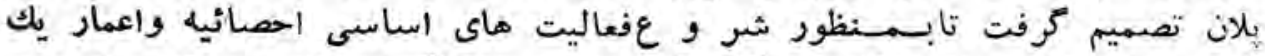

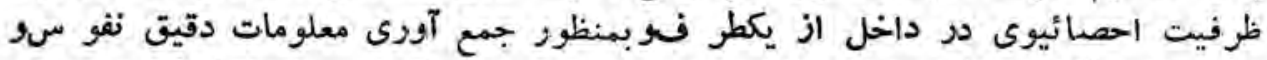

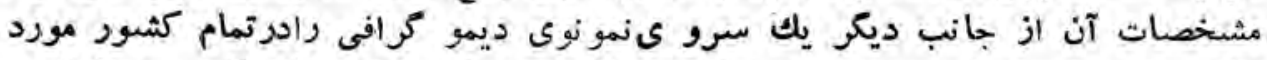

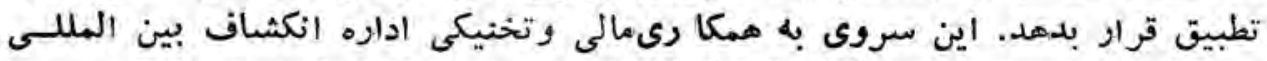

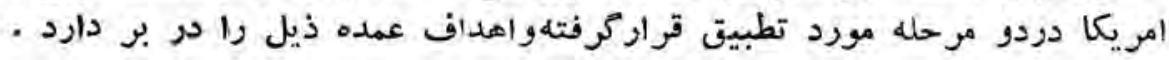

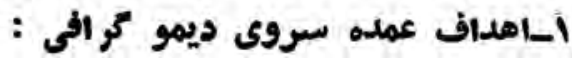

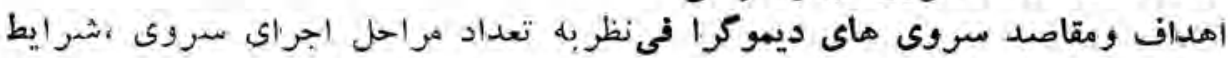




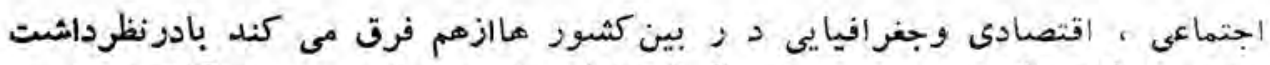

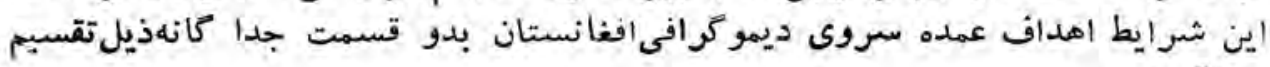

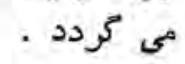

\section{الفـ اهداف كوتامدت :}

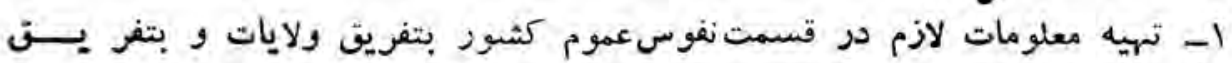

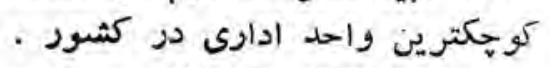

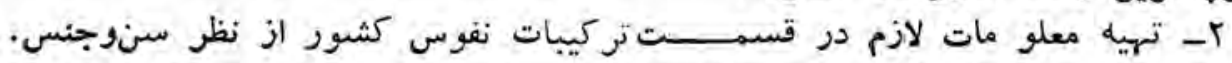

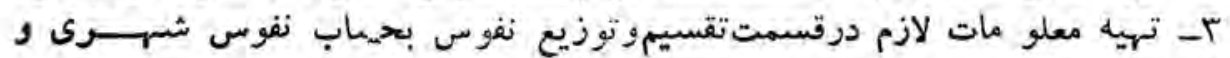

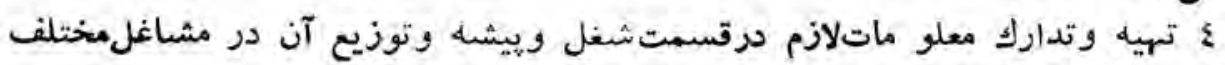

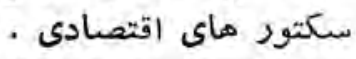

0ـ تهيه معلومات لازم در قسمت مرجه سواد ،تعليم وتربيه ،سويه استخـلام و

7- تهيه معلومات در باره رشد نفوسوادززاء مركت ومير (تولدات وفيات) ومم

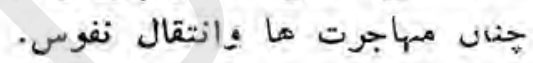

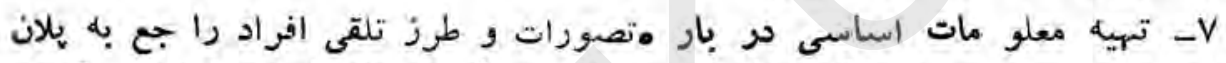

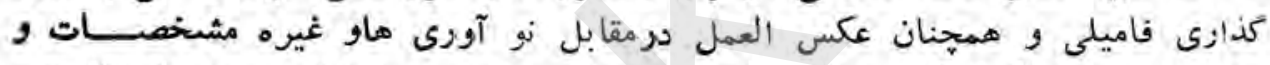

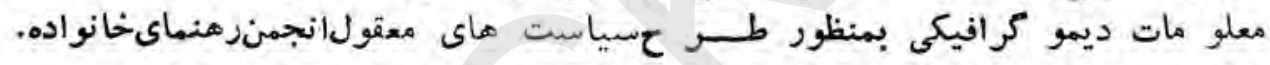

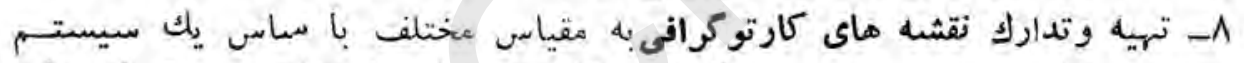

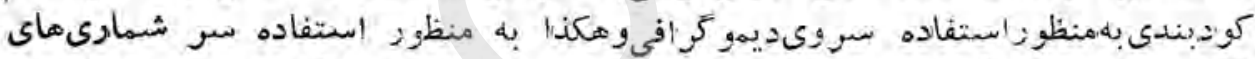

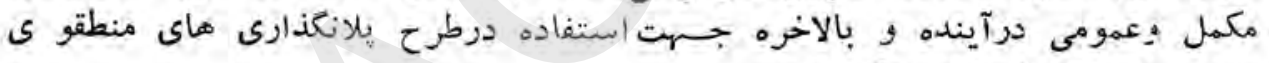

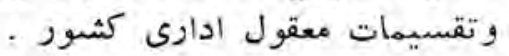

\section{ب- الهداف دراز ملت :}

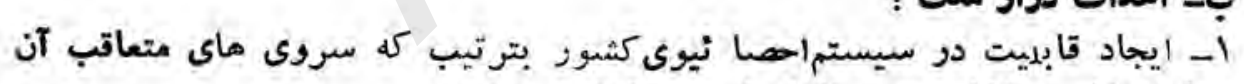

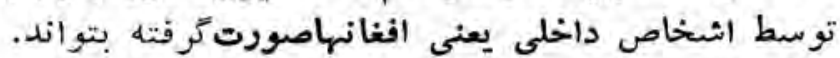

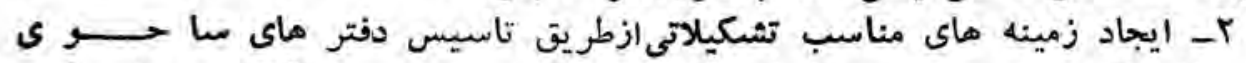

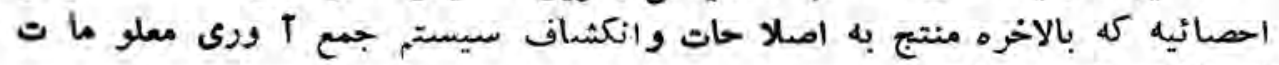

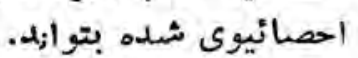

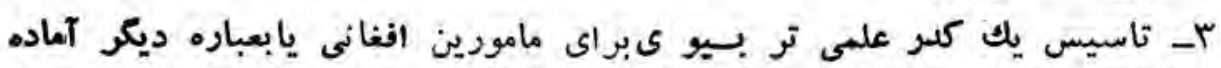

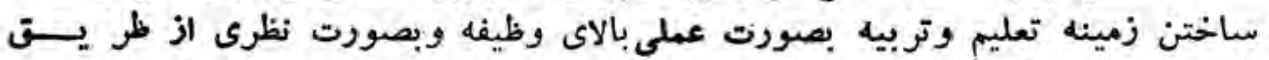

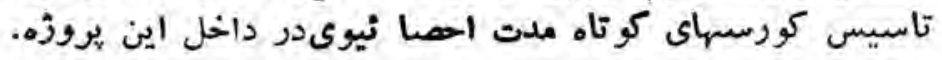

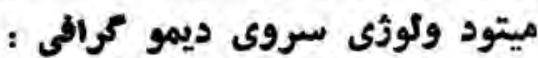

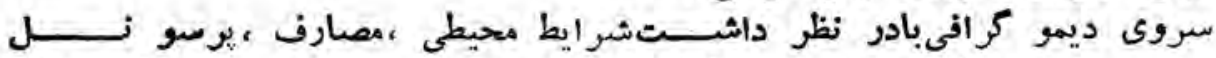

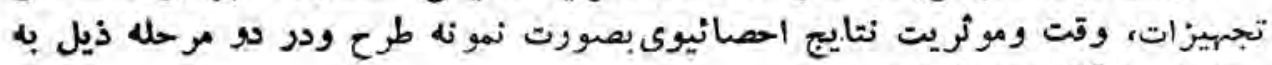

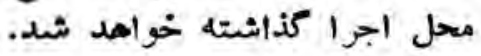


مرحله اول: تكميل كار هاى مقد ماتىسروى كهشامل فعاليت هاى ذيل ميباشد

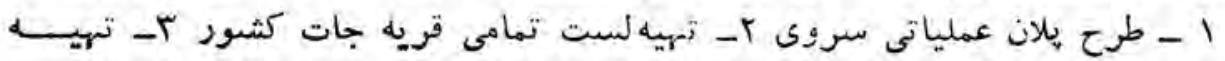

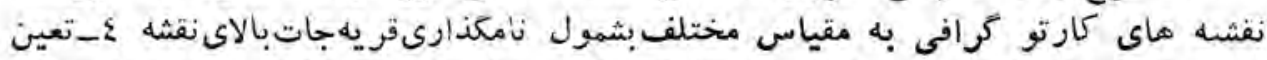

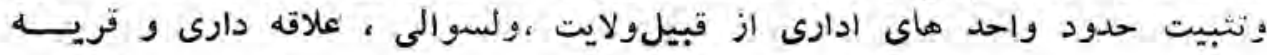

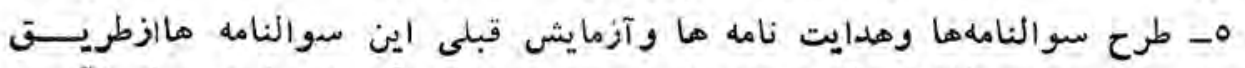

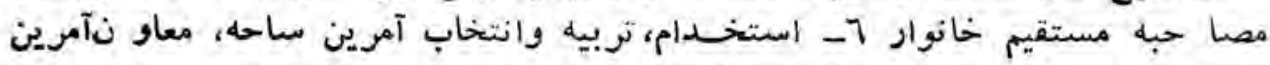

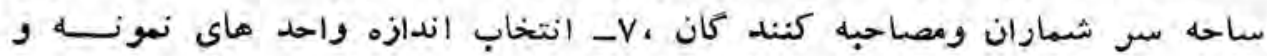

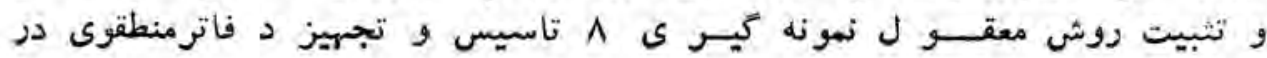
ولايات .

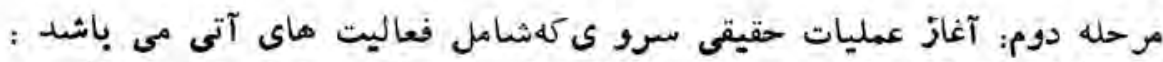

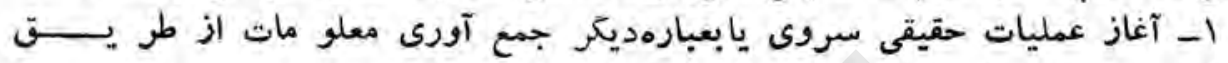
مصاحبه مستقيم خانوار آغاز عمليات

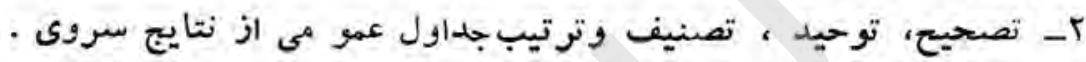

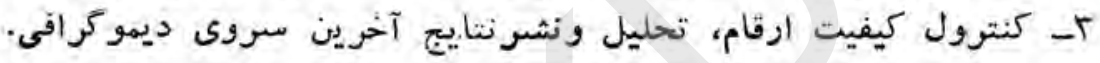

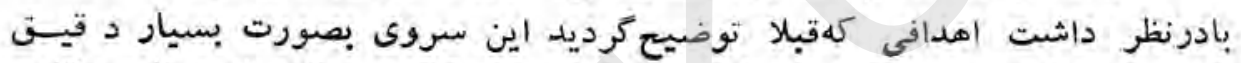

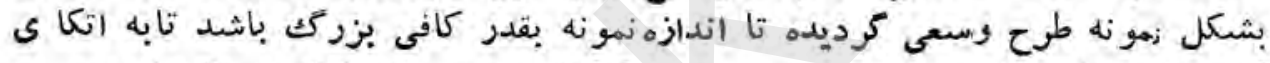

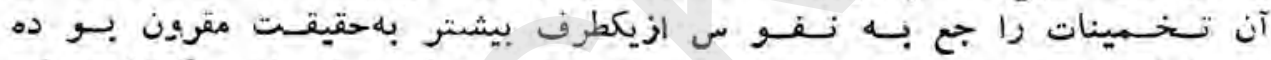

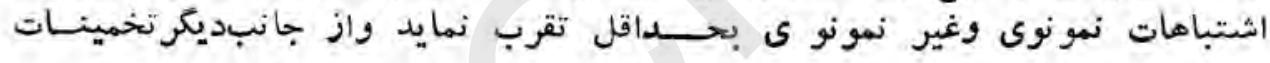

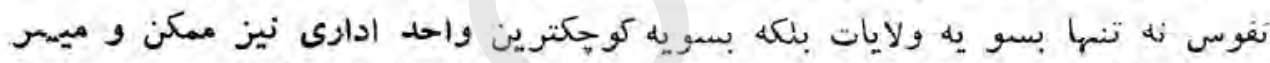

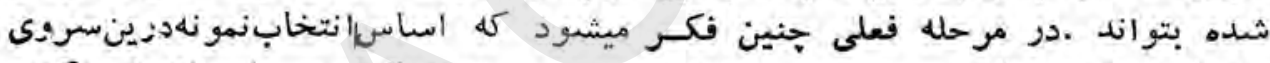

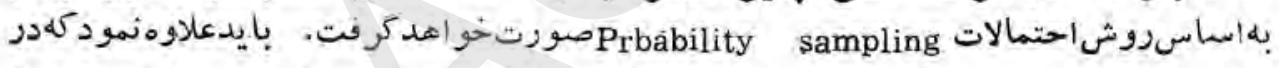

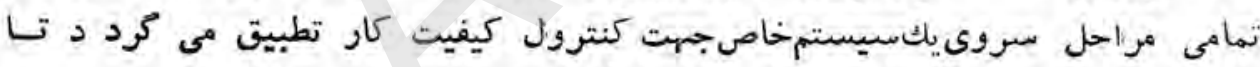

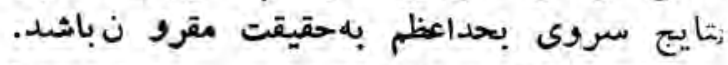

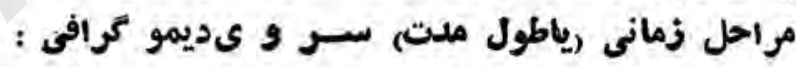

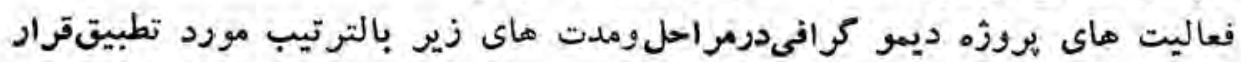
داده مىشود.

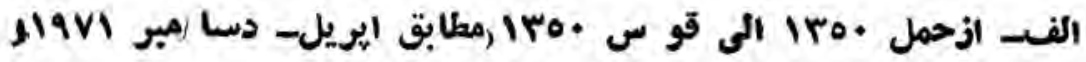

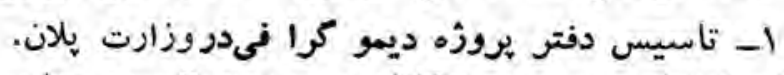

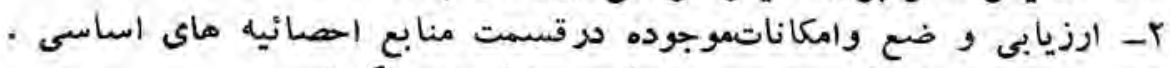

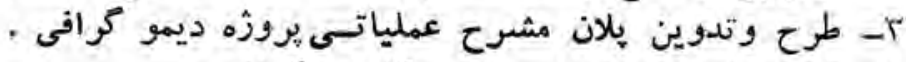

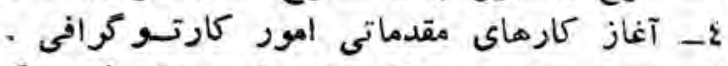

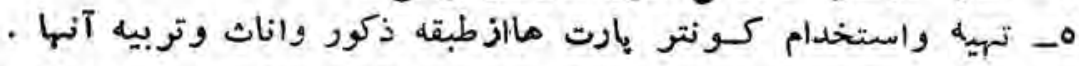

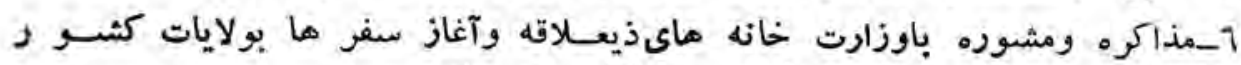

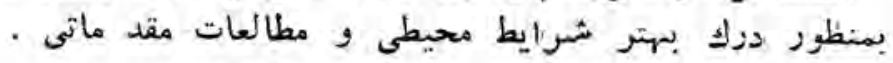


V- طرح مسو ده اول سوا لنامه ها و آزمايش سو الثنامه هادر بعضى از ولايا ت

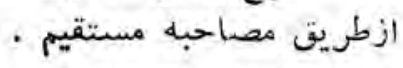

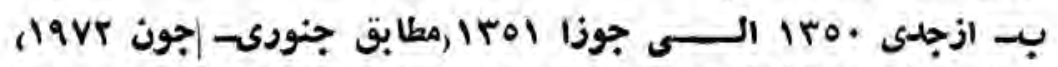

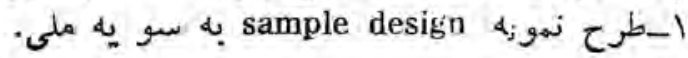

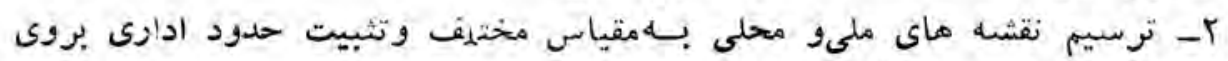

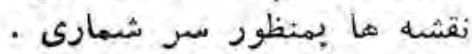

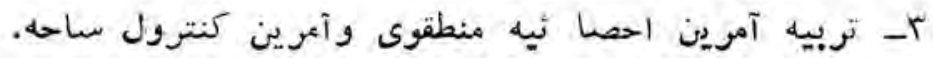

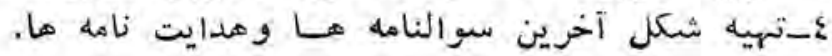

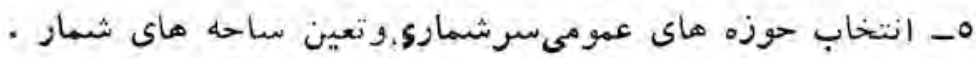

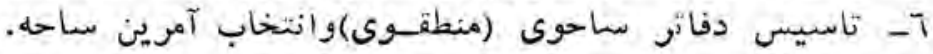

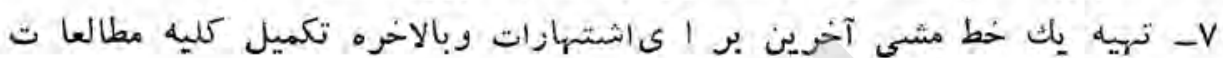

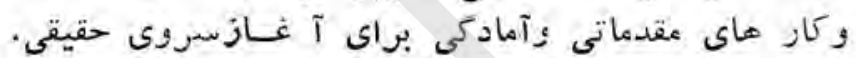

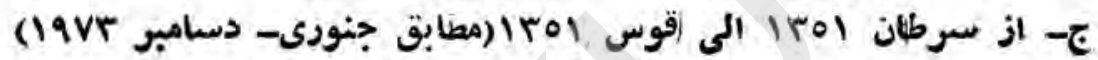

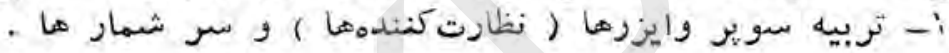

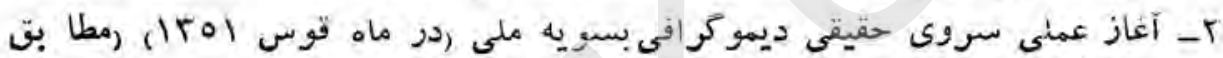

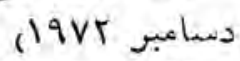

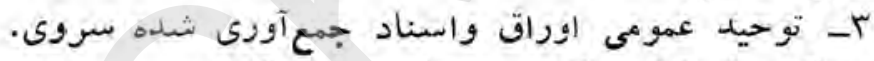

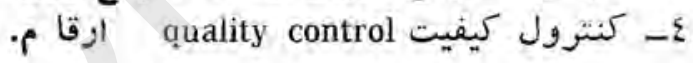

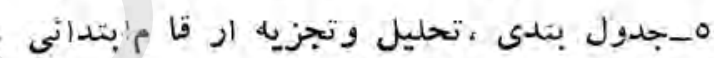

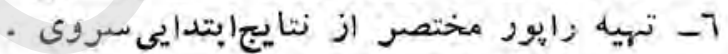

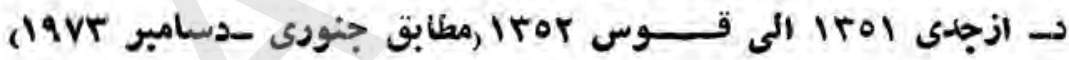

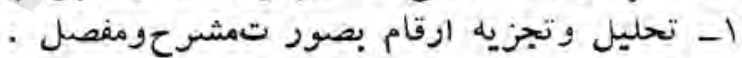

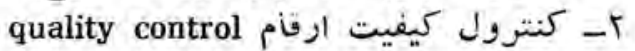

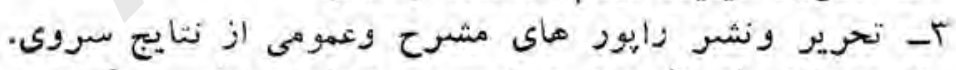

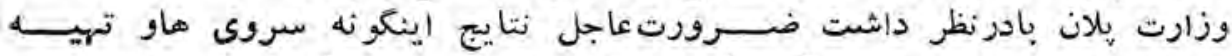

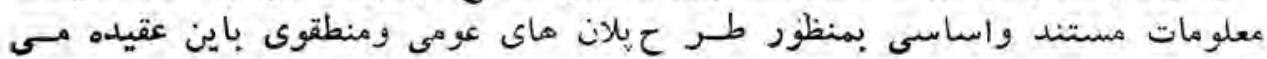

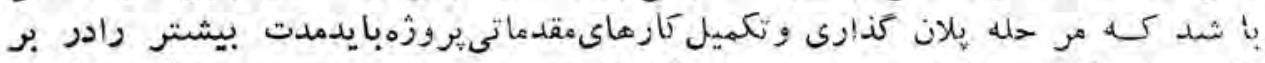

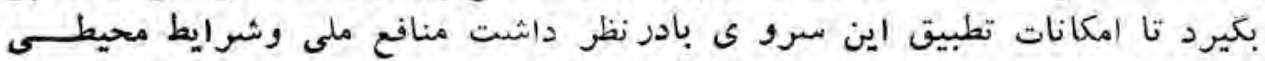

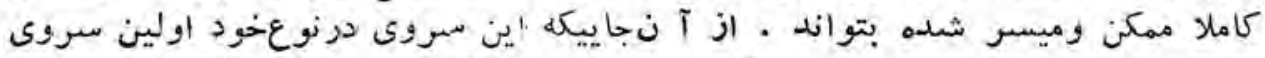

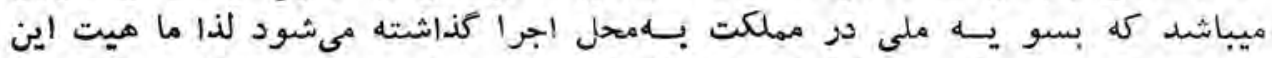

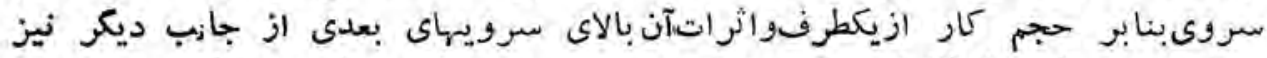

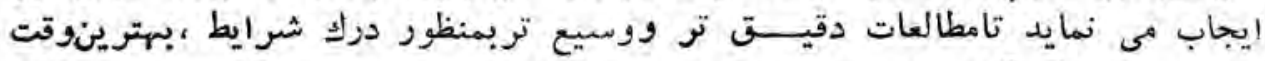

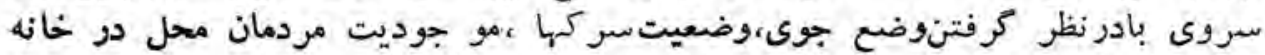

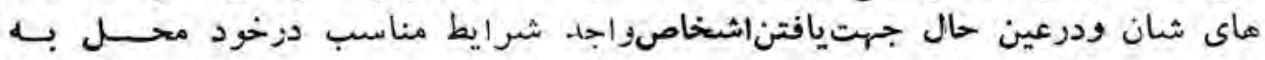

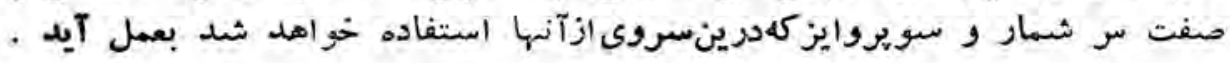




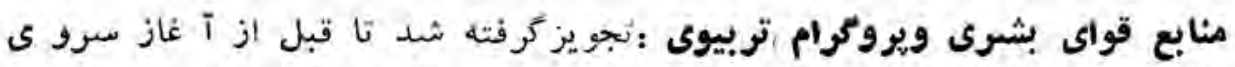

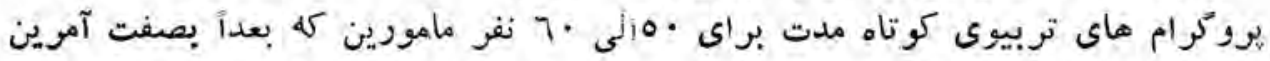

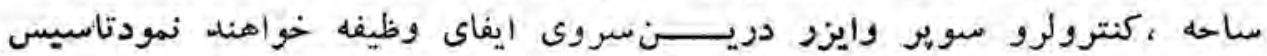

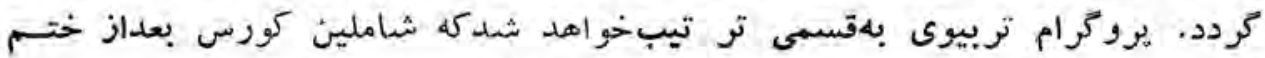

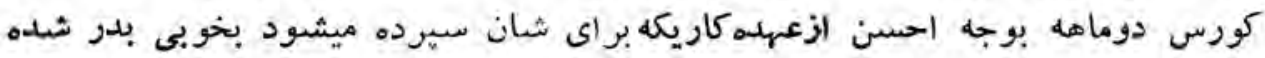

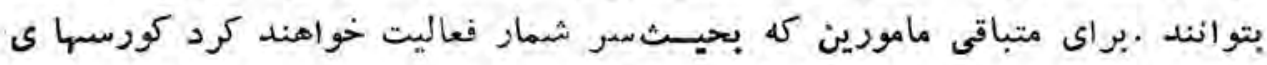

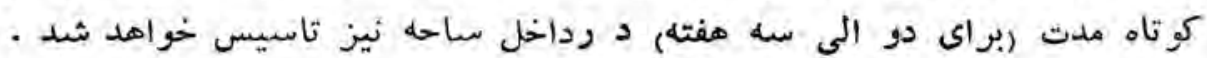

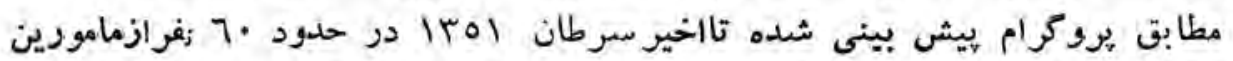

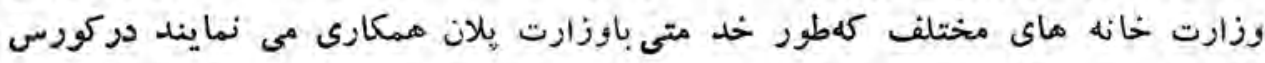

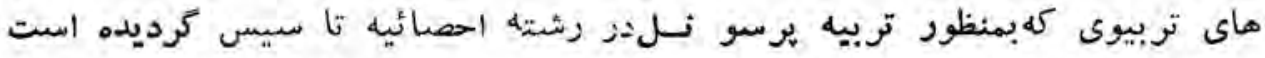

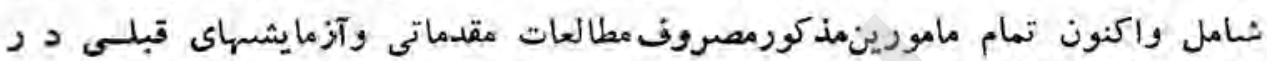

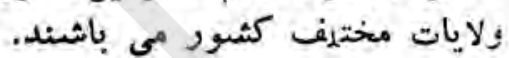


قسهت دوم

تحليلهاى سكتورى قدرم

$45 a \cdot 1$ 


\section{زراعت وآبيارى}

افغانستان 1 ساساً يك كشور زرا عتىبوده و زراعت در اقتصاد آن نقشاساسىى

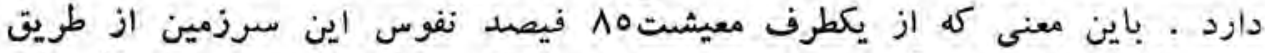

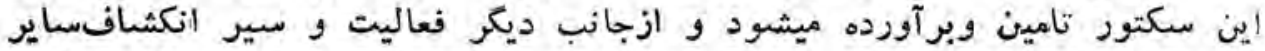

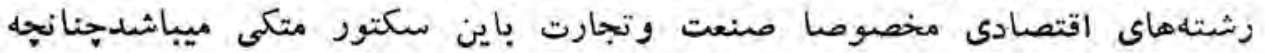

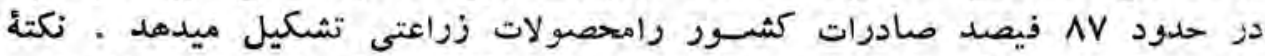

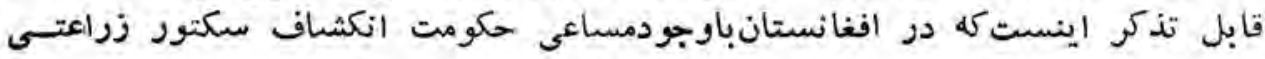

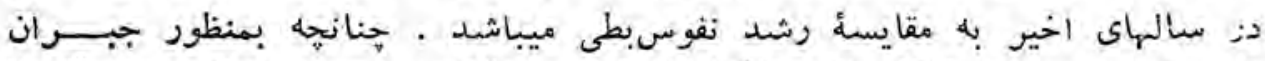

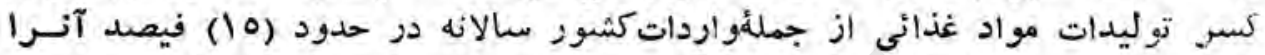

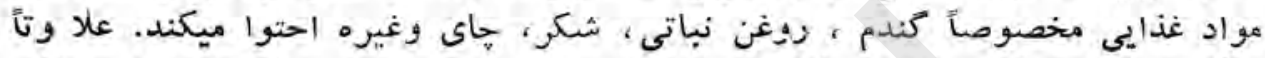

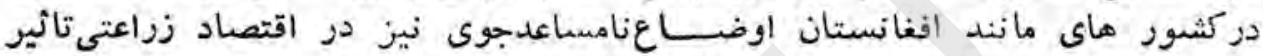

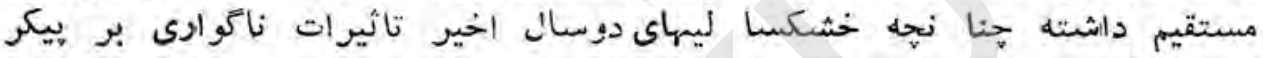

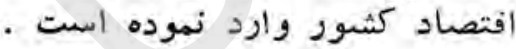

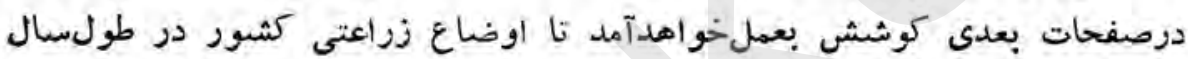

$$
\text { . }
$$

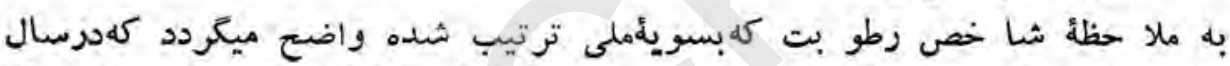
A

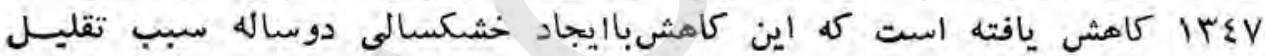

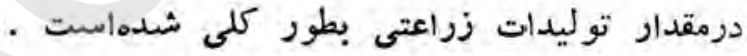

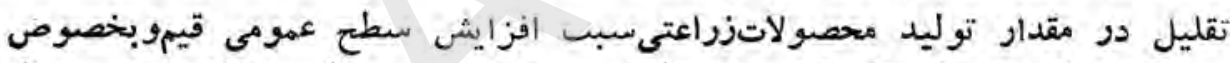

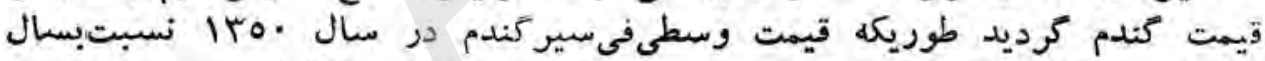

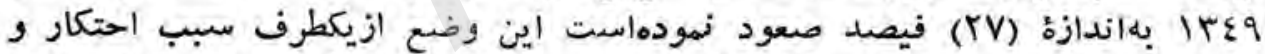

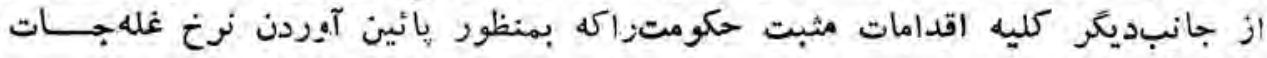
بعمل آمد خنثى كردانيد كلين اقدات

\section{(1) جدول}

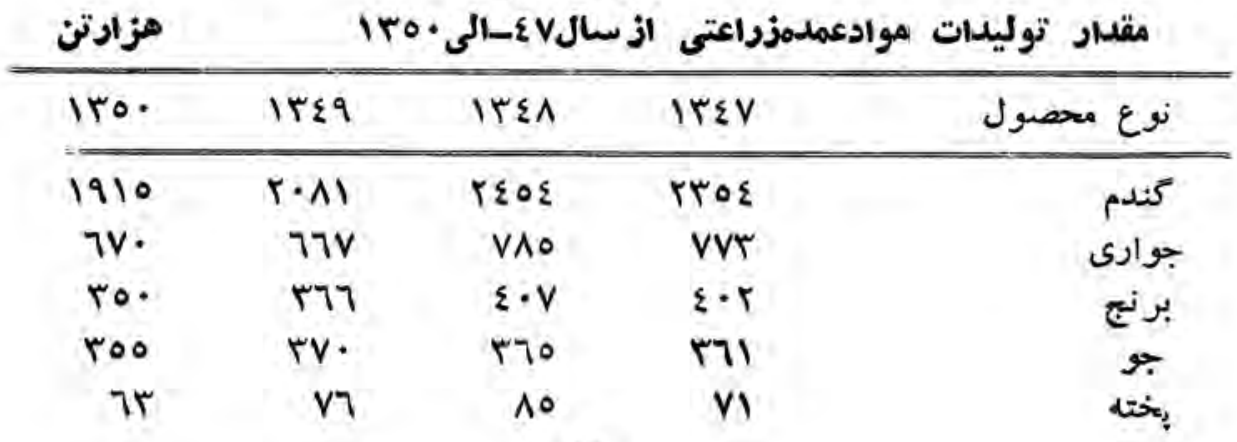




\begin{tabular}{|c|c|c|c|c|}
\hline 7 . & Tr & 71 & 75 & لبلبو \\
\hline 0. & 00 & 7. & ov & نيشكر \\
\hline KA & ro & $r v$ & ri & نباتات تيلى \\
\hline vro & רז7 & 7vi & $70 \varepsilon$ & سبزيجات \\
\hline 70. & $1 \cdot 9$ & $\Lambda \varepsilon r$ & $\Lambda r \varepsilon$ & ميوهجات \\
\hline
\end{tabular}

منبع : وزارت زراعت وآبيارى .

بملاحظة جدول فوق در مقدارثوليدات كندم درسال .

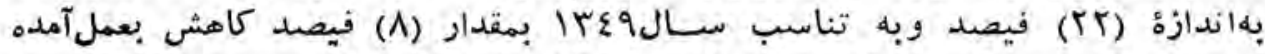

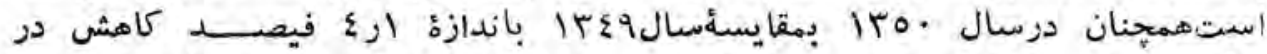

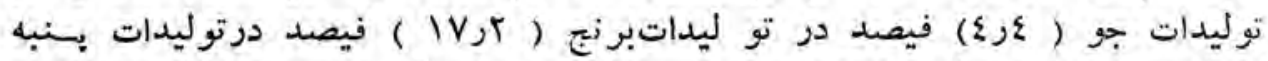

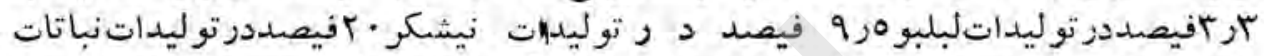

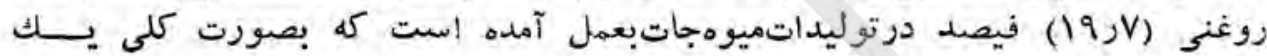

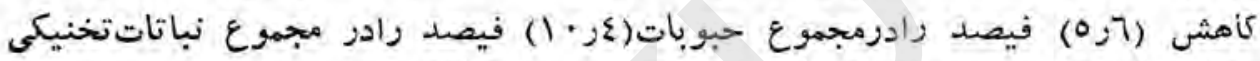

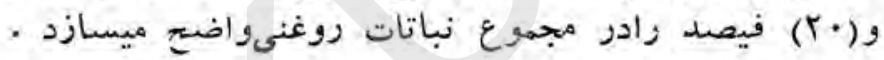

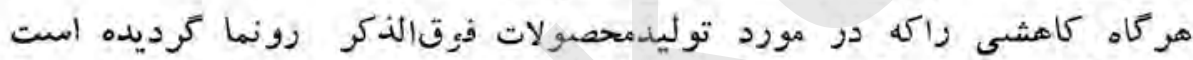

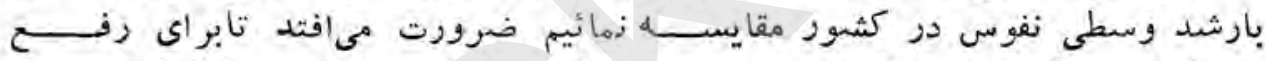

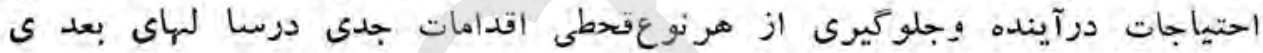

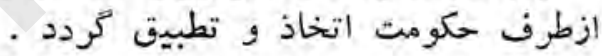

\section{(F) جدول}

تخمين قيم متوسط سنالانه غلهجـاتعمده كه بزارعين يوداخته شده

\begin{tabular}{|c|c|c|c|c|c|c|}
\hline 150. & $15 \leqslant 9$ & $1 \nvdash \varepsilon \Lambda$ & $1 K \leqslant V$ & IrET & $1 K \leqslant 0$ & غله جات عمده \\
\hline$\Lambda \cdot$ & $7 r$ & ro & $\varepsilon \varepsilon$ & or & oV & كثدمفى سير \\
\hline 7. & $\varepsilon \varepsilon$ & $T \varepsilon$ & tr & $\varepsilon \cdot$ & rT & جوارى فىسير \\
\hline 01 & $\varepsilon r$ & $\varepsilon \cdot$ & $\varepsilon \xi$ & $\varepsilon 9$ & re & برنجفىسير \\
\hline 70. & 70. & - o. & 00. & 00. & 00. & لبلبوفىتن \\
\hline $7 V$ & $7 V$ & $7 V$ & iv & or & $\varepsilon T$ & يضبهفى سير \\
\hline$r \cdot$ & r7 & $r \varepsilon$ & rq & 11 & Tt & انكورفى سير \\
\hline
\end{tabular}

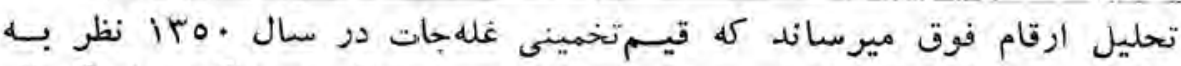

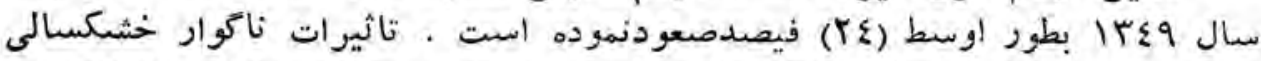
هاى بيهم مخصوصا سلال .

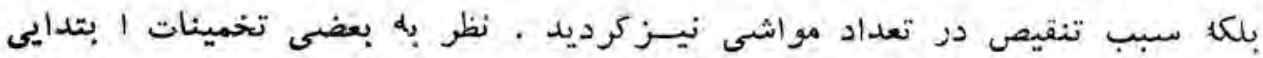

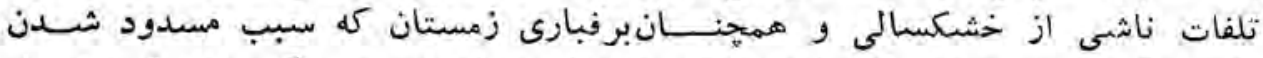

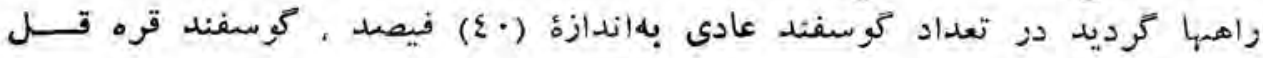




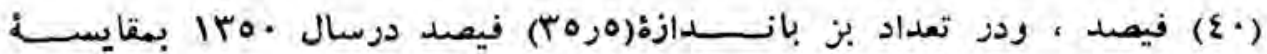

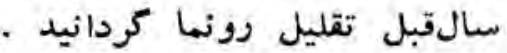

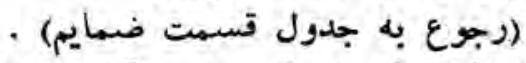

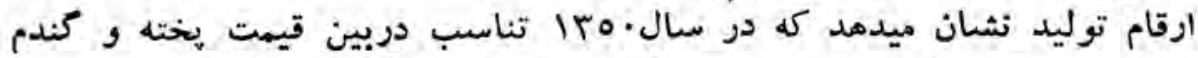

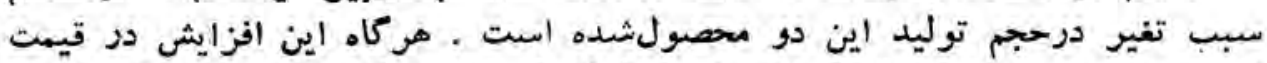

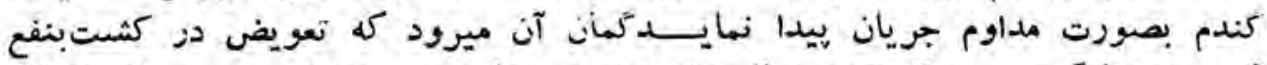

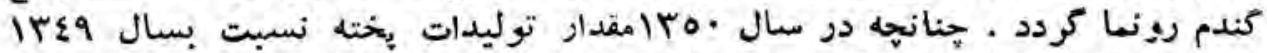

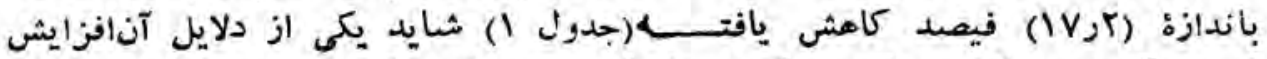

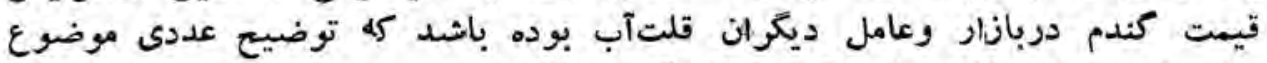

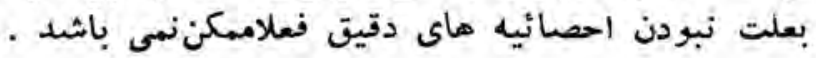

\section{(iv) جدول}

تناسب بين قيهت كندم ويختهدانهدار

توليداتبه هزارثن

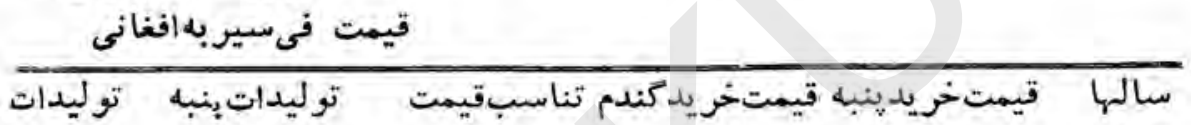

\begin{tabular}{|c|c|c|c|c|c|}
\hline كندم & دانهدار & بختهاو كندم & اززبارعين & دانهداراززارعين & \\
\hline TYAT & 10 & $9 V$ & rq & rı & IrE \\
\hline$r \cdot r$ & 09 & vo & or & $\varepsilon r$ & IrEO \\
\hline TTA. & or & $9 \wedge$ & or & or & IrEר \\
\hline rHOE & vi & lor & $\varepsilon \varepsilon$ & 77 & ITEV \\
\hline$T \varepsilon 0 \varepsilon$ & $\wedge^{\circ}$ & 191 & ro & $7 V$ & $\mid r \varepsilon \wedge$ \\
\hline$r \cdot \Lambda I$ & vา & $1 \cdot v$ & $7 r$ & $7 V$ & IrEq \\
\hline 1910 & ז & $\Lambda \varepsilon$ & $\Lambda \cdot$ & $7 V$ & iro. \\
\hline
\end{tabular}

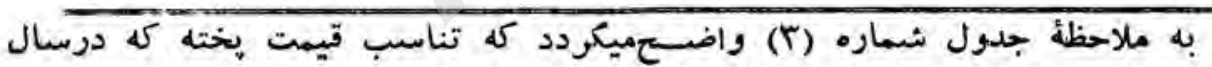

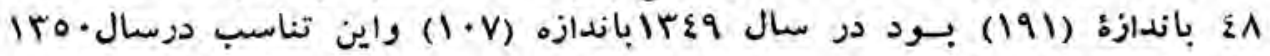

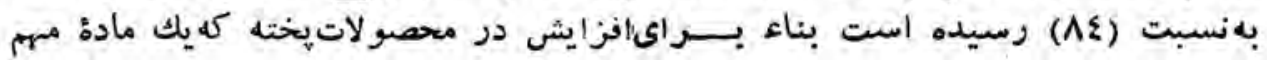

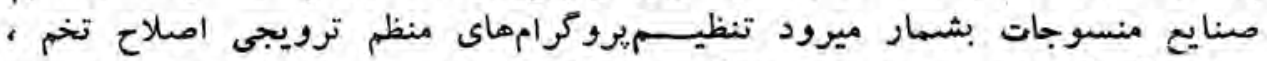

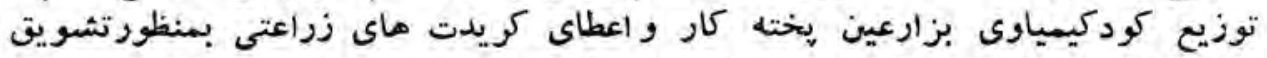

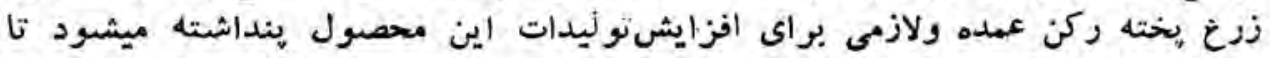

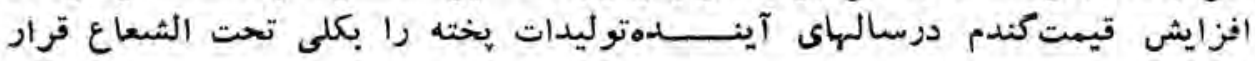

\section{يوو كرام تنلم وكود كمياوى :}

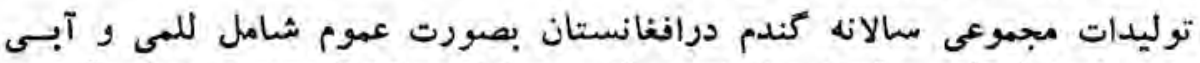

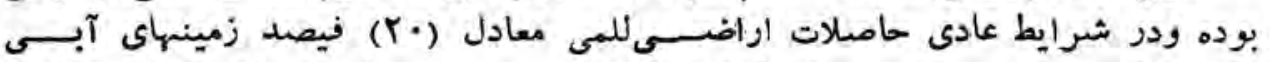

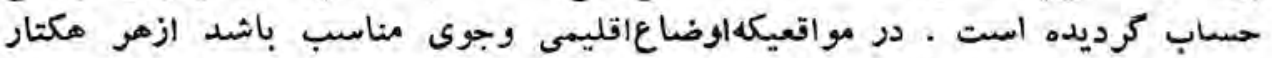




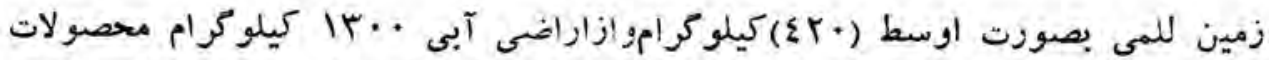

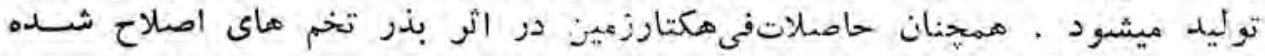

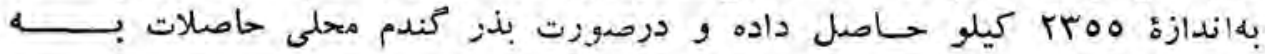

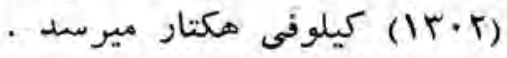

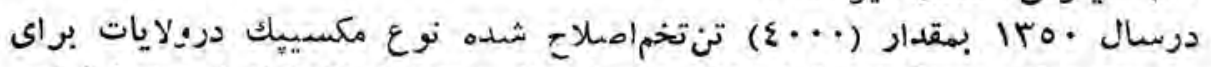

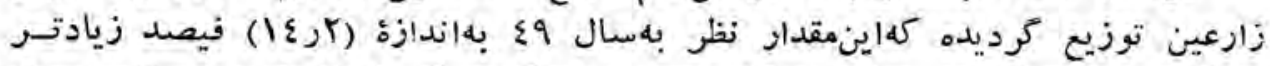

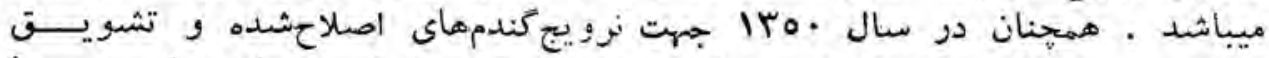

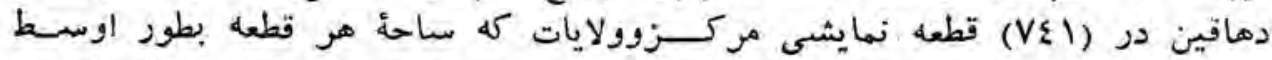

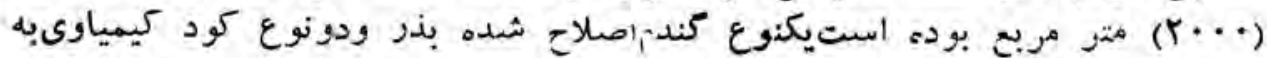

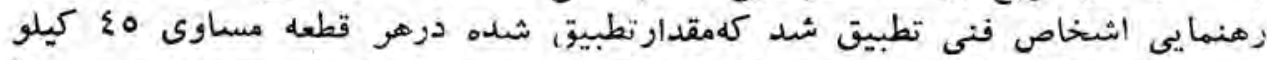

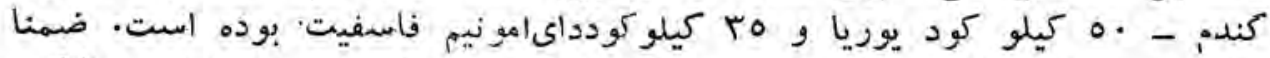

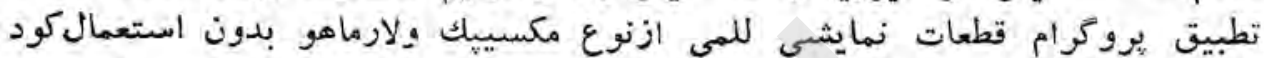

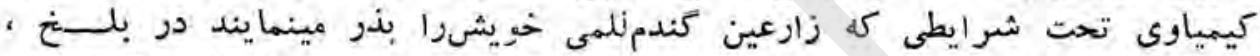

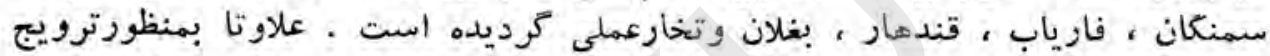

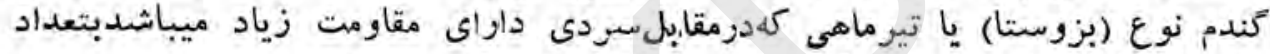

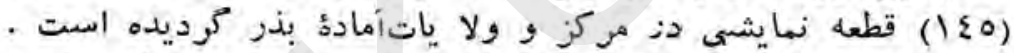

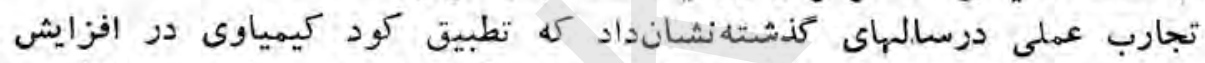

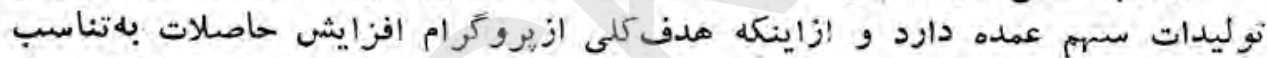

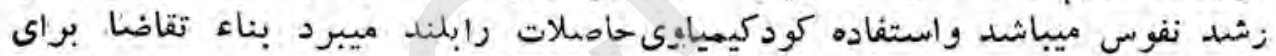

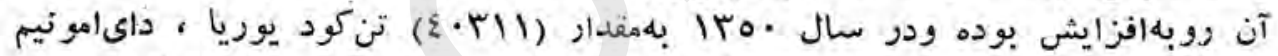

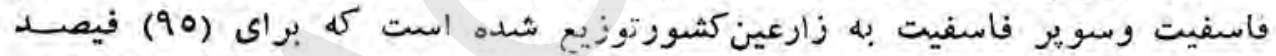

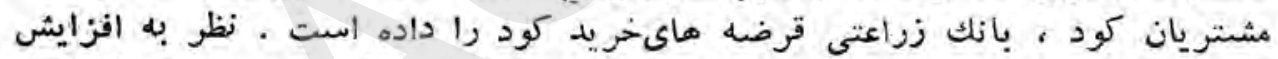

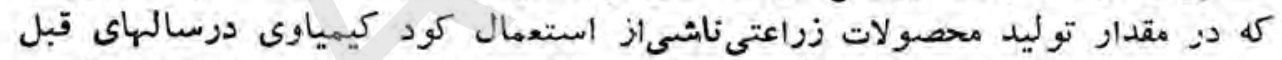

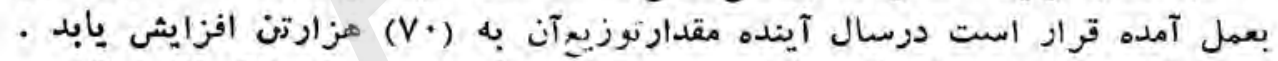

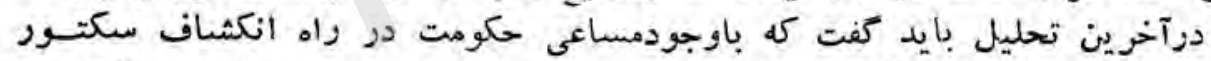

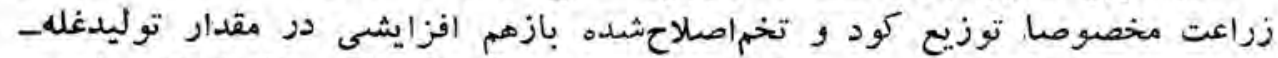

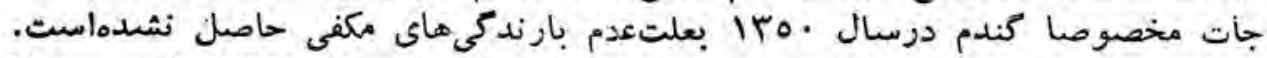

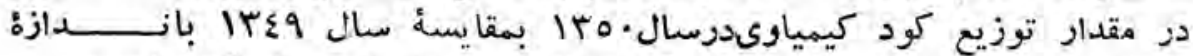

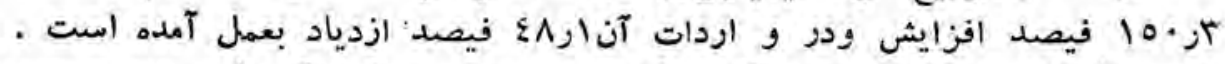

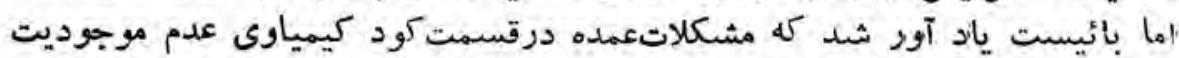

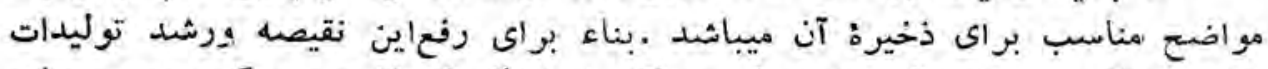

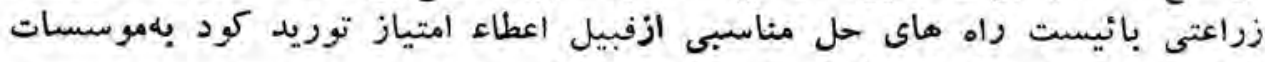

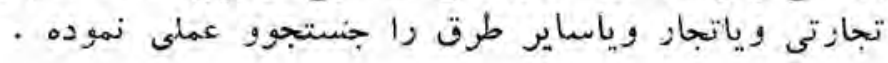




\section{(ع) جدول}

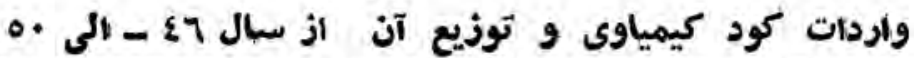

\begin{tabular}{|c|c|c|c|c|c|}
\hline شددارتوزيع & مجموع & فاسى امونيم & سويوفاسفيت & يوريـا & سالها' \\
\hline$\varepsilon \Lambda \cdots$ & $1 \cdots$ & - & re. & $78 \cdots$ & $1 r \varepsilon 7$ \\
\hline VาV7 & $|r|+$. & $7 r \ldots$ & $1 \ldots$ & $\circ 9$. & $I r \varepsilon V$ \\
\hline $1 \cdot$ vor & $179 \ldots$ & IVo... & - & $7 \cdots$ & $\| \ll \varepsilon \Lambda$ \\
\hline $171 \cdots$ & ro... & - & - & - & Irहq \\
\hline$\varepsilon \cdot 4 I$ & $\varepsilon \cdots$ & - & $\sim$ & - & Iro. \\
\hline
\end{tabular}

\section{اجرآت يروثة تحقيق وخاكثناسى :}

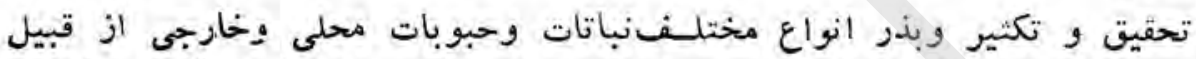

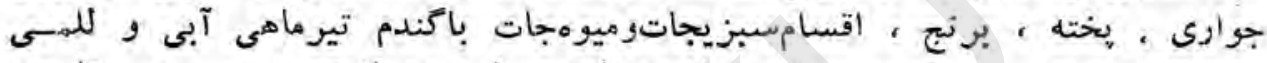

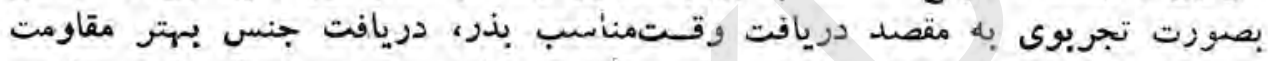

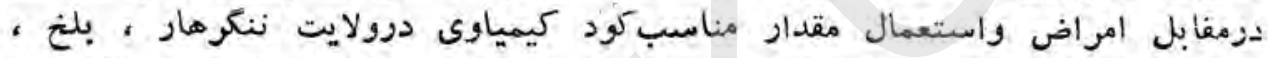

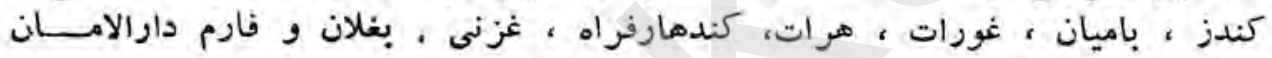

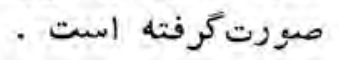

\section{فارم دار الامان :}

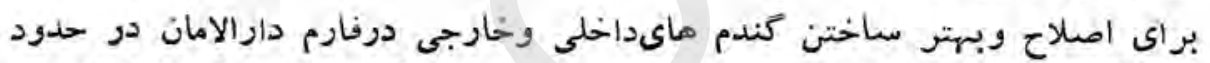

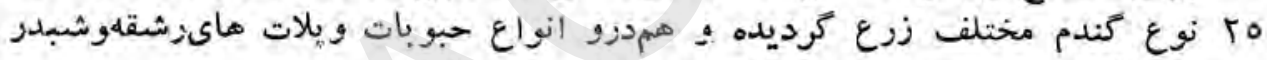

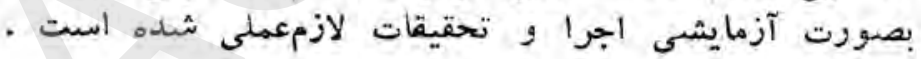

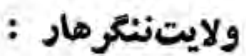

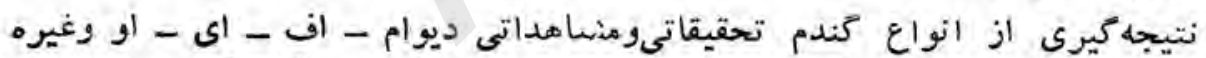

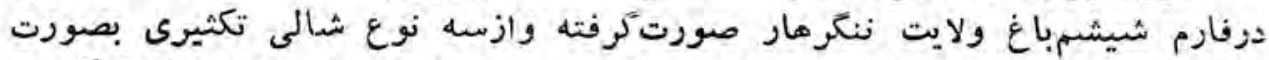

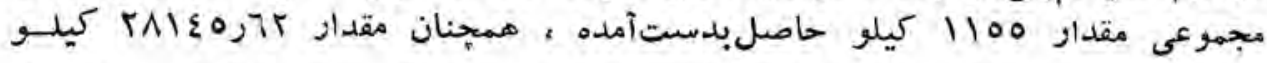

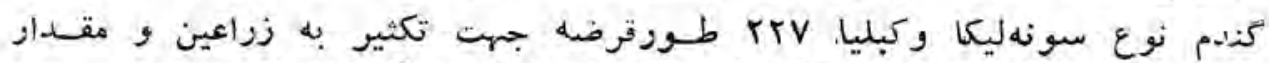

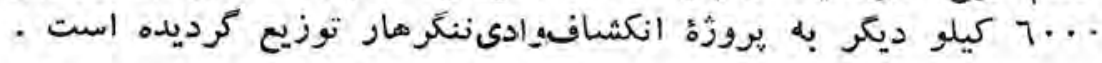

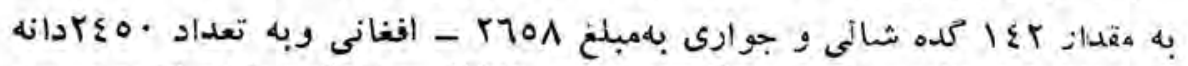

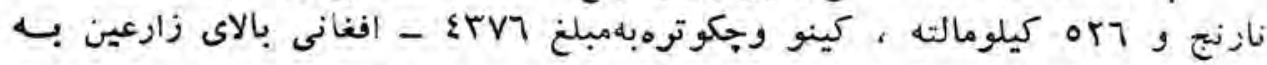

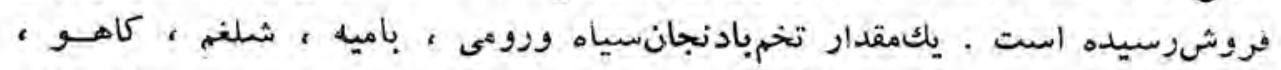

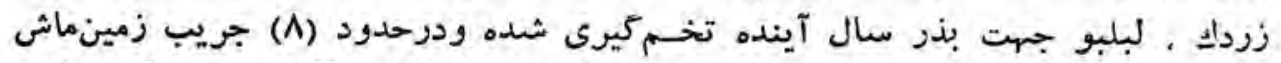

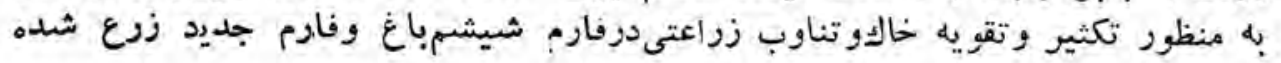




\section{ولايت كند هار :}

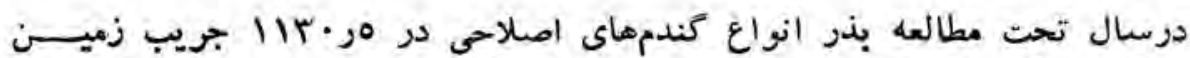

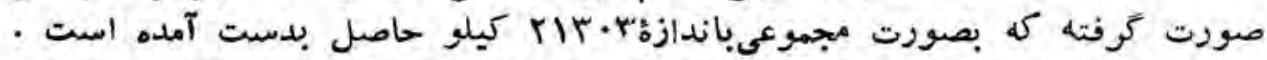

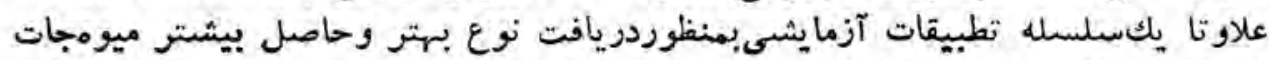

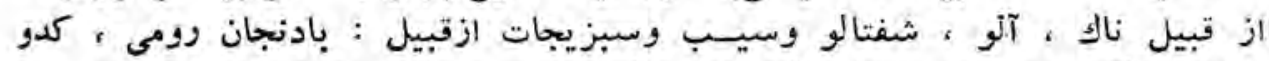

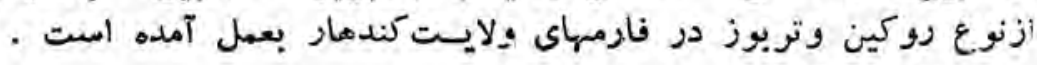

\section{ولايت كثلز}

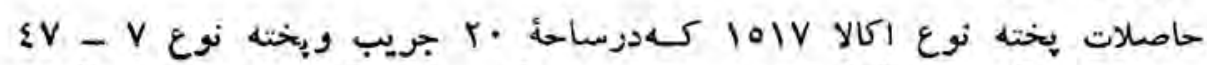

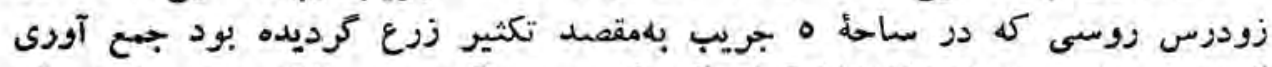

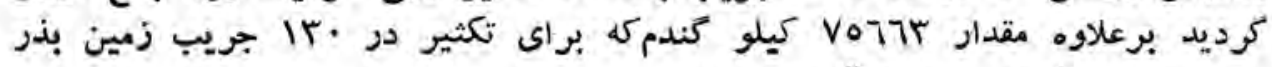

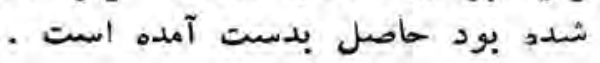

\section{: مارم على آباد كاصل}

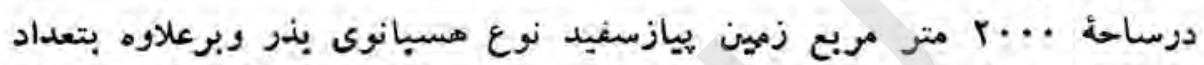
(FV·T)

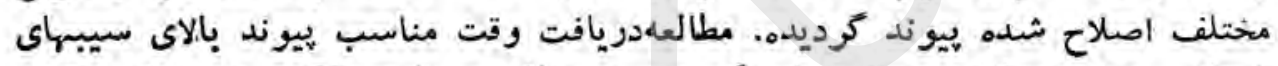

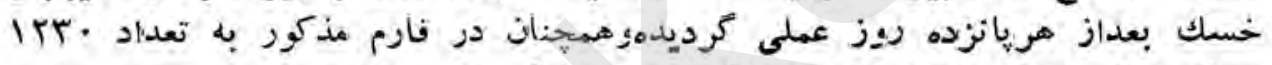

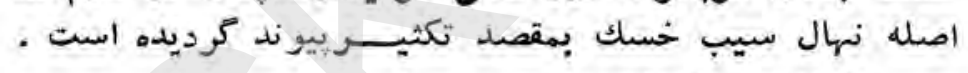

\section{فارمولايت فورات :}

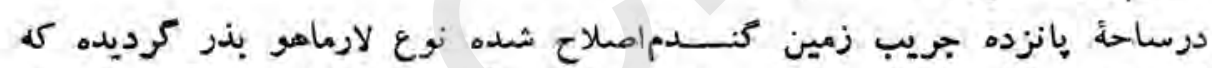

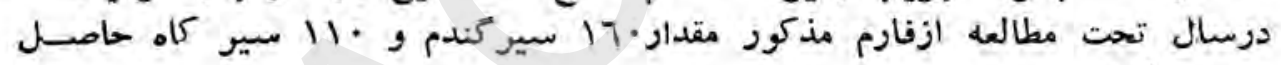

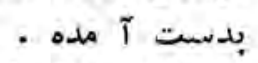

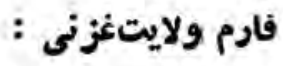

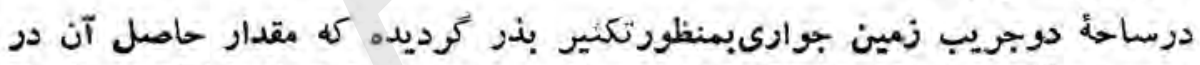

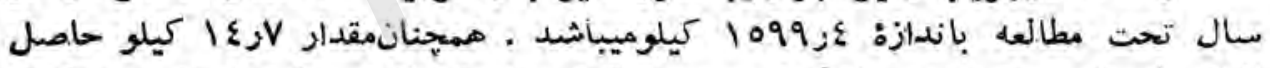

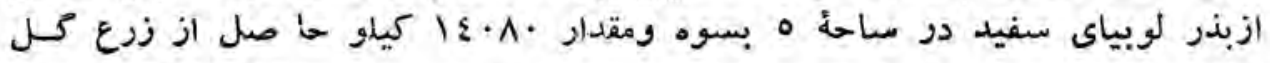

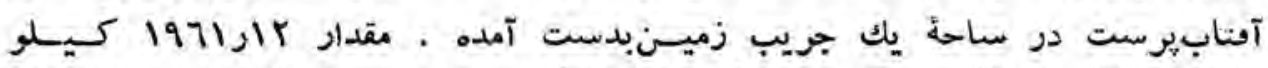

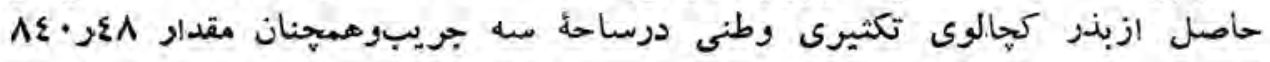

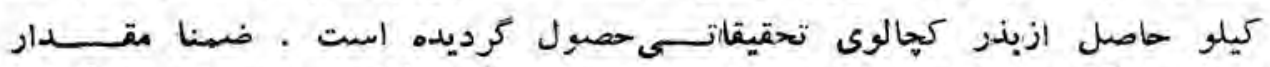

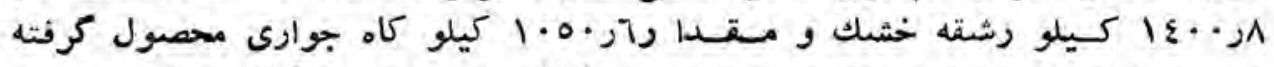

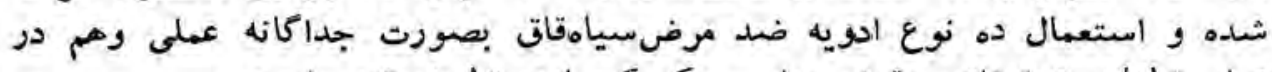

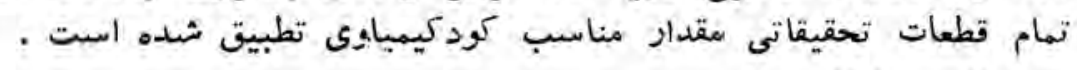

\section{ولايت بغلان :}

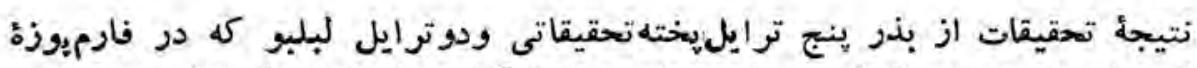

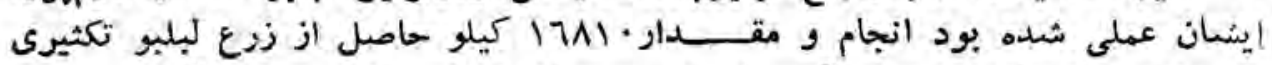

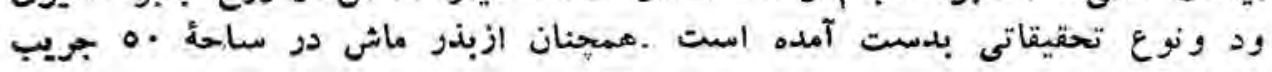




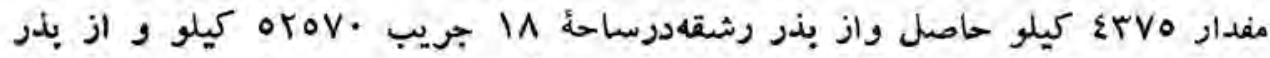

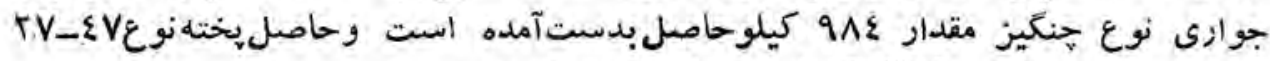

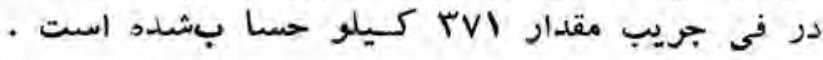

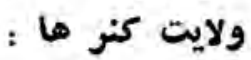

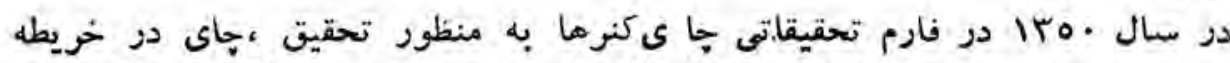

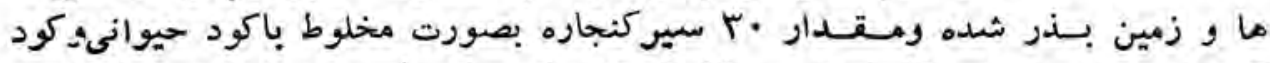

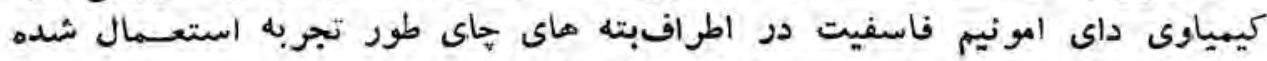

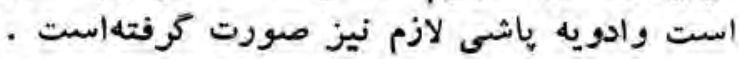

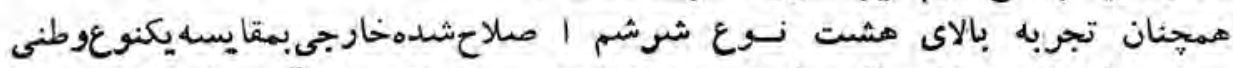

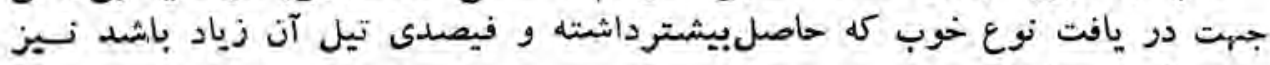

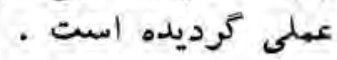

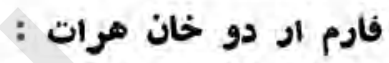

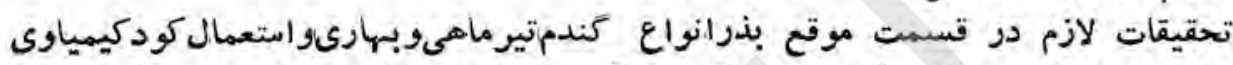

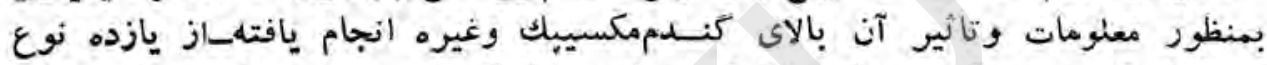

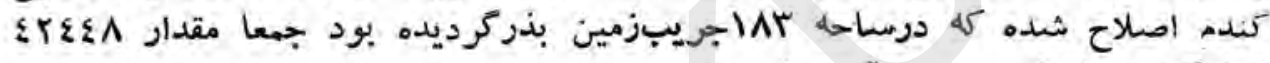

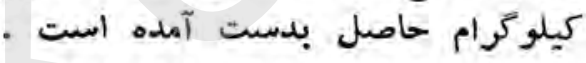

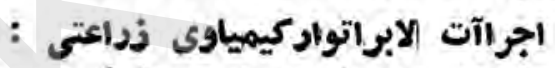

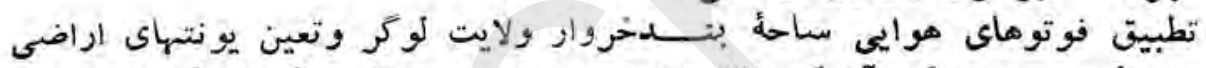

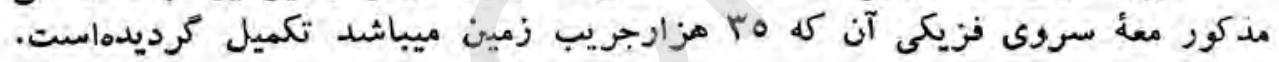

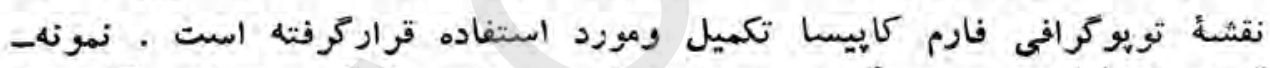

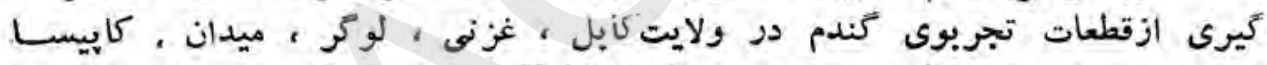

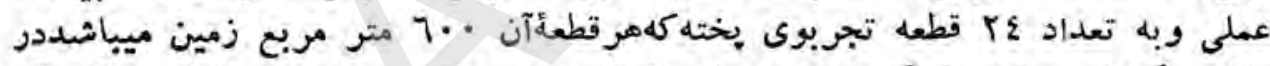

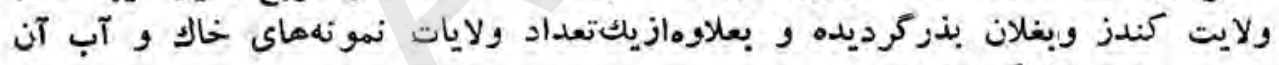

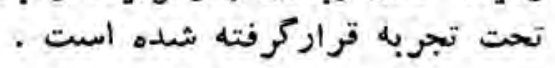

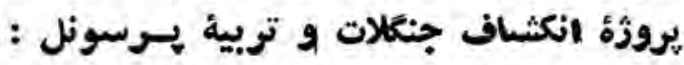

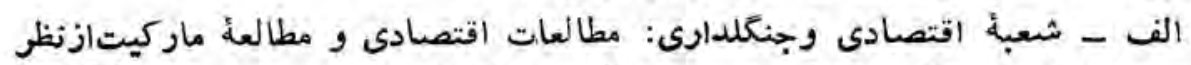

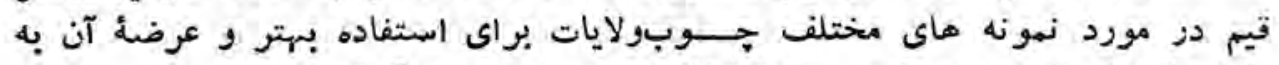

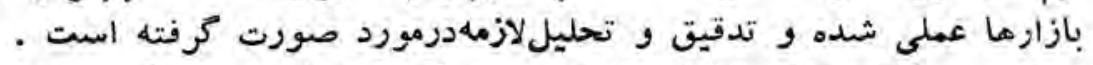

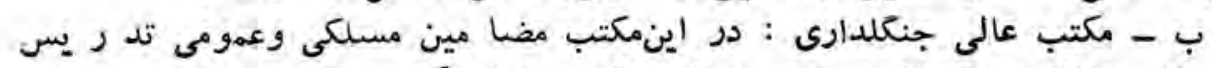

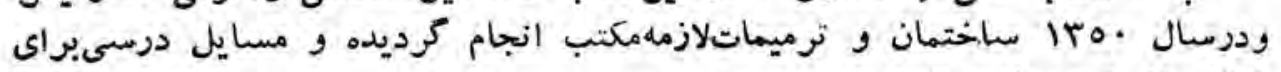

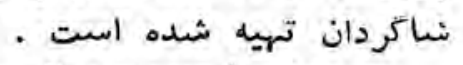

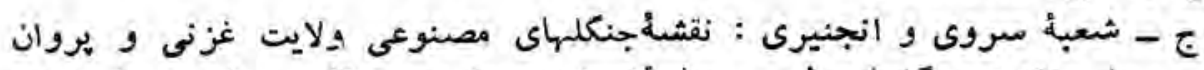

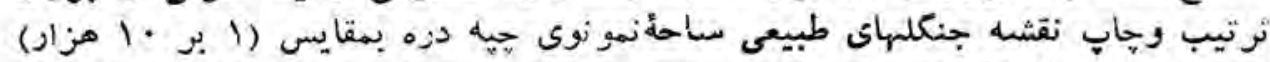

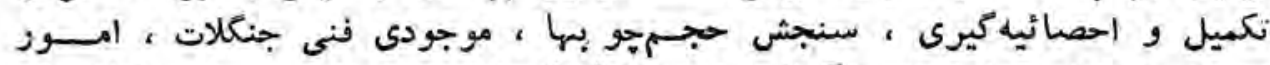

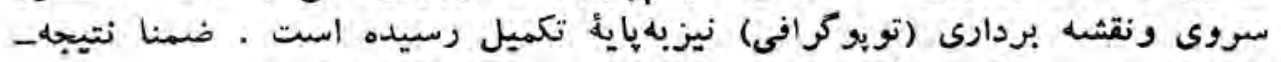

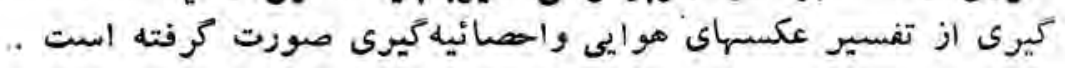




\section{جنغلات مصنوعى وعلفخرها :}

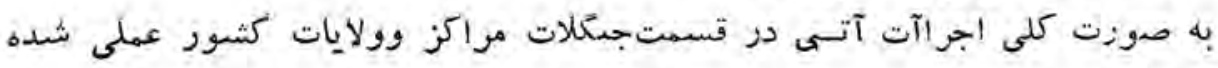

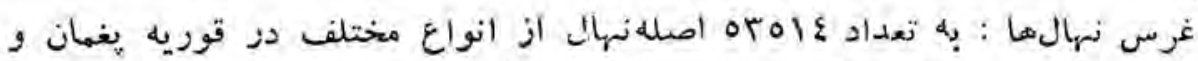
.

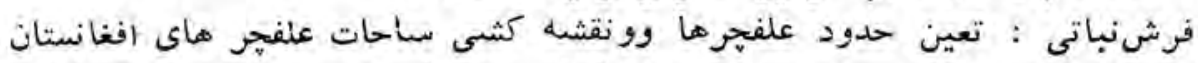

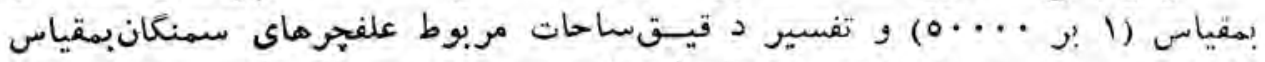

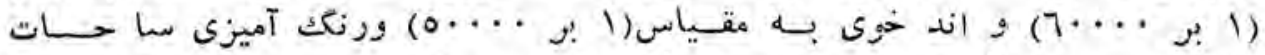

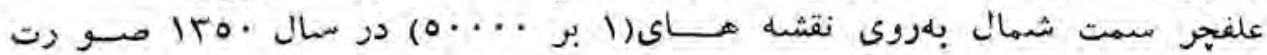
كر فتهاست

\section{اجرآت قواىسبز : آن}

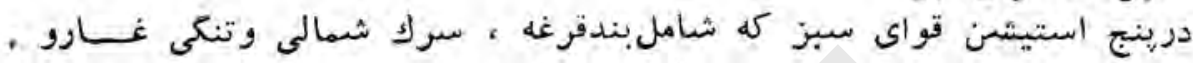

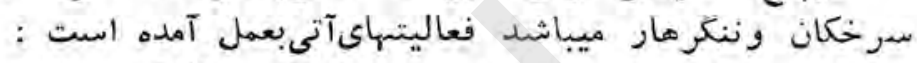

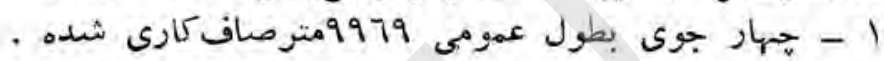

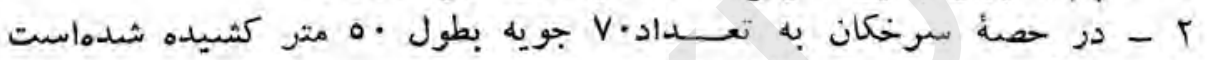

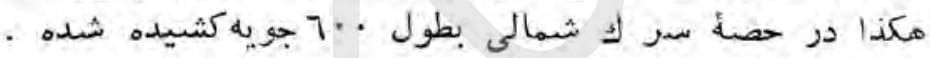
r - ب بهاندازه

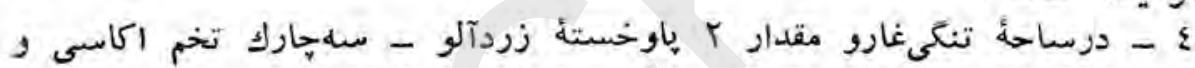

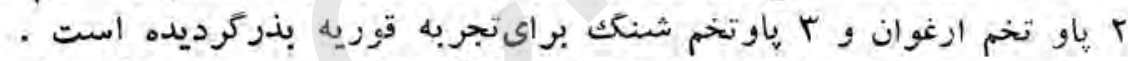

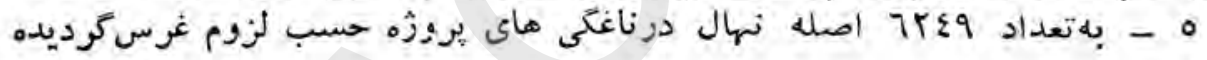

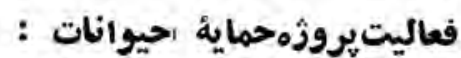

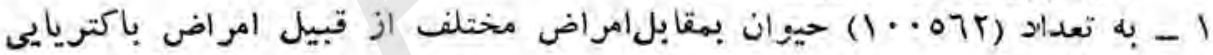

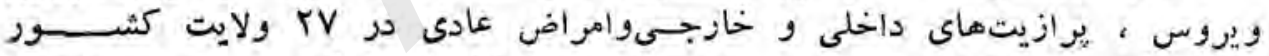

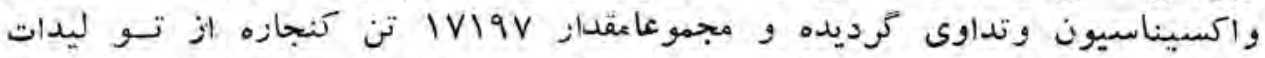

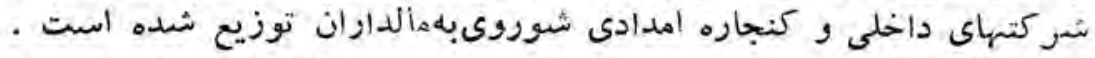

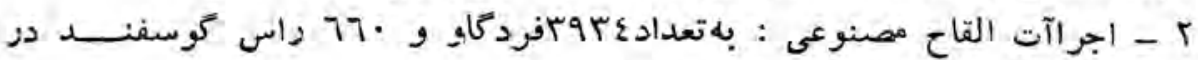

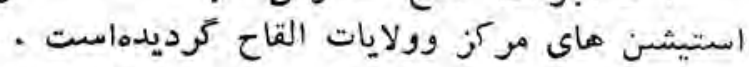

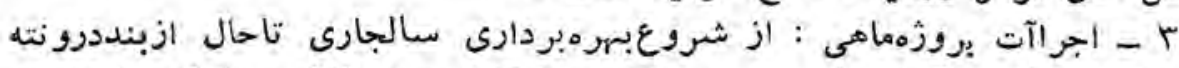

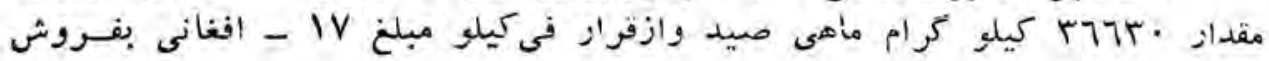

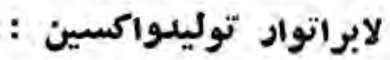

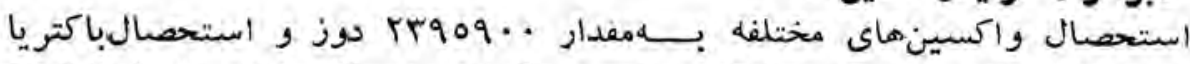

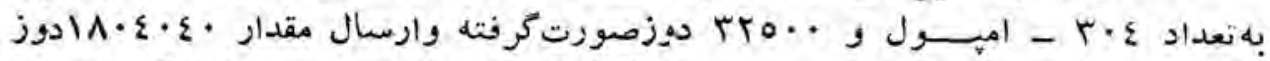

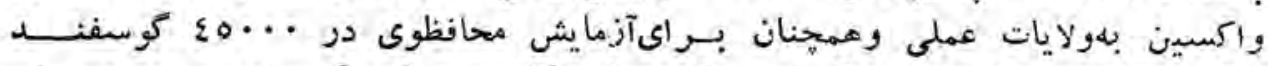

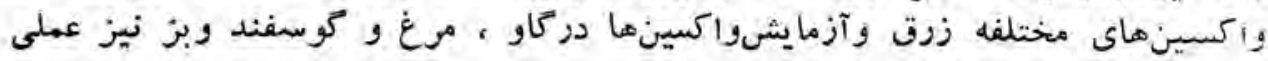




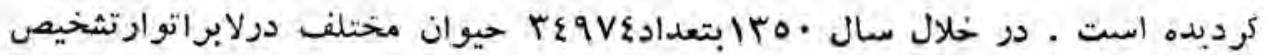

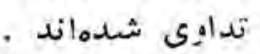

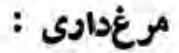

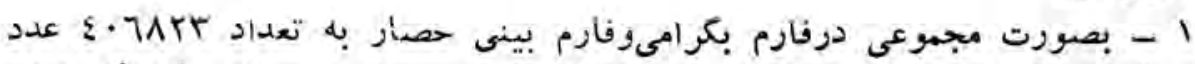

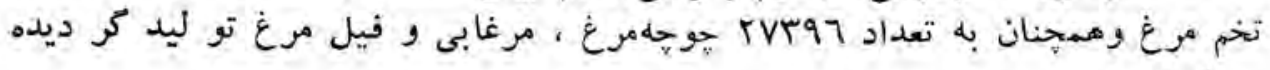
است

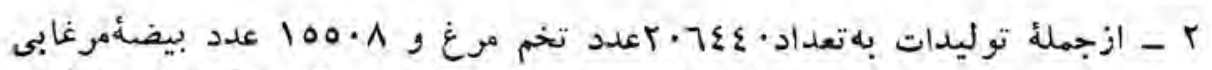

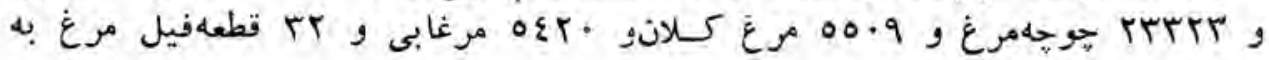

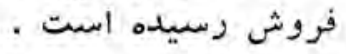

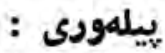

ازكمياين اول - دوم و سوم يِيلهورىمجيموعا به تعداد

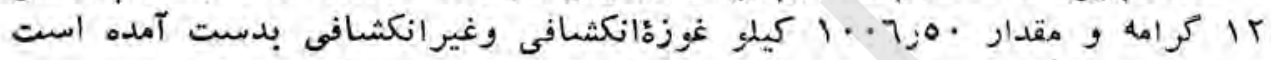

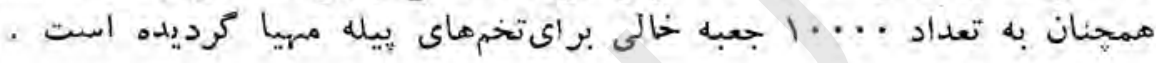

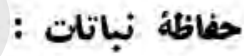

درقسهت حفاظله نباتات و قرانطيندرمركز. وولايات كشور اجرآت آت آتى صورت كرفتهاست :

1

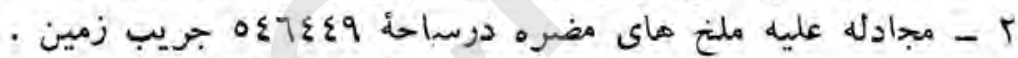

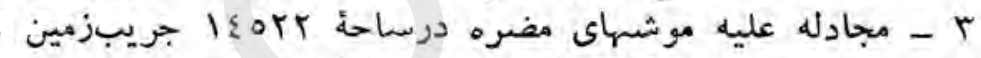

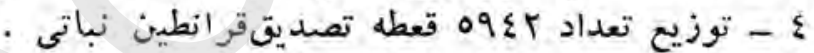

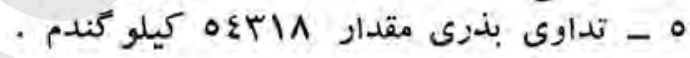

\section{احصائيه :}

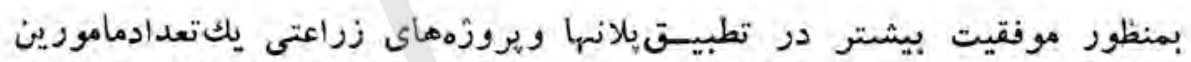

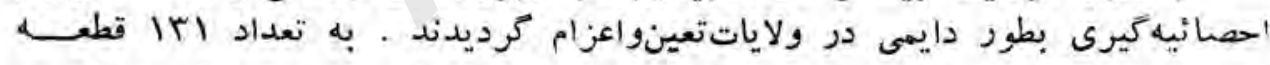

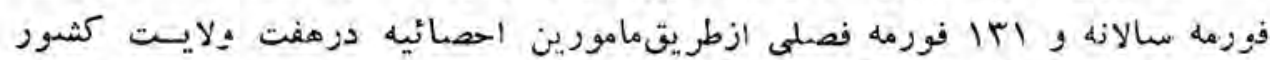

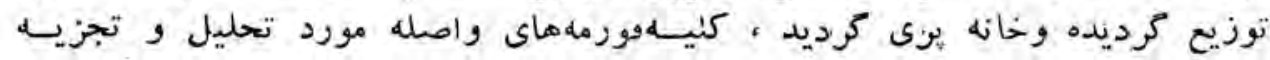

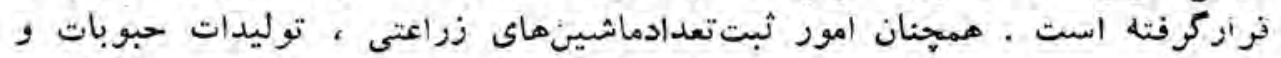

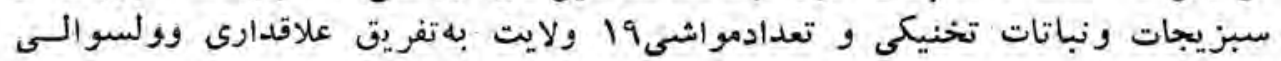
النجام شده است ونسات

\section{يروزء ثدقيق ومطالعات تخنيك وترانسميورت :}

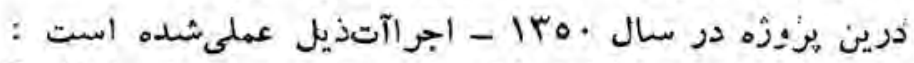

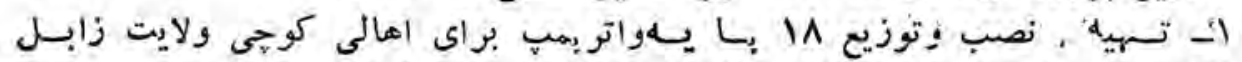

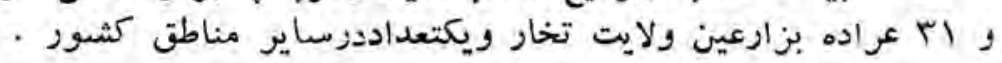

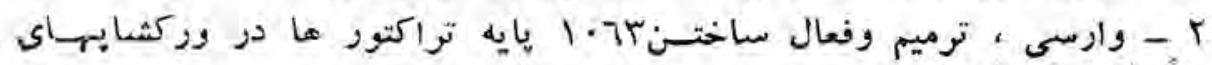

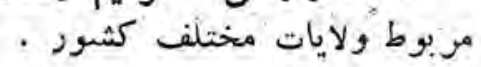




\section{إيروزة كويراتيف ها وال وكريدتزراعتى:}

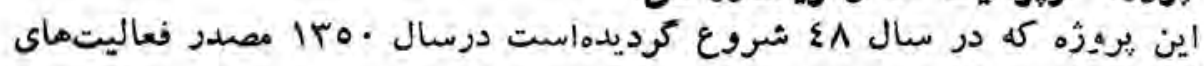
أنى الذكر كرديده است :

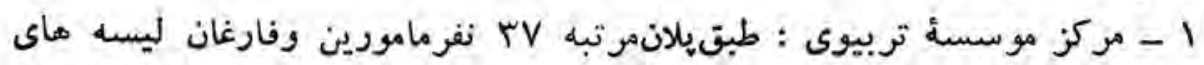

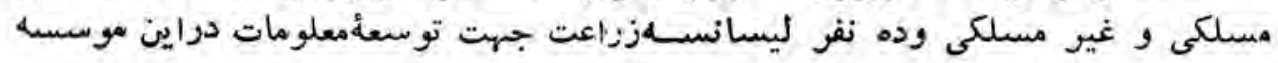

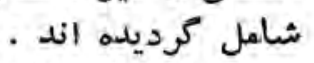

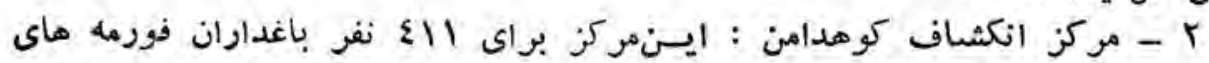

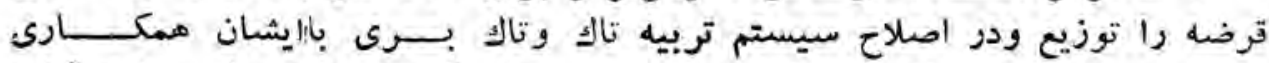

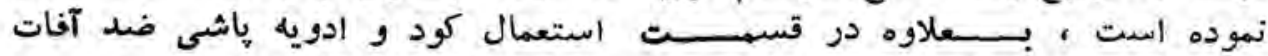

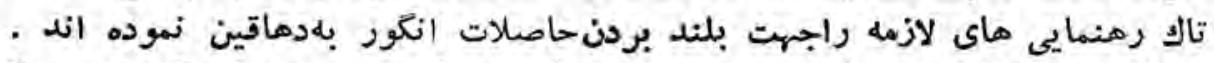

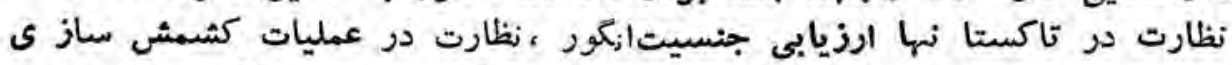

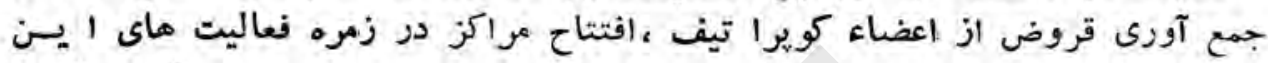

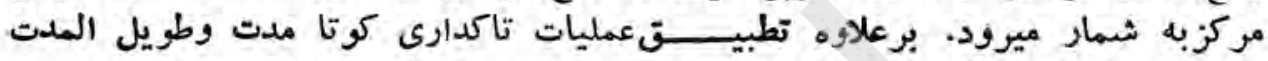

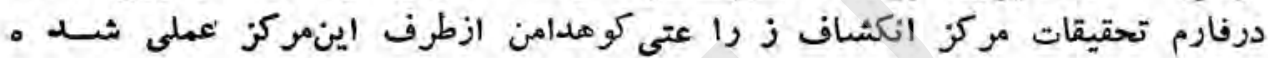

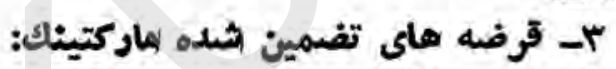

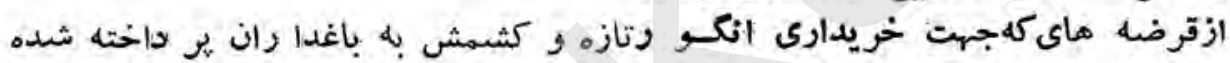

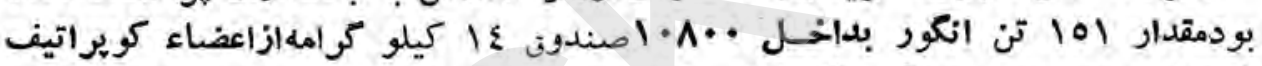

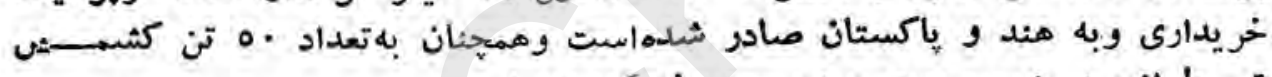

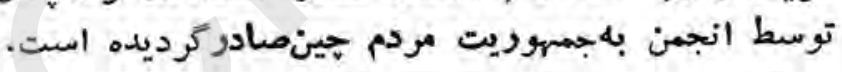

$$
\text { يوروزه هنظي آبيارى وسروى آب : }
$$

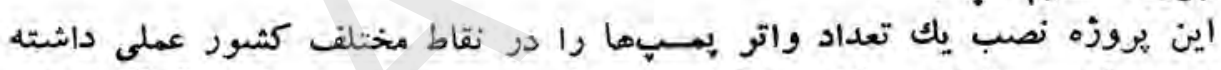

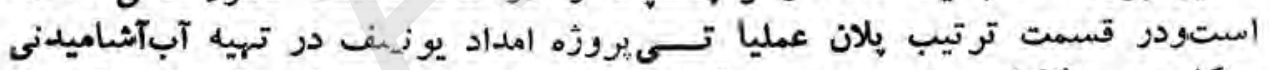

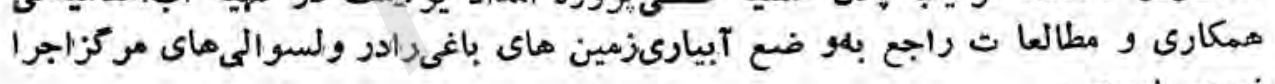

\section{يروزه هايدرولوجى : مارث}

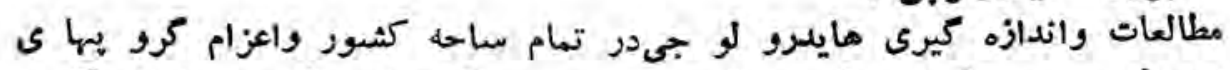

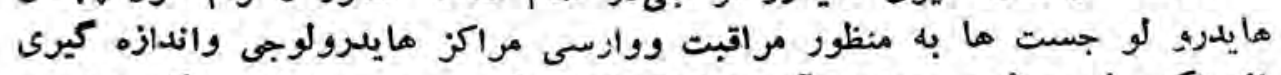

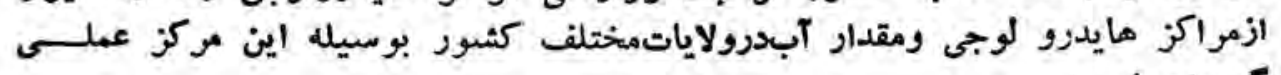

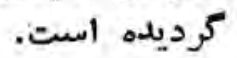

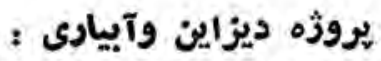

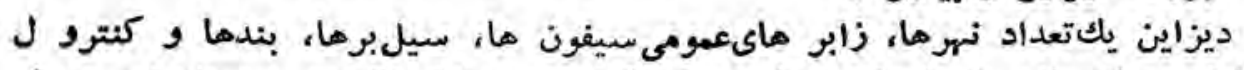

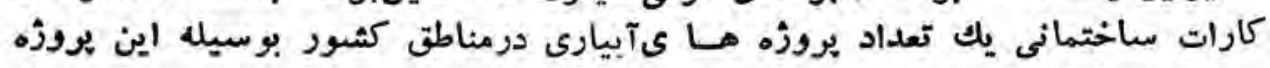
عهلى واجرا كرديده است.

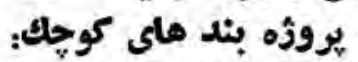

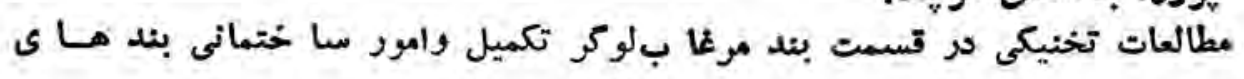




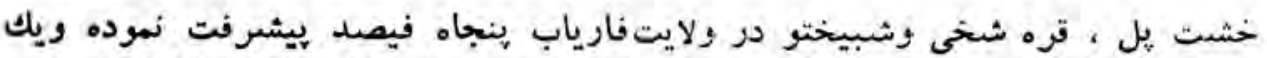

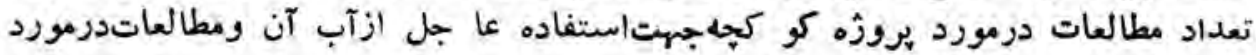

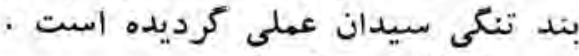

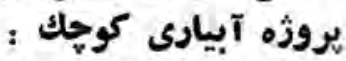

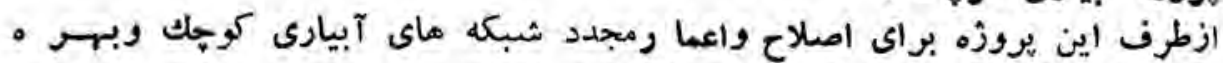

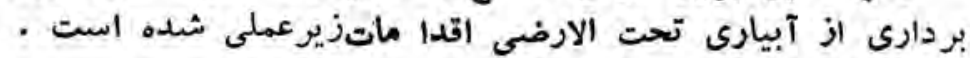

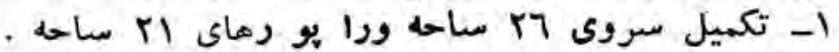

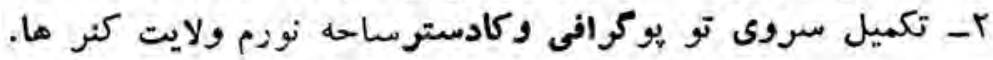

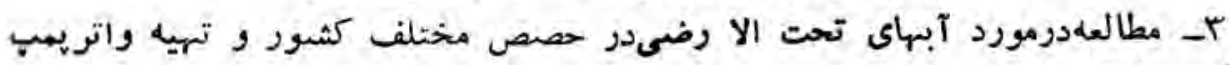

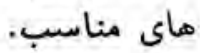
ع- بازديد ومشاهدات ماحات مربو طبهآبهاى تحت الارضى وتهيه رايور ما ى

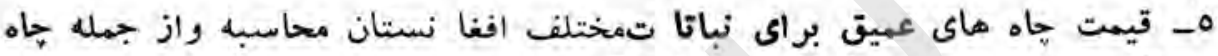

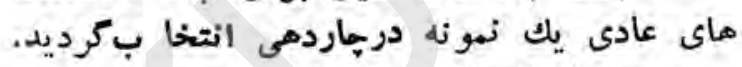

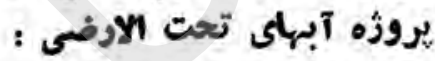

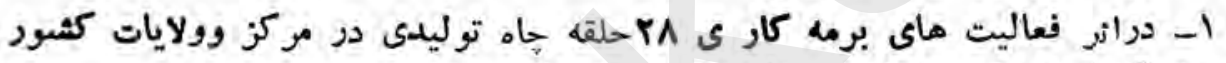

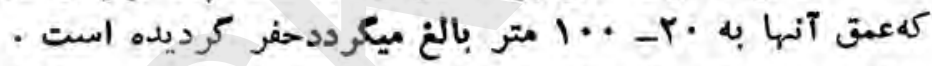
متر rا

\section{:تحقيقات جيو فزيكم :}

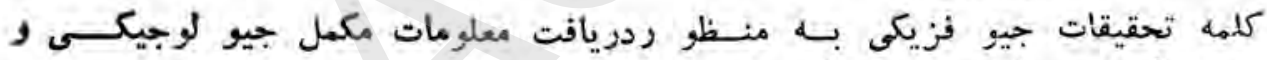

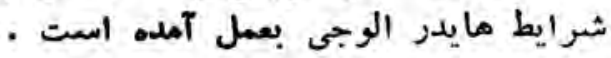

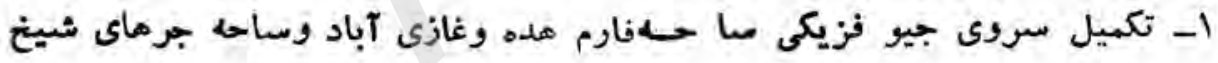
r- يورفيل جيو فزيكى ساحات تمكسىوسياه كل ولايت غزنى وساحه مر كانسى ولسوالى مقر.

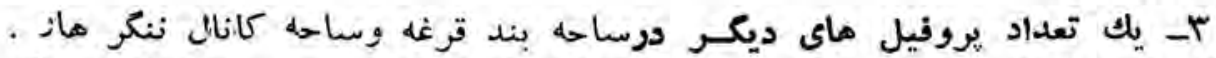

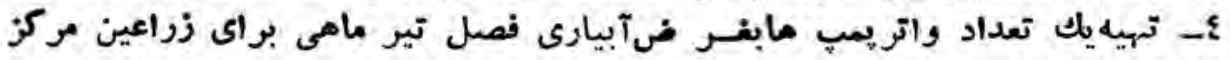
ويك تعداد ولايات . تعاد

\section{تحقيقات الهايدرو جيولوجى :}

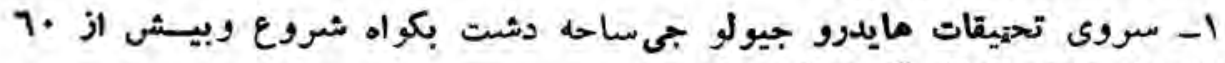

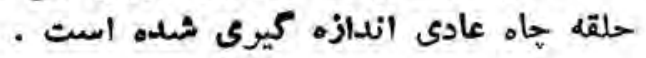

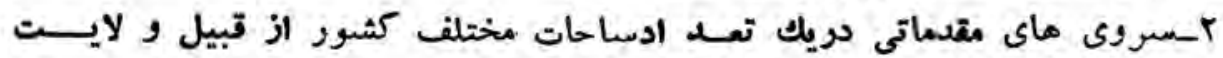

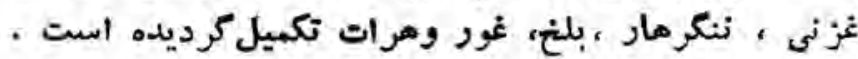




\section{فعاليت هاى تويو كراقى :}

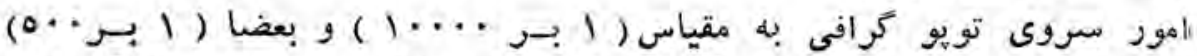

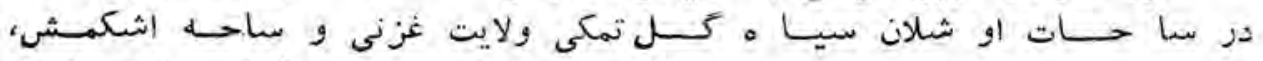

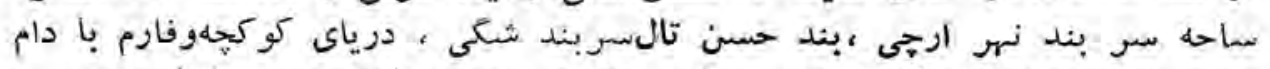

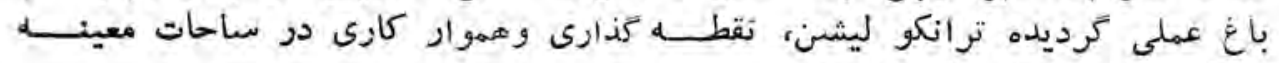

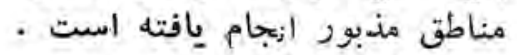

سروى جيولوجى:

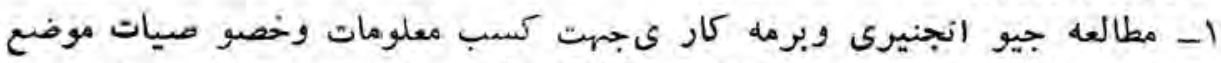

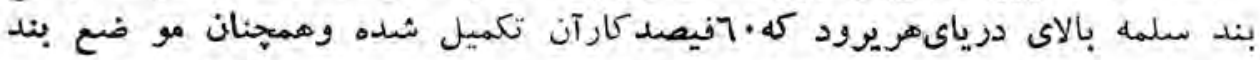

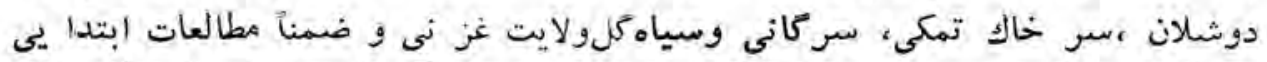

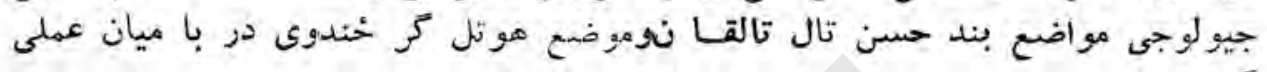

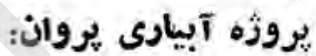

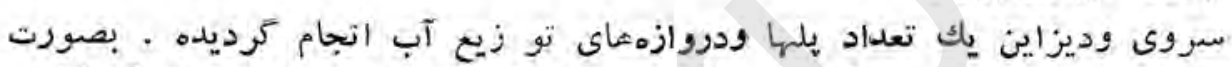

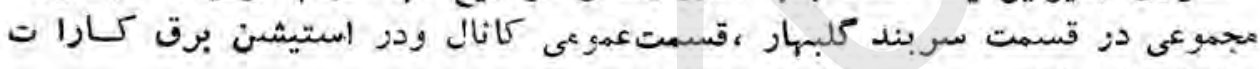

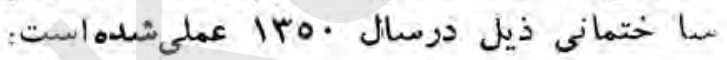

\begin{tabular}{|c|c|c|}
\hline متر مكعب & $\mid \varepsilon \varepsilon, \cdot V \wedge$ & $s, v,-1$ \\
\hline متر مكعب & $17 ; V \varepsilon 0$ & r_كانكريت ديزى \\
\hline متر مكعب & $r \varepsilon, 091$ & r- سنك كا رى \\
\hline متر مربع & $O V, T \sum T$ & ع- هنكاف كا رى \\
\hline متر مربع & $K 7 \varepsilon, \varepsilon 0 \varepsilon$ & 0ـ سلوب كارى \\
\hline متر مر & $\varepsilon, 0 \ldots$ & 7- قير ريزى \\
\hline متر مك & 9,097 & V- تهيه ريك و جغل \\
\hline متر مكع & GVTJTR & 1- كـند نكارى \\
\hline متر م & vr. & 9- يلستر كارىوغيره \\
\hline
\end{tabular}

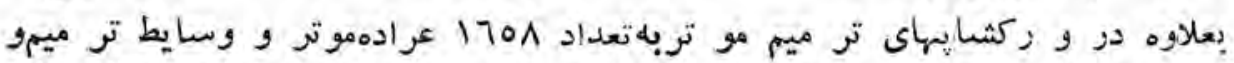

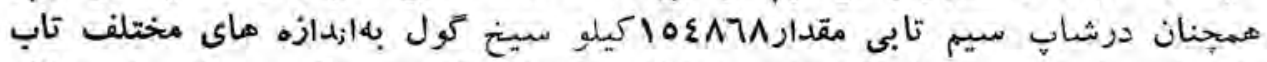

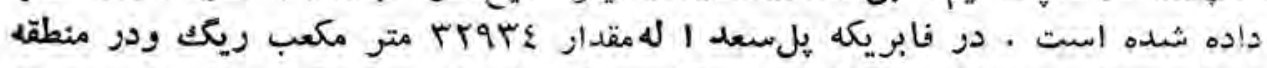

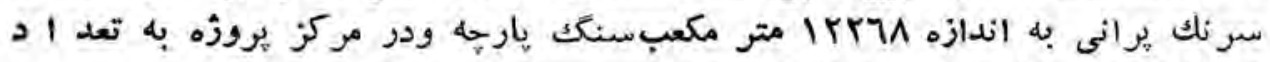

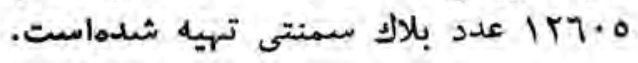

\section{: انكثاف يكتيا}

$$
\begin{aligned}
& \text { اول : فعاليت كروب جنغلات : }
\end{aligned}
$$

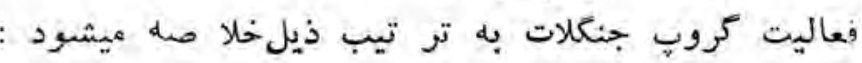

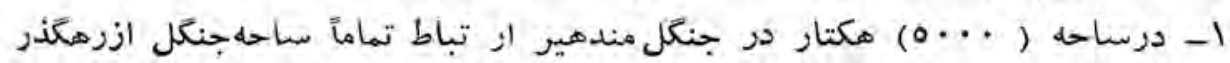

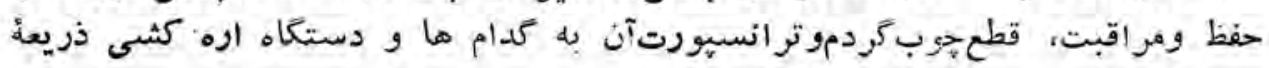




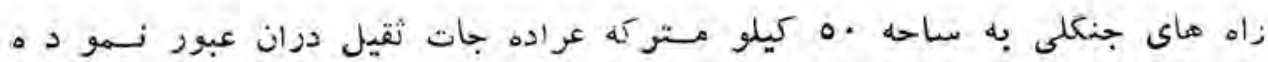

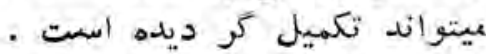

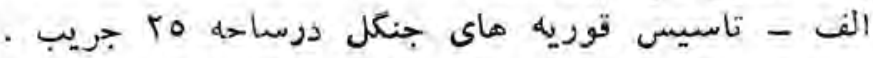

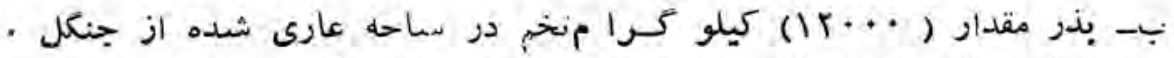

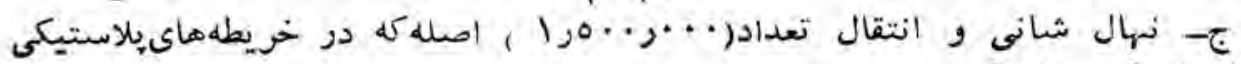

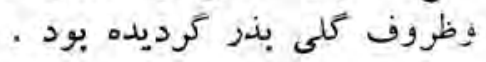

$$
\text { - - استخصطال مقدار ( }
$$

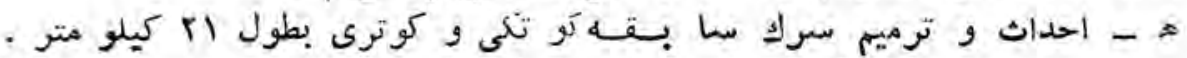

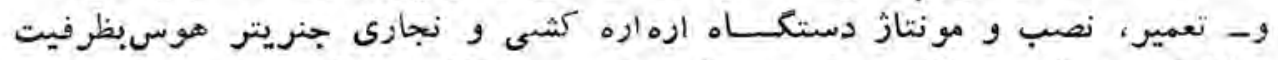

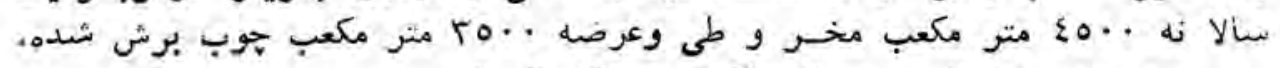

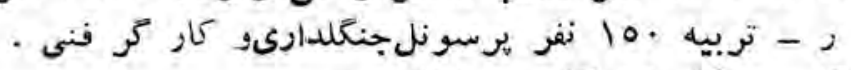

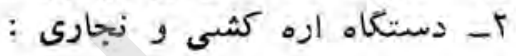

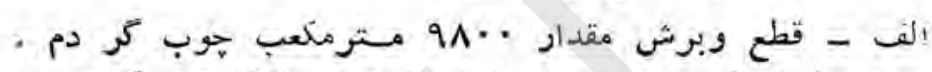

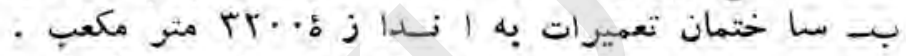

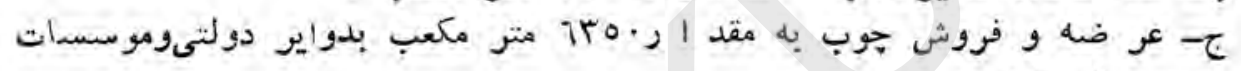

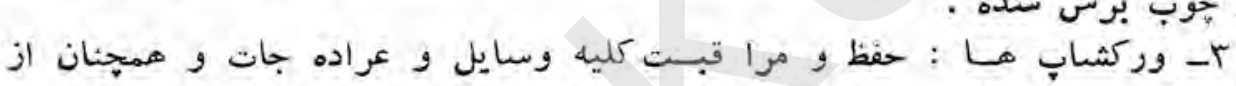

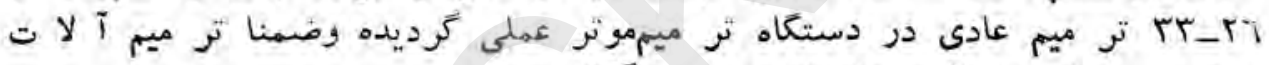

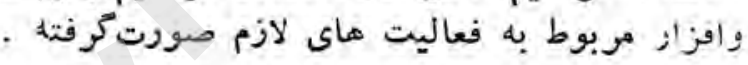

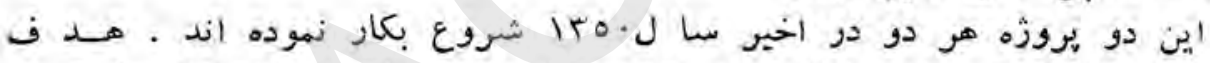

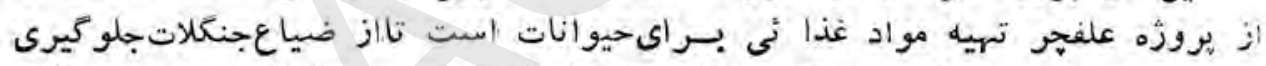

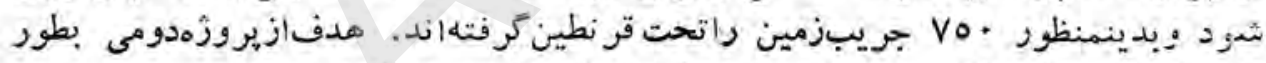

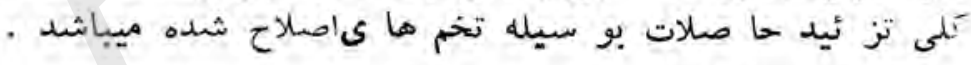

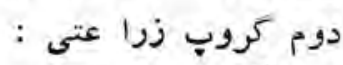

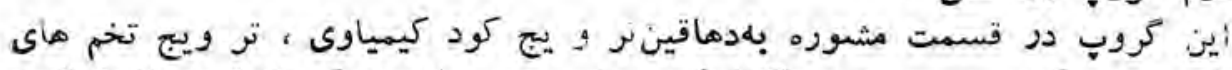

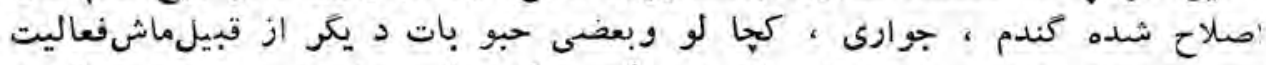

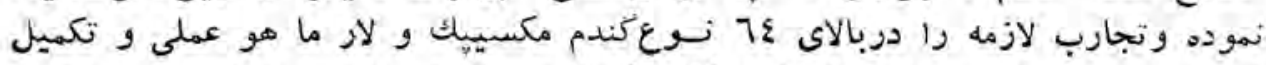

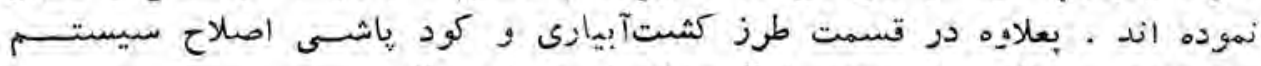

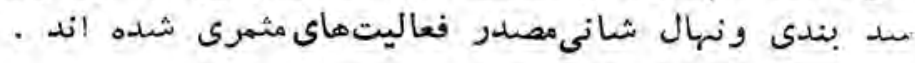
سوم - تر بيه و لسمائل

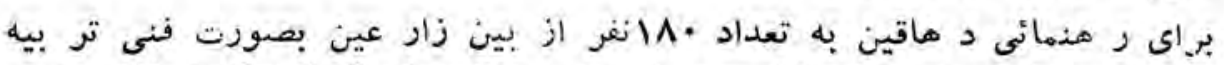

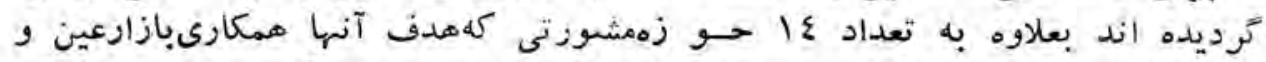

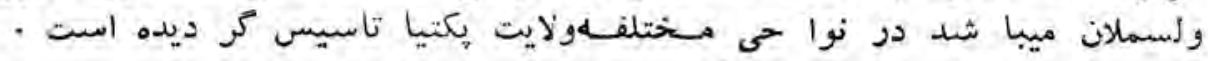

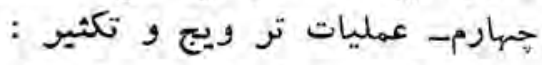
فعاليت اين يرو زه در قسمت تحقيقاتدرساحه خوست ، كرديز وائ واركون دا ير 


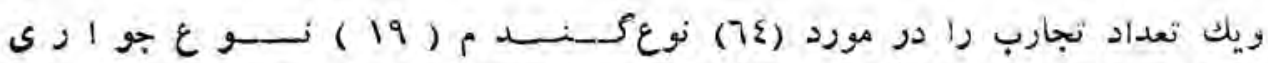

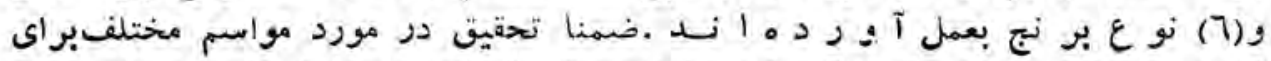

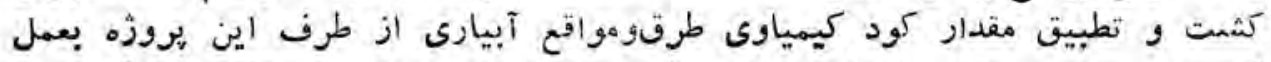

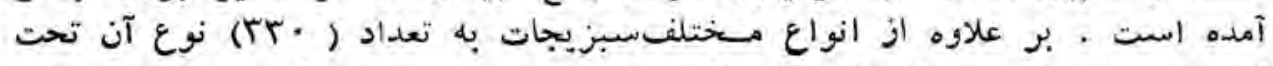

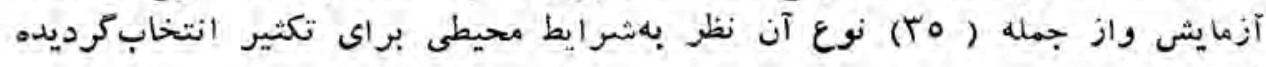

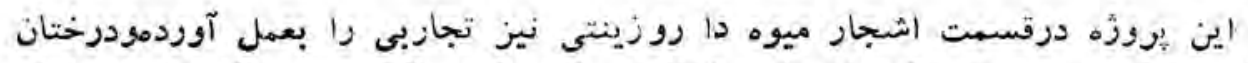

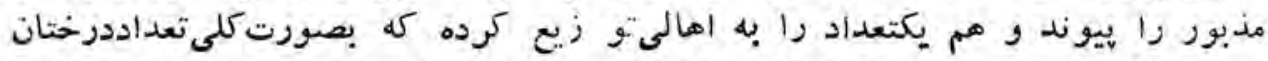

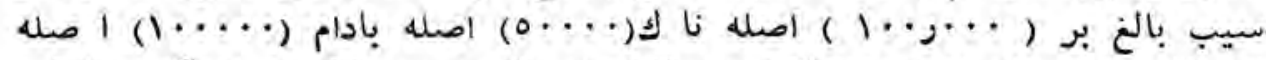

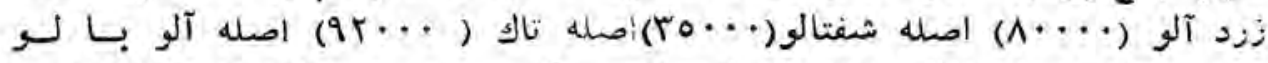
(r....)

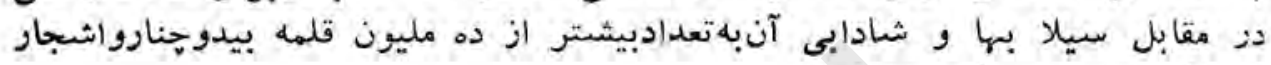

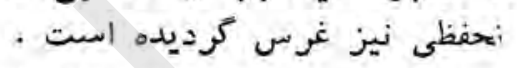

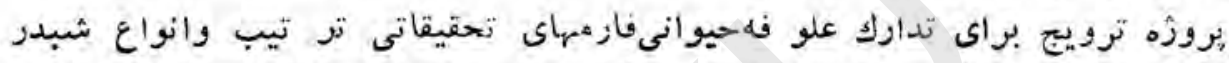

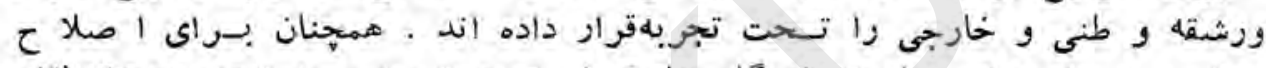

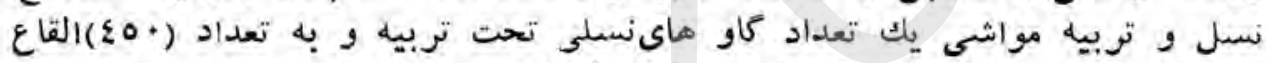

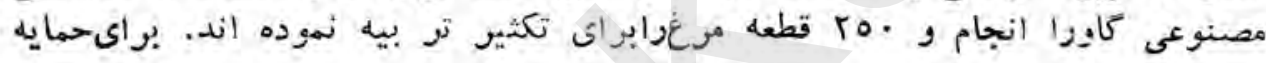

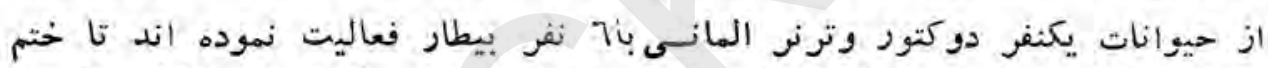

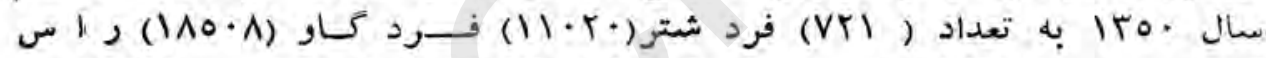

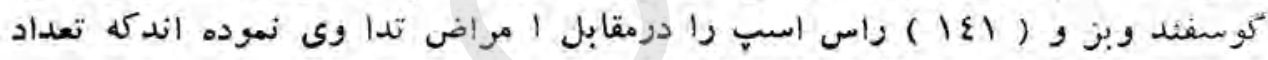

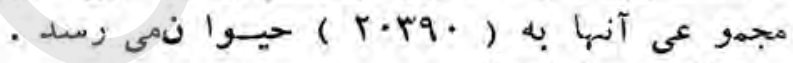

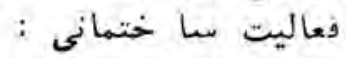

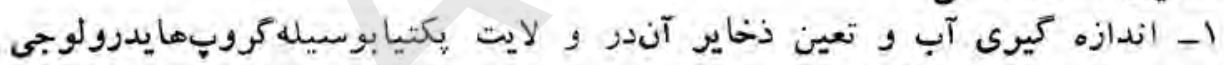

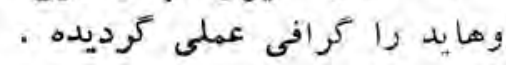

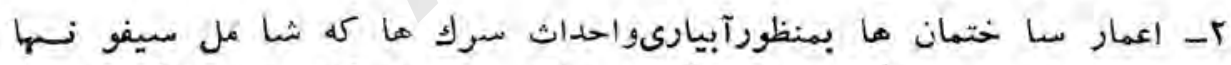

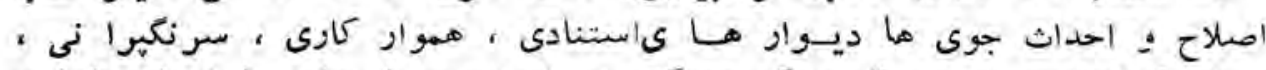

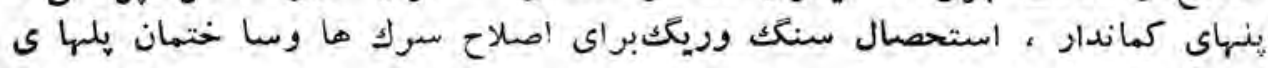

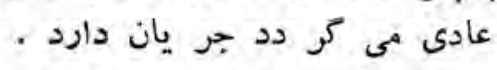

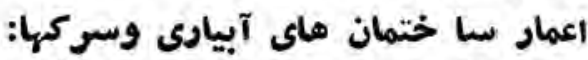

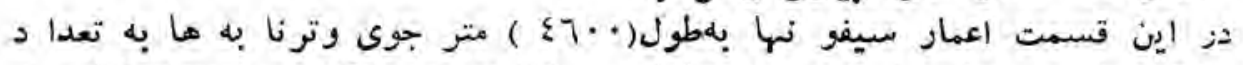

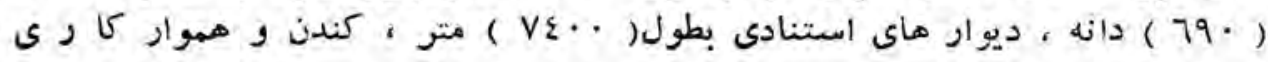

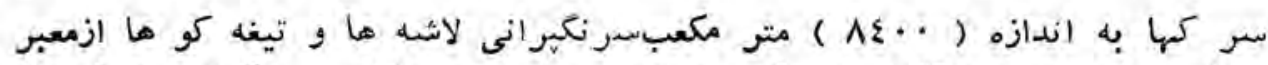

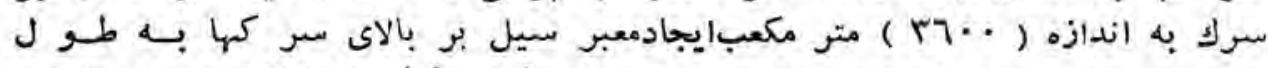

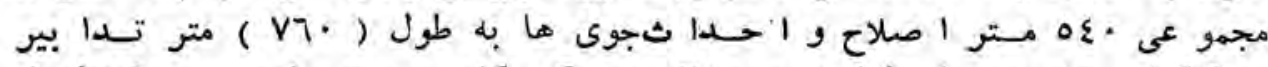

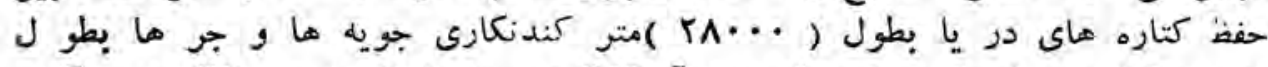
(IT...) 


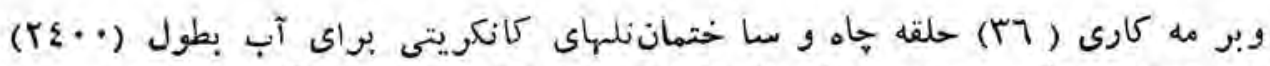

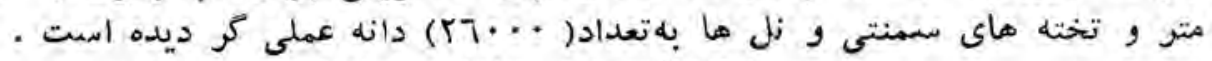
انكشاف وادى هلمند واد مارغنداب

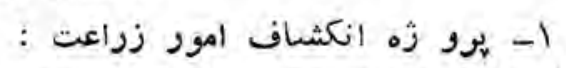

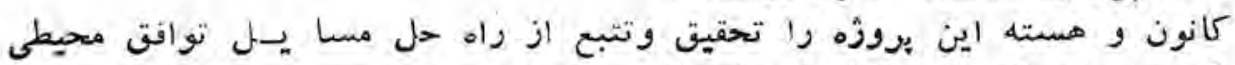

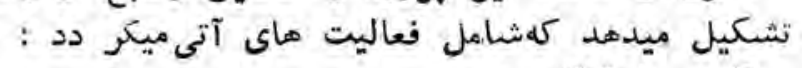

$$
\text { الف هـ ت تحقيقات : }
$$

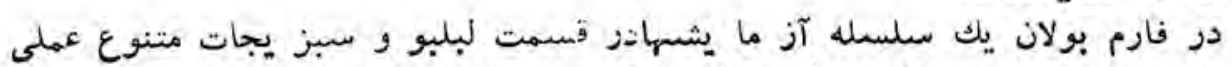

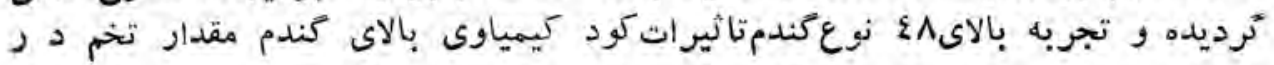

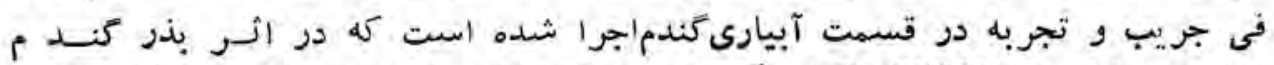

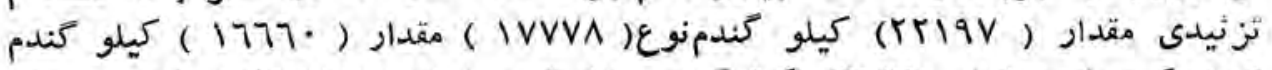

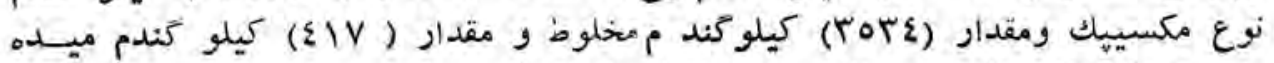

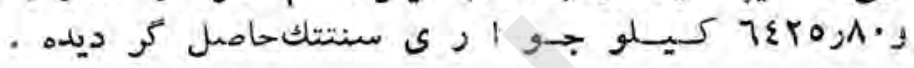

\section{: درفارم درويشبان}

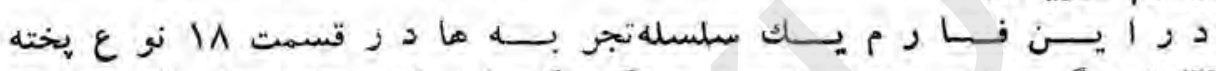

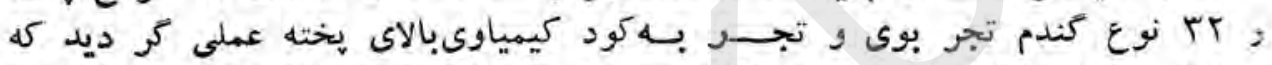

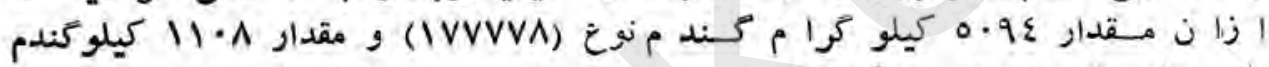

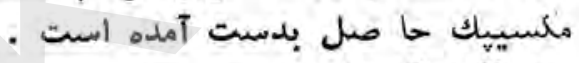

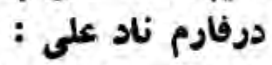

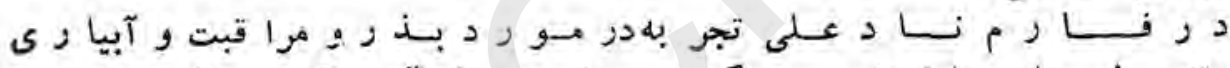

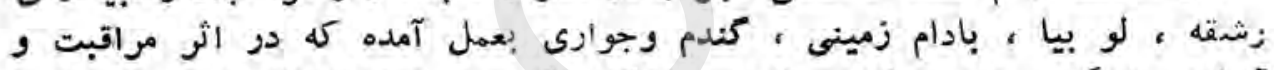

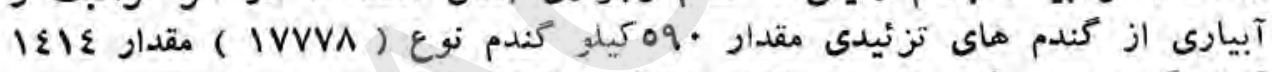

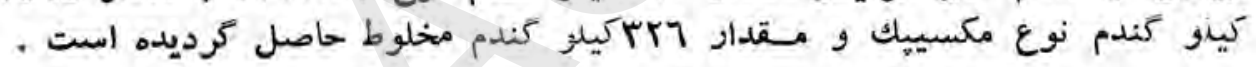

$$
\begin{aligned}
& \text { بـ فارم هاى تو ليد و تزئيد تخم : } \\
& \text { اجرا آت درفارم مارجه }
\end{aligned}
$$

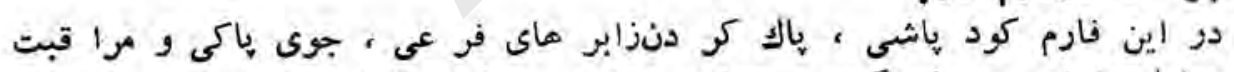

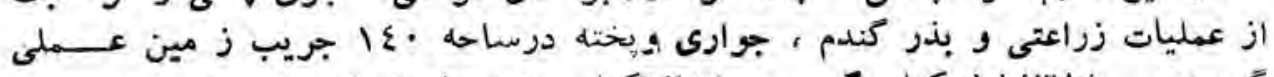

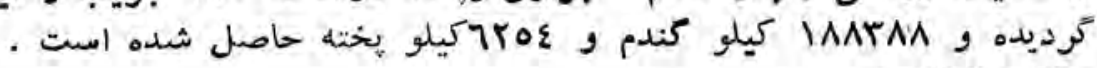
: فارم ترنك

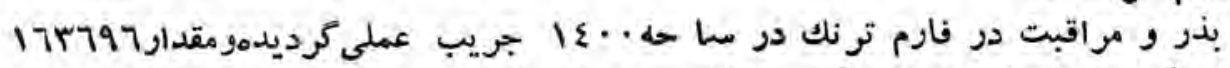

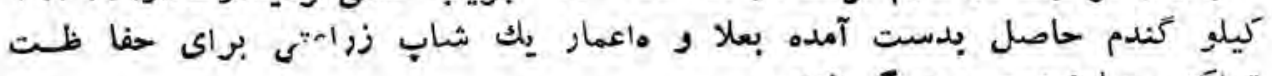

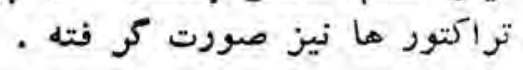

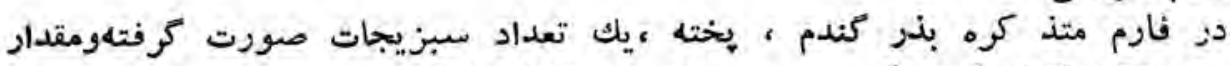
علاو (TRA )

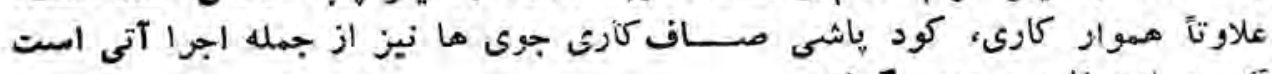

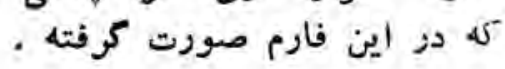




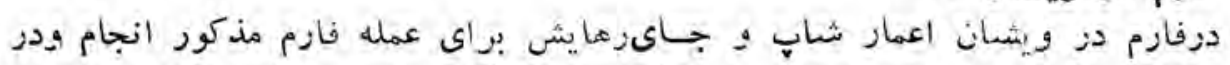

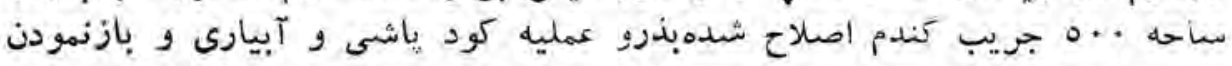
.

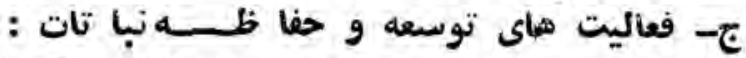

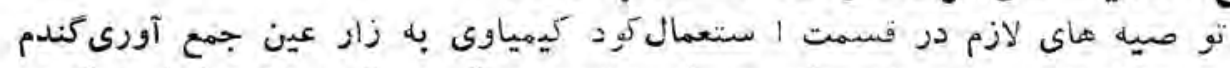

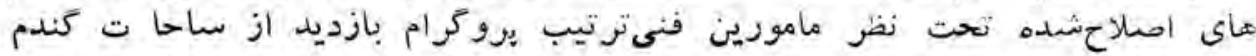

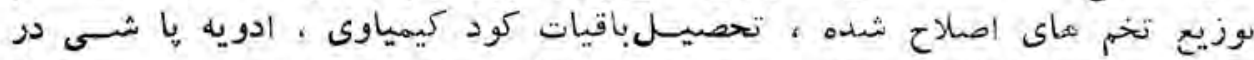

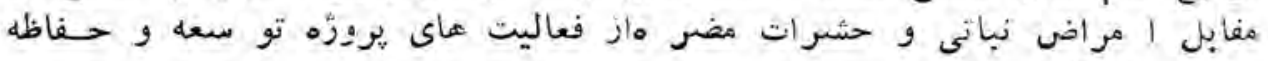

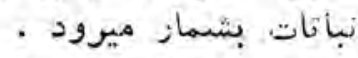

$$
\begin{aligned}
& \text { ז- זئ }
\end{aligned}
$$

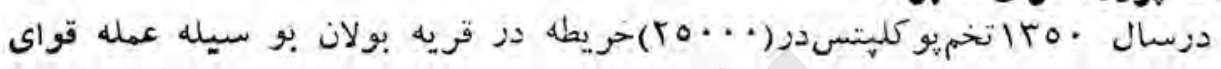

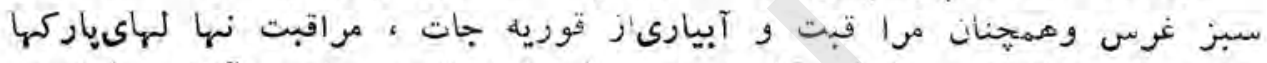

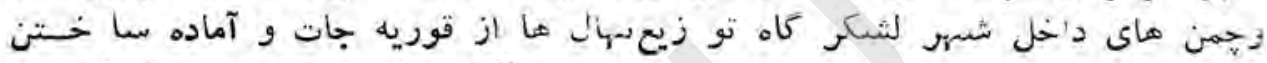

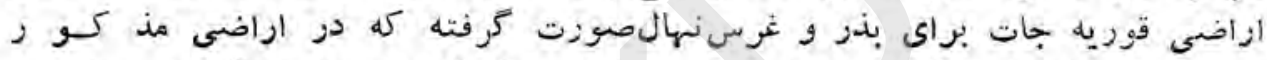
الراضى irEV7..

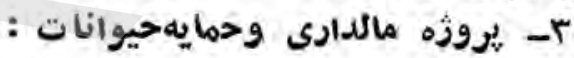

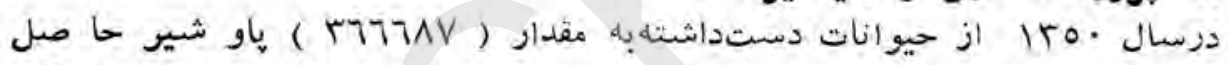

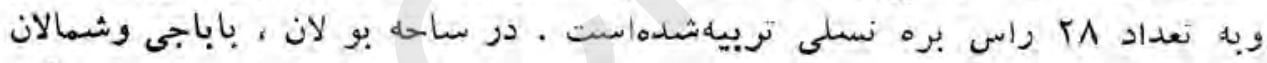

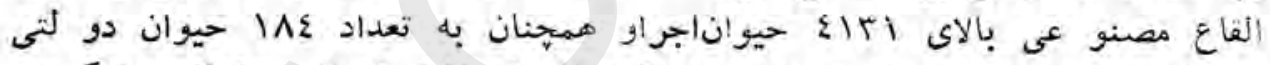

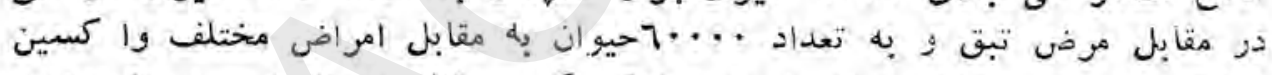

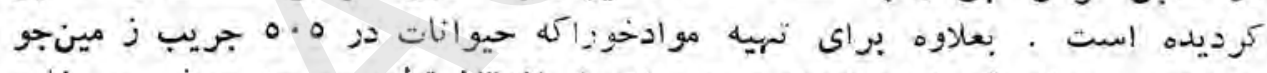

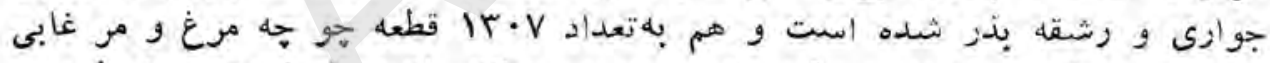

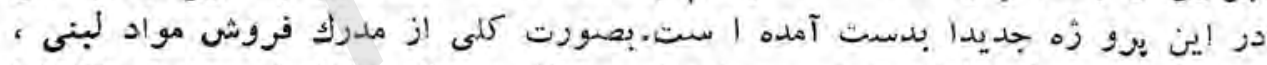

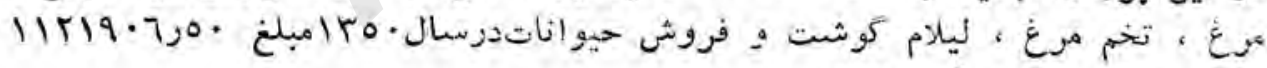

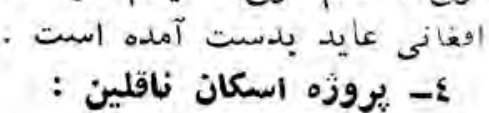

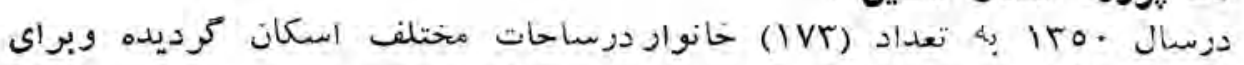

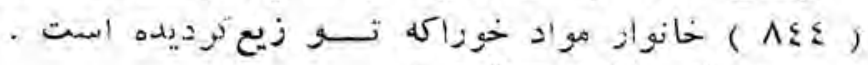
- - يروزه حفظ و مراقبت :

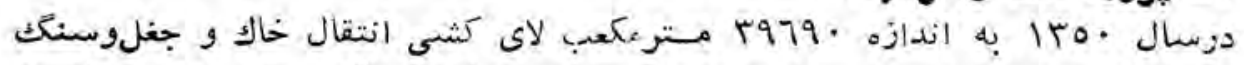

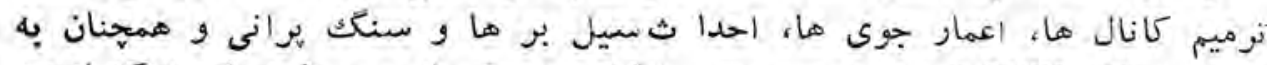

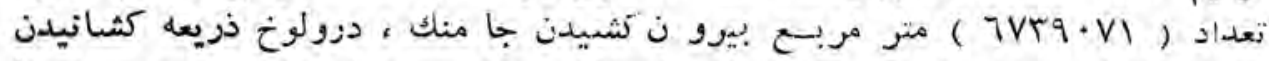

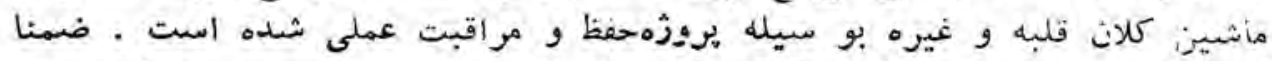

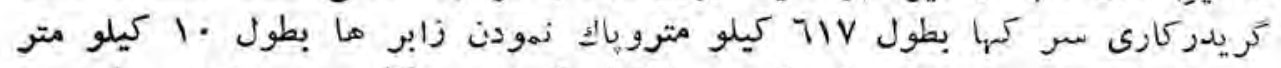

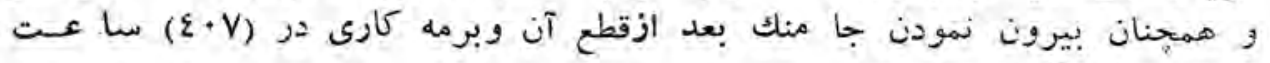




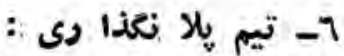

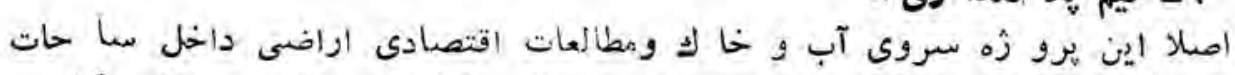

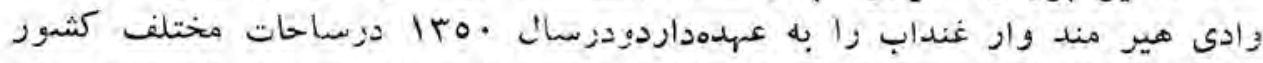

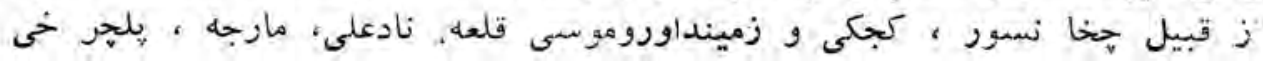

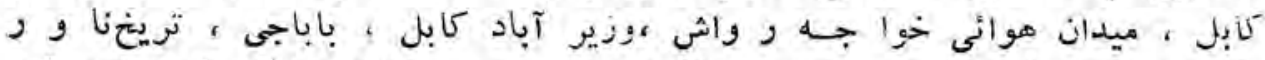

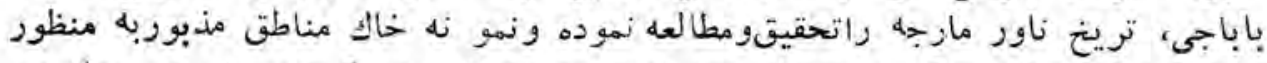

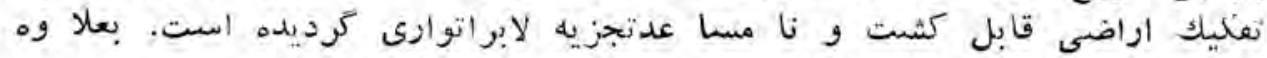

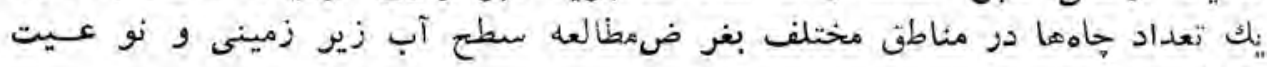

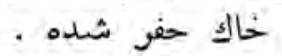

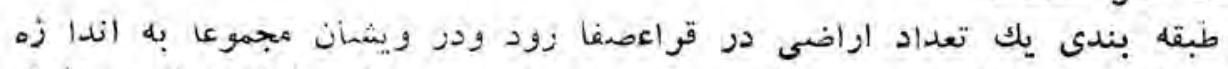
(EVT. )

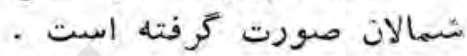

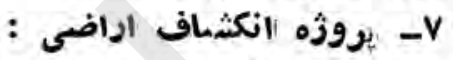

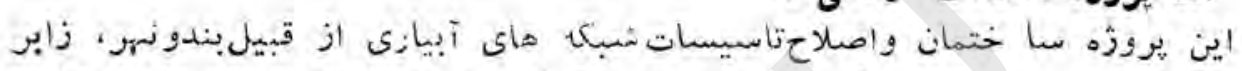

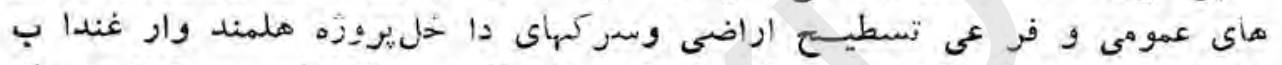

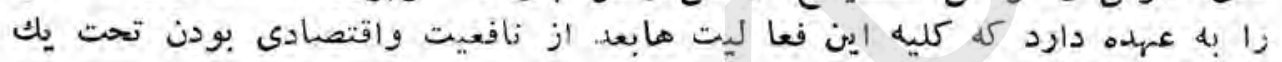

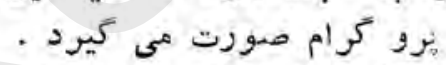

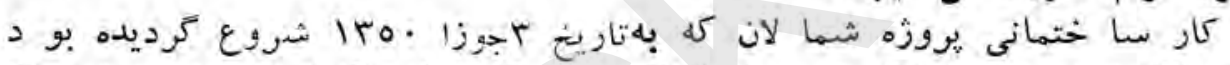

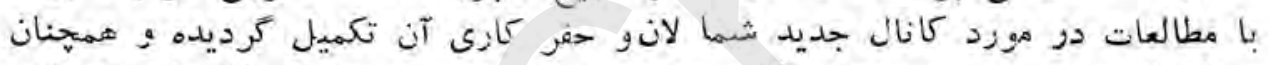

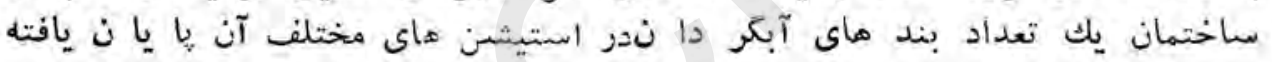

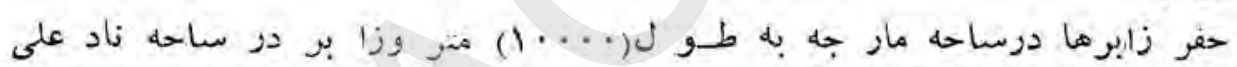

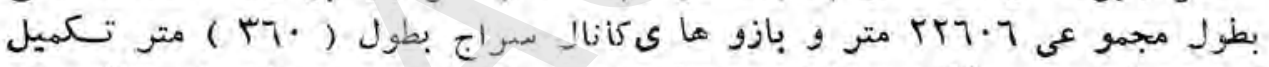

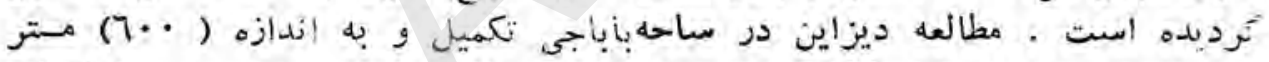

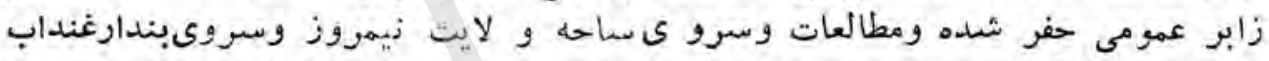

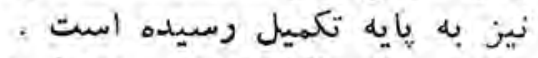

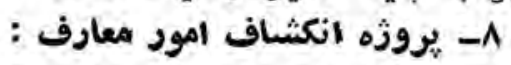

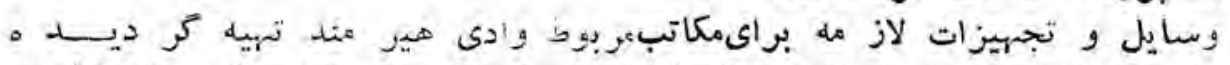

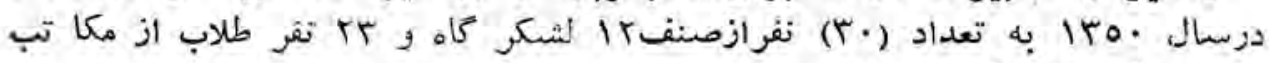

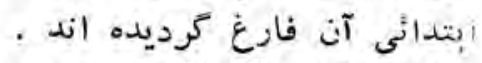

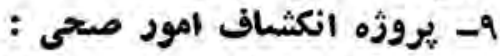

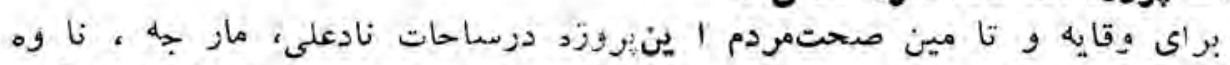

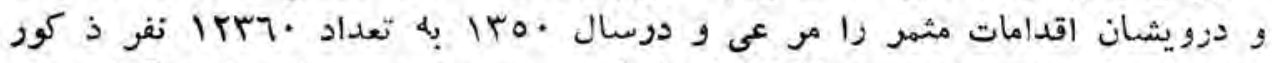

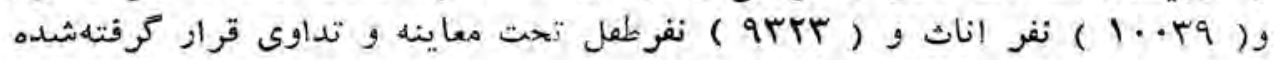

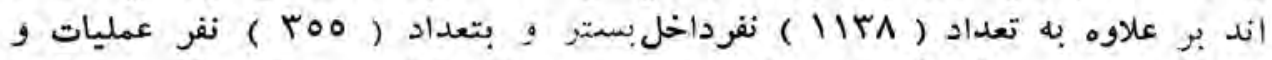

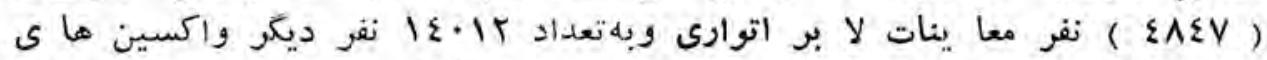

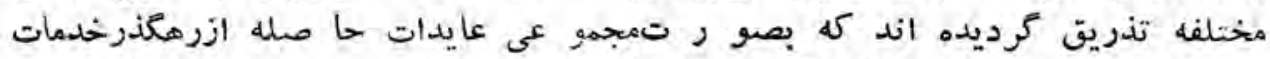

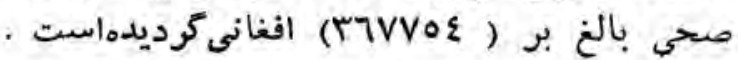




\section{انكثاف وادى ننگر هار}

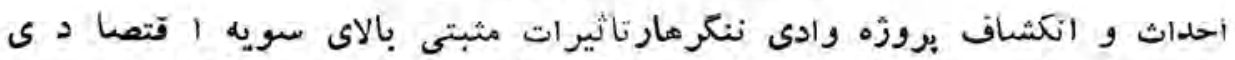

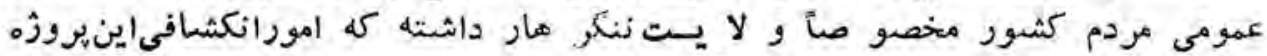

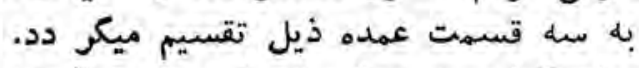

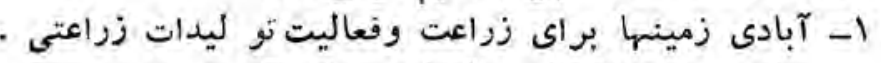

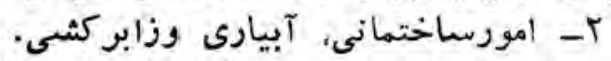

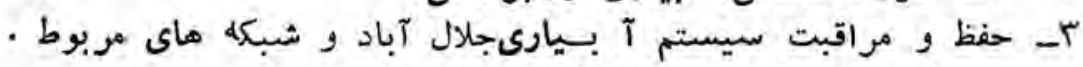

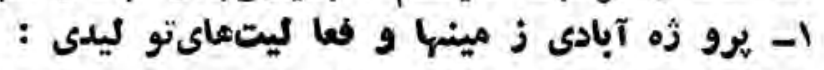

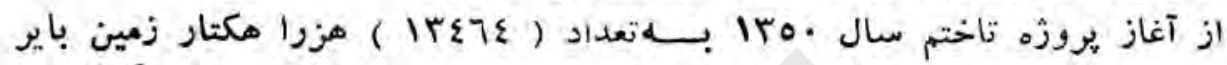

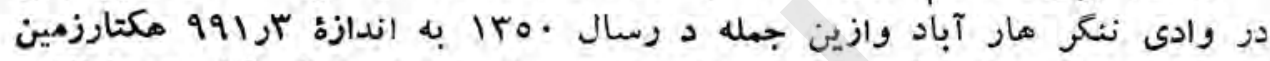

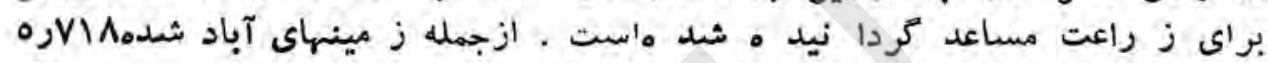

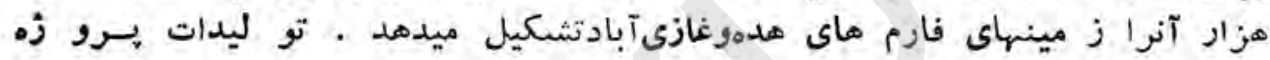

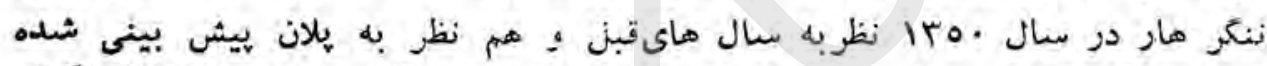

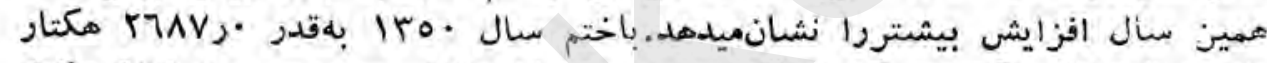

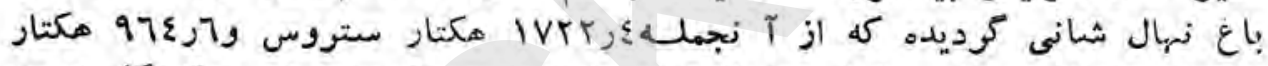

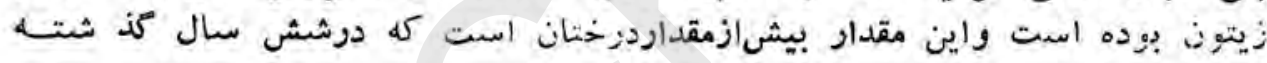

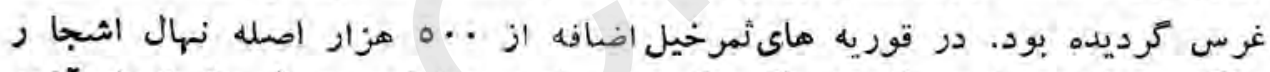

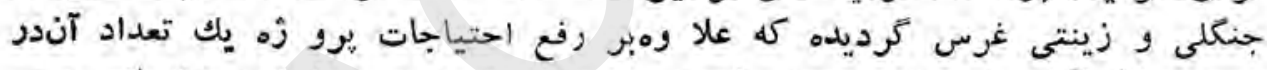

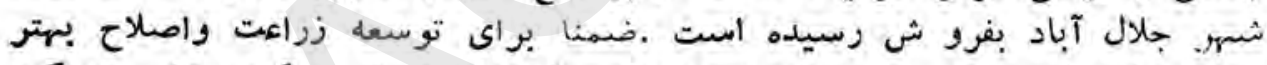

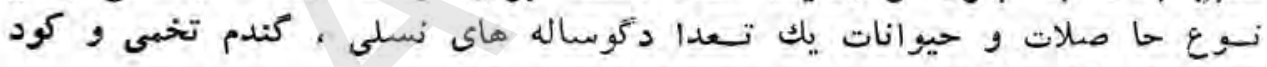

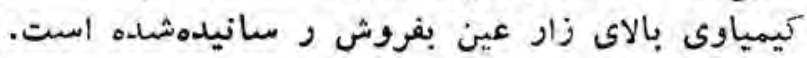

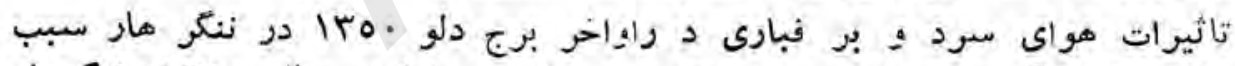

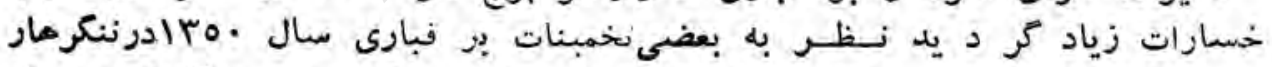

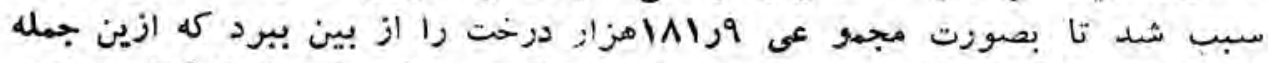

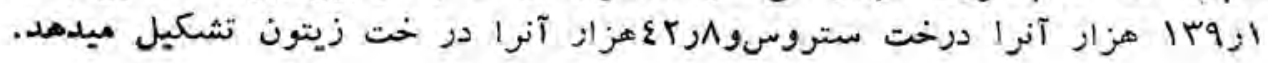

\section{توليداتزراعتى و حيوانى}

درسال تورات عتى

\begin{tabular}{|c|c|c|c|}
\hline مقدار توليدات & نوع توليدات & مقدارتوليدات & نوع توليدات \\
\hline ع & باقلى & تن roor & كندم \\
\hline 凡 $1 \cdot 1$ & كاه سفيد & . & ستووس \\
\hline ت $11 \Lambda_{0}$ & رشقه & 1را تن & زيتون \\
\hline 0ر 79 ا مزاربيضش & تخممرغ & عا تن & جو \\
\hline ت rVr & شير & & جوارى \\
\hline 797 ק راس & كوساله & تن & نخود \\
\hline
\end{tabular}




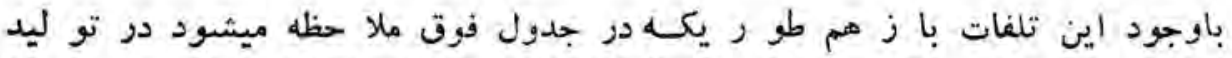
ستروس در سال •ro

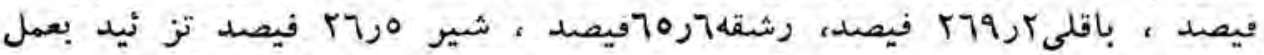

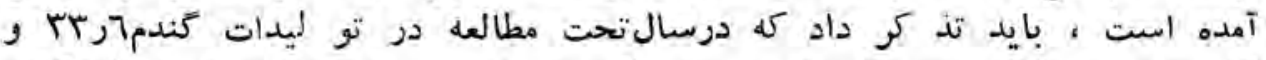

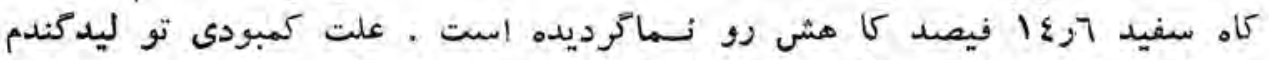

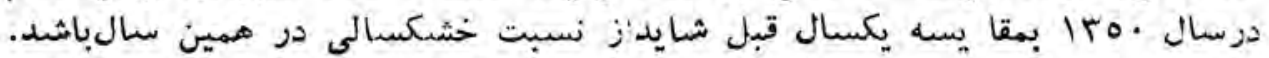

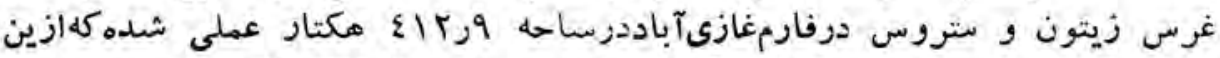

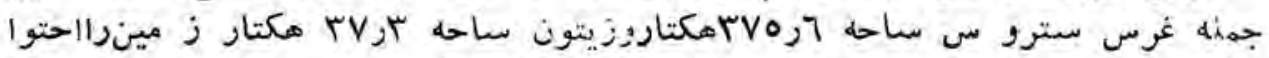

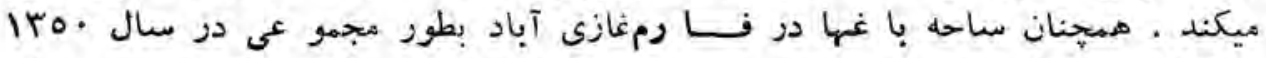

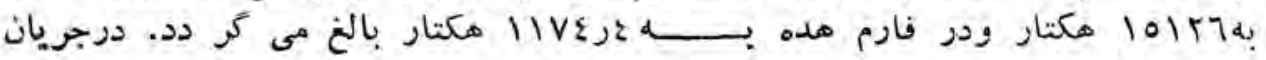

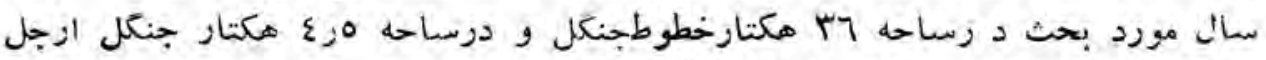

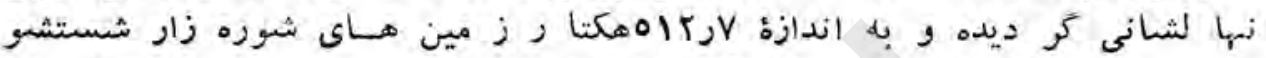

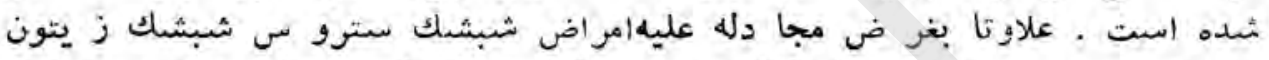

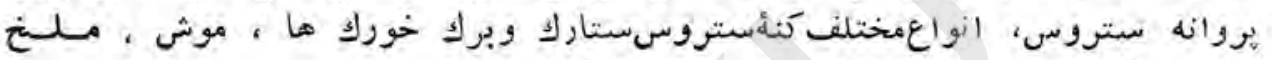

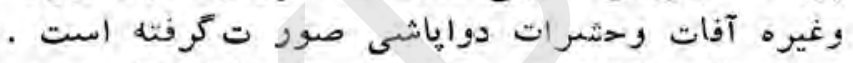

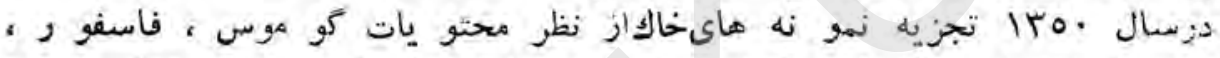

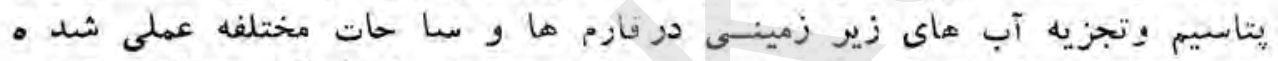

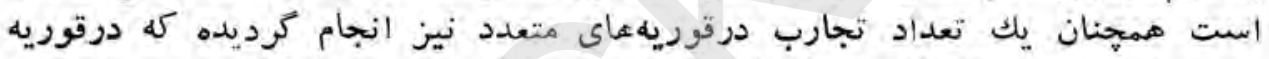

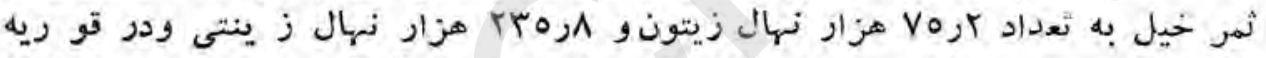

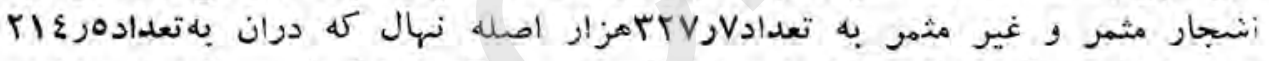

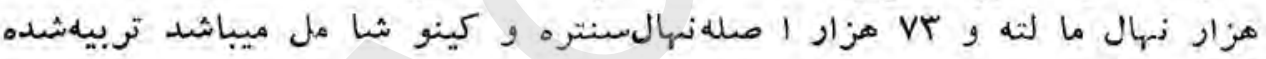

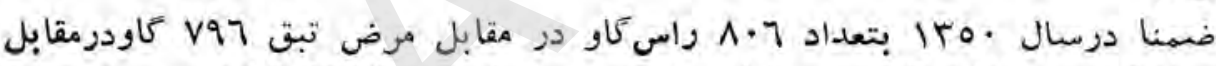

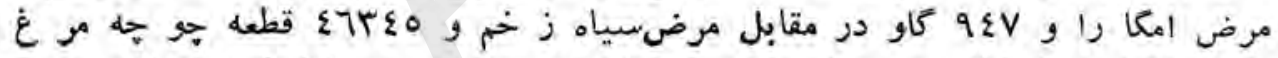

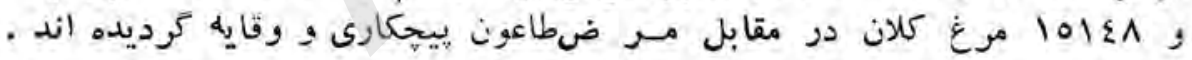

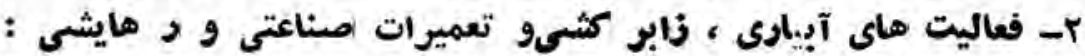

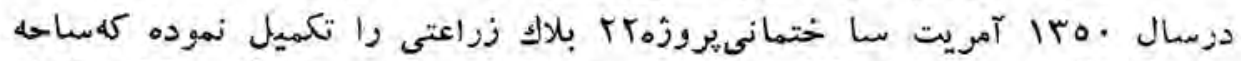

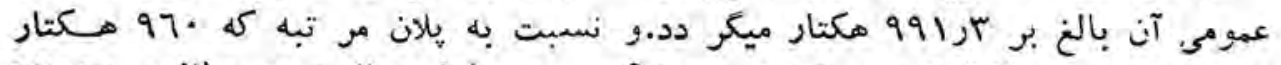

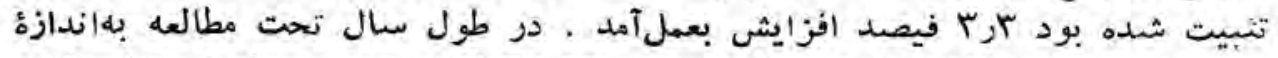

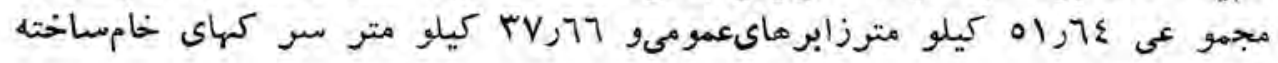

شده است عت . ش

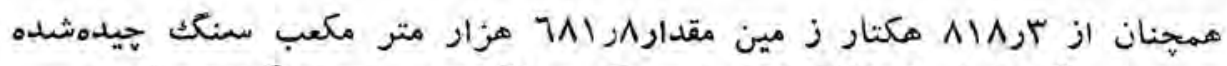

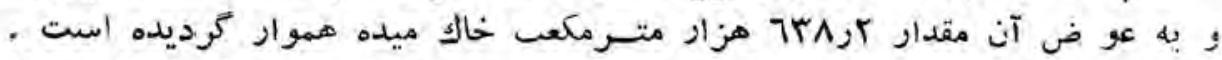

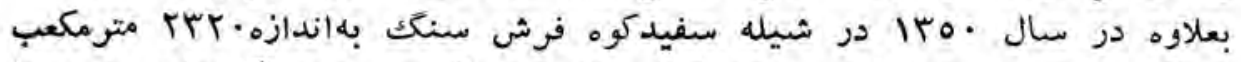

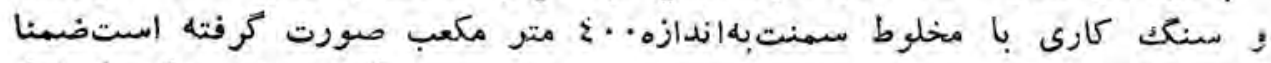

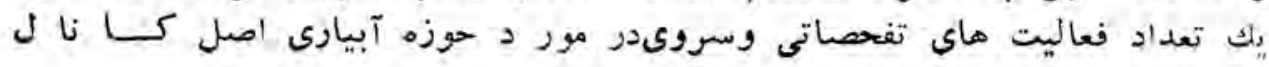


شبكة منطقوى زابر هاى دشتى و زا بسرهائ عمو مى و تاسيسات شبكما عملى

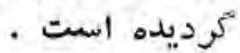

\section{r- حفظ و مراقبت سيستم آ بيا د ى:جلالرآباد و شبكه هاى مر بوط :}

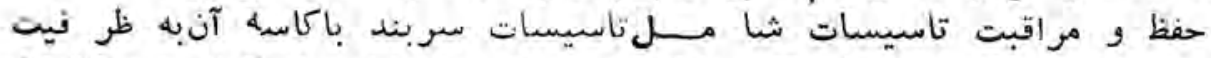

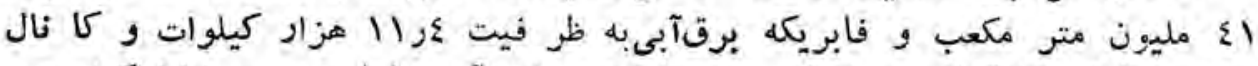

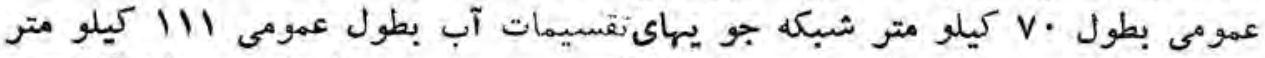

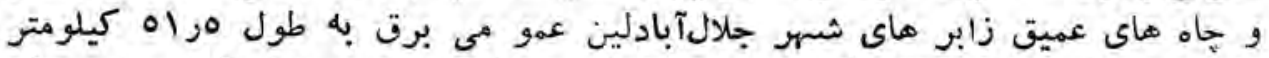

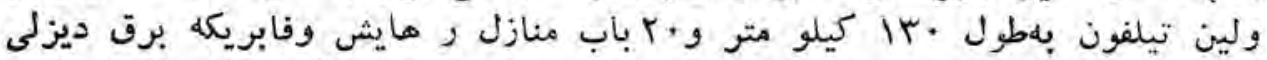

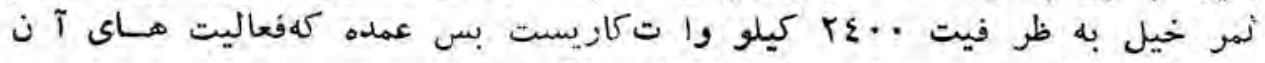

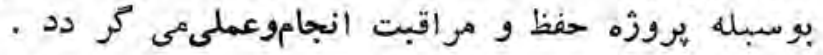

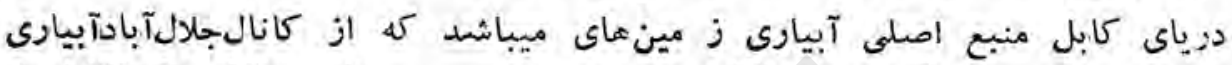

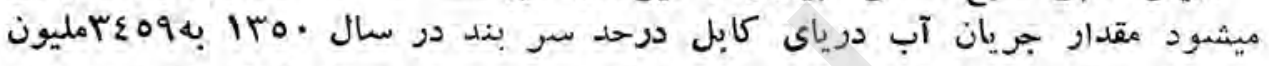

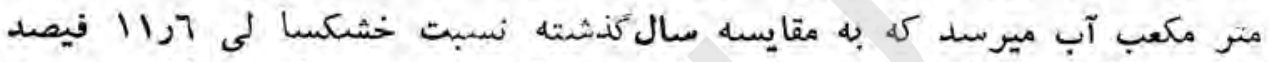

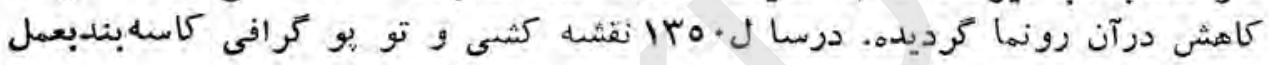

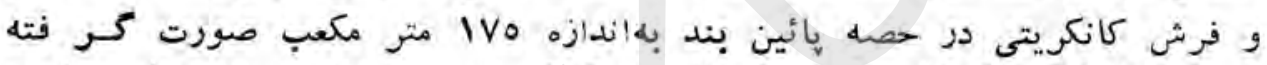

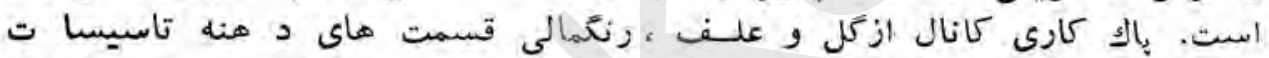

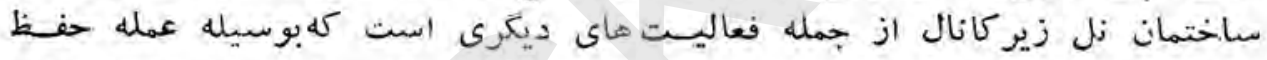

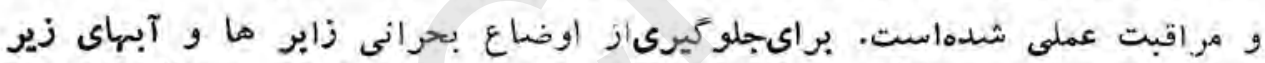

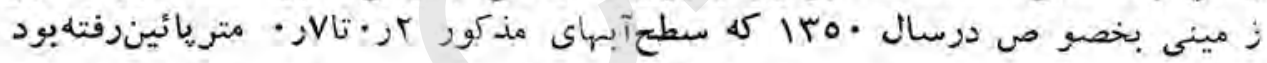

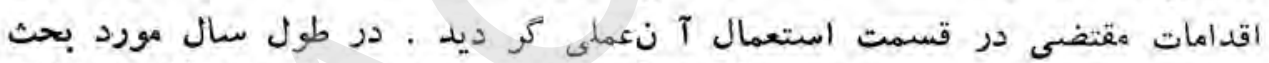

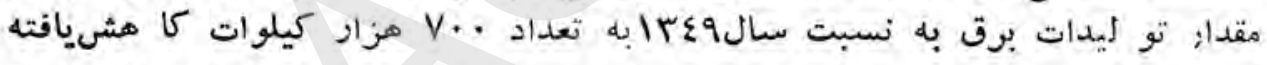

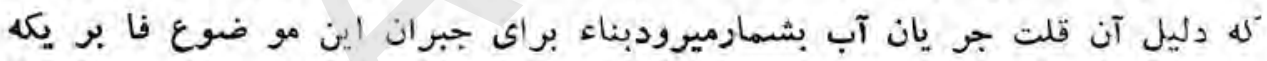

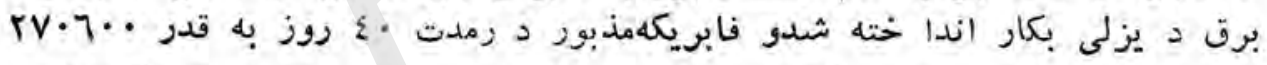

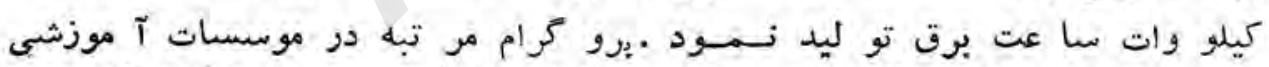

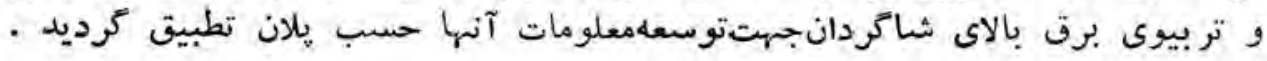

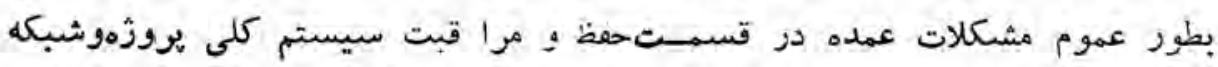

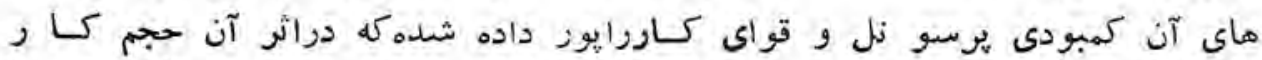

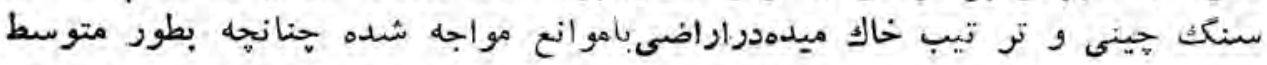

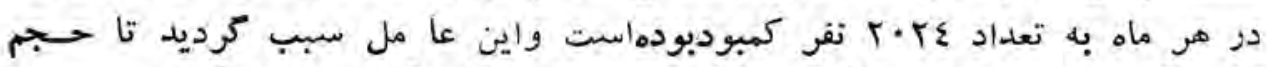

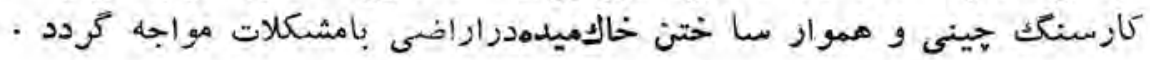

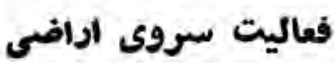

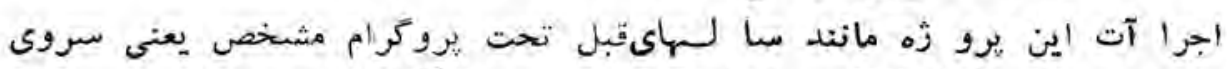

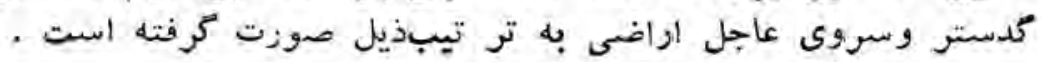




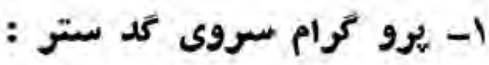

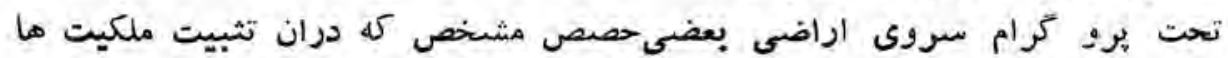

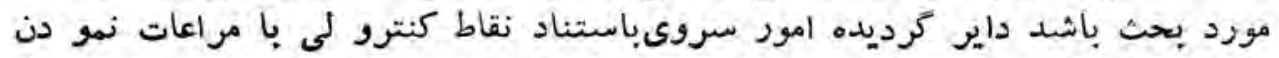

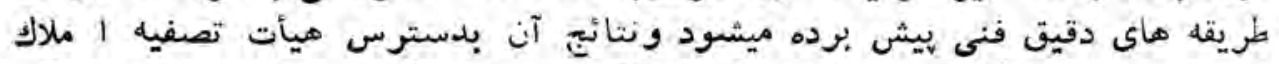

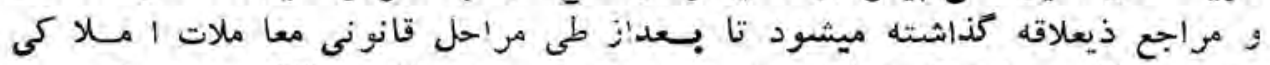

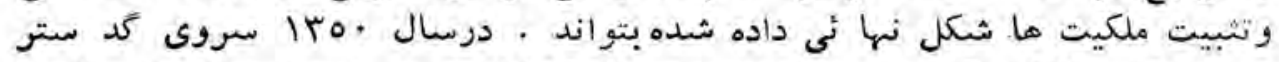

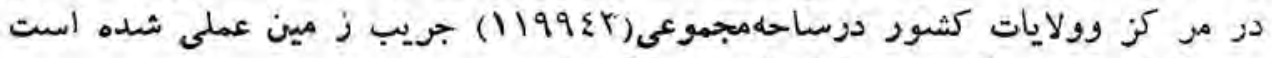

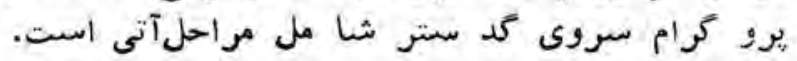

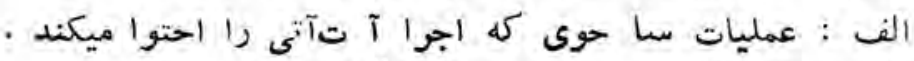

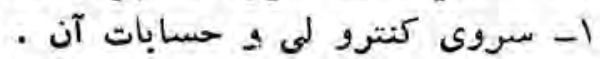

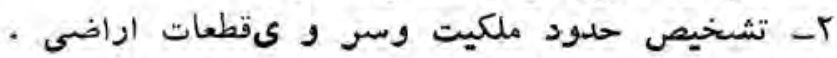

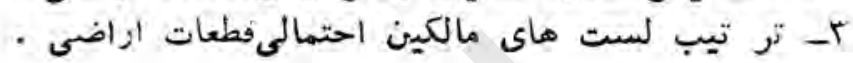

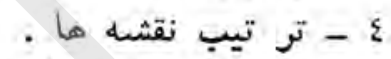

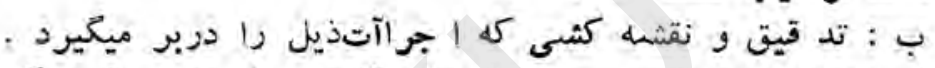

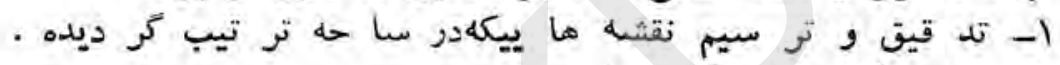

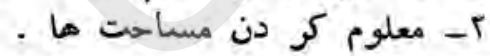

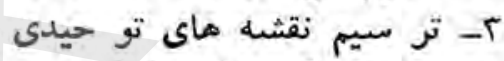

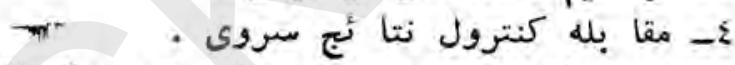

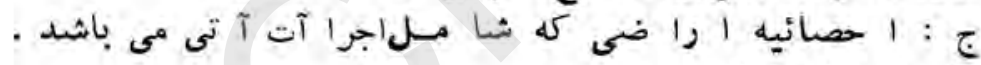
ا- إ- تصنيف أراضيه

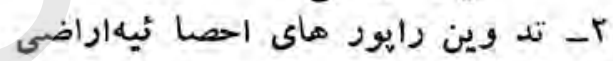
-

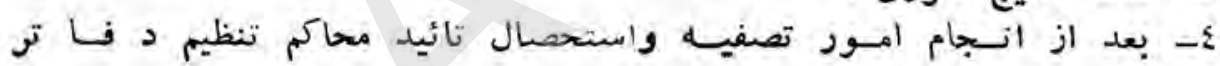
نبت 1 ملاك

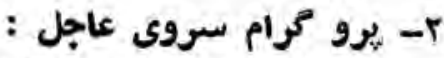

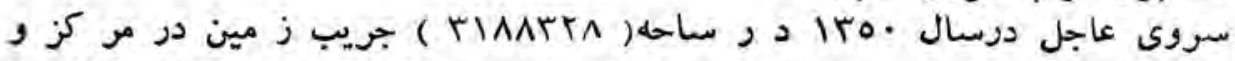

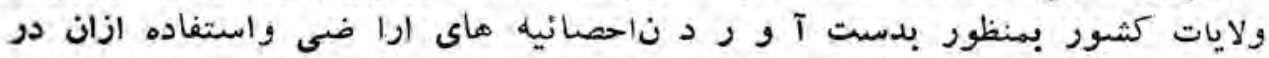

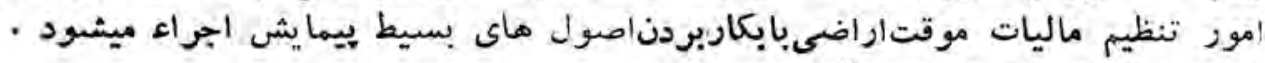

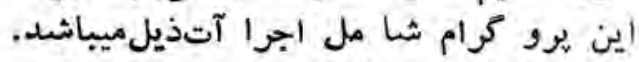

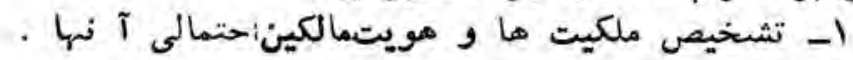
r

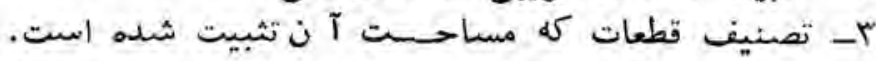

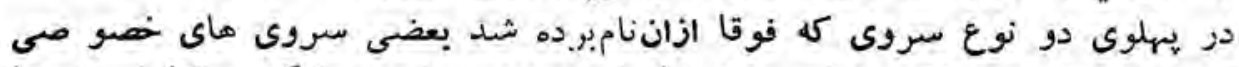

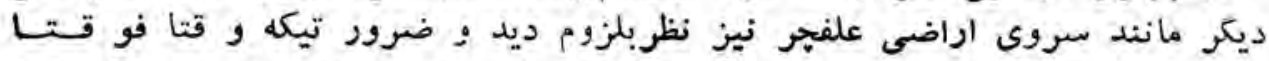

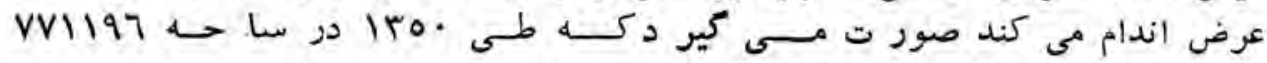

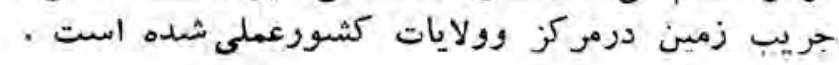




\section{معادن وصنايع}

بطور كلى رشد صنايع و معادندرهمهلمشوزها مهثل رشد اقتصادى بودهبنابوان تحو لات دز فعاليتهاى اين شقـوق بالاى ساير شقوق تاثير مستقيم دارد . بعبارة يكير ميتوان كفت كانه توسعه صنعت معيارعمد, بواى افزايش توليد ، افزايش سطح

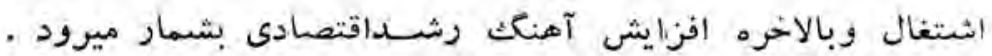

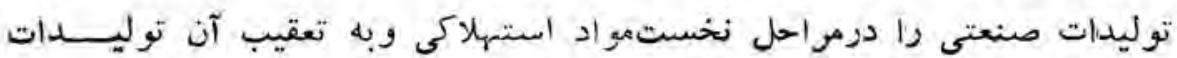

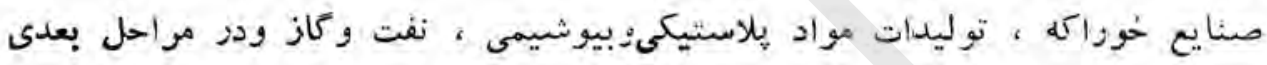

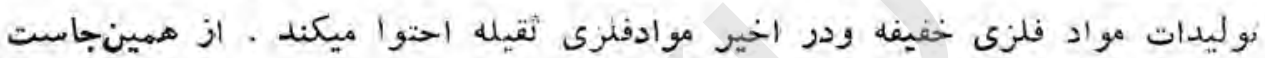
كها در كشور هاى مانند افغانستان قسمتعمده توليذات صنعتى را مواد استهلاكىى

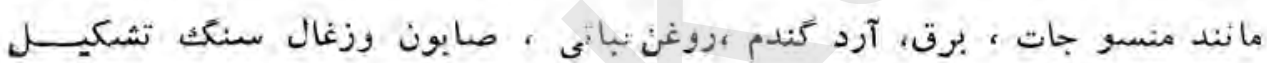
ميدهد و در قسمت تو ليدات مسعد نسى افغانستات ، توليدات كاز طبيعى داراى

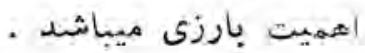

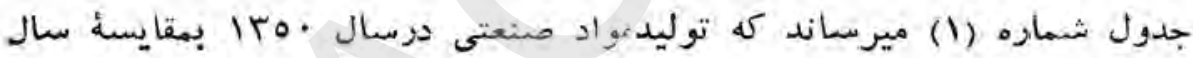

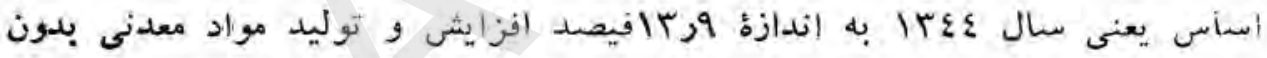
كازبه اندازة: ·ل فيصد كاهش يافنهاست.علت عمده كاهش شاخص مواد معدنى را بدريه اول عدم موجوديت ارقام مربوط به نوليدات لاجورد وعدم شمول آن در رشته معادن وبدرجله دوم كاءش در توليداتزغالمنك ميتوان حساب كرد (رجوع بهجدول

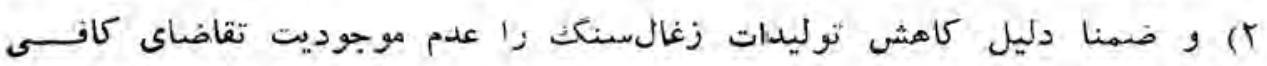
ومحدوديت بازار فروش و موجوديتمقدارمتنأبهى ذخاير سال كذشته تشكيلميدهد. 
(1) جدول

شاخصتوليداتمواد معدنى وصنعتى

$$
\text { 1ro. - IrE }
$$

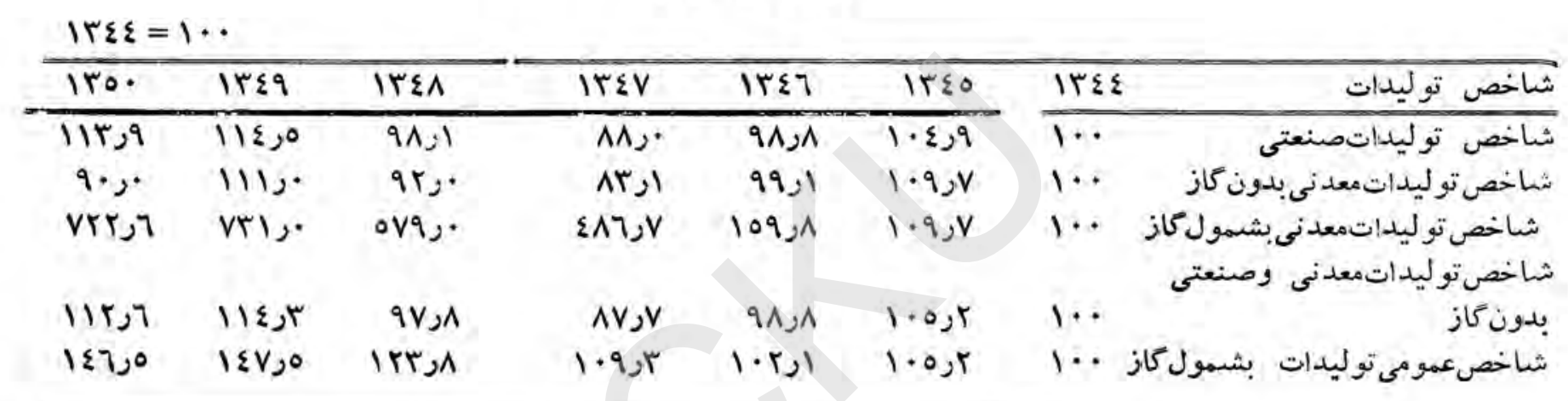

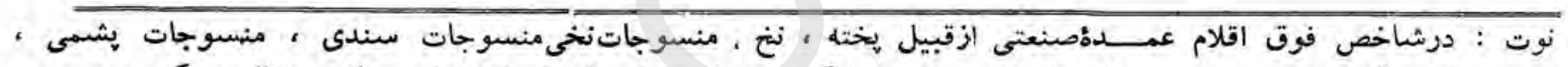

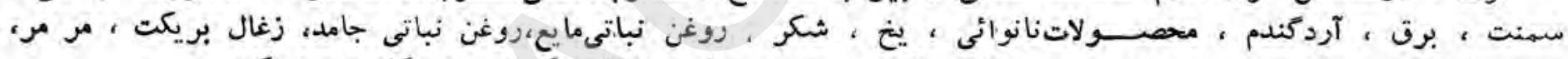

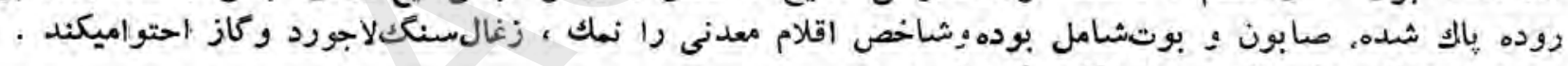

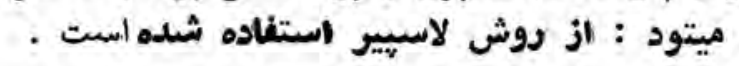




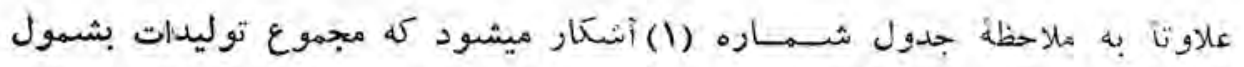

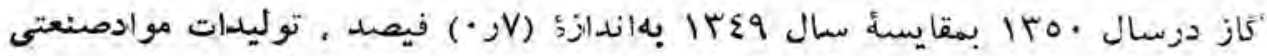

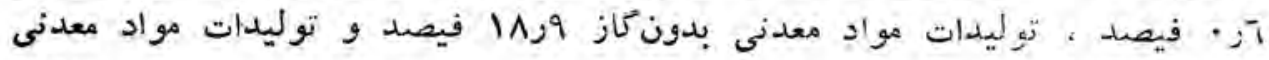

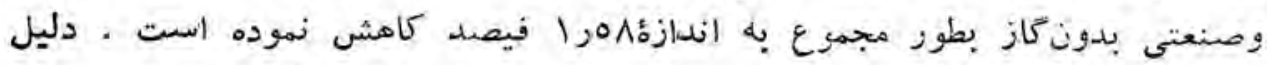

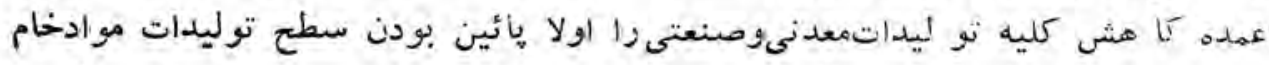

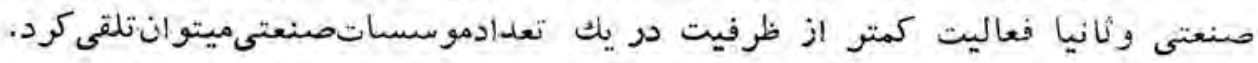

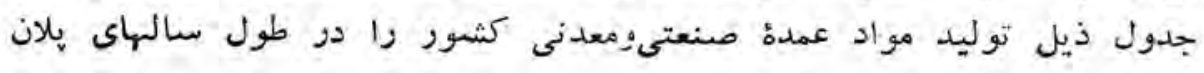

\section{(T) جدول}

توليدات عمدة صنعنىومعدنى كثود از بال

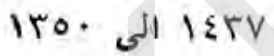

\begin{tabular}{|c|c|c|c|c|c|}
\hline 1 ro. & $1 r \varepsilon 9$ & IrEA & $\mathbb{I r E V}$ & واحدتو ليدى & نوع توليدات \\
\hline 17,1 & $r \cdot, 0$ & $r v,$. & 15,9 & هزارتن & بنبه محلوج \\
\hline$\pi$, & $\circ v, 1$ & $\varepsilon q, \varepsilon$ & $\varepsilon \wedge, V$ & مليونمتر & هنسوجات نخى \\
\hline$r \wedge \varepsilon,$. & Errj & ع ع & $\varepsilon \varepsilon 0, \lambda$ & هزار متر & تخسوجات بشسهى \\
\hline $1.0 \leqslant v,$. & Arvr,. & ror.,. & $\langle\wedge| \Lambda_{\mu}$. & مزار متر & منسوجات سندى \\
\hline vrj. & $9 \varepsilon, 5$ & 1.400 & $9 \cdot 7$ & هزار تن & سمنت \\
\hline $2 r T, T$ & r9o,. & $r \circ \Lambda, \Lambda$ & rives & مليونكليوات & برق \\
\hline $9 r, r$ & $01, r$ & $\varepsilon \cdot, \varepsilon$ & $0 \wedge, 0$ & هزاز تن & آردمثندم \\
\hline$\Lambda j 0$ & $\Lambda, 7$ & 1, & $0, r$ & هزار تن & شكر \\
\hline$\varepsilon$ ر. & $\varepsilon, 1$ & $r, \Lambda$ & $r_{\mu}$. & هزاد تن & زوغن نباتى \\
\hline $1 r_{0}$. & $17 \varepsilon, \varepsilon$ & $1+7, T$ & $1 T \varepsilon, q$ & هزار تن & زَزغال سنكت \\
\hline rרזo, & rOAt,. & $r \cdot r q,$. & 1711, & مليونمترمكعب & كاز \\
\hline
\end{tabular}

منبع : وزارت معادن وصنايع · 


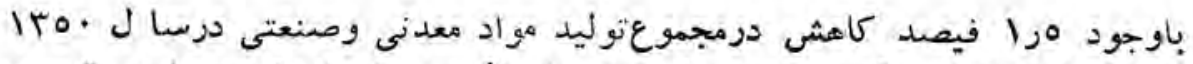

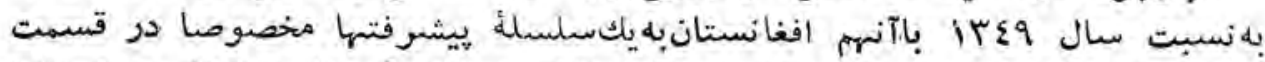

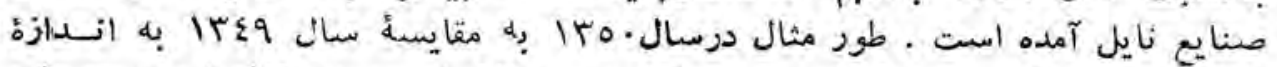

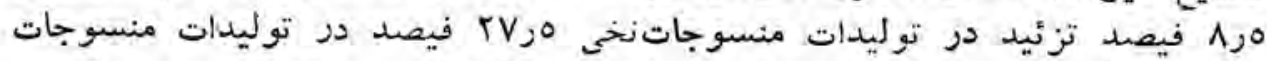

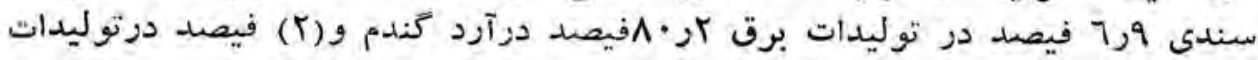

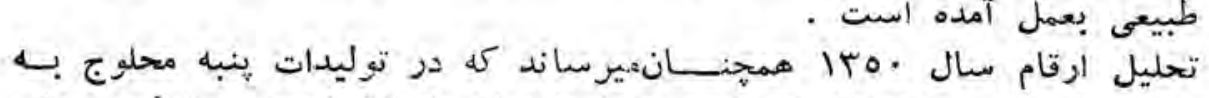

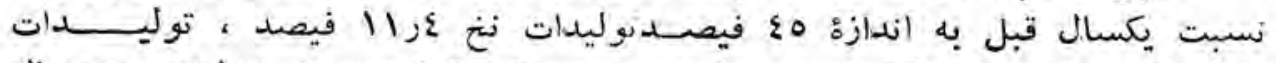

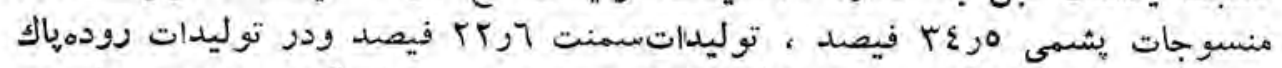

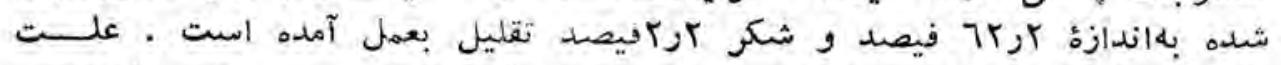

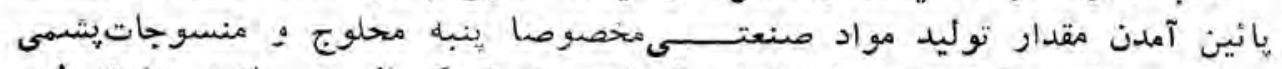

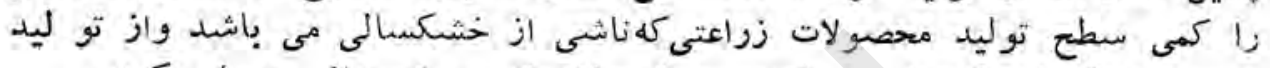

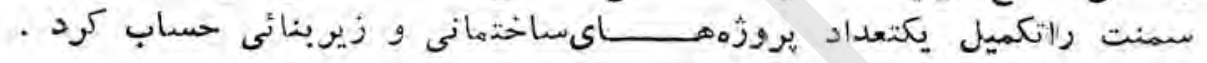

\section{(r) جدول}

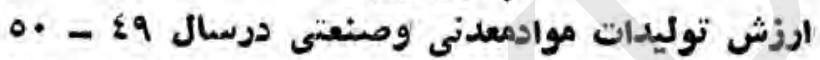

ارقام بهبليون افغاني

\begin{tabular}{|c|c|c|c|c|}
\hline فيصدى & فيصدى & 150. & $1+\varepsilon 9$ & $z$ \\
\hline $1 \cdots$ & $1 \cdots$ & हा & $\varepsilon, \pi$ & مجموع معادن وصنايع \\
\hline$V \varepsilon, \varepsilon$ & vi,. & rir & $r, \varepsilon$ & صنايع \\
\hline rost & זा. & i ا & - s9 & معادن \\
\hline
\end{tabular}

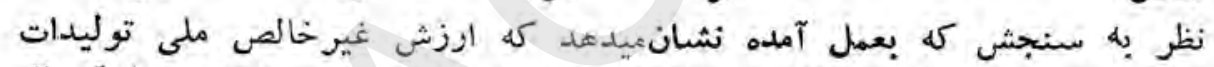

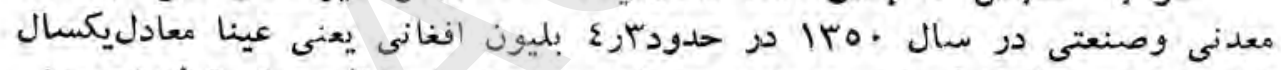

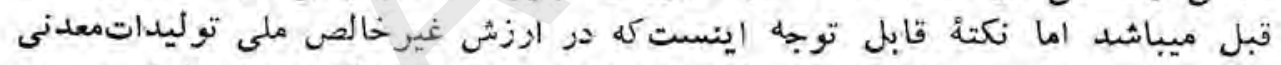

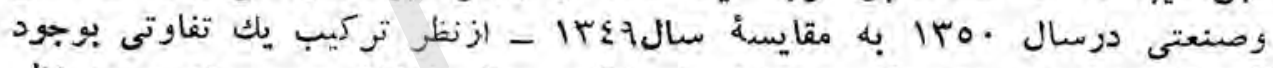

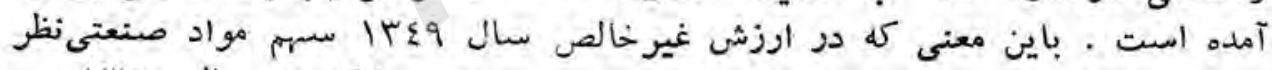

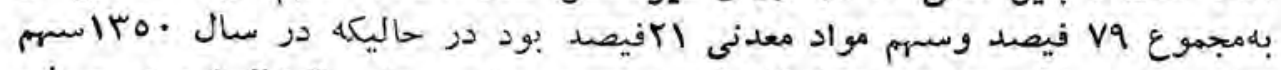

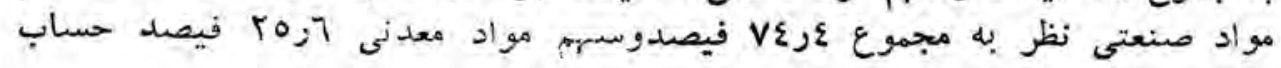

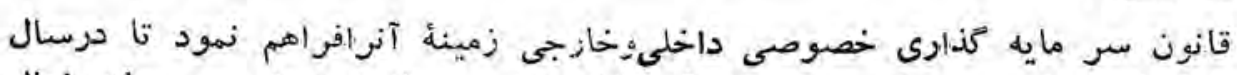
.

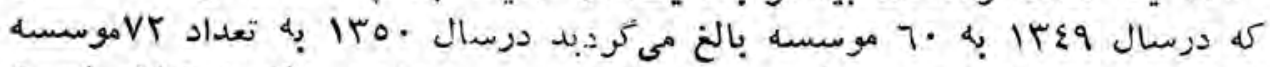

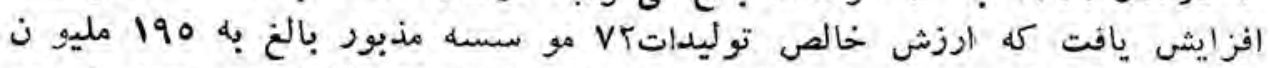

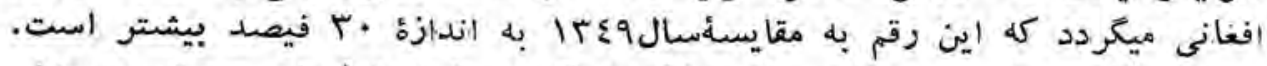

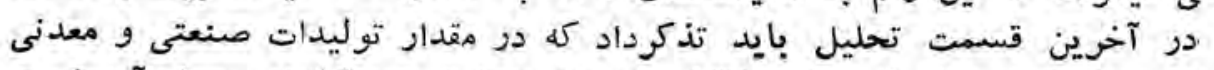

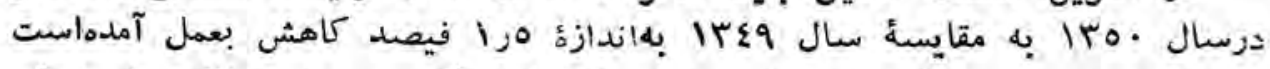

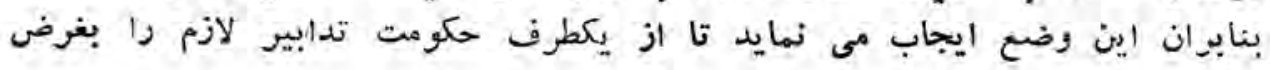




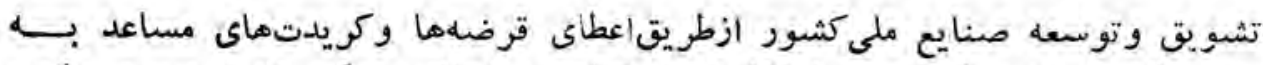

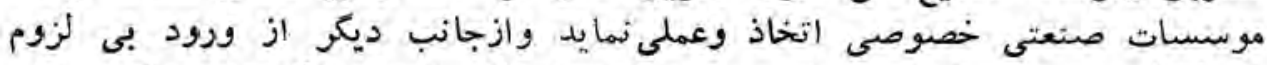

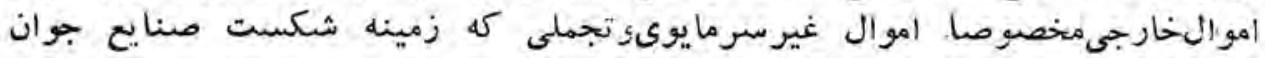

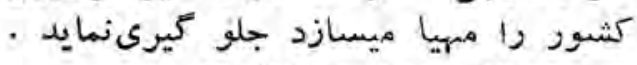

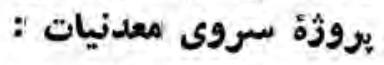

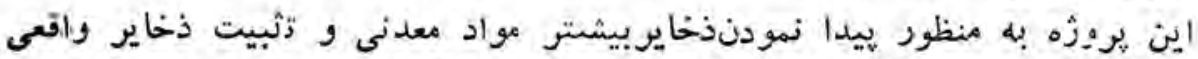

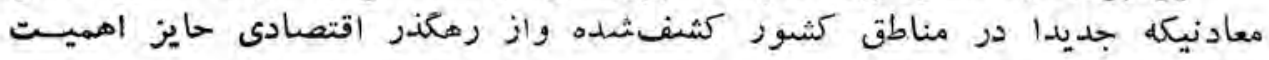

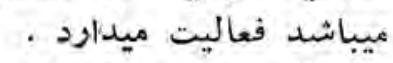

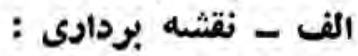

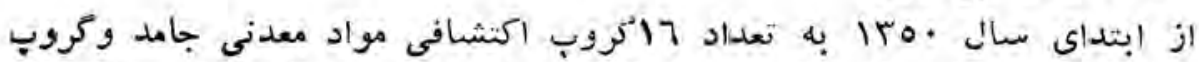

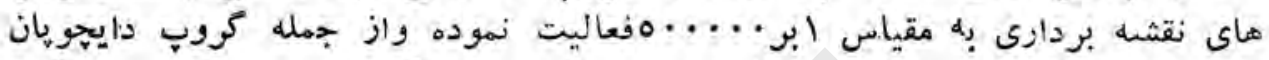

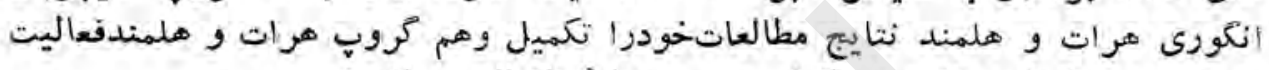

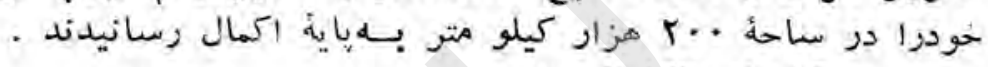

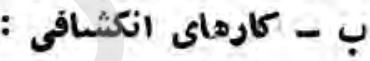

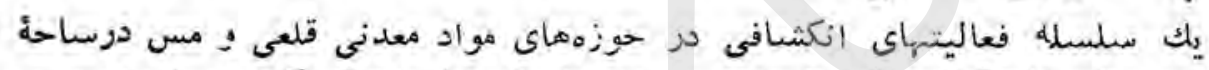

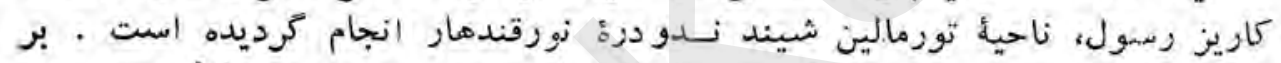

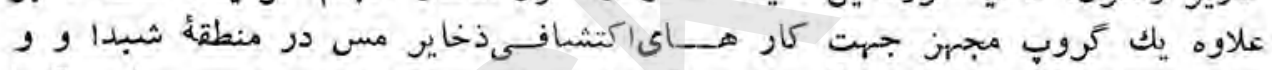

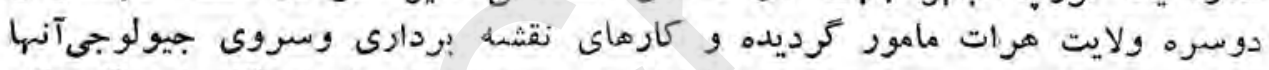

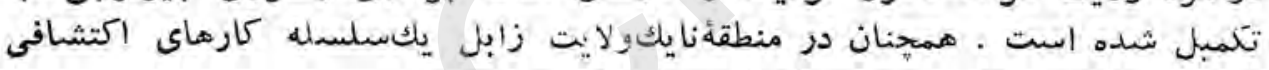

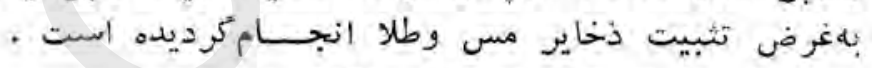

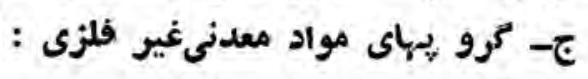

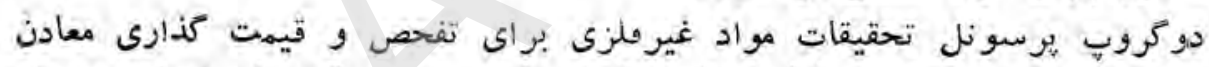

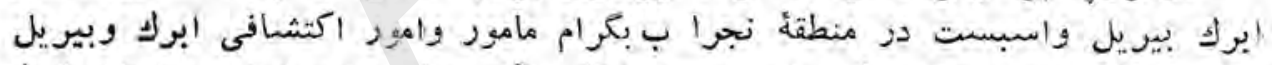

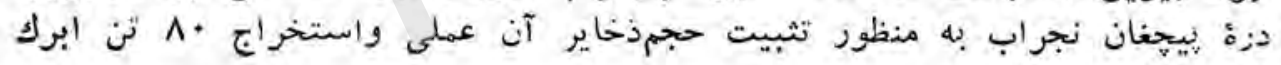

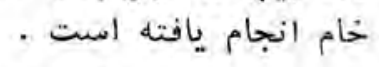

\section{د ـ مروي طلاى رسوبى نورابه :}

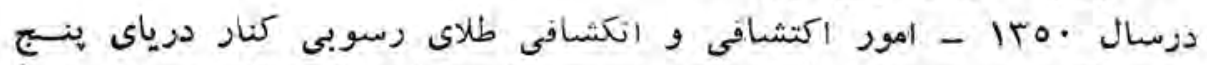

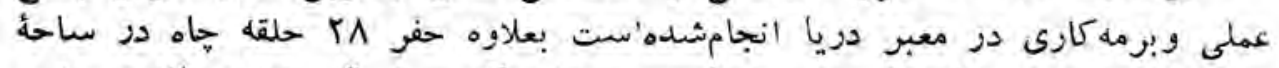

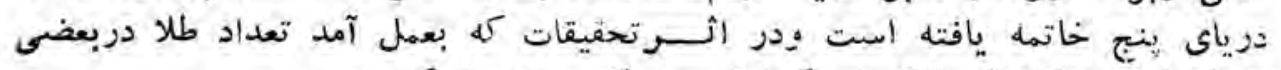

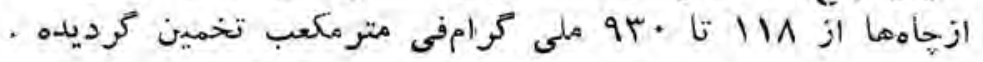

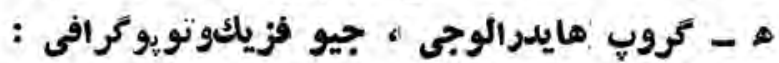

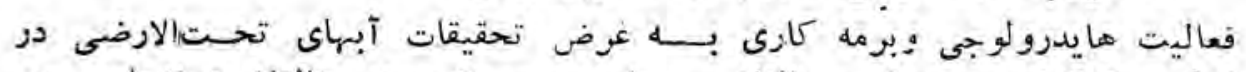

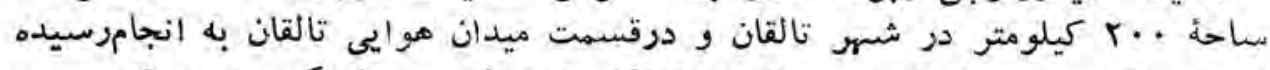

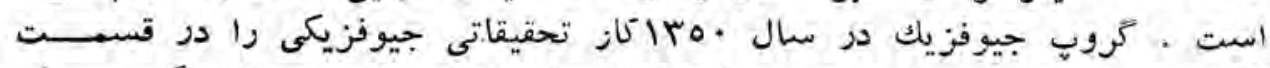

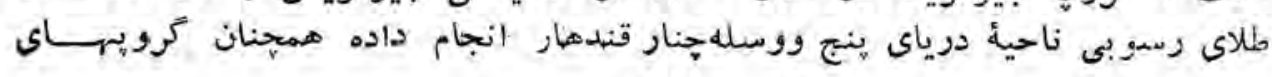




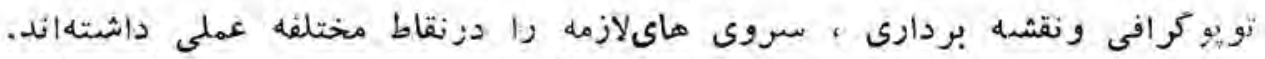

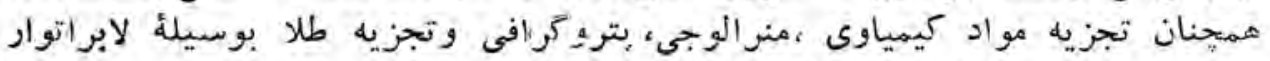

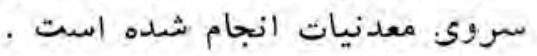

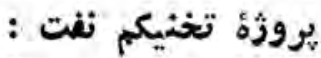

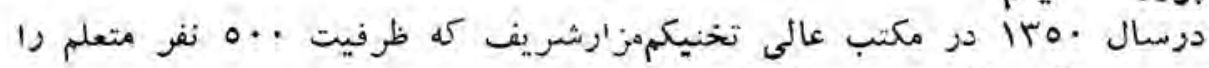

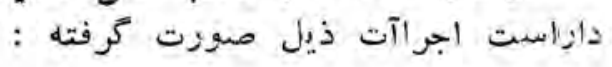

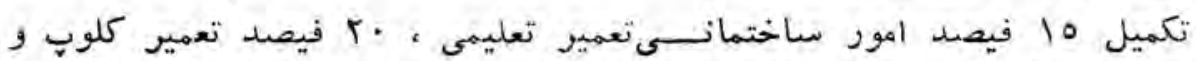

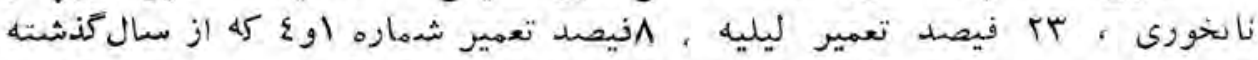

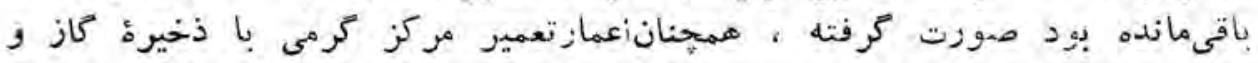

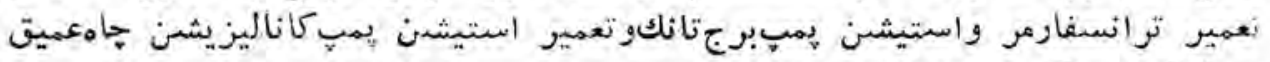

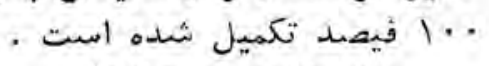

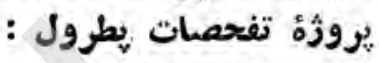

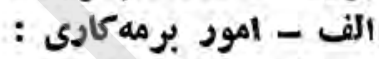

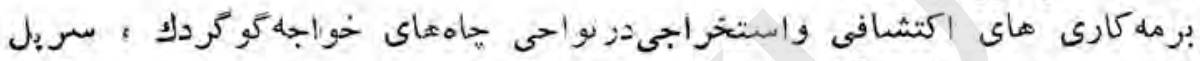

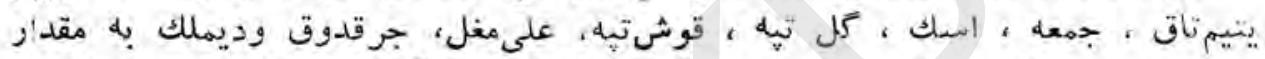

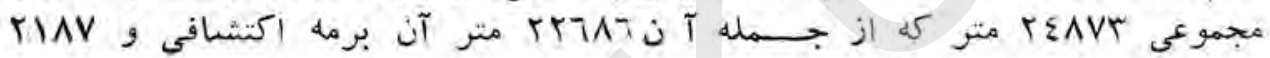

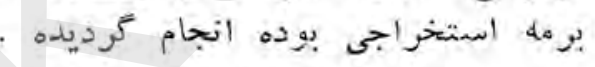

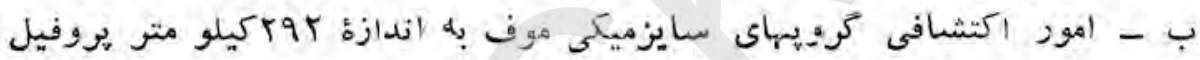

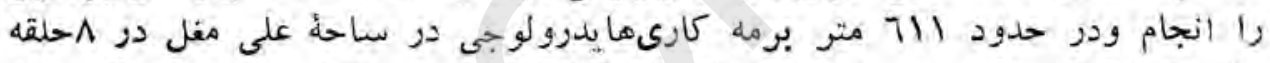

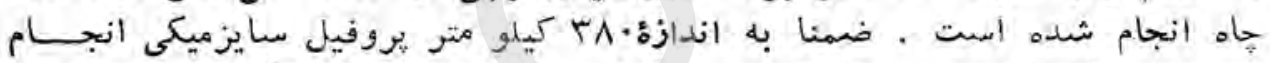

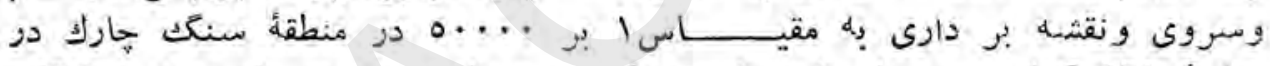

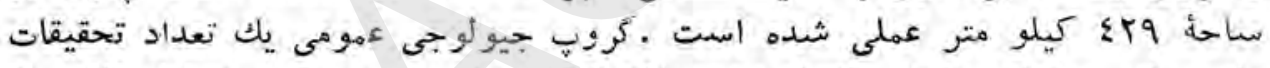

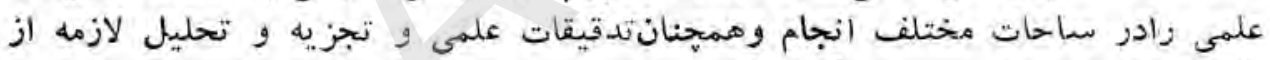

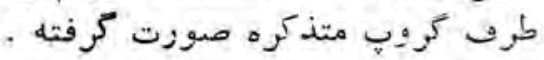

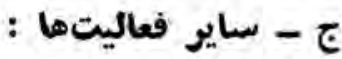

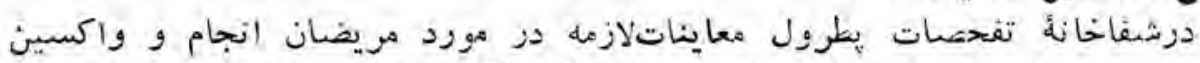

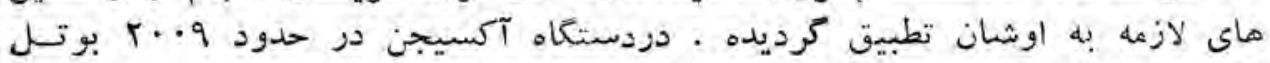

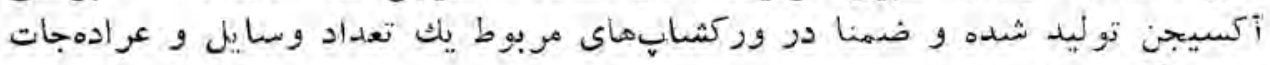

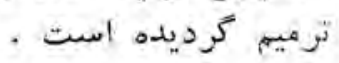

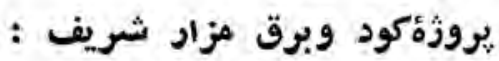

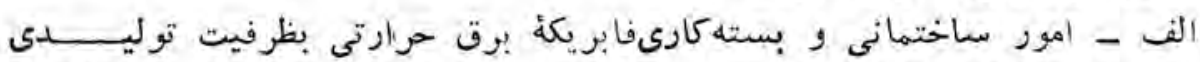

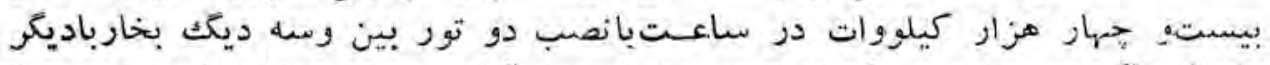

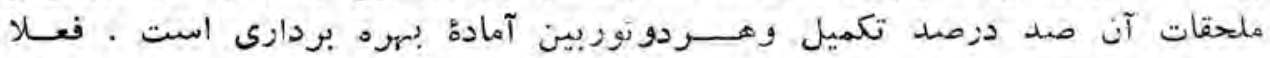

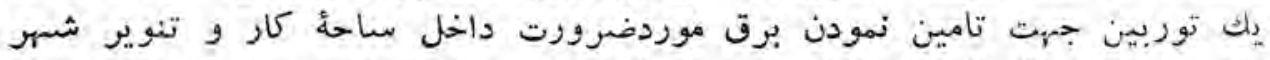

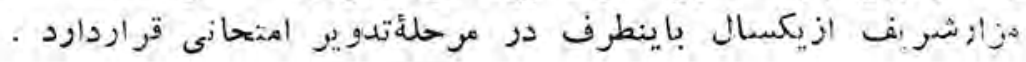


كارساختمانى توزبين سوم به ظرفيت توليدى +...

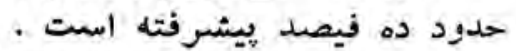

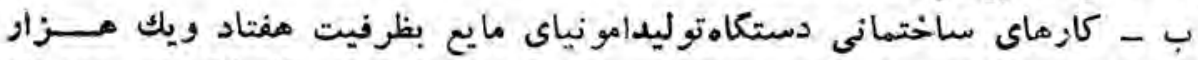

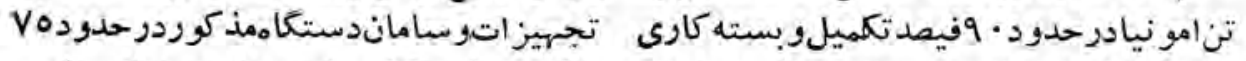

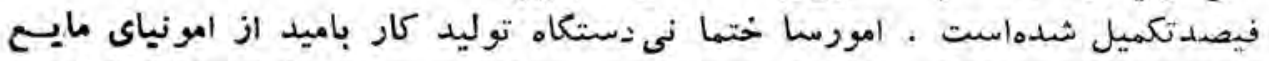

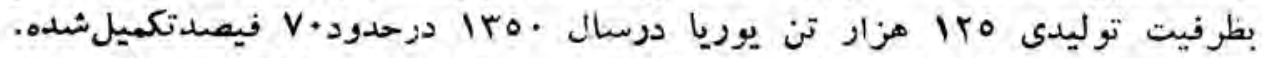

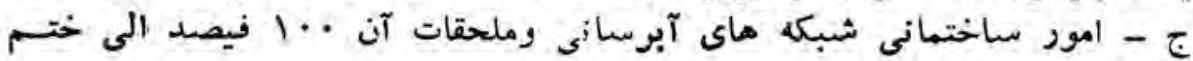

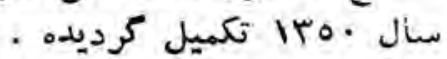

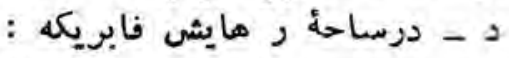

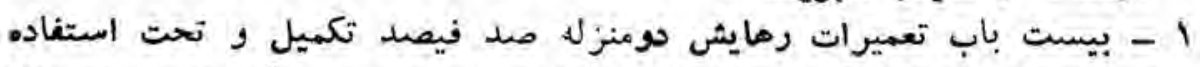

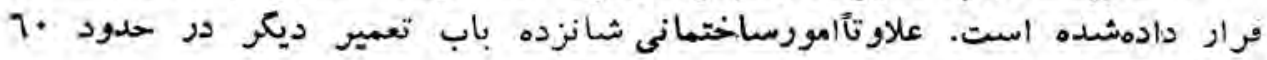

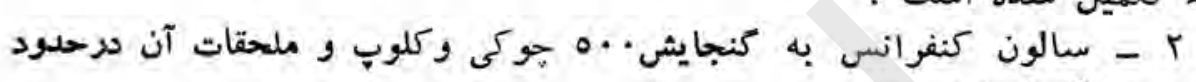
Q فيعد تكميل شده

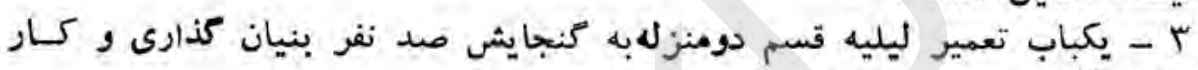

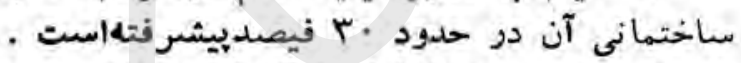

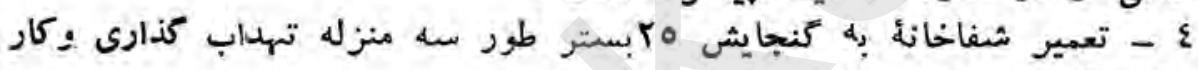

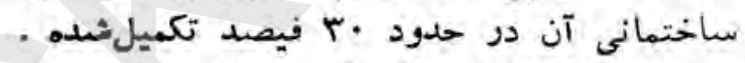

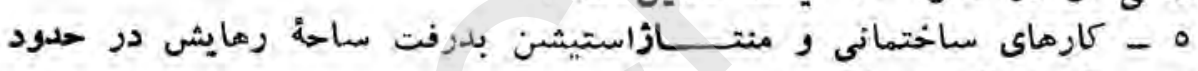

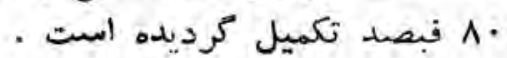

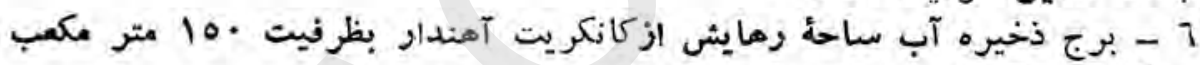

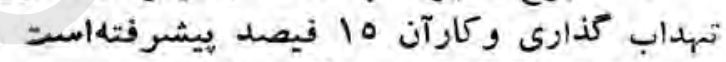

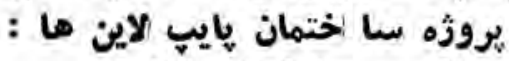

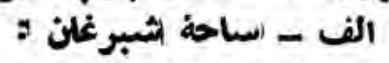

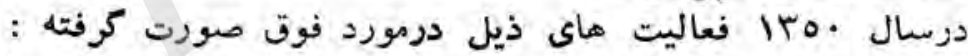

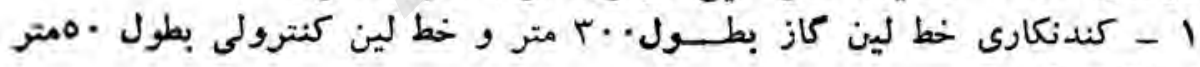
وعمق 70 منانتى كندئ

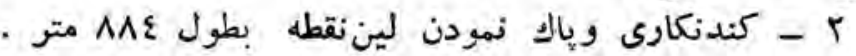

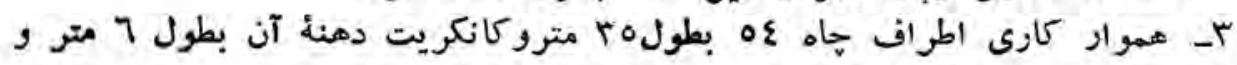

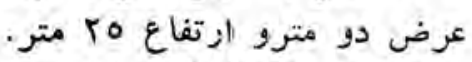

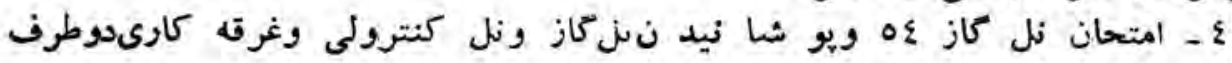

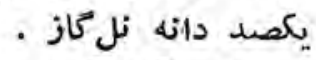

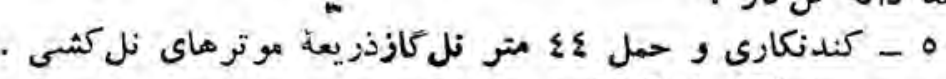

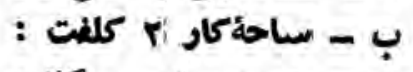

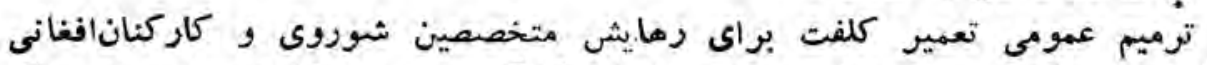

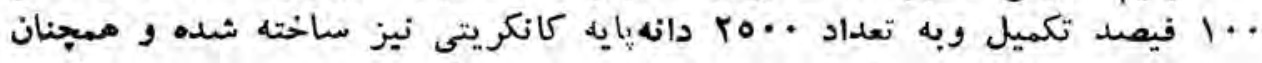

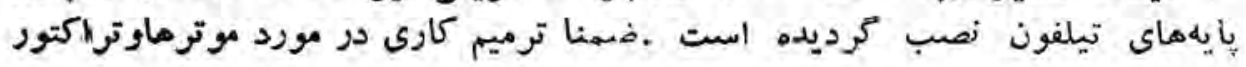


هاى مربوط يروزه وبلستر كارى هـ سفيدكازى ، جغل اندازى ، كانكريت ويزى و

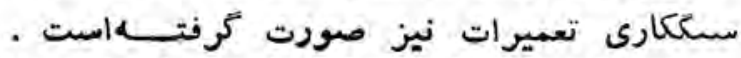

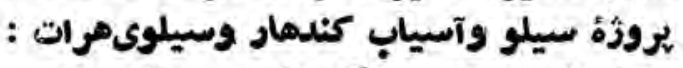

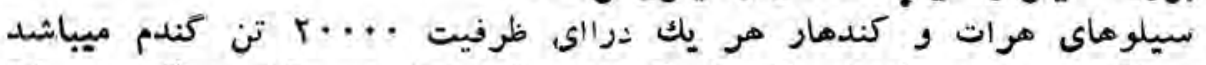

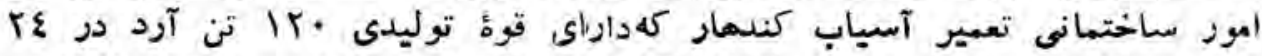

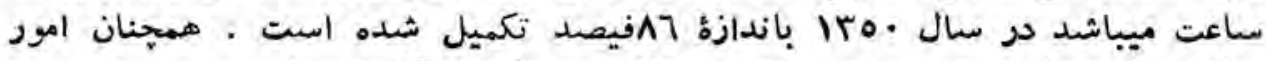

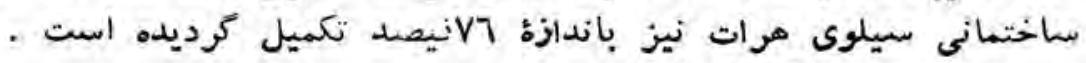

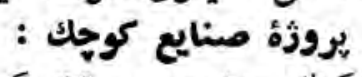

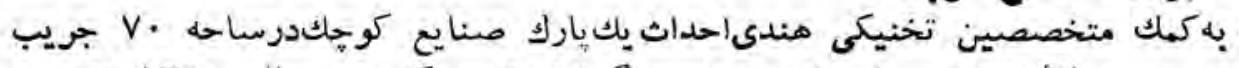

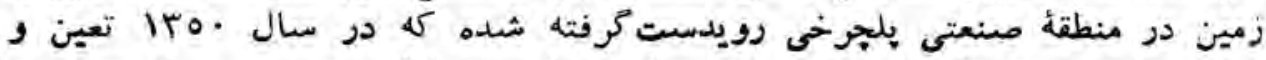

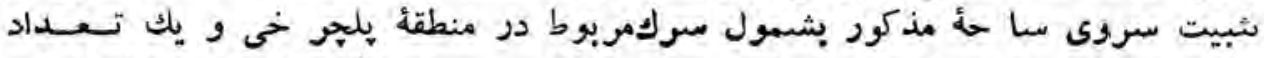

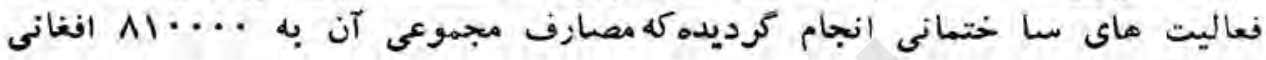

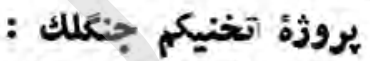

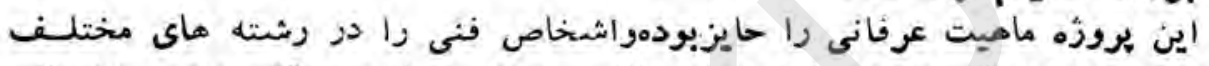

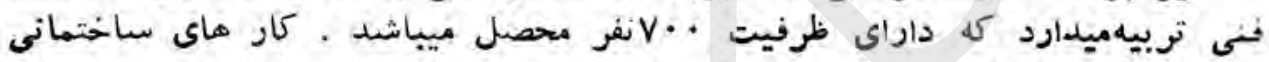

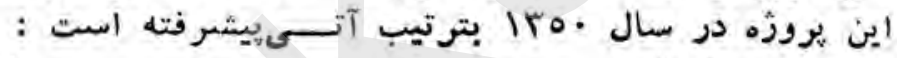

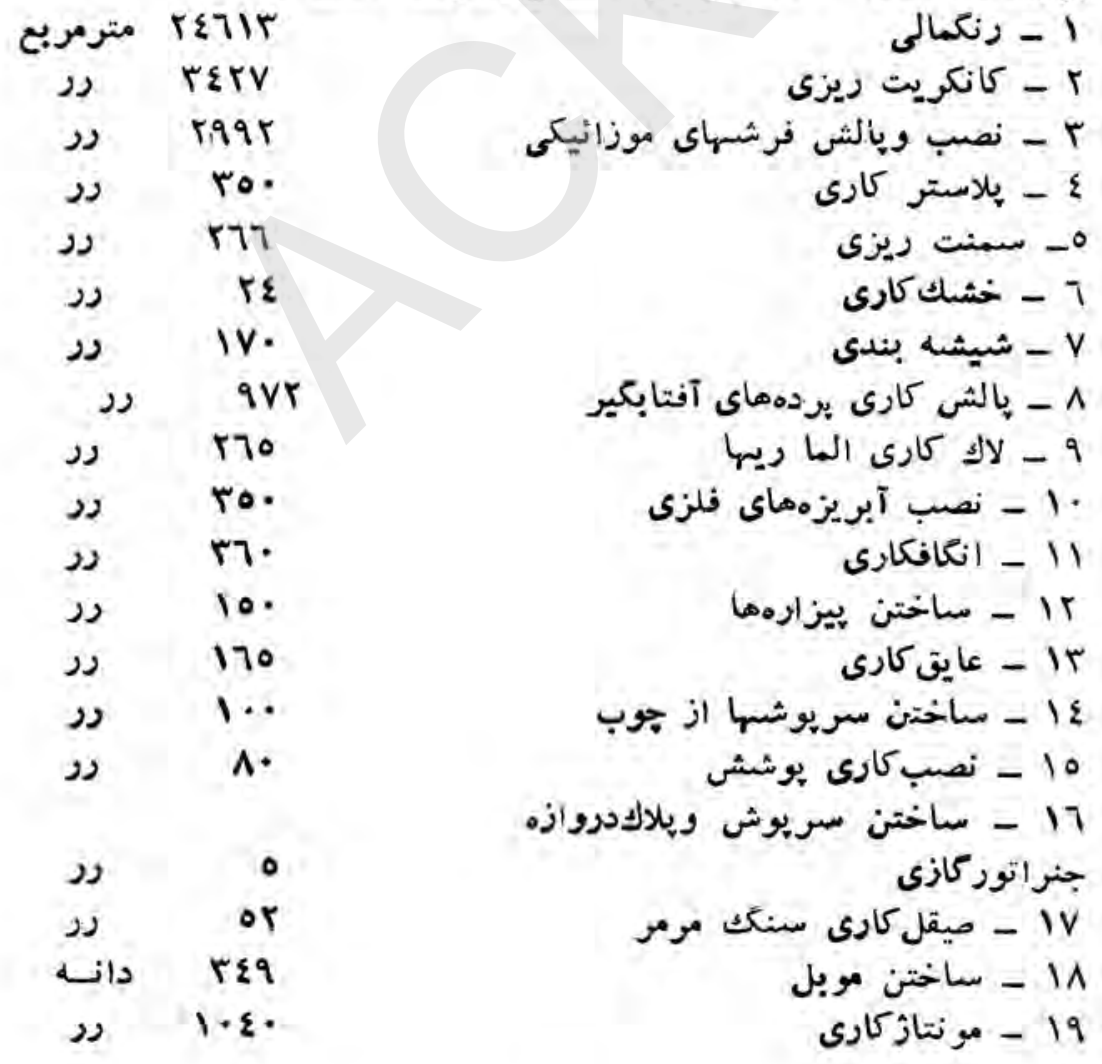




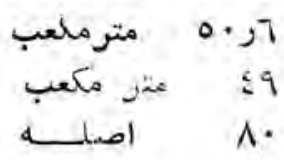

19 19

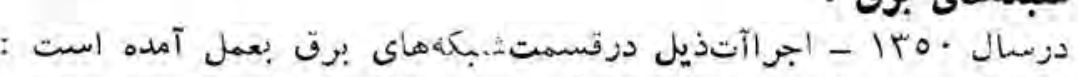

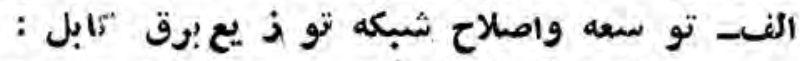

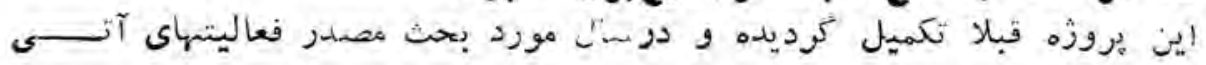

$$
\begin{aligned}
& \text { - }
\end{aligned}
$$

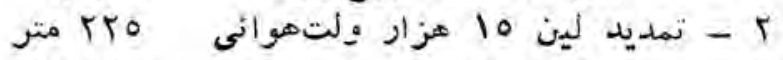

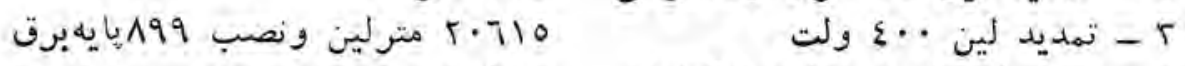

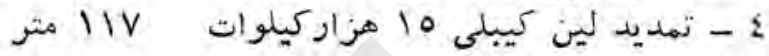

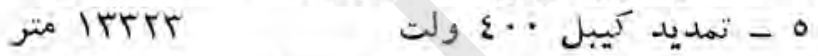

$$
\begin{aligned}
& 1
\end{aligned}
$$

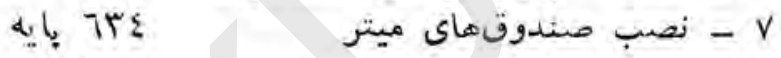

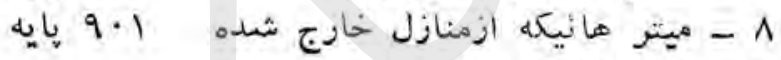

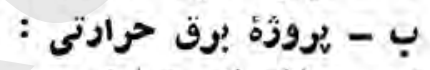

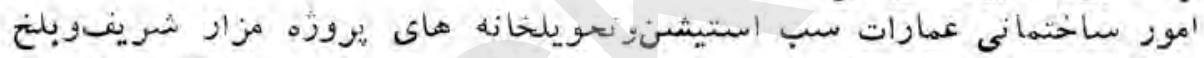

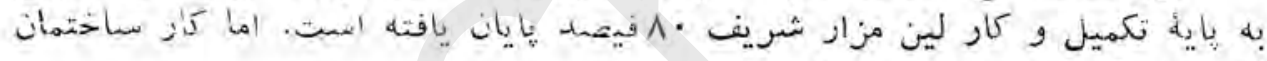

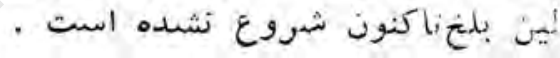

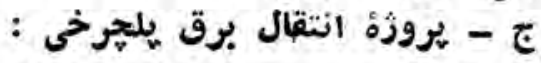

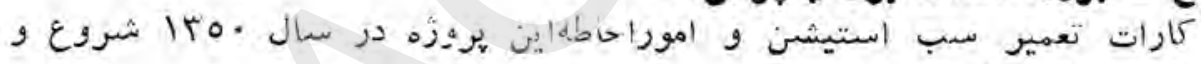

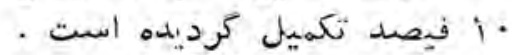

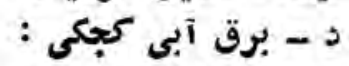

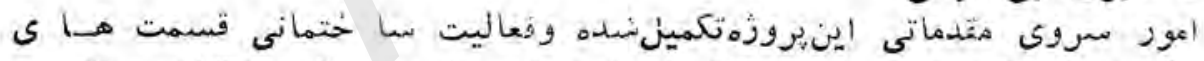

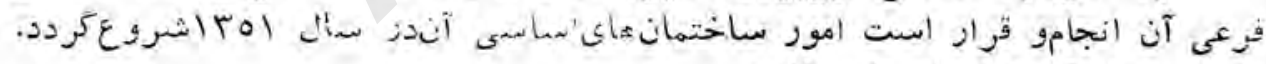

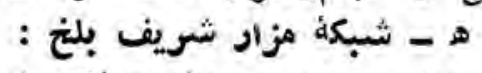

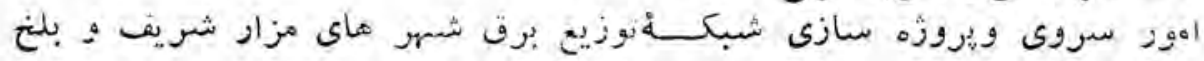

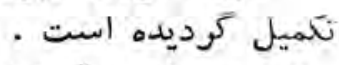

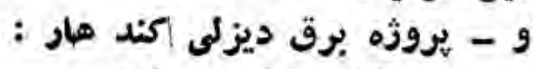

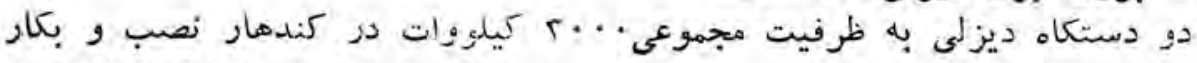

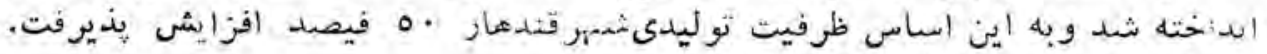

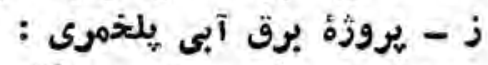

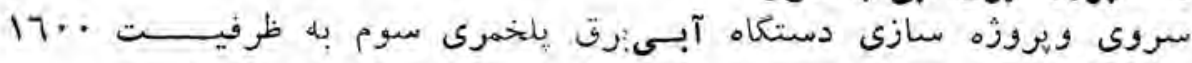

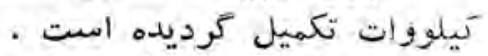

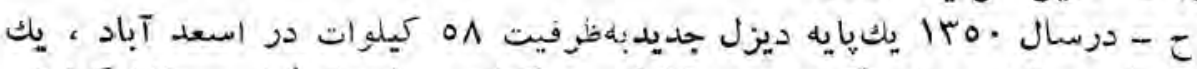

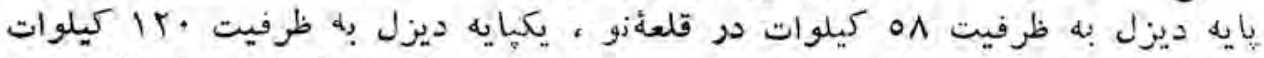

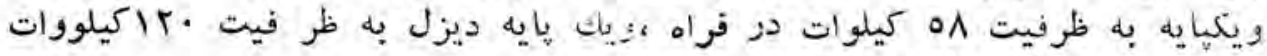
يز نالقان نصب كرديده است . 


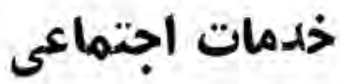

\section{معارف}

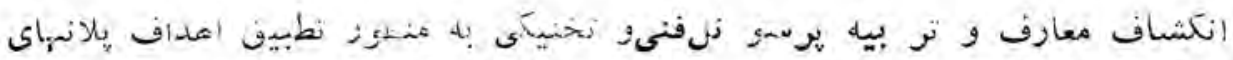

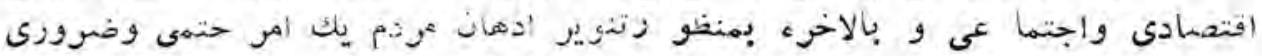

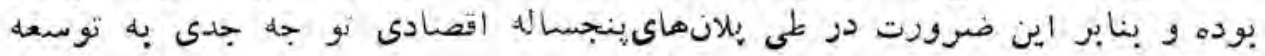

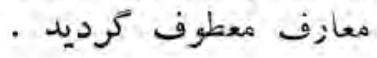

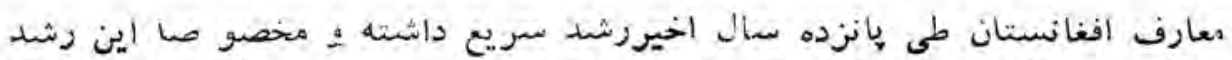
درسال هأى vلان دوم و يلان

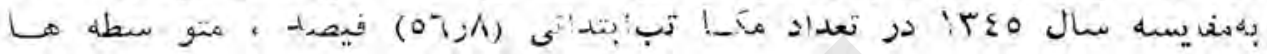

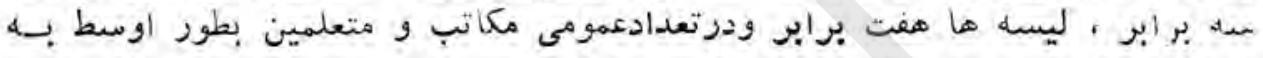

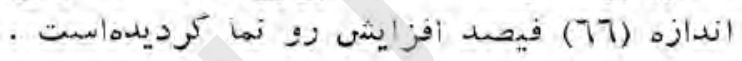

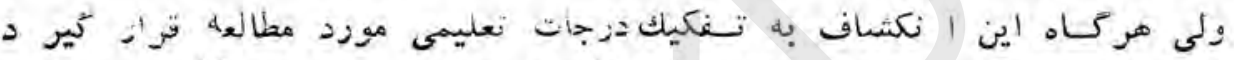

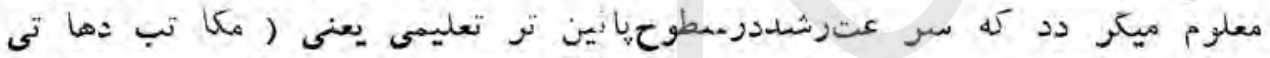

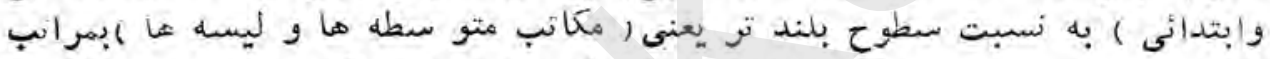

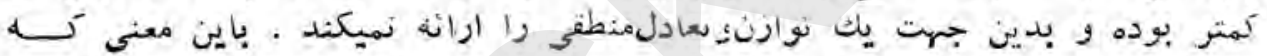

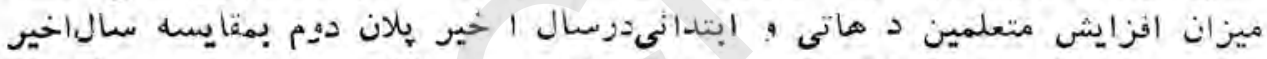

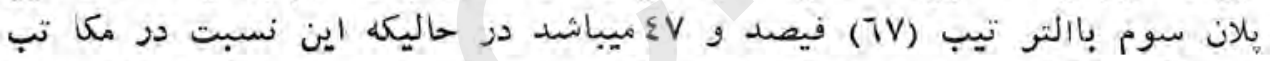

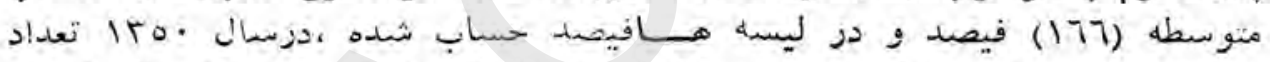

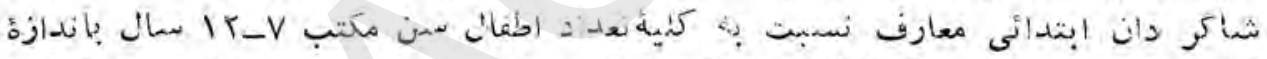

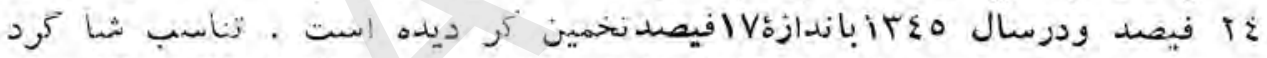

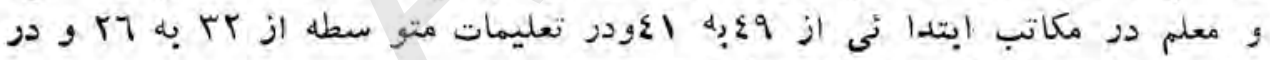

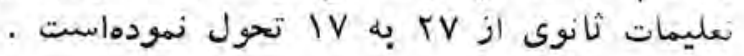

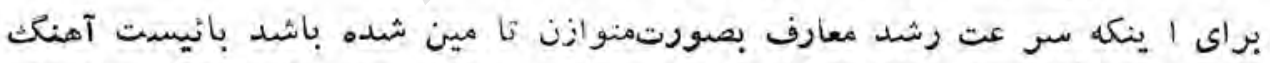

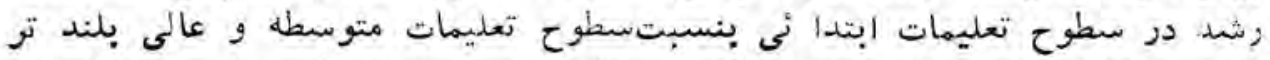

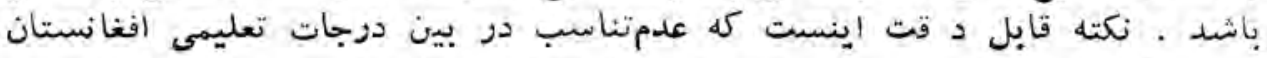

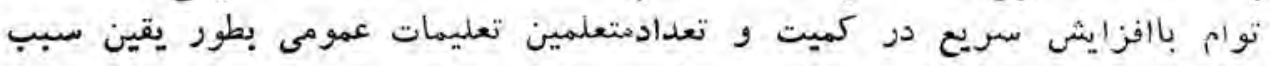

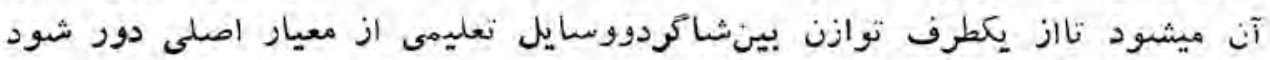

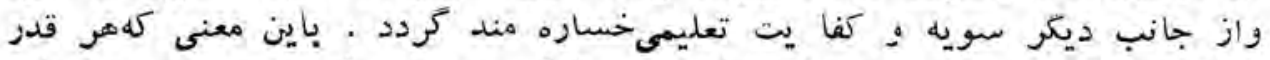

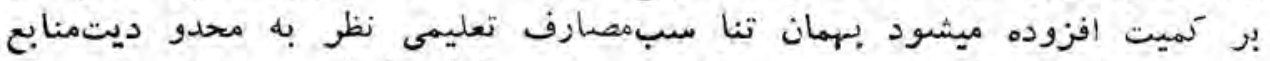

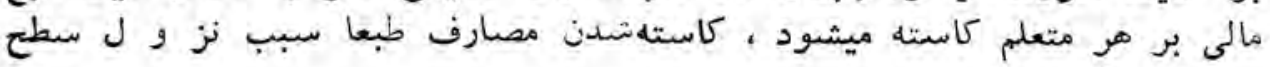
تعليهى ميكر دو مهر منعلم 
علازه بر اين و ضع عدم توازن در بـينشقوق ا ختصا صى تعليماتعالى كشو د

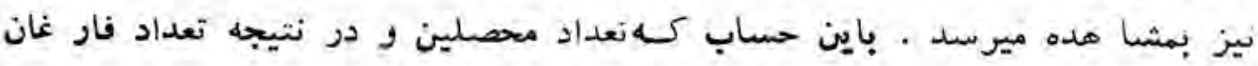
رشته علوم اجتماعى در هو هنتون كا بل وساير هوسسات تعليمات عالى به مقايسه

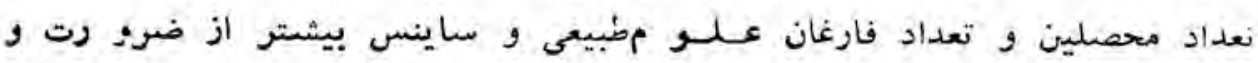
نياز هنديهاى ميباشد. أين وضعمخصوصادزسالهاى اخير سبب شده تاتعدادفارغان علوم اجتماعى بيثتر از تقا ضا و تعدادفارغان علوم طبيعى و ساينس كمتر 1 ز زياز هنديهاى واقعى سكتور هاى اقتصادىباشيد . هر كاه تدابير اساسيى در قسمت

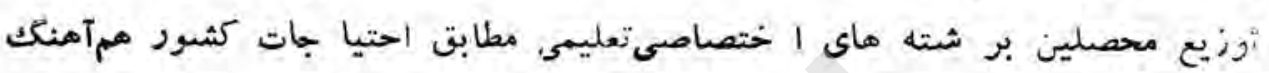

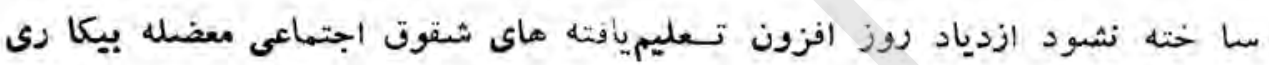
تعليم يافته ها را از يكطرف تشديدخواهدنمود واز جانب د يكر خلاىكه بعلت كمبود فارغان علوم طبيعى و ساينس بو جي دأمده از طريق استخدام بيشتر متخصصين

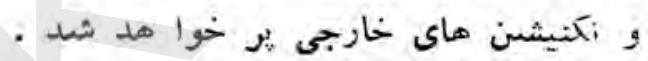

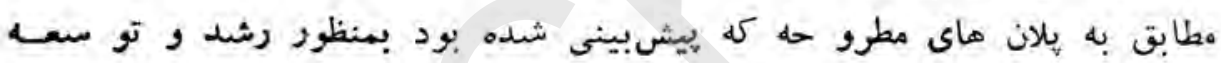

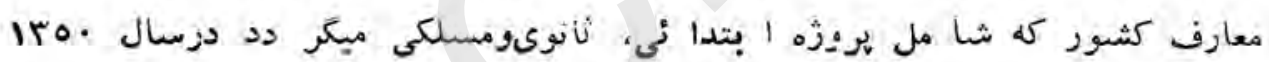

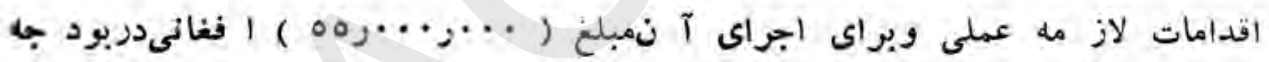

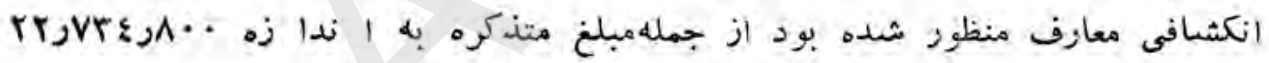

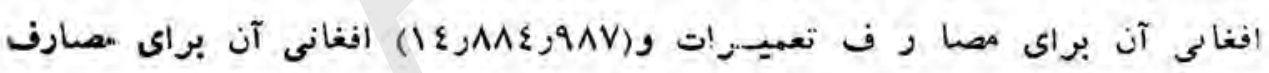

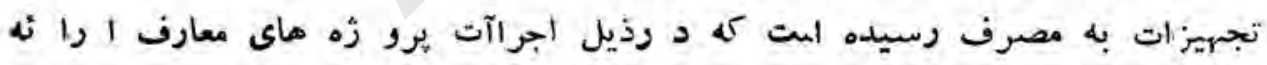


PERTA

(1) جدول

تعداد مكاتب- بتعلمين- بعلمين- فارغان وفيصدى جدول

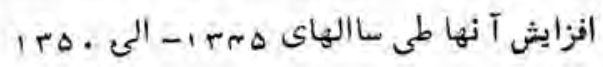

ارقاه به هزار فر

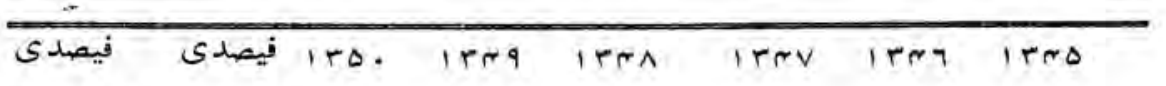

افزايشسال افز ايشسال فيهدى

.

تعليعات ابتدائى:

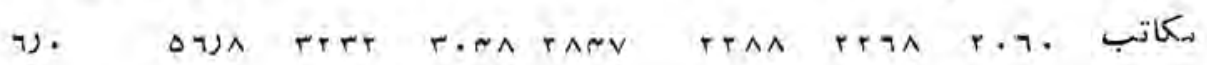

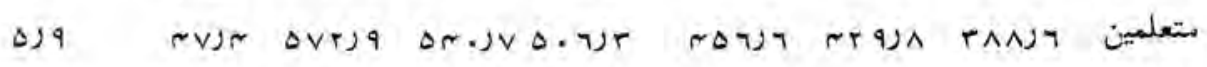

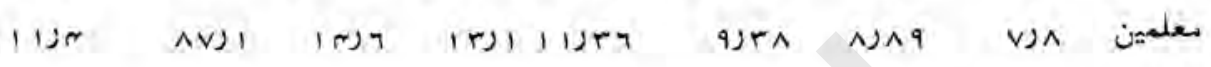

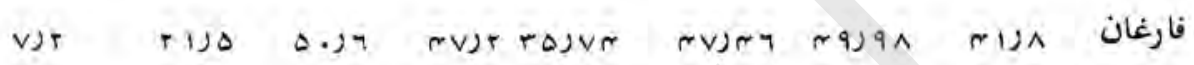

تعليمات ستوسطه:

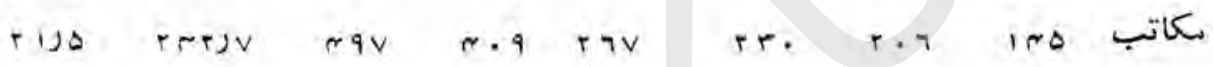

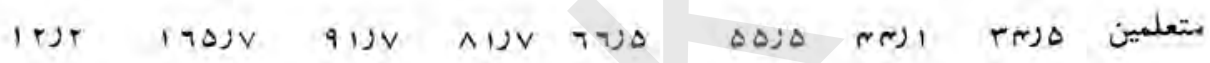

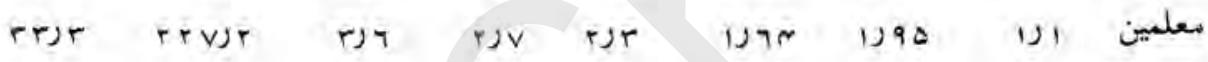

فارغان

ليسه ها:

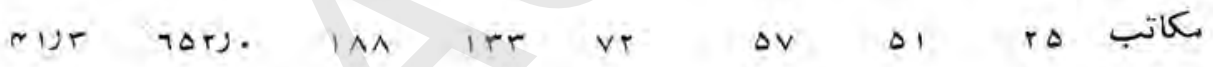

rojv ronje roje ruj. 19ja im. 1.jpo vjv

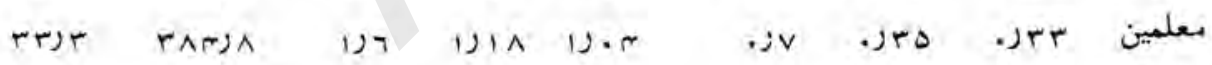

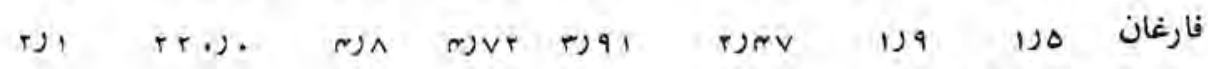

تعليمات سملكى:

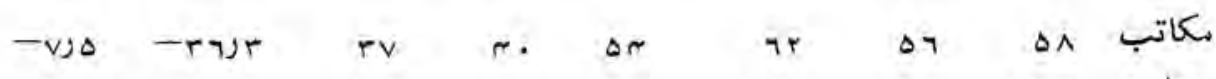

ת נ.

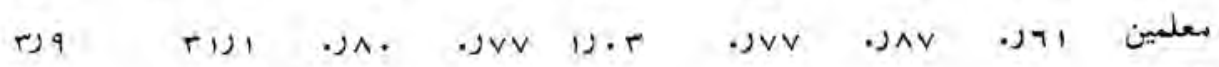

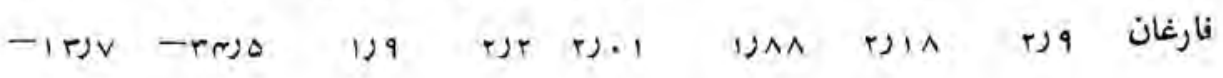




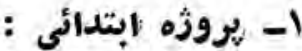

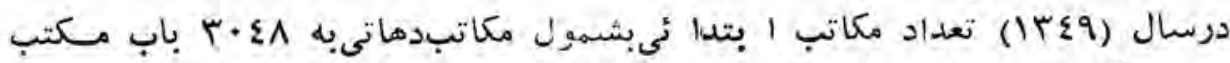

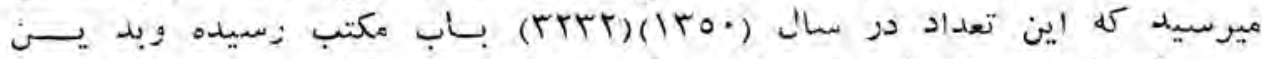

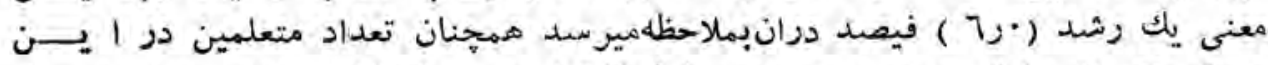

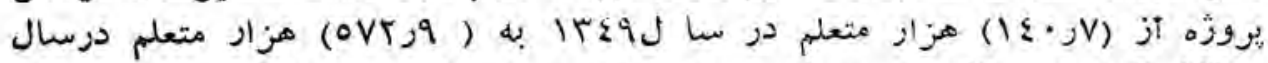

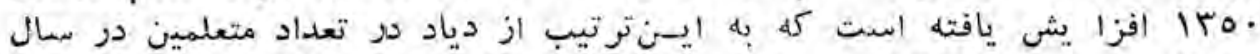

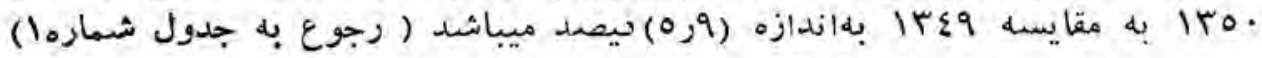

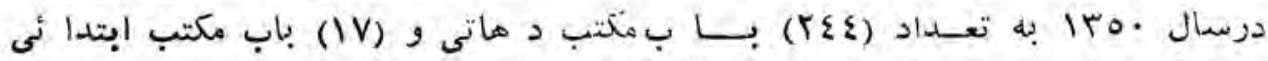

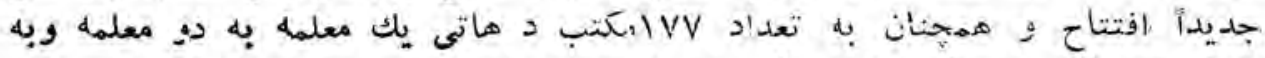

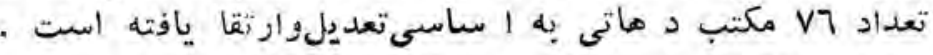

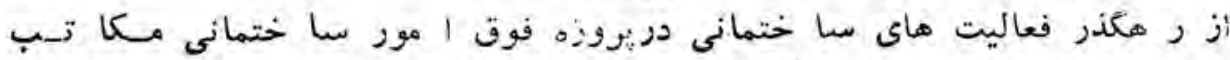

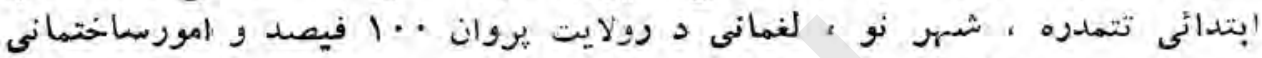

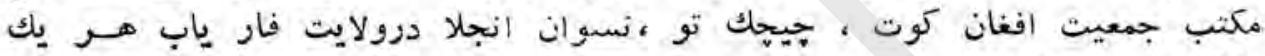

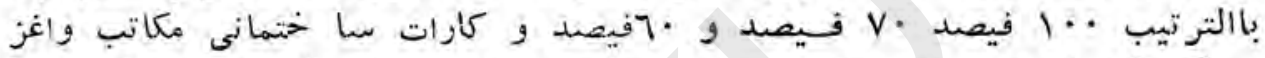

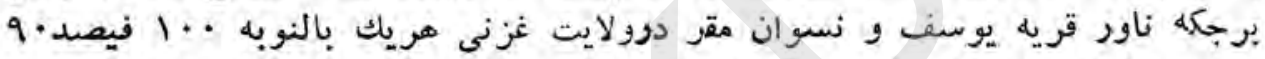

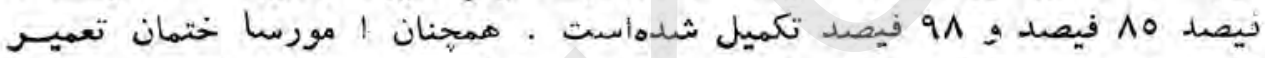

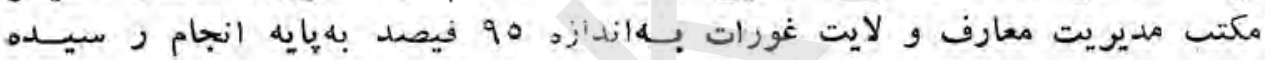

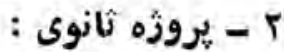

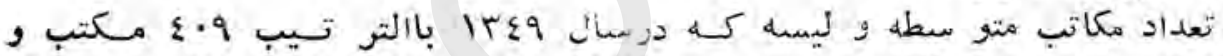

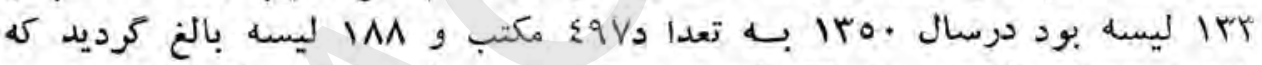

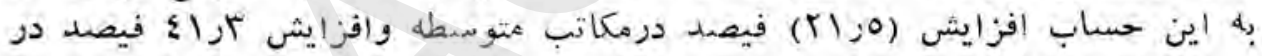

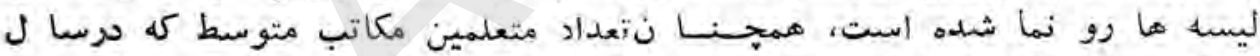

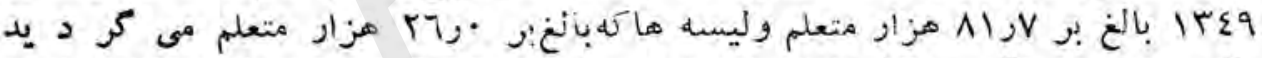

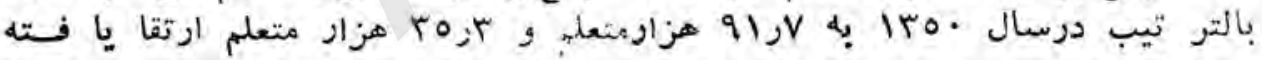

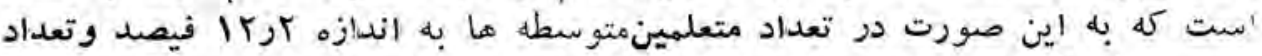

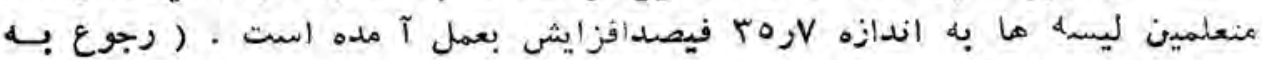

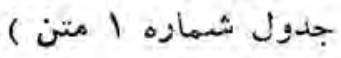

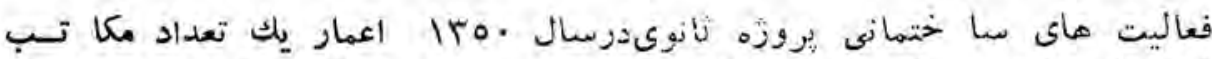

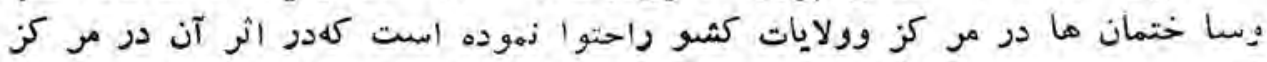

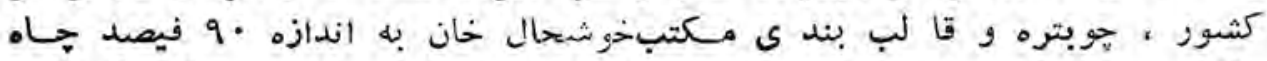

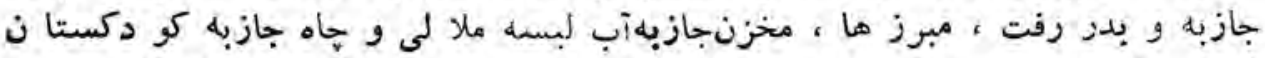

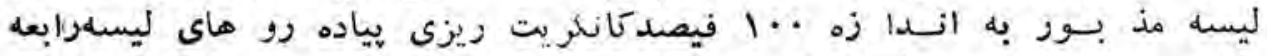

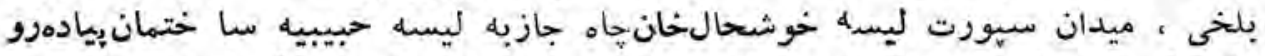

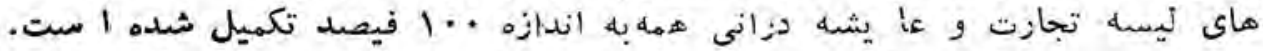

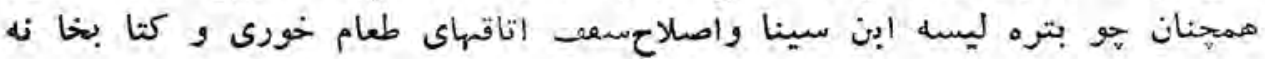


'يسيه مذ بور به اندازه •و فيصد مكلرواعمار إدتوريم ليسه زر غونه به اندازه

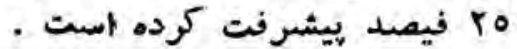

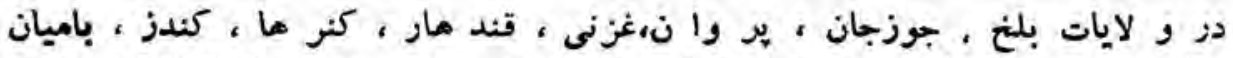

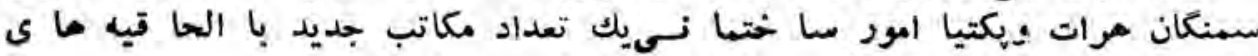

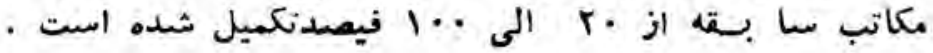

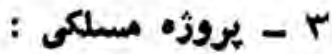

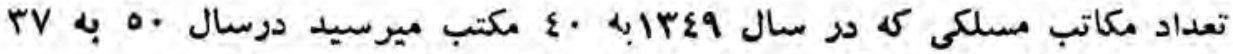

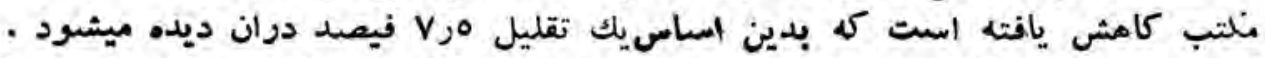

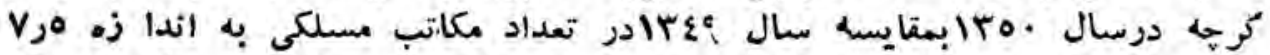

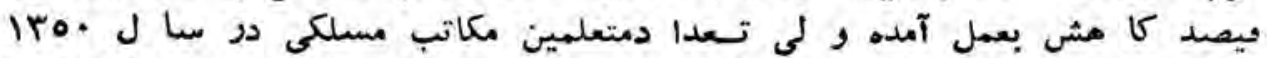

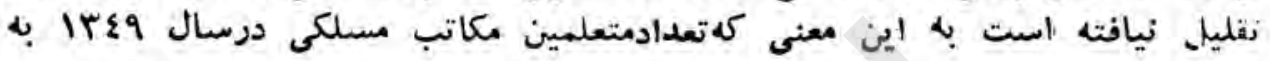

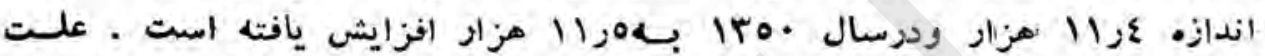

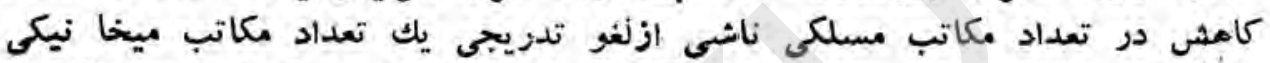

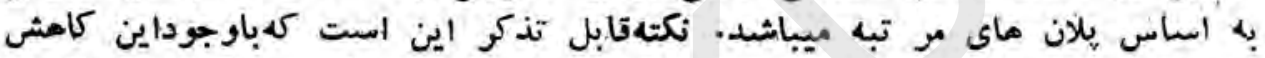

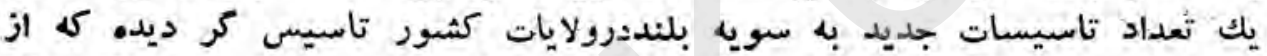

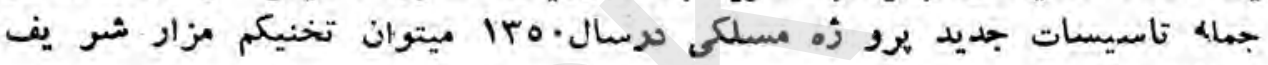

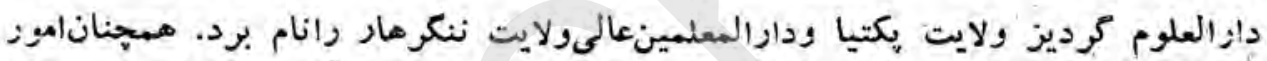

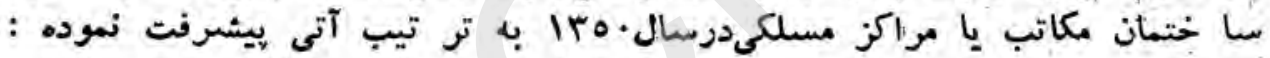

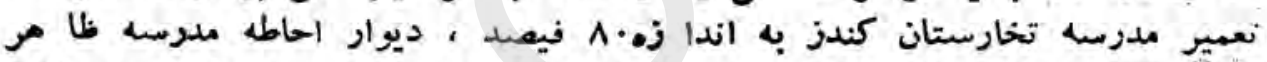

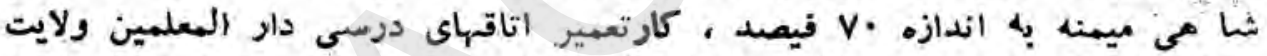

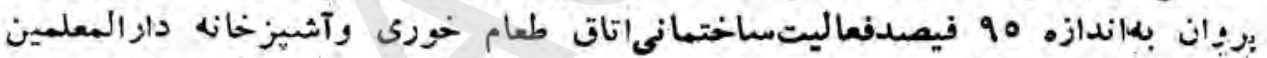

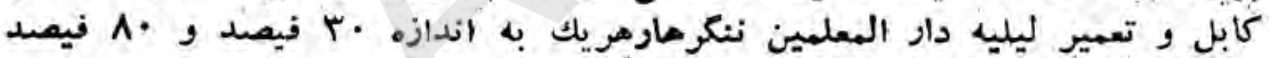

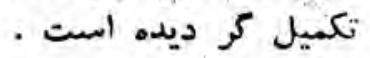

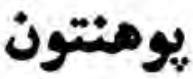

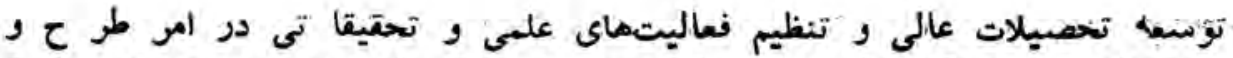

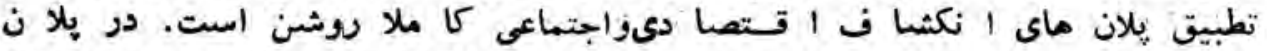

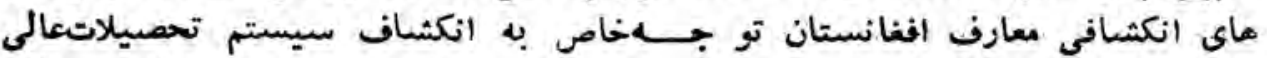

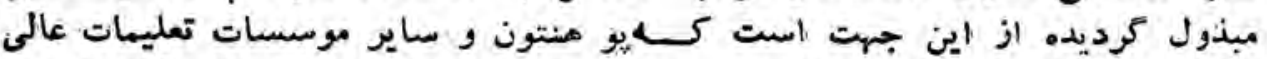

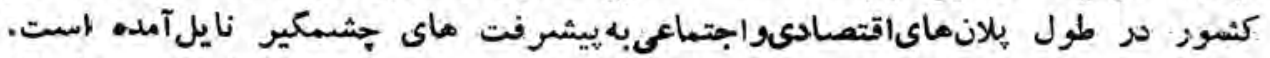

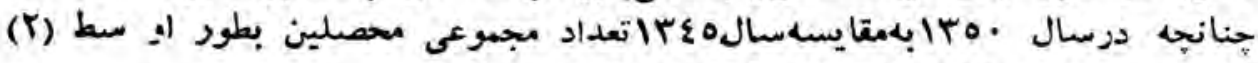

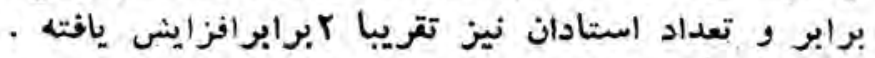

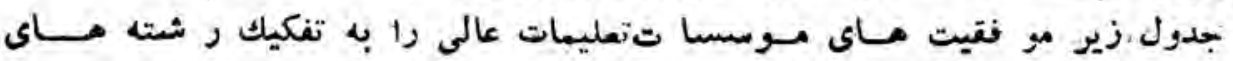

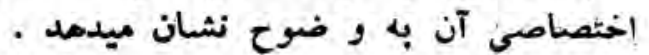




\section{تعداد محصلين دد وثته هاى مختلف وفيصدى افزايش معصلين و استا دا ن ان}

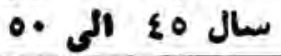

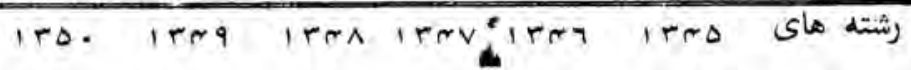

فيصدى افزايث فيصدى فيزايش

j

سالى. هنظر

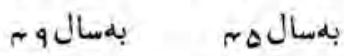

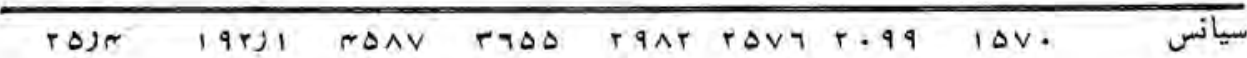

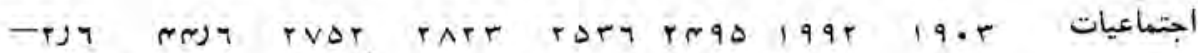

دارلمعلمين

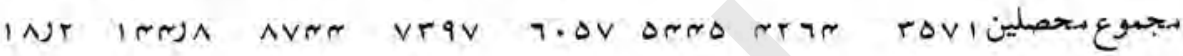

1) ^1)

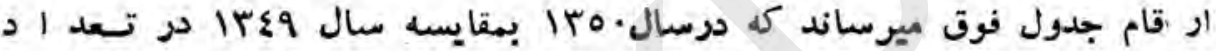

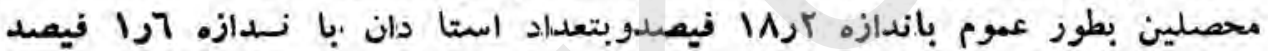

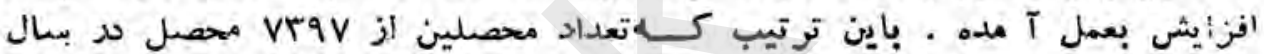
9

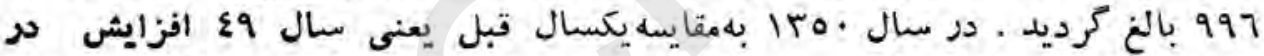

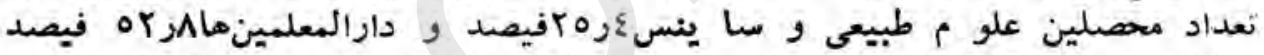

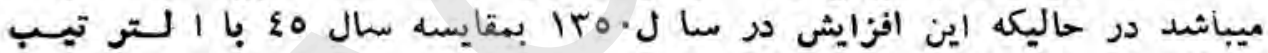

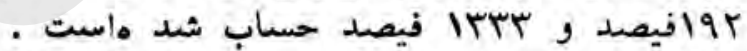

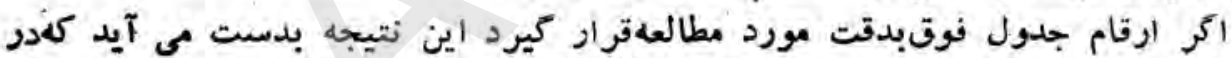

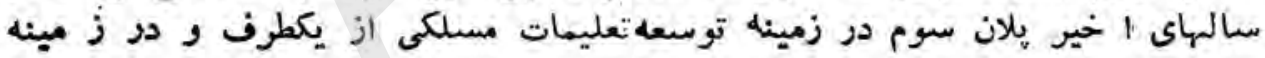
سرعت رشد محصلين علـو م طبيعى وسيانس بهنسبت مر عت رشل محصلين

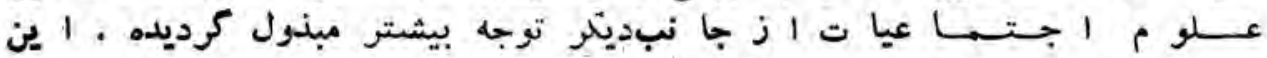

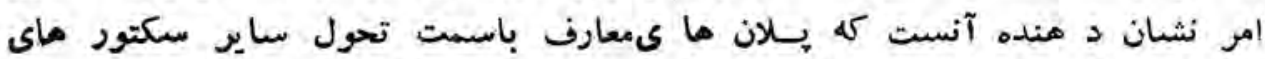

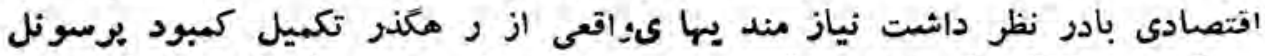

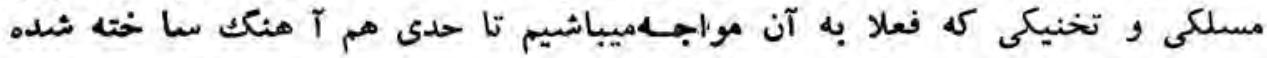
توقع ميرود كه در سالهاى آينده اقدا ماتوزارتمعارف بنابرمفكورهتعويضمتيفين و تكنيشن ماى خارجى توسط ير سو نلاففانى از يكطرف متوجه توزيع محصلين دز رثشته هاى اختصاصى واز سوى ديكرمتو جه بهلند بردن كيفيت تعليم درسطوح

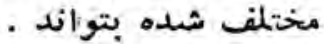
الما نكته قابل تو جه اينست كه معارفافغانستان در ز مينه اين افزايش بائ يك

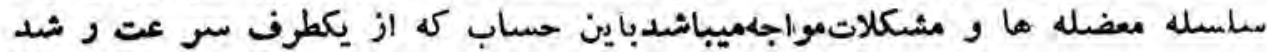
در تعليمات عالى بمقايسه تعليماتعمو ميوابتدائى سريعتر صورت يذيو فته و اين اين 


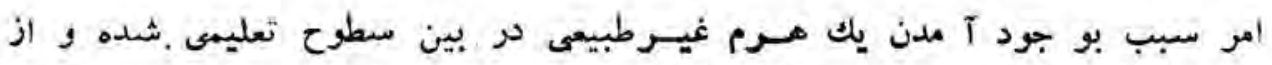

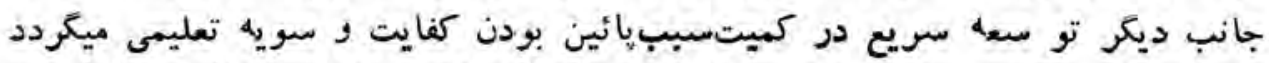

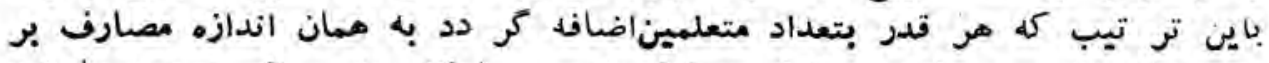

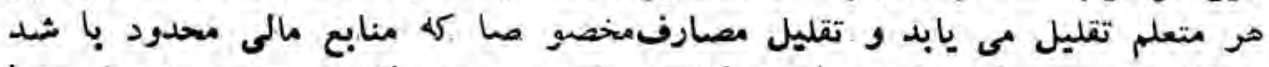

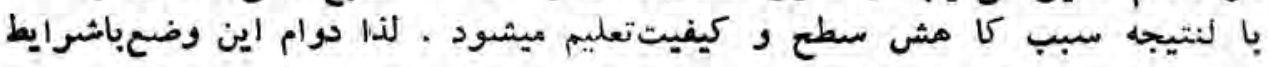

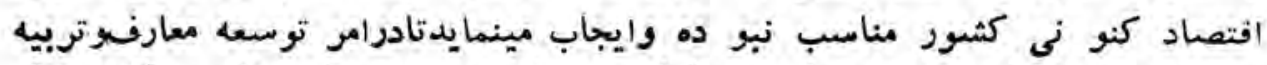

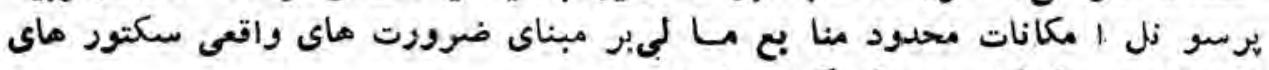

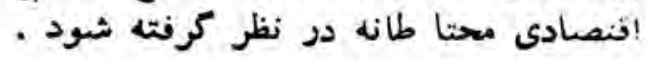

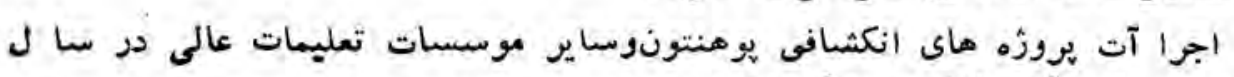

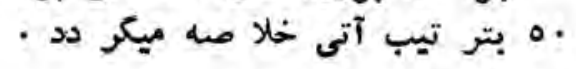

\section{ا- إيروزه التاقهاى ددسى :}

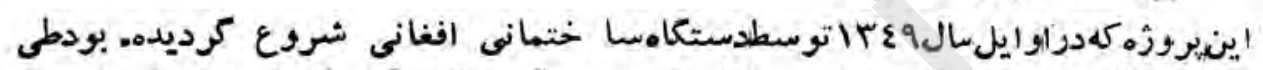

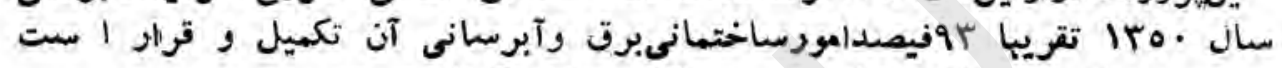

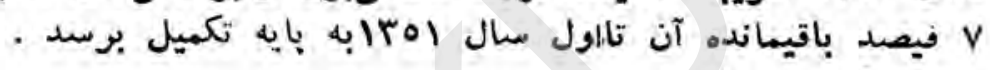

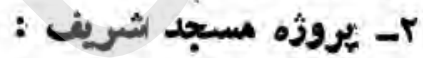

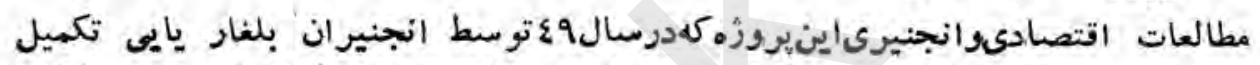

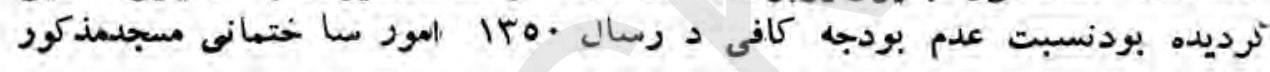

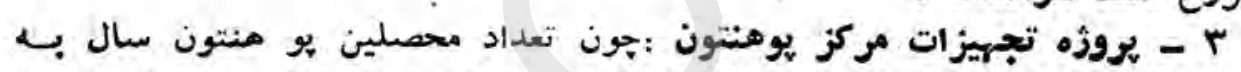

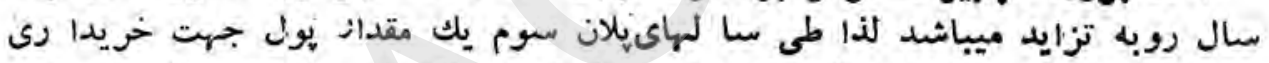

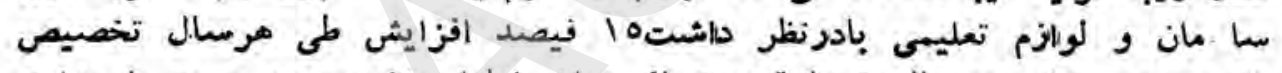

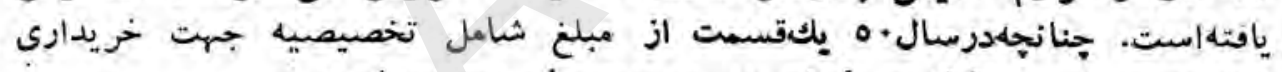

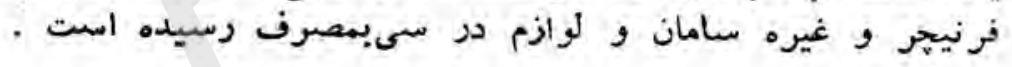

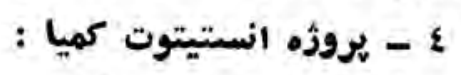

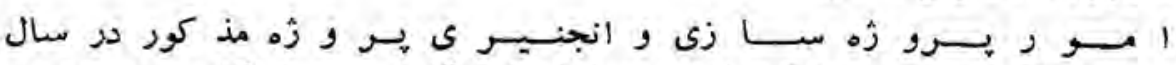

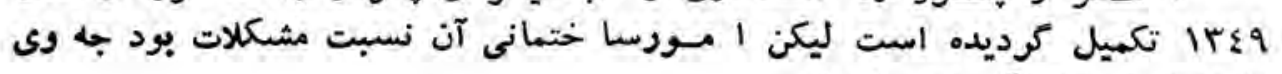

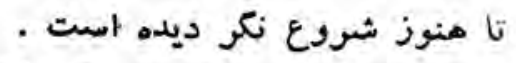

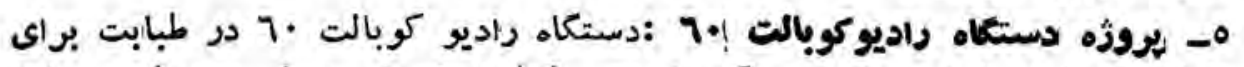

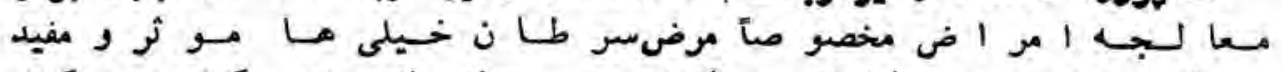

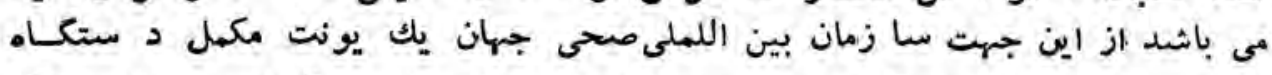

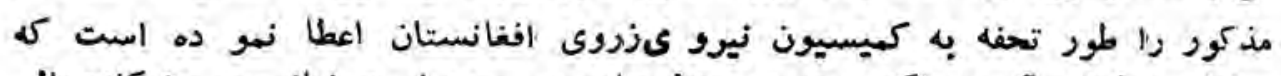

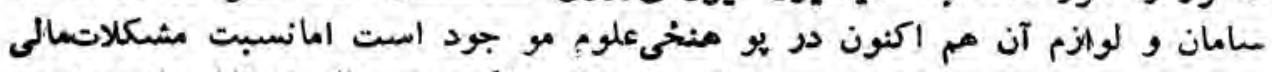

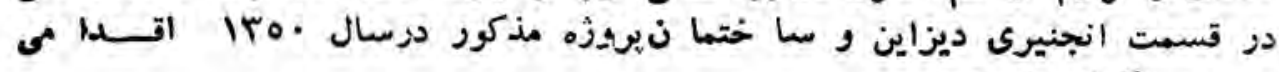




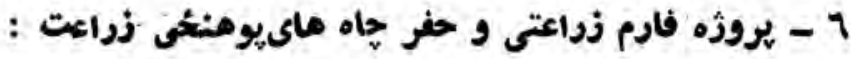

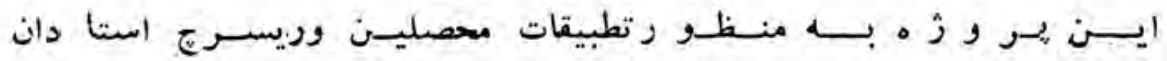

هد نظر كرفته شده است يووزه مذ كو ردز دارالاعان مو قعيت داشته و ساحه. +.1

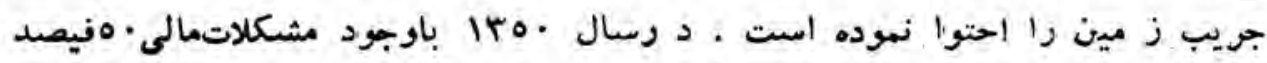

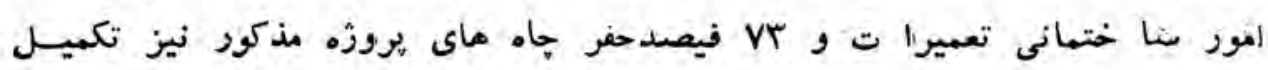

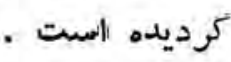

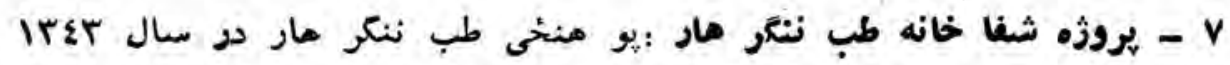
تاسيس كرديده است اين يوو زه ازنكاهكال كلينيك هاى تعليمى و لاببر اتوار

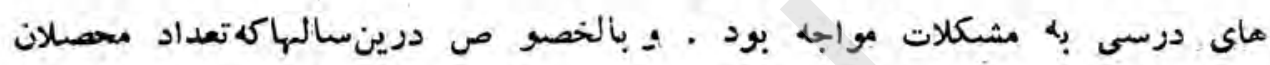

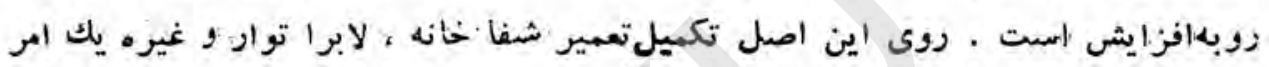

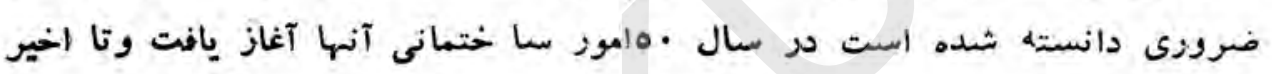

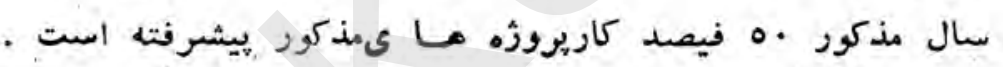

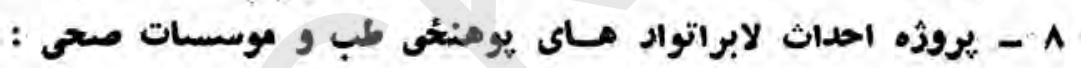

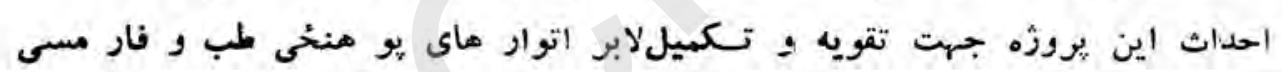

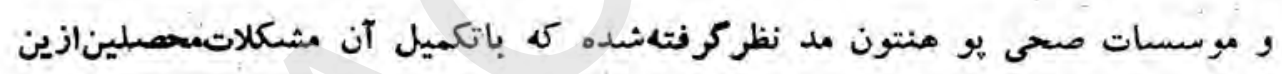

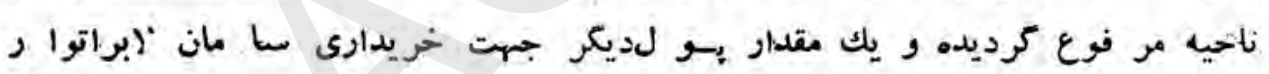

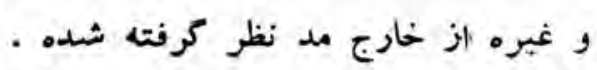




\section{dis}

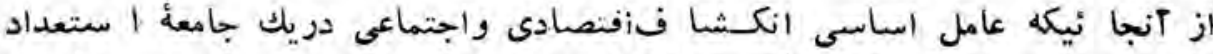

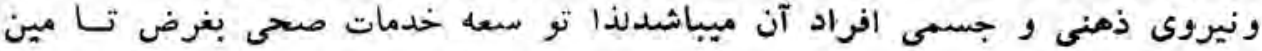

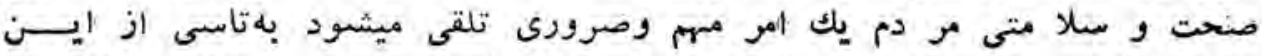

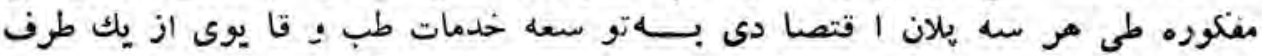

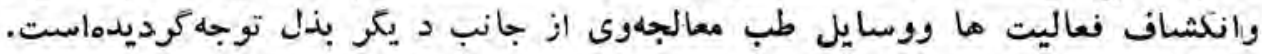

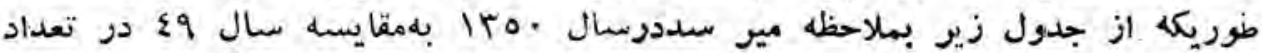

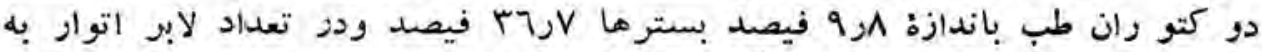

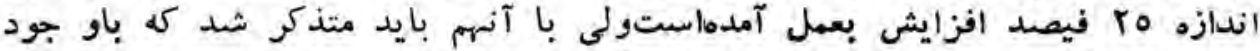

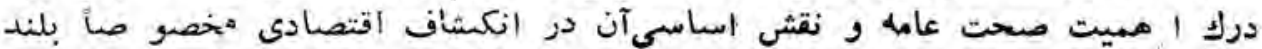

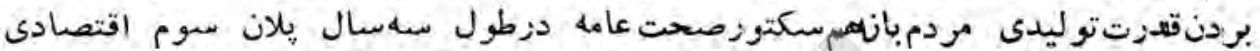

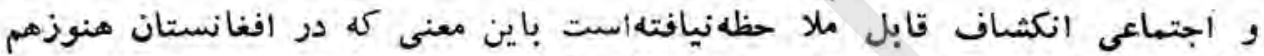

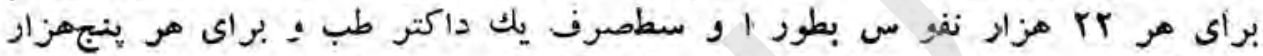

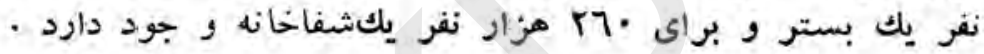

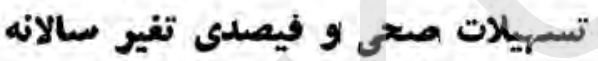

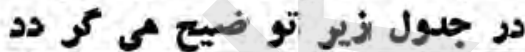

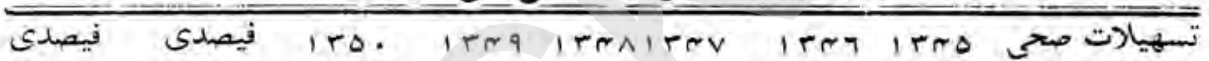

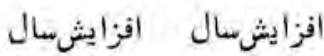

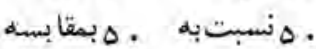

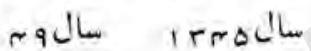

\begin{tabular}{|c|c|c|c|c|c|c|c|c|}
\hline - & r) & 77 & 77 & 77 & 70 & 70 & 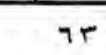 & شفاخانه \\
\hline 9) 1 & TT & $v \Delta v$ & $7 \wedge 9$ & 799 & Trr & $\Delta \wedge r$ & $\Delta r v$ & داكتر \\
\hline ruv & $\Delta U T$ & rerr & rerq & $r+q . r$ & $\Delta \Delta$ & TTt & 198 & بستر \\
\hline 1.5. & Avjی & लrq & $r \cdot \wedge$ & T7 & roq & rol & rrq & دواخانه \\
\hline ros. & (r.). & TT & 17 & 17 & 10 & 10 & 10 & لابراتوار \\
\hline INJV & $11 \mathrm{~N}, \mathrm{~V}$ & ro & ; & 17 & 17 & 17 & 17 & دستعاها \\
\hline
\end{tabular}

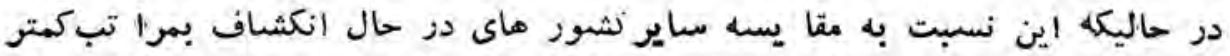

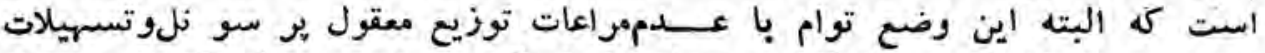

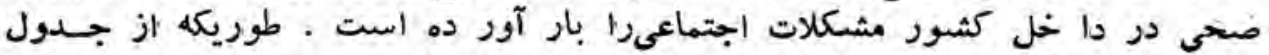

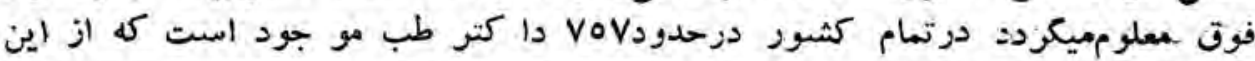

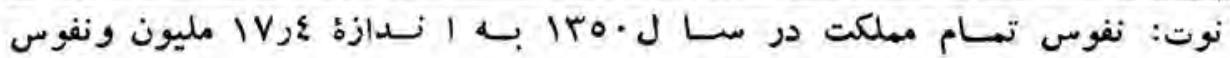
كابل در حدود ينجصد مزار نفر تسخمين كرديده است. 


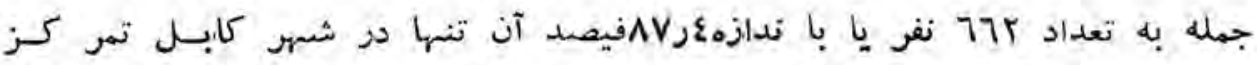

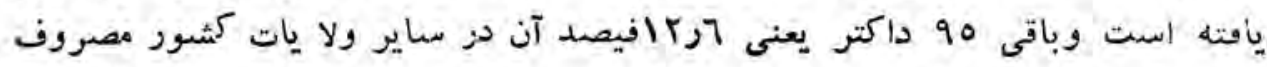

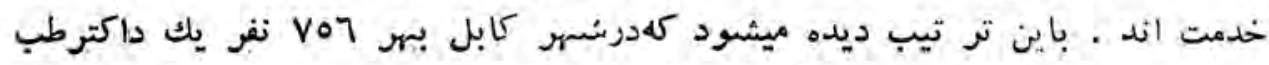

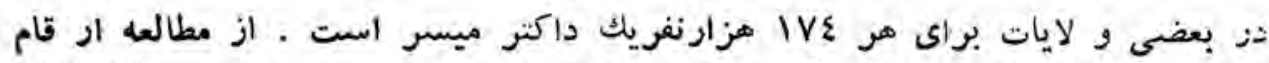

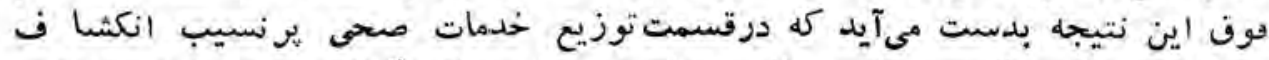

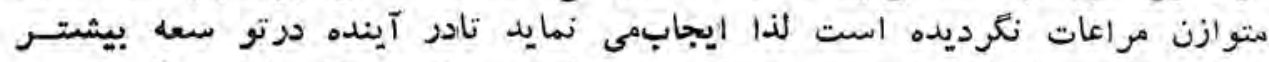

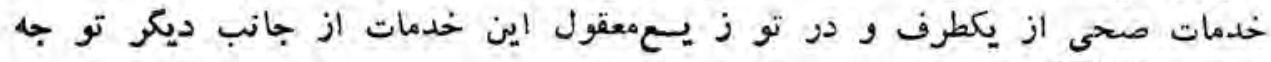

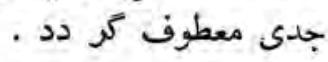

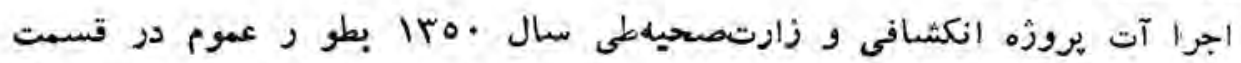

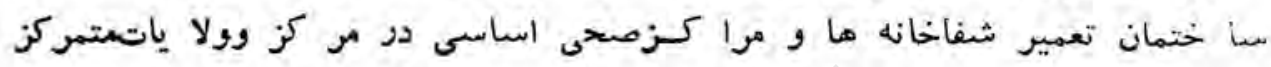

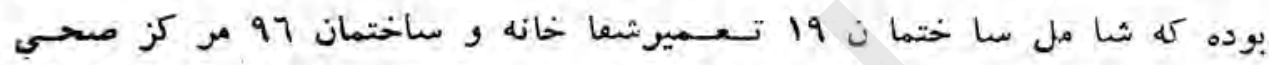

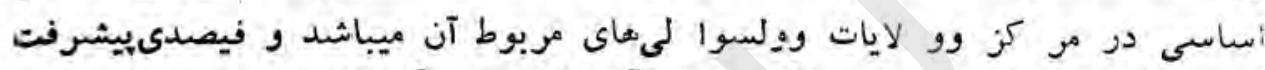

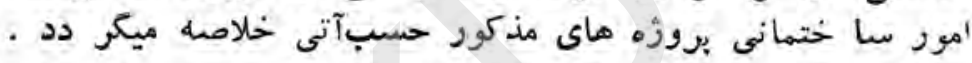

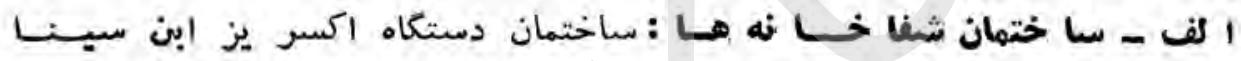

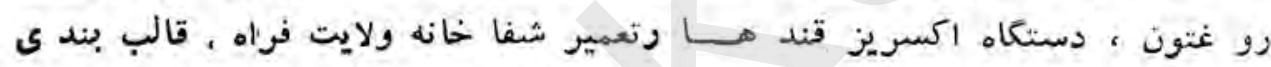

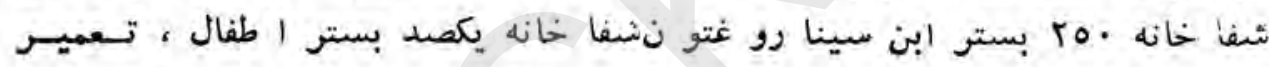

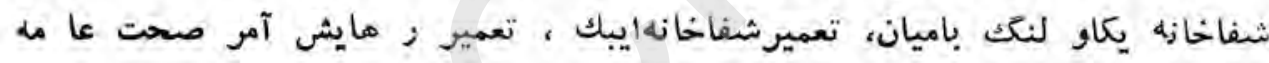

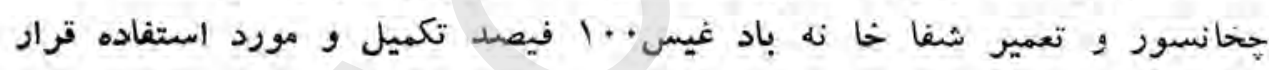

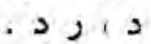

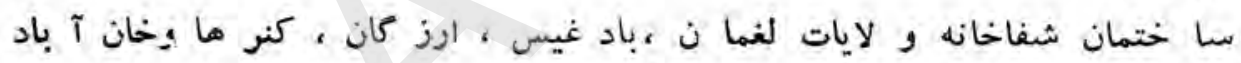

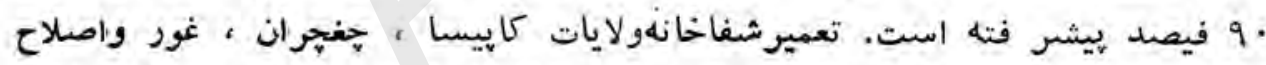

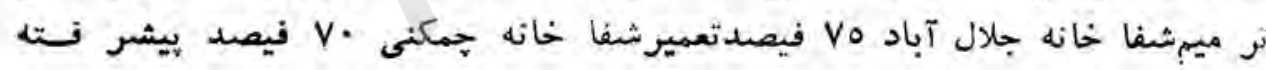

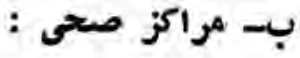

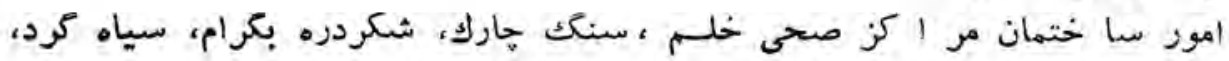

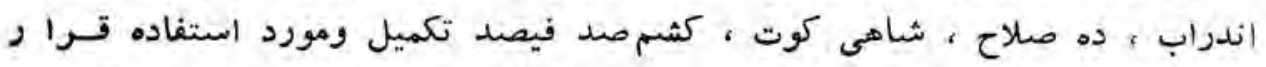

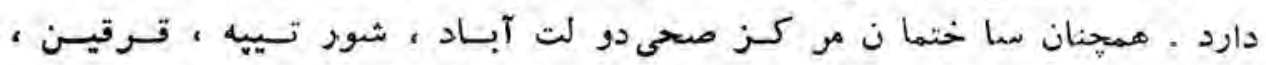

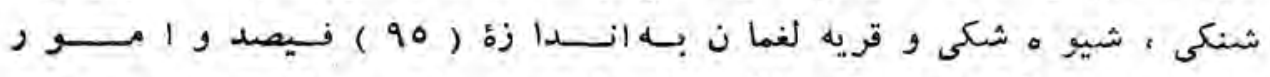

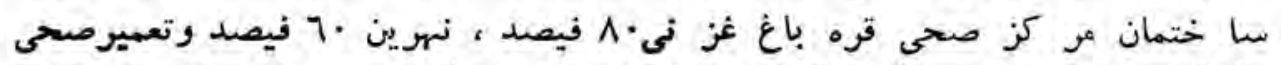

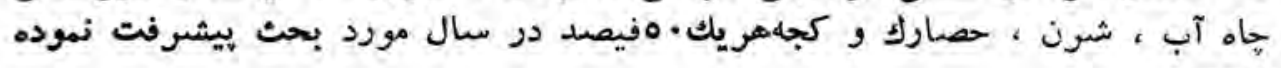

فعاليت سا ختمانى يك تعداد مرا كزديكر از قبيل نجراب، ،ور كى، سيدكرم 


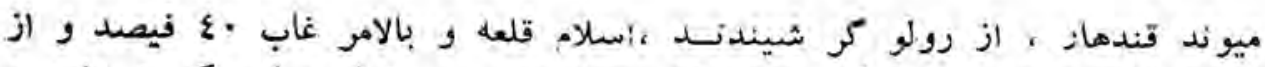

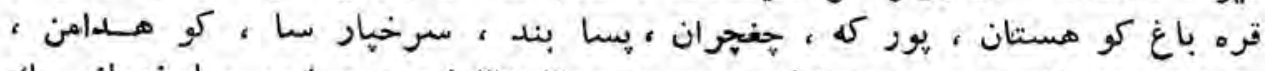

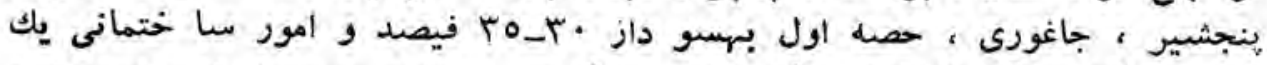

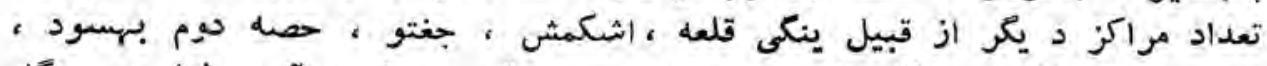

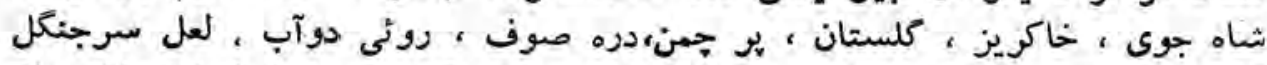

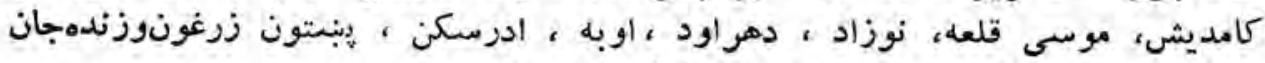

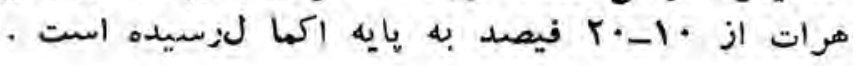

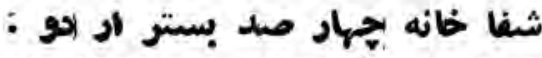

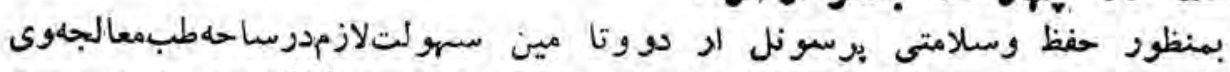

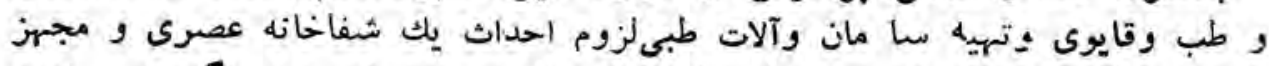

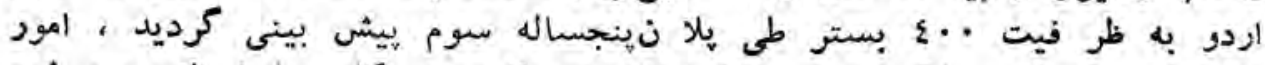

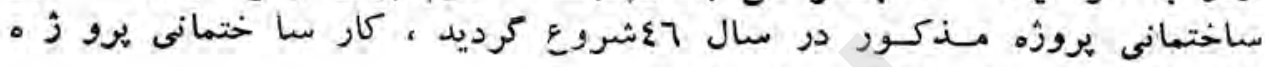

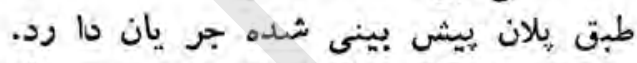

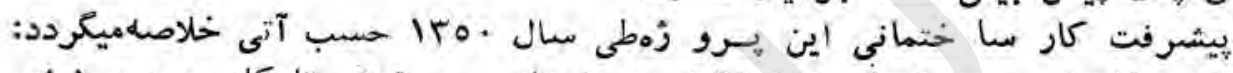

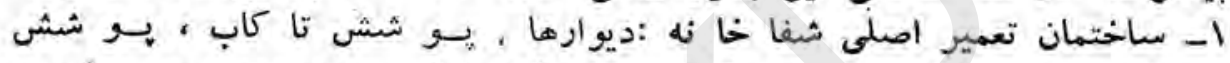

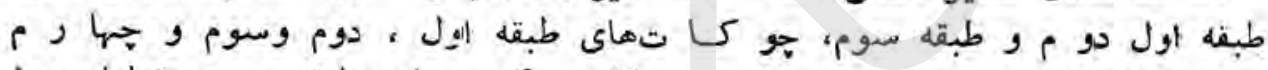

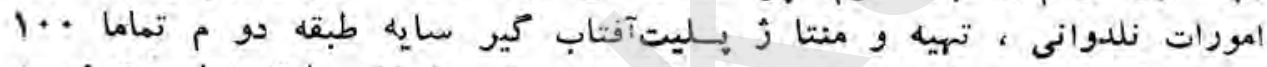

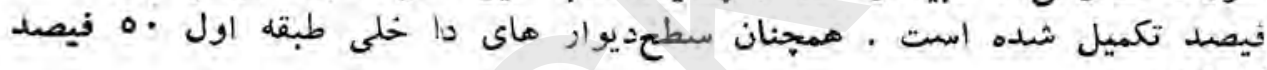

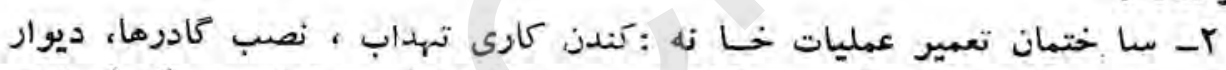

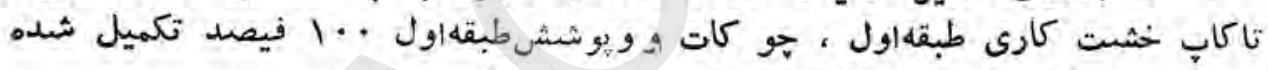

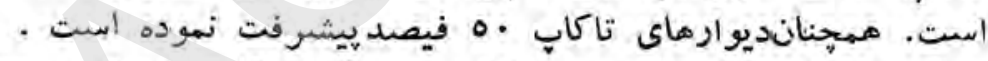

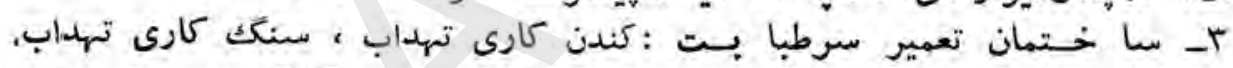

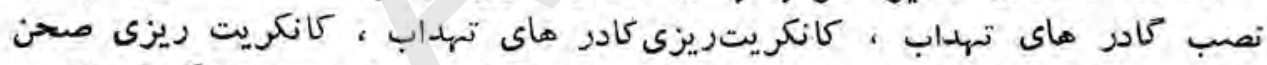

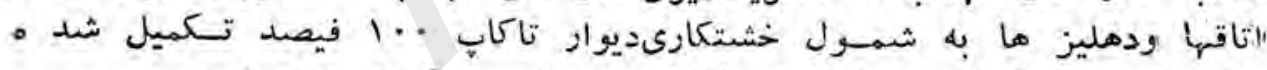

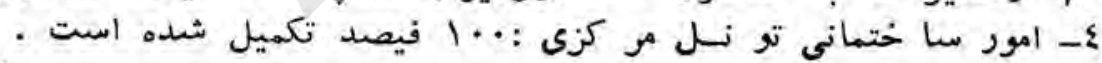

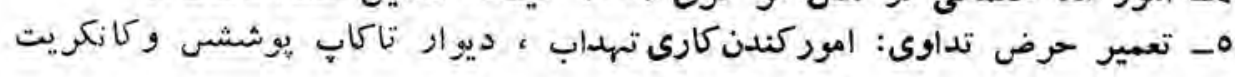

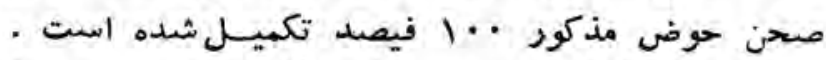

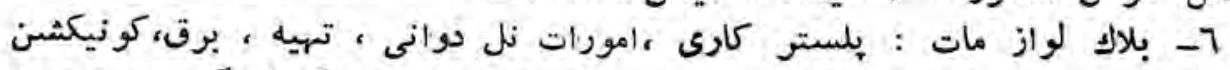

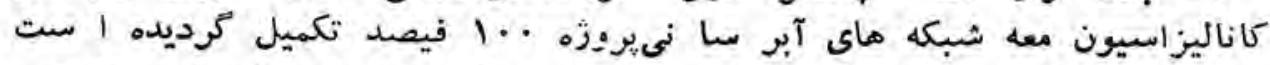

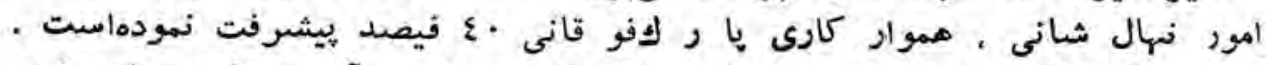

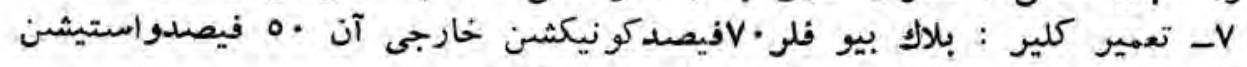

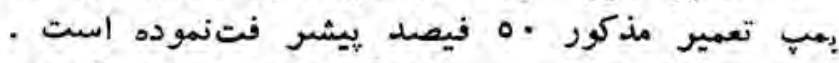

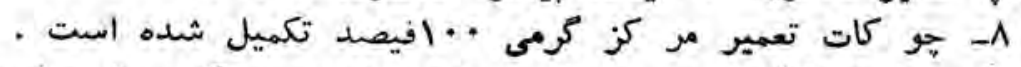

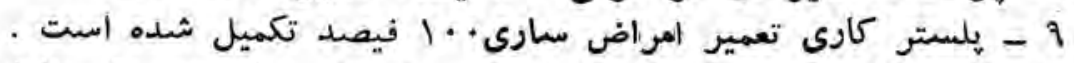

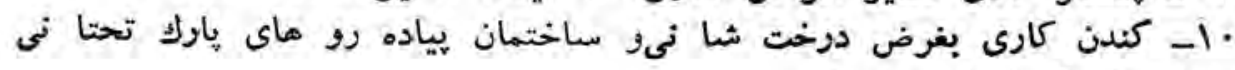




\section{ستره محكمها}

ستره محكمه يك ركن مستقل دو لـتاست كه مانند قوه تقنينيه و قوه إجرا ئيه

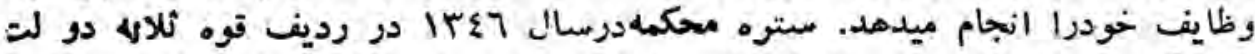

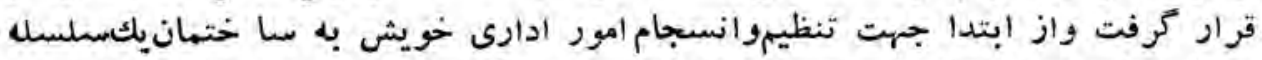

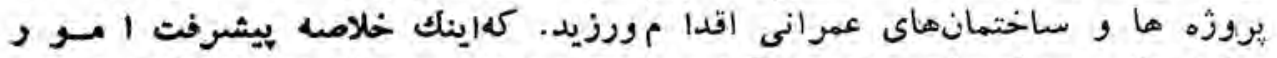

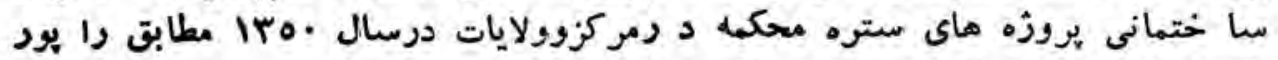

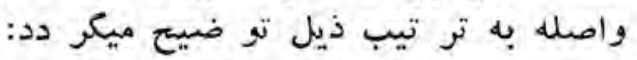

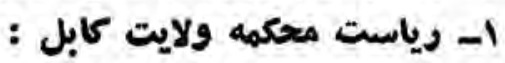

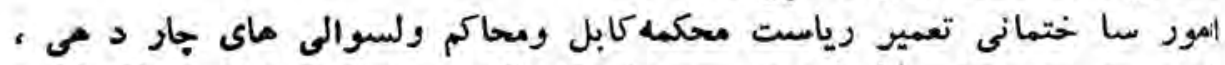

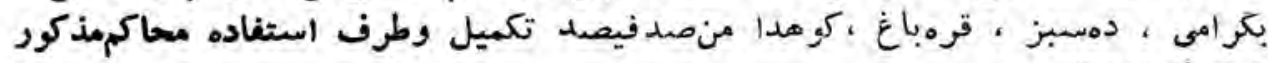

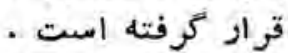
r- رياست محكمه ولايت كنر مارفه :

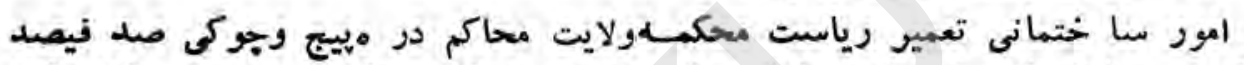

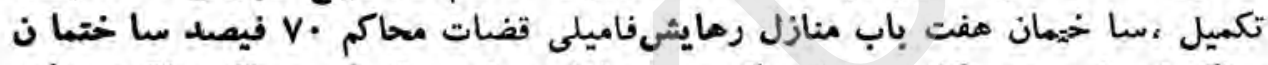

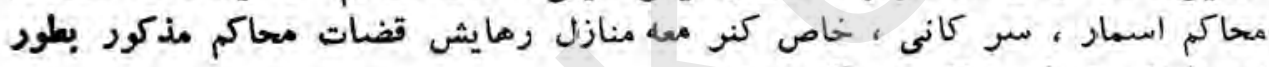

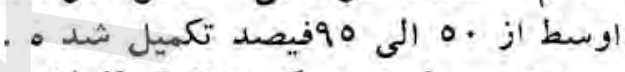

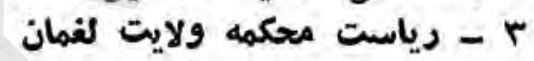

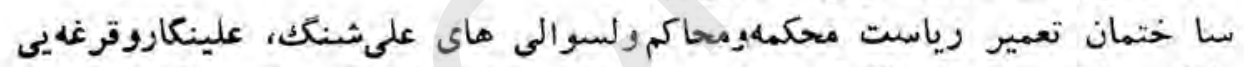

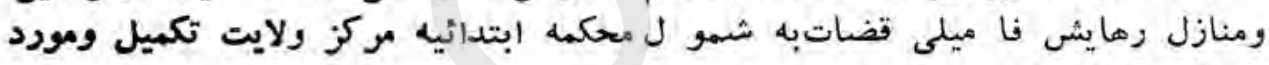

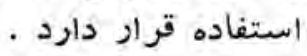

\section{ع- دياست محكمه ولايت كاريسا :}

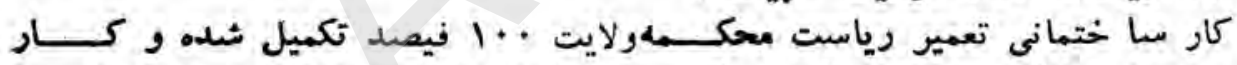

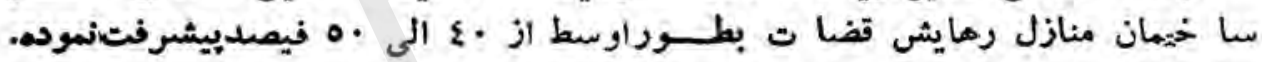

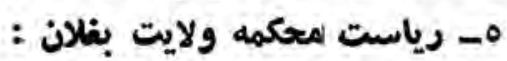

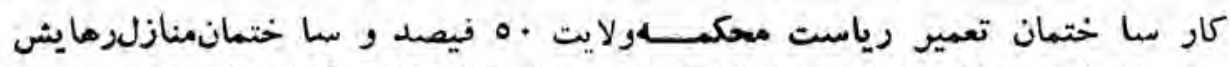

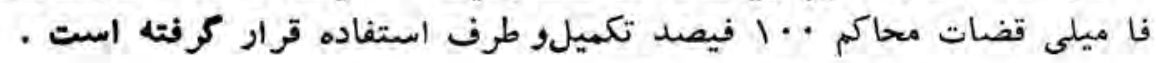

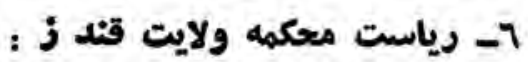

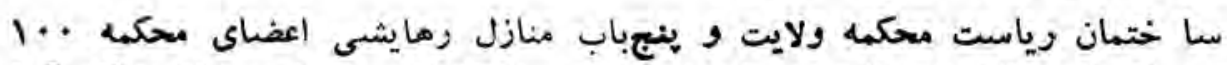

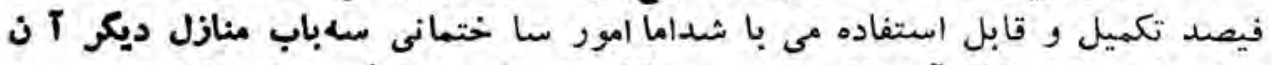

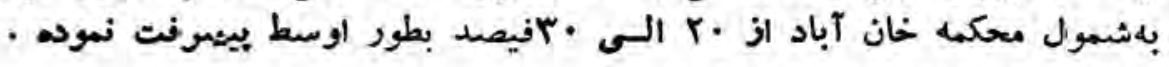

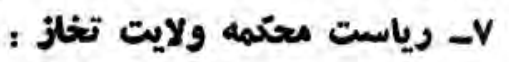

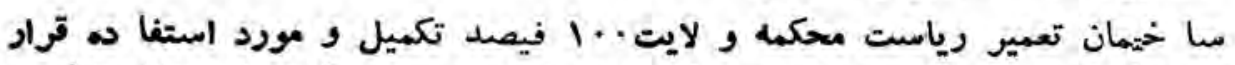

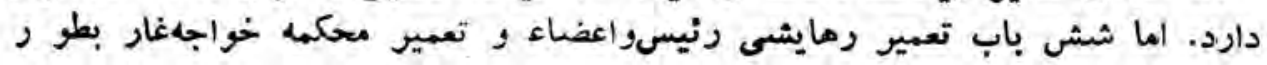

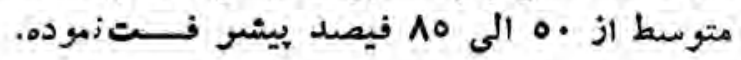


1- رياست منكهه ولايت هو وا ن:

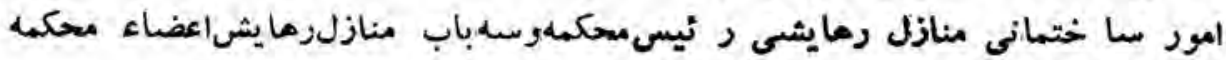

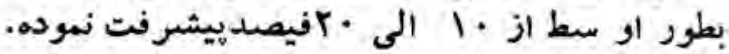

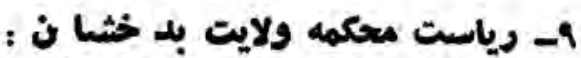

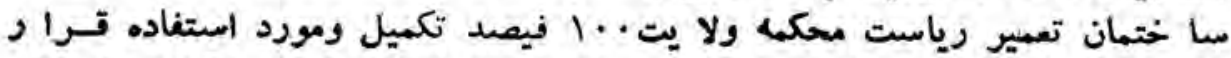

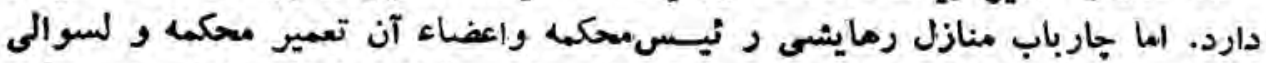

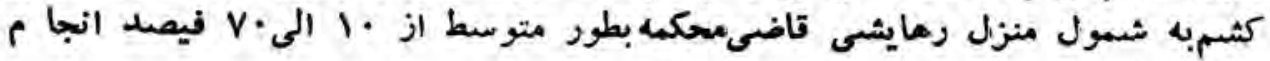
ثده است . • ا- رياست محكهه ولايت مسمنكا ذ : سا ختمان تعمير رياست محكمه ولا يت

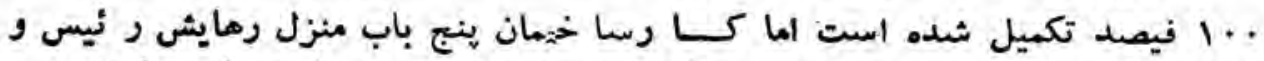

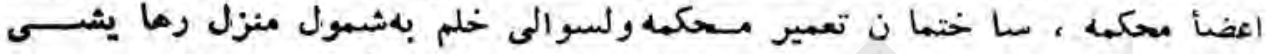

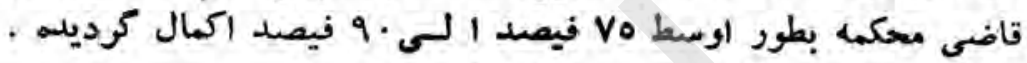

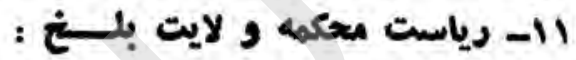

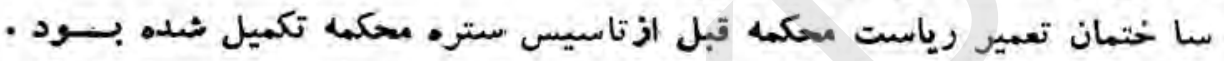

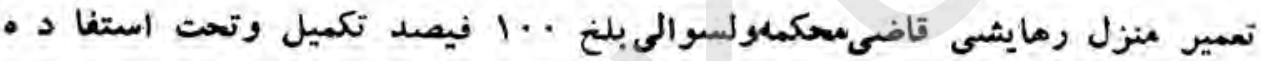

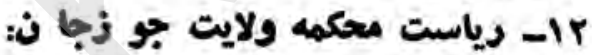

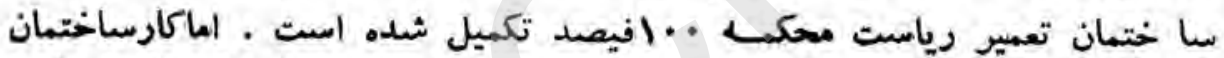

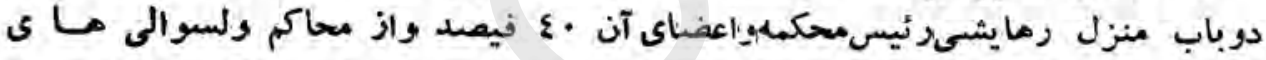

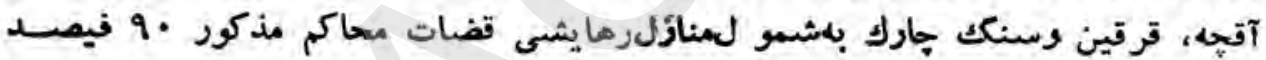
تكميل شده است قرين.

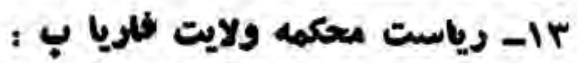

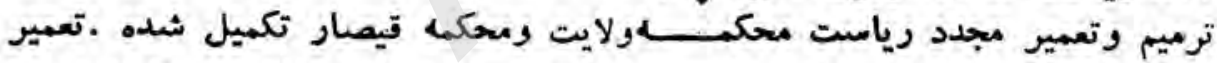

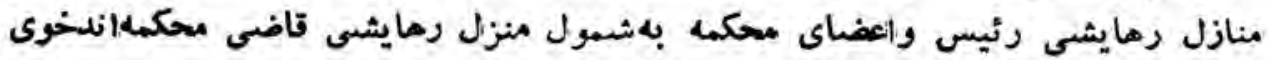

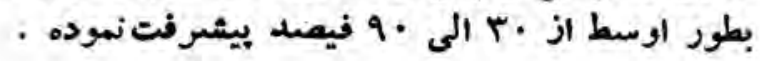

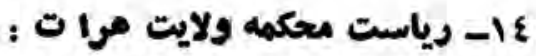

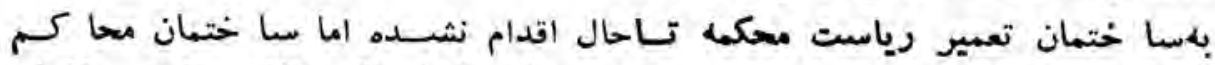

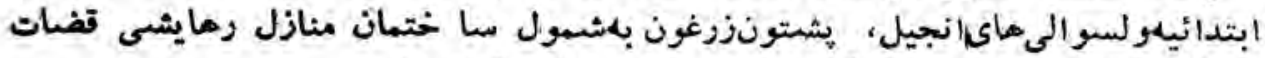

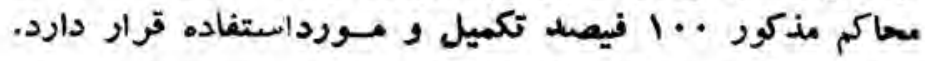

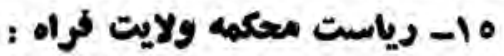

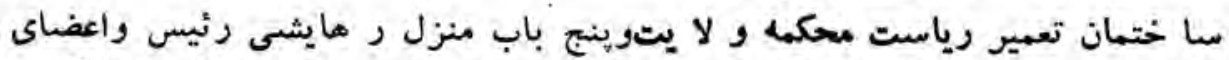

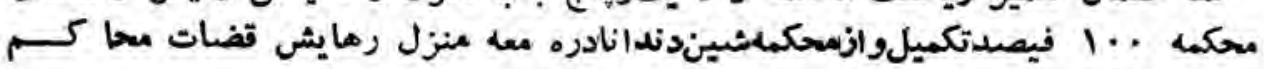

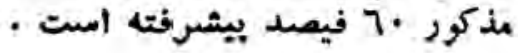




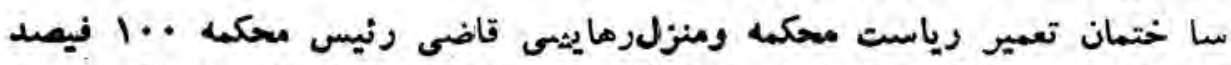

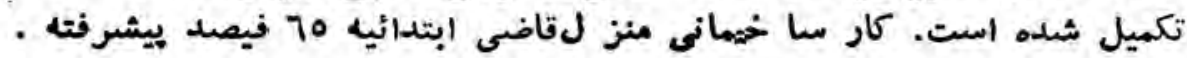

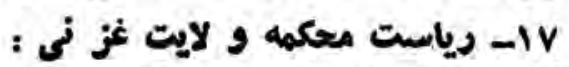

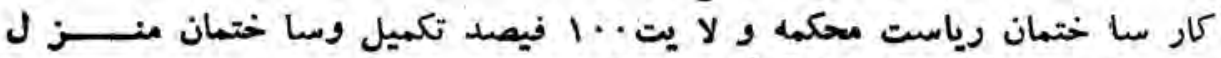

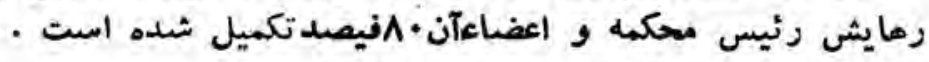

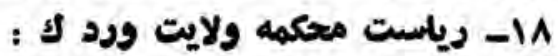

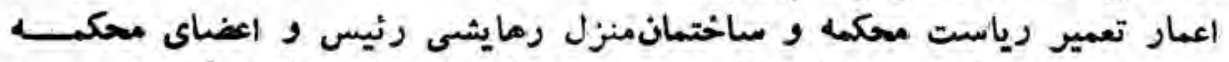

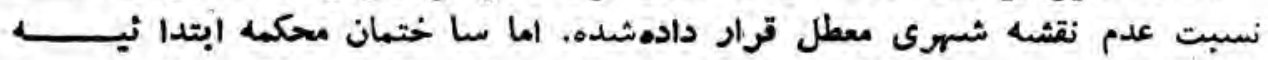

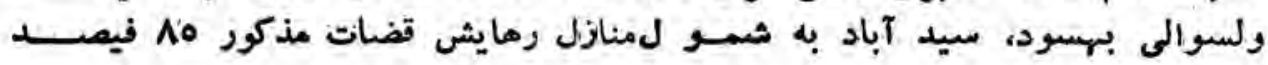

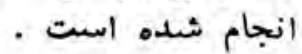

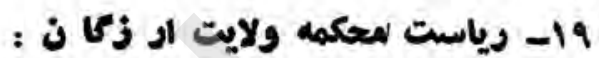

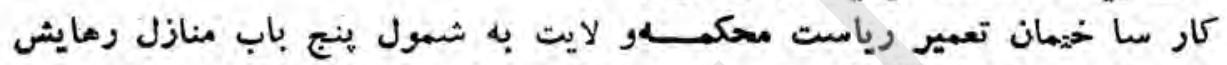

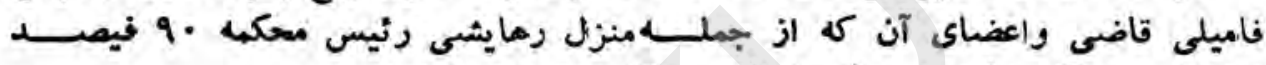

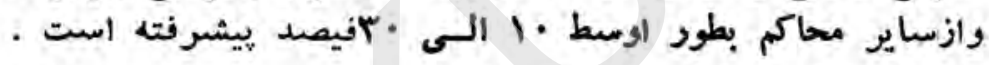

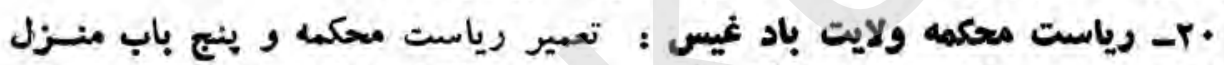

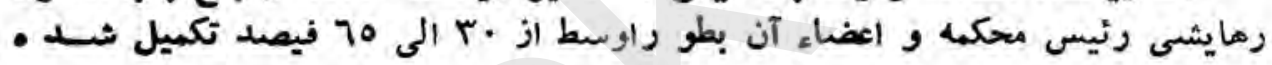

\section{الr- رياست معكمه ولايت ننغر ها ما م :}

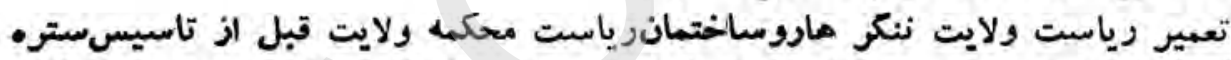

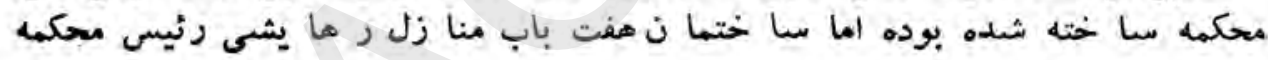

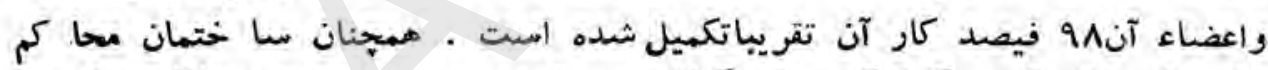

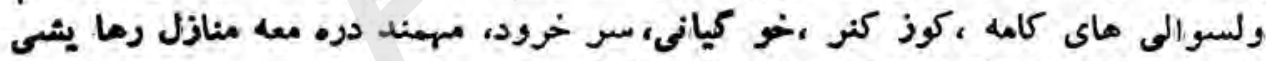

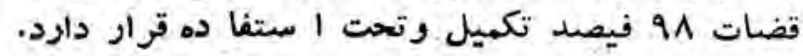

rا ك- رياست محكمه ولايت نيهرو ذ :

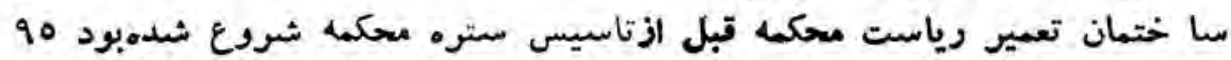

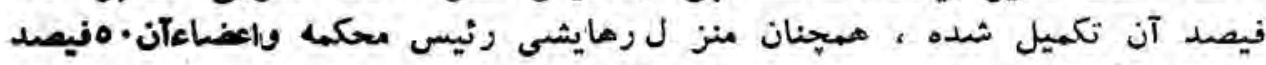
بيشرفت كرده است.

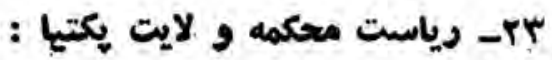

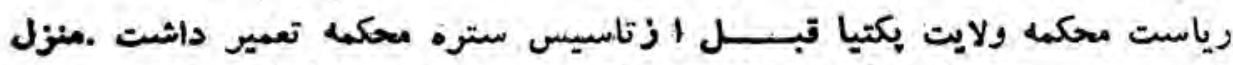

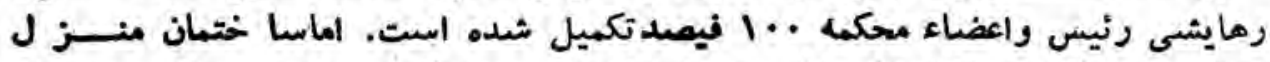

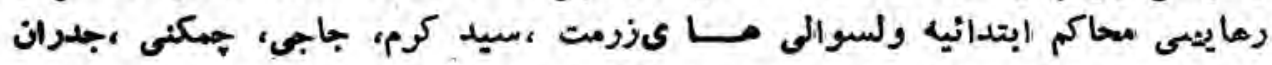

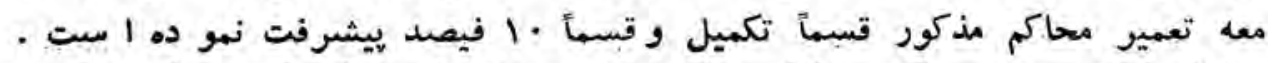

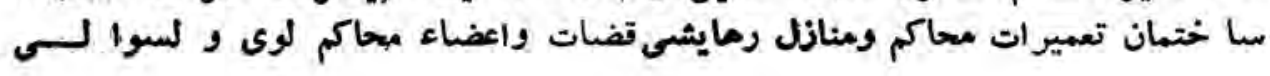


هاى خوست ولوى ولسوالى اركون بـشهول محاكم ابتدائيه آن بسطور او سط

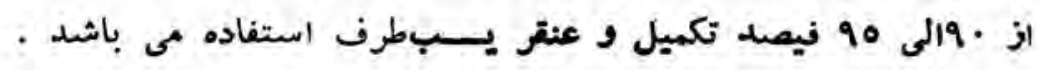

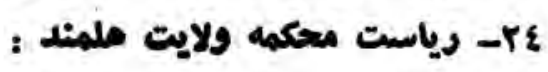

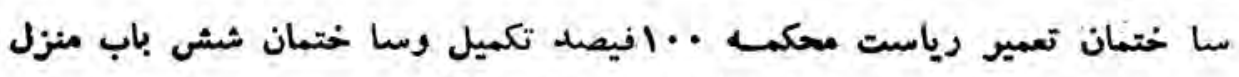

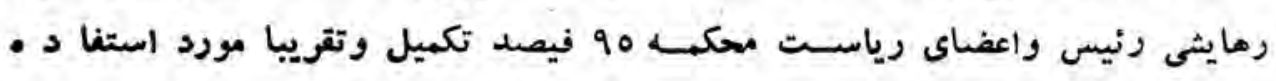

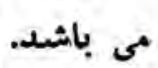

مr- رياست معكه ولايت كند مار :

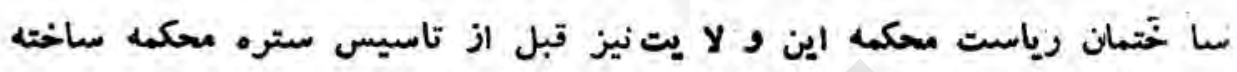

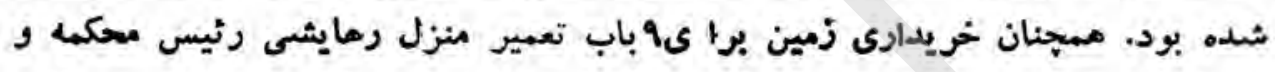

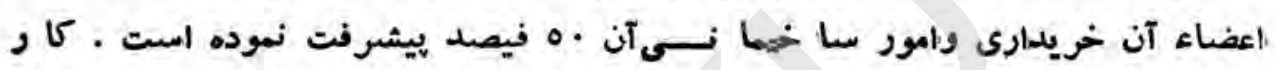

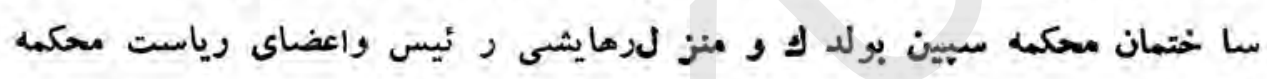
مذكور 09 فيصد تكميل شده است .

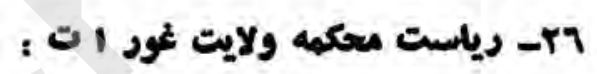

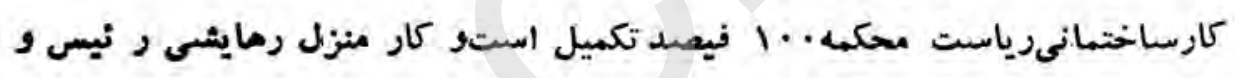
اعضاء محكم .9 فيصد تكميل شندهاست. 


\section{انكشاف محلات}

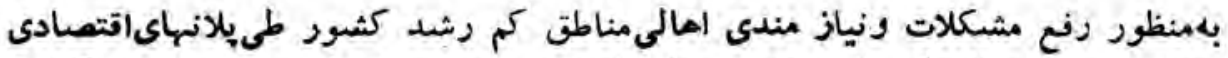

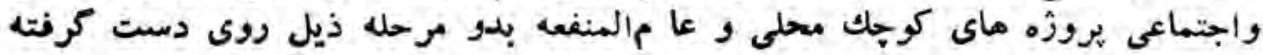

$$
\begin{aligned}
& \text { الف- يوركرام كاراز بودجه انكثا فى كنى }
\end{aligned}
$$

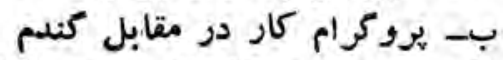

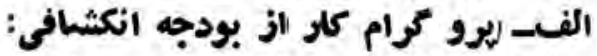

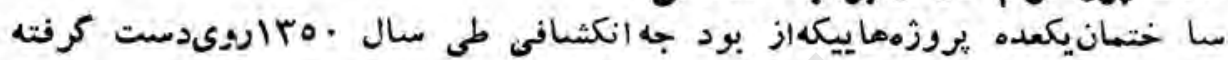

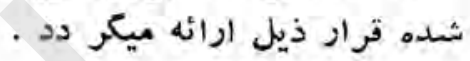

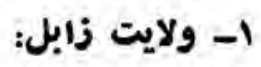

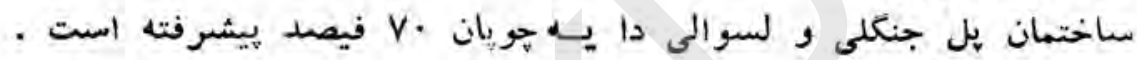

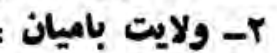

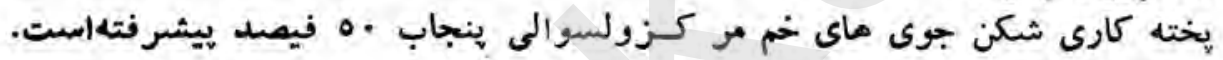

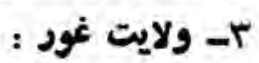

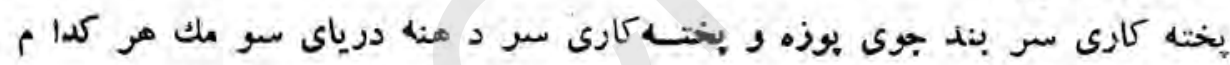

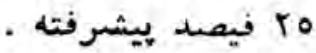

$$
\begin{aligned}
& \text { ع- و لايت غز نى : }
\end{aligned}
$$

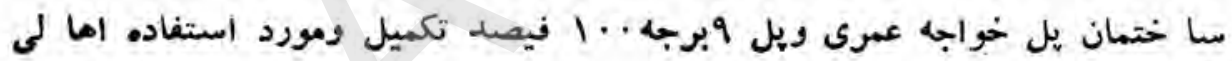

$$
\text { قرار دارد. }
$$

$$
\text { ب- بروكرام كار در مقابل كندم }
$$

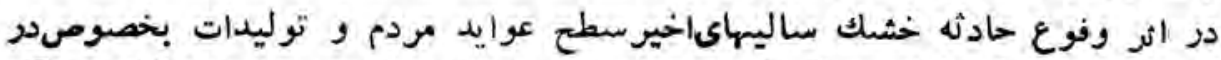

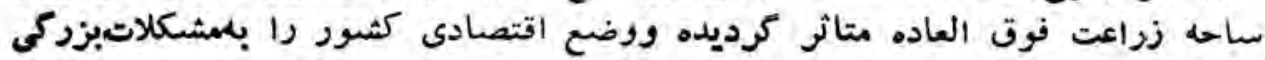

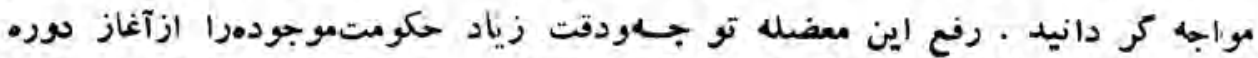

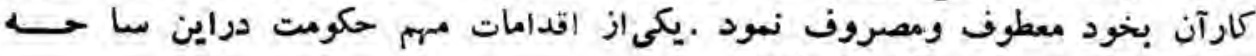

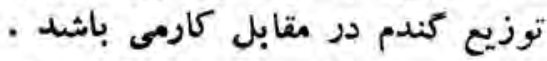

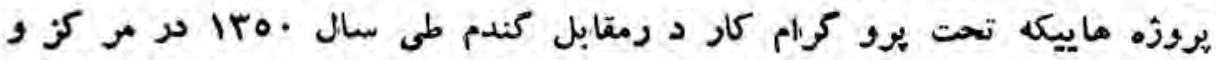

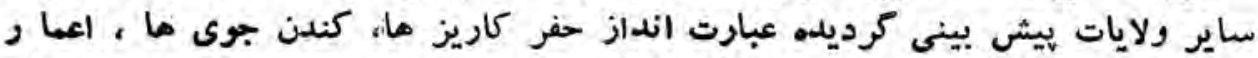

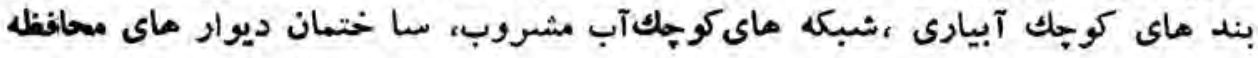

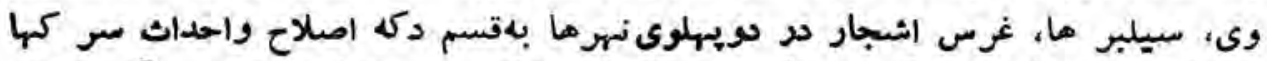

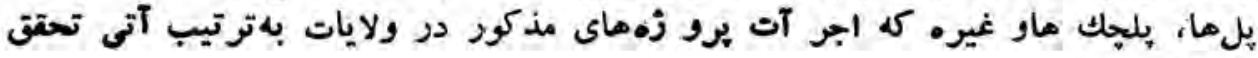




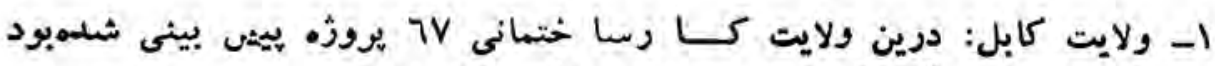

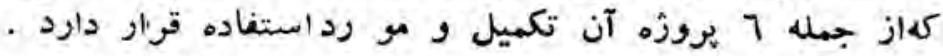

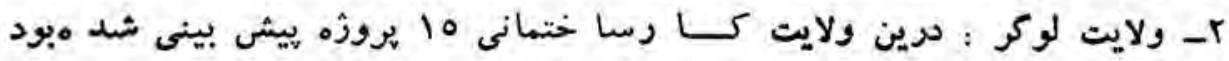

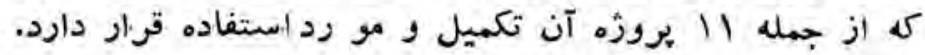

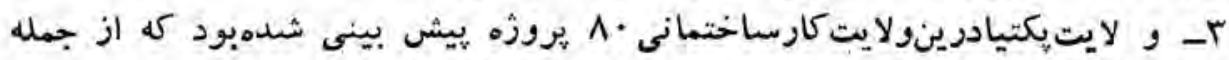

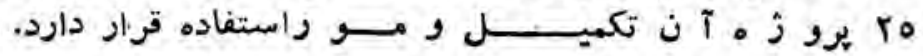

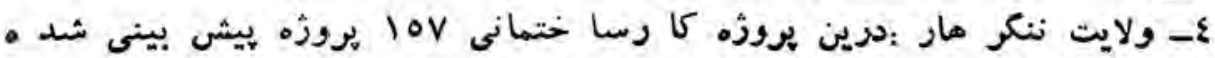

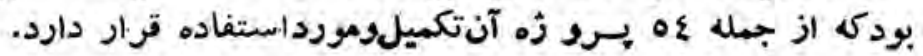

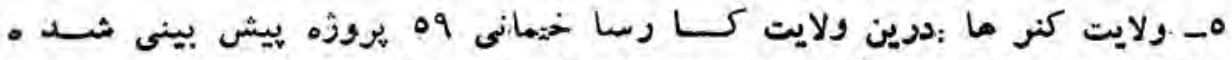

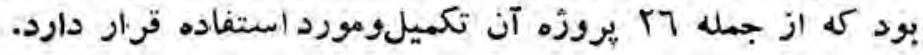

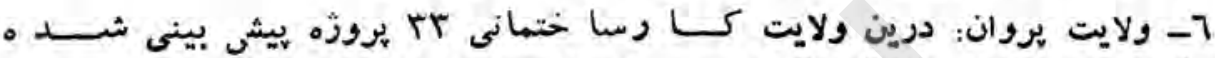

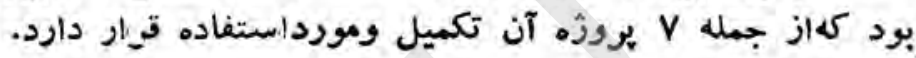

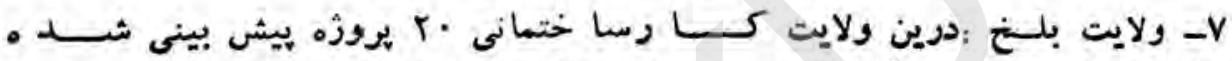

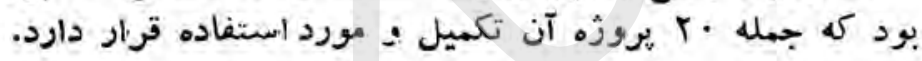

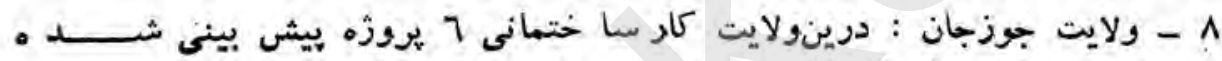

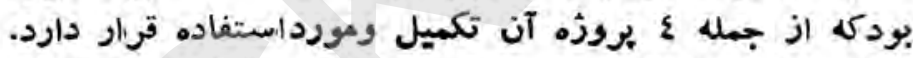

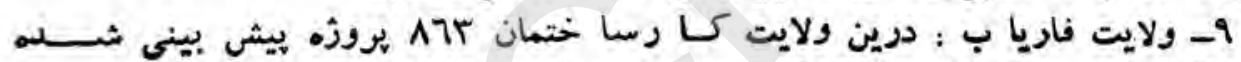

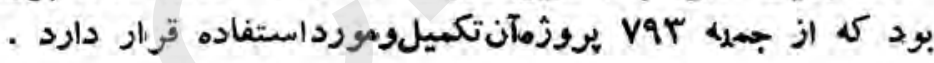

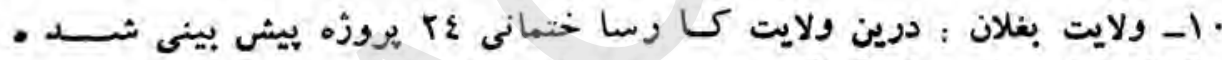

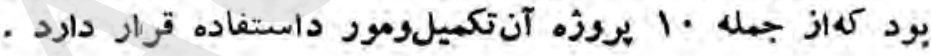

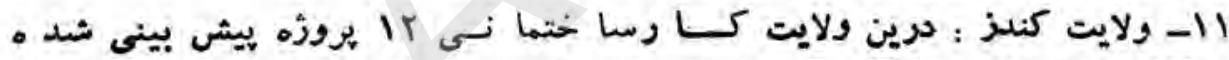

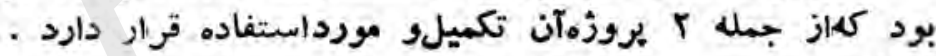

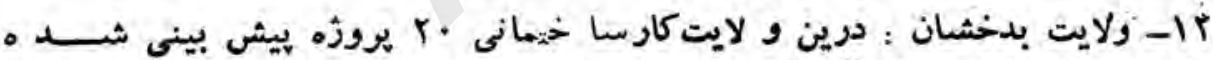

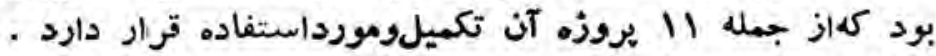

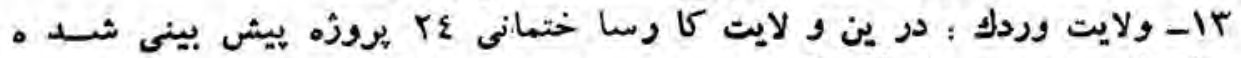

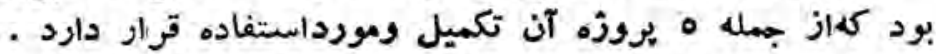

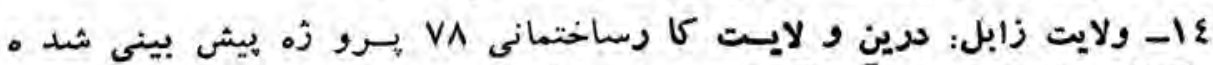

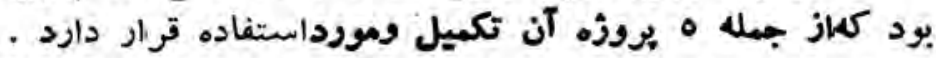

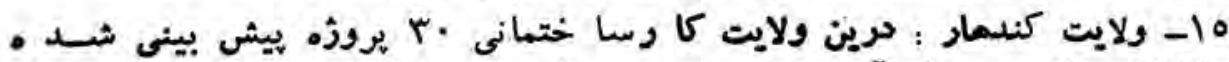

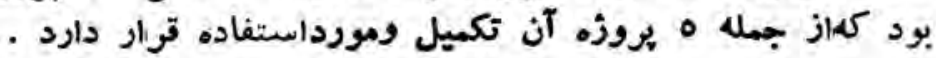

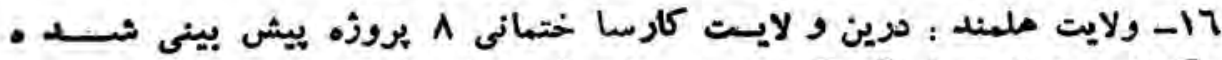

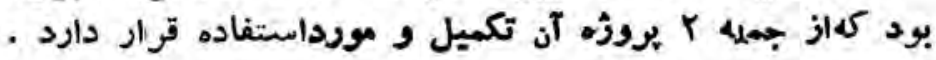

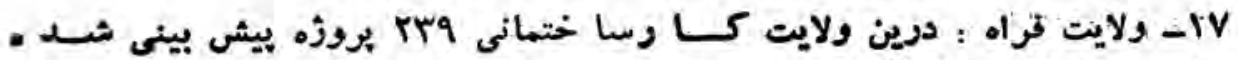

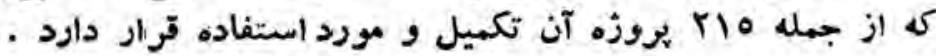




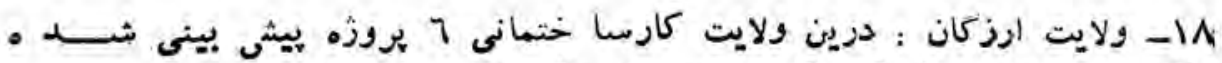

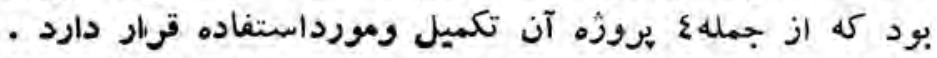

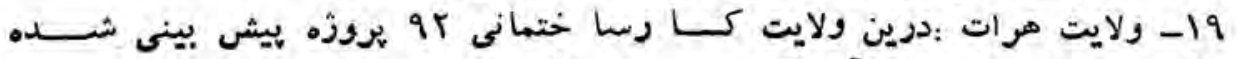

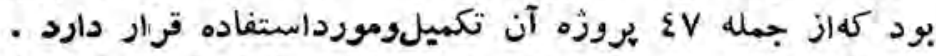

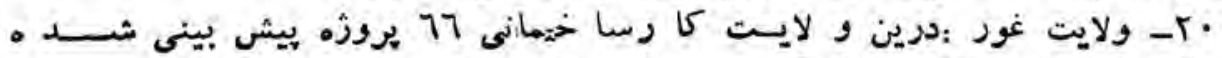

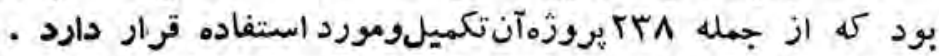

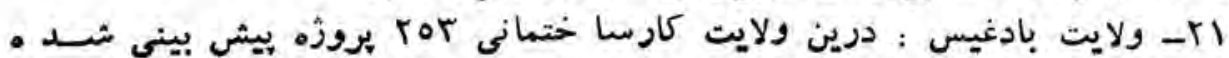

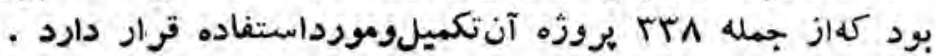

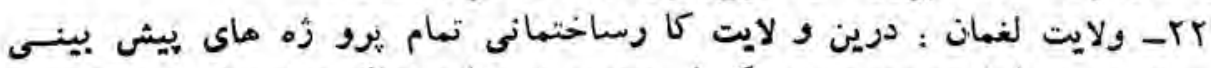

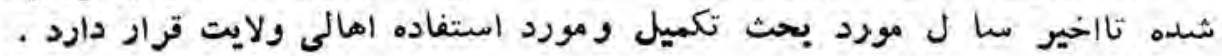

\section{شهر سازى وخانهسازى}

تيشرفت كار يروزه هاى مو بوطرياستشهر سازى وخانه سازى درسال .0بابه ترتيب ذيل خلا صه ميشود :

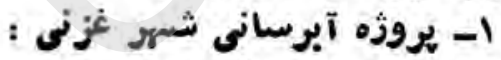

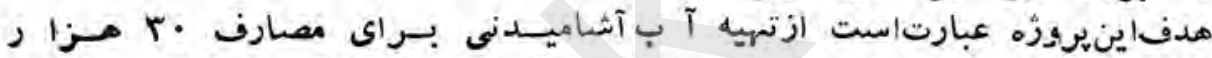

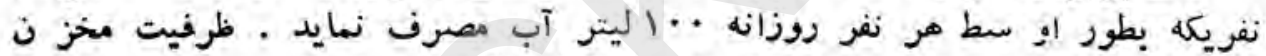

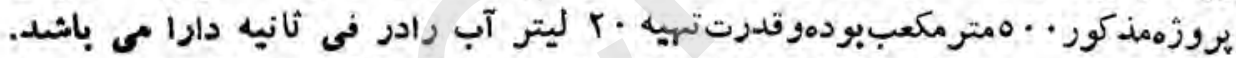

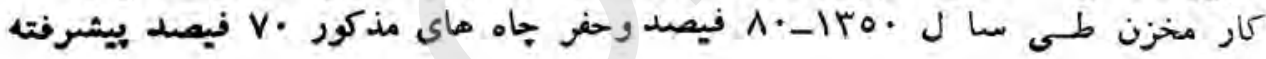

\section{r- ك- يروزه آبرسانق افشار :}

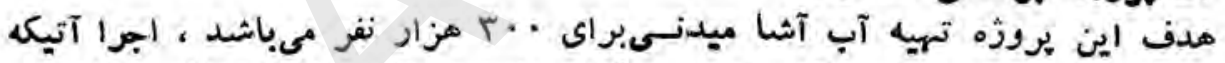

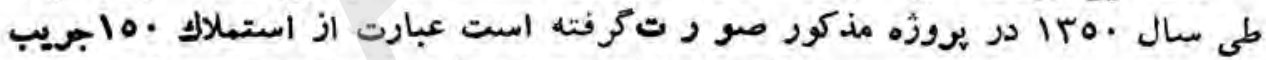

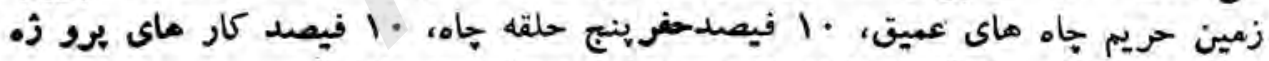

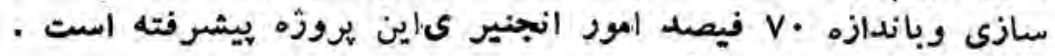
: r- آبرسانى شبه

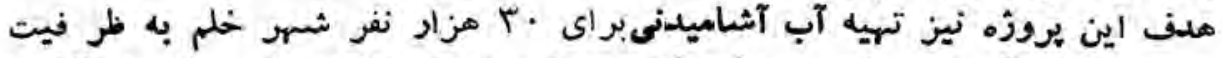

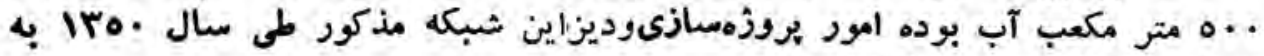

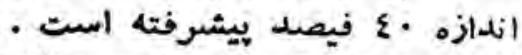

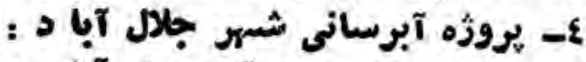

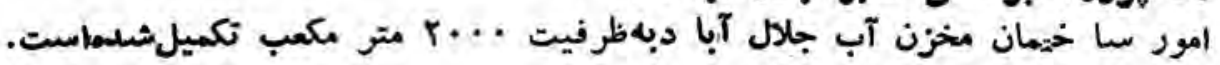
يروزه نادر شاه مينه رمكرو يان):

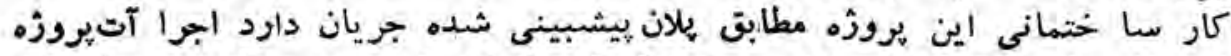

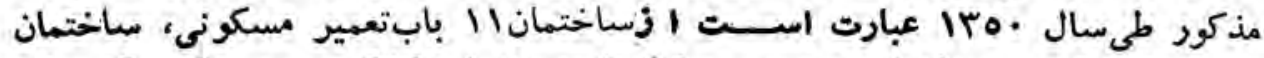

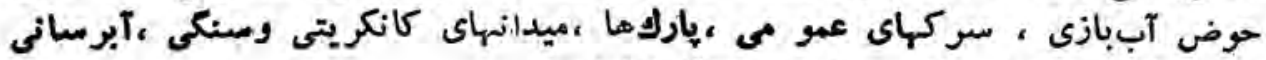

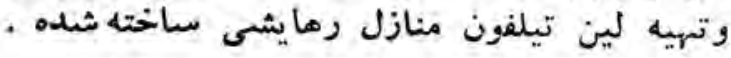




\section{بناروالى كابل}

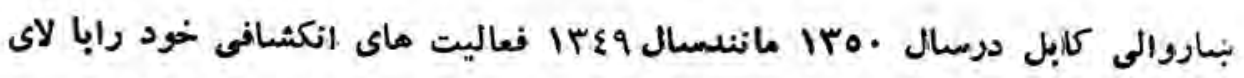

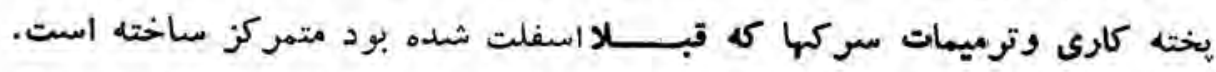

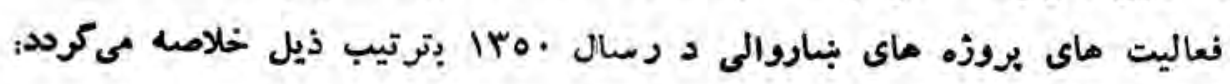

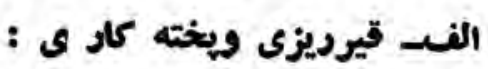

اكيلومتر

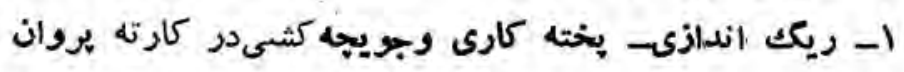
0..

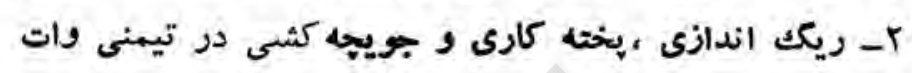

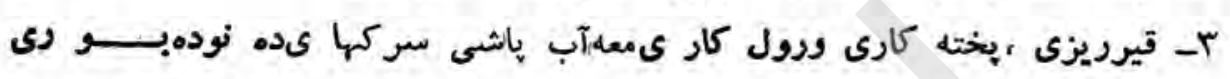
.

اكيلو متــر

$$
\text { ع- قيرديزى -بخزيه كارى و دول كارى }
$$

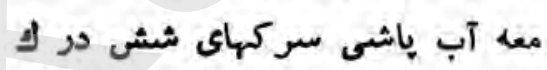

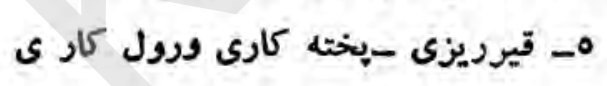

اكيلــــو متر

معه آب هاشيى سركهاى جمال مينه

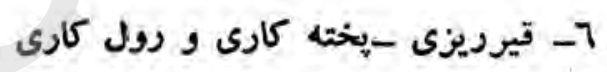

A 1.

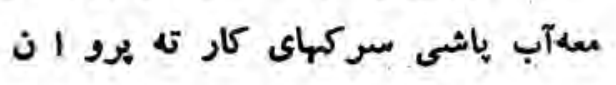

بـ ترميهات :

$\varepsilon+$

توميمات عمو مى سر كهاى نواحى شهر كابل جمعاً 


\section{اطلاعات وكلتور}

يوروزه ماى انكشافى وزارت اطلاعات و كلتور عبارت اند از يووزه ثرميم حفظ آثلار وسروى مناظق باستانى :

الف - يووزه توميم وحفظ آنار :

$$
\text { ا- كرميم آبدات : }
$$

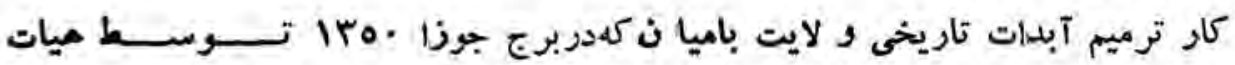

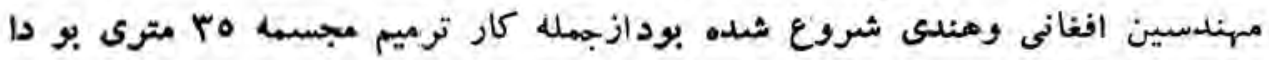

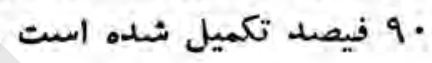
r- ترميم رواق تحازدما :

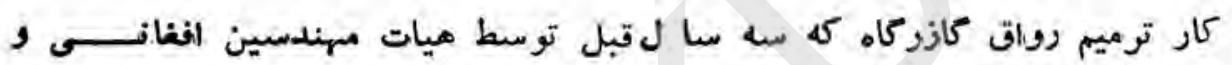
دنماركى شروع شده بود، در حدو د • 1 فيصد ترميم كارى روات مذكور طلى سال . r- حفريات وحفظ آثار هله :

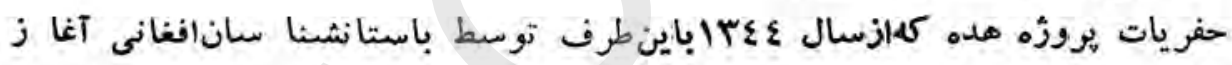
كرديده بود طبق يلان ييش بينى شده دريك سال سه ماه دوام مي كند، جونساحه

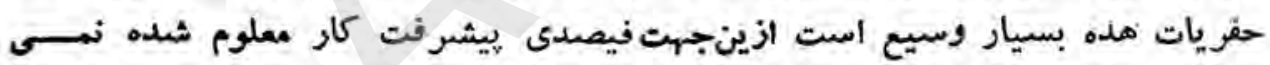

ب - يروزه سروى مناطق باستانق :

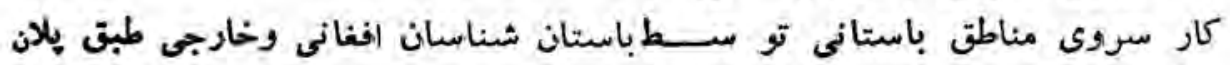
بييش بينى شدهبه بييمانه وميع در منا طق باستانى كشور همه ساله جريان دارد .

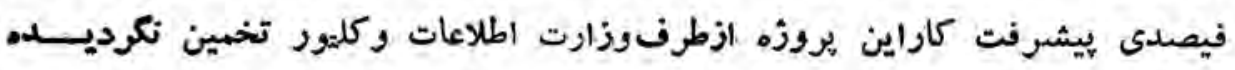




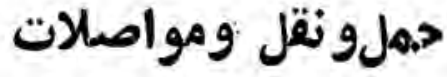

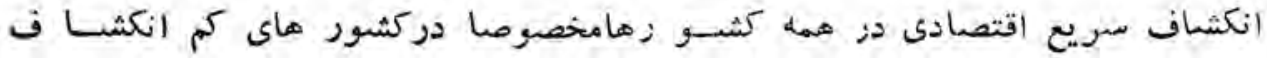

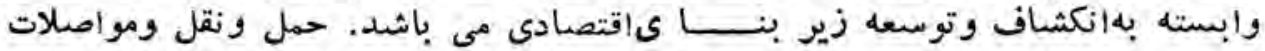

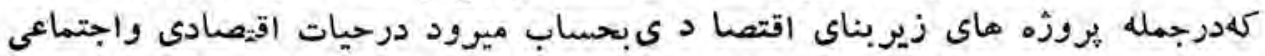

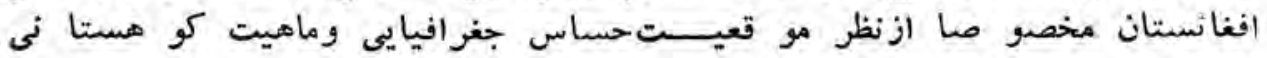

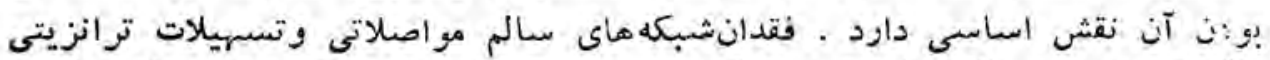

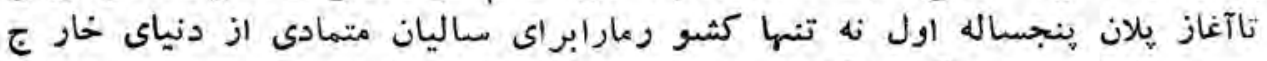

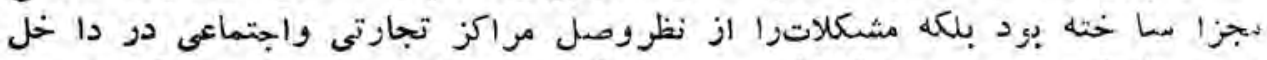

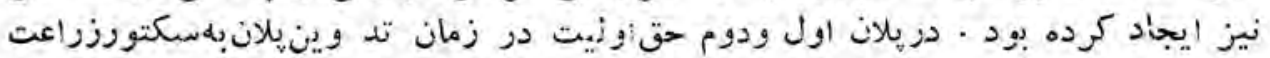

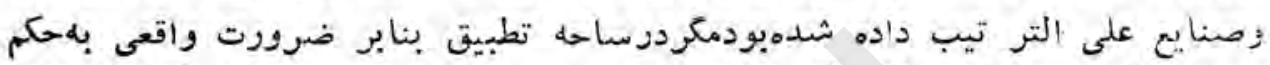

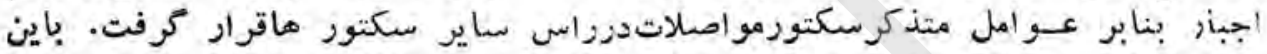

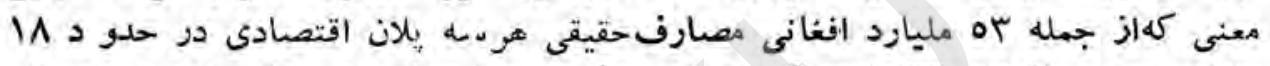

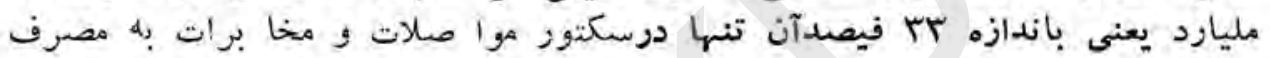

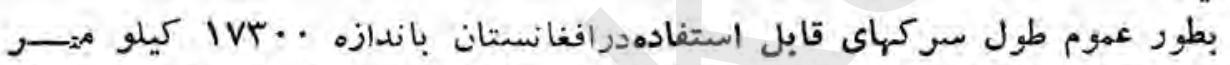

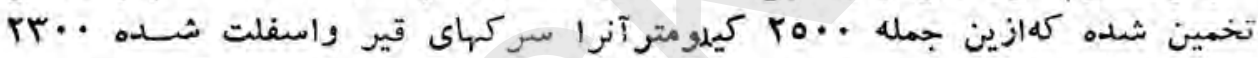

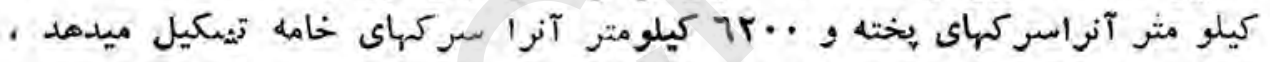

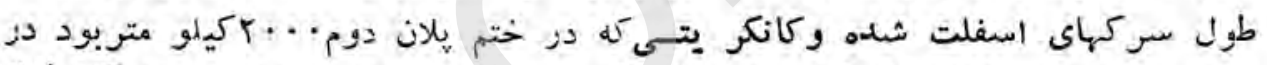

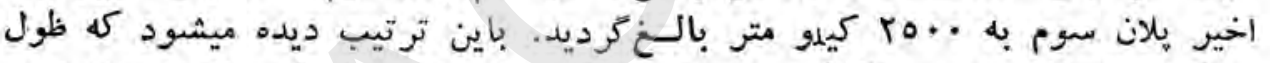

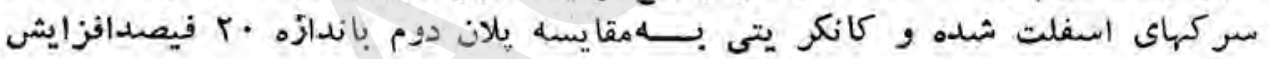

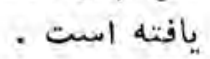

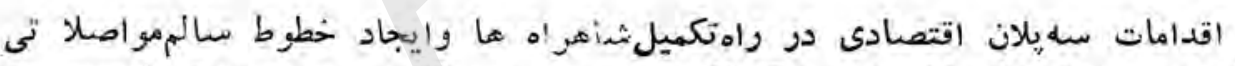

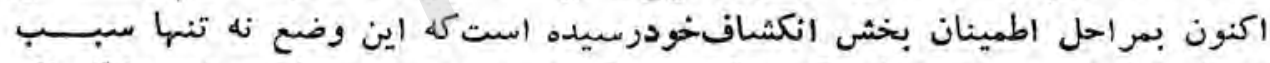

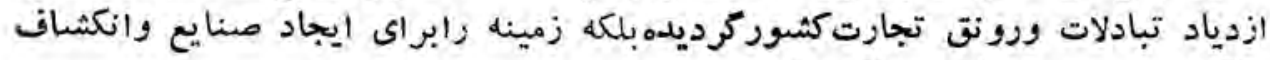

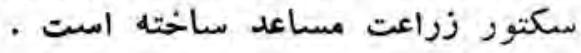

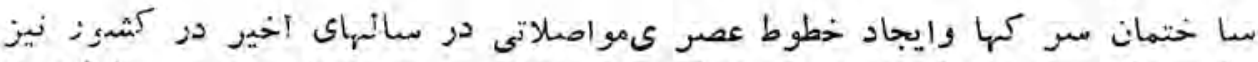

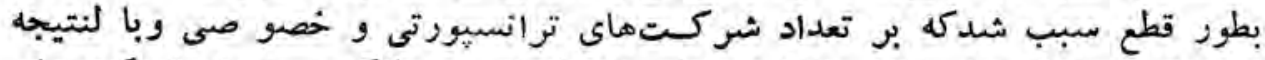

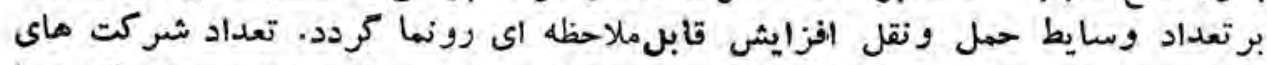

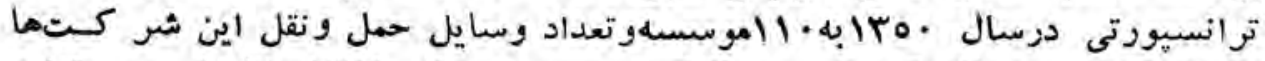

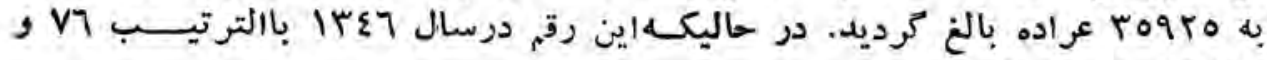
. r rqqv

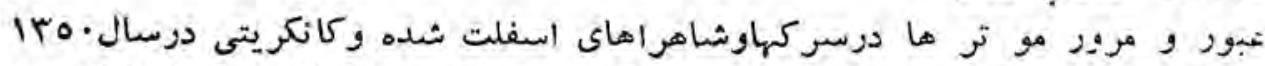

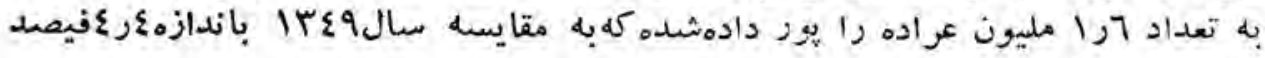
بيشتر مى باشند. 


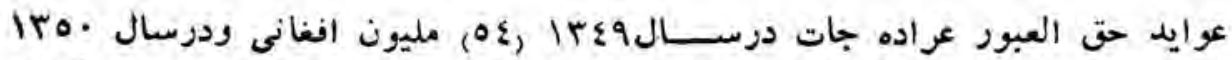

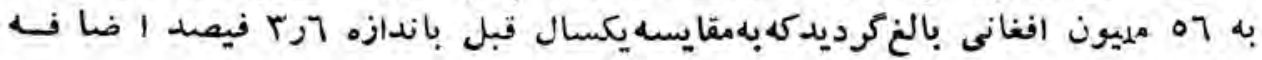

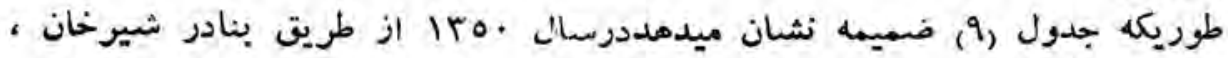

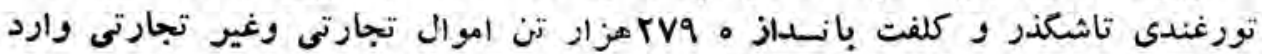

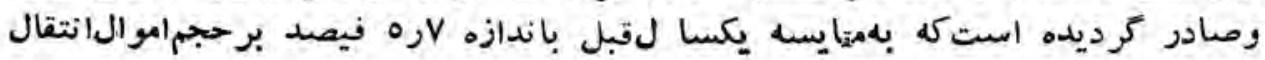

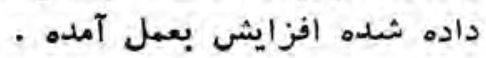

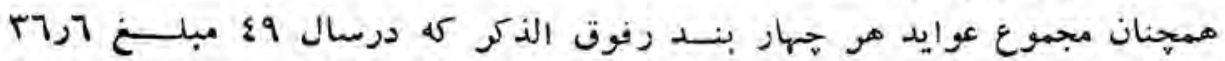

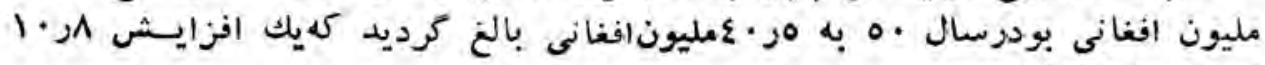

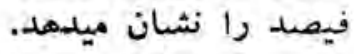

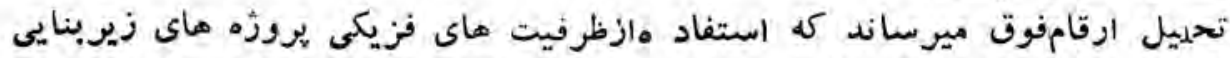

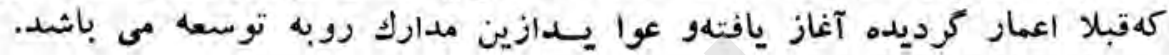

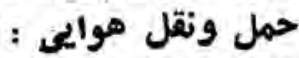

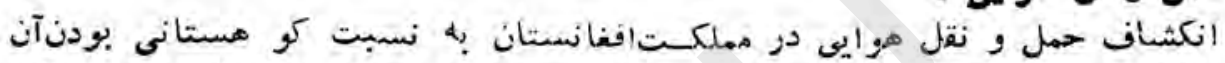

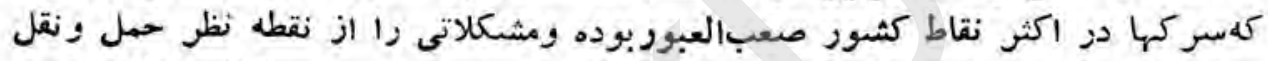

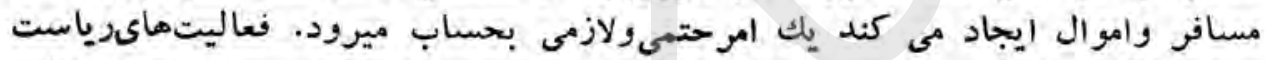

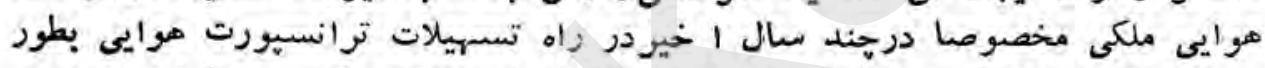

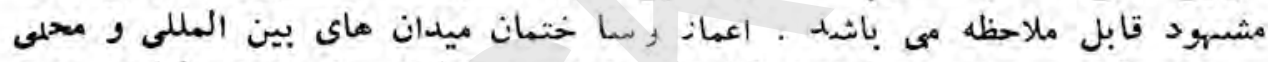

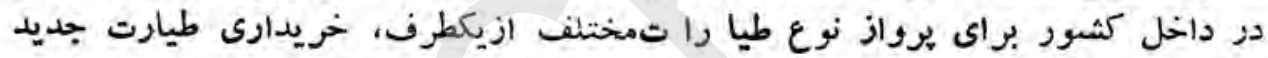

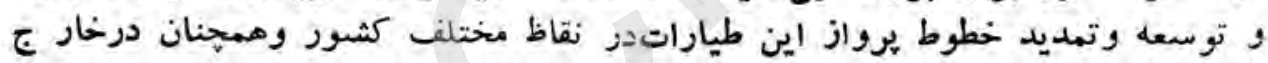

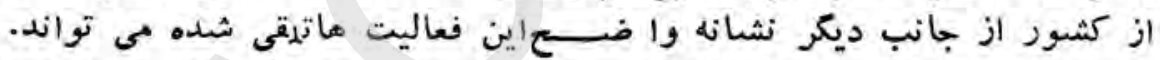

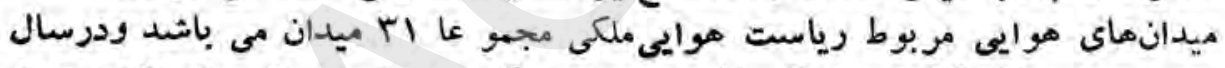
•

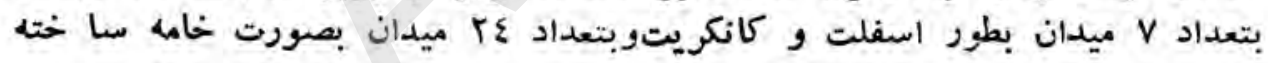

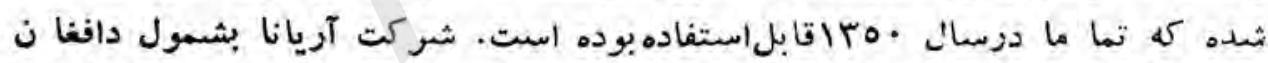

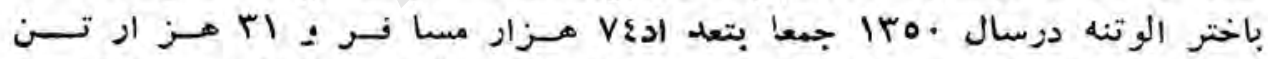

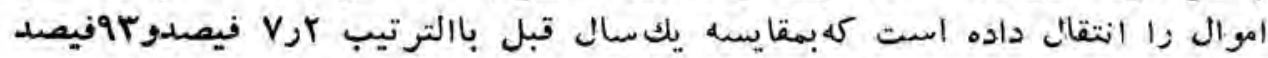

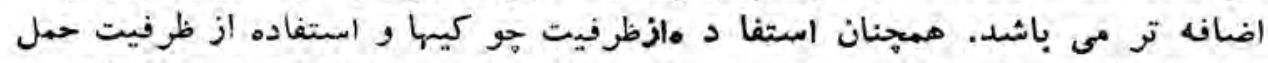

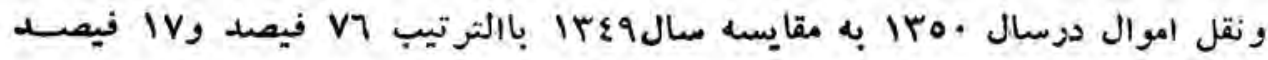

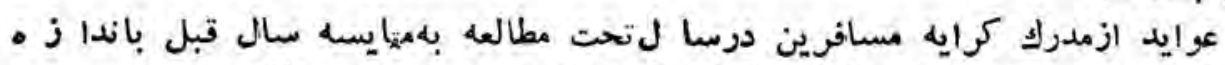

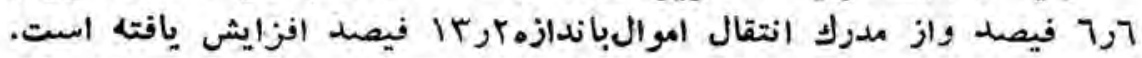

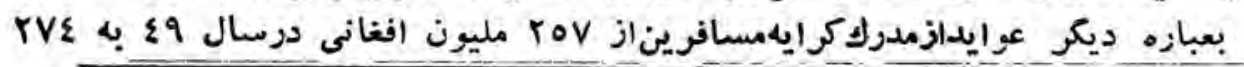

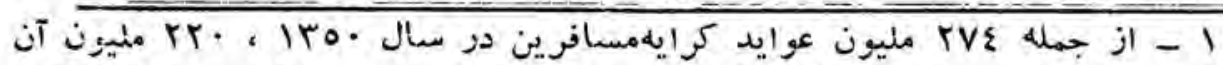

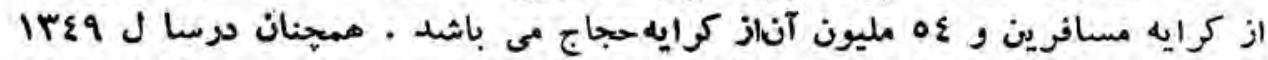

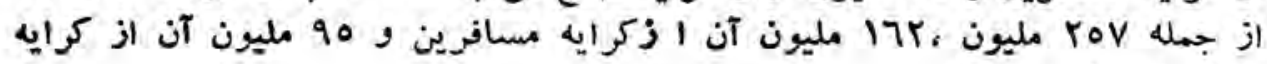




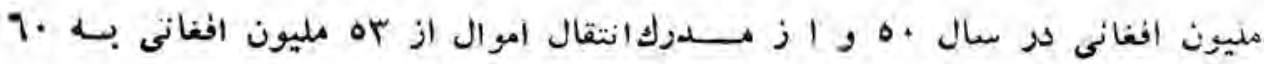

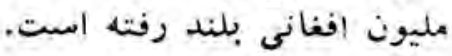

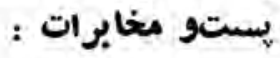

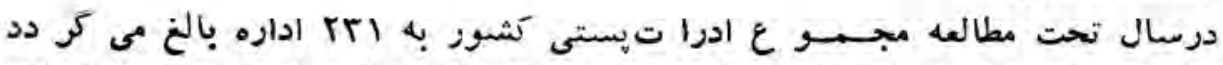

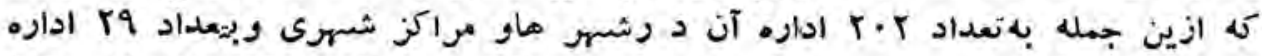

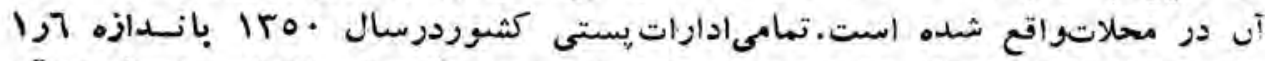

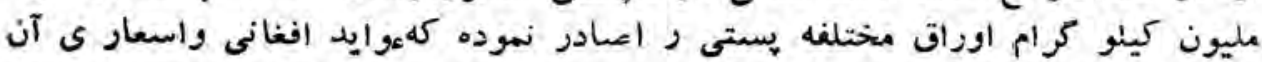

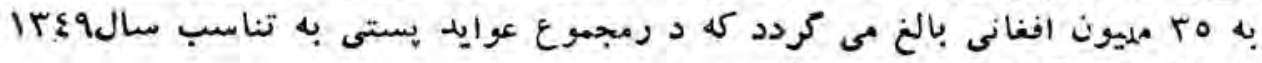
$\div$

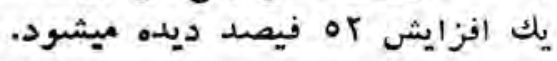

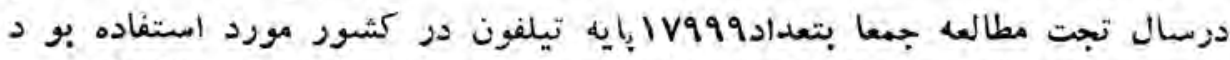

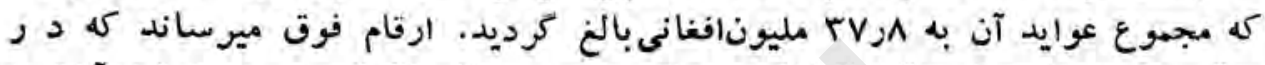

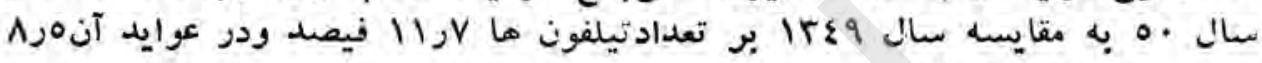

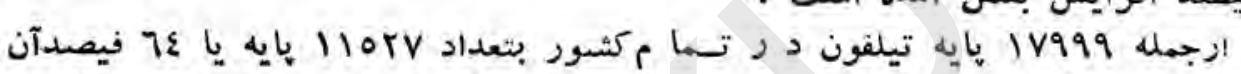

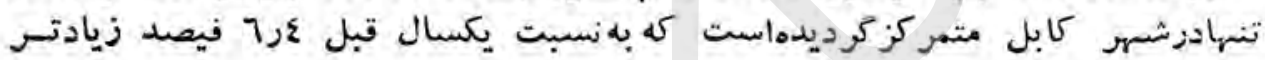
مى باشند.

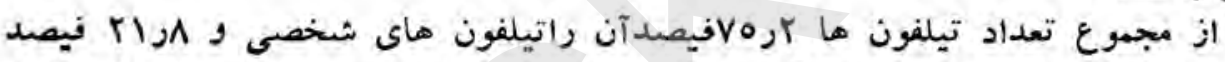

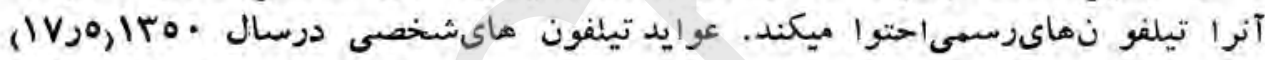

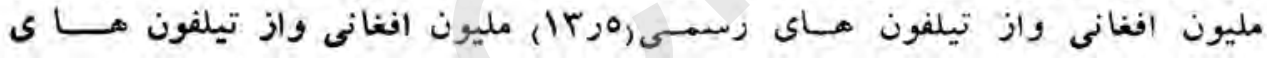

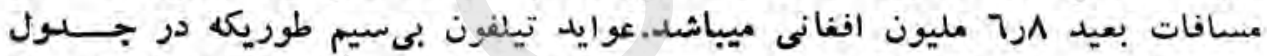

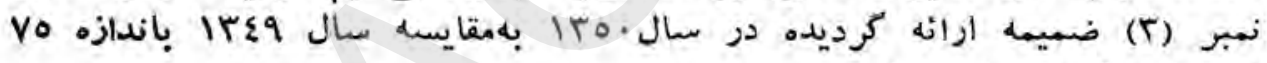

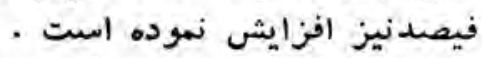

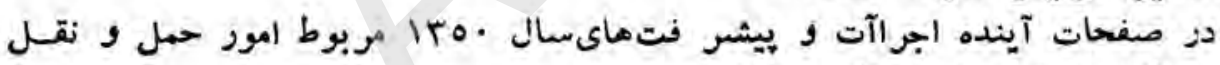
ومواصلات بترتيب ذيل خلاصه آمات ميشود :

فوايد عامه : ومرت

- 1

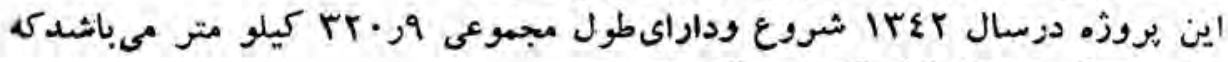

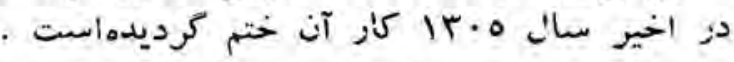

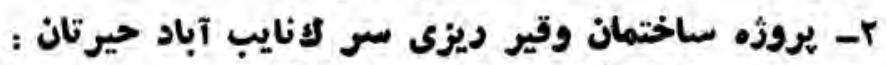

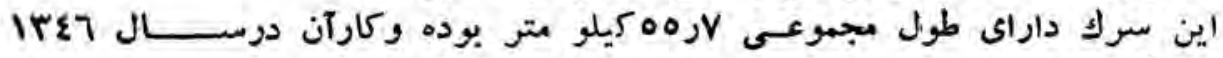

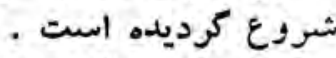

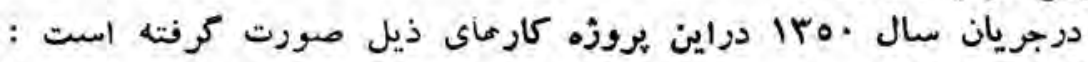

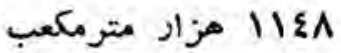
ز7

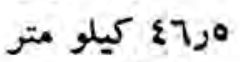
ع ع كيلو متر متر

$$
\begin{aligned}
& \text { ا- خا مه كان كارى } \\
& \text { - r }
\end{aligned}
$$

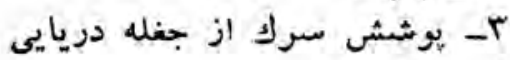

$$
\begin{aligned}
& \text { ع- استوا نى }
\end{aligned}
$$




$$
\begin{aligned}
& \text { o- }
\end{aligned}
$$

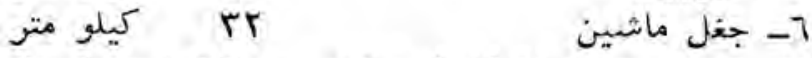

r- سمروى وسا ختمان قيرديزى سر كاكبل

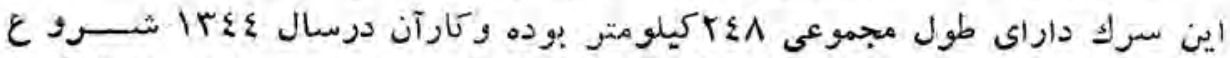

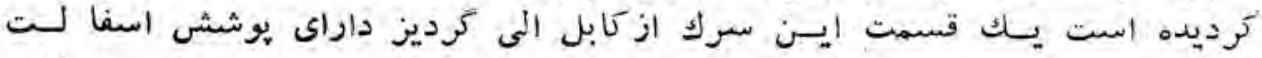

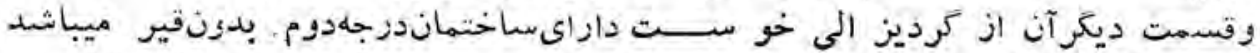

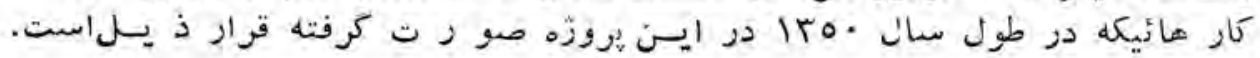

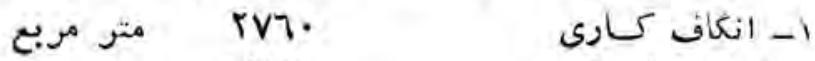

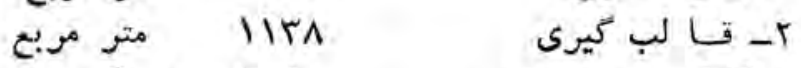

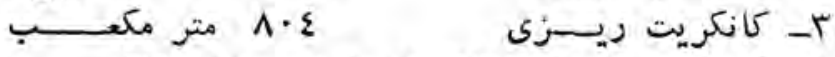

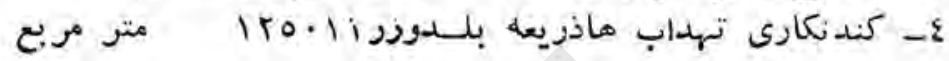

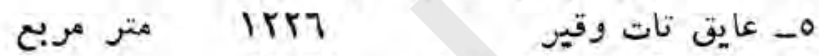

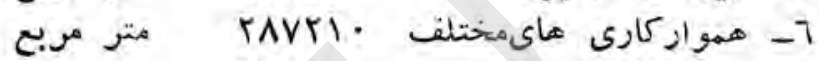

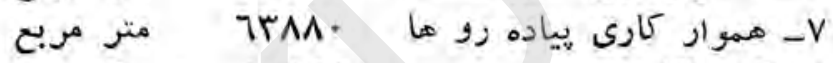

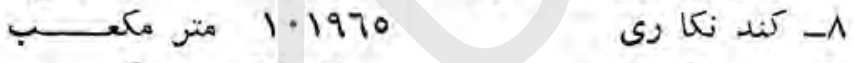

$$
\begin{aligned}
& \text { 9 }
\end{aligned}
$$

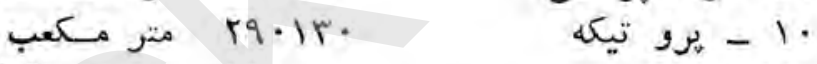

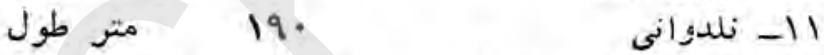

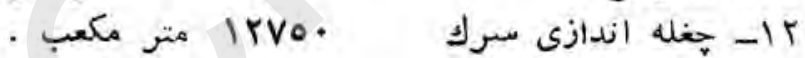

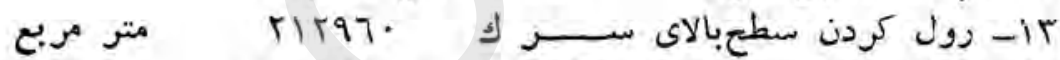

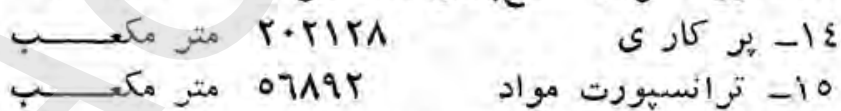

$$
\begin{aligned}
& \text { ع- يروزه حفظ ومراقبت واحدا ثمركها ئ فر فرعن : }
\end{aligned}
$$

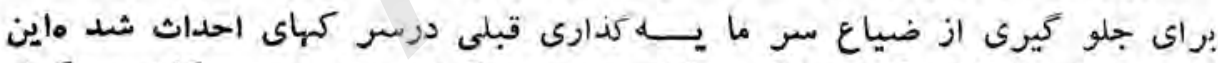

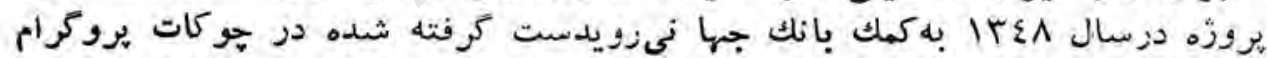

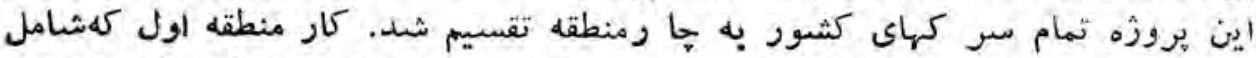

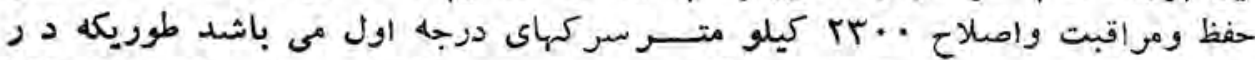

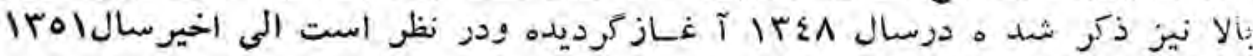

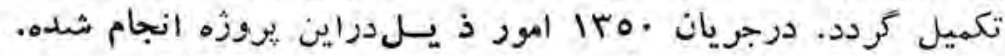

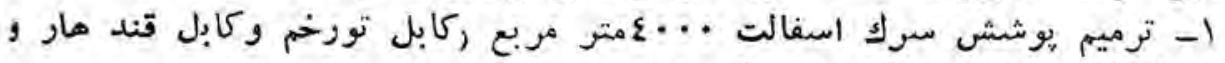

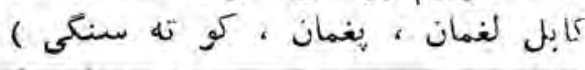

$$
\text { عايق تاث و قير: }
$$

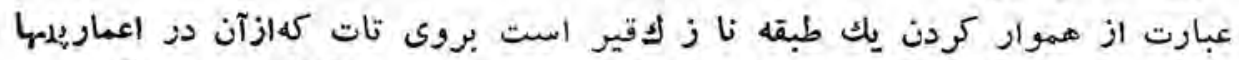

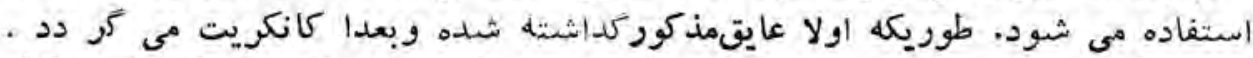

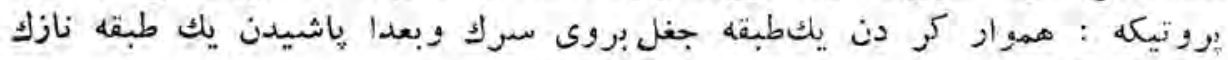




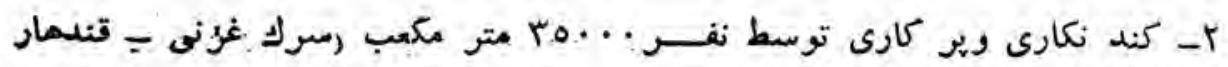
وجاريكار غوربند)

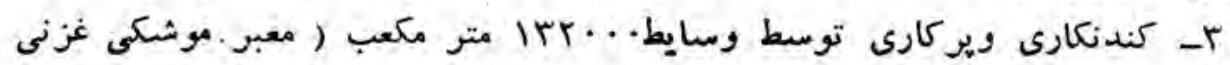

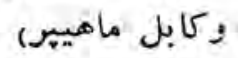

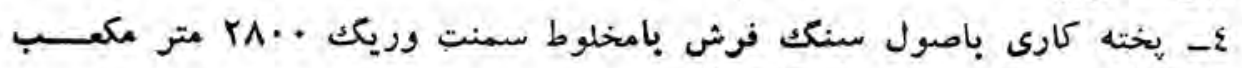

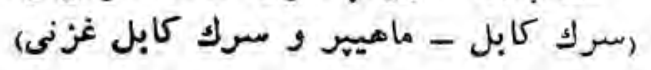

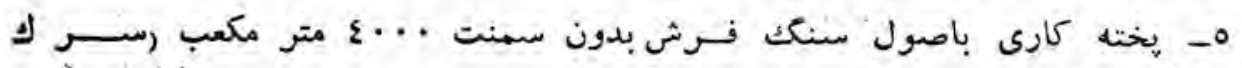

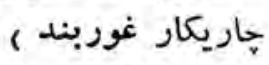

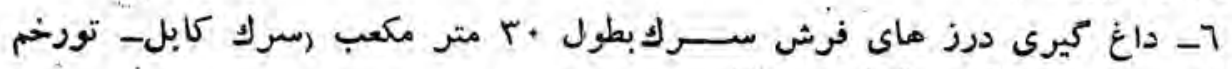

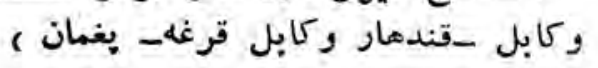

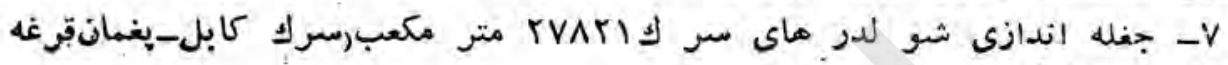
و مابل - جلال بآباد)

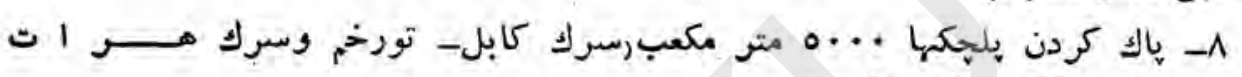
اسلام قلعه وكابل -قند ماند مار)

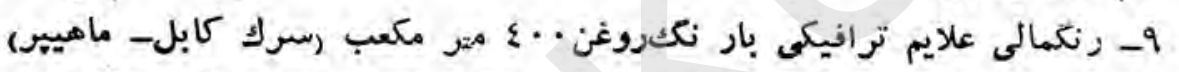

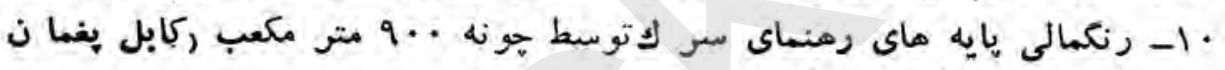

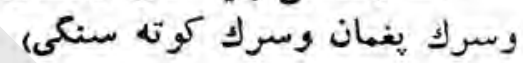

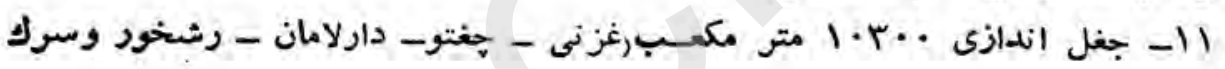
يغمان (1) rr rir

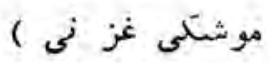

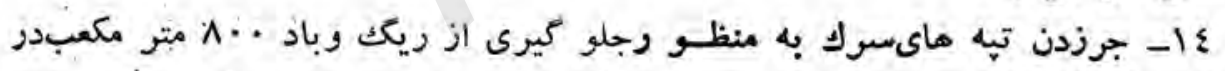

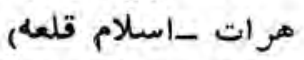

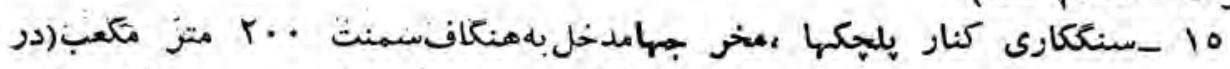

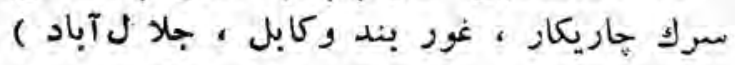

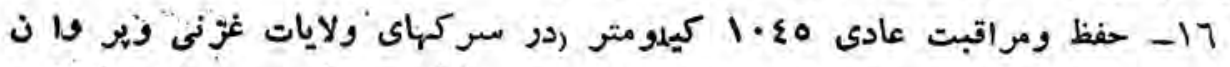
كابل -قندهار وهرات وجلال آبادم

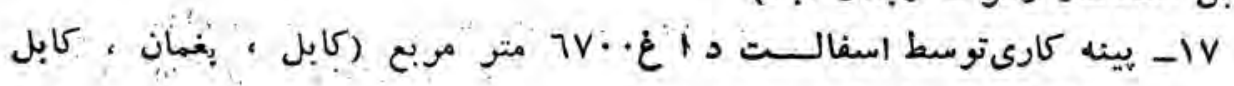

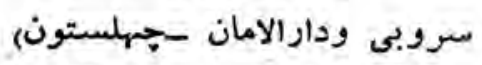

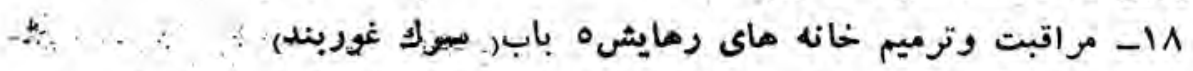

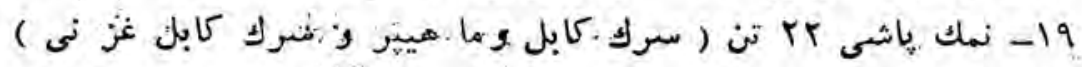

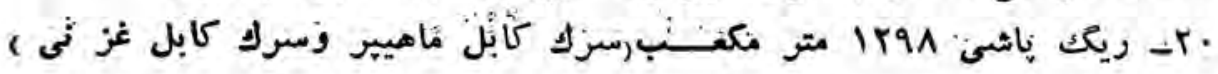




\section{•- يوفره سرك جلال آباه اسعد آبلا:}

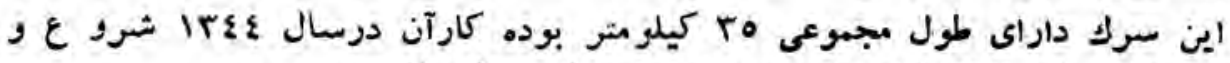

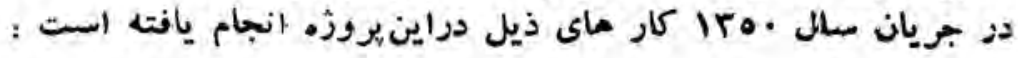

\begin{tabular}{|c|c|c|}
\hline ترت & iror & 1- كندنكارى جوى \\
\hline لم لمتر مكعب & 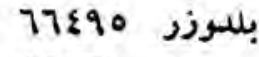 & ז- كندنكارى مدراى ج \\
\hline ت & $\varepsilon \varepsilon v 7 V$ & r- يركارى \\
\hline & $\varepsilon \cdot \varepsilon 11$ & ــ سر نكبرانى \\
\hline & $\varepsilon r r$. & 0- سلایى ربانك \\
\hline & rra. & ר- مسوار كارى ذريع : \\
\hline & 87.7 & 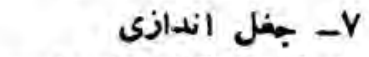 \\
\hline & $19 \Sigma 1$ & 1ــكندن كارى تهدا ب \\
\hline & rostra & 1- سنك كارى \\
\hline هـ & $1 \cdot 0,1$. & • إ- كانكريت \\
\hline 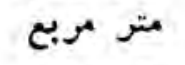 & ץ97, & || \\
\hline & $01 \%, v$ & זו- معكاف كارى \\
\hline & ir & rا- سيخ بندى \\
\hline & 10,7 & عا- عايق تات وقيـر \\
\hline متر طر & re & ها \\
\hline & im & 17- يلستر سمنت \\
\hline
\end{tabular}

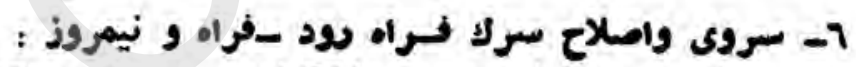

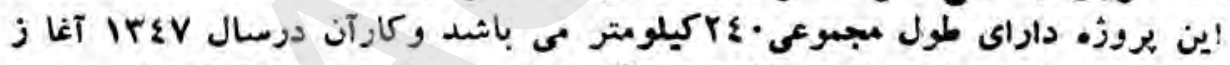

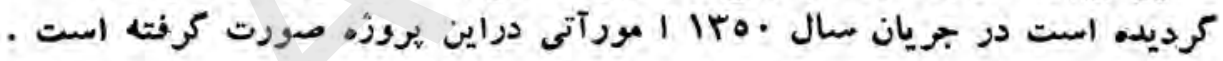

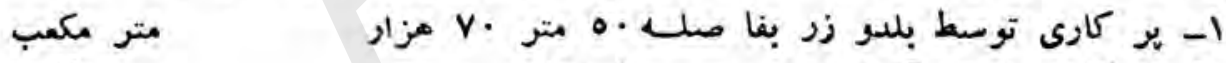

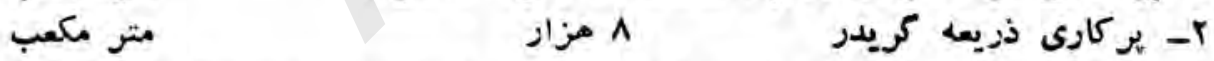

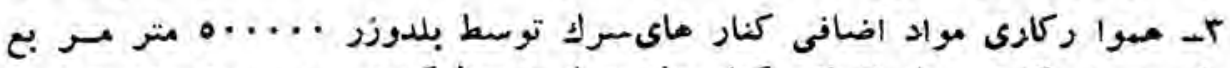

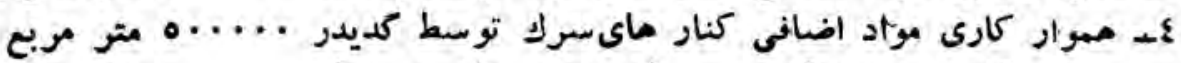

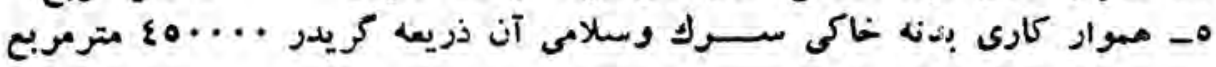

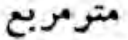

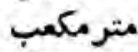

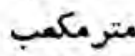

متر مكعب

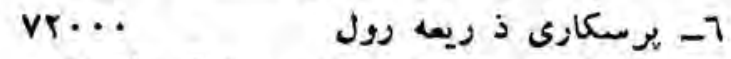

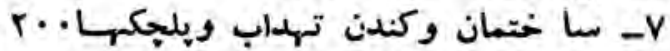

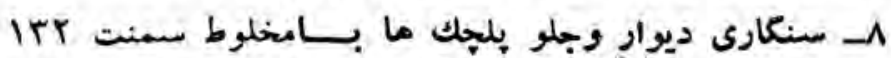

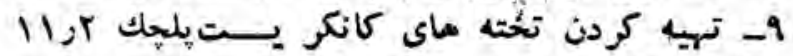

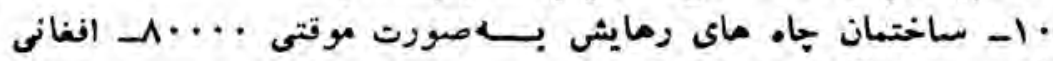

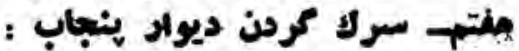

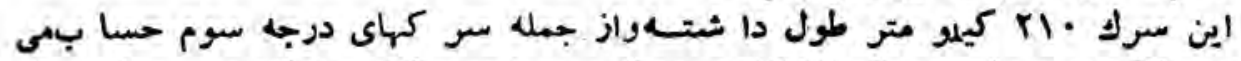

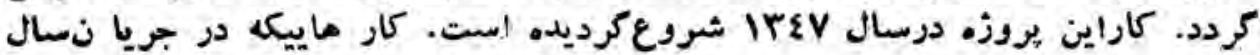
(1.1) 


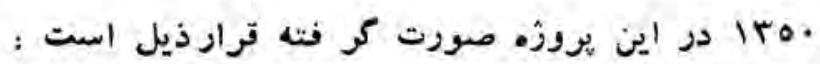

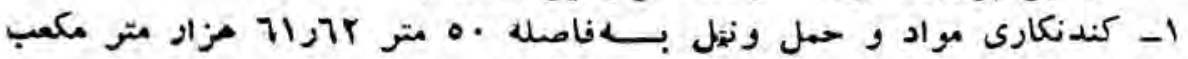

1,0r.

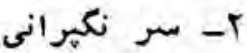

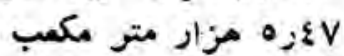

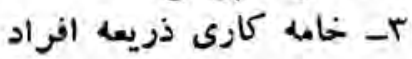

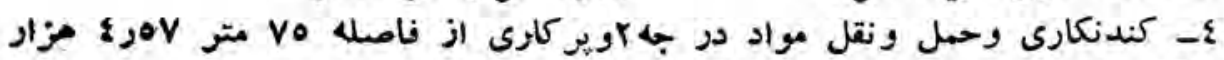

متر معبب

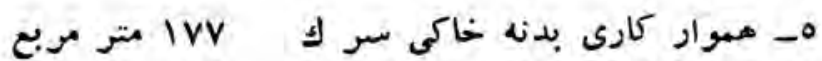

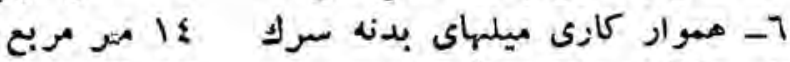

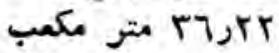

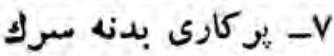

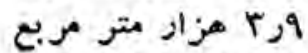

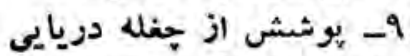

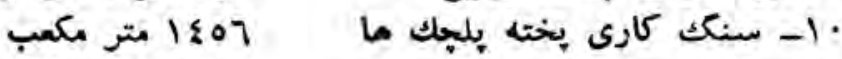

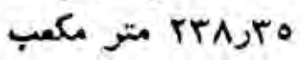

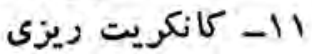

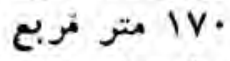

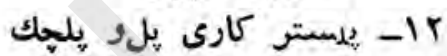

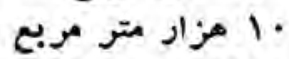

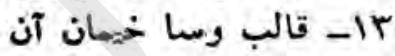

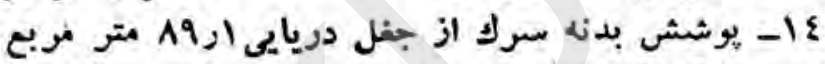

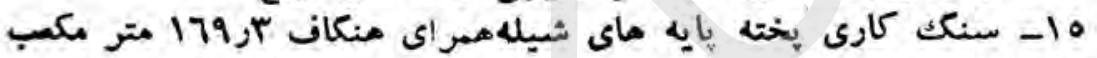

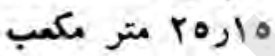

إن

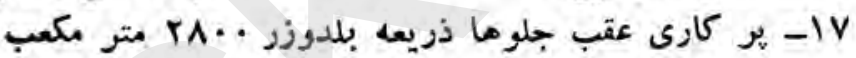

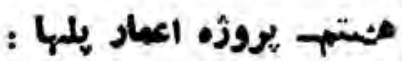

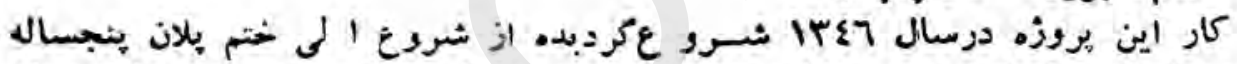

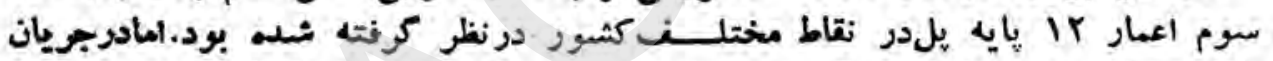

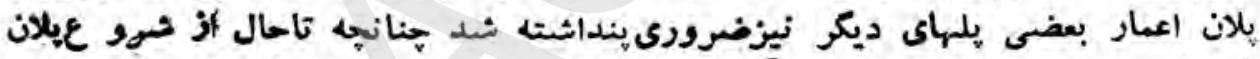

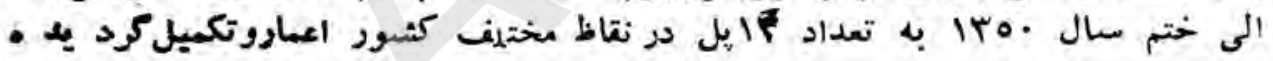

است.

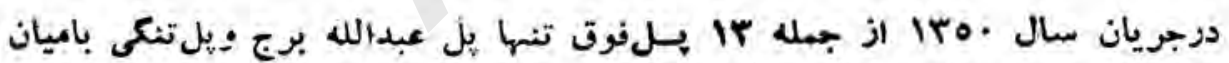

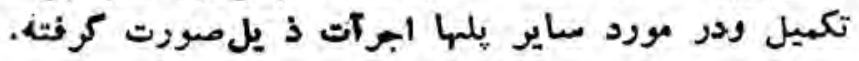

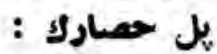

ir..

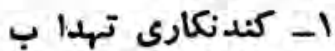

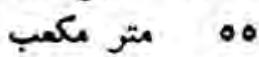

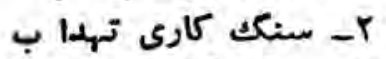

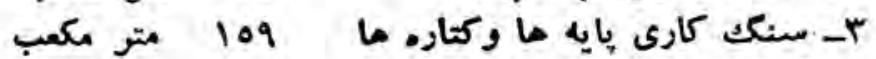

11

ع- كانكريت دو كمان كاري

Vo

•_سنك كارى خشكيد

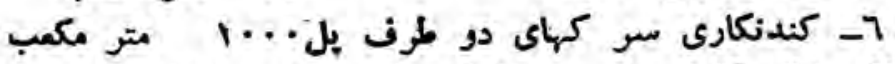

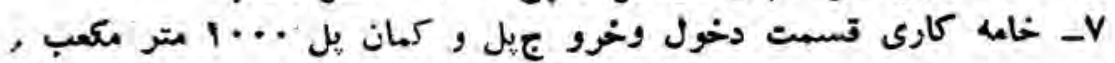

يل داى جويان :

.

ו- كند:كارى تنداق

(1. 5 ) 


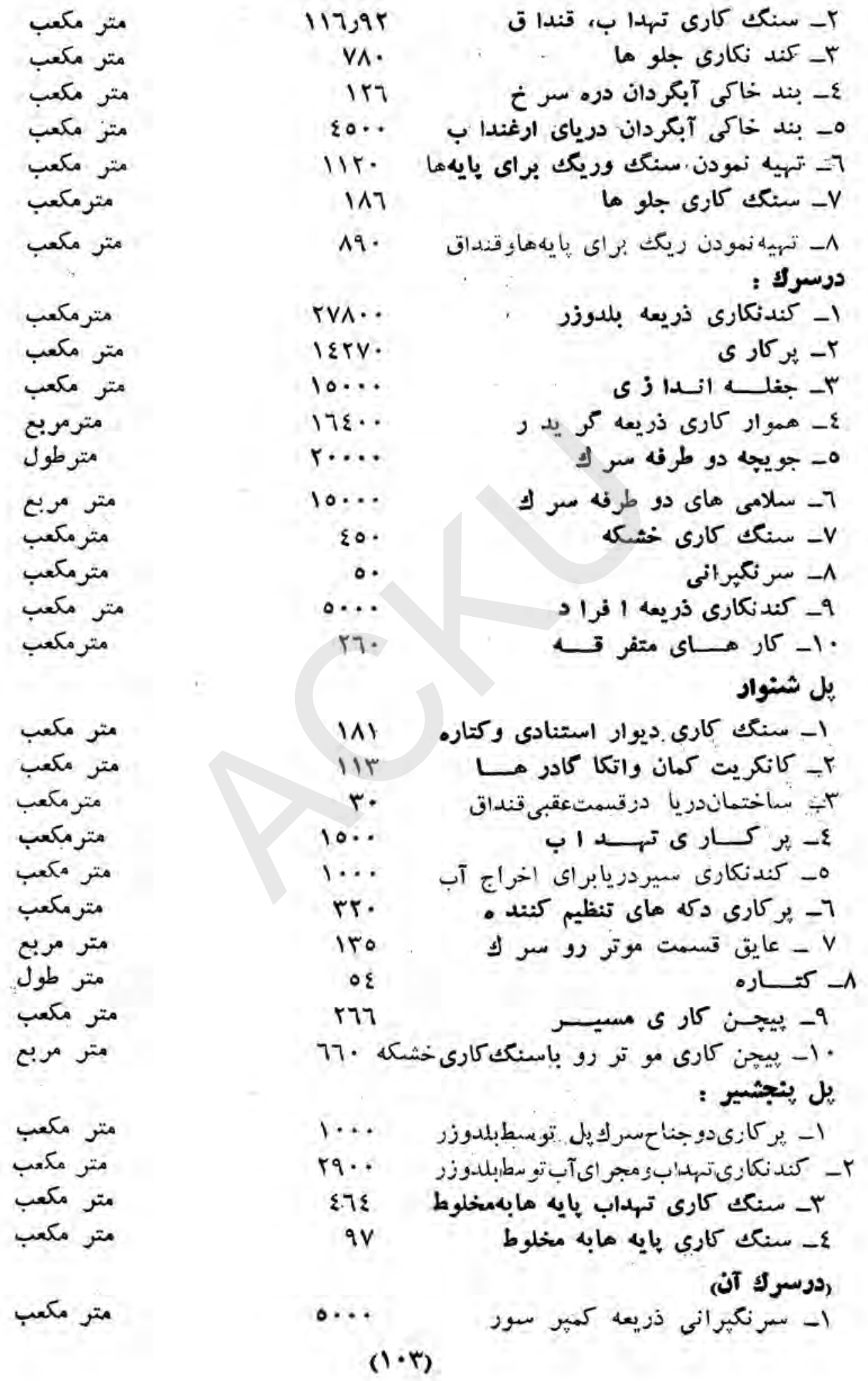


متر مكعب متعب

متر مكعب مكب مترب

متر مربع متعب متعب

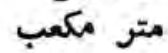

متر مكعب مترب متعب

متر مكعب مكعب
IV...

$0 .$.

$1 \varepsilon 0 . .$,

IET०

TV

150 . r- خامه كارى ذريعه بلدوزر

r- بغ جغل اندازى

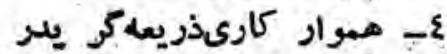

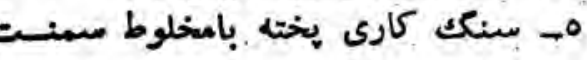

7- كانكويت سيخدار

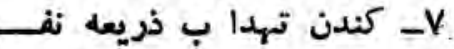

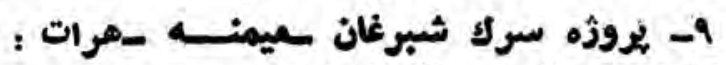

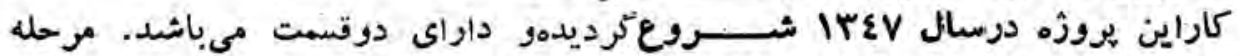

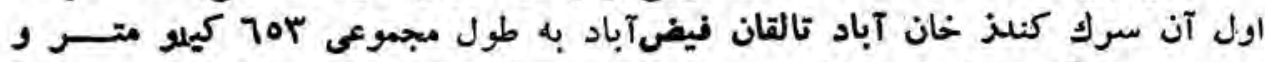

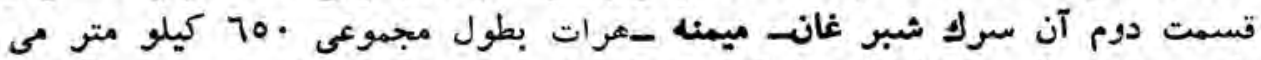

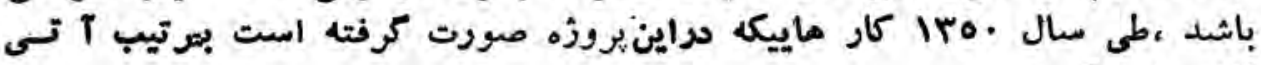

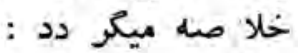

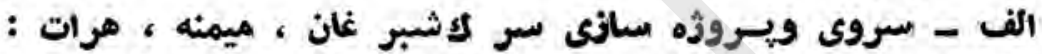

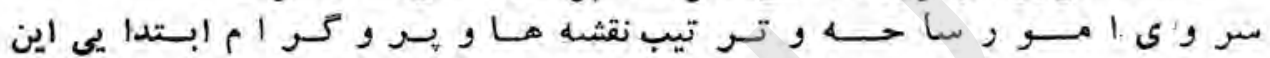

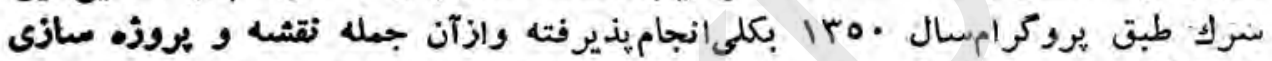

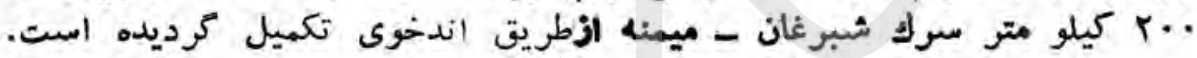

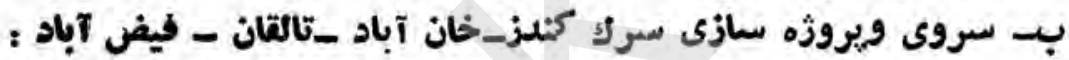

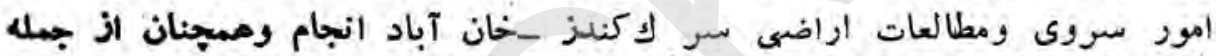

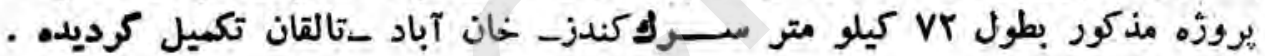
مخابوات :

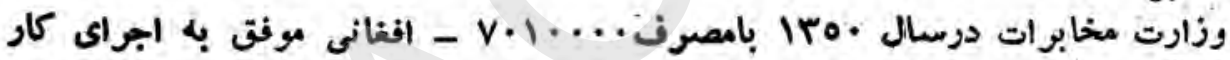

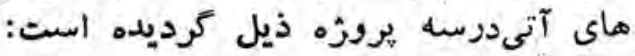

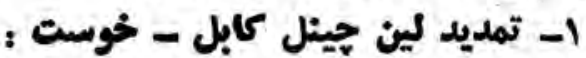

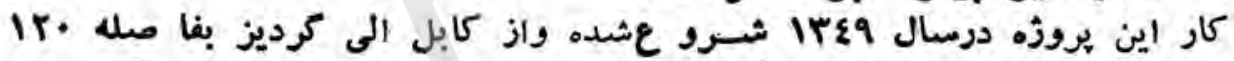

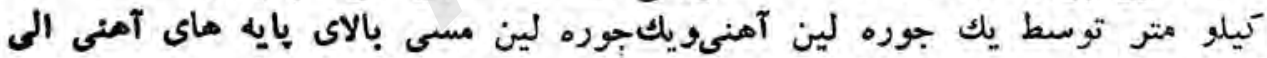

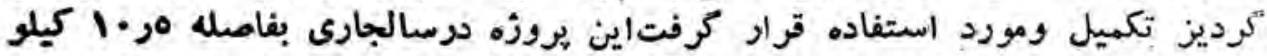

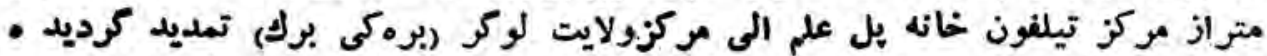

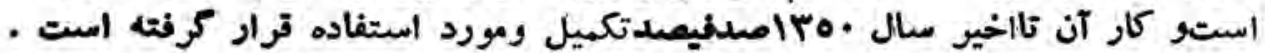

\section{ז- يروزه تعمير ليليه مراكز توبيو ى:}

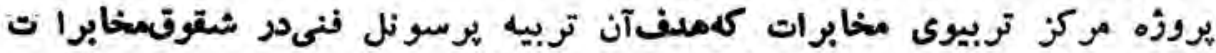

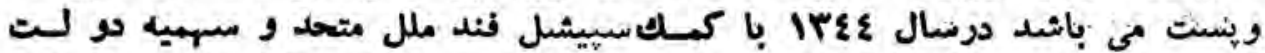

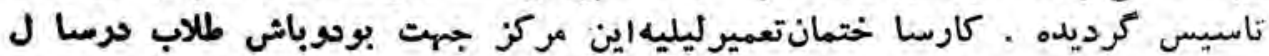

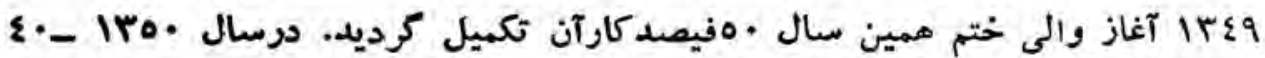

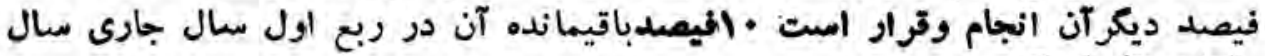
. 


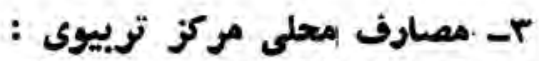

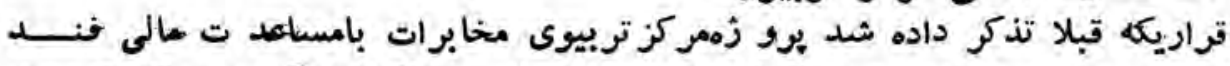

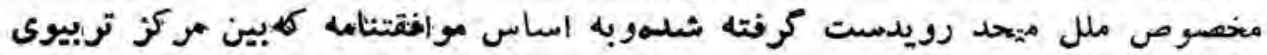

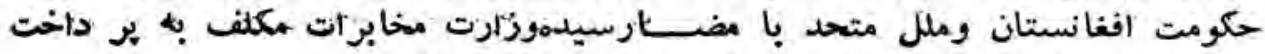

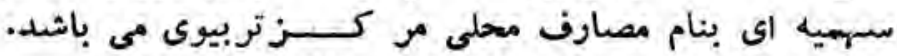

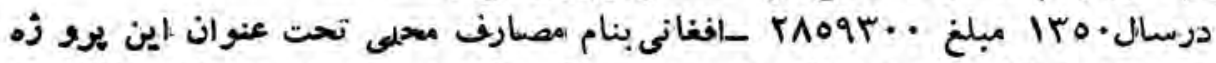

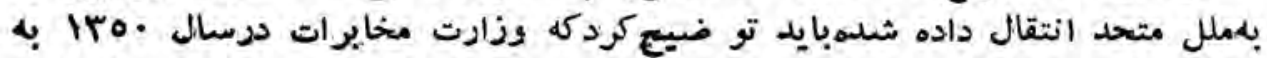

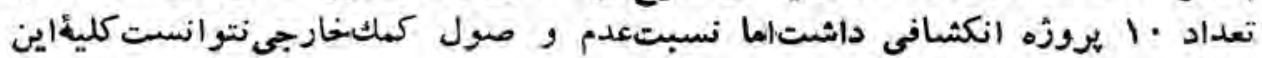

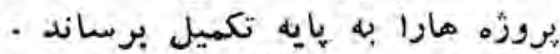

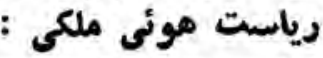

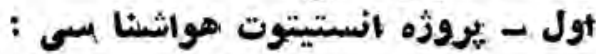

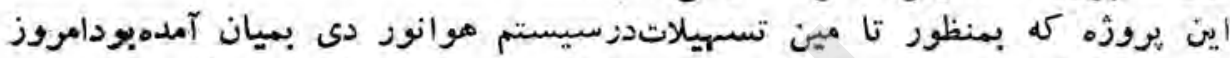

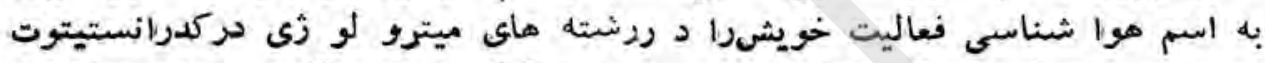

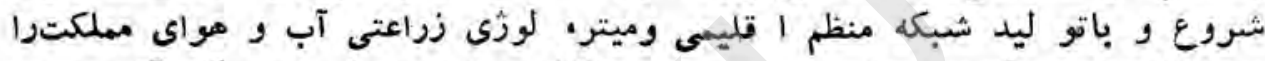

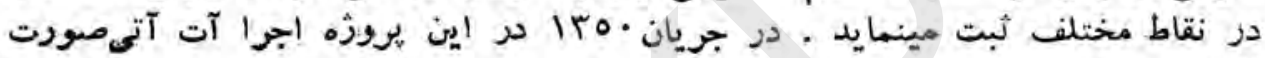

$$
\begin{aligned}
& \text { كرفته است . } \\
& \text { ا- الفميرا ت تعميت }
\end{aligned}
$$

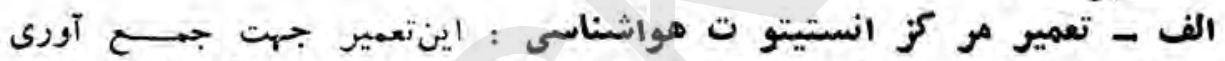

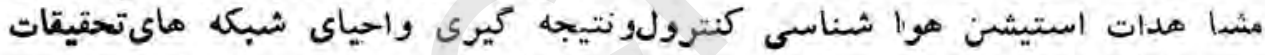

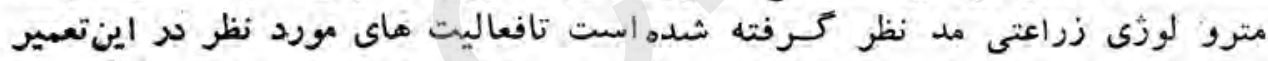

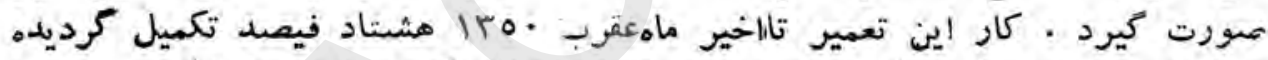

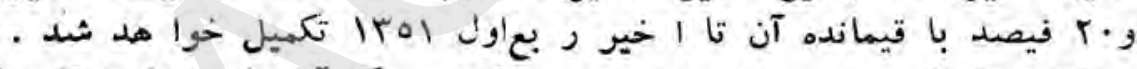

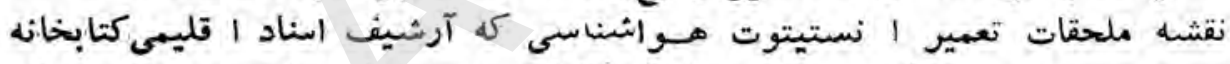

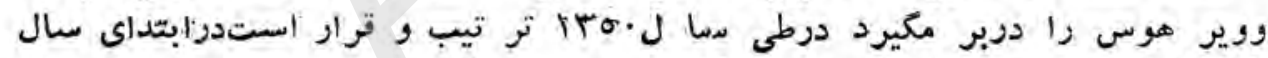

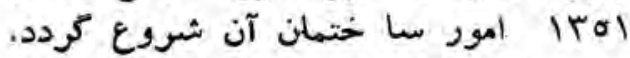

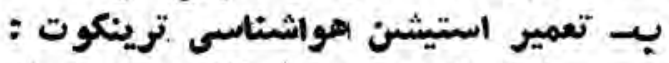

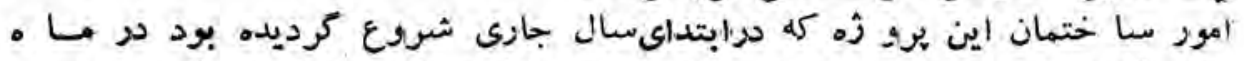

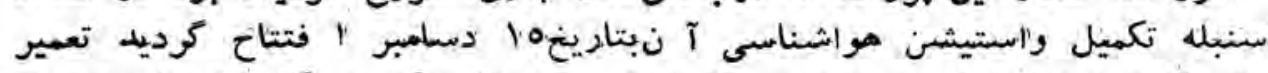

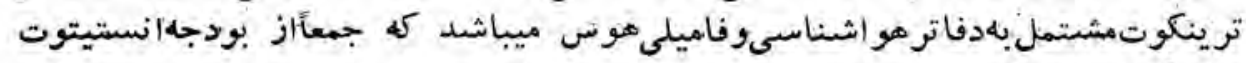

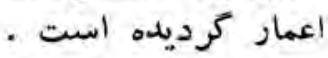

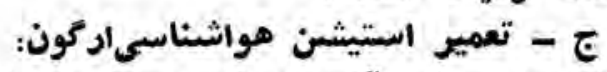

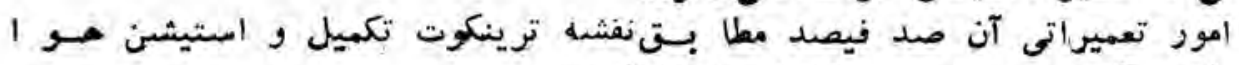

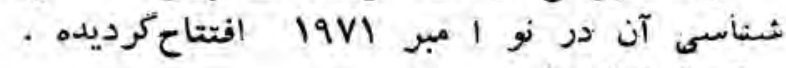

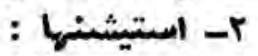

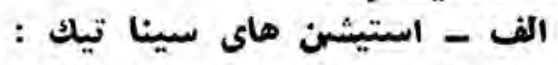

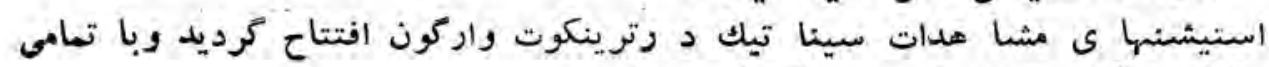

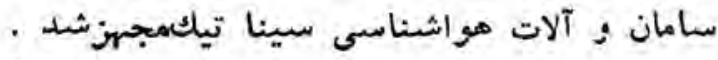




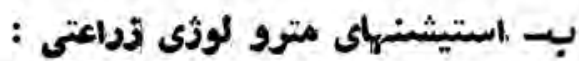

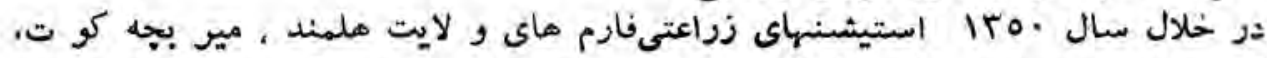

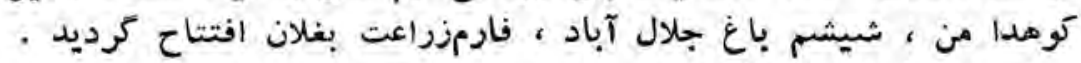

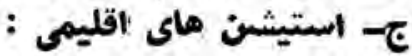

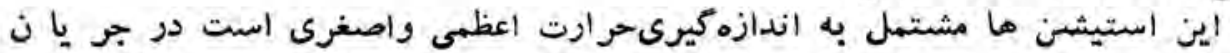

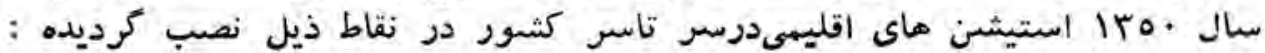

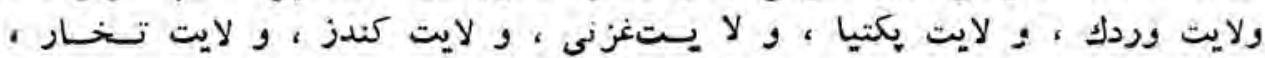

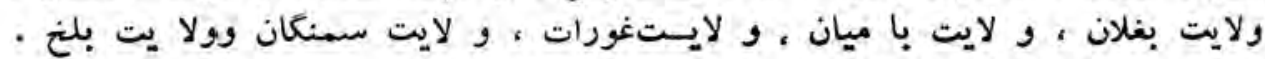

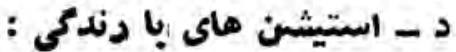

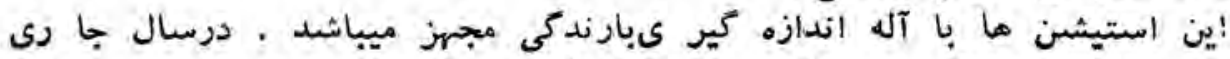

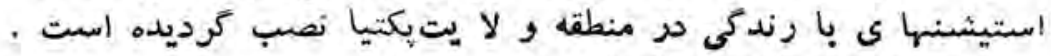

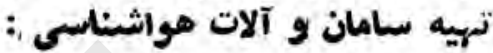

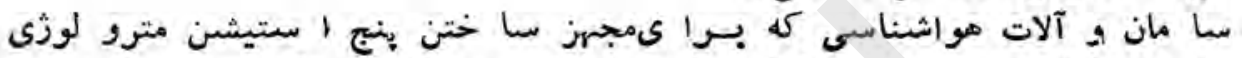

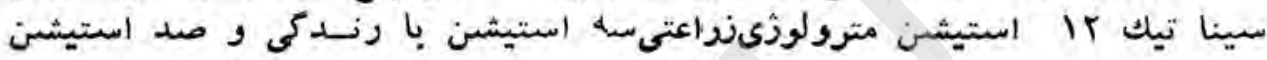

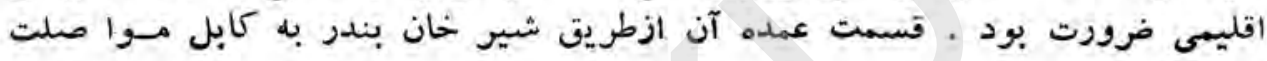

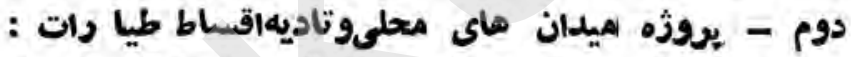

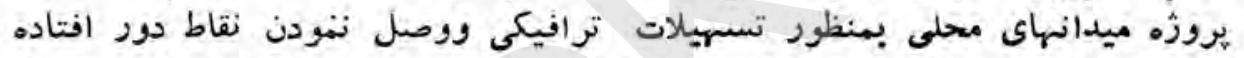

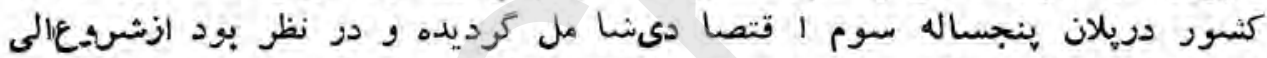

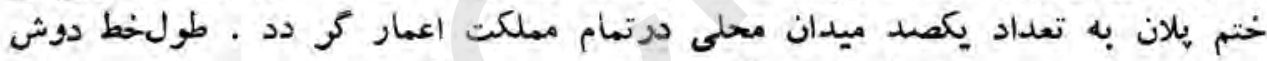

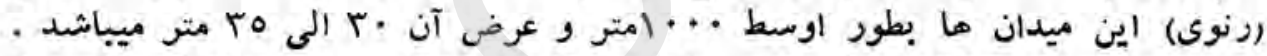

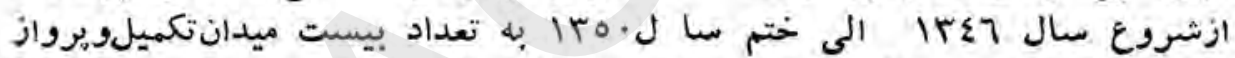

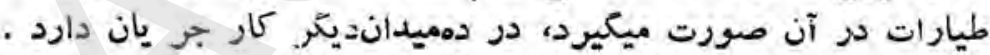

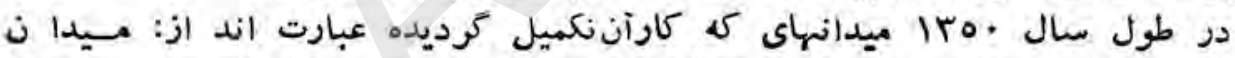

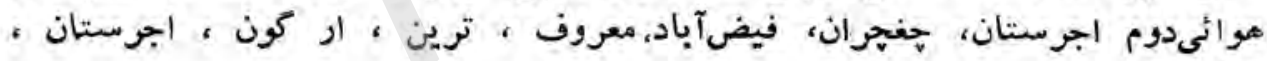

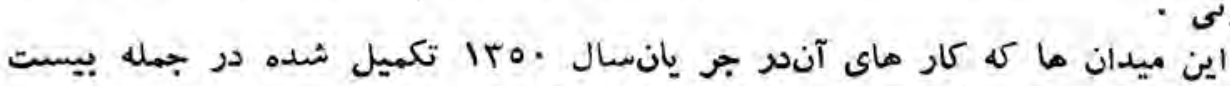

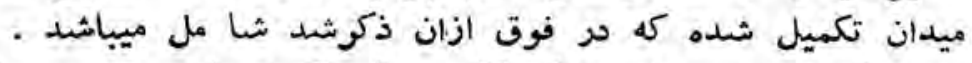

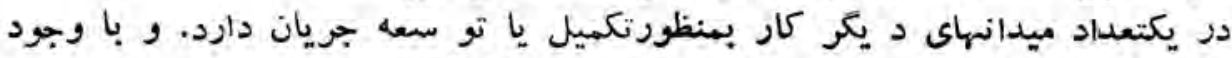

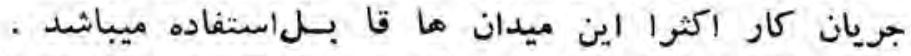

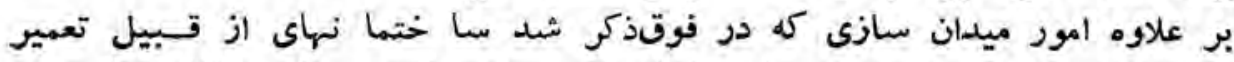

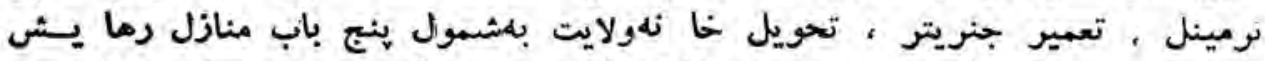

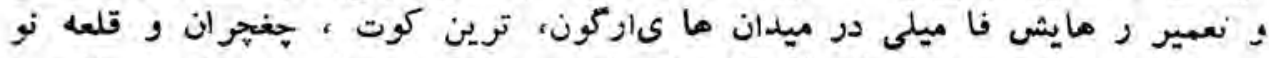

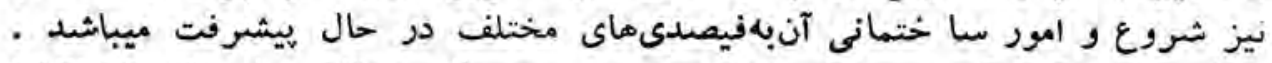

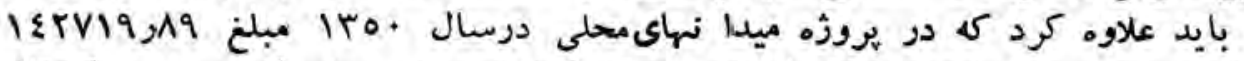

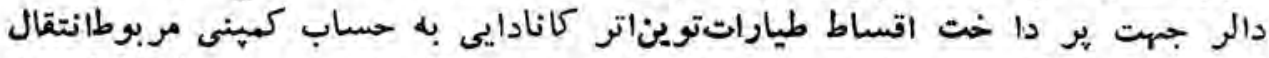

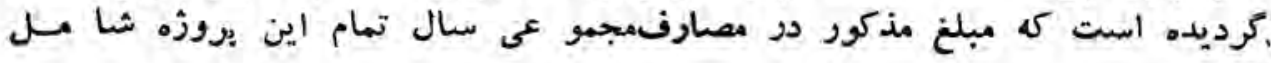


قسمتسوم

ضائماحصائيوى

107 


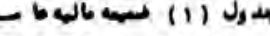

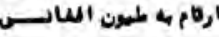

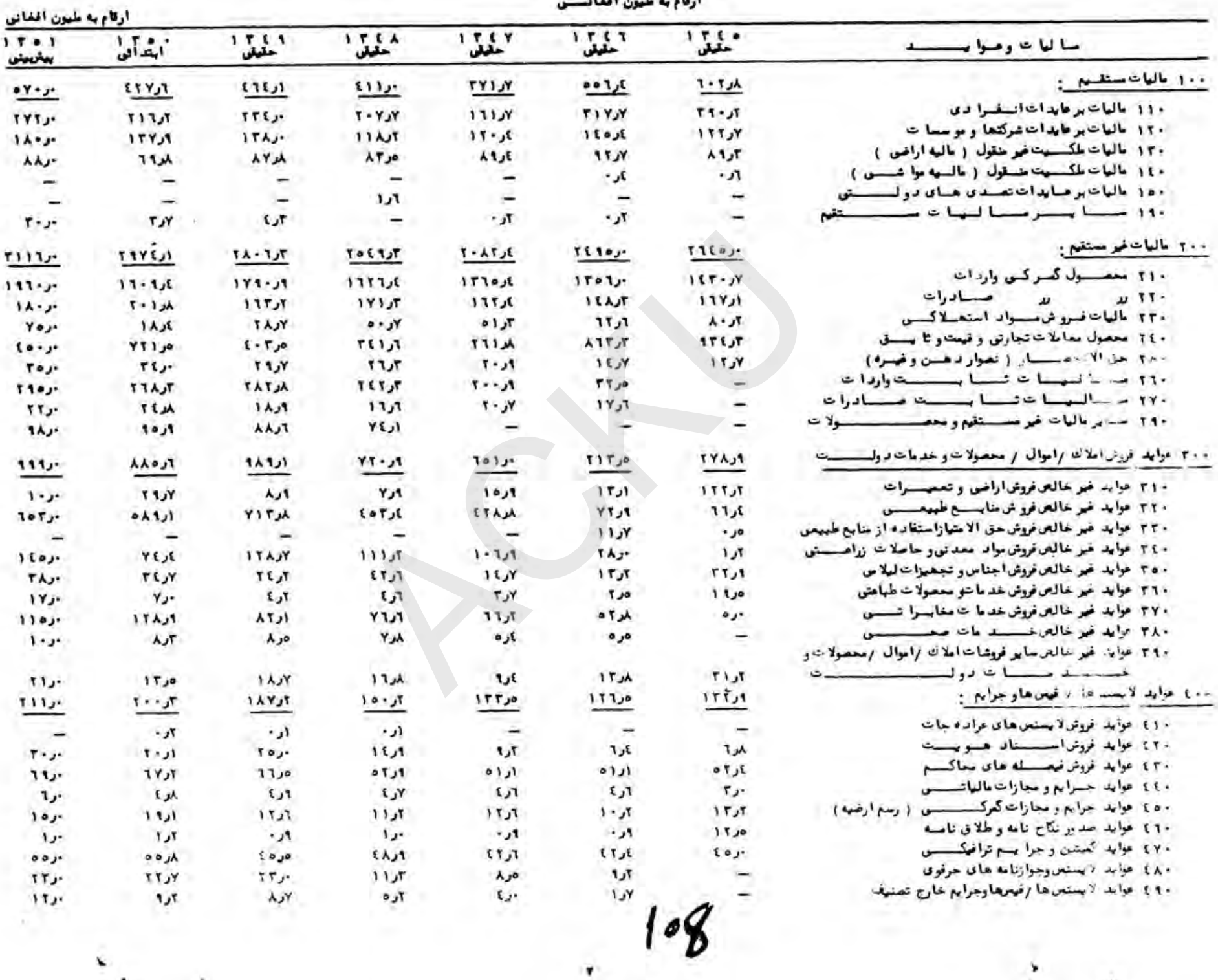




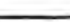

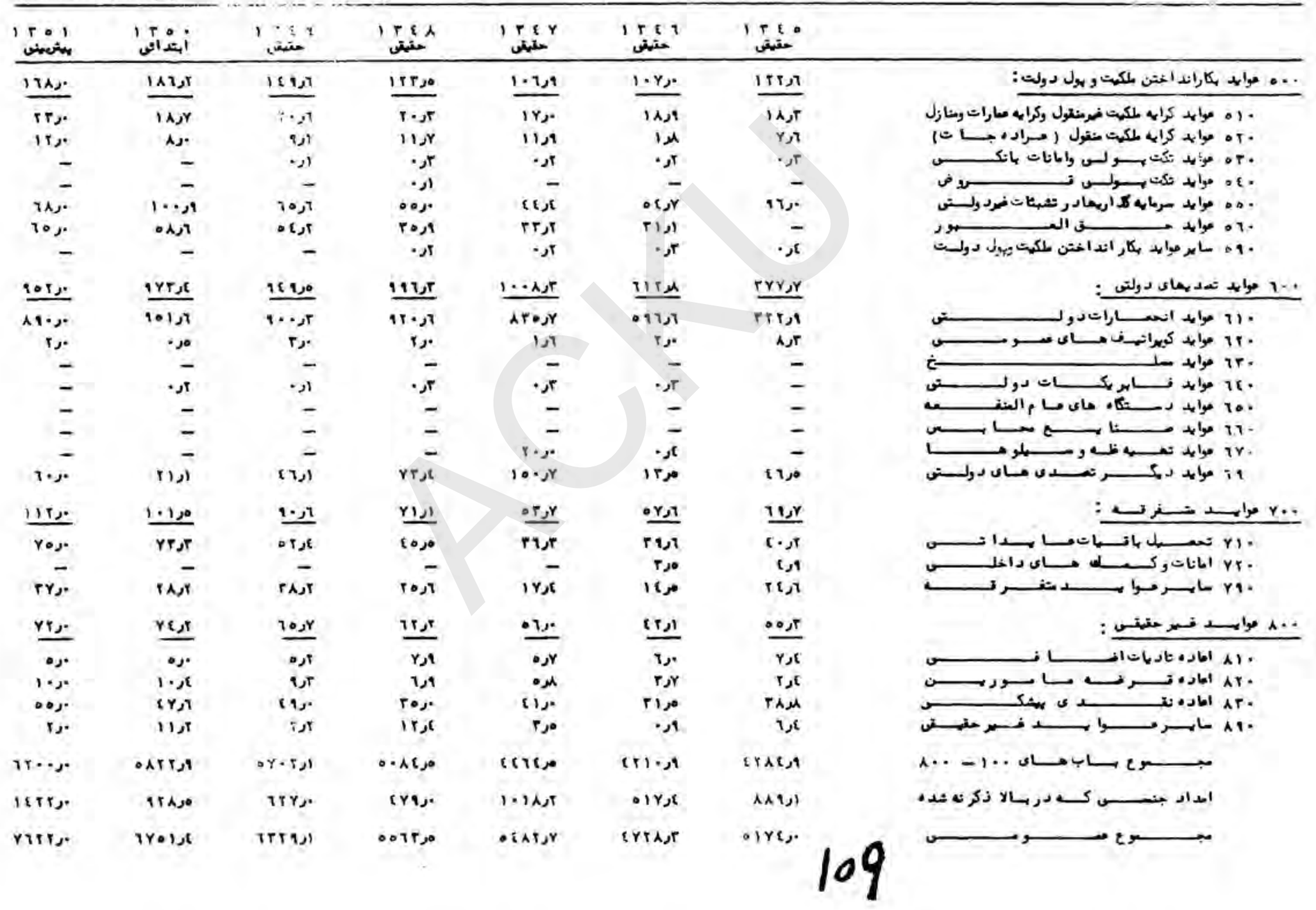


(r) جد, (r)

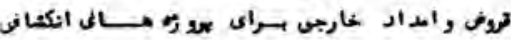

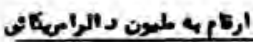

\begin{tabular}{|c|c|c|c|c|c|c|}
\hline $1 \mathrm{ros}$ & $1+89$ & $\operatorname{Irga}$ & irer & IFET & ITto & 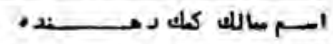 \\
\hline rixy & irstr & TAg9. & T•t & $\{\varepsilon, \gamma\}$ & 000 & 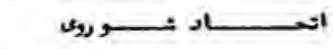 \\
\hline TTर्t & 12,5 & rA,e: & $r \cdot s r$ & $\{\varepsilon, y\}$ & 000 & קטف \\
\hline- & i, & . & $\cdot r$. & - & - & $1+1$ \\
\hline Tre & $r, \ldots$ & 1,0 & \&,Y & $y, T$ & $1 \cdot, \mathrm{rr}$ & اظلا \\
\hline I, I & 11. & - & . & $r, r$. & $\mathbf{T} \boldsymbol{t A}$ & قو ض \\
\hline T & 1, & se. & $E, 1$ & ril & rus & 1+2 \\
\hline 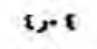 & ו וד & $r$ r. & rer & OSY : & roor & عكورت فــــرالى البـــان \\
\hline ?.96 & Iرe & r & Ef & rתוt & Y,rr & تر وف \\
\hline ז'ו & - & istr & ז... & T. & • זני & Il \\
\hline- & - & - & - & - & - & 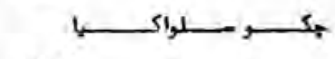 \\
\hline- & - & - & - & - & - & قر وض \\
\hline- & - & - & - & - & - & امداد \\
\hline- & 1ر. & 0,1 & •per & torA & - & مـت بـ \\
\hline- & •וرו & T 1 & $0,0 \mathrm{~T}$ & ind & - & تر وض \\
\hline- & - & - & - & - & - & اعداد \\
\hline זדתו & וונז & T, & ग्ञ & $\operatorname{sid}$ & זותו & 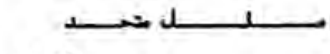 \\
\hline- & - & - & - & - & - & مد ض \\
\hline זת & ווגזי & id & T21 & -91d & זותו & المداد \\
\hline- & $\cdot \mu \cdot r$ & $\cdot y \cdot Y$ & •र्र. & - & - & 4 \\
\hline- & - & - & - & - & - & مد ثن \\
\hline - & $\cdot \mu \cdot r$ & $=\mu \cdot r$ & . & - & - & امدار \\
\hline- & - & r & שית. & - & - & 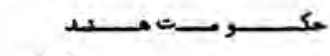 \\
\hline- & - & - & - & - & - & קروض \\
\hline - & - & +4 & 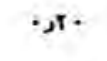 & - & - & إساد \\
\hline- & - & - & - & - & - & 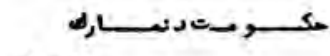 \\
\hline - & - & - & - & - & - & كسرض \\
\hline - & - & - & - & - & - & إنداد \\
\hline 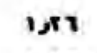 & 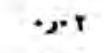 & - & 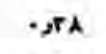 & - & . re & L \\
\hline T זر & 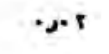 & - & era & - & - & تون \\
\hline- & - & - & - & - & sto & It \\
\hline- & 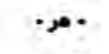 & - & - & - & - & $\longrightarrow$ \\
\hline- & - & - & - & - & - & הע ט \\
\hline- & $\cdot 0$ & - & - & - & - & ll \\
\hline $1 \Rightarrow 8$ & - & - & - & - & - & 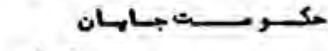 \\
\hline ت امرا & - & - & - & - & - & تص خ \\
\hline- & - & - & - & - & - & الد اد \\
\hline Pt,rt & $r r_{\rho} A$ & Extr & $0 ., \pi \cdot$ & וגA & YEAT & مبس ب \\
\hline 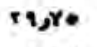 & $r \cdot y+x$ & TExt & cus. & $\bullet$ & Testo & המ מט \\
\hline t & 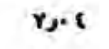 & IJYF & $1, \ldots$ & itr & $1 \cdot 211$ & ا إد \\
\hline
\end{tabular}




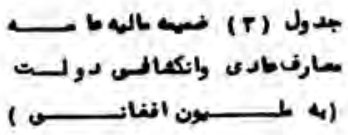

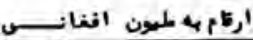

\begin{tabular}{|c|c|c|c|c|c|c|c|}
\hline 17.1 & irisi & I $P \leqslant 1$ & $1 T \& A$ & 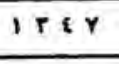 & I $1: 1$ & 150 & \\
\hline Arate. & reinen & valkse & 110ror & T.rejr & 0101 & iris. & \\
\hline TAJ) & \& & (1) & TAرo & rar & rris & Fit & \\
\hline קוקי & TAR & IIر & ז & res & TEst & 18 & \\
\hline 180 & مو: & 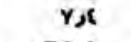 & $r, T$ & Y ו & r r & Ys & \\
\hline$r \cdot j \cdot$ & ist & एव & $r \circ \mu$ & Prot & ris & $r \bullet \boldsymbol{~ r . ~}$ & 2 \\
\hline A\&J. & $A I J$ & Yונ & r l & זעו & YC: & Yest & 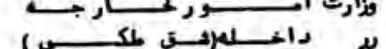 \\
\hline 1.8 & rase & $r 2,1$ & irrs & $r \cdot r$ & or & IAST & 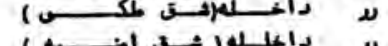 \\
\hline TY*J: & - & ra.j & זותו & $T \cdot(1)$ & $100, r$ & I 1 & 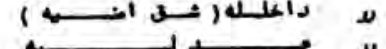 \\
\hline r.s. & $r \cdot, r$ & 196 & Tر & T: & $r \cdot \boldsymbol{~}$ & or & مـ \\
\hline וק. & 11600 & $1 \cdot 1 \varepsilon$ & A11 & $1 \cdots \gamma$ & ITy & erefe & (t) مسالسها \\
\hline rrov & VTIS & ז' & ותד וד & \&rt) & $19 \cdot 0$ & rTAps & ע \\
\hline Y90, T & Yral & 19.2. & 7๕1ை & $r \cdot \boldsymbol{r}$ & مرمبr & $\operatorname{licj}$ & 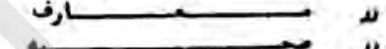 \\
\hline $19 \cdot s 1$ & TI0נY & 112. & ir.sr & 181 & ותיזו & مرا111 & $=1$ \\
\hline ryו & צTנ & YIXY & 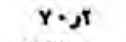 & ver & its & $A \cdot s$ & $\nu$ \\
\hline $2 \cdot 0,2$ & cises & $\{A 1)^{\circ}$ & Eras. & $c \bullet$ & ratst & $x x \cdot x^{2}$ & $\stackrel{\nu}{\nu}$ \\
\hline 101,0 & 100,9 & •रTر & $r=1, \alpha$ & $x \cdots$ & -rts & |ATS| & 2 \\
\hline (T), & EY.st & $20 . x$ & ह1ז & -IAJ & Equit & & i \\
\hline קr. & Al & rral & $r \bullet \boldsymbol{~}$ & $1.1 x$ & ונט & it & $\stackrel{\nu}{\nu}$ \\
\hline$A \cdot S \cdot$ & דוג & VE & זינr & $T$ •r & rist & (0) & "و \\
\hline סر T & 160 & 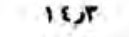 & 185 & $10 ر$ & 185 & 110 & J \\
\hline rr. & ז & V T & זתזr & $5 \cdot 21$ & אرזr & res & ون \\
\hline مرب1 10 & مره 19 & זמזז & $19 x$ & ז & IrAsr & VA, r & نو \\
\hline - & - & - & - & - & - & זरा & we \\
\hline- & - & - & - & - & - & 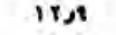 & ren \\
\hline is. & ז & Tر & ז & ז & Fr. & (1) & or \\
\hline As $r$ & $1 \cdot \gamma_{1}$ & 16,1 & $A \&, \lambda$ & AIs & IASY & itr & עل \\
\hline - & קر. & $r, 1$ & Y & Yot & 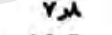 & YoA & واد \\
\hline Irro. & $1 \mathrm{r}, \mathrm{r}$ & $\| r ر$ & $|\pi r|$ & 11824 & AI & Al, & $\begin{array}{l}\nu \\
\nu\end{array}$ \\
\hline Irop & IY.s. & $r 0,$. & - & - & 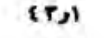 & - & ע \\
\hline - & - & - & - & - & - & - & ע \\
\hline - & - & - & - & - & $r r, r$ & ارץr & i \\
\hline- & $\cdot x$ & צ ק & ז & f.j. & Arj. & TAر & $\frac{d}{b}$ \\
\hline 10, & $9 \cdot 20$ & The & Ard & $\left(\gamma_{j}=\right.$ & rril & $r \cdot \boldsymbol{r}$ & 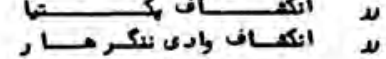 \\
\hline- & - & - & - & - & - & ro: & 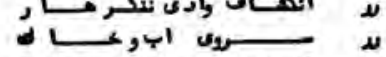 \\
\hline- & - & - & - & - & - & - & 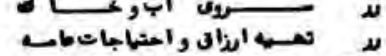 \\
\hline 10,4 & - & - & - & - & - & - & 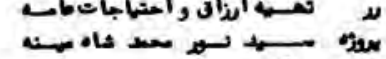 \\
\hline- & - & - & - & مرا & 18\% & I & 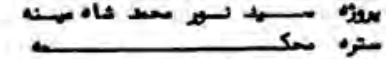 \\
\hline 1.10 & ונז1 & 1) $\mathrm{Na}$ & A. & - & rvi & - & بانه \\
\hline r. & - & AN & - & - & - & - & v. \\
\hline $189 \cdot 20$ & I Tres. & 18140 & Irtas & זנrזיו & IIASOH & 1. & (1) \\
\hline 1. & - & - & - & - & - & - & ; \\
\hline qASt & - & - & - & - & - & - & 2 \\
\hline 180 & - & - & - & - & - & - & 4 \\
\hline 10 & - & - & - & - & - & - & 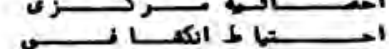 \\
\hline - 1 & - & - & - & - & - & - & \\
\hline
\end{tabular}


جدول (6) حسعه طالهه طاك

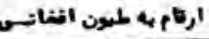

\begin{tabular}{|c|c|c|c|c|c|c|c|}
\hline 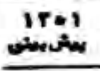 & أن & $\begin{array}{r}1 r E x \\
\sin ^{2} \\
\end{array}$ & $\begin{array}{l}1+1 \\
\text { Red }\end{array}$ & קitr & $\begin{array}{c}1+82 \\
\text { and }\end{array}$ & irco & \\
\hline -ATÉ & $\because \cdots \cos$ & $\bullet 1 \cdot Y, Y$ & (Yris) & steT & PرIוT & $r \varepsilon \cdot t r$ & 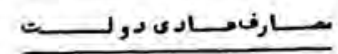 \\
\hline ras & (T). & (i) & rajo & एव, & ris & 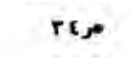 & وزارث در بــــ \\
\hline TIر. & rast & rix & ris. & 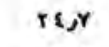 & Ix & 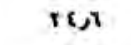 & 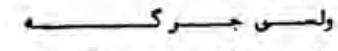 \\
\hline נת: & $1 \cdot 3 \cdot$ & $r, x$ & 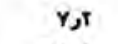 & $Y, 1$ & Y & Y, & $\longrightarrow$ \\
\hline r•, & C & ras & roph & 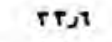 & ( & res. & 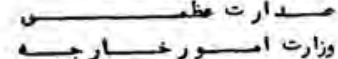 \\
\hline AEs. & $A 1, Y$ & rrol & $r(\boldsymbol{l}$ & $x$ & 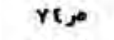 & res & 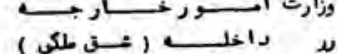 \\
\hline II & $x=2$ & ותו & -14 & ozor & erst & זركث & 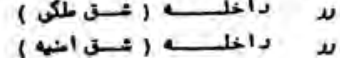 \\
\hline rres. & - & ra.ri & $r(x, t)$ & $r \cdot 1,1$ & 1/48 & זוג & 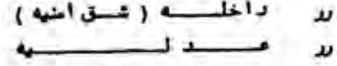 \\
\hline r.x & $r \bullet r$ & 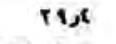 & 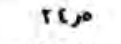 & $r \cdot \gamma$ & $r \cdot 30$ & كرن & 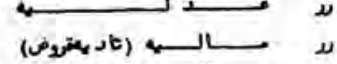 \\
\hline 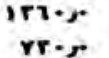 & 118. & 1.18, & Axts & r.y & 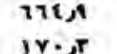 & 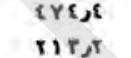 & 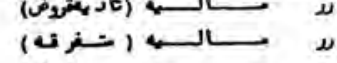 \\
\hline 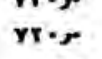 & $\begin{array}{l}\text { WTst } \\
\text { Wavis }\end{array}$ & $\begin{array}{l}\cdot 17, \pi \\
1(r, 1)\end{array}$ & $\begin{array}{l}-110 \\
01 E \text { TI }\end{array}$ & $\begin{array}{l}r r \cdot x \\
\cdots \cdot \cdots\end{array}$ & $\varepsilon \varepsilon 0, c$ & rar, & i, \\
\hline par & $12 \pi r$ & iraed & ITye & iा & $1,98 \pi$ & $1 \mathrm{x}$ & $\omega$ \\
\hline 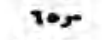 & 18 & ITr & irst & $\bullet \varepsilon r$ & $\operatorname{ctgh}$ & $2 Y, r$ & 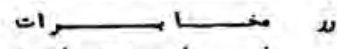 \\
\hline קיטוט & irt & مر111 & $18 \cdot 21$ & IEA, & $1 \cdot 7, \pi$ & けル & 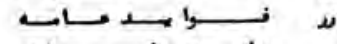 \\
\hline$\bullet$ & - & זעו & ETS & $\bullet r, r$ & $c \cdot x$ & {$[\gamma, \boldsymbol{x}$} & ست \\
\hline A.r & irit & ivre. & |rदs & ror & $Y \cdot \boldsymbol{Y}$ & $\cdots$ & 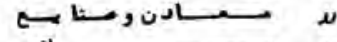 \\
\hline tro & $r Y, x$ & tres & $r \bullet r$ & $1.9 x$ & וקוז & $r \cdot x$ & ن \\
\hline ver & $r r, x$ & Vו, & וני & irs & Tr,P & $(2,1$ & 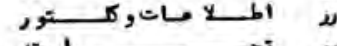 \\
\hline rrve & $16 \pi$ & $|r|$, & IT & (T) & ITת & 184 & $\approx$ \\
\hline ver & ותוז & " مرTr & 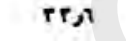 & $r \cdot \mu$ & ry & $\mathrm{rTzh}$ & * \\
\hline r*x & irase & 178,5 & IGA & IrAด & זיر: & •xر & نـتون \\
\hline- & - & - & - & - & - & مراب & 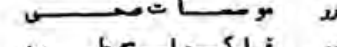 \\
\hline - & - & - & - & - & - & $1, \pi$ & ba \\
\hline tr: & T & ror & וرז & זرו & $r$ & 1 & en \\
\hline $2 \cdot x$ & $|\lambda|$, & זות & 1031 & III & [9, & TAر4 & a \\
\hline- & $\boldsymbol{r}_{\boldsymbol{j}}$ & Y, & Y & Yرo & You & Y, & ترا نسهو ر \\
\hline rro: & $r x$ & rope & $r u r$ & זנו & זנוז & T: & tis \\
\hline - & - & - & - & - & - & - & . \\
\hline - & - & - & - & - & - & - & ا \\
\hline- & - & - & - & - & ir & 110 & 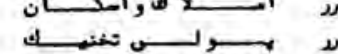 \\
\hline- & זהת & मे & $\cdots$ & - & - & مر & انكفيكافيكا \\
\hline- & - & - & - & - & - & - & وادى نعك \\
\hline- & - & - & - & - & - & - & 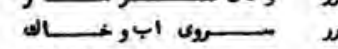 \\
\hline- & $\begin{array}{l}- \\
-\end{array}$ & $\begin{array}{ll}- \\
-\end{array}$ & $\begin{array}{l}- \\
-\end{array}$ & - & $\begin{array}{l}- \\
-\end{array}$ & - & 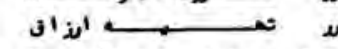 \\
\hline- & - & - & - & - & - & - & 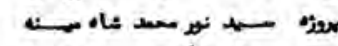 \\
\hline קוץ & |r| & is: & $r \cdot \gamma$ & cos & rug & - & 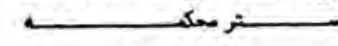 \\
\hline $16 \mathrm{x} \cdot$ & ניקצre & |rr.s & Irres & IIIII & $111 \cdot 3$ & 1.2100 & رع تصن \\
\hline
\end{tabular}


بدول (0) ) خعه ماله كاثه

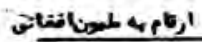

\begin{tabular}{|c|c|c|c|c|c|c|c|}
\hline 1.:1 & $\begin{array}{l}\text { Iro. } \\
\text { जisel }\end{array}$ & $\begin{array}{c}\text { irfi } \\
\text { Rat }\end{array}$ & حغلى & 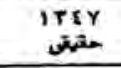 & $\begin{array}{l}1+8 \\
178 \\
0\end{array}$ & $\begin{array}{c}\text { Ir\&a } \\
\text { - }\end{array}$ & \\
\hline זะx-y & $1+18,1$ & Irr.jr & ITr & $I A T \cdot x$ & $I r+Y, E$ & irrros & مصارفانكمان دورل \\
\hline- & - & - & - & - & - & - & وزارت د درب \\
\hline- & - & - & - & - & - & - & 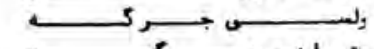 \\
\hline- & - & - & - & - & - & - & 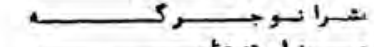 \\
\hline - & - & - & - & - & - & - & ما \\
\hline- & - & - & - & - & - & - & وزارت الــورخ \\
\hline sty. & IAs: & קtr & vit & (20) & $1 \cdot \pi$ & $\varepsilon \bullet \mu$ & N \\
\hline- & - & - & - & - & औ & - & 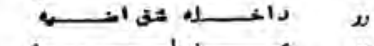 \\
\hline- & - & - & - & - & - & - & $\therefore ـ$ \\
\hline- & - & - & - & - & - & - & 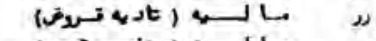 \\
\hline- & The. & 100 & A1, 1 & مريله & $r r, r$ & $v 0, \pi$ & 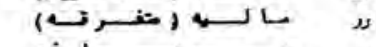 \\
\hline$r \bullet r$ & $x \cdot x \cdot$ & ext & Yve & عرt & 1.人 & 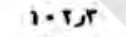 & H \\
\hline 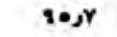 & (1). & or & $T r \mu$ & rTנr & 11,8 & IAj & $\leftarrow$ \\
\hline 1נ & 1. & $A, r$ & A. & 15,1 & 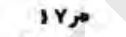 & rra & تس \\
\hline $\mathbf{I A \cdot x}$ & T(1, & Tres. & roAl & $r \cdot T \mu h$ & rrist & rtej: & $\leftrightarrow$ L \\
\hline (1) & $1 \cdot 1$, & or.g. & $r \bullet A, 1$ & - $x$ ry & - risr & $158, x$ & ندامســـا \\
\hline relp & rege & rtast & trate & rirst & Erdit & oxis. & $\underset{*}{t}$ \\
\hline- & ces: & - & - & - & - & - & $0 y$ \\
\hline 1-p & •ر. & קו & Yו & קו: & $r, r$ & $1 \cdot 0$ & $\begin{array}{ll}1 \\
\end{array}$ \\
\hline- & זر. & Pa & קו & in & هر & $T \mu$ & با \\
\hline- & - & - & - & - & - & - & b- \\
\hline$r=\lambda$ & irs. & - rut & 0 & $r y, r$ & $\ln x$ & $r \cdot \boldsymbol{r}$ & $\stackrel{\longrightarrow}{\longrightarrow}$ \\
\hline- & - & - & - & - & - & 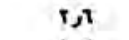 & - \\
\hline- & - & - & - & - & - & $1, x$ & التربتر مث \\
\hline- & - & - & - & - & - & - & $d \infty$ \\
\hline resr & ris. & risr & is 10 & 19,8 & $10 x$ & مر & تص \\
\hline- & - & - & - & - & - & - & ترا تســــ \\
\hline $1 \times$ & קו. & AY, & $17 x$ & Axt & - Aر. & - Ax & 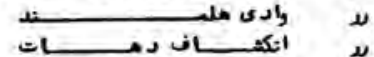 \\
\hline קיטי & 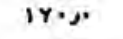 & Tas. & - & - & ist & - & 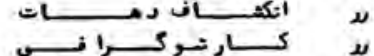 \\
\hline- & - & - & - & - & - & - & 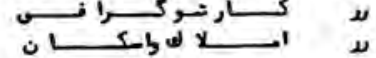 \\
\hline- & - & - & - & - & 180 & هرا & 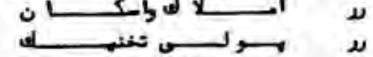 \\
\hline - & - & - & ז & (s), & Ary. & $T r, y$ & 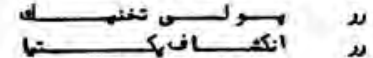 \\
\hline עטיט: & $1+30$ & tan & $\mid(Y, \mid$ & Er. & rts & r. & 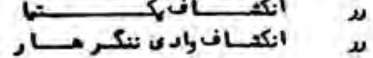 \\
\hline- & - & - & - & - & - & Tox & 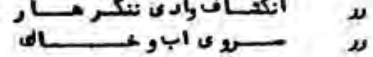 \\
\hline- & - & - & - & - & - & - & 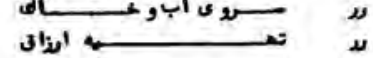 \\
\hline $1 \bullet r$ & - & - & - & - & - & - & 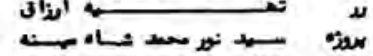 \\
\hline- & - & - & - & مر1 & קו" & irst & 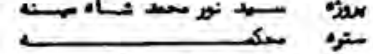 \\
\hline$T \cdot \boldsymbol{\mu}$ & ז•ر. & Try & $r x, y$ & 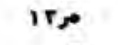 & - & - & 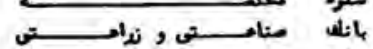 \\
\hline קיק & - & Am & - & - & - & - & 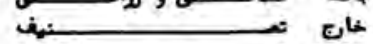 \\
\hline I.y. & rYo. & $\$ 1, \pi$ & $1 \mu$ & مراج & $r$ & - & 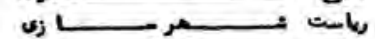 \\
\hline $1 \cdot 6 \cdot 0$ & - & - & - & - & - & $\overline{-}$ & 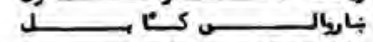 \\
\hline ixy. & - & - & - & $\overline{-}$ & - & - & 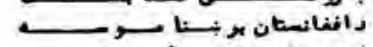 \\
\hline Mal & - & - & $\overline{-}$ & - & - & - & ا \\
\hline -ist & - & - & - & - & - & - & i \\
\hline
\end{tabular}




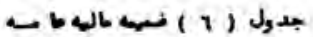

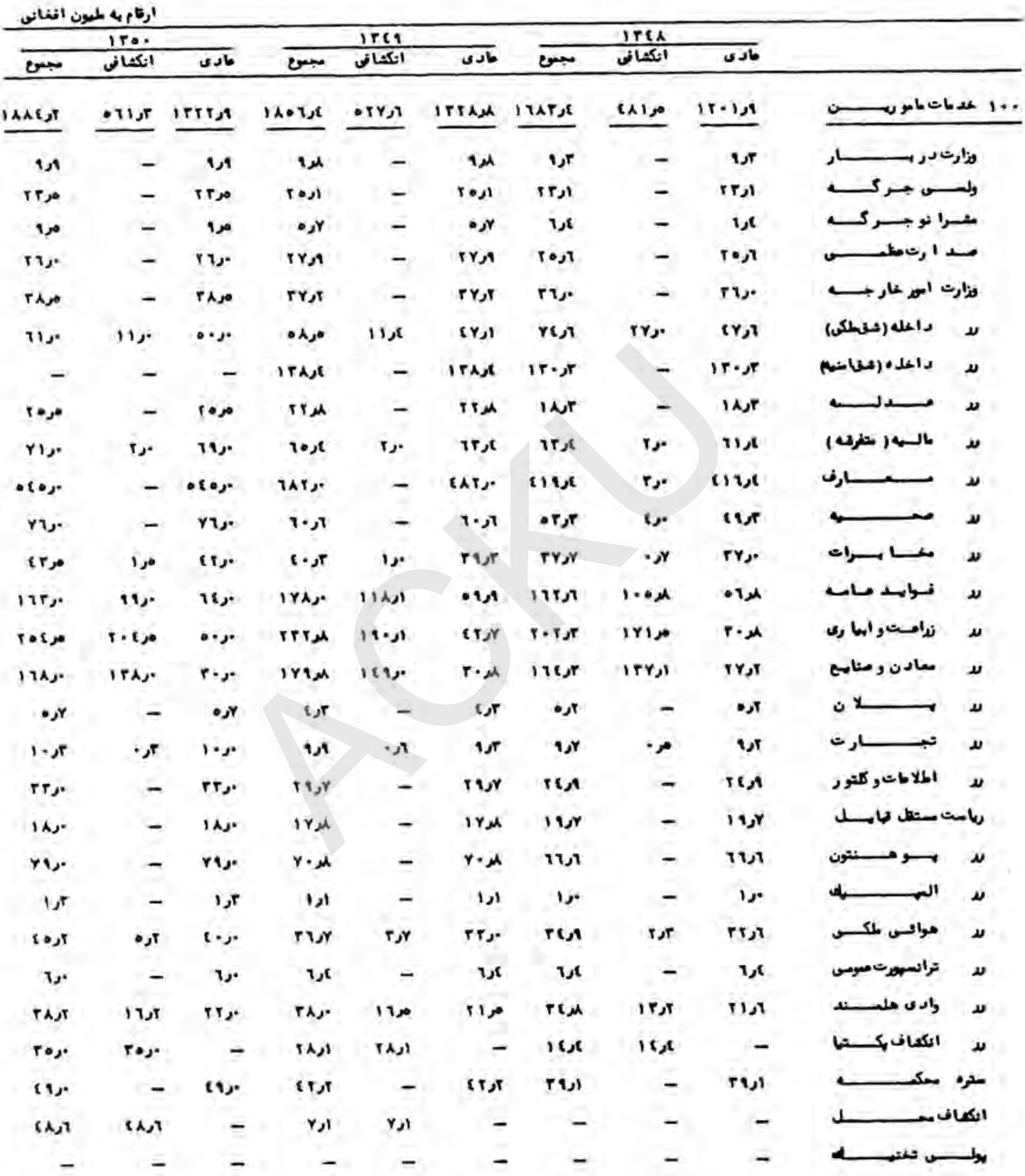




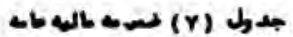

\begin{tabular}{|c|c|c|c|c|c|c|c|c|c|c|}
\hline \multicolumn{3}{|c|}{1700} & \multicolumn{3}{|c|}{ Iraq } & \multicolumn{3}{|c|}{ ITEA } & & \\
\hline مبتع & 1 & cus. & مجس & أكأ & كاد & مجنق & انكLان & طادى & & \\
\hline roven & 187 & 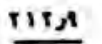 & Prite & 1.8. & riae & rrest & 1(1). & IAT, & ي & T... \\
\hline هر1" & - & " & (זק & - & $18 \gamma$ & BT & - & it & 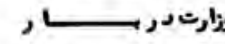 & \\
\hline זرו & - & ותו & in & - & 121 & 1,: & - & 1,0 & ولســـــ جـ & \\
\hline ו & - & ار. & ות. & - & - 1 & • & - & זر & شــر انسر جـر كـــ & \\
\hline • & - & • & it & - & 6 & 6 & - & $8 x$ & صدا رث مظلم & \\
\hline קו & - & ry & rys & - & Irt & $r y$ & - & זעו & كنارثامس - & \\
\hline קر & مرج & v. & ix & $\bullet$ & rs & 101 & x & مر & (A) & $\nu$ \\
\hline - & - & - & ונו & - & ותו & IT & - & vT & 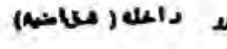 & $\nu$ \\
\hline Td & - & IA & Ty & - & tro & آن & - & rا & & $\nu$ \\
\hline | & $+\pi$ & irs: & 110 & $\cdot \pi$ & 110 & $1 \cdot 0$ & - & $1 \cdot 31$ & & $\boldsymbol{N}$ \\
\hline res: & - & Fis & $\mathbf{r} \mathbf{r}$ & - & rros & rase & - & ravo & رف & $\nu$ \\
\hline ماك & - & is: & is & - & 110 & $1+2 \pi$ & "م & 1. & & $\nu$ \\
\hline ix & $\cdot x$ & 19. & As & • & N. & in & ז & $1, x$ & م & $\boldsymbol{N}$ \\
\hline irs & $r A$ & 1. & $|\gamma|$ & $r v$ & r & res & T• & ז & . & $\boldsymbol{N}$ \\
\hline$\bullet-\lambda$ & (1) & $\cdot x$ & rygr & rril & r & ק• & irs & 1) & 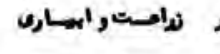 & ע \\
\hline rrid & TוA & A. & -10 & rtre & TAN & $\operatorname{cts}$ & rast & مر12 & رسعـاد, & $\nu$ \\
\hline مر & - & ه & in & - & 10 & הرץ & - & Fin & & $\nu$ \\
\hline זנז & ار• & مرr & $\mathbf{r}$ & 1) & iv & וر & ار• & Pg: & تجس & $\nu$ \\
\hline מיו & - & קוטי & 18 & - & $\mid(0)$ & IT) & - & 15. & ألاطاتو & N \\
\hline זو. & - & . & - x & - & $\cdot x$ & , $x$ & - & $\cdot x$ & |-ست سمبل | & -6 \\
\hline مעז & - & Tw. & ixt & - & $r e s$ & irst & - & IT & لحسو منتون & $\mu$ \\
\hline Ix & - & is & in & - & id & مرا & - & 120 & & $\nu$ \\
\hline Yr & Y & 1, & مر & Ir & الرث & AN & $-x$ & Y & هـوان & 4 \\
\hline -gr & - & • & $\theta r$ & - & • & דני & - & ות. & ترالسميدت & $\nu$ \\
\hline •r & F & in & T, & 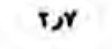 & 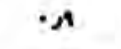 & rit & Th & $1, \pi$ & طادى هلمســــــ & $\nu$ \\
\hline MA & ix & - & in & 12 & - & Agr & Ajr & - & انكماف بك & $\nu$ \\
\hline مرغ & - & هرs & YAl & - & $Y_{\mu}$ & ty & - & קי & سـتره محكـــ & \\
\hline 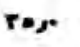 & $r \bullet$ & - & rار & זر & - & 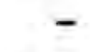 & - & - & ست انكساف معــل & -6 \\
\hline- & - & - & - & - & & & - & - & 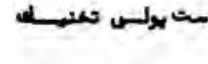 & -6 \\
\hline
\end{tabular}


بل

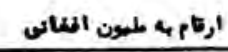

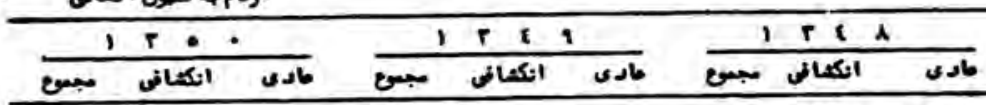

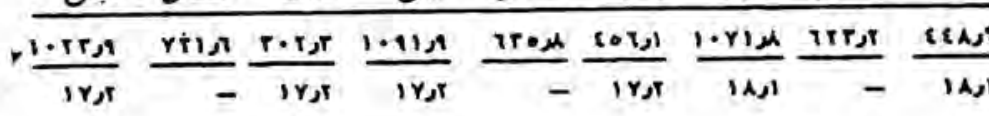

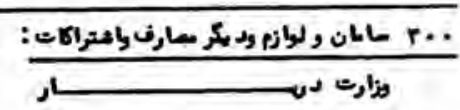

1, - $\quad$ - 1,0 ir

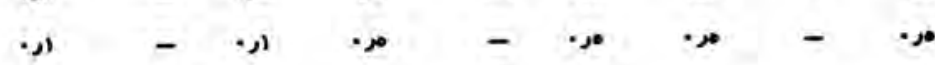

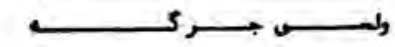

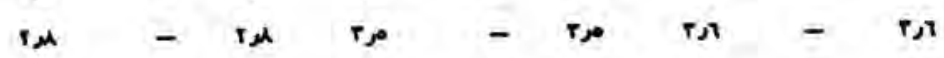

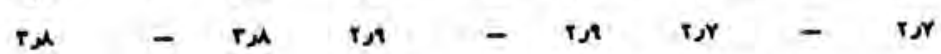

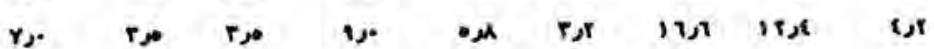

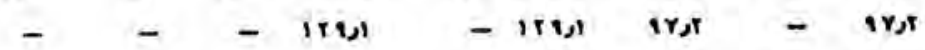

1, - 1,0 is

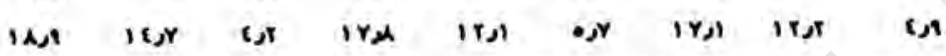

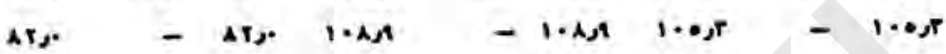

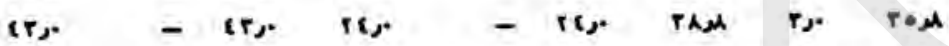

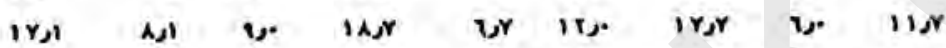

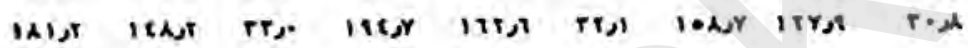

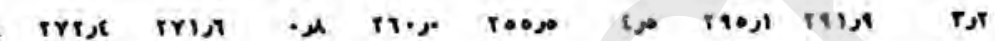

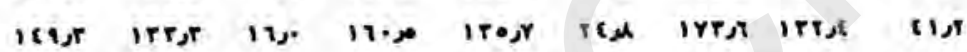

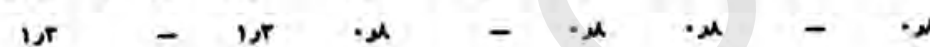

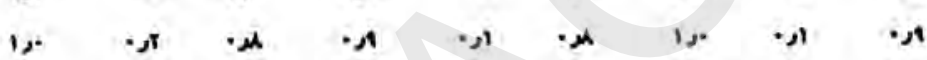

1, -

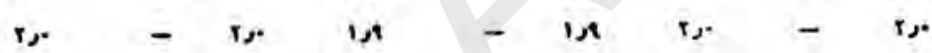

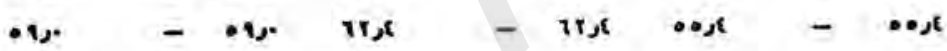

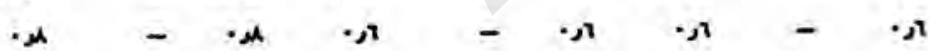

ir

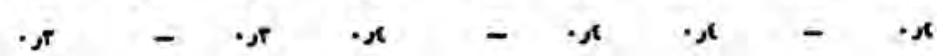

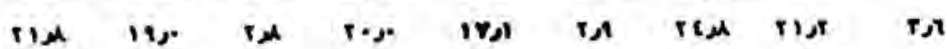

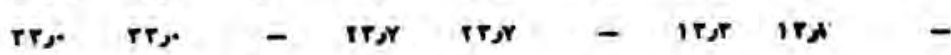

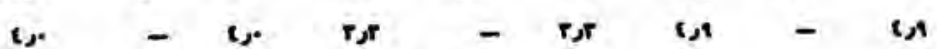

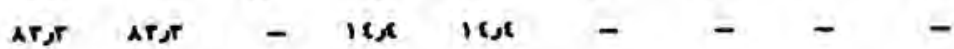

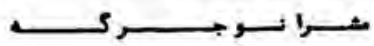

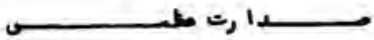

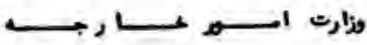

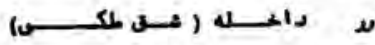

(4)
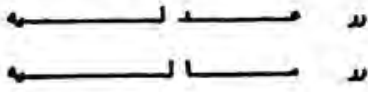

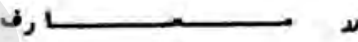

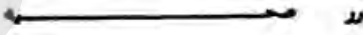

ע

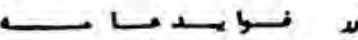

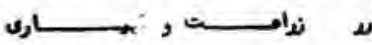

ऍ N

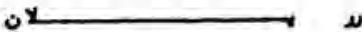

ت

له

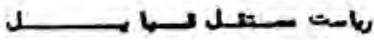
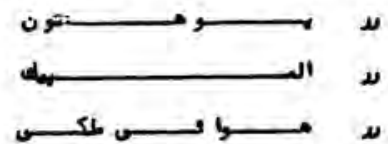

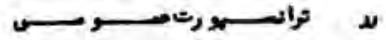

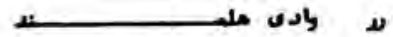

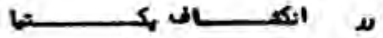

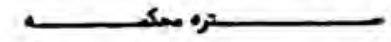

- $\quad$ - $\quad$ - -1 -

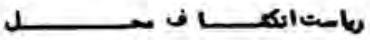




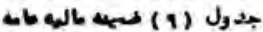

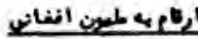

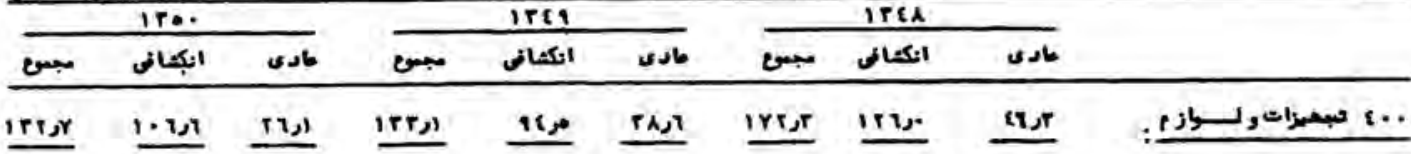

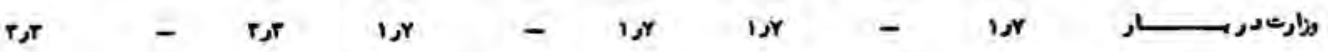

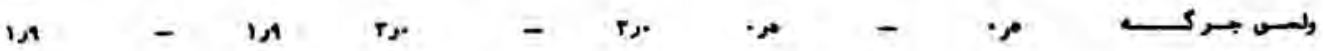

ر

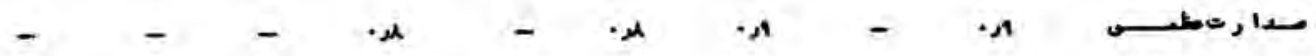

ف

1. -

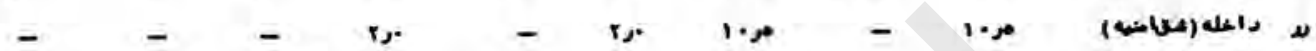

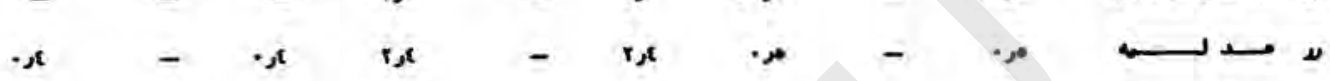

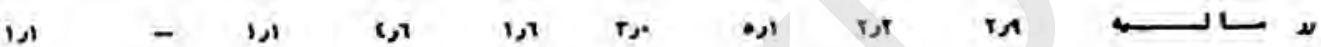

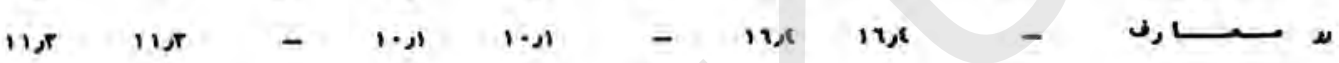

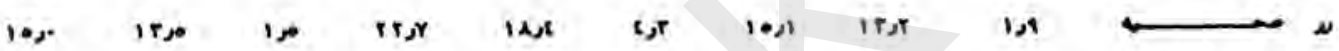

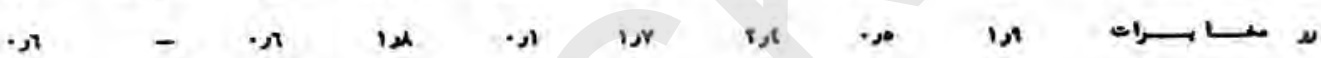

ע

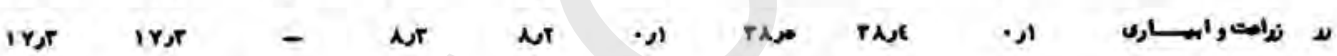

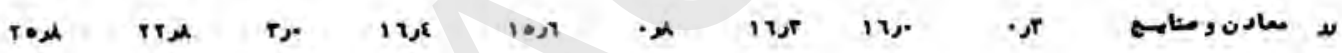

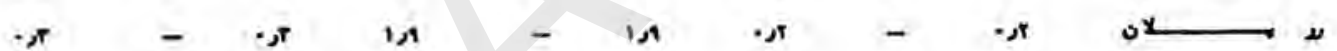

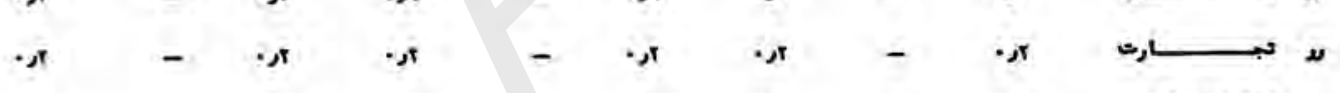

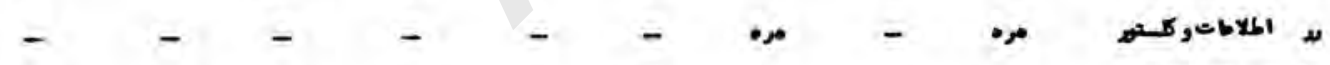

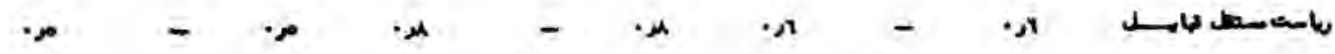

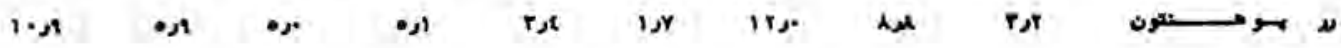

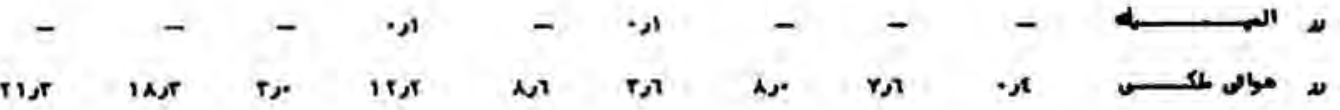

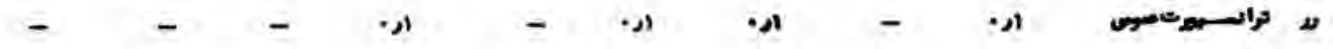

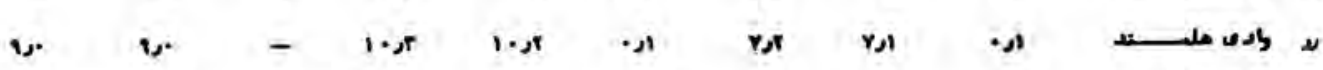

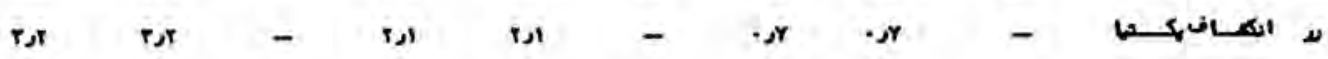

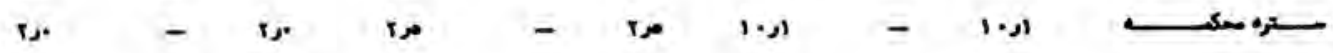

ril

$117-\infty$ 
جدول (1.)

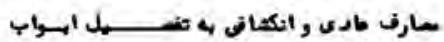

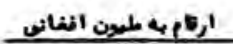

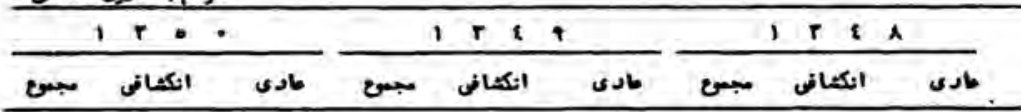

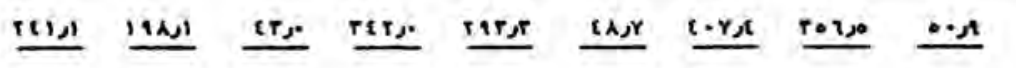

:

\begin{tabular}{|c|c|c|c|c|c|c|c|c|c|}
\hline - & - & - & - & - & - & - & - & - & هزارث د د, بـ \\
\hline 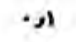 & - & ار• & . & - & . & - & - & - & ولسـى جـ \\
\hline ار & - & ار• & - & - & - & - & - & - & 4 \\
\hline- & - & - & - & - & - & - & - & - & 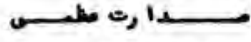 \\
\hline PA & - & TH & $\cdot \mu$ & - & $\cdot 2 \mathrm{~A}$ & $\cdot x$ & - & $\cdot x$ & 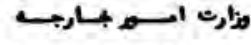 \\
\hline - & - & - & - & - & - & Aر & a) & - & 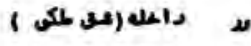 \\
\hline- & - & - & rox & - & TH & لار• & - & • & 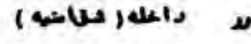 \\
\hline - & - & - & - & - & - & - & - & - & طـ \\
\hline י & - & יטו & 18 & - & ix & (•) & Pro & וצו & - \\
\hline Iast & TAlp & - & rTs & 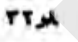 & - & $\cdot 2 x$ & • & - & - \\
\hline 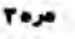 & T•ر lo & - & rasr & TAS & - & $17 x$ & آرזו & r & 4 \\
\hline- & - & - & ו & - & וני & ות. & 0 & ות & مف \\
\hline rit & ix & 10. & expr & rast & $16 \gamma$ & rर & ז'וر & $11, \gamma$ & is \\
\hline - Ij & $-1 x$ & r & Tix & Tax & - & $\operatorname{cis}$ & $10 \pi$ & $x$ & لدامت ,اب- \\
\hline$c, r$ & مر & 100 & cr & مرن & I & A. & 10 & مرا & معادن و ط \\
\hline 1 & - & $1 x$ & $=x$ & - & $\cdot x$ & r & - & r & $\dot{v}$ \\
\hline- & - & - & וا & ار• & - & - & $\cdot \pi$ & - & تي \\
\hline •r. & •r. & - & ro. & rut & - & Y ו & $Y, 1$ & مر & الطاكاك \\
\hline זٓ & - & זرا & re. & - & ני. & $1 \cdot x$ & - & 1.21 & k \\
\hline (10 & ונו31 & $\cdot x$ & $\bullet r$ & (4) & • & tT & $\mathbf{t r}$ & آر & بـ مـ \\
\hline - & - & - & - & - & - & - & - & - & الهـ \\
\hline rol & Yו & - & $\mid$ | & | ומיו & - & וرו & ונו & - & هـ \\
\hline- & - & - & - & - & - & - & - & - & تراتسمث \\
\hline int & ias & - & $t \cdot s \gamma$ & $c \cdot j$ & - & orr & טر & - & وادى ملبد \\
\hline in & xi & - & اره & • & - & ار• & 0.ر & - & انكمافيك \\
\hline مر Tr & res: & Yoo & ros & ry & Y & Y79 & res & ris & 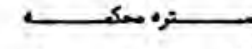 \\
\hline- & - & - & - & - & - & - & - & - & 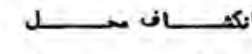 \\
\hline ה ה. & - & $\cdot x$ & $\Rightarrow$ & - & $\rho \gamma$ & Ext & Er & - & d \\
\hline
\end{tabular}




\begin{tabular}{|c|c|c|c|c|c|c|c|c|c|}
\hline & $1 F \bullet$ & $\bullet$ & & $1 F \varepsilon$ & 1 & & r $\varepsilon$ & A & \\
\hline مجع & اتكاتى & كادى & مجسع & أكان & 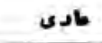 & مبصع & اتكمانف & (5) & \\
\hline 1) & I I & YAY & TAC, JE & $r r$ & $17 \cdot, \mathrm{Y}$ & Yits & I raph & - Yox & 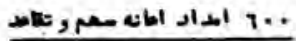 \\
\hline
\end{tabular}

\begin{tabular}{|c|c|c|c|c|c|c|c|c|c|}
\hline - & - & - & - & - & - & - & - & - & وذارت درب بـ ر \\
\hline- & - & - & - & - & - & - & - & - & مغـران \\
\hline - & - & - & - & - & - & - & - & - & 4 \\
\hline$x, 1$ & - & xi & - & - & - & - & - & - & 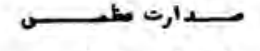 \\
\hline \& & - & 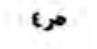 & $r, 0$ & - & Pر & $r_{\mu}$ & - & $r \mu \lambda$ & 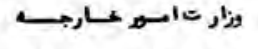 \\
\hline- & - & - & $* x$ & r & r & اת & - & • & داطل (هشلى ) \\
\hline- & - & - & ו & - & $\cdot \pi$ & $1 \lambda$ & - & ix & 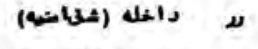 \\
\hline • & - & • & ו" & - & $\cdot x$ & . s & - & $+\pi$ & ע \\
\hline 18 & - & - 18, & inys & - & EqYor & tyar & forl & ETा: & ע \\
\hline ITHי & - & ז & IAst & - & IA, & ir. & - & נזו & ر) \\
\hline ris & - & rix & rAر & - & TAM & rAs & - & TA,Y & 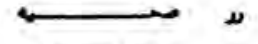 \\
\hline مر & - & 10 & וرن & - & tol & isr & - & Iرy & رات \\
\hline YAl & $r r_{p}$ & - 1 & $1, t$ & Ay & וג & 1ر & Al, & ות & فــا \\
\hline A. & $1, \pi$ & קו & Th & Th & 1, & $10 x$ & Ast & 100 & نامت , البهارى \\
\hline 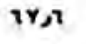 & ותו & 12. & rYp & $r$ & ros & ט. & זرז & 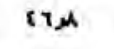 & معادن ورمنا \\
\hline דע. & 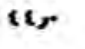 & rre. & inte & - & late & 106 & - & 10,6 & 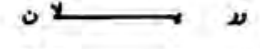 \\
\hline- & - & - & - & - & - & - & - & - & 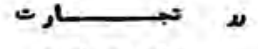 \\
\hline its & - & קו" & ritr & - & Tri & $1 \cdot 1$ & - & 1.2 & s, الطاكا \\
\hline r & - & זر. & • & - & • & • & - & r r & טا-ست مستط \\
\hline$Y, t$ & - & 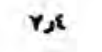 & $r, x$ & - & 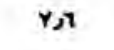 & r & - & זת & - نتون \\
\hline - & - & - & $\Rightarrow$ & - & • & - & - & - & 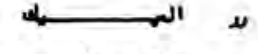 \\
\hline וT & - & ire. & 161 & $\cdot \boldsymbol{\mu}$ & 16, & 112 & - & זתוו & هواشـ \\
\hline - & - & - & - & - & - & - & - & - & ترانسهت \\
\hline - & - & - & - & - & - & - & - & - & وادى علعـــــــ \\
\hline- & - & - & - & - & - & - & - & - & انكساف كانـا \\
\hline- & - & - & ז & - & ז & ו & - & ו- & 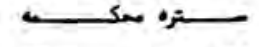 \\
\hline- & - & - & - & - & - & - & - & - & 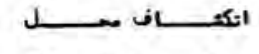 \\
\hline- & - & - & - & - & - & - & - & - & 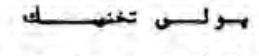 \\
\hline- & - & - & 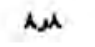 & $A \mu$ & - & - & - & - & بانسله صنستى و دامسـتى \\
\hline
\end{tabular}




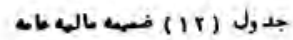



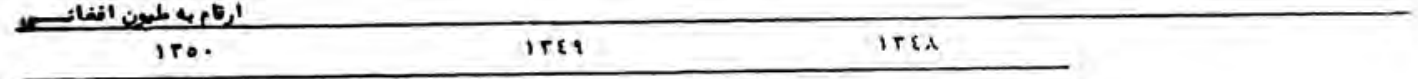

طادى

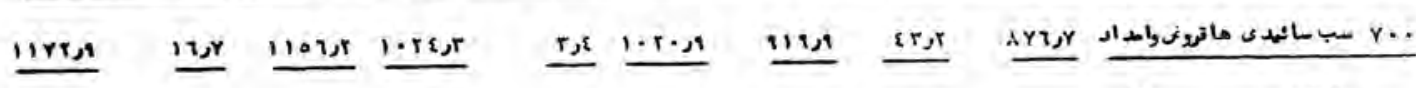

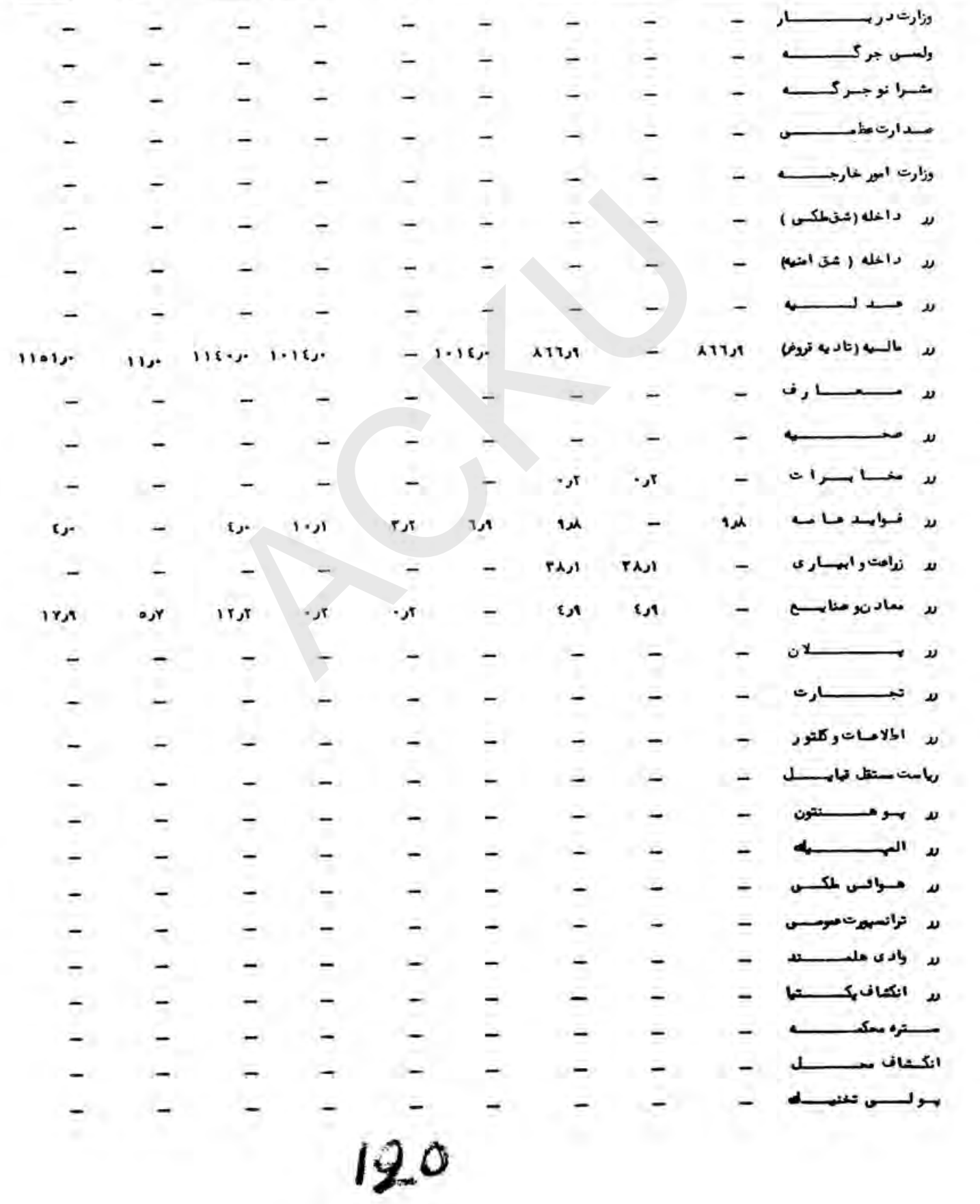




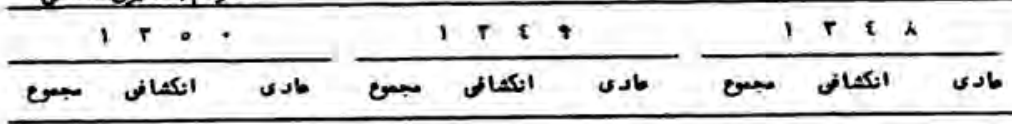

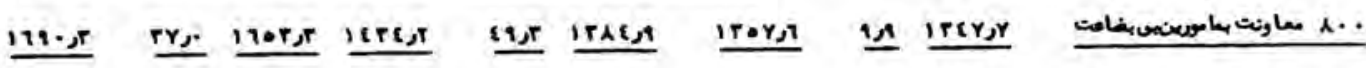

\begin{tabular}{|c|c|c|c|c|c|c|c|c|c|}
\hline ار. & - & ا & ار. & - & ار• & ار• & - & - & 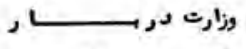 \\
\hline- & - & - & - & - & $\cdot 3$ & - & - & - & ولسـى جـــر \\
\hline - & - & ار. & - & - & - & - & - & - & مغــرات \\
\hline IرI & - & IOr & ז & - & $r \boldsymbol{r}$ & ارا & - & זנו & مسدار \\
\hline$\cdot r$ & - & كر & r & - & $\cdot r$ & וر. & - & ر & x خـارجســ \\
\hline . & - & •r & •ر & - & مر & $\cdot x$ & וر. & مر. & داخله (شتصلى ) \\
\hline- & - & - & r & - & זر" & - & - & - & داحله (شتاسته ) \\
\hline . & - & זوث & ז & - & $\theta$ & ك & - & r & 4 \\
\hline برد & - & ני. & ir & - & ist & $y_{0}=$ & - & Y,० & 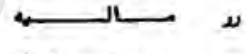 \\
\hline 1, & - & וر & E & - & $\varepsilon, \pi$ & it & - & ז & رف \\
\hline$\pi$ & - & . & - & - & ro & مر & - & $\cdot 0$ & ע \\
\hline - & - & - & r & - & r & ז & - & זית. & رات \\
\hline - tr & - & -sr & - & - & $\cdot x$ & عر" & - & أر & 2 \\
\hline $1, r$ & - & iر & , & - & - & 1 & - & זת & (1, \\
\hline זת. & - & r & آر- & - & ז & مر & - & مر & منايه \\
\hline آ ر- & - & r & • & - & וر. & זرי & - & זे & $\dot{y}$ \\
\hline$\cdot \mu$ & - & $\cdot \operatorname{sil}$ & •r & - & ro & 1 & - & • & ت \\
\hline ונו & - & זת & $\cdot x$ & - & $\cdot x$ & r & - & • & كالا طات \\
\hline וر. & - & ו & - & - & - & - & - & - & - \\
\hline is & - & צנו & $1, x$ & - & is & ות & - & ד & هـو هـــــــــن \\
\hline - & - & - & - & - & - & ار• & - & ارث & Ji \\
\hline 1 & - & 11 & ות & - & ונ• & $\cdot x$ & - & •x & $\omega$ \\
\hline- & - & - & - & - & - & - & - & - & ترانســهمت موس \\
\hline- & - & - & וر & - & ו & ו & - & • & לادى هلبـــــ \\
\hline - & - & - & - & - & - & - & - & - & اتكــافريـــا \\
\hline וر. & - & ות• & $\cdot \pi$ & - & $\cdot r$ & וرا & - & וرו & ستره مسك \\
\hline - & - & - & ו & ו & - & - & - & - & اتكعــــاف \\
\hline - & - & - & - & - & - & - & - & - & d- \\
\hline
\end{tabular}

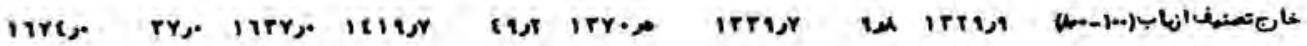

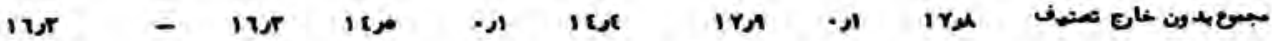


جدول (ii)

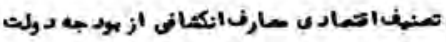

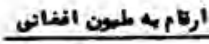

\begin{tabular}{|c|c|c|c|c|c|c|c|c|}
\hline הهد & iro. & 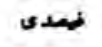 & ITE & نهمدى & $\operatorname{IrtA}$ & לمصدى & Irey & 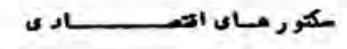 \\
\hline 1... & דנזו & , & irror & $1 \cdots$, & ו & 1.s. & |AT·, & 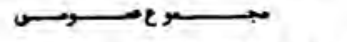 \\
\hline r०s & irtrs & $11 \pi$ & Mor, & IY & IrAx, & 1A, & $\mid r \circ \varepsilon, 1$ & اول : :Lاغت \\
\hline Y & $18 \cdot \pi$ & - را & ותו & $\cdot x$ & Aرr & Th & $r \cdot s$ & $\longrightarrow$ \\
\hline $18 x$ & rryjh & $r \cdot s$ & rot & $17 x$ & $r \mid x$ & 181 & x०r,r & تعل ورس \\
\hline TASI & 口كte & $T T_{2}$ & ragy & res & $(Y, 2$, & 182 & orf 2$\}$ & جتصـا \\
\hline$I \mu$ & - ret & 1 & IAر. & ת. & Y & וرن & $1 \cdot \pi$ & \\
\hline C & $A Y, i$ & T & -19. & ish & PTA & $1 \mu$ & $F x$ & \\
\hline$\cdot \pi$ & $r_{2}=$ & - & $1 \bullet 01$ & 11 & रा & $-\mu$ & 10. & \\
\hline Y & 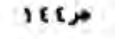 & $1, x$ & rest & T & 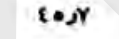 & $r$ & $(1,1)$ & $=$ \\
\hline 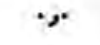 & 1,1 & ار & קז. & $x$ & ו & ות & tני & ك, \\
\hline Tft & ק• & ז & ors. & i & A) & 5,2 & مر & - \\
\hline مر1 & $|A| \mu$ & Ast & If1) & 3.21 & ry.s & ITH & $T \cdot x$ & \\
\hline As & $100 \pi$ & $18 x$ & reos: & 185 & IAT & $1 \mathrm{ren}$ & ITTs & السيارى وكستول ســا ب \\
\hline 3 소 & iris & $y_{1}$ & $\mid r A s$ & $1 . \pi$ & $r$ ra스 & 스쓰 & $109 x$ & الكهـافر اسكـان ' \\
\hline & EITY & 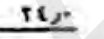 & $11 \gamma_{0}$ & IT & $(A \bullet, \lambda)$ & $x \bullet s$ & sodes & 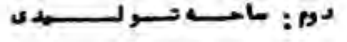 \\
\hline IA & $\bullet \mu$ & ות & iro. & A, 1 & ins & 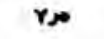 & Irרץ & - \\
\hline $1 Y_{j}$ & Trite & $18 x$ & rove & 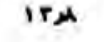 & ryos: & II & זTा & 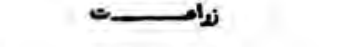 \\
\hline 1ת & $r \cdot x$ & to. & $\gamma=\boldsymbol{r}$ & rin & - & $\bullet$ & IT) & مسـعـــــن \\
\hline $1 \pi, \pi$ & $\operatorname{tec} x$ & vir & 121,8 & Y pe & 168 스 & •x & $1 . \gamma \mu \mu$ & - \\
\hline T & STt & 1, & î. & 1 & +1, (10 & ו1 & $t \cdot 2$ & ن نامـ \\
\hline Yת & 101,8 & $r \Delta$ & IT•p. & •r & $1 \cdot \hat{A} \boldsymbol{~}$ & \&) & ren & سـمــادن \\
\hline 1,1 & $t \cdot \pi$ & ז & •r. & $-x$ & مر & 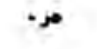 & $\mathrm{ses}$ & $\cdots+1 \cdots$ \\
\hline$\cdot \Leftrightarrow$ & $1 \bullet \gamma$ & +1 & r. & - & is & آر & T) & حطل وبلــل \\
\hline - & - & - s. & ז & 一 & - & - & - & منا ب \\
\hline
\end{tabular}




$$
\begin{aligned}
& \text { جدول (1) اخمهه تبارت خارجى } \\
& \text { ( ) طليون دالر ) }
\end{aligned}
$$

\begin{tabular}{|c|c|c|c|}
\hline 150. & $1+19$ & $\operatorname{crcs}$ & تبـ \\
\hline & & & 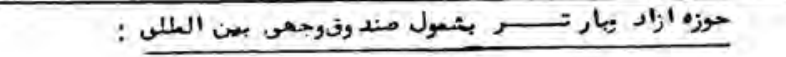 \\
\hline 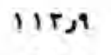 & 11,0 & $90, y$ & ו- الفف: صادراتاموالر, خد بـ \\
\hline ir. & $\Lambda T, T$ & A1, & مادراتاعتهه" تجارتىرساند• كرة \\
\hline 9,4 & - & - & توازن ارتاكرك وعرايد اسعـــا \\
\hline$\varepsilon, t$ & $\lambda, r$ & $1,$. & 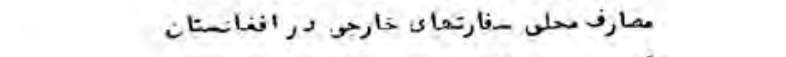 \\
\hline 1,8 & $Y, y$ & 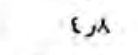 & $\longrightarrow$ \\
\hline - & $-1 \times t, 0$ & $-1\{t, 0$ & 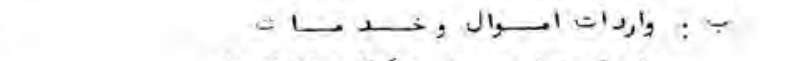 \\
\hline$-\lambda 1, t$ & $-Y i$, . & $-Y T, 0$ & 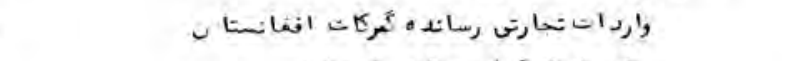 \\
\hline - & $-r$ & $-1>0$ & 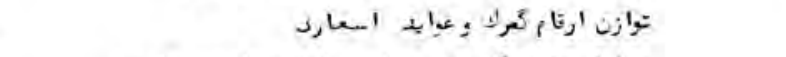 \\
\hline$-1,0$ & $-1,8$ & $-1,0$ & ملارف نعايثل كى هائ سياسي افنانستان \\
\hline$-1 j$. & $-t$ & $-1,4$ & $\longrightarrow={ }^{\longrightarrow}$ \\
\hline$-\varepsilon y, \gamma$ & $-r y, x$ & $-\varepsilon \varepsilon, t$ & وارد اتك از تروت خارجى نمريل ثبـ \\
\hline$-10,$. & $-16, y$ & $-1 \cdot$, & وأردات غير بريزه وك كم از مساعد \\
\hline$-\lambda$, & $-1,1$ & -1, & تاديات تيت بوالى بر قرض خارجى \\
\hline $1 \cdot, 1$ & $r, r$ & 9,8 & 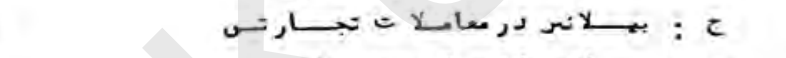 \\
\hline$-\{1, \lambda$ & $-r \varepsilon$, & -81, & 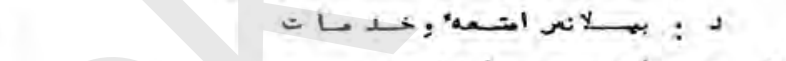 \\
\hline orol & rA, & $\{1, y$ & $: \ll \iota^{2}$, \\
\hline$\varepsilon y, r$ & $r Y, \lambda$ & $\varepsilon \varepsilon, r$ & بحع تروض وامداد انكشافى بر \\
\hline 10, & $1 \mathrm{~L}, \mathrm{Y}$ & $1 \cdot 2$ & اهد اد بخ عوضمأز درك مواد استملا كى \\
\hline $11, \pi$ & $r, 9$ & rst & انتثالا تيلا عوض ( بيلانين) \\
\hline $17 x$ & $-17,5$ & $-1 \varepsilon, \gamma$ & تادياتاتساط ازدرث اداى تروفن . \\
\hline 0, & $\{$ \&. & $\varepsilon, \imath$ & r- حق بر د اشت از صند وق وجهى بين العلى \\
\hline$r \cdot r$ & $-1,1$ & $-\cdot \boldsymbol{r}$ & $(r-r-1)$ r \\
\hline$-1,1$ & $1, r$ & $-\cdot, y$ & 1 \\
\hline 11,0 & . & $-\bullet 2$ & بيسلا نسرتLاد بـL \\
\hline$-11<0$ & זע.- & .9 & هـ تحول در ذخاير اسعار بمنالعلل معلكت وارثابارتباطن ان \\
\hline$-r, r$ & re & - & تحول درز زخاير طــــلـا \\
\hline •أ & $-1,1$ & $-\varepsilon, 9$ & تحول در ذ خاعر حق بر داثيت ازص \\
\hline- & - & - & تحول سهعه افنانستاندر صندوَّ وجعى بن الطلل \\
\hline 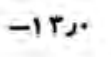 & $-1,1$ & 11 & تحول درذ خاعر اسعار توىد رمروطات د افنانستانهاثل \\
\hline - & $-r$ & r & تحول درذخاير البعار خعيف ر \\
\hline r & - ג & $-\bullet$ & 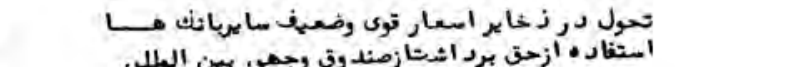 \\
\hline 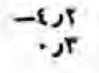 & $\begin{aligned}-\varepsilon, \gamma \\
0, \lambda\end{aligned}$ & : & 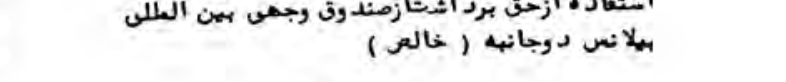 \\
\hline
\end{tabular}




\section{اد امه جد ول ( 1 ) ضميه تجارت خارجى \\ ( به مليون دألر )}

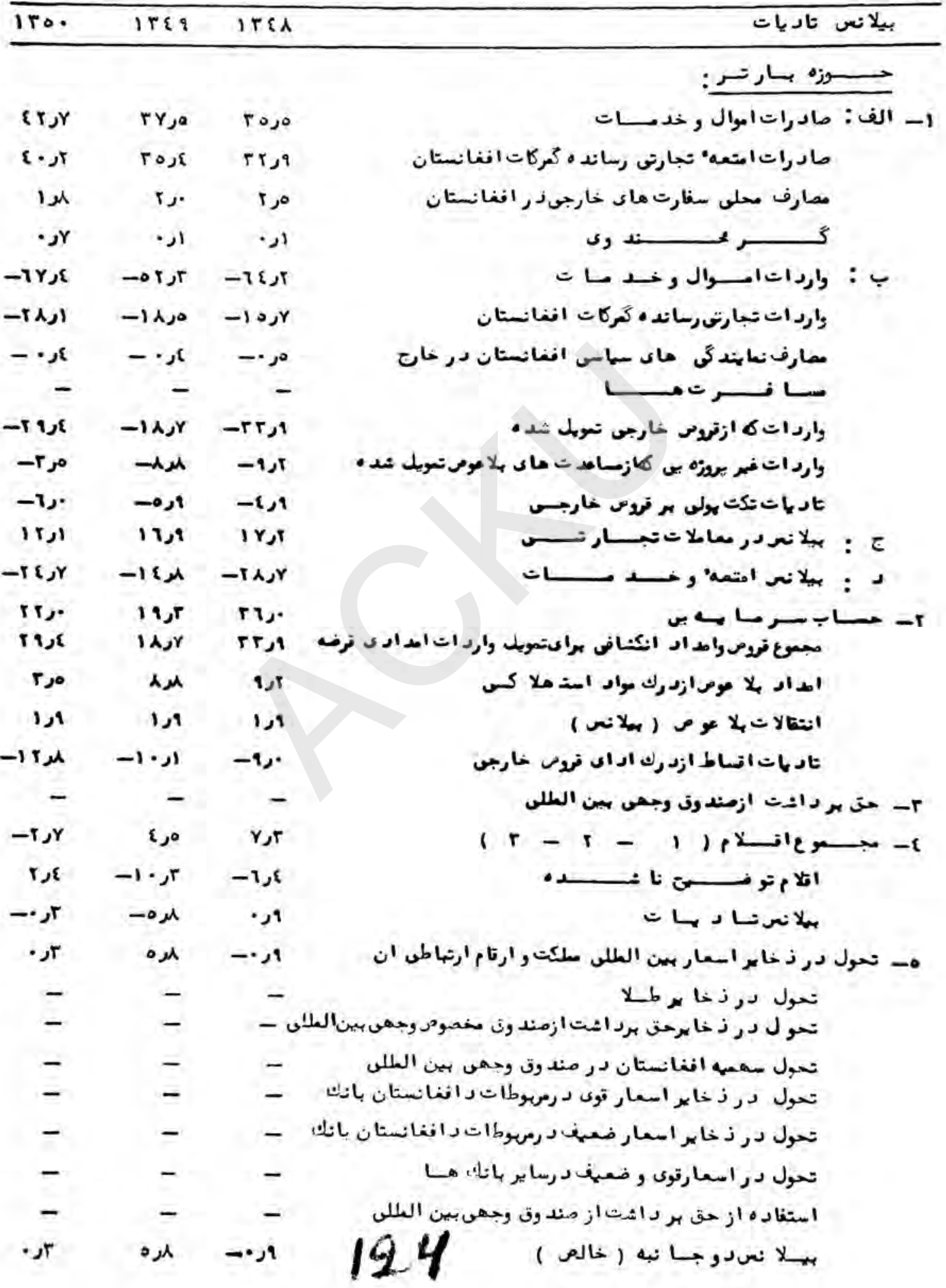




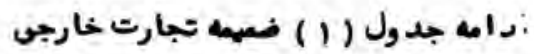

) : به ملون دالر ( )

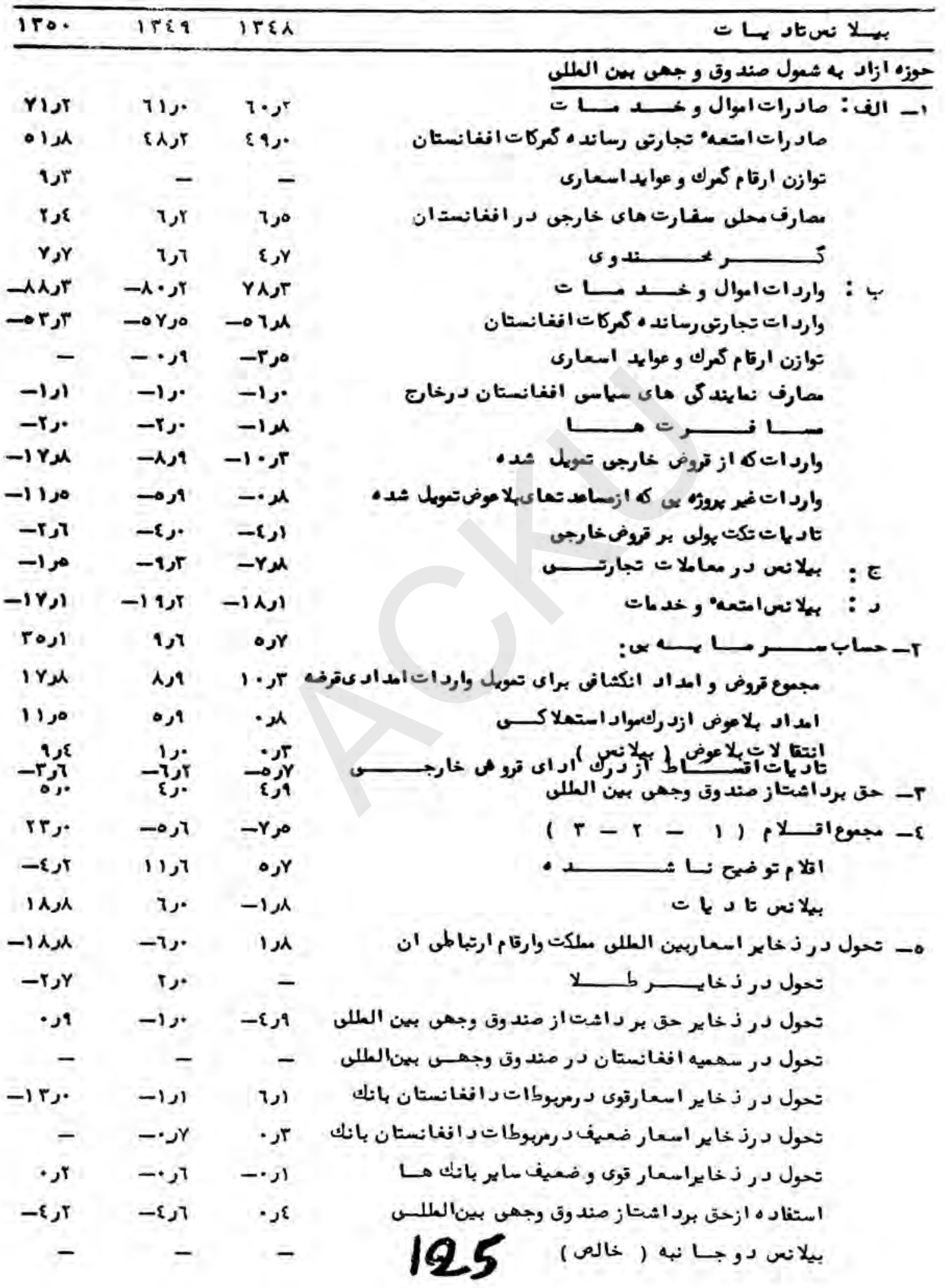




\section{ites iten iter itet ite ite}

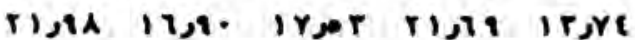

- - - - - - -

risa itge irger rist irge

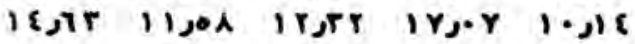

r, r r

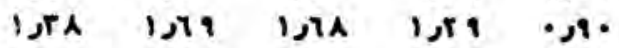

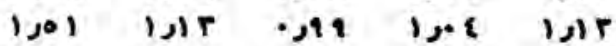

r.

ror rje r,il r...

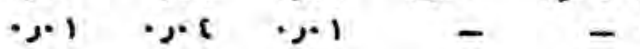

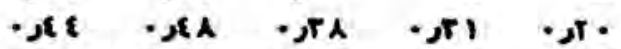

rJA rotr rot rofe ise

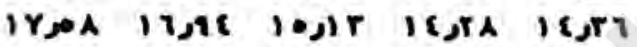

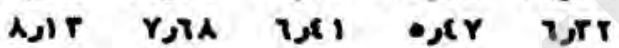

Ise ist Ajt Anl Ajet

•r

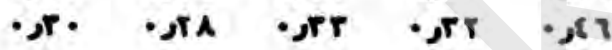

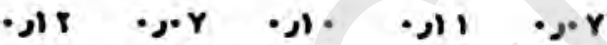

צr.

r.

ejer oja ent tola tur

r.

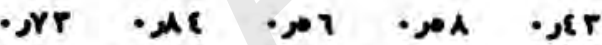

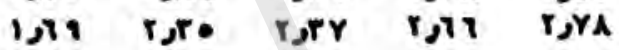

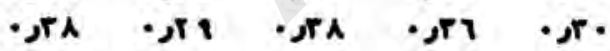

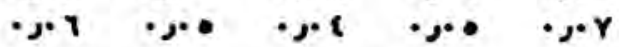

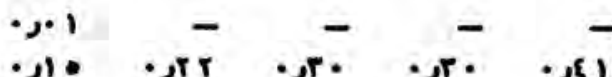

ונו

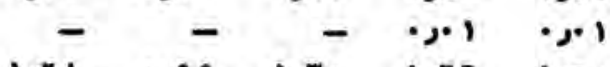

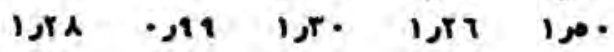

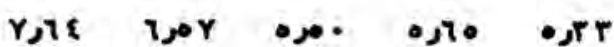

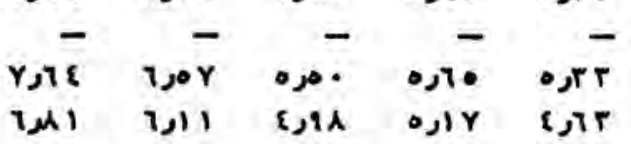

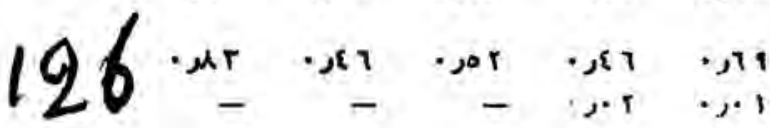

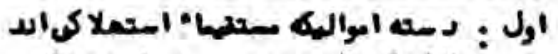

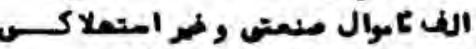
ب : إبناسواموال استمل

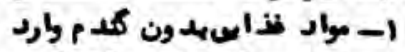

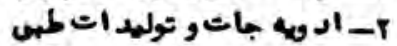

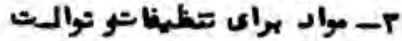

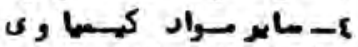

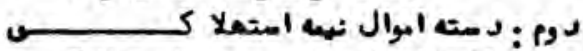

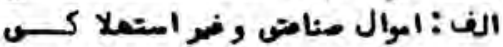

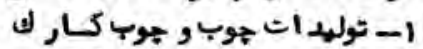

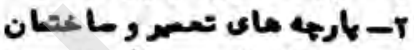

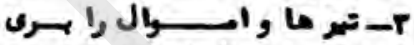

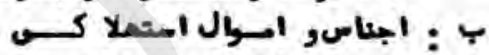

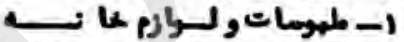

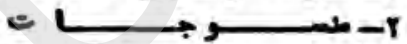

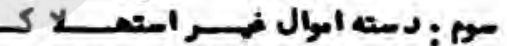

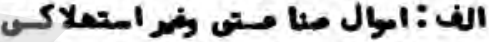

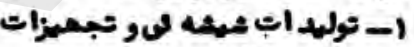

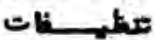

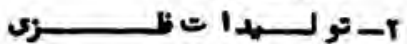

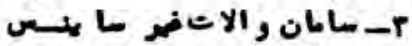

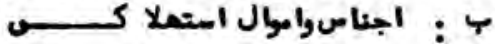

1-

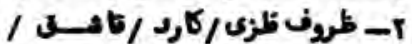

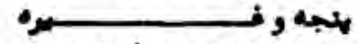

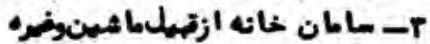

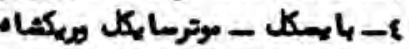

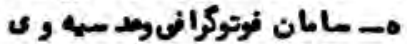

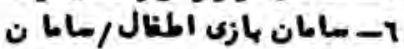

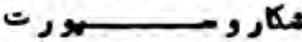

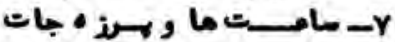

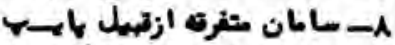

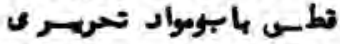

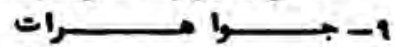

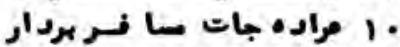

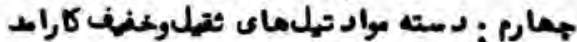

مراد • ماته

الف:كوه مواد صناعت و فراستملاكى

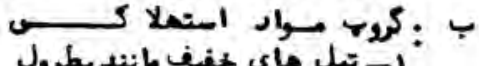

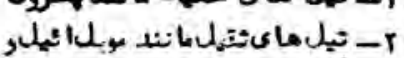




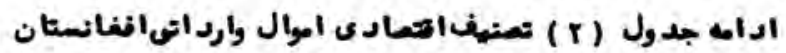

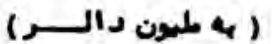

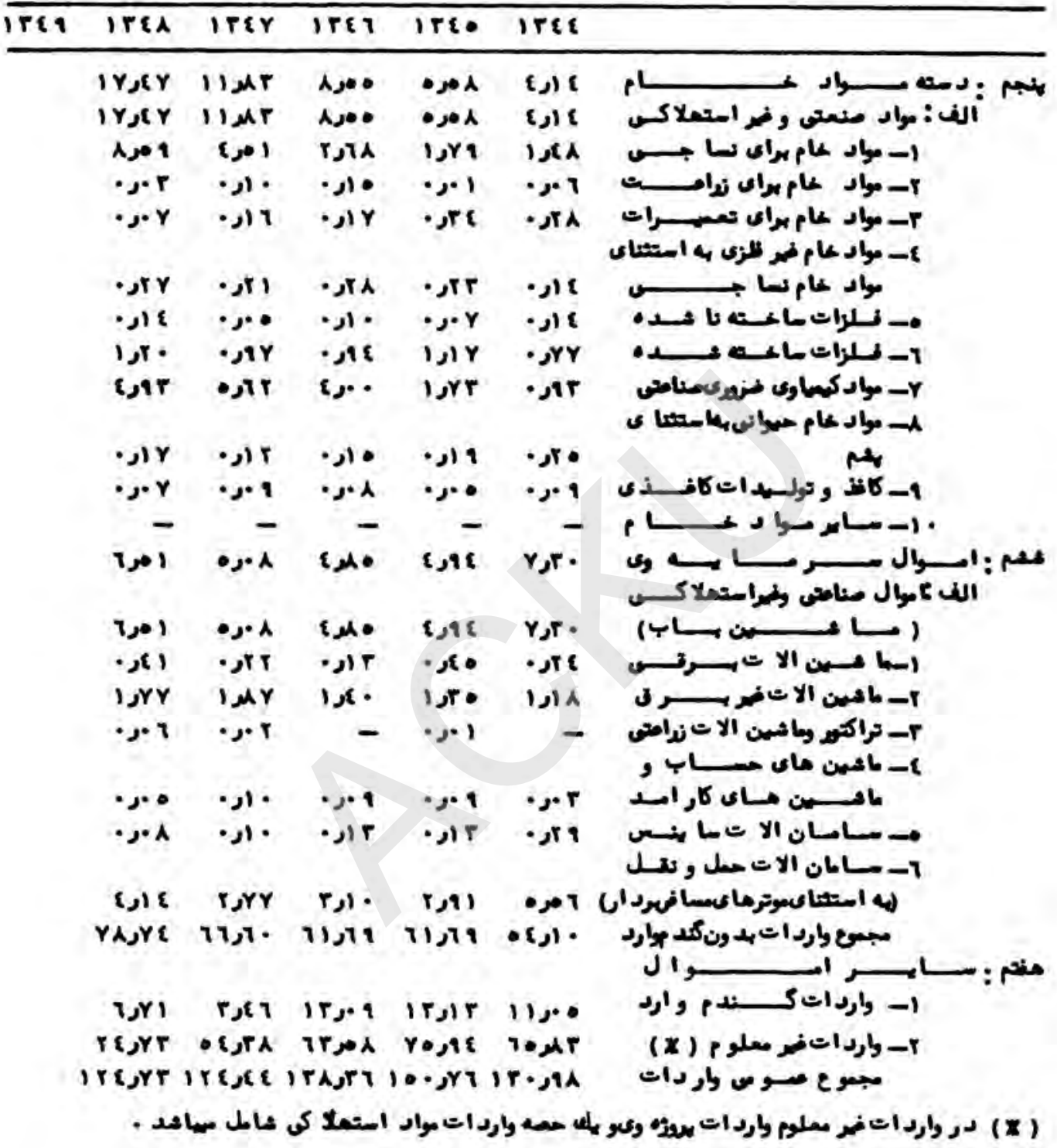

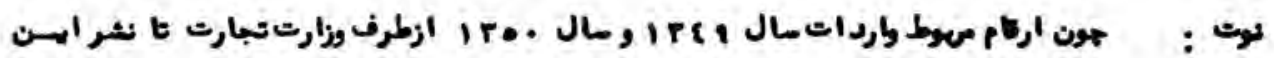

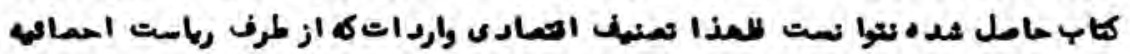

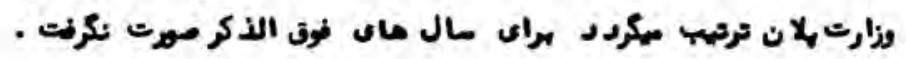




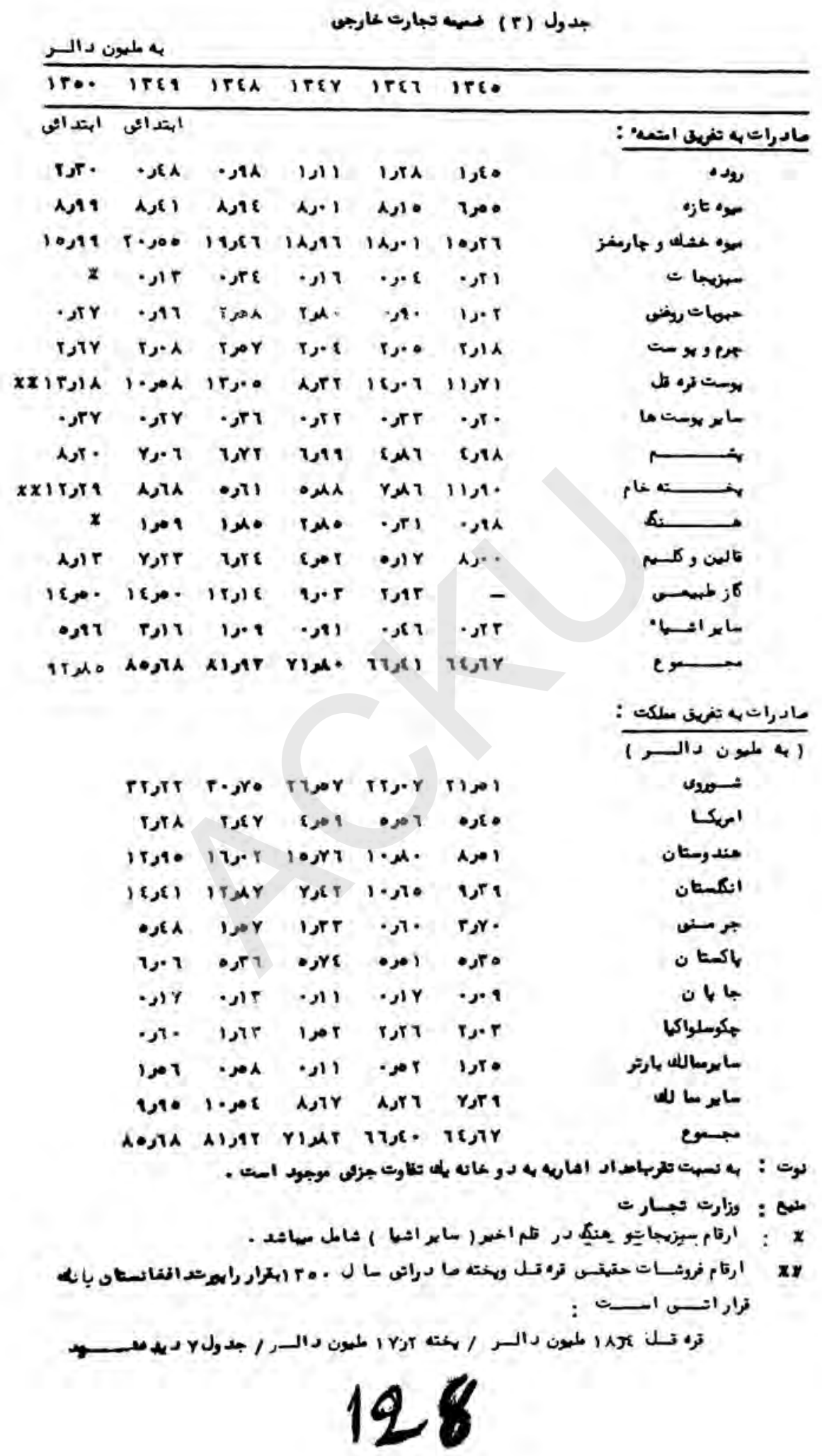


جدول ( \& ) خعيه تجارت خارجي

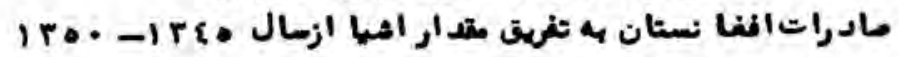

\begin{tabular}{|c|c|c|c|c|c|c|c|}
\hline 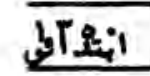 & 1 & IreA & irer & IrET & $1+20$ & 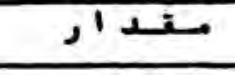 & \\
\hline $8 \cdot 10$ & AIY & IETY & iave & $\boldsymbol{Y I} \cdot \varepsilon$ & TEYT & مزارحلتـ & رود• . . . \\
\hline$A \cdot I r A$ & YoITA & ATYAT & 7997. & $111 .$. & YrY.A & تن متر له & ميره تازء \\
\hline \multirow[t]{2}{*}{ (1)19 } & รหมT & $r \bullet Y A 1$ & rM\& & cotix & gt. & ע & ميوخشك و جارمغز \\
\hline & $1 \cdots$ & PACT & $01 r$ & rYi & rry & ע & منهنجات حشدك و تازه \\
\hline$r \varepsilon 0$ & Yqu & IEQYE & irti & (1r) & YATT & ע & "حهو بات روغسنى \\
\hline$r \cdot 1 \cdot$ & 1018 & pryo & $19 \cdot r$ & lnor & 1109 & هزارجلــ & هرع ورست باب \\
\hline 1111 & $1\{\varepsilon \varepsilon$ & 17ir & WAE & IIrr & Irra & $\nu$ & هو ســت قره تـلـل \\
\hline orr & rio & EY & ril & rqa & rya & ע & ساير يوتست ما \\
\hline $1\{\cdot 1$ & or.r & orto & ocrr & PYIT & $7 \cdot 10$ & تن متر بك & $\stackrel{\longrightarrow}{\sim}$ \\
\hline \multirow[t]{2}{*}{$r \cdot 17 \cdot$} & ITETY & Yror & $Y \bullet Y \varepsilon$ & 1.70. & $r \cdot r \in t$ & ע & 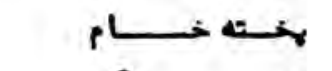 \\
\hline & rosq & ratr & 718 & Iyer & rroy & ע & $\longrightarrow$ \\
\hline Eve 190 & $r \varepsilon \cdot \lambda \wedge \mid$ & raril & r918.. & r.rryy & ereeta & متر مر بـى & تالــين و كــم \\
\hline \multirow[t]{2}{*}{$r+\ldots$} & 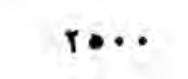 & rish & $11 \ldots$ & orr & - & طليونمترمكب & كاز طيهـ \\
\hline & & & is & & & & شنع : وزارت تجارت \\
\hline
\end{tabular}


جد ول ( • ) ) وارد ات به تغريق امتعه

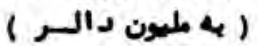

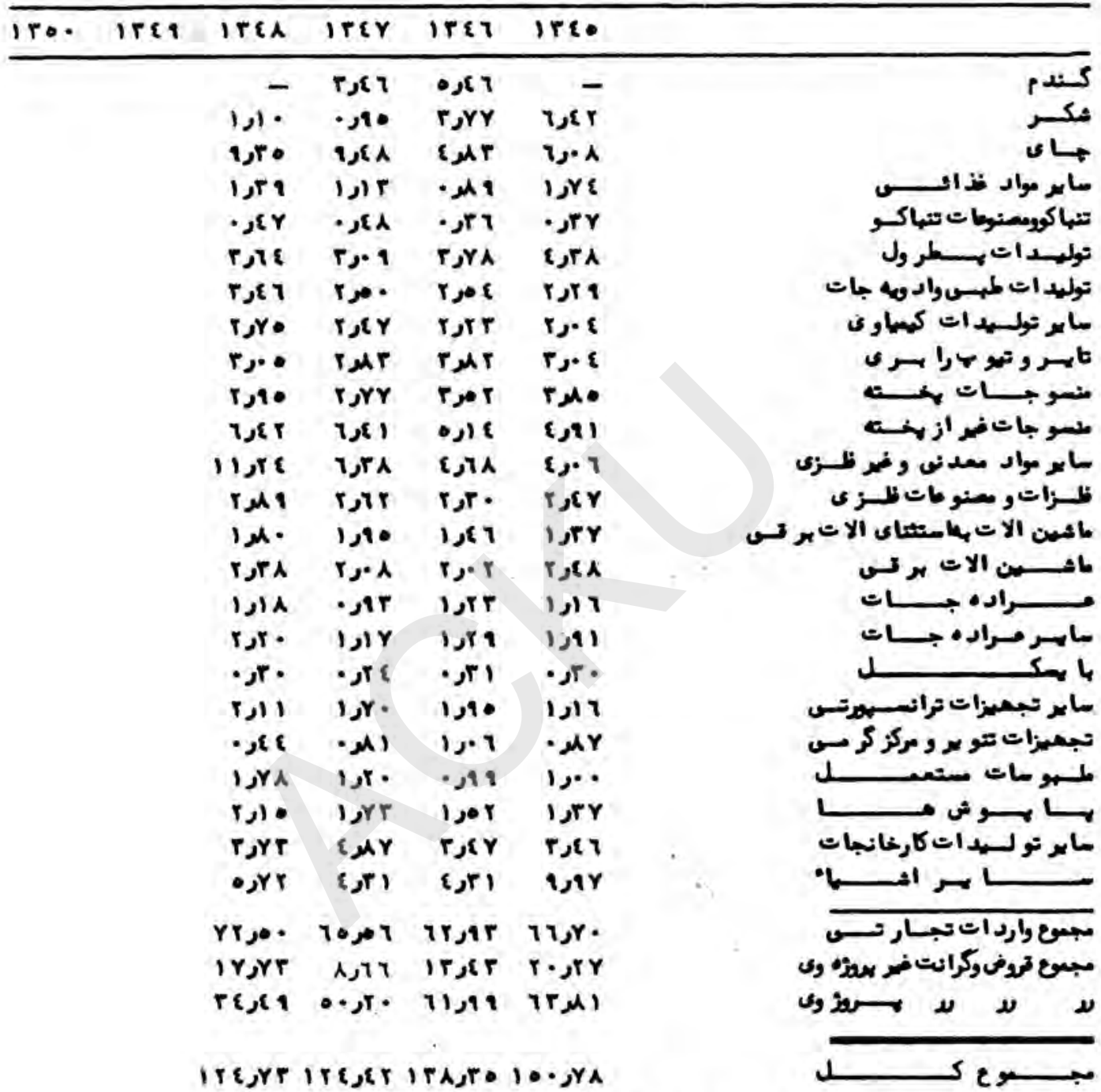

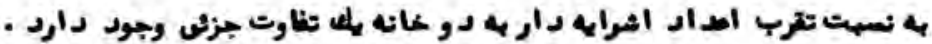
متع : وزارت تبـارت

اركام مروط واردات سال . . r او و ع r ا از وزارت تجارت حاصل شده نتوانست .

\section{0}


جدول (17) خمه تجارت خارجسى

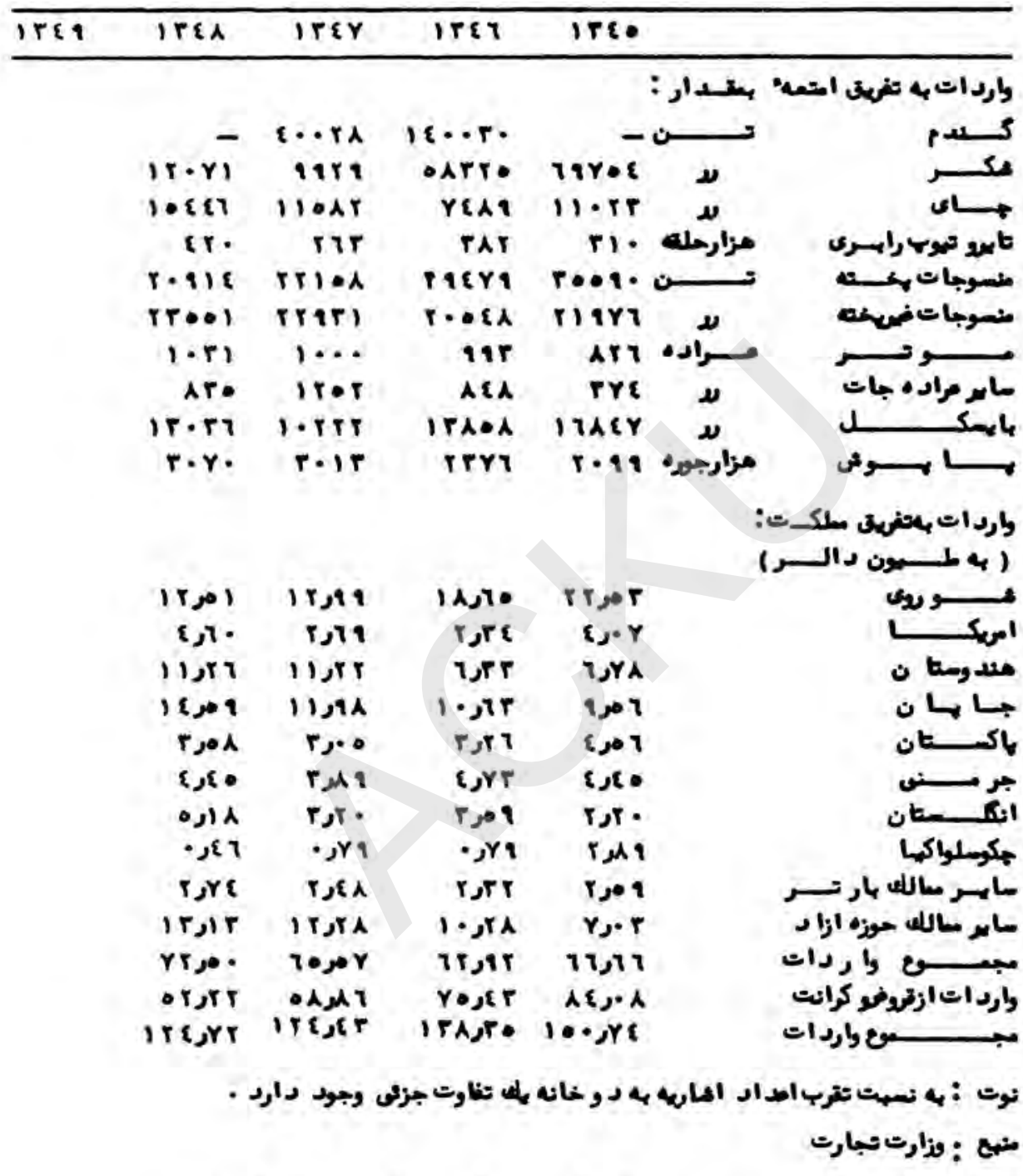

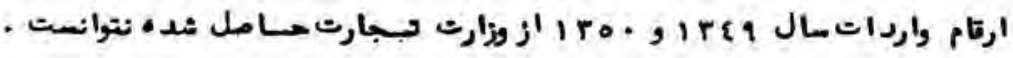




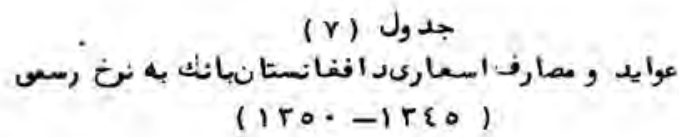

(1 ro. - r r $\left.\varepsilon_{0}\right)$

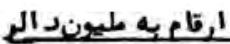

ITO. ITE ITEA IrEY IrET IYEO

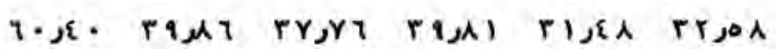

IAرA I,

$r$, $\quad r$,

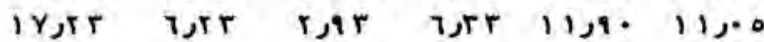

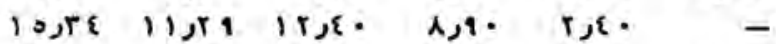

ז.

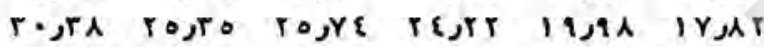

Y, Y,A Y,T0 Y,a 0,

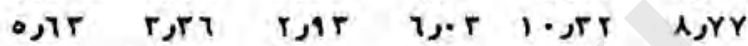

10,rE I,

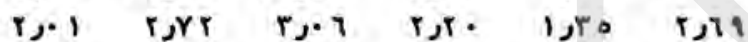

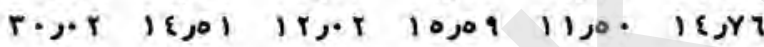

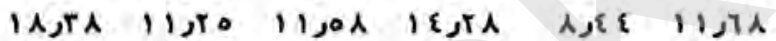

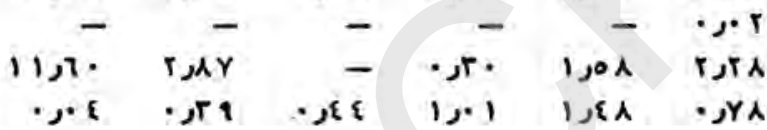

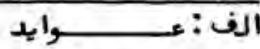
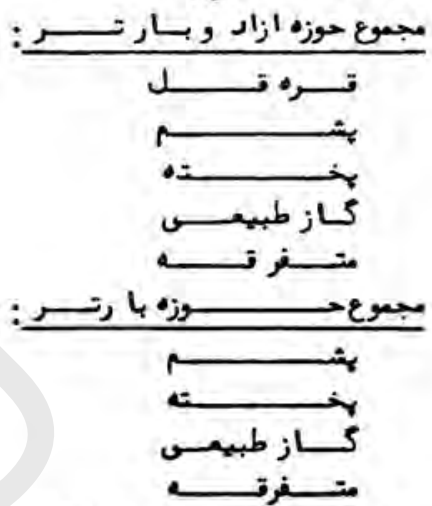

$$
\text { }
$$

\begin{tabular}{|c|c|c|c|c|c|c|}
\hline$r \cdot \partial r$ & rवा & $r \wedge, r$ & 12,1 & $1 \varepsilon 0$ & $1 x, r$ & مجسع حسوزه ازاد , بار تســر: \\
\hline$Y, 9$ & $y, r$ & 1,0 & 7. & $0, r$ & $r_{\text {, }}$ & مصــارف دولت \\
\hline ו ונrr & 1ر & 19,9 & r r & $\lambda$ & גرr & تروض د ولـــت \\
\hline . & • Y & - رr & عر • & عرر & r & متغــر قـــــــ \\
\hline$r \cdot \gamma$. & 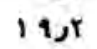 & $1 r, r$ & וر. & ונ & عرr & 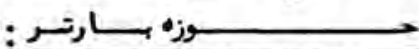 \\
\hline rolq & عر. & $\varepsilon, x$ & r. & مر 1 & rرr. & مصارقدرولت \\
\hline$|Y, \mu|$ & $10, \pi$ & וرזו & וر & $\varepsilon, r$ & - & تسرضد ولدت \\
\hline- & - & - & - & - & . & متغـــــر تســـــ \\
\hline $1 \cdot \pi \cdot r$ & 9 १९ & 110 & 1رo & $\wedge ر$ & ir & وزه ازاد \\
\hline$r$ r. & 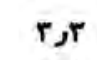 & r & f. & rjo & हा & مصــارف دورت \\
\hline גוرר & 0,9 & $r, r$ & ار0 & $\varepsilon, 0$ & גرr & قرو ضد ولــــت \\
\hline ع عر. & • & rر & ع & عر· & \&ر & متغـــــر تســـــ \\
\hline
\end{tabular}
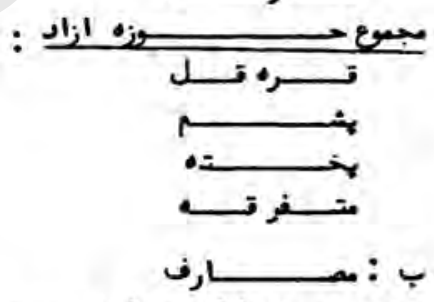

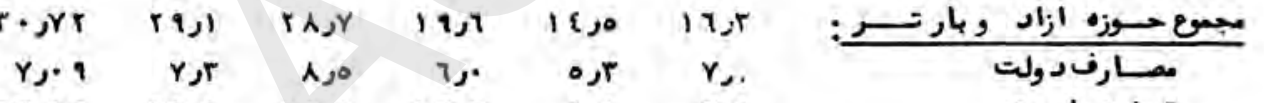

Aرr 1, 1,

r ש ש

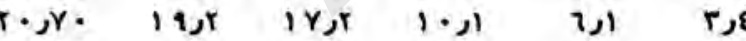

r, ת

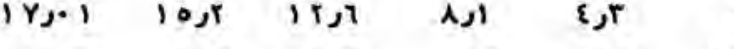

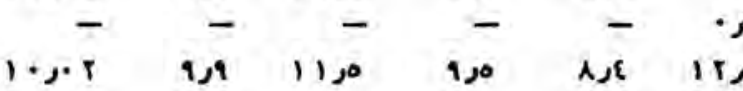

$r$ r, $r$ r, $r$ r

متبع : داففانستان بانك 


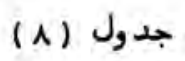

ذخاير اسعار بين اللبلى افغانستان واقلام ارتباطى ان

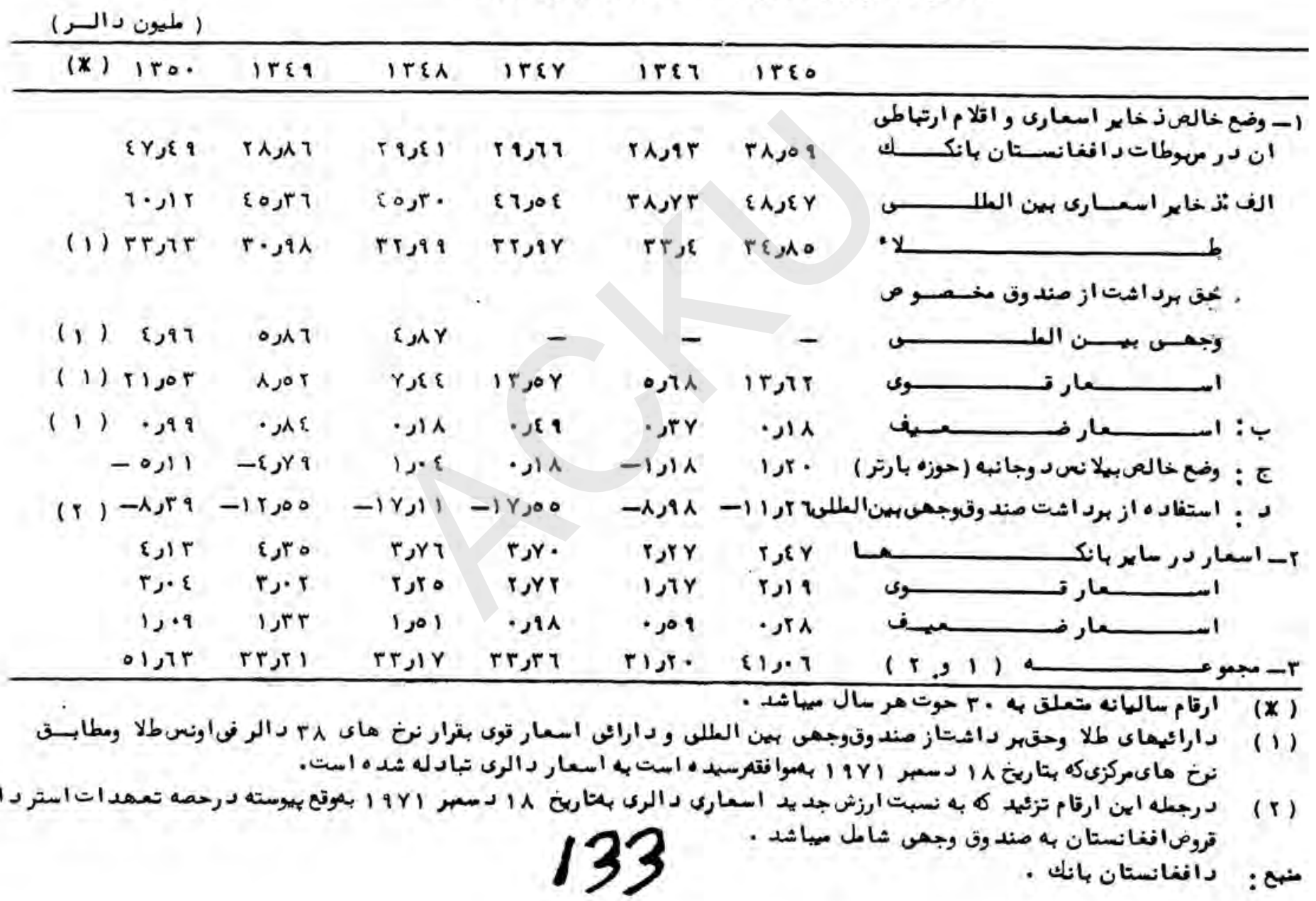




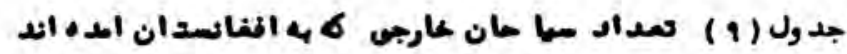

\begin{tabular}{|c|c|c|c|c|c|c|}
\hline Iro. & irea & IPCA & ITEY & IFET & Ires & \\
\hline $1 \cdot 7 \cdot \bullet r$ & 1..rrr & $T H \cdot A T$ & IEOT & TYAA & resir & مجمق: منجله: \\
\hline (7T•) & - Iro. & ritre & I IATY & IOATE & $I r \cdot r$ & باكـــــــان \\
\hline | | & gort & ries & $7 \cdot r 8$ & c250 & $\varepsilon \bullet r \bullet$ & \\
\hline irre & Ir. 1 & $\boldsymbol{A} \cdot \boldsymbol{A} \cdot$ & - IEr & ori. & $r \cdot 7 \lambda$ & الكســـــان \\
\hline YTYT & - EYT & P917 & YYII & I IAY & $r \cdot \varepsilon \cdot$ & مسنى \\
\hline$r \cdot Y I I$ & TETT. & irree & $1 \cdot v \cdot \varepsilon$ & I IYAA & 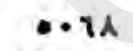 & مالل \\
\hline AYOTT & $A E \cdot A t$ & - YY. T & PI. IY & $|Y \cdot| r \mid$ & IEPAT & زعنى : مغبل : \\
\hline eritr & $(A \cdot B)$ & (स) & $|A \cdot M|$ & IPIT & rorr & S6 \\
\hline Irrt & SYoo & eicr & Pror & PrT. & דזרו & \\
\hline Arre & ATE. & rira & crar & צri & $10 r A$ & ith \\
\hline orr. & etre & PIIT & $r \cdot 2 A$ & icts & דוזו & سـن \\
\hline rrAOA & |AAA|. & If.Tr & $\wedge r \cdot\{$ & ors. & rPIT & ماير معاله \\
\hline IA(1) & Ixice & I. TAR & $A \in S$ & 1. Y9E & 1. ir & موال : عجسه : \\
\hline ruat & FI1 & I IAC & IYYT & $1 \times 79$ & ITY & 56 \\
\hline S21 & EAIY & $r \cdot r$ & rYYY & קום & TATT & امט \\
\hline $1<29$ & 1.78 & $A \bullet r$ & YET & IVAE & 1.8. & الكمــــان \\
\hline lect & 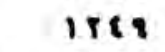 & $A \cdot \mathbf{C}$ & rer & - EA & IYe & جـــــــ \\
\hline ruor & -Al: & rT(E) & re.. & $I \cdot Y A$ & rroo & ماير مالده \\
\hline
\end{tabular}


جدول (1) هول و بانكدارئ

\begin{tabular}{|c|c|c|c|c|c|c|}
\hline $1+0$. & $1 \pi \varepsilon 4$ & $1 \mathrm{rEA}$ & $1 \mathrm{rEY}$ & ITET & $1 r \varepsilon 0$ & - \\
\hline & & & & & & \multirow{13}{*}{ 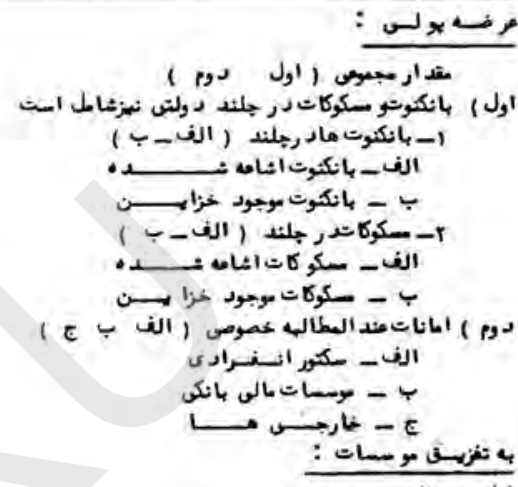 } \\
\hline YAET & YorAs & $Y \cdot T \cdot \lambda$ & $09.0,1$ & $000\{\pi$ & ofyrj & \\
\hline $11 \times \lambda, 5$ & $1+\varepsilon 1, r$ & $r \cdots r$, & $0.91,7$ & $\{\lambda \cdots$, & $\{x \mid r, 0$ & \\
\hline $10 \cdot A, r$ & תזTז & $0 \times 11,1$ & 89970 & (Y.T) & 8719,4 & \\
\hline$y+8 \cdot, 8$ & $Y £ \mid \lambda$, & $\operatorname{Tr}\{\varepsilon, \gamma$ & 0714,1 & $0\{99,1$ & $00, T$, & \\
\hline ifri,r & 1אג & $A \circ T \mu A$ & |rTנ & Y१1, & $A \wedge \varepsilon, t$ & \\
\hline $11 y, y$ & 115, & $11 \cdot x$ & $1 \cdot r$ & $I Y, Y$ & IT TA & \\
\hline $1 \varepsilon \pi, \pi$ & $18 x$ & $I T \& \mu$ & Irys & ITT & irts & \\
\hline 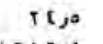 & זA. & TES & $r \varepsilon$ & $r 0, r$ & 19,0 & \\
\hline |riार & דתזה & $1.0 \wedge, \lambda$ & $A \cdot 1, \cdot$ & $Y=T, Y$ & $Y \circ \lambda, Y$ & \\
\hline 1rajo & $1+1,9$ & YT•• & זرا •. & $0 \wedge 0,0$ & $T(x, 1$ & \\
\hline $18 x, 2$ & $18 \%, \pi$ & $I A A, T$ & ris & $17 A, T$ & $I T T, T$ & \\
\hline $1 \pi 9, \pi$ & $1 \pi T \pi$ & 100,7 & $V Y j$ & $\overline{-}$ & & \\
\hline IET & $16 r, t$ & $1 T \varepsilon, 1$ & $1 \pi y, 2$ & $1+\pi$ & $1 r r, r$ & 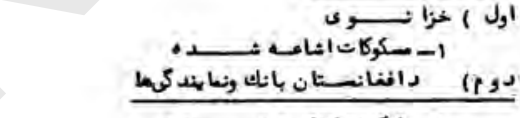 \\
\hline 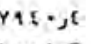 & YSIAT & $T Y\{\varepsilon, y$ & آر19 & $0\{91\}$, & $00 . r, 9$ & \multirow{13}{*}{ 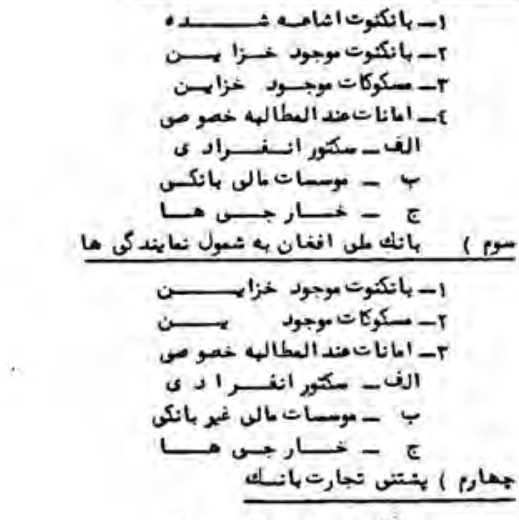 } \\
\hline$\cdots, \pi$ & oors & $\{* 0,0$ & EYs,y & 157,9 & $y_{0}, r$ & \\
\hline$T(\lambda)$ & $r y, t$ & $r \varepsilon$, & 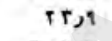 & To, & Thjo & \\
\hline R & $T A \varepsilon, 0$ & rat, & rort & $T \times T \lambda$ & $\operatorname{tr}\{s$ & \\
\hline$x \times s$. & $r \cdot y, r$ & TAAS & $T \cdots 0,6$ & ร१ดณ & \{£०, & \\
\hline$r 121$ & Tr, 1 & مر14 & $r i, r$ & 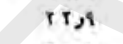 & $r x, 0$ & \\
\hline rost & $\{1,2\}$ & $00,$. & ios & 0.00 & $T=1, Y$ & \\
\hline$r T \cdot, y$ & 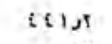 & ונרזז & $\| y, \lambda$ & إ & $\{1, r$ & \\
\hline er & . & , tr & זינ. & זיر. & $\cdot 9$ & \\
\hline A & $P T \cdot Y$ & $\{r \circ \mu$ & rats & 10020 & Irtor & \\
\hline : & 2151 & rrat, & $11 y, 1$ & $11 \gamma, 9$ & $7 \varepsilon$, & \\
\hline 1. & 111,9 & مر 101 & $19 \pi 1$ & ITY, & $1, \lambda, \gamma$ & \\
\hline$r \cdot, 1$ & $3, y$ & $\leqslant x$ & זر & - & - & \\
\hline 11,4 & $\mid A A, T$ & Tा:T & A. & 91,6 & $1 T$ Y & 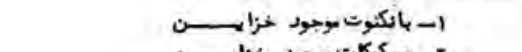 \\
\hline म & 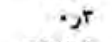 & $\cdot x$ & • & - & , & 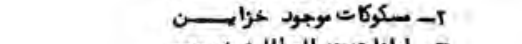 \\
\hline $\operatorname{TAA\lambda }$ & rinst & $r T q \mu$ & $17 \cdot 0$ & 180,9 & 114,1 & T- المانات عثد العطاله خصوص \\
\hline 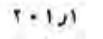 & $1 A r, t$ & $1 E 50$ & $1.7, t$ & $17 \AA, 5$ & 11 & 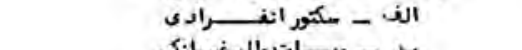 \\
\hline$\varepsilon, 1$ & $y, 0$ & 1, & $\because \mu$ & $r, y$ & $r$ & e - - - مارسسات مالىغيربانكي \\
\hline AT, & $y v, \pi$ & $A=x$ & tas: & - & - & $\longrightarrow$ ط \\
\hline
\end{tabular}


جدرل (I ) هول و بالهك اره

\begin{tabular}{|c|c|c|c|c|c|c|}
\hline iro. & litin & Ires & its & Irts & Irso & \\
\hline & & & & & & : \\
\hline rur & riety & Torr, & (גזrז & 1010,9 & $1719 \mathrm{gh}$ & ا \\
\hline rres: & $r \cdot y, r$ & TaAfi & $r \cdot 0, \varepsilon$ & $r 91,6$ & รE०) & الغ-_مكرانرادى \\
\hline \&YT & rix, & TrEst & rorst & $r \cdot 1, r$ & rix & 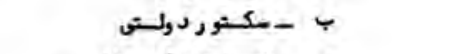 \\
\hline |धाر & Irast & lorys & $M$ & $0 \cdot \lambda>0$ & orrs & ع عتمد مان دولثى \\
\hline$r(1, \lambda$ & $r \cdot r$ & TATA & rict & $T T Y, Y$ & $r=1, r$ & د - - سـاير بانه ماف تجارتى \\
\hline$r \times$ r. & $T r, T$ & ra & TI, T & trot & 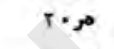 & مـ - موسيـات مالن مهانك \\
\hline 10,1 & $\{1,5$ & 00, & rasi & $\bullet \rightarrow 0$ & $r \cdot 1, r$ & $\rightarrow$, - , \\
\hline $7 \cdot 9, \lambda$ & 00001 & $\varepsilon E-, 1$ & $\varepsilon \cdot \gamma, \gamma$ & זAT, & $T 01 \mu$ & 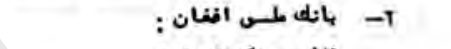 \\
\hline$[7=0$ & \&ा & trat & I1Yנ & Ir, & 18, & الف-_ ككمانغراده \\
\hline ع & - & - & - & - & - & - - مكسور د, لـتى \\
\hline$\lambda, \pi$ & $11 \mu$ & A, & 29 & ir & $y, 1$ & C - عدص هـاص دولتق \\
\hline I. & 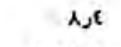 & ונ & | & |ر| & 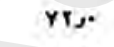 & 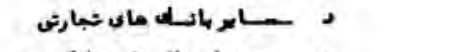 \\
\hline $1 \cdot Y, 1$ & 111 & $|=-x|$ & $\mid 9 T, 1$ & Irysy & $1 \cdot A j r$ & م - موستات مالق خر بنك \\
\hline Tre & $1, r$ & $\mathrm{~T}$ & $r$ & - & - & , \\
\hline ropdr & $r r \cdot s$ & रणधा & $\tau \cdot r, q$ & 118, & ו1ר & 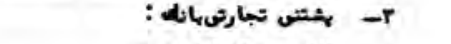 \\
\hline$T \cdot 1,1$ & 1גז & irs & $A T, T$ & I IAt & 11, & الغ - سكتوانغرا د ا \\
\hline 11,0 & זנת & Tf & $5 \pi$ & AN & ות & 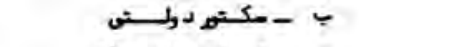 \\
\hline $10 x$ & \&Aر. & EAjo & $r 9,1$ & 19,1 & (1, & C - عدى هـان دولتى \\
\hline ז & r & $\cdot 9$ & - & • & •ו & د - ساير بانه عاى تجارتى \\
\hline is. & Y pa & 1, & sed & $r, r$ & $r x$ & م - موسطات مالى خر \\
\hline Artr & $r y, r$ & $A T, Y$ & \&1, & - & - & 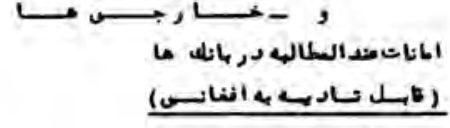 \\
\hline corts. & זrसा & זر & trtogk & תונים & ixaty & الول مب بو \\
\hline Iros & $1=1,1$ & oritr & $0.9, \pi$ & $\Delta \wedge 0 ر 0$ & $\operatorname{lin}$ & 1--سكو انغادى \\
\hline $\cos \{x$ & rytri & $T T Y, T$ & T110 & $\pi / 0,4$ & - & r- سكــور ردورتن \\
\hline$r \varepsilon 7 \varepsilon \mu$ & IETtr & ا & $1 \cdot \varepsilon \cdot \sin ^{-1}$ & 10.0. & $1 \times 1, \pi$ & 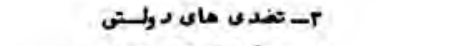 \\
\hline זथरा & $r \cdot 9, r$ & ites & trat & एะ ד1 & IYq. & أ- ديكاسل هاى تجارتس \\
\hline IEAرY & $1 \& Y, r$ & $1 A 70^{\circ}$ & $119, \pi$ & $1 \mu, \pi$ & Iזत & هـ موسيات مالى خر باككيى \\
\hline r & IrT & $\mid 8=5$ & $Y Y, T$ & - & - & كار جـ بـ \\
\hline
\end{tabular}

\section{6}


جدرل

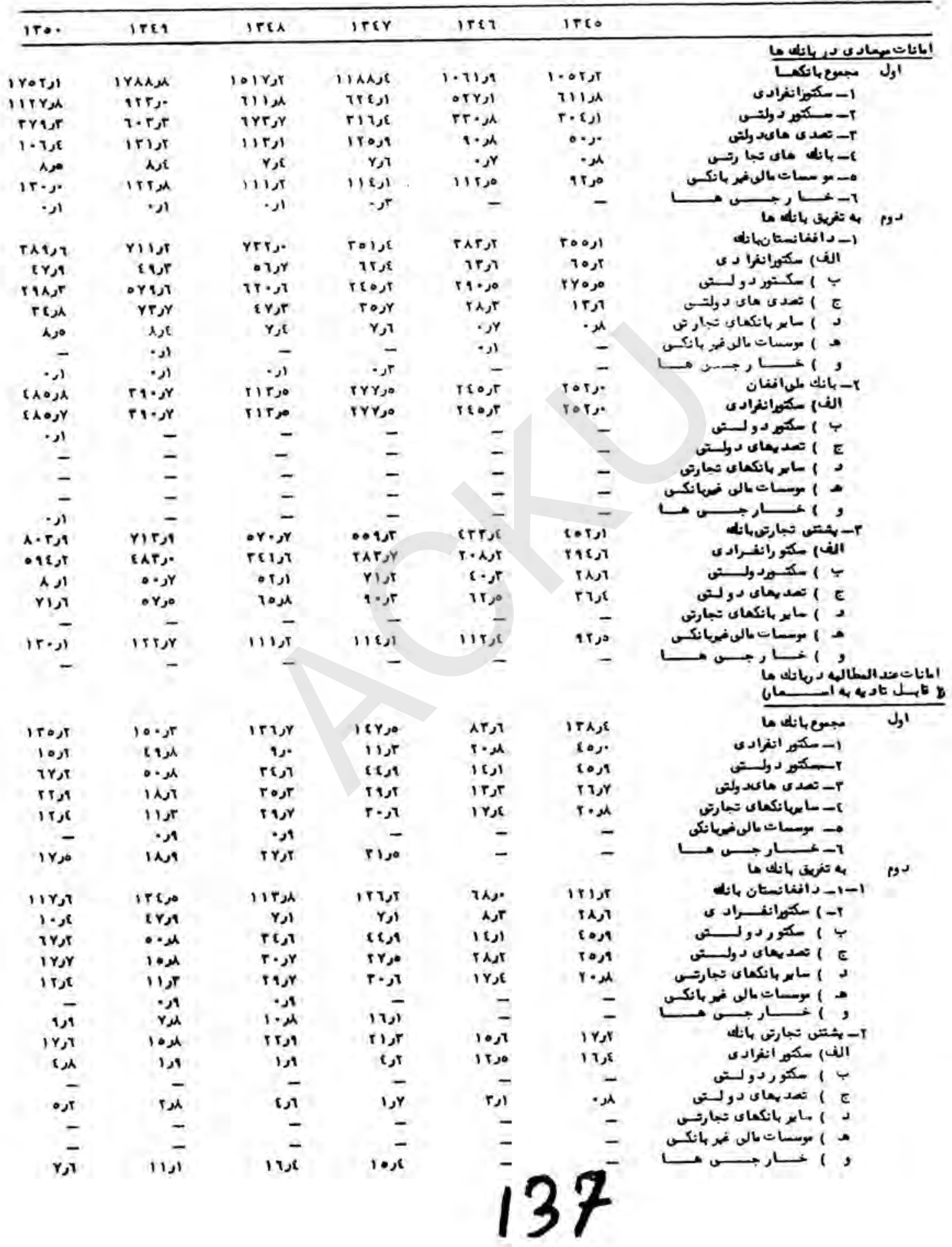




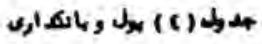

\begin{tabular}{|c|c|c|c|c|c|c|}
\hline 1700 & ires & ITEA & irCY & ITE & irse & \\
\hline & I. AY,E & aratis & retror & Threg & $1 \cdot \gamma /, 0$ & 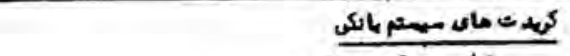 \\
\hline Vir $A, T$ & $11 \cdot 1,0$ & I. Ta, & (YT) & Eceste & rive & أرل ب الكهم دولكسي \\
\hline rrias & T\&A.) & ritro & rYTIJT & retafe & rutro. & دو \\
\hline ATIA & IAT & $1.1 Y x$ & $A|r|$ & גיניו & 1. IA. & 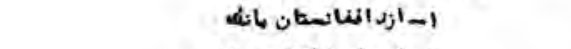 \\
\hline terts & respo & $\operatorname{tre} \cdot x$ & $191 \mathrm{R}$ & IVT.M & $|Y=A|=$ & r-از ماسيسكان تجارتسى \\
\hline rt\{A\} & $r r \cdots r$ & $r+x, 9$ & $r r \Leftrightarrow, r$ & WAYt & trith & 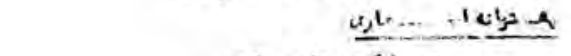 \\
\hline $30 \cdot A, y$ & म - & OAMIJ & 0.00 & $\varepsilon y \cdot r, r$ & $\varepsilon \| 1, \gamma$ & 1 \\
\hline rters & I110. & II 10,9 & $r+\ldots, t$ & riaref & rtirger & 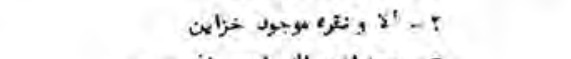 \\
\hline ני. & •x. & os. & og. & •x= & 0). & r- وجه الفتر الك الى _ان- - \\
\hline קוק & $r \bullet r$ & $r y, x$ & \&T\} & 270 & $\{9\}$, & 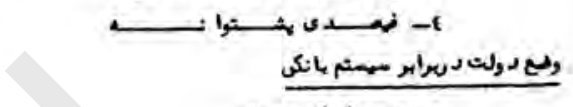 \\
\hline ASIE & YTIAנ & Wris & וرז •0. & \{AYT & โะาด & ا - كلاد طول العدت \\
\hline 1919,0 & IrYat & 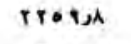 & סגזיט & orgy & - & 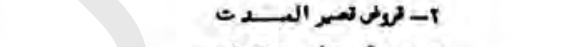 \\
\hline ITIر & $\operatorname{trtg}$ & $r-1,0$ & $r \cdot \gamma$ & $r \cdot T, t$ & ret, & r-r بشكى ها بـ افغانس \\
\hline$(1, \mu)$ & $17 \cdot 0$ & 1729 & 11,0 & $00 \pi$ & ras. & 40 \\
\hline 1हार & IET & $1+c, \lambda$ & IrYנo & $1 r r, \pi$ & itrot & ن \\
\hline- & IAY, & IArjo & $1 \wedge \gamma>0$ & IAYjo & $1 \wedge \gamma, 0$ & 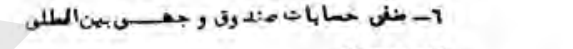 \\
\hline $10 \times 1,0$ & 1E0) & AYYT, & iErr, & or. T, & $\{A T r, \gamma$ & 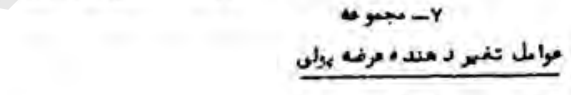 \\
\hline Tic, & 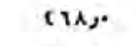 & Irost & ra.ja & $Y A$ & $-1 \lambda$ & مبr \\
\hline $0 T 1, \lambda$ & oyrt & Iray, & YTT,Y & $1 \cdot 1$. & $-i x$ & 1-كريد ث 4 -كتورد ولتى \\
\hline 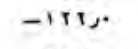 & | & $-67 t 0_{0}$ & $T \cdot \varepsilon, T$ & $r+1, r$ & 11 & 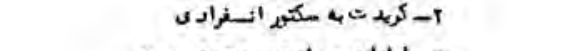 \\
\hline 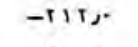 & $-\operatorname{rrr} \mu$ & $-1 \cdot 9 x$ & $-1 \times 7,0$ & $-r$ & -118 & r-rانات ميعادى ( تزّهد ) \\
\hline Whe. & $1 \ldots 0$ & $-1 \cdot 7,0$ & $-r \circ x$ & $-r T r$ & -119 & 1- دارائ شالـماسعار خارجــــ \\
\hline$\rightarrow\{1, x$ & -AYri & גנד -0 & $-r \cdot 1,4$ & -trr & ror & 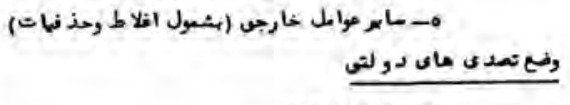 \\
\hline 169 & 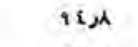 & זा & $7 \alpha, \lambda$ & $7 A_{2} \lambda$ & 110,1 & 1) تصو (x) \\
\hline$\cdot 0$ & TYTנ० & ixt & (19 & Irxit & $\cdot 0$ & T- كهشك با ب الفنانت \\
\hline$r y o$ & $r x, r$ & 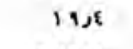 & $r t r$ & 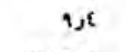 & $1, \varepsilon$ & 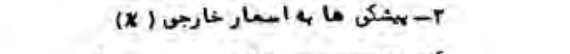 \\
\hline irost & ras,* & irted & 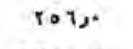 & אנד & $190, Y$ & $\longrightarrow$, \\
\hline $1,96 \%, t$ & 9106,9 & $1+\{y, \lambda$ & 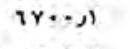 & ค97ย, & $0.11,9$ & مبعر ع تروض دولت , تصد بلى در لستى \\
\hline $\begin{array}{l}r \lambda \cdot \lambda_{2} 1 \\
\text { vhrist }\end{array}$ & 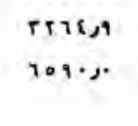 & $\begin{array}{l}P \cdot \Gamma \wedge ر 0 \\
1 . \lambda \lambda r\end{array}$ & 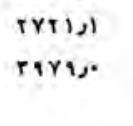 & $\begin{array}{l}1010, y \\
\text { EEteso }\end{array}$ & 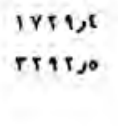 & 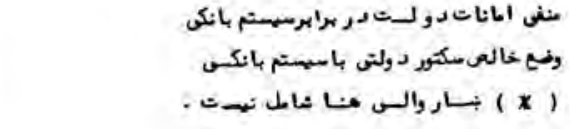 \\
\hline
\end{tabular}


(1) مدر )

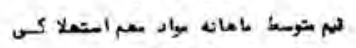

I T.

\begin{tabular}{|c|c|c|c|c|c|c|c|c|c|c|c|c|c|c|}
\hline اوبسط & مر & دلو & جدى & توص & غلرب & سزان & 4 & -1 & سرطان & بسوزا & 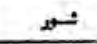 & عل & $\rightarrow$ & \\
\hline & & & & & & & & & & & & & & خهو \\
\hline$s \cdot, y$ & vy,t & $y \in d A$ & res & rro, & rro. & $A s x$ & rist & $A \cdot, 0$ & $A r, r$ & $A=0$ & 1hxt & $y y, t$ & & ارد كدم \\
\hline$r$ ra & 11,0 & $\cdot 1,0$ & $0 \wedge \lambda$ & $=A, T$ & or, & 110 & $11, \lambda$ & 10,4 & $10 \mu$ & $21 x$ & Yi, & זره & ע & ارد بوار \\
\hline ITAN & 1149 & inst & $i n t, t$ & $1+A \beta 3$ & $114 \pi$ & $1+r, 1$ & 106,5 & 1029 & ictes & $\mid T A, T$ & $11 \times, \pi$ & $1+1,0$ & $\nu$ & . رن باري4 \\
\hline 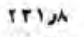 & Tirst & $r \cdot 4, r$ & TCT & T., & $\gamma \cdot \gamma, \theta$ & $r \cdot r, \gamma$ & $\tau=y_{j}$. & 119,5 & $\pi \cdot \mu$ & זा & Pla,y & rat, & $\nu$ & \\
\hline $1 C t \lambda$ & 100 & $1(1,4$ & leces & $\pi$ & $1 T \cdot, \gamma$ & $184 x$ & |r|ر| & in & (1ז & $1(1)$, & $1 \circ r, r$ & $\operatorname{lir} r$ & ע & كـاو \\
\hline 10,1 & - & - & - & $10, \pi$ & A9. & us & $r(s, y$ & (rנ) & مربم. & Al, & - & - & $\nu$ & انه" \\
\hline$\bullet \bullet, Y$ & - & - & - & - & - & - & - & - & $\because \mu$ & - ist & הות & - & $\nu$ & دد الو \\
\hline $1+1,8$ & $18 \pi 0$ & is & 1082. & irest & $10 r, y$ & 1 iresy & IrTh & | & ITI & $|r \bullet|$, & 151,5 & $1 T \cdot \pi$ & ע & كسضر \\
\hline r.,y & ris & $r \pi, 0$ & 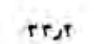 & זנזr & rer & rex & •, & r0, & is, & $19, \gamma$ & rA, T & rito & ע & 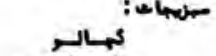 \\
\hline$r i, 1$ & - & - & - & - & - & $r i x$ & res & TrT & ris. & itso & - & - & 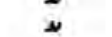 & بادئلمان ردص \\
\hline raje & 19,1 & rA,Y & $T A, T$ & $r x, 9$ & iA, & $x$ & $r i, y$ & ix & $r 0, r$ & अवर्र & -Y, & 10,8 & $\Delta$ & (6) \\
\hline$r \cdot \mu$. & - & - & - & - & - & 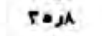 & iA>l & ונוז & r., & - & - & - & 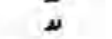 & بادنهان - \\
\hline $11, y$ & "र & 11 & 19,1 & $+8,0$ & זיזי & $P, 1$ & - & - & - & - & - & זו ומ & N & נ, \\
\hline 19. & 11т & 19. & תזוג. & 1981 & 111 & $|x| x \mid$ & $1(1, T$ & itr, & סקוזו & 10.0. & $1+1, y$ & $1 t A, 1$ & . الهاته & ديكربادلالى : سمرع \\
\hline |Tנ & | & "Ir. & וזי & $\|+\|$ & $\| r, \mid$ & וرا & $\| r \mid$ & 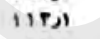 & ins & $\| r$ & וקונ & $\| r \mid$ & & sc/ \\
\hline$i s, r$ & $1 t, \gamma$ & $i x$ & $18, y$ & $1 t, y$ & ist & $|x|$ & 160 & 182 & 110 & $|c|$ & Ir & $16 \mathrm{se}$ & עد & r \\
\hline Alts & $\mid A A, t$ & 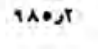 & 1A9, & nex. & 1Trose & raYs & ruese & Yiा. & YATS & rot,r & vise, & $v+1$ & 2 & - \\
\hline$i r, r$ & $15 \pi$ & ir, & זנדו & אקיו & |rt & irs & $|r|$ & irst & irf & ITR & ir & $i r \boldsymbol{x}$ & ف - سـر & 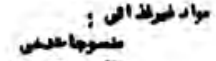 \\
\hline A 11,1 & ir. & $\cdots$, & w, & 1.. & $A \Lambda \cdot \boldsymbol{N}$ & $A A+D$ & $A T+$, & יני & $A \cdot 0$, & A1, , & $A \cdot A, \cdot$ & vas. & لى مثرصه & كالسنر كالهي \\
\hline $17 r 0$ & $|r \cdot s|$ & $\mid r \cdot \rho r$ & ires & $1 \times 0,1$ & مراY & $\mid 1 \cdot \pi$ & $\cos 2 \pi$ & linst & مر.ب1 & irres & $|(t)|$ & 117 & 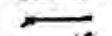 & م6 \\
\hline ire. & Tro & $i r$, & $i y_{2}$ & rr. & 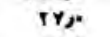 & irs. & $r p$. & קצ" & $r y,$. & ir. & $T r, x$ & tr, & 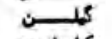 & 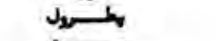 \\
\hline t, & ار & rer & ז & $t, x$ & $i x$ & ix & is & th & (1) & r, & ist & is & كلمول = & \\
\hline A.ग & ATر & AT, & AT & $r a x$ & $r a, t$ & rist & rist & $r a r$ & rax & rast & val & rw & & كلذاكا \\
\hline$A_{j}$. & $1 \mu$ & A, & $Y_{\mu}$ & $y, 1$ & $r / \mu$ & $\forall \mu$ & $r, A$ & $r \mu$ & $r / \mu$ & Y Y & $r \mu x$ & 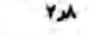 & N & $\longrightarrow$ \\
\hline
\end{tabular}


(T) جدول

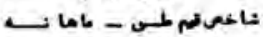

o. - er

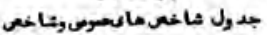

orsosis

\begin{tabular}{|c|c|c|c|c|c|c|c|}
\hline شاغمر مجمى & ماد ميرغذ ائى & ماد فالى & تهزيات & مهرث جات & كوشت & =6rar & Lo / \\
\hline 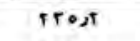 & $1 \cdot \varepsilon, 4$ & $18 \cdot \pi$ & $r \cdot r, 0$ & Iarst & $\ln x t$ & $T A \bullet \boldsymbol{d}$ & $J_{-1} \pi t r$ \\
\hline rTre & $\mathbf{V y} t \mathrm{t}$ & ictir & $T \cdot T, 0$ & $\mid 1101$ & TI & $T A \bullet \boldsymbol{~}$ & 0 \\
\hline ז†人נ. & $1 Y, 1$ & $100 x$ & $r=\gamma, \lambda$ & |נטו & 11 & משtrit & جوز1 \\
\hline תtr: & $1, r, \pi$ & isto & $1 x r, x$ & I & latest & $r(0, r$ & مرطلان \\
\hline शזי & $1.1 \mathrm{n}$ & 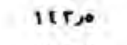 & $18 \cdot x$ & irise & $\mid Y \bullet \theta 0$ & trex & ا \\
\hline R & آ & $150 \mathrm{ph}$ & נrזי & $1 A \cdot 3 *$ & |A1, & rtrit & سنهلبـ \\
\hline 1280 & $1-1, x$ & 1003 & $1 \mathrm{r} \cdot \mathrm{A}$ & $1 \times t, 1$ & 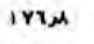 & Ix & سزن \\
\hline Itrat & $1=1,0$ & $1 \& r, x$ & iste. & $19 \cdot 2 \mathrm{~A}$ & هر|A| & riAd & \\
\hline זנוצו & $11 \mathrm{r}, 1$ & $\mid s \gamma, 0$ & $1 \cdot A, y$ & גוזי & 1A1, & irr & ص \\
\hline $1 \cdots x$ & irs & 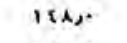 & irest & TET & $r \cdot x, 8$ & II•נ. & بـ \\
\hline 1000 & $1 . A_{21}$ & $1: x, t$ & six & r t & $T \cdot 1, \lambda$. & $r i \cdot r$ & \\
\hline$r=x$ & $1 \cdot x_{2}$ & $16 x, 1$ & $111 \%$ & וגו & 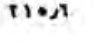 & ris & \\
\hline התז & 110,8 & isten & rivir & rry & $1+1,0$ & $\mid r \cdot s$ & mea \\
\hline $\sin x$ & $110 \mathrm{x}$ & $1 \times x y$ & $r+r, c$ & $r 10, r$ & $18 \cdot x$ & ז & دــو \\
\hline 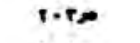 & 38 & 1ets & irsor & $T \cdot A J$ & IIII & TRT & 49 \\
\hline IAISE & 1163 & 100, & $I A \cdot \lambda$ & $\mathbf{t}$ & $11 \cdot x$ & ITCST & ou \\
\hline 19189 & זرب 11 & $1 \mathrm{crs}$ & $1+y, E$ & IATR & $t \cdot c$ & rest & \\
\hline זעת & קرك 11 & $1 \mathrm{es}$ & itror & Iדע & IVAT & Trt & سنــ \\
\hline IAten & 1120 & $1 x \cdot \mu$ & $1 \cdot 1,7$ & $T \cdot 1, x$ & I 1ax & $T \cdot \bullet$ & ol \\
\hline $12 x$ & IT•ק & براז & קرx & $T=A D T$ & $5 \cdot 8$, & $r \cdot 1,1$ & \\
\hline$T \cdot C \mu$ & 1081 & 1. 1 & ותזד & rratr & 111,4 & $r=0$ & w \\
\hline $11 \pi$ & $1+x$ & $18 r, r$ & $r Y \cdot g$ & مرזד & גנוזי & T Y Y & S \\
\hline$T \cdot \bullet \boldsymbol{t}$ & $118 x$ & I satr & $r \cdot c, 5$ & $x+21$ & $\mathbf{\nabla Y} \mathbf{Y}_{\boldsymbol{j}}$ & $T+r, r$ & \\
\hline$t r \cdot e^{2}$ & $\| \gamma, \alpha$ & icher & 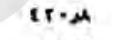 & Pvis & rivr & Pر Pر & \\
\hline$T \in T, r$ & $110 \pi$ & 1805 & $r Y \cdot, Y$ & T15, & retor & $r \cdot 1,1$ & - I Fes \\
\hline$r+1, \mu$ & $|18|$, & $1 \leq \pi x$ & $T \cdot T \mu$ & $t \in c \pi t$ & $T(1)$ & 1280 & \\
\hline ITA1 & 1 I 1 , & $186 \pi$ & $10 \cdot \mathrm{A}$ & I $16, \gamma$ & זरा & TAYST & \\
\hline rtas & I 1 & $18 \cdot \pi$ & $178 x$ & $\begin{array}{l}\text { I Yaxi } \\
\text { lory }\end{array}$ & $1 / 6,0$ & TATA & إنساند \\
\hline rror & 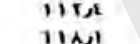 & $\begin{array}{l}167,1 \\
168,5\end{array}$ & זע $18 x$ & $\begin{array}{l}10 \gamma \mu h \\
10 r, y\end{array}$ & $\begin{array}{l}r \cdot r \mu h \\
r+1, \mu\end{array}$ & $\begin{array}{l}10 \mathrm{x} \\
\mathrm{r}+\mathrm{s}\end{array}$ & r. \\
\hline 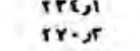 & 11 & 186 & $10 \mathrm{xi}$ & I & $11 \cdot, E$ & resir & مزلن \\
\hline TAS & $11 x$ & 101,8 & זוגו & $176 \mu$ & זוז & T(1) & ملرب \\
\hline $111 \%$ & Irs & 10.01 & Tras & Tris & $T \cdot A x$ & rex & لو س \\
\hline rior & II I & $100 \pi$ & Trर, & rit & Tris & וגינה & \\
\hline rrigr & $15 \cdot \pi$ & 101,4 & Trs, & พงดx & 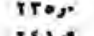 & rive & دעت \\
\hline TrT & $|5 \cdot|$ & 16121 & ragr & مر = & 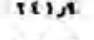 & FAT & 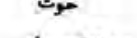 \\
\hline ז・ & $1+301$ & $1 \mathrm{BAT}$ & rit & rrest & $r \in T, r$ & rvase & $\underset{0}{1} \mathrm{r}$ \\
\hline$r \cdot 1, r$ & $11 x$. & $1(x)$ & 771,1 & Trve & 11101 & $\varepsilon \bullet \mathbf{r} \boldsymbol{s}$ & 0 \\
\hline rist & lingo & $100, y$ & ז1, & $T \cdot[\boldsymbol{J}$ & 118,1 & cris & جـ \\
\hline $\begin{array}{l}r+1, r \\
T+1 \times 2\end{array}$ & $\begin{array}{l}\text { Irת } \\
\text { IIyge }\end{array}$ & $\begin{array}{l}100 \pi \\
10 r x\end{array}$ & $\begin{array}{l}\text { IATSI } \\
\text { IALE }\end{array}$ & 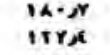 & $\begin{array}{l}\text { iatse } \\
\text { iry, }\end{array}$ & $\begin{array}{l}\text { (3.) } \\
\text { C.ant }\end{array}$ & 1 \\
\hline$x A \bullet x$ & 110 & 101 & ivr & $128 \pi$ & ints & PAIA & - \\
\hline Pis & IIAs: & $1 \bullet \mu \mu$ & IAAgl & $\mathbf{x} \cdot 1 \pi$ & IATpe & cilar & مزلن \\
\hline $7 \cdot 1,1$ & I IAS & קAC & 125,6 & $r \cdot v r$ & IATK & TATST & غترب \\
\hline$r=1$ & ils & IAt, & 170,7 & $r \gamma r, \gamma$ & 192,6 & קرFAT & تس, \\
\hline$r+r$ ז & 112, & $1 \gamma \cdot x$ & $T \circ A, A$ & TYA, & TIOS & rYis: & קد v \\
\hline$r \cdot T \Omega \gamma$ & $1+1,8$ & 145 & $17 x, 1$ & $\tau \times T, 1$ & $150 \gamma^{2}$ & ridor & נגינ, \\
\hline$\Gamma_{1} ; 0$ & $\mid x+1$ & & 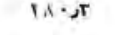 & $r A T, \mid$ & I. I I & TrY, & حسبـوت \\
\hline
\end{tabular}


جدول (T) فيه ثم

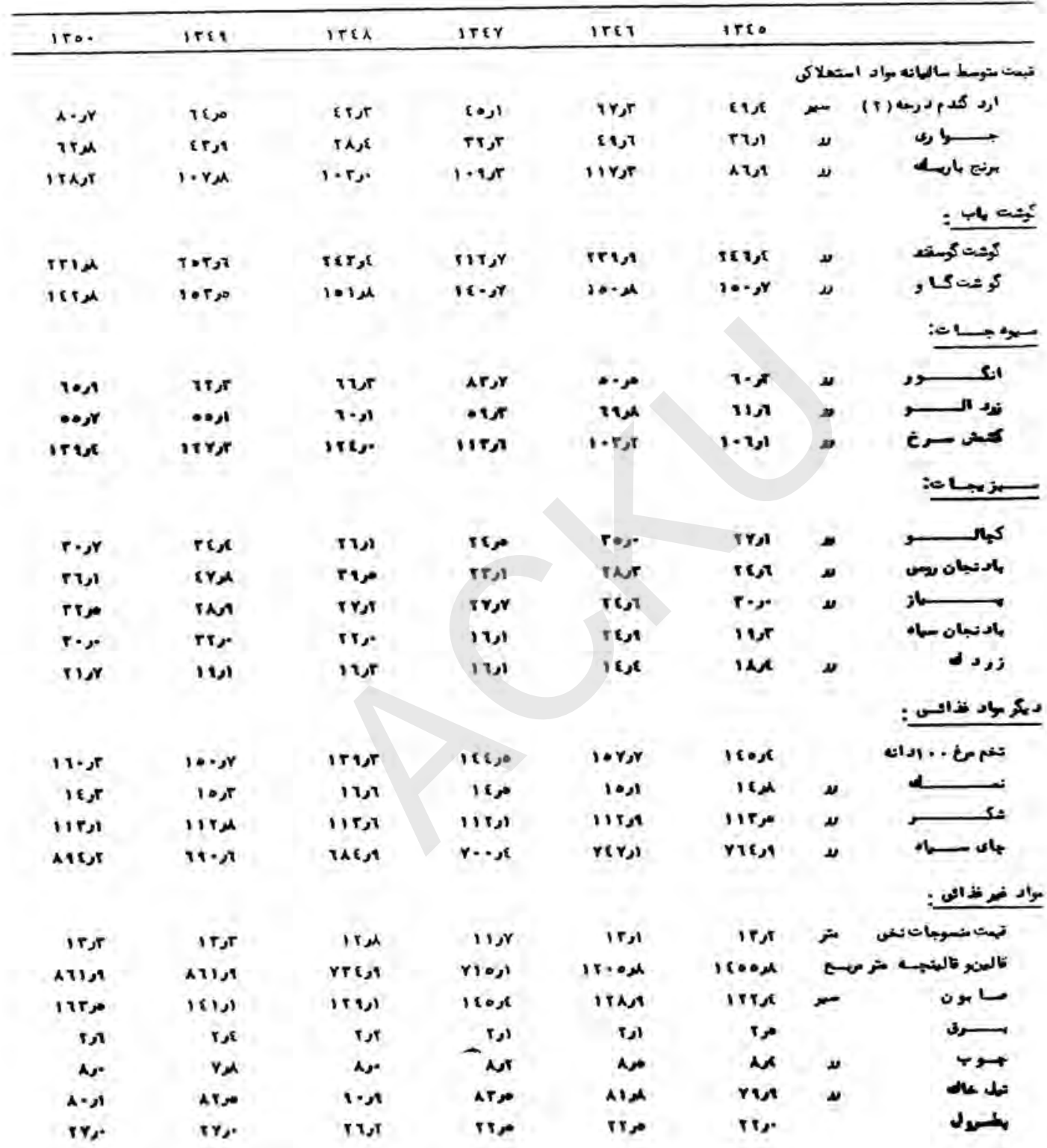


جدول (t) مسه مـم

\begin{tabular}{|c|c|c|c|c|c|c|}
\hline 150 & $3 \times 82$ & irca & IrEr & erex & itea & \\
\hline & & & & & & ماغس تم طلسي \\
\hline T-1, & $r x-g$ & $r \cdot r, t$ & $r=x, r$ & र्रहs & IE & فالخع مجعو بسلى \\
\hline ras & riar & Tin & rtrar & ritr & IEx, & $=$ \\
\hline erist & مر-0 r & Tाง, & $r(\bullet)$, & ritr & rase & الرد كدمبرجه | \\
\hline reAst & $r \in x, 0$ & 10100 & :AB, & Tragr & $T \cdot r, \gamma$ & بـــــ \\
\hline 5 & $r r \cdot j$ & $1+2,5$ & tits & rTI, & irye & مرن- \\
\hline$x-1, \pi$ & rros. & Iits & 1218 & rivr & rire & كوثــــابـ \\
\hline$r-\varepsilon,-$ & itrit & rist & 121,1 & ris & rix & Sوثست \\
\hline$r \cdot[\boldsymbol{x} T$ & 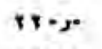 & TIAS. & ivrer & $\sin x$ & $x$ & s s s s \\
\hline$r r \bullet x$ & rivs & rrter & ו9ד & Iryex & IAA, & $:=L$, \\
\hline זערו & IAD,r & 1180 & $r \cdots, x$ & 10, & Iris & Sil \\
\hline 109 & 120,1 & ivis & Itast & $t \cdots$ & קرוץ| & ندو الـــــ \\
\hline teat & rres & 1190 & $x+1,=$ & 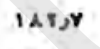 & IArye & 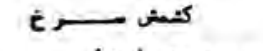 \\
\hline ITA, T & rex & $r 2 \cdot \pi$ & ivre. & 1002 & lor & : 0 L \\
\hline 10000 & xוגו & WAas & זע• & r|ris & העזו & كيـا \\
\hline los, r & $r=1, x$ & Irres & $w 0, y$ & $\mid r(s)$ & $1 \cdot \gamma, 1$ & كادنجان لا \\
\hline$r \circ t, r$ & +rye. & rise. & 198,0 & 11Tा & irefi & 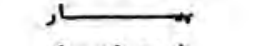 \\
\hline IS: & 100. & 1.1 & iris & IIs & $1 \cdot x$ & كان نجسان \\
\hline reve & $\operatorname{rts} 20$ & $19 \cdot 1$ & $\mid+1$, & $\ln x$ & W1, & ز \\
\hline هر1 & I $\{\gamma, 0$ & $1 \in 0, \lambda$ & |ह1, & 101,2 & مرات1 & ديكر ماد ثداتي : \\
\hline ITा & IIT & 199 & $r \cdot r, t$ & Iritr & $V \cdot A, T$ & \\
\hline IrAs & iras: & |r内 & ITR & WAA & هو & ني \\
\hline שرז & $18 \cdot x$ & ir & Iryo & 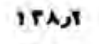 & ITA, & SA \\
\hline Inest & icts & I:T) & 120,1 & 100, & $1 \cdot A, y$ & • \\
\hline 111,1 & גוד & r & $1 \cdots x$ & 110,4 & ונו & مواد خرك \\
\hline $1 \ldots, 1$ & 11,0 & ir & ANA & $19 x$ & 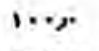 & متسوجاتن \\
\hline ונזזו & ונזיו & 100 & IY, & ivtr & $r \cdot r, t$ & كالسن , كالينجـ \\
\hline 181,2 & 1812 & 112. & גדוגו & 1100 & וניו & 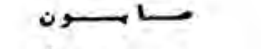 \\
\hline $18 x$ & Ira, & 131 & 1110 & litor & iran & 3 \\
\hline 1108 & IIAx & $17 \cdot x$ & 130 & Iivex & 110,1 & r \\
\hline iris & مرعأ & $\mid r \gamma, 1$ & ivis & 1 גתו & iscen & ( \\
\hline irs & irror & $1+2, x$ & Wx & $111 x$ & $1 \cdot A A$ & \\
\hline
\end{tabular}

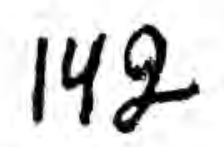




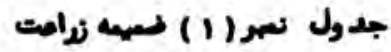

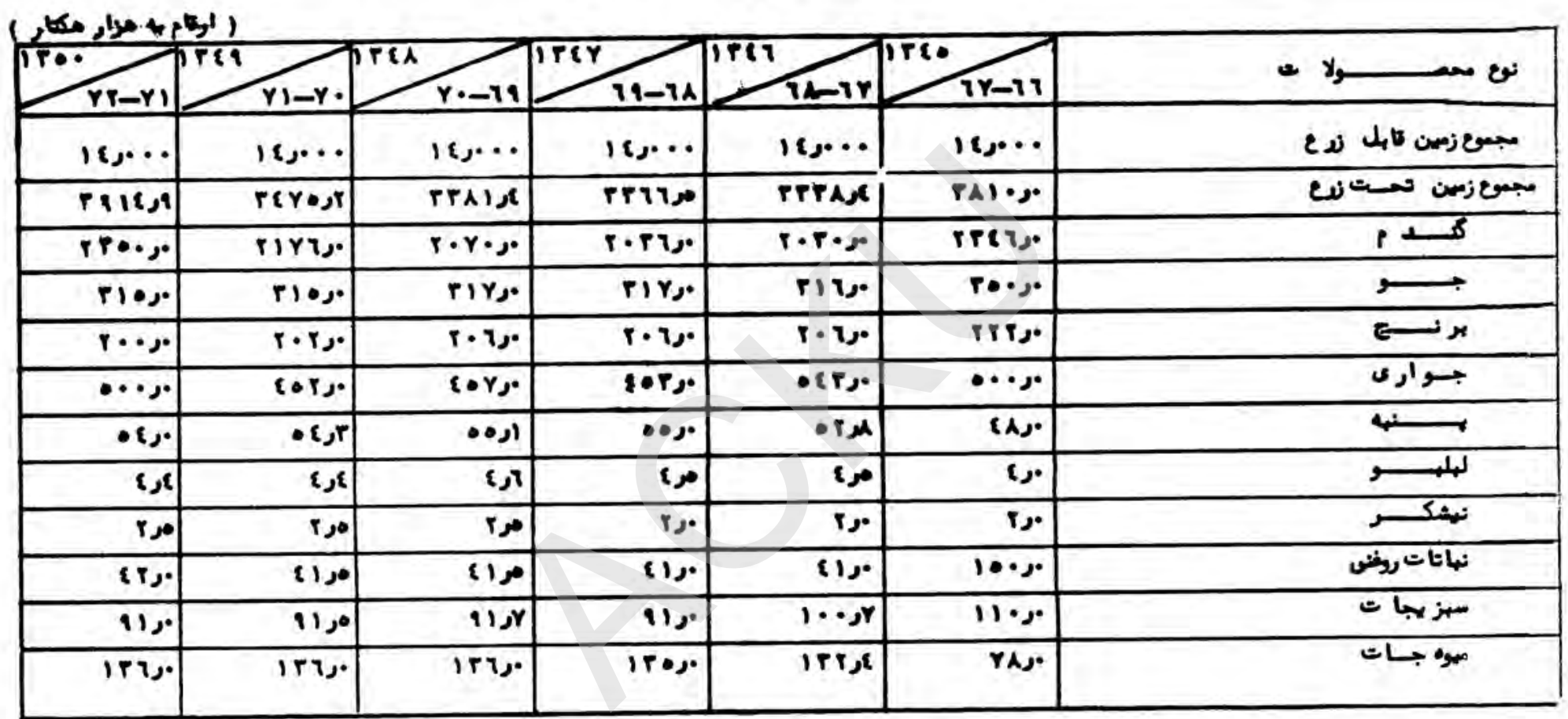


جد ول نمهر ( r r ) ضمعه نرامت

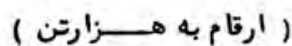

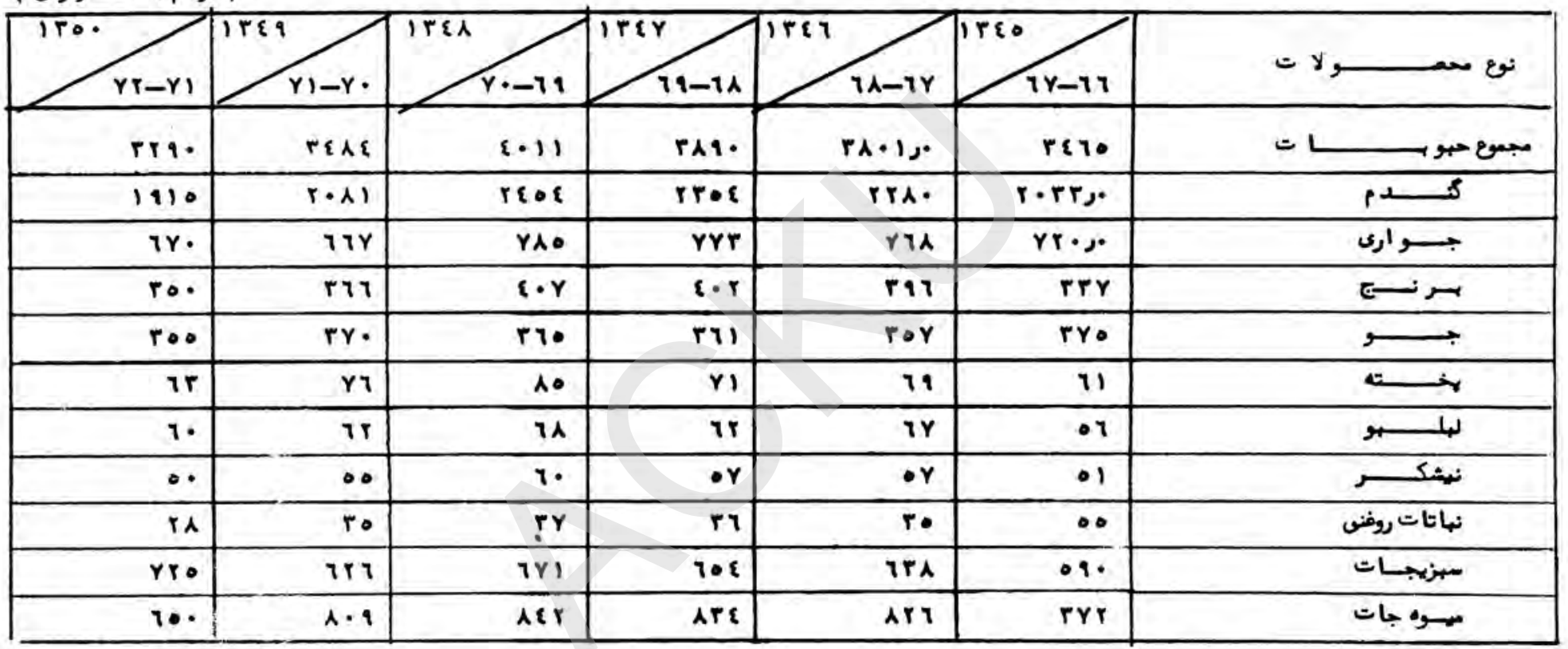

\section{4}


جدول نعهر (r) خميه نداهت

تعداد مواثى به مزار مسر خدر

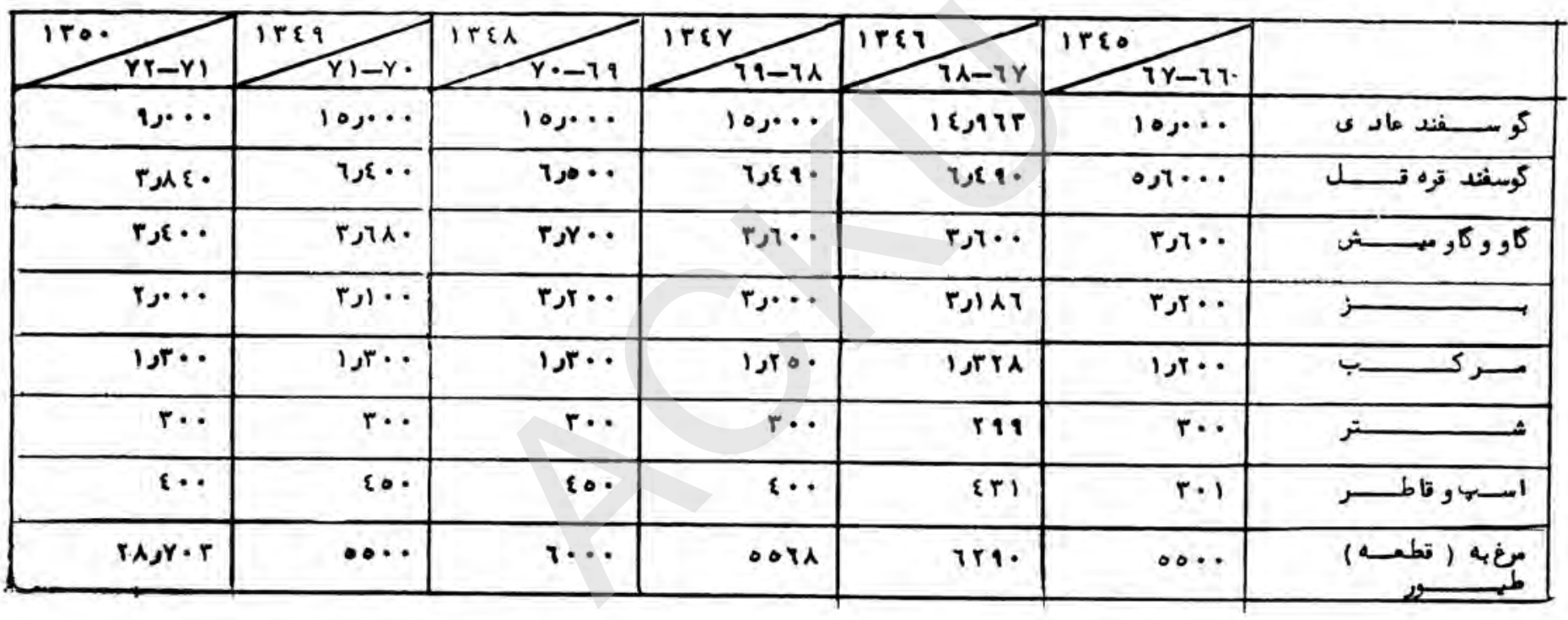

\section{5}


جد بل نسر ( )

مقدار بار ندكى طبق الهتكاه ماع مواشناسى

\begin{tabular}{|c|c|c|c|c|c|c|}
\hline 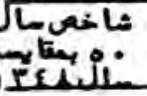 & 1ro. & IT\&9 & $\operatorname{IrEA}$ & $1 r \varepsilon \gamma$ & 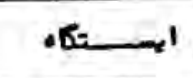 & شعاره \\
\hline 090 & TEX. & וر & וرץ| & مرor & بغــــان ن & 1 \\
\hline & $\{\wedge,$. & ᄉᄉر & $r \cdot 1, r$ & - & باسسيا ن & $r$ \\
\hline Iry & $7 \varepsilon$ & | $01 ر\{$ & 0.50 & 10,7 & بســــت & $r$ \\
\hline rygr & I \& r & זركاهו & |사. & - & بنغران & $\varepsilon$ \\
\hline - & 1998 & - & - & - & دارالسان & - \\
\hline ז & TAฯ, & rorga & $r \cdot r$, & Oو $\{1$ & فيقاباد & 1 \\
\hline $\mid \& 1,7$ & $9 \cdot 0$ & $1 \cdot \ldots$ & $1 r$, & $A Y \lambda$ & فـــــــراه & $Y$ \\
\hline qoग & Trا & $1 \wedge \varepsilon,$. & rTr. & rYs,o & ترد يس ســ & $\wedge$ \\
\hline$\wedge \wedge, \lambda$ & 170,8 & $r \varepsilon r, r$ & $1 \wedge 1, \varepsilon$ & הر וI & غز نــــــــ & 9 \\
\hline Yנו & I VOR & 1 & $r \wedge r \mu$ & r7A,9 & غلميـــــن ن & 1. \\
\hline ०و. & 10\% & - & rorel & T978 & & 11 \\
\hline$|r| r$ & 111,9 & $r \varepsilon 0, r$ & ₹\&ุภ & $r\{1, Y$ & جبلالص & 15 \\
\hline$r \wedge, \gamma$ & YI, & $11 \wedge, \gamma$ & $110, x$ & 1970 & جلال ال & ir \\
\hline$Y Y A$ & $r \mid \wedge, Y$ & זונדו & 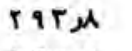 & rry, & -6 & $1 \varepsilon$ \\
\hline$Y Y,\{$ & $1 \cdot\{, 1$ & $1 \varepsilon \cdot \gamma$ & $\mid r 0,1$ & riks & & 10 \\
\hline $1 \cdot r, r$ & oY, & 118,1 & or, & 191,9 & قيد هــا ر & 17 \\
\hline Y१. & rYA. & rof, & $r 01, \pi$ & हा & كاريز & ir \\
\hline$\| \gamma, Y$ & וرا & ונ•rז & 110,1 & ז'人, & خو ســـــ & 11 \\
\hline- & $r 9 r$ & - & - & - & خوا & 19 \\
\hline o\& $\{9$ & $r(\tau, \mu$ & $r \cdot r, \lambda$ & \& T०० & $r$ rA, & $\rightarrow$ & T. \\
\hline Y) ภ & $1 T \cdot 0^{0}$ & IYAT & $1 \lambda \mid r$ & גנזיז & & TI \\
\hline$\{\gamma\}$, & 187,0 & IYT,0 & $r Y *, \varepsilon$ & $r q \lambda, \lambda$ & 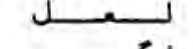 & tr \\
\hline 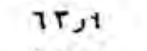 & $1+1,8$ & $1 \cdot y \boldsymbol{x}$ & ritr & ז०१ & لوكـ & rr \\
\hline$\{\varepsilon\}$, & זודו & $r r r, t$ & $\{\lambda T\}$ & $\{0 \gamma, 0$ & $\longrightarrow$ & $T \varepsilon$ \\
\hline 0 T & $1 \varepsilon 7,1$ & $|r T|$ & rYT & זᄉด & مزارشريحف & ro \\
\hline 1. & 157 & $19 \varepsilon x$ & مر & $r\{Y, 0$ & & TI \\
\hline - & 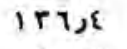 & 11, & - & - & لـاور & TY \\
\hline 181 & $\{\wedge ر \gamma$ & $r \wedge 0, Y$ & $r \varepsilon \varepsilon, r$ & $\varepsilon\{\wedge, \wedge$ & يغعــــان ن & $r \lambda$ \\
\hline Iros & $r r o, r$ & rri, & $17 \pi$ & r r r r & ينجســا ب & 19 \\
\hline 10,1 & ז\&. ใ & $r r \varepsilon, 0$ & גرד & - & قــــــــ & $r$. \\
\hline - & $r r r, r$ & $\mid$ | | & - & - & قلعه نســـــو & PI \\
\hline 00 r & $\{r T, r$ & $\{$ qY & VAIJ. & Ir.r. & سالنث شعالى & rt \\
\hline Aر & ATr & 1980 & גנرr 19 & ATro & سالثك بنهاى & rr \\
\hline$r \cdot \boldsymbol{s}$ & $r \cdot r$ & T०וر & $r \& r, \lambda$ & - & شهـــــــــ & TE \\
\hline rAر & 1 ro, & 1.9 9 & roos & rT\&, & ثيرغـــان & ro \\
\hline $0 \mathrm{~T}$ & $\{r \cdot s)$ & $001, \mathrm{r}$ & $r u r, r$ & - & تالعــــان & ri \\
\hline - & res & 0001 & - & - & زر نـــــ & ry \\
\hline
\end{tabular}

منهع : مد يرعتاتلم شناسى رياست هوائى ملكى

\section{6}




$$
\text { اراهه جدول (ع) }
$$

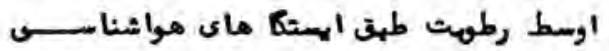

\begin{tabular}{|c|c|c|c|c|c|c|}
\hline 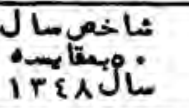 & iro. & I & Ir\&A & Ir\&Y & اره ايستــك هـا & شمار \\
\hline NAر. & 77 & $r$. & ro & YY & بغــــــان & 1 \\
\hline$A r \Delta$ & $\{\lambda$ & $\{7$ & $\circ 1$ & - & بـاكـا ن & r \\
\hline YT. & $P$ & $\{1$ & 87 & - & $\longrightarrow$ & $r$ \\
\hline זr & $\circ$ & or & 7. & - & جغجسرا ن & $\varepsilon$ \\
\hline - & \&Y & - & - & - & دارلامـان & 。 \\
\hline- & $\{\lambda$ & 00 & - & - & فهفاليــا د & 2 \\
\hline Yroo & ra & $\varepsilon r$ & $\varepsilon$. & \&) & i & $r$ \\
\hline a.s & $\varepsilon Y$ & ६१ & $\{Y$ & 00 & s & $\wedge$ \\
\hline $90, y$ & \&o & \&) & $\varepsilon Y$ & 01 & فـز & 9 \\
\hline rrr & $\varepsilon \varepsilon$ & or & T. & 09 & غلــ & 1. \\
\hline vrot & $\varepsilon r$ & $\varepsilon \wedge$ & or & $\{\lambda$ & $\rightarrow$ & 11 \\
\hline ותו1ו & 7 . & 00 & ० \{ & o \{ & جــلا ل اباد & ir \\
\hline مו & IT & $\varepsilon r$ & 01 & $\varepsilon \varepsilon$ & جبلالسرا ج & ir \\
\hline Ar. & \&o & $\{\gamma$ & oo & or & J_L بـ & $1 \varepsilon$ \\
\hline YAرt & r & $\varepsilon$ & \& T & \&人 & $=$ & 10 \\
\hline- & $r$ & $r r$ & - & rᄉ & تـند هــار & 17 \\
\hline rat & $\varepsilon r$ & $\varepsilon Y$ & of & 00 & كاريسـز ميسـر & IY \\
\hline 918 & or & 00 & 01 & ir & خو ســــت & 11 \\
\hline - & \& $Y$ & - & - & - & خـــاهـــان & 19 \\
\hline $11, r$ & er & 01 & $7 r$ & or & 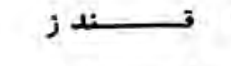 & $r \cdot$ \\
\hline $1 \gamma$. & \&人 & o. & 0. & - & لغـــــــان & 1 \\
\hline ונוץ & $\varepsilon \wedge$ & or & IY & 70 & 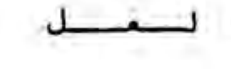 & $r T$ \\
\hline
\end{tabular}




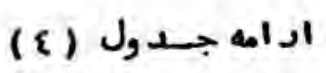

\begin{tabular}{|c|c|c|c|c|c|c|}
\hline شاخْ بمعا يعاله & ITO. & IT\&: & IT\&A & IrEY & ايسـ_ــا & شعاره \\
\hline 910. & 0. & 0 . & $\infty$ & o\& & 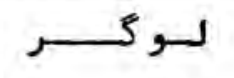 & rt \\
\hline$Y \gamma, \xi$ & $\varepsilon \wedge$ & 01 & ir & 7 & 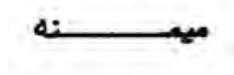 & $r \varepsilon$ \\
\hline- & $\varepsilon r$ & \&o & - & - & مزارشريـــف & ro \\
\hline 18. & \&o & $\varepsilon \varepsilon$ & $\varepsilon q$ & $\circ$ & مقـــــ & rT \\
\hline- & $\varepsilon \wedge$ & - & - & - & كاور & rr \\
\hline AV & ra & rq & EY & $\varepsilon \boldsymbol{A}$ & يغ. & $r \lambda$ \\
\hline 79. & $\varepsilon \varepsilon$ & 0. & $7 \varepsilon$ & - & ينجـــــــاب & rq \\
\hline זرו & or & $\varepsilon Y$ & or & - & قــــاد س & r. \\
\hline- & or & - & - & - & قلعه نــــــو & ri \\
\hline lapr & ०१ & $7 \varepsilon$ & 77 & $7 \varepsilon$ & سالنك شالى & rr \\
\hline$Y \varepsilon$, & ry & $\varepsilon r$ & 0. & ६१ & سالنكجنوبي & rr \\
\hline 17,1 & or & 01 & 70 & - & شـــــــــرك & $r \varepsilon$ \\
\hline Yq. & $\xi 9$ & of & ir & 07 & شـــرغــان & ro \\
\hline qur & 7. & 01 & Tr & - & تـالقــان & rT \\
\hline 11001 & $r \wedge$ & $\varepsilon r$ & rr & - & نر نـــــ & ry \\
\hline
\end{tabular}

\section{8}




$$
\text { جد ول (0 ) معهم زلاعت }
$$

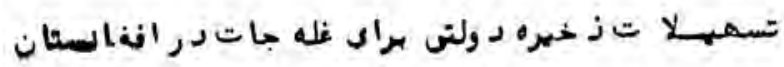

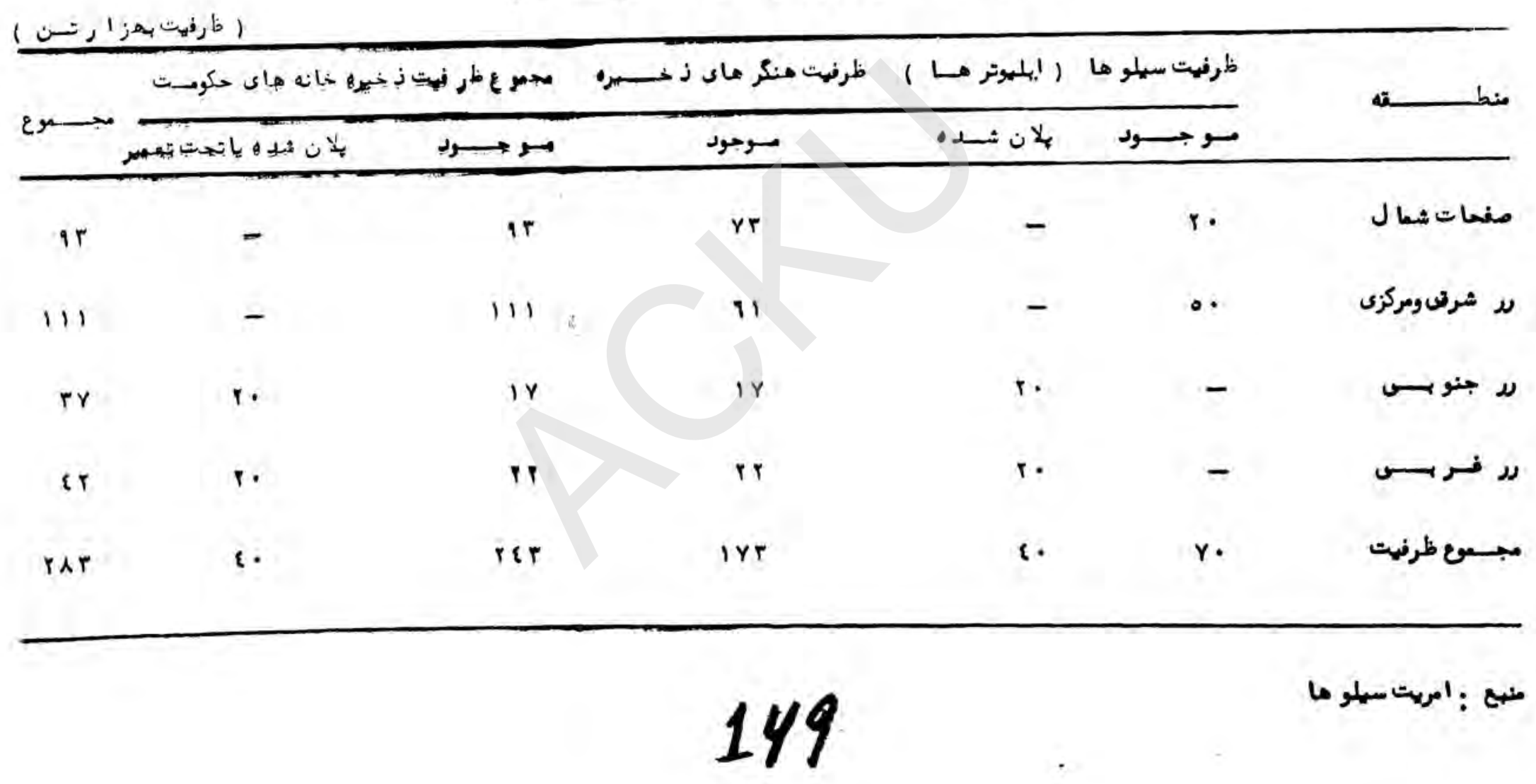


جدول (T) ضعيهه نرا مـت

خريد ارى كندم - توزهه و تخعين ذ ماير درافنانستان

\begin{tabular}{|c|c|c|c|c|c|c|c|c|}
\hline تخمين ذ ماير در & بجمـوع & ولاكسات & كابــل & 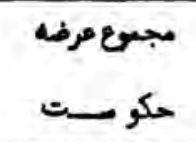 & خريدارىكثدم & كـــند موطنى & تخعين ذخ خايرد & سال هـــ \\
\hline rypo.. & l\&q,rr. & r.Y. & llAte. & rrY,Yr. & 1 - & $r r$. & W व गq & IT\&O \\
\hline AYJYA. & IEY,YY. & $17,19$. & Ir.shr. & rropo.. & $108, \ldots$ & $\wedge \cdots$ & ryrjo... & ITET \\
\hline ros... & $\mid r \cdot \partial \wedge$. & iצر... & ITSYA. & $100, y \lambda$. & $\varepsilon, \ldots$ & $r \wedge, \ldots$ & $\wedge Y, Y \wedge$. & $1 r \xi y$ \\
\hline $1 \ldots, \ldots$ & Ti,o... & - & - & $177,0$. & $97,0 \ldots$ & $\varepsilon \cdot, \ldots$ & ro,... & Ir\&A \\
\hline $7 \gamma, \ldots$ & $\wedge \gamma, \ldots$ & - & - & $\mid 0\{J \cdot T \mid$ & $7 ., \ldots$ & - & $q\{, \cdot r\}$ & Ir\&a \\
\hline so,YYO & rEr,tos & IY०תז & YI,YYA & rqr.Yq & rrt. Yq & - & tro... & iro. \\
\hline
\end{tabular}

منع : رياست تهيه ارزات و احتياجات عامه

\section{0}




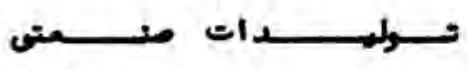

\begin{tabular}{|c|c|c|c|c|c|c|c|}
\hline iro. & Ires & $\operatorname{lr} \& A$ & irey & IrET & ires & واحســـ & \\
\hline 17,1 & $r \cdot, 0$ & זY. & irg & injo & TES. & مزارتــن & بـنه ملـــــوع ع \\
\hline irre. & 1048 & 11. & $\lambda \cdot \vec{r}$ & I Ir & $r \varepsilon 0, r$ & مزاسندل & نسـخ براى فرو ش \\
\hline קr. & or l & $\{q,\{$ & $\{$ \{人, $\}$ & Tr, r & קות & مليون متر & منسو جات نسل \\
\hline ries. & $\varepsilon r r, r$ & عرrri & $\varepsilon\{0, \lambda$ & \&\&r. & \& & مزارمــر & منسوجات هثس \\
\hline $1.0 \& y$ & ATYT & ror. & rAlA & $|r| \mid$ & $17 \cdot \varepsilon$ & مزارمسـتر & منسوجات سندى \\
\hline vre. & $1 \varepsilon, r$ & $1 . r$ ر & ות & וזנr & ives. & مزارتسـن & 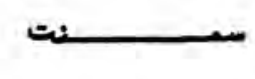 \\
\hline Err, & rqas. & ropse & riys & riost & ritr & 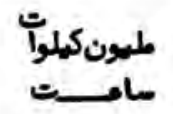 & - \\
\hline
\end{tabular}

منع · وزارت معاد ن مناع 


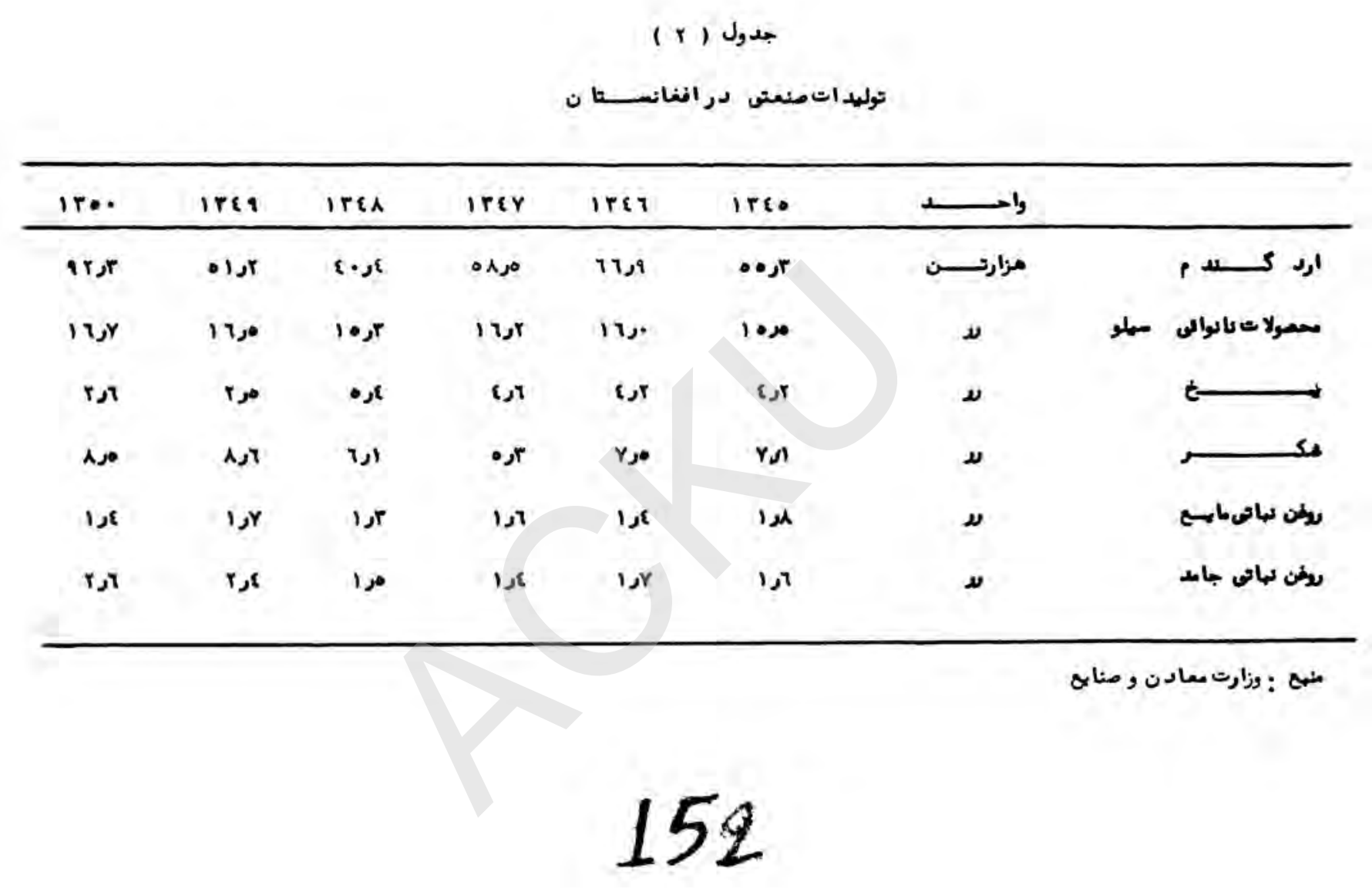




\begin{tabular}{|c|c|c|c|c|c|c|c|}
\hline 170 & IT\&9 & $\operatorname{Ir\varepsilon A}$ & irsp & Iret & $\operatorname{lrg} 0$ & 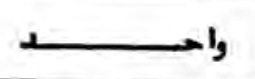 & \\
\hline ra & $r \cdot \mu \cdot$ & קr. & ry & ry,r & T I, & 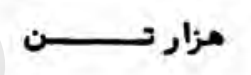 & ذنال مر يكت شـدـ \\
\hline 110 & ז & ונ & \&رy & 8,8 & $\varepsilon$ & مزارمتر مــــع & \\
\hline \&r, & r I & $r \varepsilon r$ & 19,1 & ritr & ارוr & ע & 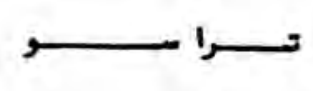 \\
\hline $1 \cdot 1,$. & rAגs. & r. & ונונז & irs & $T r \mu$ & مزار حلتــــــ & رده هـاك يــــــ \\
\hline is. & $7 x$ & $r, r$ & $r, r$ & 1,0 & ر & طليون كلجــ. & Lـ بـ بـ \\
\hline \multirow[t]{2}{*}{ rirj. } & 1918. & |נוגו & irrse & $\mid r r s$ & $1 \cdot y, r$ & مزار جــــره & $=$ \\
\hline & & & & & & & منبع : وزارت معادن و, \\
\hline
\end{tabular}


تولسيدا تا معدنســ افغانستا ن

\begin{tabular}{|c|c|c|c|c|c|c|c|}
\hline iro. & Ireg & Iren & irer & Iret & irso & واحســــــــ & \\
\hline$\varepsilon \cdot \jmath$ & ras. & $r y, t$ & ry, & ru. & rAsY & مزار تـــــنـ & 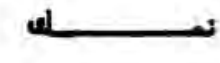 \\
\hline iros. & $178 x$ & דנצזו & irese & 101,1 & 14ו & لد & ذفال ـــــــ \\
\hline- & $1 .,$. & مرع & - & •ره & r r & هزار كلــــــو & 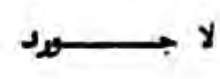 \\
\hline \multirow[t]{2}{*}{ rito } & rost & $r \cdot r q$ & $|11|$ & ror & - & طلونمترمكبب & ; \\
\hline & & & & & & & منه : وزارت معا \\
\hline
\end{tabular}


جدول (0) منعت

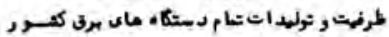

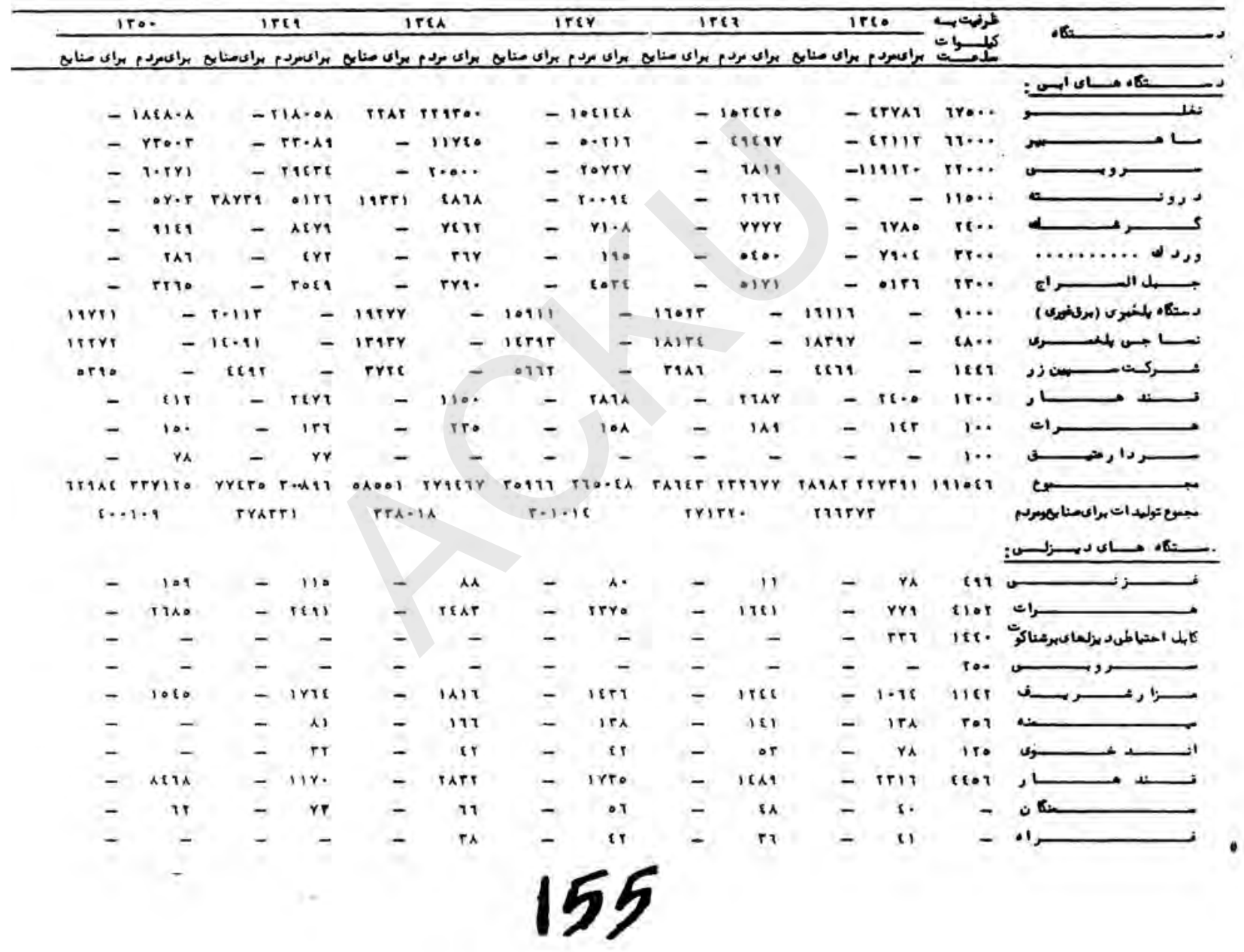




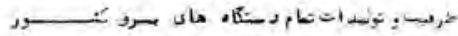

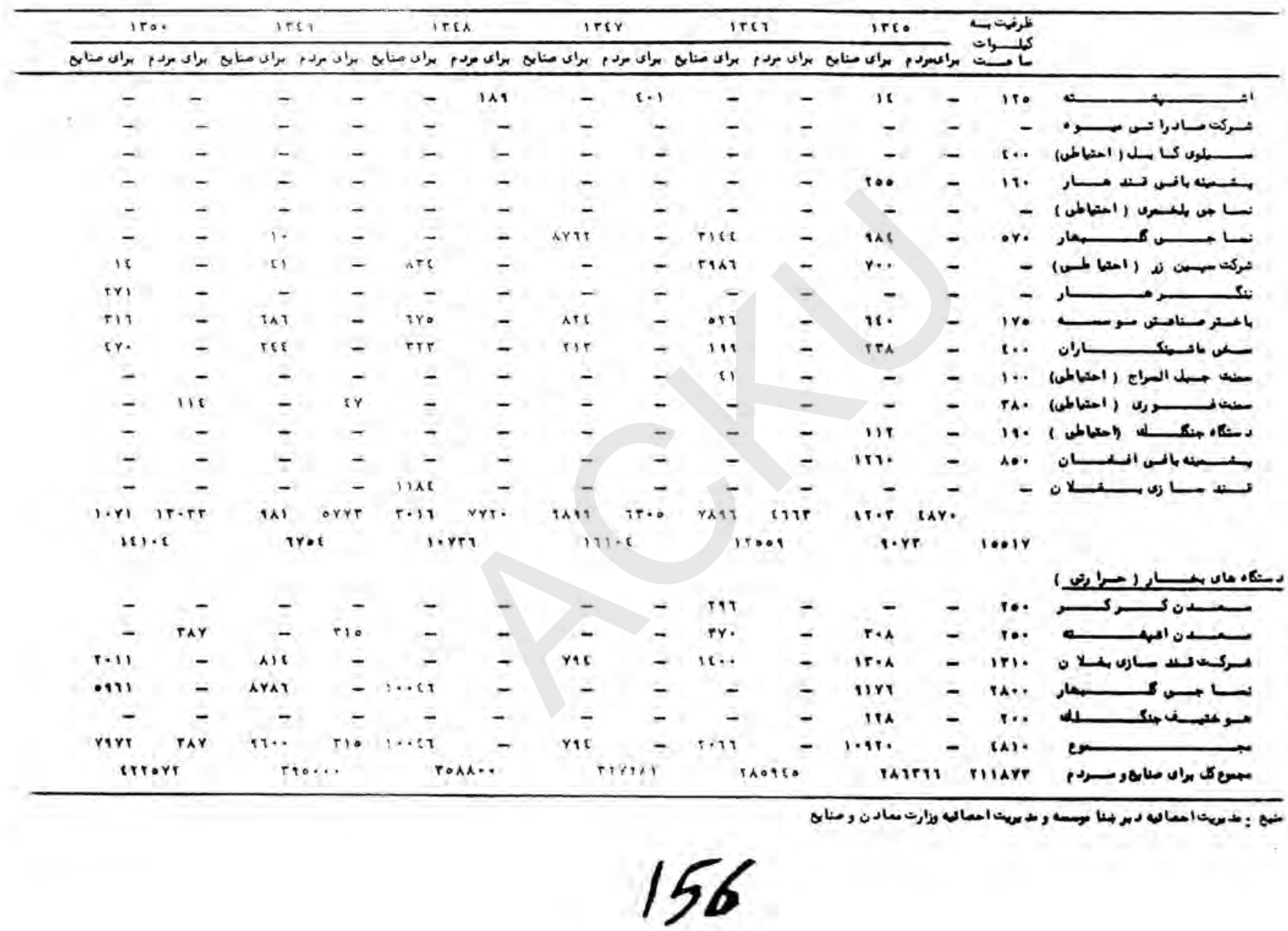


جذول (i) is (i)

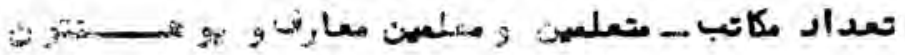

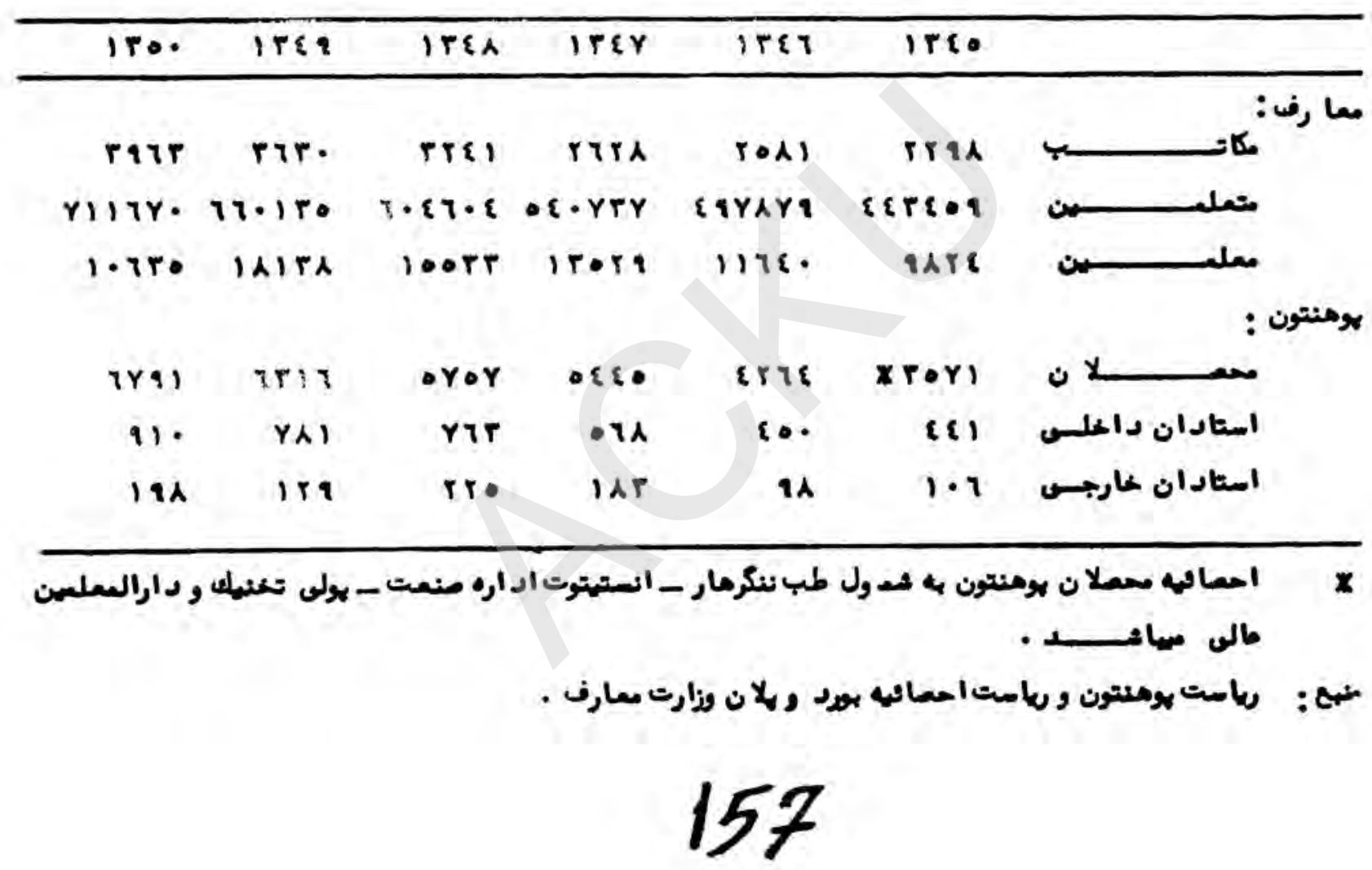


جدول (r) (r) معارت

تمداد مكاتب_- متعلعن - معلسنو مارظن

\begin{tabular}{|c|c|c|c|c|c|c|c|c|c|c|c|c|c|}
\hline \multicolumn{6}{|c|}{ متعلعـــــن } & \multicolumn{6}{|c|}{ مكيـا تـــبـ } & & \\
\hline Iro. & Ires & $\operatorname{Ires}$ & IT\&Y & I TEY & irto & 150. & IT\& & ITEA & ITEY & ITET & ireo & & \\
\hline 1. Arar & זיזם & $1.90 A 1$ & ATr9 & $109 \cdot 1$ & reorr & 1799 & $\mid 7 T$ & lorl & 18.7 & Ire & 117. & ذكر & كلانسب دـ ماتسن \\
\hline ITAAO & $18 T \cdot 1$ & Iforo & 1 भव & I. EIT & $|\lambda|\rangle$. & TTA & Pr & irt & lor & IA. & 17. & اناث & \\
\hline PAOA.E & r०Q⿻日 & rrAleo & TITIE & reose. & roted & 1119 & 1.5 & ATE & A1Y & MIT & IrY & زكر & 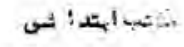 \\
\hline$T E A \bullet T$ & TIE & -PTPY & $\ldots$ & $(A) \cdot D$ & ETrE & 179 & 171 & 188 & Mr & 13 & 1.5 & ا & \\
\hline$A \cdot r T$. & $r \cdot 18 r$ & OY.Tr & $\{$ \{YY & riv. & TAI9 & \& 9 & rir & RT. & 117 & IYY & ir. & ذكو & $3-i \leq-4$ \\
\hline 118.9 & 1. yor & 1011 & A.TT & YTTT & ITYO & $\{\lambda$ & \& & TY & ro & ra & ro & ا & \\
\hline$r \cdot r \cdot 1$ & Tוז & ITq0 & $1 \cdot 810$ & $A 1 \cdot Y$ & - var & 17. & IIY & 01 & $\varepsilon \varepsilon$ & $\varepsilon$. & TA & ذكر & iـ \\
\hline CTCt & rill & Tatr & Trot & risr & 179 & TA & 17 & ir & IT & 11 & $y$ & اناث & \\
\hline $1 \cdot Y_{Y 1}$ & IIrV. & IEITY & $10 \cdot Y A$ & ITIAS & Ites. & $\mathrm{rt}$ & rq & or & II & D. & or & ذكو. & \\
\hline rir & OYI & - Ir & $\{\{\}$ & ETt & C. T & 1 & 1 & $i$ & 1 & 1 & 1 & انات & \\
\hline$(\mid 2 \cdot A)$ & - ratho & ortole & $\$ 711.7$ & \&rवots & rYas.1 & pqq. & riY. & $r A \cdot r$ & TRIT & rtes & $r \cdot r$ & ذكّ & \\
\hline $100 \times 2$ & Mro. & A1. 1. & YIITI & TATT. & IroOA & \&A & 57. & $\varepsilon r \varepsilon$ & Tio & trt & rit & اناث & \\
\hline Yilr. & $7 \pi \cdot 150$ & $1 \cdot\{7 \cdot 8$ & OE. YTY & EArars & CETEQ & rथा & rar. & $7 x \leq 1$ & גזד & rOAI & Trin & $\operatorname{rrqu}$ & , \\
\hline
\end{tabular}


ار امه جدول نسر (r) معارف

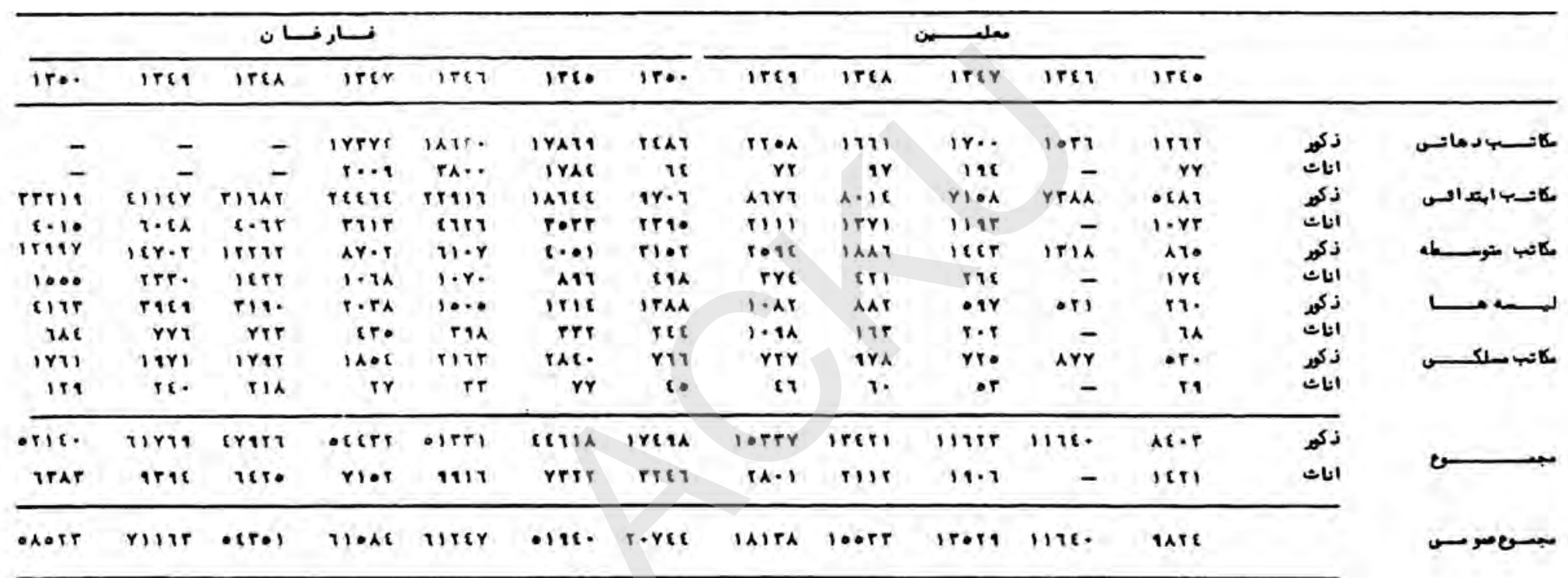


جدول (r) معارف

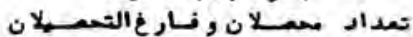

\begin{tabular}{|c|c|c|c|c|c|c|c|c|c|c|c|c|c|}
\hline \multicolumn{5}{|c|}{ نابع التحميلان } & \multicolumn{7}{|c|}{ 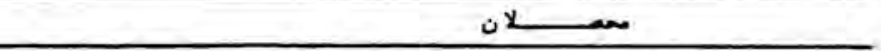 } & & \\
\hline iro. & irea & irse & ITEY & Iret & ireo & iro. & Ir\&9 & IreA & irer & $1 T E T$ & irco & & \\
\hline \multirow[t]{33}{*}{$(x)$} & 11 & \&. & rq & $\bullet$ & $\bullet$ & Tט & (1) & דזי & 0.1 & OYr & -rt & ذكر & ومنعى طـــــبـ \\
\hline & ir & 1. & 11 & is & 1. & ir & iro & 18 & $11 \mathrm{r}$ & ito & 118 & اثاث & \\
\hline & זי & 1. & ir & is & IE & - TA & ero & rAT & ryt & Tit & in & ذكل & 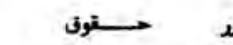 \\
\hline & 1 & $\wedge$ & . & ir & 1. & \&. & rr & TA & IA & (1) & $\mathrm{cr}$ & اناث & \\
\hline & \&. & זי & 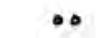 & of & TI & 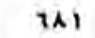 & 118 & (1) & Tra & TIE & $T \cdot r$ & نكم & علـــــــوم \\
\hline & ז & $r$ & $r$ & 1 & 1 & 11 & 1.1 & $\wedge \wedge$ & $r_{A}$ & IE & 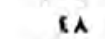 & انات & \\
\hline & 19 & 1.1 & yo & 10 & 17 & AYo & YAT & iri & r.1 & \&र & rya & ذكم & ادهـLات \\
\hline & rT & ra & tr & r. & ir & 189 & 18. & $M$ & IYA & $|r|$ & $1 \mathrm{~A}$. & ا اناث & \\
\hline & .1 & 19 & $r$. & r. & it & rT. & rra & 141 & iri & lor & irs & ذكو & شرعا ت \\
\hline & r. & 18 & - & - & - & .1 & AI & 11 & 1.1 & ir & ir & اناث & \\
\hline & $r$. & in & 11 & rr & ir & $\ldots 1$ & YT. & $\cos$ & ry & $\operatorname{SAA}$ & $1+\lambda$ & ذكو & نرامست \\
\hline & - & - & - & - & - & r & $T$ & 1 & $T$ & I & - & اناث & \\
\hline & - & o. & 10 & a. & rr & 211 & TIT & rTo & rir & $r\{1$ & $r \cdot r$ & ذكه & انجنرى \\
\hline & or & 1 & - & - & - & 11 & 1 & 1 & $T$ & $\varepsilon$ & $r$ & اناث & \\
\hline & ra & ro & - \& & or & it & ויחז & TOT & T\&I & TIE & TA. & זו. & ذكم & اتتهـار \\
\hline & $r$ & $r$ & $r$ & ir & $\varepsilon$ & 10 & 17 & ir & $T$. & ri & re & اثاث & \\
\hline & $\lambda$ & - & - & - & - & 1.1 & 11 & - & - & - & - & ذكه & نار ســـ \\
\hline & - & - & - & - & - & ir & $\gamma$. & - & - & - & - & اناث & \\
\hline & ye & $r A$ & or & it & $1 \lambda$ & rat & TYT & rTs & TYY & דזו & IAT & ذكر & تعلى وتهيه \\
\hline & II & \& & \&A & ra & ro & 17. & 11. & 11. & rry & 198 & in & اناث & \\
\hline & - & - & - & - & - & - & - & - & - & - & - & ذكم & ثديرمنزل \\
\hline & IT & rT & r. & - & - & - & - & - & - & - & - & ا أt & \\
\hline & Tו & $r T$ & r. & - & - & $\varepsilon \varepsilon r$ & rio & וו & ror & 119 & iro & ذكه & ومنتون طب ننكرهار \\
\hline & - & - & - & - & - & $r$ & c & - & $r$ & 1 & 1 & ا ا & \\
\hline & $r$. & ז & ir & ra & r r & 10. & 108 & IrA & ry & 9 & p. & ذكم & نستيتوت لد اره منعت \\
\hline & $r$ & $r$ & $T$ & $\varepsilon$ & 1 & 1 & $r$ & $A$ & $\lambda$ & ir & $r$ & انات & \\
\hline & - & - & - & - & - & MT & 110 & 111 & TET & ro. & - & ذكم & 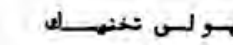 \\
\hline & - & - & - & - & - & 17 & $\lambda$ & c & - & - & - & اناث & \\
\hline & of & or & $\lambda$. & o\& & c. & $1 \cdot 11$ & YIA & $\{-1$ & 109 & 168 & A. & ذكم & 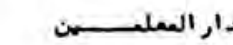 \\
\hline & 18 & 10 & ir & 18 & 1 & ris & 190 & irs & To & iq & is & ا انات & \\
\hline & 718 & ora & .11 & etr & PIY & roio & ietr & .TIT & ETEY & rori & TAAS & ذكر & \\
\hline & irr & itr & $\pi$ & $1+1$ & YY & $1 \ldots$ & 171 & Af\& & ras & YTT & inr & انات & 2 \\
\hline & AIY & ril & 111 & Tor & ere & A $\{10$ & vin & r.or & of $\varepsilon_{0}$ & ETt & Tors & & 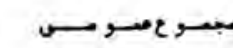 \\
\hline
\end{tabular}


جد ول (e)

تمداد مكاتب-معلسن - متعلسند لالا كات

\begin{tabular}{|c|c|c|c|c|c|c|c|c|c|c|c|c|c|c|c|c|c|c|c|c|}
\hline \multirow[b]{2}{*}{150.} & \multicolumn{5}{|c|}{ تعلع_ــي } & \multicolumn{6}{|c|}{ 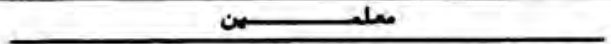 } & \multicolumn{6}{|c|}{ r w } & & & \\
\hline & ITE9 & ITEA & ITEY & ITET & $1 T E 0$ & 170. & ITEI & ITEA & irey & $1 \times 27$ & $1 \mathrm{rEo}$ & iro. & irci & Ires & irer & $1 \mathrm{ret}$ & ires & & & \\
\hline 19001 & 111.1 & Aq०\{. & ATAY9 & YATTE & $Y \cdot T E A$ & TAAE & rese & reos & THAY & Ir.e & irg. & 190 & IYA & IAT & 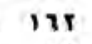 & ITA & ite & נكס & كا بـــ & ولاهـ \\
\hline SIAT. & PYITT & TPATT & TIAAY & T181T & TIรA) & rior & $|x| 1$ & ITAT & $11 \cdot r$ & 1172 & 118 & $r$. & 7. & -1 & EY & I & 19 & اثاث & & \\
\hline rerry & . IT. & T. T10 & 11001 & |АTIA & $I Y \cdot Y Y$ & $A \& T$ & $r \circ 9$ & Tre & $2 \cdot 1$ & oAY & - TA & 171 & lor & $|r|$ & IT & 17. & 119 & ذكم & كد مـــار & $\mu$ \\
\hline rEP & TEOY & tear & 191. & ro. & rryr & irs & ir & $r$. & ro & or & iq & 11 & 11 & $1 \cdot$ & 1 & it & it & ا انt & & \\
\hline rest & TTRAT & PEYTT & TTISO & $T \cdot 010$ & $r \cdot 1 \mathrm{r}$ & |r| & $Y \cdot 1$ & $Y \bullet A$ & 191 & .27 & $\Delta \cdot T$ & 170 & 120 & $1 \cdot 1$ & $1 \cdot 8$ & $1 \bullet$ & it & زكه & & L \\
\hline orre & - 11. & orry & 0.60 & CAYY & $\{101$ & TrF & 110 & 198 & irr & Irr & 1.0 & tT & 11 & IA & Ir & 11 & 10 & اثاث & & \\
\hline$r(0,1 T$ & TRAYT & Tוז & IITT & T.TY & Irecr & YET & $1 \cdot A$ & •re & PYT & or 1 & (1) & 101 & 100 & 189 & irs & IrA & 189 & ذكه & $\dot{\varepsilon}-$ & 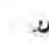 \\
\hline - TA. & orat & sir & Etit & EEYA & ווצו & 108 & ira & $1 \cdot 1$ & $1 \ldots$ & - 1 & - 1 & $\mathrm{TC}$ & T1 & ic & 11 & IA & rT & اناث & & \\
\hline ETIAE & (i) & roor. & $r i f=r$ & rilY & TETYo & irty & III & IET & YET & $3 \cdots$ & - ir & 108 & $16 \mathrm{r}$ & 1.1 & 18. & $1 \cdot Y$ & $1 \ldots$ & ذكه & نتكر. & t \\
\hline$r \cdot \Delta$ & rAIR & rytr & rop. & rit & rity & $1 \cdot$ & ro & 19 & \& & rr & $r \cdot$ & 19 & ir & TT & 11 & $r:$ & 17 & أناث & & \\
\hline TAMIE & rYTi. & rri.o & rilr & TYAT & riti & 171 & 118 & A91 & irr & 78. & es & |A| & IYT & 188 & 16. & ITY & Ir & ذكد & $\Rightarrow$ & لد \\
\hline EYr & Ire & \&rr & 7.9 & $0 . \varepsilon$ & IfA & $1 \cdot$ & $\mathbf{Y}$ & 10 & IT & - & - & $\mathbf{x}$ & 7 & 7 & 1 & E & C & أناث & & \\
\hline rite. & rTYYA & Ir.or & 1211 & 10197 & IETT & 191 & IIY & 201 & \& 18 & $i \cdot r$ & ris & IYA & $|Y|$ & irs & 111 & 118 & $1 . r$ & ذكه & فـزنت & L \\
\hline$r \cdot 1 t$ & IAAT & $|r 0|$ & $1 \mathrm{r} \cdot \mathrm{T}$ & |rr| & I. YE & IY & $T T$ & 17 & 11 & 8 & 1 & $T \cdot$ & 11 & Ir & ir & 18 & 1. & ا اناث & & \\
\hline I91As & 19719 & 170.1 & Iraol & IYTYY & I ra & (10 & - tr & Pri & rr. & PIT & rit. & 17 & 18 & $1 \cdot 8$ & 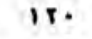 & Ir. & $1 \cdot r$ & ذكم & ملتـــــ & עل \\
\hline 1101 & A10 & 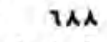 & 170 & Art & YRT & ri & ri & 17 & IY & $\$$ & I & - & - & - & 1 & 1 & I & اناث & & \\
\hline IraYz & 15018 & 1.01 & I. TrT & $1,(2)$ & MIA & \&IT & (T) & rtT & rto & rA. & ris & 11 & 1. & ire & VT & $\mathrm{rr}$ & ir & נ50 & & 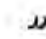 \\
\hline 1A\& & 91 & Arq & ATE & 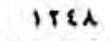 & $\lambda=\lambda$ & 10 & ir & 18 & IT & 1 & 1 & 1 & $\boldsymbol{A}$ & $r$ & $Y$ & $r$ & $r$ & أاث & & \\
\hline राTा & TiAer & 1111 & irerr & $10.7 r$ & $\mid(|A|$ & 17. & TrY & -ri & ECS & [AT & ry. & IIA & II & $1 \cdot r$ & A. & 11 & ye & ذكم & $-6,6$ & 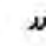 \\
\hline 110 & - Trt & 0118 & Exy & $\{719$ & ETOT & A 9 & Ir & $\bullet$ & YE & YT & 81 & $\{\lambda$ & f. & $r r$ & $r \cdot$ & ry & re & اناث & & \\
\hline 13810 & IOTTT & $18 \cdot 78$ & IrATr & ITTOT & IrT. T & PI & rit & 190 & 101 & IFY & 198 & ITY & $1 \cdot r$ & IT & Ar & 11 & 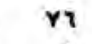 & S3 & جوز بان & $\mu$ \\
\hline rior & TI\&A & IYTT & IXY & ITr & 1010 & $r \bullet$ & II & 19 & \&1 & ir & 11 & 11 & ir & 9 & 1 & 1 & 1 & اناث & & \\
\hline ICOAK & ITYIA & $I r \cdot T A$ & 11010 & Irrol & $1 \cdot \lambda A \mid$ & Ito & rY. & ToR & riv & IAT & TIT & 110 & $1 \cdot 0$ & $A \lambda$ & Ar & $r A$ & $7 x$ & ذكم & تهـ & ע \\
\hline IIY9 & IIR & ATY & YTT & YYA & VAT & ir & 10 & 9 & 18 & 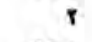 & $r$ & 1 & 1 & $r$ & $r$ & $\hat{A}$ & $Y$ & الات & & \\
\hline TIRE & 1910 & 17011 & It918 & 187.9 & ITOTA & - $r 1$ & (A) & 811 & TII & TE० & TE. & 191 & 189 & 119 & $1 \cdot A$ & 1.1 & 11 & ذكة & بدشان & ע \\
\hline$r \cdot r_{0}$ & rer & IYOA & $18 \cdot A$ & Iror & Ire. & is & 19 & $r \cdot$ & $r$. & it & ir & TY & TY & ir & 11 & 18 & 1 & انات & & \\
\hline 1.188 & IYTI & VRTT & Mro & orrt & 0111 & rie & IA. & TrY & v. & 109 & $|T|$ & 11 & $1 \ldots$ & 11 & 1. & - T & 01 & ذكه & 46 & لد \\
\hline ro. & TYA & דונ & oגY & OAT & or. & $r$ & $r$ & IT & TE & 1 & - & 11 & 1 & 1 & 1 & 1 & 1 & اناث & & \\
\hline $10 \mathrm{rlo}$ & irota & 11810 & 1.011 & $A r \cdot 1$ & YTAI & rie & |1 & TTE & 110 & $|v|$ & IT & $\| A$ & $1 \cdot 1$ & AE & Y & $1 \mu$ & ir & ذكم & 'ارנטان & 'נ \\
\hline roy & rFe & TIT & Pri & rho & TEO & ⿷ & I & 1 & 1 & $\varepsilon$ & $T$ & $r$ & $I$ & $r$ & c & $t$ & $T$ & اناث & & \\
\hline
\end{tabular}


اداله جدول (c) المارف

\begin{tabular}{|c|c|c|c|c|c|c|c|c|c|c|c|c|c|c|c|c|c|c|c|c|}
\hline \multirow[b]{2}{*}{ iro. } & \multicolumn{5}{|c|}{ متعلع } & \multicolumn{6}{|c|}{ 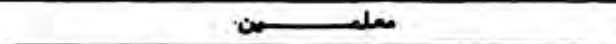 } & \multicolumn{6}{|c|}{ مكس } & & & \\
\hline & $1 \mathrm{rEs}$ & ITEA & irey & $1 \times 87$ & ire. & Iro. & Ires & $1 \mathrm{FEA}$ & ITEY & IrET & ires & ITo. & ircs & IreA & irey & ITET & Ire. & & & \\
\hline $17 \cdot 17$ & I. YTY & ITI. & ค19. & YTAT & IYTY & rir & $r \cdot r$ & rT. & 110 & IAT & iry & IrT & MT & $y$ & A9 & ro & 11 & נكي & & $\approx y$ \\
\hline MY & -1. & $\bullet r$ & EYT & - Ir & eir & 11 & - & $Y$ & is & 1 & - & $\Lambda$ & $\lambda$ & $r$ & $r$ & A & $\lambda$ & تاك & & \\
\hline rerta & rIYAo & IAIYT & ITIY & Ifrre & Ir.yc & rri & 001 & - TT & ST. & $(1)$ & $r T$. & ITT & 18. & $A \cdot$ & $A_{1}$ & 1. & $\bullet \wedge$ & ذك & & ע \\
\hline T००T & $r \bullet$. & IYTo & 1011 & ITY9 & Ir9. & 78 & II & c. & tr & Ti & r. & r. & rr & is & it & IT & 11 & ثان & & \\
\hline $5 \cdot 1 \cdot 1$ & $|r| r \mid$ & $1 \cdot T \cdot R$ & Irotr & $1, \div \therefore 1$ & 1900 & $\bullet 1 T$ & cte & $r \cdot 1$ & $r \bullet 1$ & Trt & $r \cdot r$ & ir & IT & AT & Ac & 11 & $M$ & 35 & كـــدر & 2 \\
\hline rear & rCIT & ITtA & $T \cdot T \cdot$ & IY16 & irir & or & (1) & or & ry & IA & ir & 10 & ir & ir & 1. & 1. & 1 & اناث & & \\
\hline$P \cdot A A C$ & I 9ATE & $|A| 10$ & Irtr & ITAIT & $1 \cdot A \lambda T$ & - tr & 011 & (r) & PTV & riY & $\nabla \cdot 0$ & 111 & $1 \cdot A$ & 11 & $r r$ & 11 & $\cdots$ & ذ5 & ن & \\
\hline TEOO & rose & IIt & 19.5 & IETY & 1118 & .1 & - 8 & $\bullet \varepsilon$ & is & $r r$ & tA & ir & 11 & ir & 1 & 1. & 1. & ا انات & & \\
\hline $1 \cdot 11$ & ATr & $M A \cdot T$ & ITAT & 7187 & $\cdot 7 \cdot 1$ & TTA & $r \cdot 1$ & IAS & IYT & lor & ITE & $A \&$ & 11 & - 7 & of & $\cdot A$ & - $T$ & زكه & - & 1 \\
\hline IIr & 1.18 & 111 & ATr & AIT & Too & IT & II & \& & 1. & 1 & 1 & 1. & $\boldsymbol{A}$ & $r$ & $\boldsymbol{A}$ & $r$ & - & & & \\
\hline YIAT & -rry & - IT & $\{\lambda \bullet T$ & ETAT & ryie & Iro & 180 & IFA & 162 & IA & 10 & $\lambda \lambda$ & 01 & IT & $r \lambda$ & $\mathrm{rr}$ & re & ذكر & & 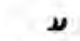 \\
\hline ITY & - YI & EYo & rVi & \& $2 A$ & r9 & $r$ & $\lambda$ & 1 & $r$ & r & 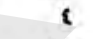 & $\varepsilon$ & $\varepsilon$ & \& & $\mathbf{r}$ & $r$ & $T$ & اناث & & \\
\hline $7 \lambda \cdot 1$ & ryYo & 1188 & or-a & EAIT & \&\&บ & 197 & rre & IT & iro & $1 \cdot r$ & ir & - 1 & 19 & c. & () & ra & rt & ذكر & & 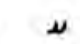 \\
\hline $1 . Y$. & 161. & AAI & AIA & $Y \lambda$. & 178 & - & - & - & $A$ & - & 1 & 10 & rT & $1 T$ & 11 & 10 & 1 & اناث & & \\
\hline -YIA & otet & - $(1)$ & etri & rits & ryte & Ixt & 118 & Ite & is. & ra & $r r$ & 1. & -1 & $\cdots$ & $\{7$ & s. & 77 & ذكه & & 2 \\
\hline 116 & IIA & ITP & ret & 111 & 187 & - & - & 1 & $\mathbf{Y}$ & - & - & 1 & 1 & 1 & 1 & 1 & 1 & انات & & \\
\hline I.AT. & $18 \mathrm{YTO}$ & IIYY & 1. Art & Irro & 1) & EYE & rIY & PI. & YTE & IT & 111 & 1. & IA & $r \lambda$ & TT & ri & IT & ذكر & & 2 \\
\hline I.AY & IYr. & TAE & 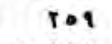 & res & 1109 & tr & $r \varepsilon$ & $T$ & $T$ & - & 1 & 10 & 11 & t & $r$ & $r$ & $T$ & انات & & \\
\hline ISAAT & I TAIY & I IATY & $1 \cdot A \wedge A$ & NATC & YIT & (r) & FYA & PI & TRE & $I A A$ & $1 \cdot 1$ & ir & A 1 & $Y r$ & Ix & Tr & \& & ذكل & دل & 2 \\
\hline Ire & 181 & AY & ra & 11 & of & - & - & - & $\boldsymbol{A}$ & - & - & $r$ & $r$ & 1 & 1 & $r$ & 1 & ا الا & & \\
\hline 11111 & IrIA & $\mid\{A||$ & IreTr & 185. & $17 \cdot 7$ & rAT & EtA & PII & TES & ret & $r \circ \lambda$ & $1 \cdot 1$ & As & $1 A$ & $y$ & 18 & -1 & ذكم & ك & 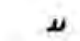 \\
\hline TrTE & III & PIT & TEA & TrAT & TTT. & TT & \& & TE & $\bullet r$ & YI & $\mathrm{YA}$ & ro & rr & Is & rt & 17 & 19 & اناث & & \\
\hline 19711 & Irrot & I CATt & ITOAE & $|r A \cdot|$ & H $\cdots r$ & $\bullet r$ & EYA & rrt & TAT & rir & IIY & $Y T$ & 11 & 01 & \& & or & Ct & ذك & لغسـان & L \\
\hline 1187 & irtr & AAT & ITrY & $1 \cdot A$ & 1.81 & 1. & 1 & ir & T. & - & 1 & 11 & 11 & 11 & 11 & $\boldsymbol{A}$ & $r$ & ا ا ا & & \\
\hline 19. & $1 \lambda .0 f$ & ITЯ०T & ITES. & $1 \cdot(r)$ & $1 \cdot 1 r$ & ITR & $\varepsilon \bullet T$ & TAT & $\{-\varepsilon$ & ro. & in & $17 \lambda$ & 11 & YT & $M$ & - $r$ & \& & ذكو & كر هـ & ل \\
\hline 17r & TrY & $M A$ & 119 & EET & CTT & $Y$ & $r$ & E & $\mathbf{r}$ & - & - & To & ry & 1 & $Y$ & $Y$ & $Y$ & ا ا & & \\
\hline
\end{tabular}

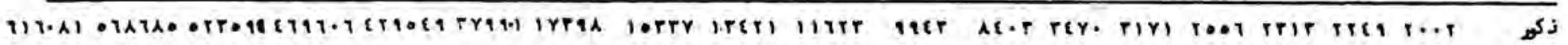

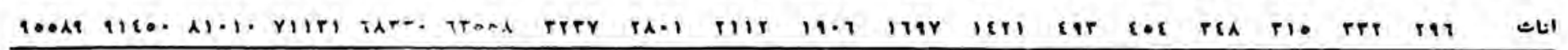

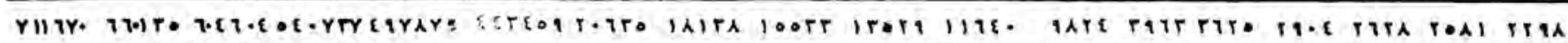

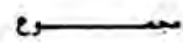

مبسنقصو مسنى 
Iro. J J

\begin{tabular}{|c|c|c|c|c|c|c|c|c|}
\hline 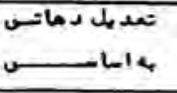 & 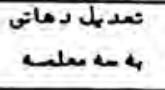 & 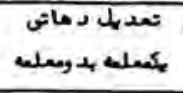 & جدانس & جديكا & توسطب & ل & رو اسم, ولاهLات & عسارة \\
\hline$r$ & 1 & 1. & ᄉ & - & $\varepsilon$ & 1 & الزيكان & 1 \\
\hline 1 & - & - & ir & - & 1 & 1 & بادغسس & + \\
\hline 1 & $s$ & - & $r$ & - & T & 1 & 064 & $T$ \\
\hline $\mathbf{t}$ & 1 & 1. & 18 & - & $r$ & t & بهشان & $t$ \\
\hline - & r & - & - & - & $c$ & $r$ & خـا نان & $\cdot$ \\
\hline t & $T$ & 11 & IT & - & - & $T$ & $\dot{1}$ & r \\
\hline t & $r$ & $r$ & $\wedge$ & - & 8 & r & تصرלان & $Y$ \\
\hline$\varepsilon$ & - & 1 & 9 & 1 & • & $\varepsilon$ & $\mathrm{L}$ & $\boldsymbol{A}$ \\
\hline - & $r$ & 1 & - & - & $r$ & r & تيــــ & 1 \\
\hline - & - & $\wedge$ & 1 & - & 1 & I & جمبان & 1. \\
\hline$r$ & 1 & T & $r$ & - & , & , & $\longrightarrow$ & M \\
\hline$r$ & 1 & $r$ & $r$ & - & , & - & bـ & ir \\
\hline - & - & $r$ & $r$. & - & $T$ & ' & سعكان & it \\
\hline - & - & - & - & 1 & $r$ & r & شمر كلمل & " \\
\hline$\wedge$ & it & 1 & A & - & $\varepsilon$ & $r$ & غزنس نس & 10 \\
\hline - & 1 & $T$ & - & - & $T$ & $T$ & لغعــان & 11 \\
\hline - & 1 & - & \& & - & $T$ & 1 & لوكــــــ & ir \\
\hline - & 1 & ir & $r$ & - & t & T & نيكرمـــار & ix \\
\hline 1 & 1 & $r$ & 1 & - & 1 & 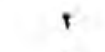 & ورد له & 11 \\
\hline$r$ & $\top$ & A & ir & ? & $T$ & 1 & فـــــ & r. \\
\hline$T$ & 1 & A & r. & 1 & $r$ & 1 & با با با & ri \\
\hline$y$ & T & $r$ & i & - & t & $r$ & كــــــــ & $r r$ \\
\hline$r$ & - & 1 & $A$ & - & $\varepsilon$ & $T$ & I & ir \\
\hline$r$ & $r$ & ' & $r$ & - & $r$ & $r$ & r & re \\
\hline$r$ & $\wedge$ & - & $A$ & - & $r$ & $r$ & كــــــــــ & ro \\
\hline 1 & 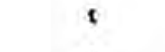 & $r$ & 1. & - & r & 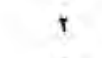 & كد مــــار & n \\
\hline 8 & ' & $v$ & 3 & - & $\mathrm{t}$ & $r$ & $\longrightarrow$ - & ir \\
\hline $\mathbf{T}$ & 1 & - & - & - & ' & 1 & ملــــــــ & TA \\
\hline 1. & $r$ & 1 & 1. & t & - & $r$ & مـــــ & ti \\
\hline$r_{1}$ & As & irr & Tit & ir & AT & -r & $t$ & \\
\hline
\end{tabular}




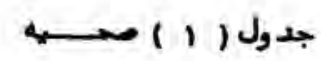

شفاخانه هاو تعميلا تصحى درافغانستان

\begin{tabular}{|c|c|c|c|c|c|c|}
\hline iro. & ITEI & $\operatorname{Ir\varepsilon \lambda }$ & IrEY & $I T \& 1$ & Ireo & \\
\hline & & & & & & : \\
\hline ir & 1. & it & ir & ir & ir & شفاخانـهـهــــا \\
\hline TTT & $0 \wedge T$ & orr & 007 & $0 \cdot 1$ & sor & دوكـــتر هـــا \\
\hline YT\&Y & Iros & 1870 & IETo & Irtr & irtr & 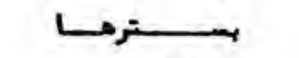 \\
\hline 1ז & ir. & AT & YT & YE & vi & دوراخانــهـــا \\
\hline 9 & - & $\bullet$ & \{ & 8 & t & لا هـراتـــــاد \\
\hline \multirow[t]{2}{*}{9} & 1 & 0 & - & - & - & 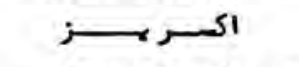 \\
\hline & & & & & & r- رلايحت قند مار: \\
\hline$r$ & $r$ & $r$ & $T$ & $r$ & $r$ & شناخهانه هـــا \\
\hline 1 & 9 & 9 & Y & Y & $\checkmark$ & 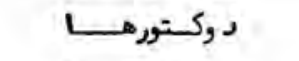 \\
\hline IT. & ir. & it. & ir. & $1 \cdot$ & $1 \ldots$ & 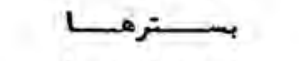 \\
\hline Yᄉ & Th & rt & rt & ri & TI & دراخانه هـــا \\
\hline$r$ & 1 & 1 & 1 & 1 & 1 & ע بـــرا تـــــوار \\
\hline \multirow[t]{2}{*}{ r } & 1 & 1 & 1 & 1 & 1 & 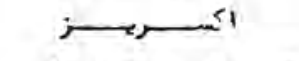 \\
\hline & & & & & & $:=1,0=s,-r$ \\
\hline$\varepsilon$ & $\varepsilon$ & $\varepsilon$ & $\xi$ & \{ & $\varepsilon$ & شافانه هـ \\
\hline 1. & 1. & 1. & 7 & 7 & 1 & در وكتو ر هـ \\
\hline 11. & 11. & 11. & 11. & 11. & 11. & 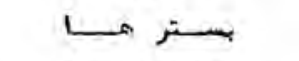 \\
\hline$r\{$ & ri & ri & rt & $r \varepsilon$ & $r \varepsilon$ & دروانهانه \\
\hline r & 1 & 1 & 1 & 1 & 1 & لا بـــراتــــــار \\
\hline \multirow[t]{2}{*}{$t$} & 1 & 1 & 1 & 1 & 1 & 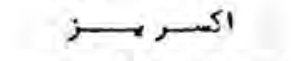 \\
\hline & & & & & & $:=-1,=-1,-\varepsilon$ \\
\hline$\varepsilon$ & f & \{ & \{ & ⿷ & $\varepsilon$ & شفاخانه هـ \\
\hline$\lambda$ & $\lambda$ & $\wedge$ & 1 & 1 & 3 & در وكتور ر هــــــ \\
\hline YE & tr & 10 & 10 & 10 & it & دواخانه هــــ \\
\hline Yo & Yo & $y=$ & $r$. & $\gamma$. & $Y \cdot$ & 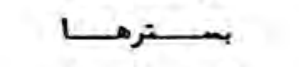 \\
\hline$r$ & 1 & 1 & 1 & 1 & 1 & لا بــراتـــــار \\
\hline 1 & 1 & 1 & 1 & 1 & 1 & 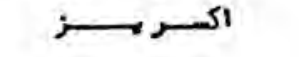 \\
\hline
\end{tabular}




\section{IFo. IFET IFEA IFEY IFET IFE}

$\underline{: 00}$

$\begin{array}{rrrrrr}r & 1 & r & r & r & T \\ 1 & 1 & 1 & 1 & 1 & 1 \\ 10 & 10 & 10 & 10 & 10 & 10 \\ 1 & 18 & 18 & 18 & 18 & 18 \\ r & 1 & 1 & 1 & 1 & 1 \\ 1 & 1 & 1 & 1 & 1\end{array}$

\begin{tabular}{|c|c|c|c|c|}
\hline c & I & $\varepsilon$ & $\varepsilon$ & $\varepsilon$ \\
\hline ᄉ & ᄉ & $\lambda$ & $Y$ & $r$ \\
\hline 1. & $y$. & v. & $r$. & $p$. \\
\hline$\lambda$ & II & IT & IT & ir \\
\hline 1 & 1 & 1 & 1 & 1 \\
\hline 1 & 1 & 1 & 1 & 1 \\
\hline
\end{tabular}

L

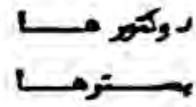

טواحاته

'

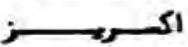

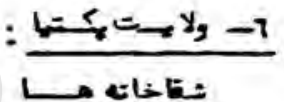

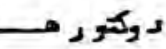

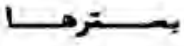

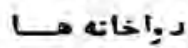

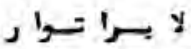

اكســر عـ

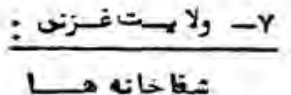

دركتور هــــ

بس

دواخانه هـــ

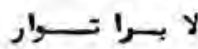

اكس

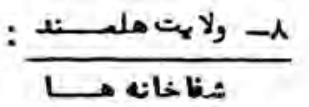

$\circ 0$ \& $\circ$ \& $r$

r.

$1 \quad 1 \quad 1,1,1$

$\begin{array}{lllll}1 & 1 & 1 & 1\end{array}$

8 \& $r$

165
دوكتور هـ

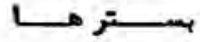

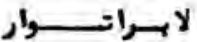

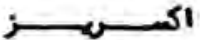

دوامانه مـــ 


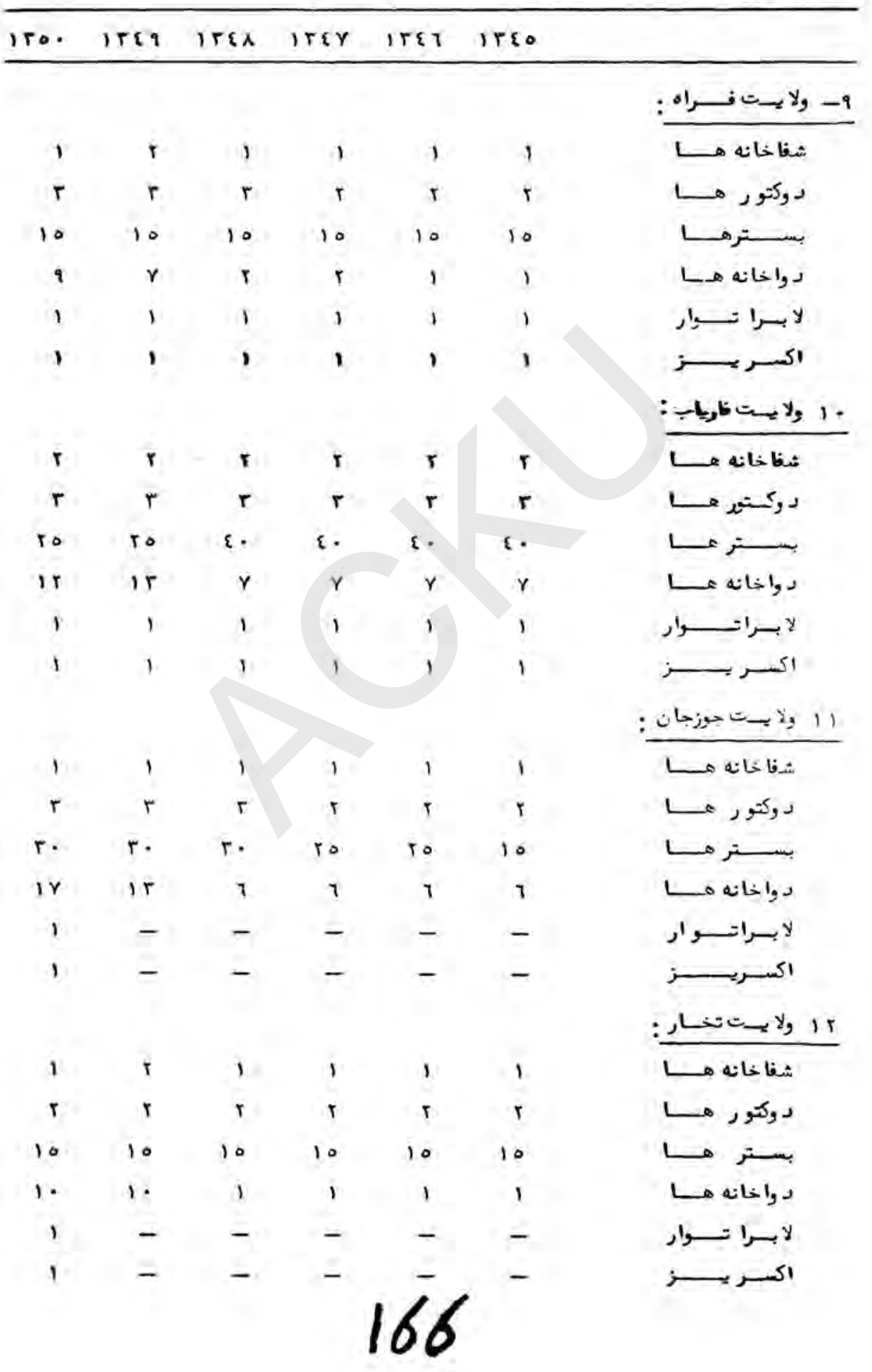




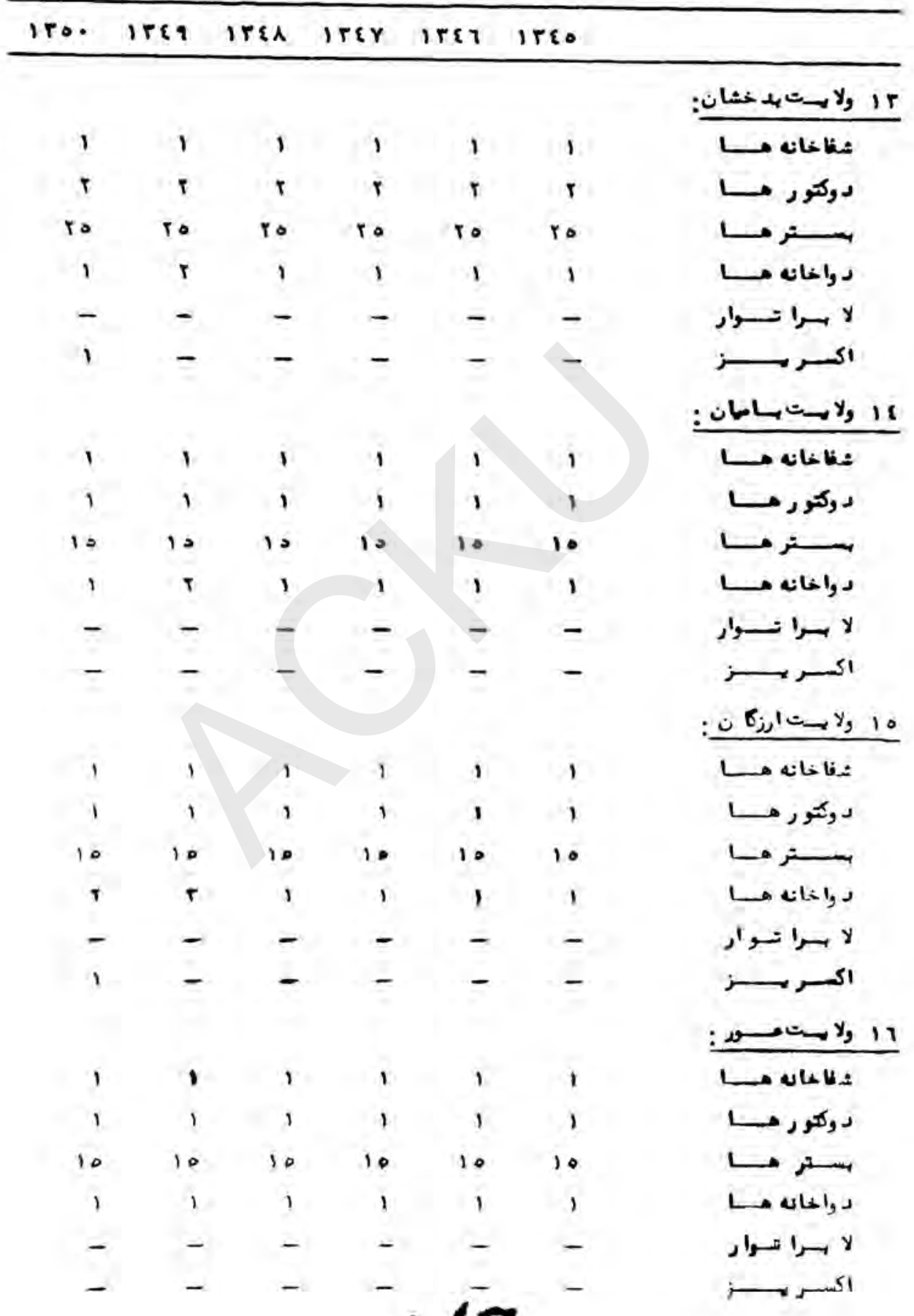


$-0-$

I HO. I

$\begin{array}{cccccc}r & 1 & 1 & r & r & r \\ 0 & 0 & 0 & r & r & r \\ 1 . & r & 10 & r o & r o & \text { r } \\ 1 & 1 & 1 & 1 & 1 & 1 \\ 1 & 1 & 1 & 1 & 1 & 1\end{array}$

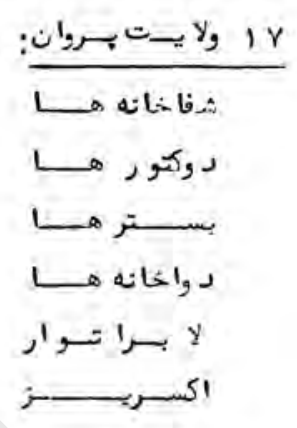

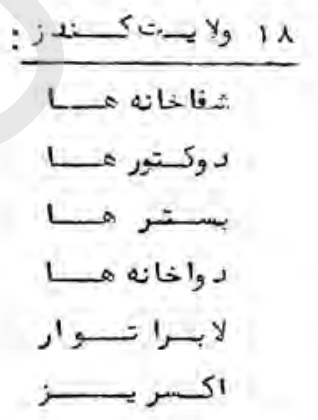

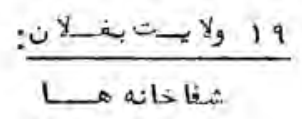

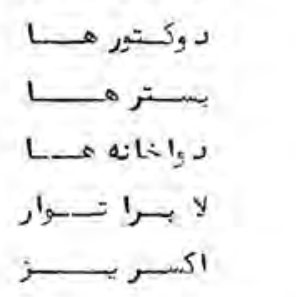

$: \underline{\text { : }}$

$\begin{array}{ccccccc}1 & 1 & 1 & 1 & 1 & 1 \\ r & r & r & 1 & 1 & 1 \\ 1 . & 1 \cdot & 1 \cdot & 1 \cdot & 1 \cdot & 1 \cdot \\ 1 & 1 & \varepsilon & i & r & - \\ 1 & - & - & - & - & \end{array}$




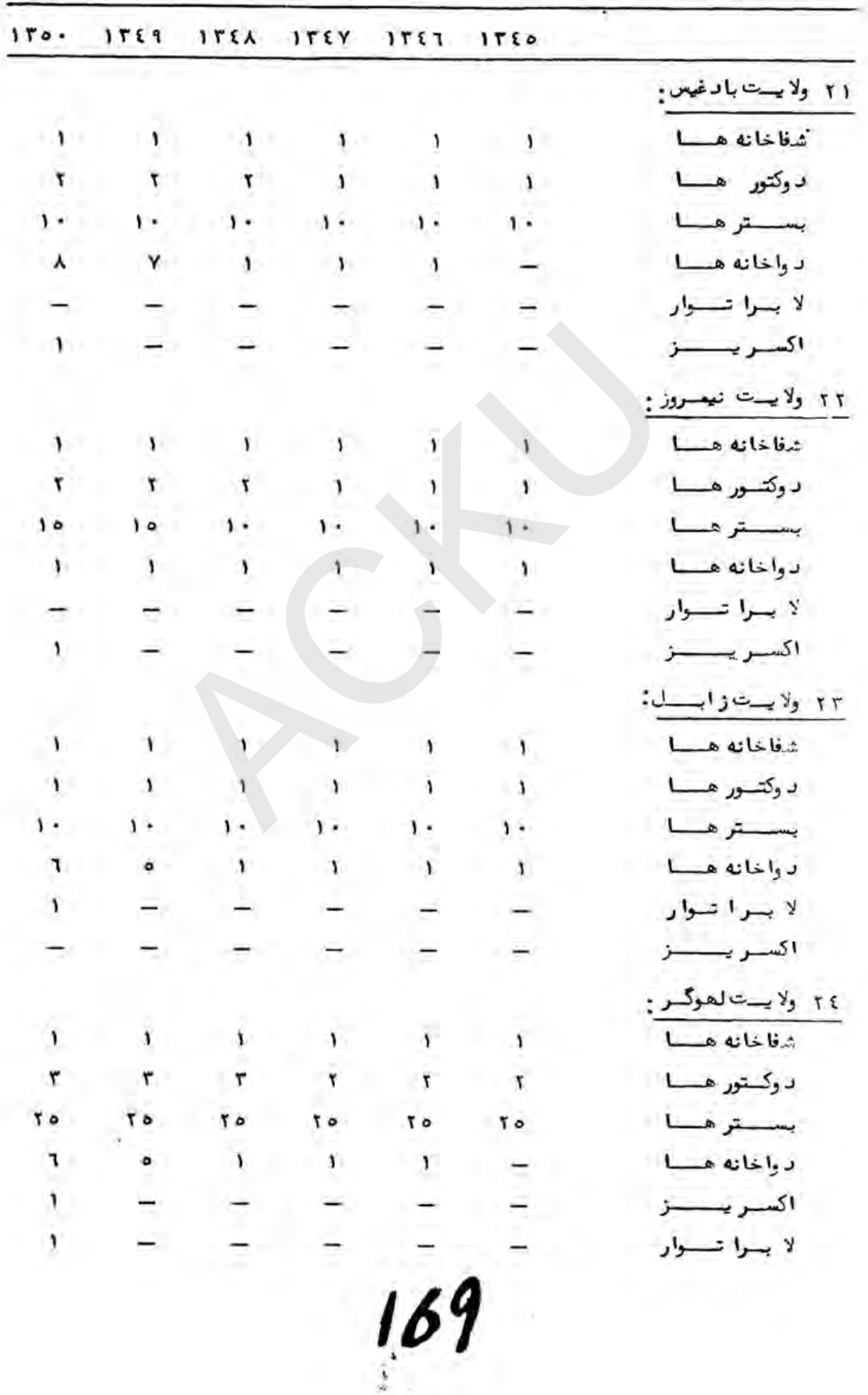


$-\gamma-$

Iro. IrEg Ir\&A IrEY IrET ITEO

: ro

$\begin{array}{ccccccc}1 & 1 & 1 & 1 & 1 & 1 \\ 1 & 1 & 1 & 1 & 1 & 1 \\ 1 . & 1 . & 1 & 1 & 1 & 1 \\ 1 & 1 & 1 & 1 & 1 & - \\ - & - & - & - & - & - \\ - & - & - & - & - & - \\ 1 & 1 & 1 & 1 & 1 & 1 \\ 1 & 1 & 1 & 1 & 1 & 1 \\ 10 & 10 & 10 & 10 & 10 & 10 \\ 1 & 1 & 1 & 1 & 1 & 1 \\ 1 & - & - & - & - & -\end{array}$

شفاخانه هـــ

دركـتور هـــ

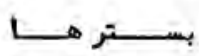

دوانهان

لا بــرا تـــــــ

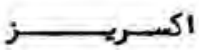

:

شفاخانه هـ

دوكستور هـ

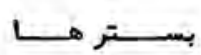

داخدانه

لا بــرا تـــــار

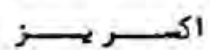

: باهب

1

1

I

شقاخانه

r

$T$

,

دوكـتو رمــــا

1.

1.

1.

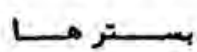

。

,

1

1

دواخانه هــــ

- $\quad-$

لا بــرا تـــــوار

- $\quad$ - $\quad$ -

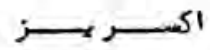

17 


\begin{tabular}{|c|c|c|c|c|c|c|}
\hline 1 & 1 & 1 & 1 & 1 & 1 & شفاخاته هـ ـــا \\
\hline $\mathbf{r}$ & $r$ & r & 1 & 1 & 1 & د وكـتو رهـــا \\
\hline 1. & $1 \cdot$ & $1 \cdot$ & 1. & $1 \cdot$ & 1. & 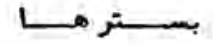 \\
\hline$T$ & I & 1 & 1 & 一 & 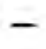 & دواخانه هـ \\
\hline 1 & - & 一 & 一 & 一 & - & ע بــــــــــ \\
\hline 1 & - & - & - & - & - & اكســــــ \\
\hline
\end{tabular}

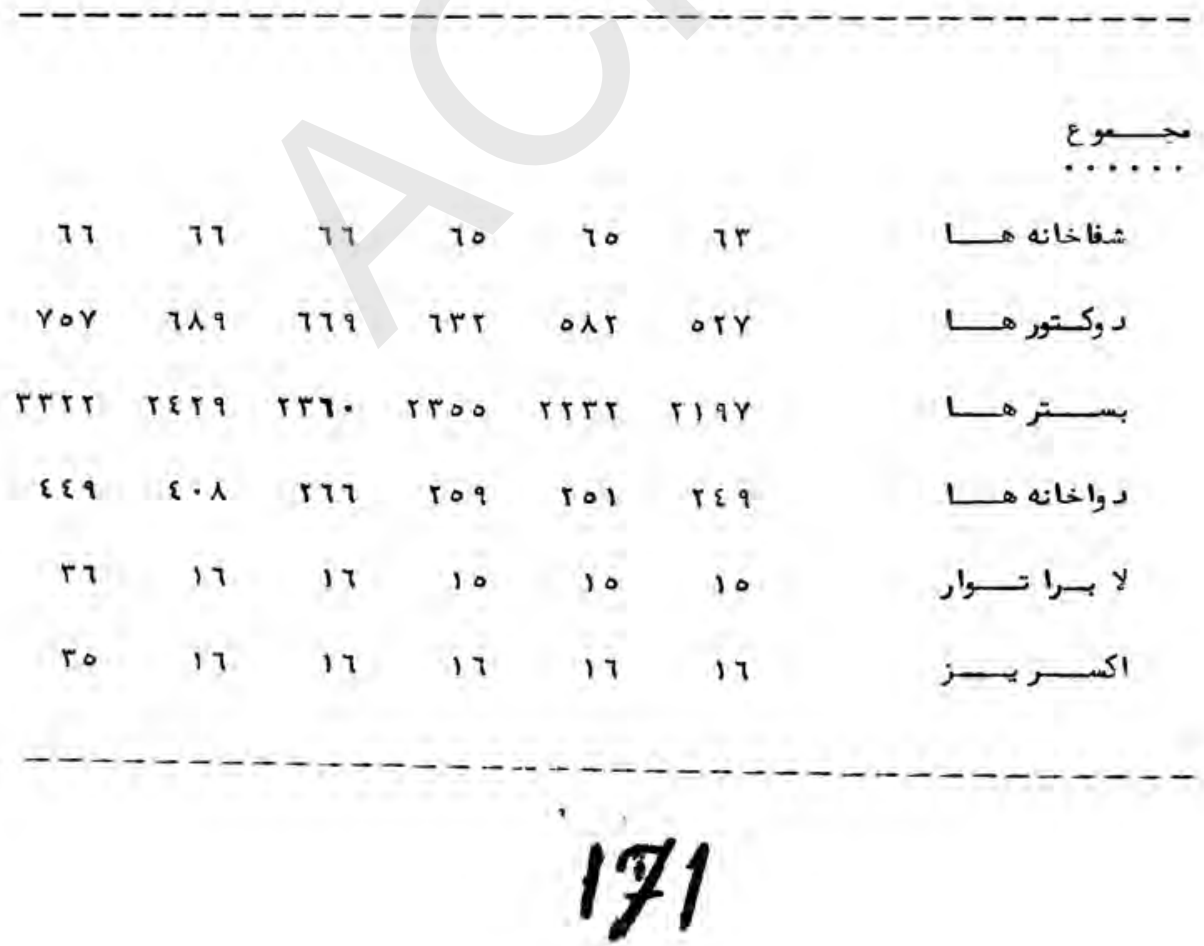




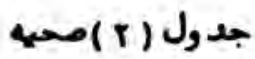

واتعات امراضسارى در شفاخانه ها

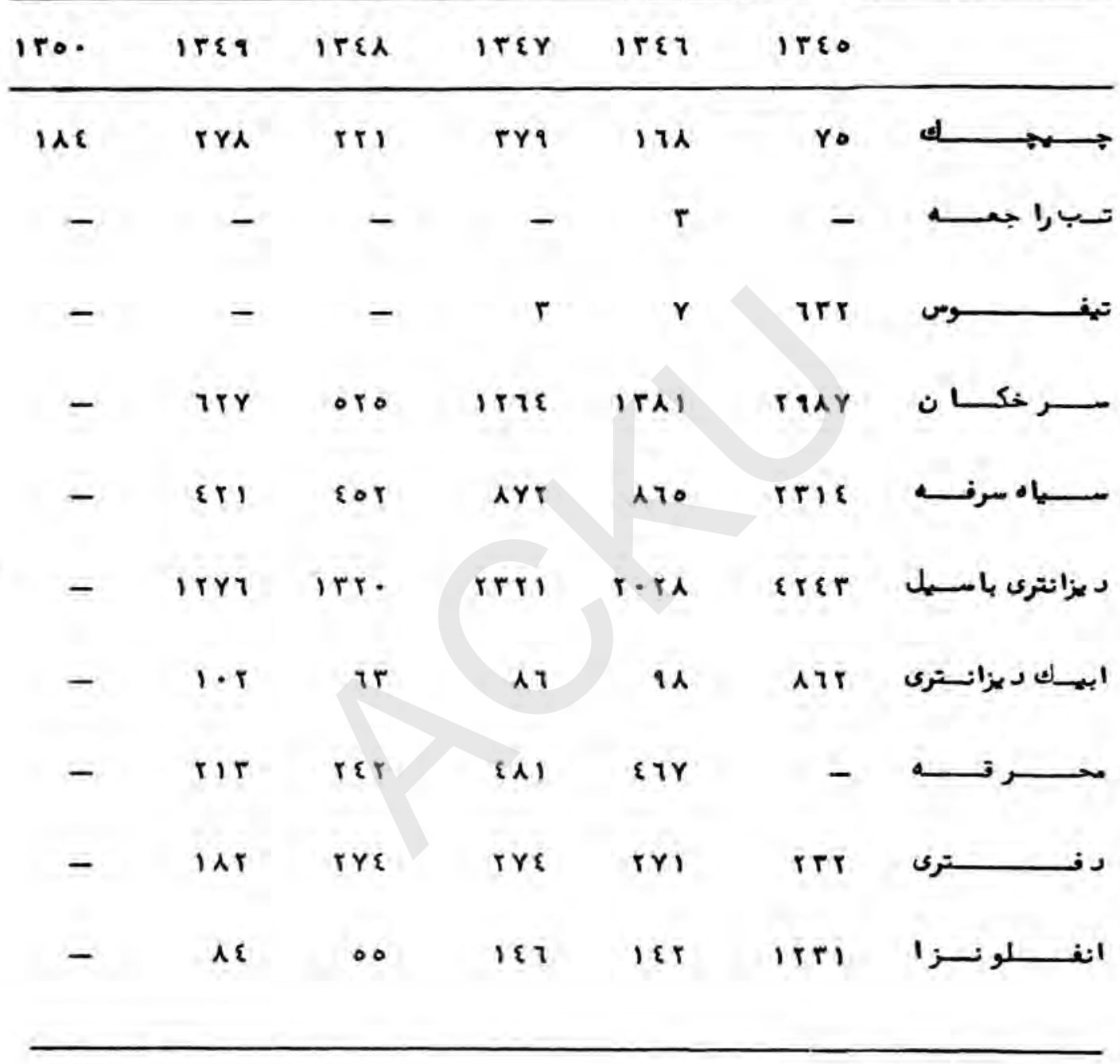

نوت : راسهر ساير امراض به استثناى جيجك نرميد ه است .

172 


$$
\text { جدول (r) }
$$

فعاليت و مجاد له علــيه مـر ض- تـو بر كليوز

\begin{tabular}{|c|c|c|c|c|c|c|}
\hline iro. & Irqq & $\operatorname{lr\varepsilon \lambda }$ & Ir\&Y & $1 \Gamma \varepsilon T$ & Ireo & \\
\hline roti. & $r r \varepsilon \cdot 1$ & $r \cdot \xi \cdot \gamma$ & IYTAs & $1 \varepsilon 707$ & orogr & مراجعين براى معاينات رادير كرافسى \\
\hline$\{1 \wedge \cdot T \varepsilon$ & ryorty & orr.r & ATOOY & 17179 & $\{1 \vee १\}$ & وتا يه شد كان وتطبيق واكسين توبركو ز \\
\hline $79 \cdots$ & $1 \cdot 7,1 \varepsilon$ & 7090 & 1171 & $\varepsilon \cdot \gamma$ & TrI & 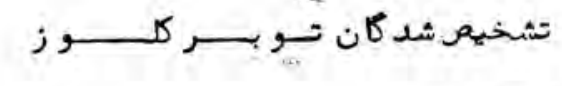 \\
\hline$\{r \mid \varepsilon$ & $r \varepsilon \gamma_{0}$ & tr人o & एqई & $r \lambda \circ \lambda$ & $r \cdot \gamma$ & 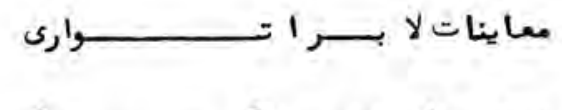 \\
\hline TधाT & IATIT & $1 \% q 1$ & $1 \varepsilon \lambda ?$ & Y) & qr? & 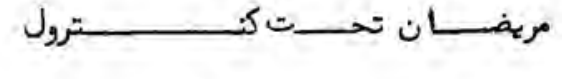 \\
\hline$\{r\}$ & $r T\{\lambda$ & ort & S人t & $10 \varepsilon$ & 7. & 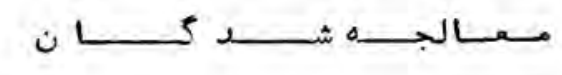 \\
\hline
\end{tabular}




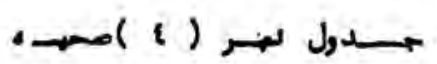

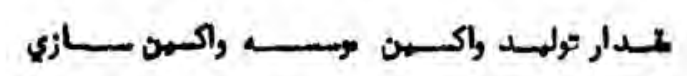

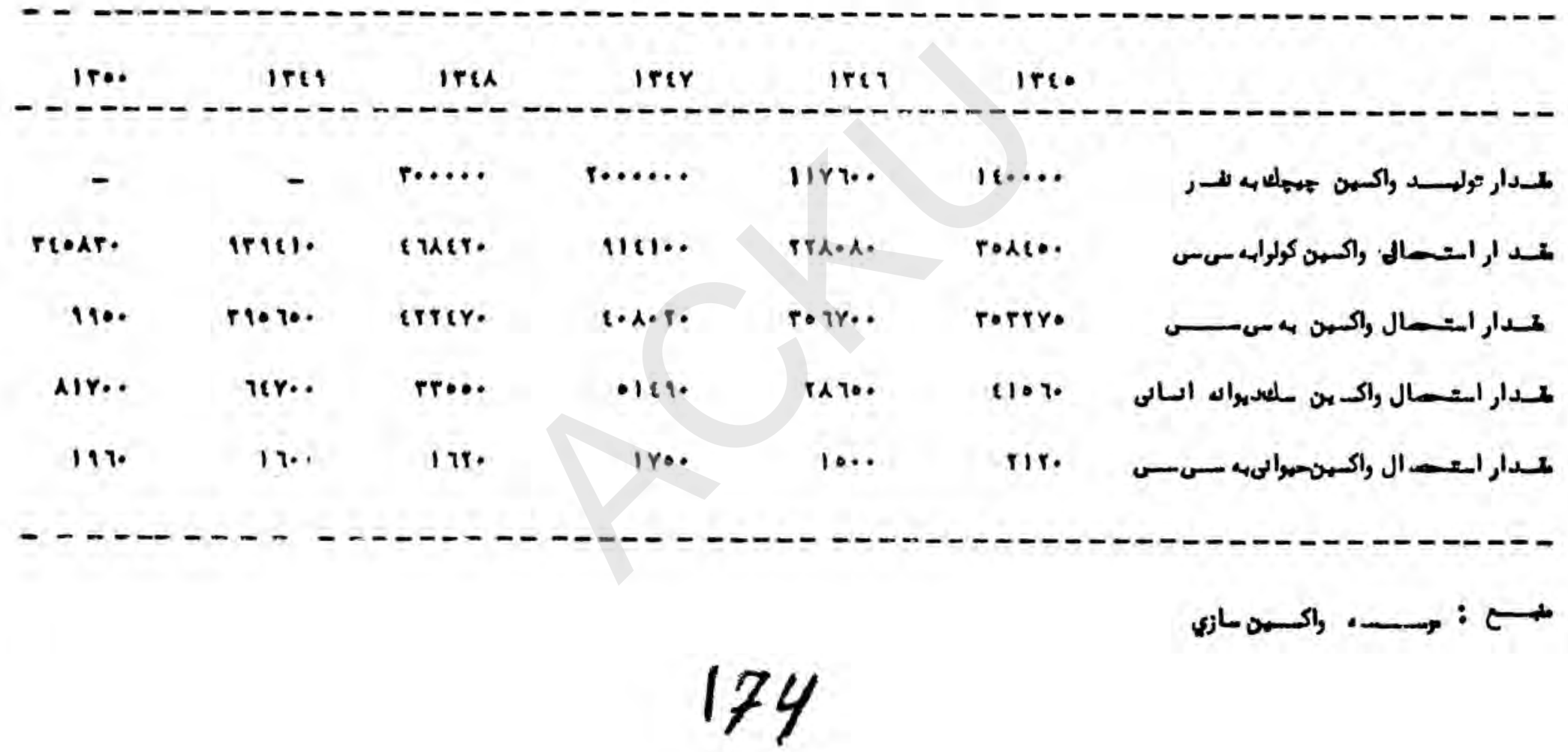


جدول

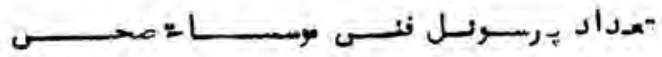

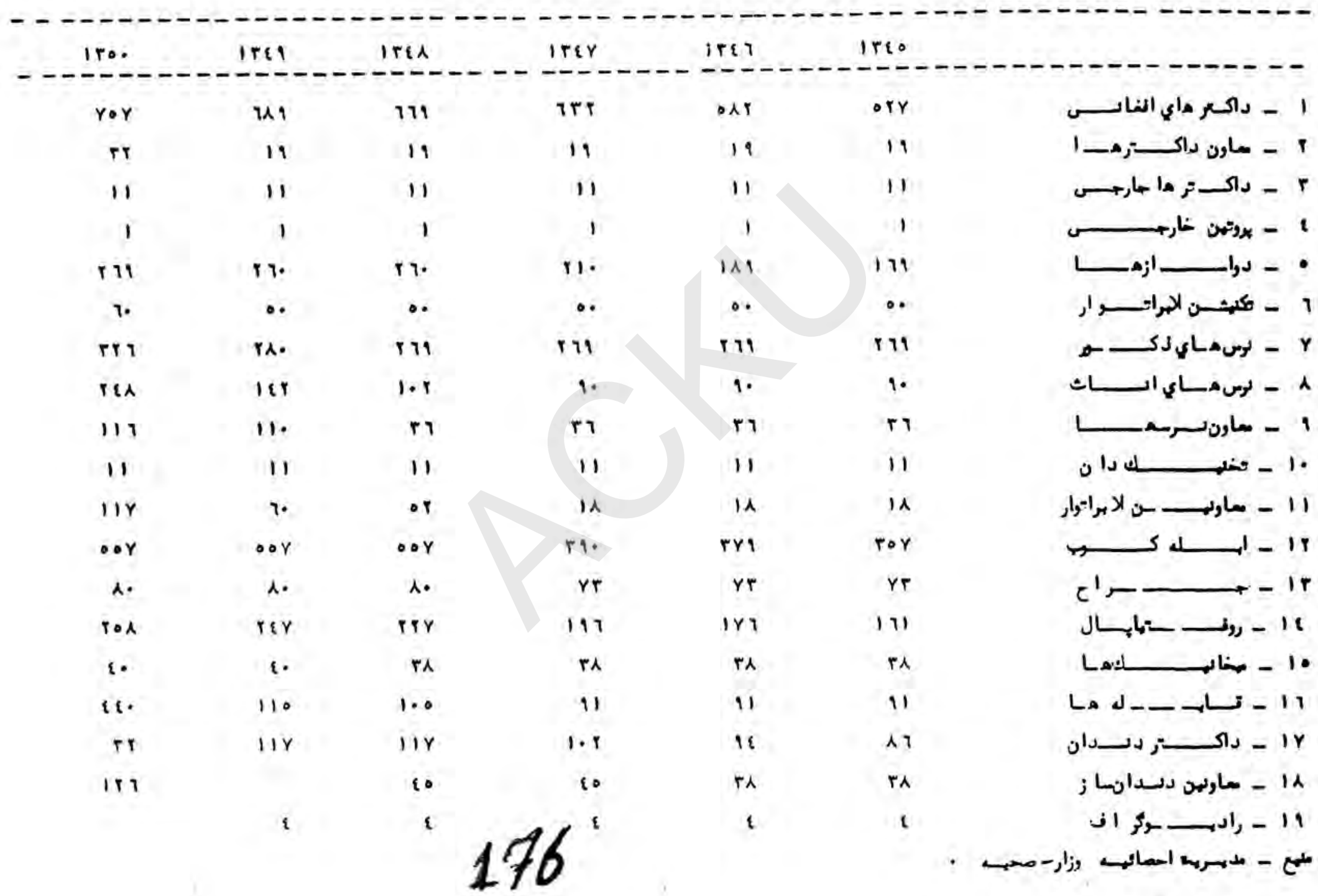




$$
\begin{aligned}
& \text { جدول (1) ) ضعهه مخابرات }
\end{aligned}
$$

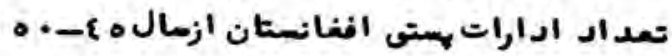

\begin{tabular}{|c|c|c|c|c|c|c|}
\hline iro. & $\operatorname{lr} \varepsilon 9$ & $I T \& A$ & irer & IrET & irso & نـــــــادارات \\
\hline ra & rt & rr & rr & rr & rr & 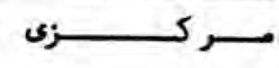 \\
\hline ir & ir & 11 & 11 & 11 & 11 & 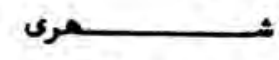 \\
\hline$\varepsilon$ & $\circ$ & \{ & $\varepsilon$ & $\varepsilon$ & $\varepsilon$ & ســدان موا ثــى \\
\hline r & r & 1 & 1 & $y$ & 7 & حـــ \\
\hline rr & rr & II & ri & r & ri & $\omega$ \\
\hline 101 & 108 & 108 & 104 & lor & 108 & مسو ط حكو مــات \\
\hline$y$ & - & - & - & - & - & قهـــله مسكــــــرى \\
\hline rri & rTt & tra & rTt & Trt & rit & 2 \\
\hline
\end{tabular}

فماليت د ستكاء بهت وزارت مخابرات

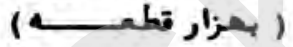

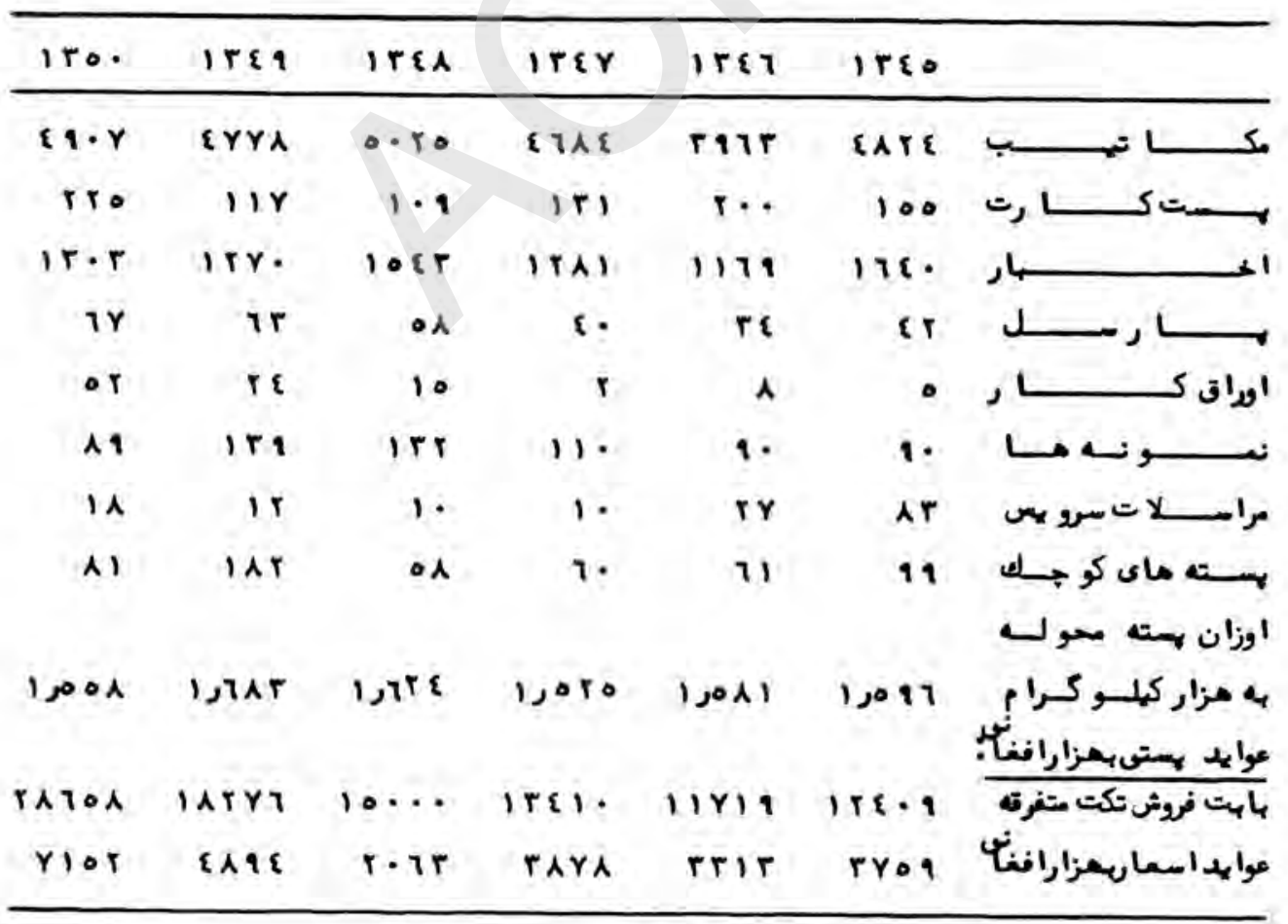


جد ول ( T) ضعيعه مخابرات

تعب اد تيلغون هاىولايات به تغريق متطقه

\begin{tabular}{|c|c|c|c|c|c|c|}
\hline iro. & IrEq & $\operatorname{irgA}$ & ITEY & $1 T \varepsilon 7$ & irso & 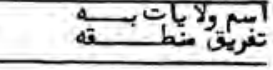 \\
\hline & & & & & & شعال : \\
\hline YI & Yr & (1) & Vr & (i) & 71 & بدخثــــان \\
\hline 10 & $V \xi$ & $1 \varepsilon$ & 77 & $7 \varepsilon$ & 7. & تخــــــ \\
\hline Tr. & $r \cdot \varepsilon$ & $\tau \cdot \varepsilon$ & ror & trt & $r \cdot r$ & 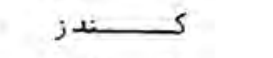 \\
\hline 11. & IYT & 171 & lor & rEY & rri & بــــــان ن \\
\hline$Y \varepsilon$ & it & 09 & or & $\varepsilon q$ & ra & منيكــا ن \\
\hline $11 \varepsilon \varepsilon$ & rya & TYT & 179 & TQT & ror & بلــــــ \\
\hline$|1|$ & IVY & 104 & 155 & $1 \varepsilon \varepsilon$ & $15 \varepsilon$ & جـــــان \\
\hline TT & 190 & IAY & $1 \times 7$ & int & 1100 & فاريســــــا ب \\
\hline & & & & & & \\
\hline 91 & it & 10 & $\wedge \cdot$ & Y & $r \lambda$ & كايستـــ \\
\hline 118 & 118 & irr & TI & irt & $1 \pi 1$ & بـــــن \\
\hline loor & D.人tE & 9710 & $3 x \cdot A$ & 0119 & ofAt & 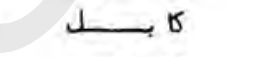 \\
\hline$r \wedge$ & ry & in & rt & rT & rq & لـ, \\
\hline rv & rr & $r$. & r. & 19 & 11 & ورد ك (ميد'ن) \\
\hline YT & 10 & TT & or & IT & or & كان بـان \\
\hline$\varepsilon \varepsilon$ & \& $\varepsilon$ & $\{1$ & $\xi Y$ & or & $\circ$. & ارزكــان \\
\hline \multirow[t]{2}{*}{ or } & of & $\varepsilon_{0}$ & \{\} & $\varepsilon$. & \& & غ \\
\hline & & & & & & نـرق : \\
\hline Tr & 01 & 00 & 09 & of & or & كـــــــ \\
\hline TTA & TA & Tr & $r \cdot$ & $r \cdot$ & rT & لغعـــان \\
\hline TY & $r \cdot r$ & सr & 110 & $\mathrm{r} \cdot$ & 111 & ننكر مــار \\
\hline $1+\varepsilon$ & 171 & 101 & Jor & 108 & ITT & $L=S$ \\
\hline \multirow[t]{2}{*}{$\varepsilon \lambda$} & $1 \varepsilon r$ & $1+7$ & Irr & IT & 198 & غــز نســى \\
\hline & & & & & & غـرب : \\
\hline 11 & \& T & $\varepsilon r$ & \&o & \&T & \& & باد فيس \\
\hline IT & 1870 & $r \cdot \lambda$ & ril & rir & Tis & مــــــــ \\
\hline $1 \cdot r$ & ar & १. & 11 & 90 & 11 & فـــــــــ \\
\hline of & or & $\varepsilon 1$ & \&. & rI & trt & 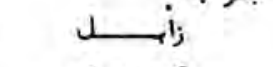 \\
\hline$|r| \mid$ & irir & irag & iror & Irof & Itet & كد هـ ر \\
\hline $11 r$ & IVT & 109 & lor & IOT & 101 & هلبـــــــ \\
\hline Yr & 09 & or & ₹Y & ry & ra & نيــــــــــــ \\
\hline 19999 & 1311. & Iraty & $11 \cdot \pi 9$ & 9017 & 1117 & r \\
\hline
\end{tabular}




\begin{tabular}{|c|c|c|c|c|c|c|c|c|c|c|c|c|}
\hline 11. & 1. & 11. & 1. & 110 & 1. & 11. & 1. & 11. & 1. & 110 & 1. & 4دبـان \\
\hline$r \cdots$ & 1. & is. & $\Lambda$ & 100 & 1 & 10 & 1 & 10 & 1 & 10. & 1 & تيـــــار \\
\hline$\varepsilon \cdots$ & 1. & 19. & $\boldsymbol{A}$ & ra. & $\wedge$ & r. & $\Lambda$ & ry. & $\lambda$ & rto & 1 & كــــــ \\
\hline$\varepsilon \cdot 0$ & 11 & rT. & 1. & it. & 1. & tre & 1 & tr. & 1. & it. & 1. & تحــان ن \\
\hline is. & $\varepsilon$ & $A$. & 1 & A. & 3 & $A \cdot$ & 3 & $\lambda$. & 1 & A. & 1 & سعكـان \\
\hline IYE. & 10 & rie & 10 & $r=$ & it & $r \cdots$ & it & rYo & 1. & rio & IT & it \\
\hline ro. & $r$ & ir. & $\checkmark$ & ir. & $y$ & Ir. & $\mathbf{Y}$ & IY. & $r$ & ir. & $v$ & جــن جان \\
\hline$r \cdot 0$ & it & TYo & is & rYo & IT & rTo & 11 & ra & 11 & 170 & 11 & ن. \\
\hline 110 & 1 & 10 & I & $y=$ & - & $Y=$ & - & A. & - & $A$. & • & S \\
\hline 100 & $Y$ & Ir. & $r$ & ir. & $r$ & ir. & $r$ & ir. & $r$ & ir. & $r$ & بــدان \\
\hline itiry & rt & irere & $t$. & IrTie & Al & IrteE & $A T$ & YרA & $7 x$ & VxA9 & 1. & كـا بل \\
\hline$\Lambda$. & - & A. & - & 10 & - & $A$. & 1 & . & - & $r$. & 1 & 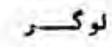 \\
\hline$\gamma$. & 1 & ro & - & 10 & - & $\cdots$ & - & $\cdots$ & - & •. & - & ورد d. \\
\hline 19. & 11 & ir. & 1. & 18. & 1 & 17. & 1. & it. & 1 & is. & 1 & باكيان \\
\hline 110 & 1 & IT. & 1 & ir. & 1 & 1. & 1 & 1. & 1 & A. & 1 & اندان \\
\hline its & $A$ & A० & $A$ & A. & $A$ & A. & $\lambda$ & re & 1 & $r \cdot$ & 1 & فــــــر ر \\
\hline
\end{tabular}

\begin{tabular}{|c|c|c|c|c|c|c|c|c|c|c|c|c|}
\hline 110 & 1 & 11. & 1 & 10 & $Y$ & $1 \ldots$ & $r$ & A. & $Y$ & 1. & $\forall$ & كنر مـا \\
\hline 7. & - & $7 \cdot$ & - & c. & $r$ & c. & $r$ & t. & $r$ & t. & $T$ & لشفـا ن \\
\hline$r$. & 19 & 12. & in & $r$. & 19 & 19. & in & rye & 11 & TAE & in & W_s \\
\hline 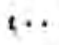 & 10 & rio & if & rae & 10 & 2100 & 17 & To. & is & re. & is & نيكرهــر \\
\hline TAS & ir & $r \cdots$ & in & ri. & 11 & TAE & 11 & TAE & IA & rio & IA & فـر هـ \\
\hline
\end{tabular}

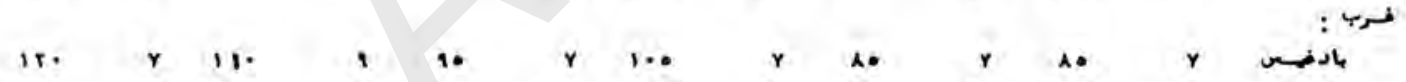

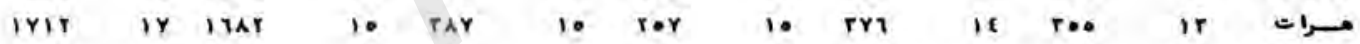

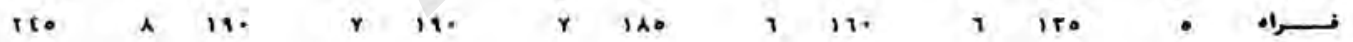

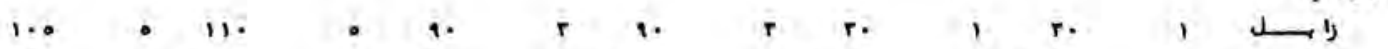

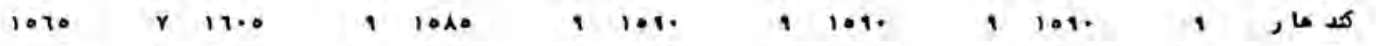

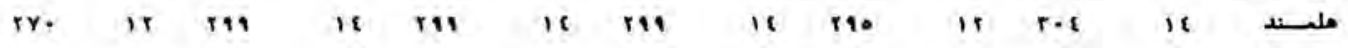

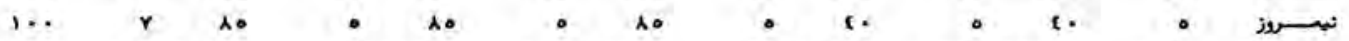

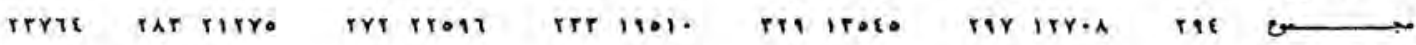

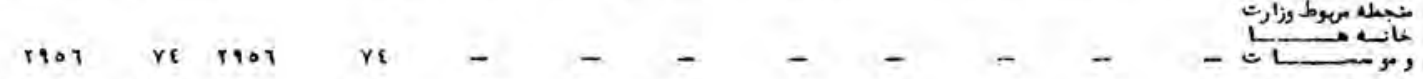

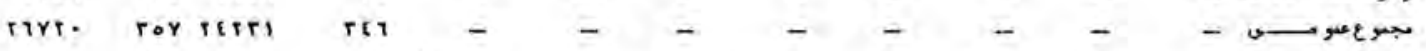

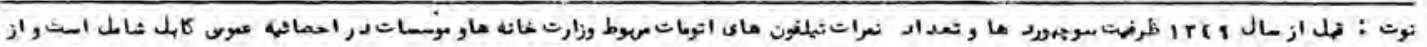

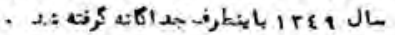


جدول ) r r ) خسه مخاهرات

مـرا هـــ تهلفـون بهمزار اففا نـ

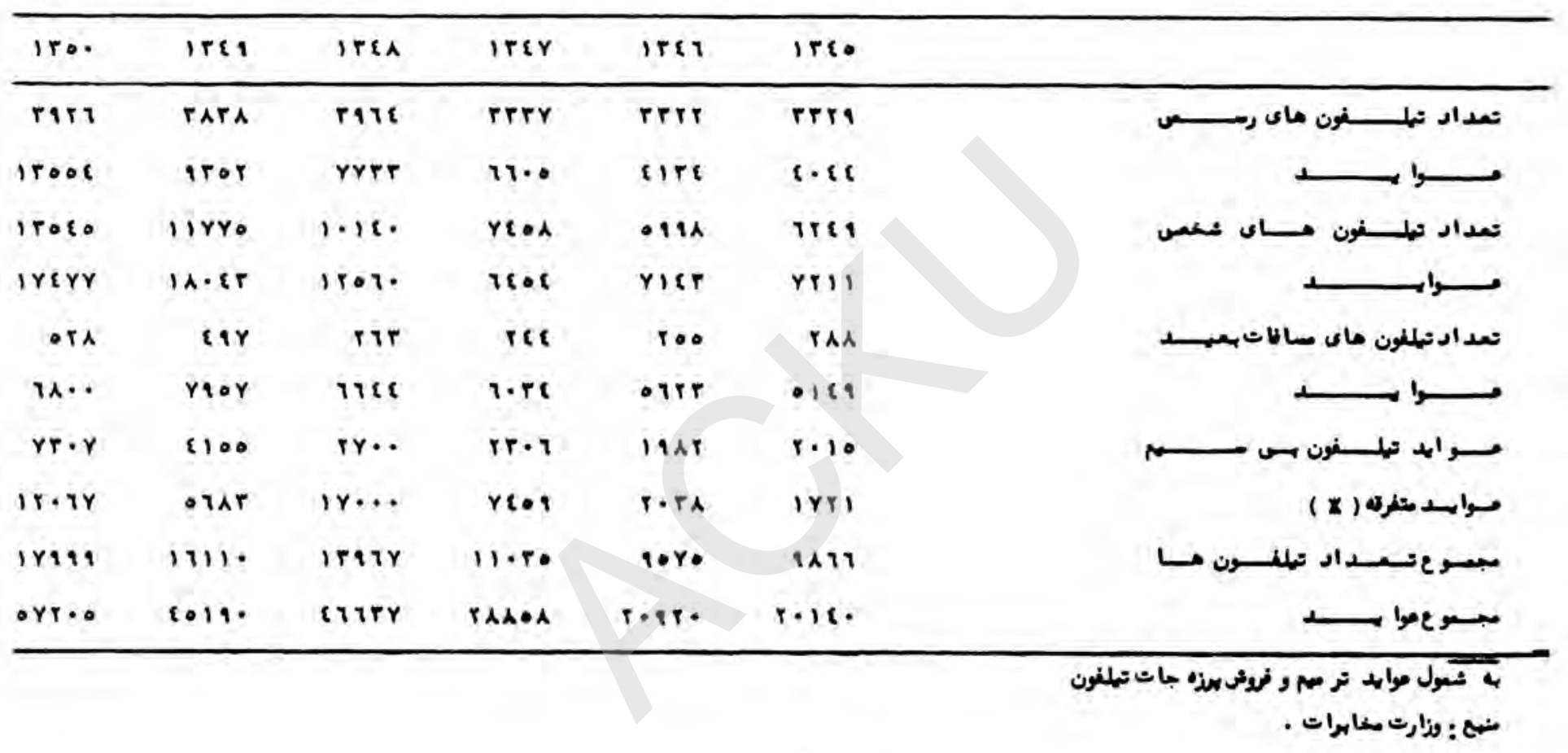


جدول (ع ) ضعيهه مخابرات

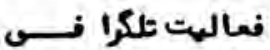

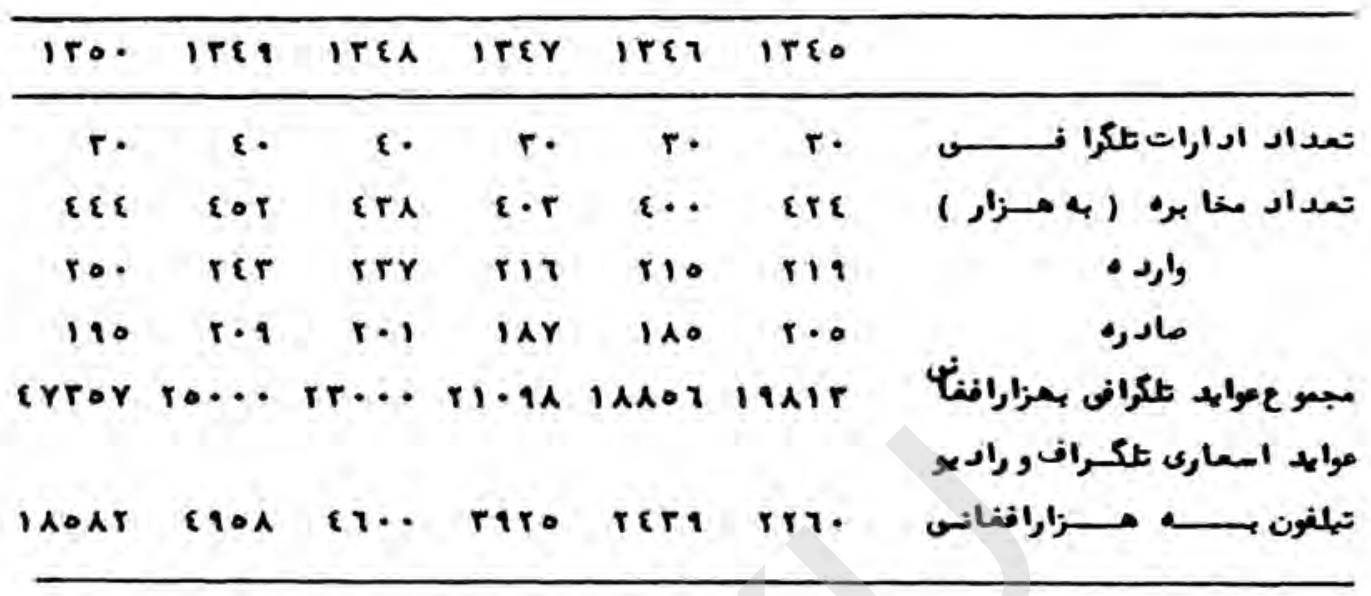

اجصائه سوجيورد ماكوزارت مخابرات

iro. ires irea irey iret ireo

ror tet ret rig ras tis

تعسداد سو مهبهرد

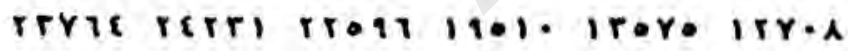

تصعسداد نمــره

181 
جدول (0) خعيع مخابرات

تعد اد مامورغن دستكاه هاى بهت - تيلفونو ثلكراف

iro. ireg itea irey iret ireo

EYY \&7. \&10 \&IT \&IT

(7) rol t.r rqs trr

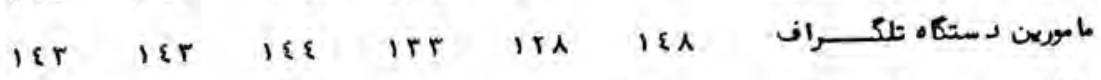

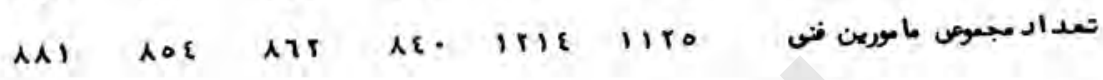

تعداد تيلفون هاى مركز وولايات

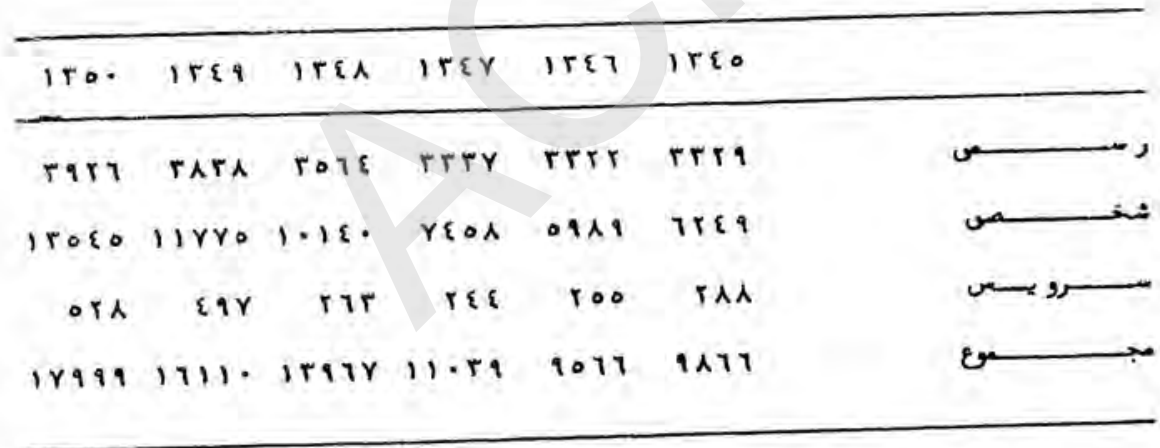


جدول (1 ) خسعه مخابرات

تعداد راد يو مـاى تسوريد شده مواهدراديو

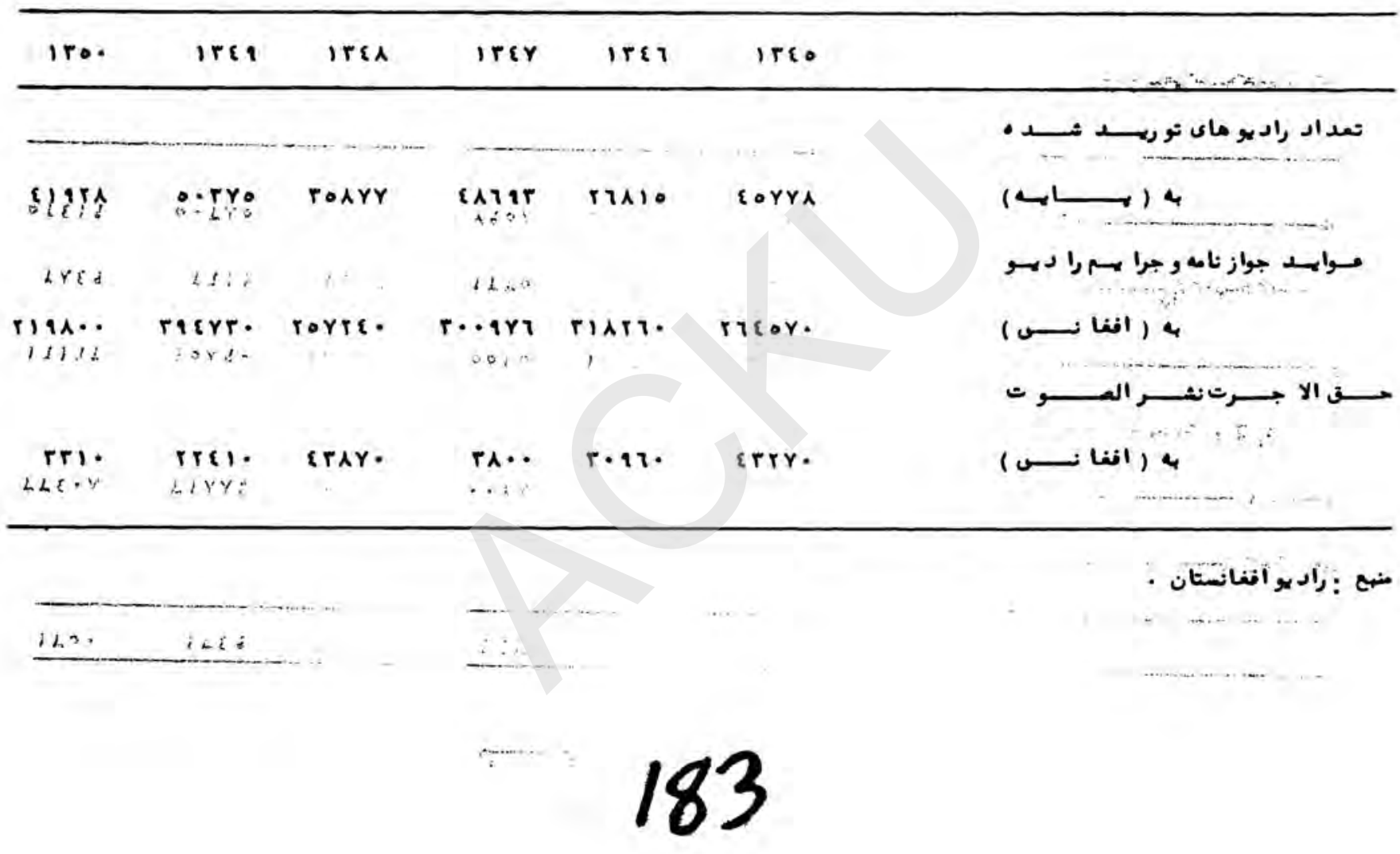


جدول (Y) ضعيه ترانسيورت

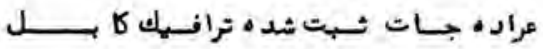

\begin{tabular}{|c|c|c|c|c|c|c|}
\hline 190. & Ir\&9 & $1 \Gamma \varepsilon \lambda$ & Ir\&Y & 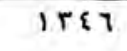 & $\operatorname{lr} \varepsilon 0$ & \\
\hline & & & & & & انـــاع تيز رفــــار هـ ثـــــــول \\
\hline $\operatorname{rre\cdot A}$ & PIAAE & $r \cdot \gamma \wedge \lambda$ & $r \cdots Y \lambda$ & TMOT & rYoot & 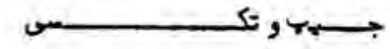 \\
\hline (117 & 1019. & IOYY. & $100 \leqslant 0$ & $10 \& Y A$ & $10 r \cdot 1$ & t \\
\hline rA\& 9 & RII & $r \varepsilon \varepsilon r$ & rrTo & rrqo & reste & ـرو هـس واك \\
\hline - $Y\{19$ & 0. r $_{0}$ & $\{q \cdots\}$ & $\{Y १ \circ \lambda$ & ET1Y0 & $\{01 \cdot \tau$ & 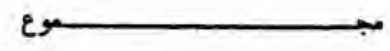 \\
\hline & & & & & & منبح : مدريت ترافله كايل \\
\hline
\end{tabular}


جدول )

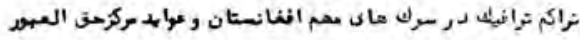

\begin{tabular}{|c|c|c|c|c|c|c|c|c|c|c|c|}
\hline \multicolumn{5}{|c|}{$1 r \& r$} & \multicolumn{5}{|c|}{$1+\& 1$} & \multirow{3}{*}{ 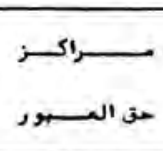 } & \multirow{3}{*}{ 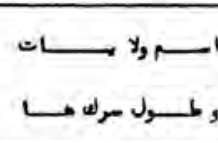 } \\
\hline \multicolumn{3}{|c|}{ مـوأ هـ به مــزار افــــا نسـن } & \multicolumn{2}{|c|}{ تعد اد موترها كعبورودركرد كي } & \multicolumn{3}{|c|}{ 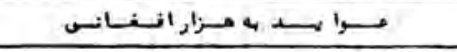 } & \multicolumn{2}{|c|}{ تعداد موترها كعبرومردركردكي } & & \\
\hline ren & تمنرفtر & لارى سرعي & تمندفستار & لا & 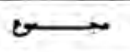 & ثيز رفـــار & لارى وسرويى & تيز رنــتار & لا رى وسתטى & & \\
\hline MP. & 1108 & \&ิY & $T T \cdot 10$ & EQYOY & $7+90$ & $1.7 r$ & $0 . T r$ & MitT & $0.5 t r$ & مالنك جنقيس & كل الشركان شثدر \\
\hline ดทา & $1 \cdot 9$ & cor. & 119. & cor. & $T \cdot A A$ & 1.18 & $0 . Y_{7}$ & $T \cdot T \circ T$ & $0 . Y_{0} 9$ & خنجبــــان & 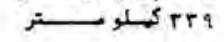 \\
\hline 1900 & $T \bullet \mathcal{E}$ & 1018 & $|E|\{\mid$ & TITP. & t.TIR & $r=1$ & 19.40 & Irrer & TAIS. & كنغ نان & \\
\hline isos & $r+1$ & 1160 & irtr & TTATT & Iryi & tra & istr & on & resir & الجــــــــ & \\
\hline$r \cdot r r$ & A18 & 1419 & $\varepsilon \cdot 1 \wedge \varepsilon$ & $T \cdot \Sigma \lambda T$ & TTI. & צוד & 189 & TATAT & yrro. & يوكى ارئد ى & كلد / تـــ هـــ \\
\hline 19 & $s \cdot y$ & YAA & $T \cdot P T A$ & 1919 & $1 \cdot 2 \lambda$ & tar & 101 & MoN9 & 136.5 & , s. & = ك- S(A) \\
\hline 1181 & re. & $9 \cdot 8$ & Alor & 100.9 & 1.10 & rri & nol & yorr & IETIY & شــر مسنة & \\
\hline$T(A)$ & TAI & IA, & trite. & $r \boldsymbol{r} \ldots$ & rux & 1.95 & roro & rTEध & $010 \ldots$ & درو & كالـ / تص بـ \\
\hline rrr. & Mry & rtr. & TYOOT & $\cos 10$ & TtTo & 1.10 & rri. & rtht. & $\{t r \cdot A$ & ك- كزيزخان & 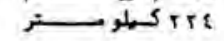 \\
\hline- & - & - & - & - & - & - & - & - & - & - & \\
\hline IAYT & rry & 1090 & ooro & 10970 & $1 \cdot 10$ & $17 \pi$ & $9 r r$ & rrt & (r) & P & تلد هار/ هــــــرات \\
\hline$|r Y|$ & its & NCA & esr. & WEAE & irir & $T, T$ & 1118 & $6.7 r$ & Ner & ادر كکـن & ו1 كـلمو ـــر \\
\hline tas & $r \cdot$ & CIT & rtor & ATM & ro. & AY & ז & ग१ & irrea & تيسته بـ & تثد هار| سهنهولد ل) \\
\hline EAT & YI & 11 & rtor & ATtT & ofa & 1. & $\{\wedge \lambda$ & $r \cdot r$. & |บา1 & سهن بولد d- & 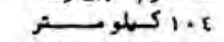 \\
\hline $\cos$ & yr & \&io & ryit & ATat & \{A\} & yr & $\$ 10$ & $T \& \varepsilon \varepsilon$ & $A T=1$ & ك-رك & مـرات / تهفـدى \\
\hline 89. & Ar & $t=A$ & syoq & A10. & $.1 \mathrm{x}$ & 10 & \&Tt & TIYT & aft & 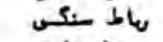 & 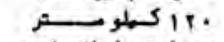 \\
\hline- & - & - & - & - & - & - & - & - & - & مسراى نابت & هـرات / اسلام تلعه \\
\hline- & - & - & - & - & - & - & - & - & - & كمبــــ ن & \\
\hline - & - & - & - & - & - & - & - & - & - & سراقطواجه & كابل / صراكسواجه \\
\hline- & - & - & - & - & - & - & - & - & - & عبل السراج & بــ \\
\hline - & - & - & - & - & - & - & - & - & - & بشه شـــ & بلبع \\
\hline - & - & - & - & - & - & - & - & - & - & مزارشصــف & 1 \\
\hline- & - & - & - & - & - & - & - & - & - & نسراء رود & فـــ \\
\hline 118 & res & ANA & ATIS & icters & 1A1 & ITq & YET & rara & ITPA & نانصتره أl & 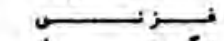 \\
\hline- & - & - & - & - & - & - & - & - & - & ثمر طســلـ & نئرt \\
\hline- & - & - & - & - & - & - & - & - & - & دنســــ & كــد مــــ \\
\hline- & - & - & - & - & - & - & - & - & - & زتجمر كـاء & علــ \\
\hline - & - & - & - & - & - & - & - & - & - & 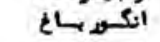 & تس \\
\hline - & - & - & - & - & - & - & - & - & - & عبر عانهثر & ت \\
\hline- & - & - & - & - & - & - & - & - & - & $d u$ & سكبـان \\
\hline retra & YE.. & rexya & TTOYAE & rrasir & rrica & $Y \cdot T T$ & RTIO & TrEATt & S. ITrt & & rـ \\
\hline
\end{tabular}




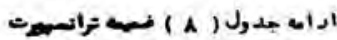

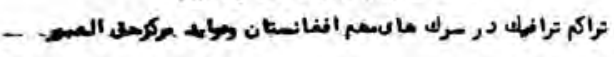

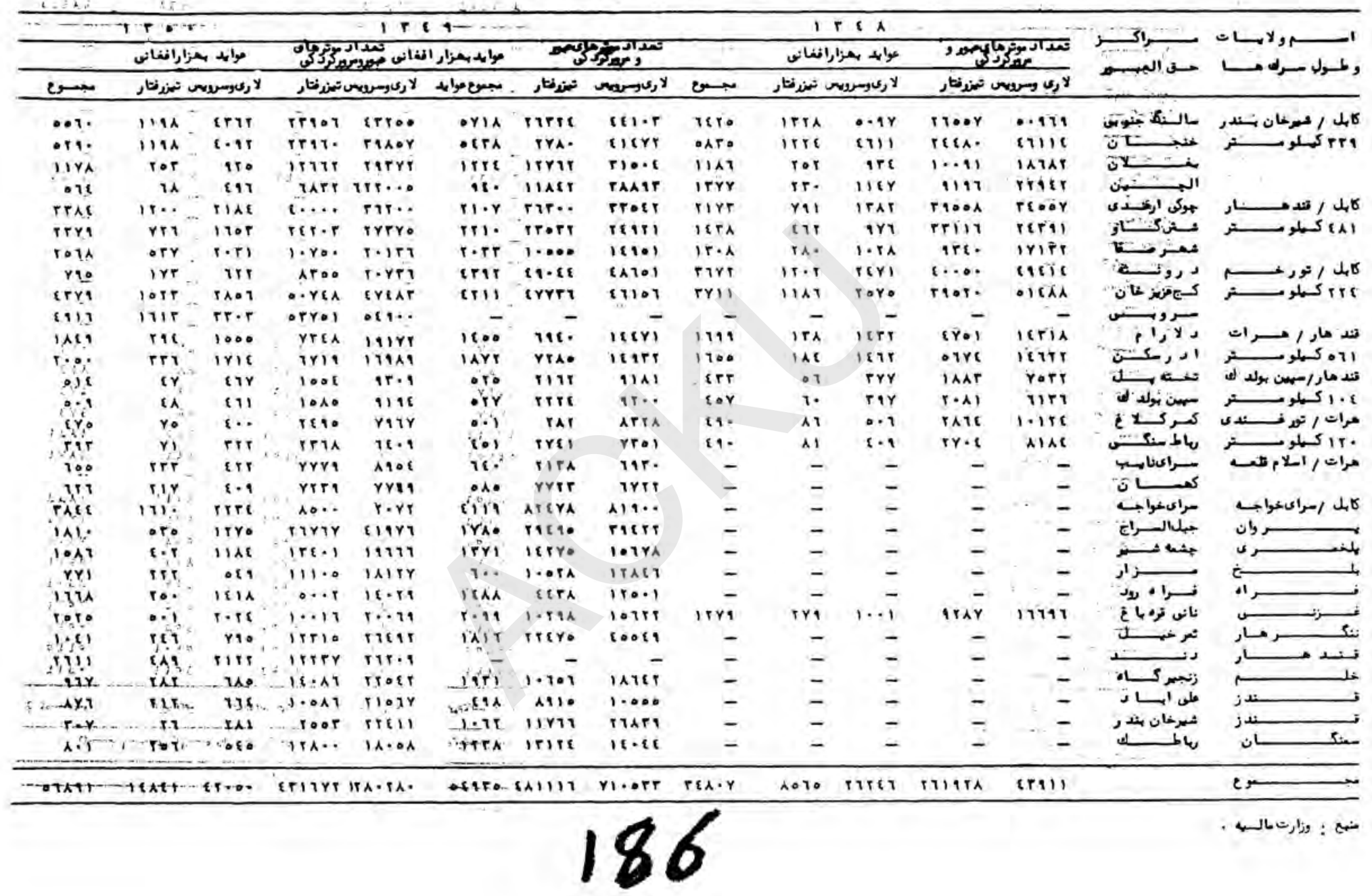




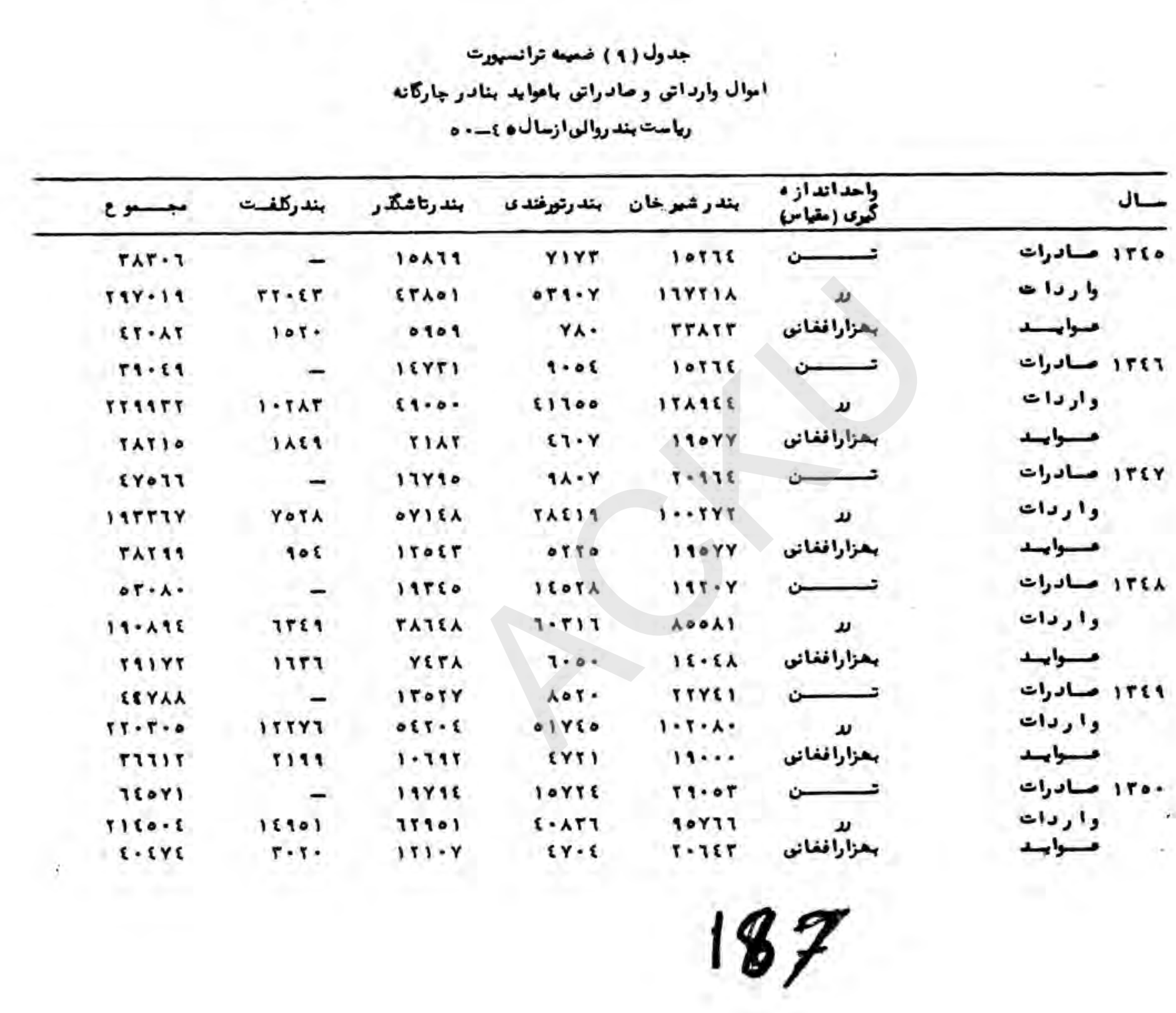




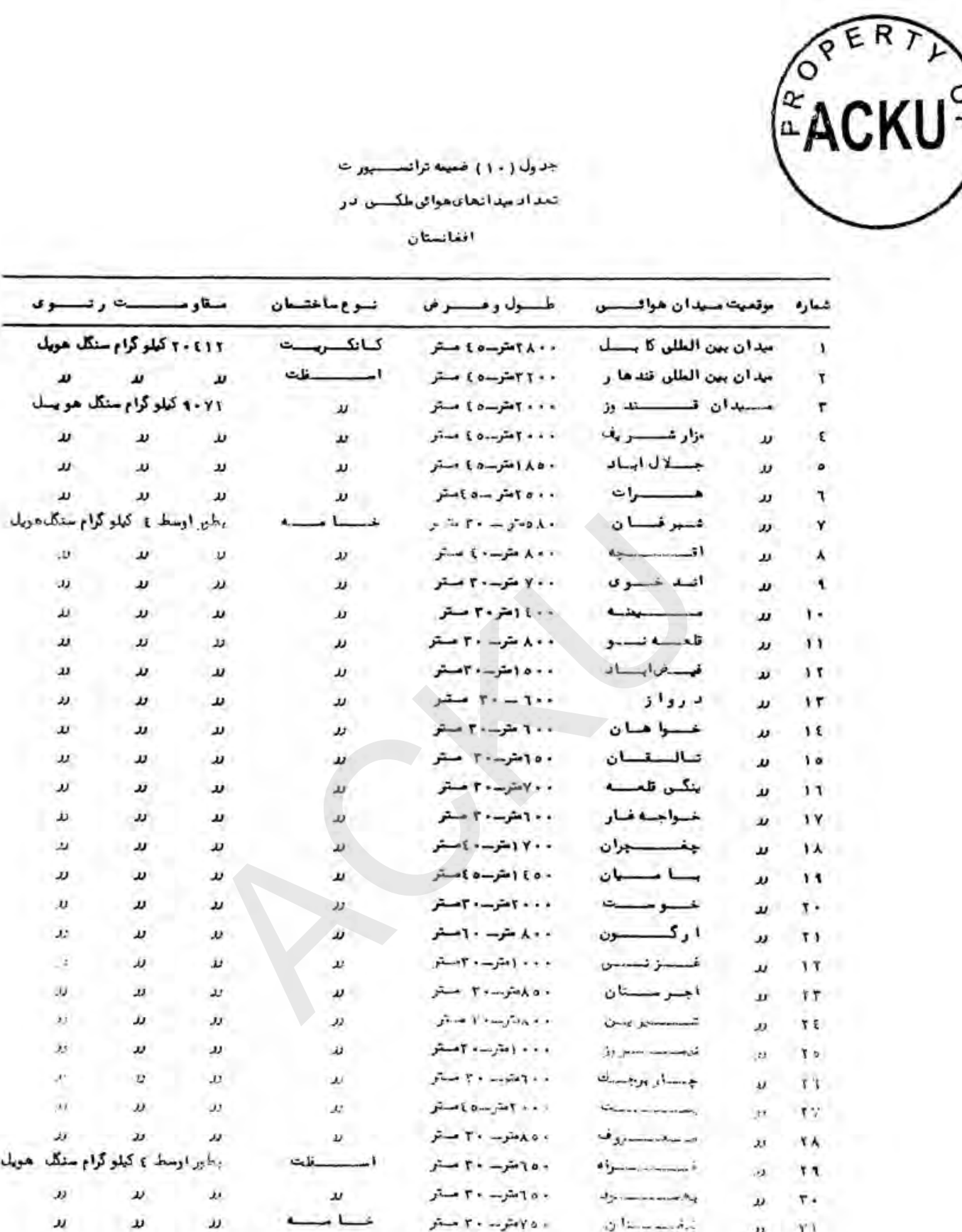

188 
